\title{
Waste Isolation Pilot Plant Biennial Environmental Compliance Report
}

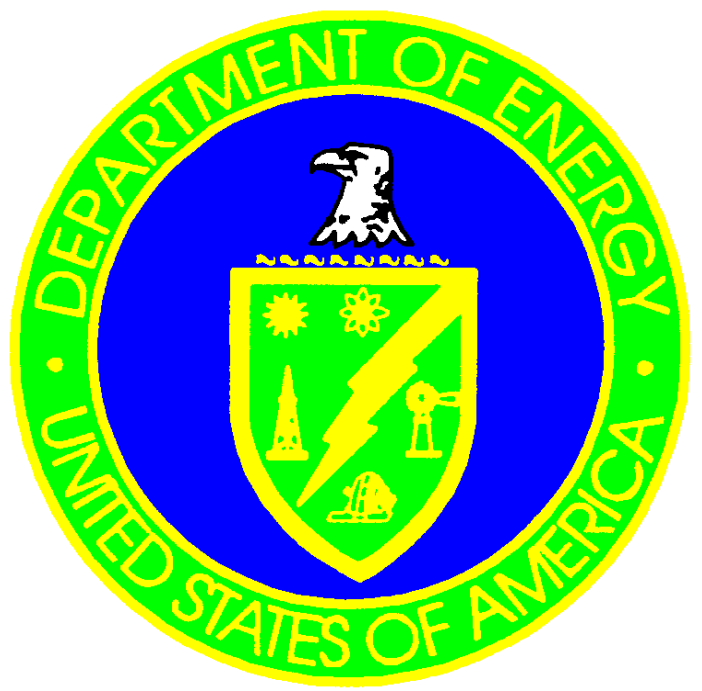

October 2000

\author{
United States Department of Energy \\ Carlsbad Area Office \\ Carlsbad, New Mexico
}


This document has been reproduced directly from the best possible copy. It is available to the DOE and DOE contractors at the following address:

Office of Scientific and Technical Information

P.O. Box 62

Oak Ridge, TN 37831 


\title{
Waste Isolation Pilot Plant
}

\author{
Biennial Environmental
}

Compliance Report

October 2000

Processing and final preparation of this report was performed by the Waste Isolation Pilot Plant Management and Operating Contractor for the U.S. Department of Energy under Contract No. DE-AC04-86AL31950. 
This page intentionally left blank. 


\section{TABLE OF CONTENTS}

ACRONYMS AND ABBREVIATIONS xvii

$1.0 \quad$ INTRODUCTION . . . . . . . . . . . . . . . . . . . . . . . 1

$1.1 \quad$ Background of the Waste Isolation Pilot Plant . . . . . . . . . . 2

1.2 Biennial Environmental Compliance Report under the WIPP Land

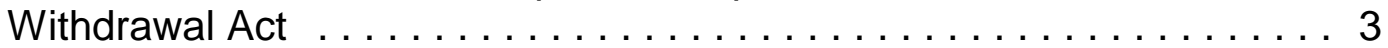

1.3 Regulatory Requirements Hierarchy $\ldots \ldots \ldots \ldots \ldots \ldots \ldots \ldots \ldots$

1.3.1 Federal/State Laws .................... 4

1.3.2 Implementing Regulations $\ldots \ldots \ldots \ldots \ldots \ldots \ldots \ldots 4$

1.3.3 Permit Conditions ...................... 5

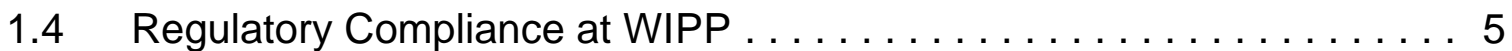

1.4.1 Compliance Assurance . . . . . . . . . . . . . . . 6

1.5 Organization of and Reporting Period for the Report $\ldots \ldots \ldots \ldots \ldots$

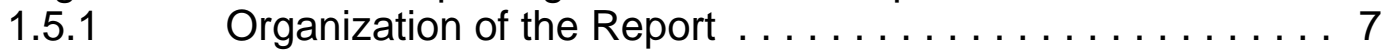

1.5.2 Reporting Period $\ldots \ldots \ldots \ldots \ldots \ldots \ldots \ldots$

2.0 RESOURCE CONSERVATION AND RECOVERY ACT AND SOLID

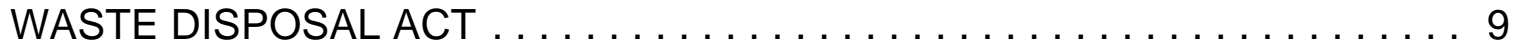

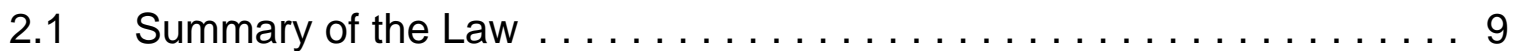

2.2 Status of Compliance with the Regulatory Requirements ......... 10

2.2.1 Compliance with the Resource Conservation and

Recovery Act ................... 10

2.2.2 Compliance with the Land Disposal Restrictions,

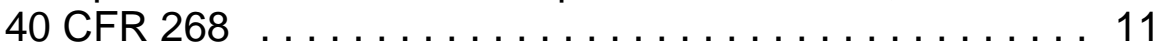

3.0 COMPREHENSIVE ENVIRONMENTAL RESPONSE, COMPENSATION,

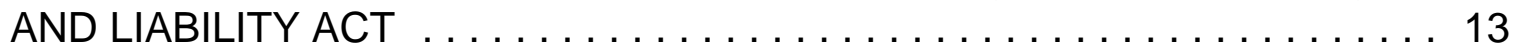

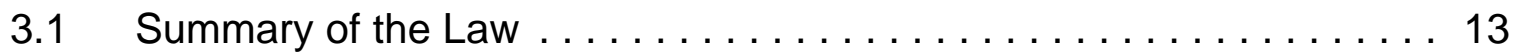

3.2 Compliance Status of the Regulatory Requirements . . . . . . . 14

3.2.1 Designation of Hazardous Substances, 40 CFR $\S 302.4$. . 14

3.2.2 Determination of Reportable Quantities, 40 CFR

3.2.3 Notification Requirements, 40 CFR $\$ 302.6(a) \ldots \ldots \ldots \ldots 14$

3.2.4 Releases of Mixtures or Solutions, 40 CFR $\S 302.6(b)(1)$ (i) and (ii) .................. 14

3.2.5 Notification of Releases of Radionuclides, 40 CFR

3.2.6 Notification of the Release of Heavy Metals, 40 CFR

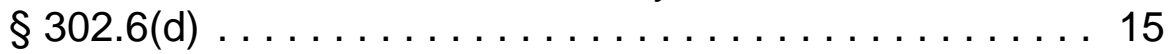

4.0 EMERGENCY PLANNING AND COMMUNITY RIGHT-TO-KNOW ACT $\ldots 17$

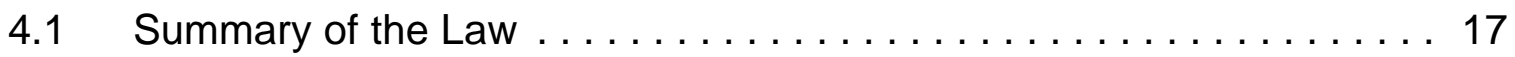

4.2 Compliance Status of the Regulatory Requirements . . . . . . . . 18

4.2.1 Emergency Planning, 40 CFR $\S 355.30$ (a) . . . . . . . . 18

4.2.2 Emergency Planning Notification, 40 CFR $\S 355.30$ (b) $\ldots 18$

4.2.3 Facility Emergency Coordinator, 40 CFR $\S 355.30$ (c) $\ldots 18$

4.2.4 Provision of Information, 40 CFR $\S 355.30$ (d) . . . . . . 18

4.2.5 Emergency Release Notification, 40 CFR $\S 355.40 \ldots . .19$ 
4.2.6 Material Safety Data Sheet Reporting, 40 CFR § 370.21 . . 19

4.2.7 Inventory Reporting, 40 CFR $\S 370.25 \ldots \ldots \ldots \ldots \ldots 19$

4.2.8 Reporting Requirements and Schedule for Reporting,

40 CFR $\S 372.30 \ldots \ldots \ldots \ldots \ldots \ldots \ldots \ldots \ldots \ldots$

5.0 ATOMIC ENERGY ACT AND THE ENVIRONMENTAL PROTECTION

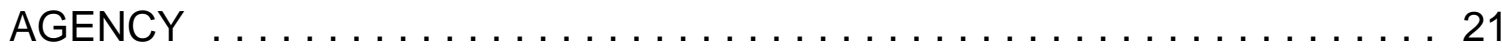

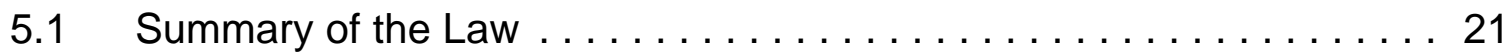

5.2 Compliance Status with the Regulatory Requirements .......... 22

5.2.1 Radiation Protection Standards, 40 CFR $191 \ldots \ldots \ldots .22$

5.2.2 WIPP Compliance Certification Criteria, 40 CFR $194 \ldots 23$

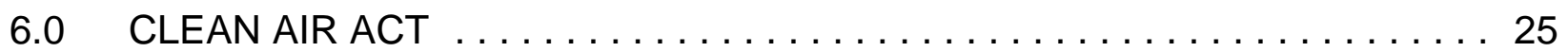

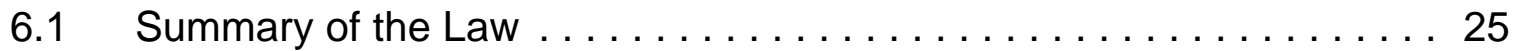

6.1.1 Title I, Air Pollution Prevention and Control . . . . . . . . 25

6.1.2 Title II, Emission Standards for Mobile Sources . . . . . . . 27

6.1.3 Title III, General Provisions ................. 28

6.1 .4 Title IV, Acid Deposition Control . . . . . . . . . . . . 28

$6.1 .5 \quad$ Title $\mathrm{V}$, Permits ........................ 28

6.1.6 Title VI, Stratospheric Ozone Protection . . . . . . . . . 29

6.2 Compliance Status with the Regulatory Requirements . . . . . . . 30

6.2.1 Control of Pollution from Federal Facilities, CAA $\S 118 \ldots 30$

6.2.2 National Emission Standards for Hazardous Air

6.2.3 State Operating Permit Programs, 20 NMAC 2.70

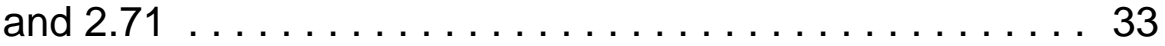

6.2.4 Protection of Stratospheric Ozone, 40 CFR $82 \ldots \ldots \ldots 35$

6.3 Compliance Status of Permit Conditions . . . . . . . . . . . . 42

7.0 FEDERAL WATER POLLUTION CONTROL ACT OF 1972 ("CLEAN

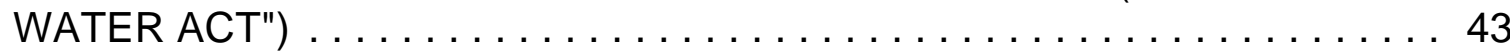

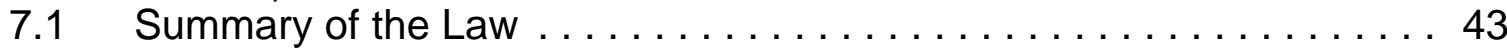

7.2 Compliance Status of the Regulatory Requirements .......... 44

7.2.1 SPCC Plan Requirements, 40 CFR $\S 112.3 \ldots \ldots \ldots \ldots 44$

7.2.2 Amendment of the SPCC Plan by the Owner/Operator, 40 CFR $\S 112.5 \ldots \ldots \ldots \ldots \ldots \ldots \ldots \ldots \ldots 44$

7.2.3 Notification of Discharge of a Reportable Quantity,

40 CFR $\S 117.21 \ldots \ldots \ldots \ldots \ldots \ldots \ldots \ldots 44$

7.2.4 NPDES Permit Requirement, 40 CFR $\S 122.1$ (b)(1) . . . 44

7.2.5 NPDES Permit Assessment, 40 CFR $\S 122.21$ (c)(2) . . . 44

7.2.6 Requirement for NPDES Permit for Storm Water

Discharges, 40 CFR $\S 122.26(a) \ldots \ldots \ldots \ldots \ldots \ldots 45$

7.2.7 Application Requirement for Storm Water Discharges

Associated with Industrial Activity, 40 CFR § 122.26(c) . . . 46

7.3 Compliance Status of Permit Conditions . . . . . . . . . . . . . 46

7.3.1 Notice of Intent to File for a General Permit, IV(A) and

Appendix B, II(A) .................. 46

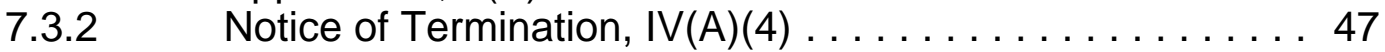


7.3.3 Prohibition on Non-Storm Water Discharges, IV(B)(1)

7.3.4 $\quad$ and Appendix B, III(A) . . . Releases of Reportable Quantities of Hazardous

Substances and Oil, IV(B)(2) and Appendix B, III(B) . . . 47

7.3.5 Storm Water Pollution Prevention Plan, IV(C) and

Appendix B, Part IV .................. 47

7.3.6 Pollution Prevention Team, IV(C)(1) and Appendix B,

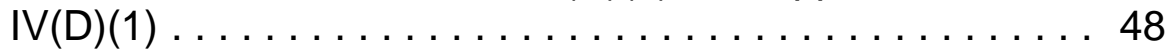

7.3.7 Identification of Potential Pollution Sources, IV(C)(2)

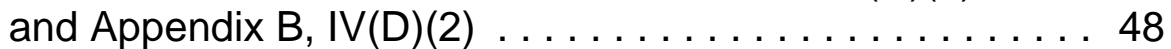

7.3.8 Site Assessments, IV(C)(2) and Appendix B, IV(D) . . . . 48

7.3.9 Measures and Controls, IV(C)(3) and Appendix B,

$\operatorname{IV}(\mathrm{D})(3) \ldots \ldots \ldots \ldots \ldots \ldots \ldots \ldots \ldots \ldots . \ldots \ldots$

7.3.10 Comprehensive Site Compliance Evaluations, IV(C)(4)

and Appendix B, IV(D)(4) . . . . . . . . . . . . 49

7.3.11 Requirements for Storage, Processing, and Handling Areas for EPCRA § 313 "Water Priority Chemicals," IV(D)(1) and Appendix B, IV(D)(7) . . . . . . . . . . 49

7.3.12 Enclosure or Covering of Outdoor Salt Piles, IV(D)(2)

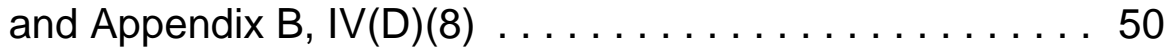

7.3.13 Notification to Municipal Large and Medium Separate

Storm Water Systems, IV(D)(3) and Appendix B, $\operatorname{IV(D)(5)\ldots \ldots \ldots \ldots \ldots \ldots \ldots \ldots \ldots \ldots .\ldots \ldots } 50$

7.3.14 Monitoring and Reporting Requirements, IV(E) and Appendix B, Part IV and XI (C)(vi) . . . . . . . . . 50

8.0 SAFE DRINKING WATER ACT $\ldots \ldots \ldots \ldots \ldots \ldots \ldots \ldots \ldots \ldots \ldots \ldots \ldots \ldots \ldots$

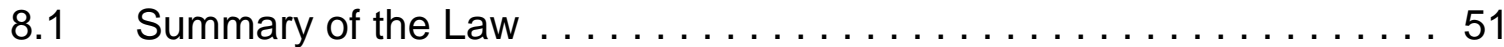

8.2 Compliance Status of the Regulatory Requirements ......... 51

8.2.1 State Program Requirements, 40 CFR $\S 142.4 \ldots \ldots \ldots 51$

8.2.2 Underground Injection Control, 40 CFR $144 \ldots \ldots \ldots .51$

9.0 TOXIC SUBSTANCES CONTROL ACT $\ldots \ldots \ldots \ldots \ldots \ldots \ldots \ldots$

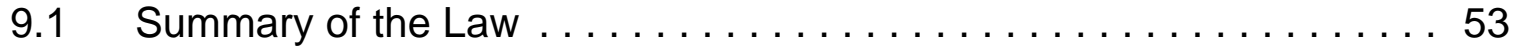

9.1.1 Asbestos Hazard Emergency Response Act of 1986 . . . . 53

9.1.2 Indoor Radon Abatement ................. 53

9.1.3 Polychlorinated Biphenyls ................ 54

9.2 Compliance Status of the Regulatory Requirements . . . . . . . . . 54

9.2.1 Study of Radon in Federal Buildings, TSCA, $\S 309 \ldots \ldots 54$

9.2.2 Prohibition of PCBs, 40 CFR $\S 761.20 \ldots \ldots \ldots \ldots \ldots .55$

9.2.3 Disposal Requirements for PCBs, 40 CFR $\S 761.60 \ldots 55$

10.0 FEDERAL INSECTICIDE, FUNGICIDE, AND RODENTICIDE ACT . . . . 57

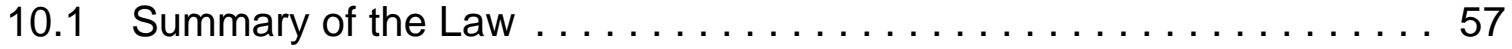

10.2 Compliance Status of the Regulatory Requirements . . . . . . . . 57

10.2.1 Registration of Pesticide Products, 40 CFR $\S 152.15 \ldots 57$

10.2.2 Storage and Disposal of Pesticides and Containers, 40 CFR $\S 156.10 \ldots \ldots \ldots \ldots \ldots \ldots \ldots \ldots \ldots$ 
11.0 NOISE CONTROL ACT OF $1972 \ldots \ldots \ldots \ldots \ldots \ldots \ldots \ldots \ldots \ldots \ldots \ldots$

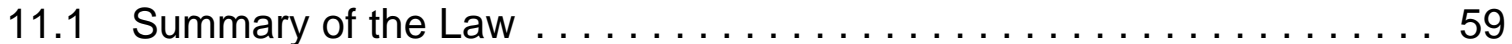

11.2 Compliance Status of the Regulatory Requirement . . . . . . . . . 59 11.2.1 Compliance with Hearing Protection Standards, 29 CFR

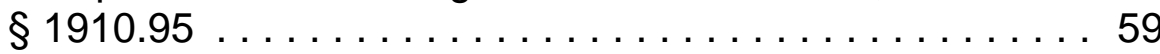

12.0 NATIONAL ENVIRONMENTAL POLICY ACT $\ldots \ldots \ldots \ldots \ldots \ldots \ldots \ldots \ldots$

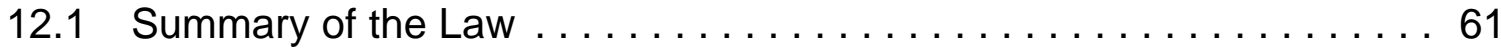

12.2 Compliance Status of the Regulatory Requirements ..........6 61

12.2.1 Provision of Environmental Information to Public

Officials and Private Citizens, 40 CFR 1500 through $1508 \ldots \ldots \ldots \ldots \ldots \ldots \ldots \ldots \ldots \ldots \ldots \ldots \ldots \ldots \ldots$

12.3 U.S. Department of Energy Compliance with NEPA . . . . . . . . . 61

12.3.1 Summary of the Law $\ldots \ldots \ldots \ldots \ldots \ldots \ldots \ldots \ldots$

12.3.2 Implementing DOE's NEPA Regulations at WIPP,

12.3.3 Operational Compliance with NEPA at WIPP $\ldots \ldots \ldots 64$

13.0 ATOMIC ENERGY ACT AND THE U.S. DEPARTMENT OF ENERGY . . . . 65

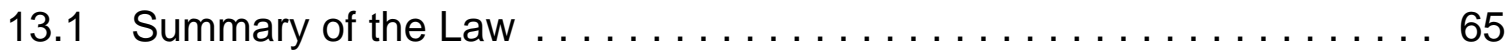

13.2 Compliance Status with the Regulatory Requirements . . . . . . 65

13.2.1 DOE Order 151.1, Comprehensive Emergency

Management System .................66 66

13.2.2 DOE Order 225.1A, Accident Investigations ........66 66

13.2.3 DOE Order 231.1, Environment, Safety and Health

Reporting ....................66 66

13.2.4 DOE Order 232.1A, Occurrence Reporting and

Processing of Operations Information . . . . . . . . 66

13.2.5 DOE Order 414.1A, Quality Assurance . . . . . . . . 67

13.2.6 DOE Order 420.1 , Facility Safety . ............. 67

13.2.7 DOE Order 435.1, Radioactive Waste Management .... 67

13.2.8 DOE Order 440.1A, Worker Protection Management for

DOE Federal Contractor Employees ............. 67

13.2.9 DOE Order 451.1A, National Environmental Policy Act

Compliance Program ................. 67

13.2.10 DOE Order 460.1A, Packaging and Transportation

Safety ..................... 67

13.2.11 DOE Order 460.2, Departmental Materials

Transportation and Packaging Management ........68 68

13.2.12 DOE Order 5400.1, General Environmental Protection

Program ..................... 68

13.2.13 DOE Order 5400.5, Radiation Protection of the Public and the Environment ................ 68

13.2.14 DOE Order 5480.4, Environmental Protection, Safety and Health Protection Standards (portions) . . . . . . 68

13.2.15 DOE Order 5480.21, Unreviewed Safety Questions . . . . 69

13.2.16 DOE Order 5480.22, Technical Safety Requirements ... 69 
13.2.17 DOE Order 5480.23, Nuclear Safety Analysis Reports ... 69

13.2.18 DOE Order 5484.1, Environmental Protection, Safety and

Health Protection Information Reporting Requirements ... 69

13.2.19 DOE Order 5530.4, Aerial Measuring System .........6 69

13.2.20 DOE Order 6430.1A, General Design Criteria . . . . . . . 69

13.3 Other Regulations - 10 CFR 830 Series . . . . . . . . . . . . 70

13.3.1 Taking Action(s) Inconsistent with the Requirements of 10 CFR 830, 10 CFR $\S 830.4(a) \ldots \ldots \ldots \ldots \ldots .70$

13.3.2 Implementation and Compliance with Requirements of

13.3.3 Plan or Program Required by This Part as the Basis for Determining Compliance, 10 CFR $\S 830.4$ (c) . . . . . . 71

13.3.4 Records to Substantiate Compliance, 10 CFR $\S 830.6$. . . 71

13.3.5 Use of a Graded Approach, 10 CFR $\S 830.7 \ldots \ldots \ldots .71$

13.3.6 Development and Implementation of Contractor's QAP

To Be Approved by the DOE and Conduct of Work in

Accordance with 10 CFR $\S 830.120(a)$ and 10 CFR

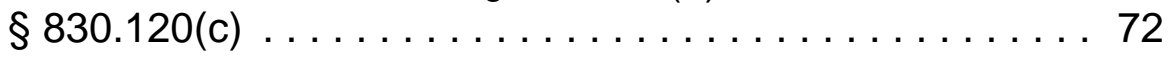

13.3.7 Application of the Appropriate QA Criteria in the QAP and Annual Submittal of Substantive Changes in the

QAP to the DOE, 10 CFR $\S 830.120$ (b) . . . . . . . . 72

13.3.8 QA Criteria To Be Included in the QAP, $10 \mathrm{CFR}$

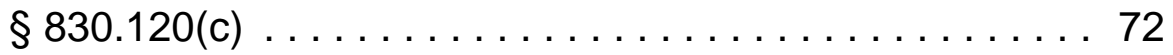

13.3.9 Occupational Dose Limits for General Employees,

10 CFR $\S 835.202(a) \ldots \ldots \ldots \ldots \ldots \ldots \ldots \ldots . \ldots . \ldots 74$

13.4 Nuclear Safety Noncompliance and the Price-Anderson

Amendments Act of 1988

14.0 ATOMIC ENERGY ACT AND THE U.S. NUCLEAR REGULATORY

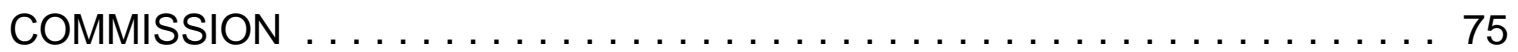

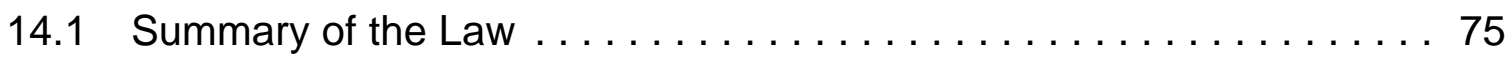

14.2 Compliance Status of the Regulatory Requirements $\ldots \ldots \ldots \ldots 75$

14.2.1 General License, 10 CFR $\S 71.12 \ldots \ldots \ldots \ldots \ldots \ldots 75$

14.2.2 Contents of Application and Package Description/

Evaluation, 10 CFR $\$ 71.31$ through 71.39

14.2.4 Standards for All Packages, 10 CFR $\S \S 71.43$

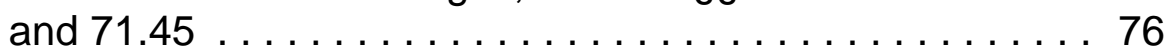

14.2.5 External Radiation Standards for All Packages,

10 CFR $\S 71.47 \ldots \ldots \ldots \ldots \ldots \ldots \ldots \ldots \ldots . \ldots 77$

14.2.6 Additional Requirements for Type B Packages,

10 CFR $\S 71.51 \ldots \ldots \ldots \ldots \ldots \ldots \ldots \ldots \ldots \ldots 77$

14.2.7 Requirements for All Fissile Material Packages,

10 CFR $\S \S 71.55$ through $71.61 \ldots \ldots \ldots \ldots \ldots \ldots 77$

14.2.8 Special Requirements for Plutonium Shipments,

10 CFR $\S 71.63 \ldots \ldots \ldots \ldots \ldots \ldots \ldots \ldots$

14.2.9 Tests under Normal Conditions of Transport, 10 CFR

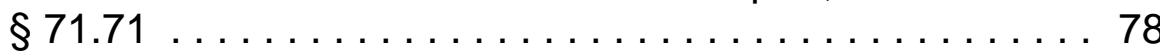


14.2.10 Tests under Hypothetical Accident Conditions, 10 CFR

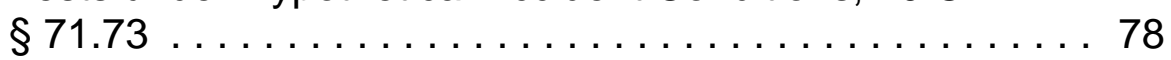

14.2.11 Compliance with Operating Controls and Procedures, 10 CFR $\S 71.81 \ldots \ldots \ldots \ldots \ldots \ldots \ldots \ldots \ldots . \ldots 79$

14.2.12 Assumptions Regarding Unknown Properties, 10 CFR

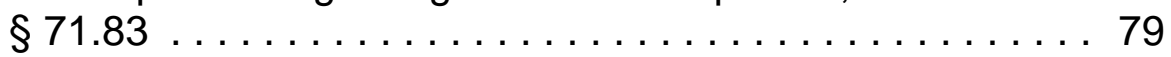

14.2.13 Preliminary Determination of Integrity of Packaging,

Pressure Testing, and Marking, 10 CFR $\S 71.85$. . . . . 79

14.2.14 Routine Determinations Prior to Each Shipment, 10 CFR

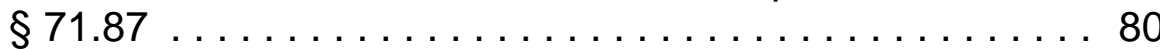

14.2.15 Special Opening Instructions, 10 CFR $\S 71.89 \ldots \ldots .80$

14.2.16 Maintenance of Records, 10 CFR $\S 71.91 \ldots \ldots \ldots .80$

14.2.17 NRC Inspections and Tests, 10 CFR $\S 71.93 \ldots \ldots .81$

14.2.18 Reports Regarding Decreased Effectiveness or Defects with Safety Significance, 10 CFR $\S 71.95 \ldots \ldots \ldots . .81$

14.2.19 Advance Notification of Shipment of Nuclear Waste, 10 CFR $\S 71.97 \ldots \ldots \ldots \ldots \ldots \ldots \ldots \ldots \ldots . \ldots 1$

14.2.20 NRC Quality Assurance Requirements, 10 CFR

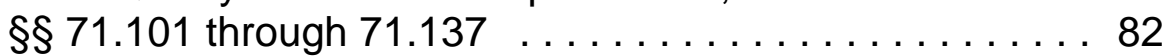

14.3 Compliance Status of the Certificate of Compliance ......... 83

14.3.1 Overall Specifications for the TRUPACT-II, C of C,

Page 1,5(2), Paragraph $1 \ldots \ldots \ldots \ldots . \ldots 3$

14.3.2 Overall Weight, $C$ of C, Page 1, 5(2), Paragraph $1 \ldots 83$

14.3.3 Outer Containment Assembly of the TRUPACT-II, C of C, Page 1, 5(2), Paragraph $2 \ldots \ldots \ldots \ldots . \ldots . \ldots 4$

14.3.4 Inner Containment Vessel of the TRUPACT-II, C of C, Page 1,5(2), Paragraph $3 \ldots \ldots \ldots \ldots . \ldots . \ldots 4$

14.3.5 Drawings Showing Construction of TRUPACT-II, C of C, Page 2, 5(a)(3), Paragraph $1 \ldots \ldots \ldots \ldots . \ldots . \ldots 8$

14.3.6 Drawings Showing Position of Contents in TRUPACT-II, C of C, Page 2, 5(a)(3), Paragraph $2 \ldots \ldots \ldots . .85$

14.3.7 Physical Form of Allowable Material and Receptacles, C of C, Page 2, 5(b)(1) ................ 85

14.3.10 Restriction of Free Liquids, C of C, Page 2, $5(\mathrm{~b})(1) \ldots .86$

14.3.11 Restriction of Flammable Organics, C of C, Page 2,

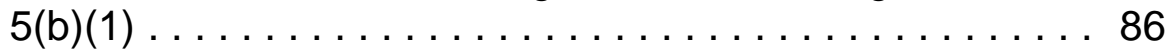

14.3.12 Maximal Allowable Weight, C of C, Page 2, 5(b)(2), Paragraph $1 \ldots \ldots \ldots \ldots \ldots \ldots \ldots \ldots$. 87

14.3.13 Maximum Number of Payload Containers Per Package and Authorized Configurations, C of C, Page 2, 5(b)(2), Paragraph $2 \ldots \ldots \ldots \ldots \ldots \ldots \ldots \ldots \ldots$

14.3.14 Amount of Allowable Fissile Material, C of C, Page 2, $5(b)(2)$, Paragraph $3 \ldots \ldots \ldots \ldots \ldots \ldots \ldots \ldots$

14.3.15 Allowable Decay Heat, $C$ of $C$, Page 2, $5(b)(2) \ldots \ldots .88$

14.3.16 Criticality Transport Index, $C$ of $C$, Page 3, 5(c) . . . . . 88 14.3.17 Restrictions of Form, Properties, and Other Parameters, $\mathrm{C}$ of $\mathrm{C}$, Page $3,6 \ldots \ldots \ldots \ldots \ldots \ldots$

14.3.18 Shipping Category Designations, $C$ of C, Page $3,7 \ldots 89$ 
14.3.19 Labeling Requirements, $C$ of C, Page 3, $8 \ldots \ldots \ldots 89$

14.3.20 Preshipment Venting or Aspirating Requirements, C of C,

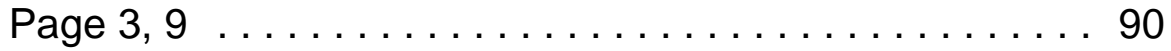

14.3.21 Requirements of Subpart G of 10 CFR 71, C of C,

Page $3,10 \ldots \ldots \ldots \ldots \ldots \ldots \ldots \ldots \ldots . \ldots \ldots$

14.3.22 Preparation of Packages for Shipment and Operations,

C of C, Page 3, 10(a) ................. 90

14.3.23 Testing and Maintenance of Packages, C of C, Page 4,

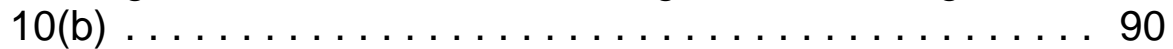

14.3.24 Leak Testing, $C$ of $C$, Page 4, 10(c) . . . . . . . . 91

14.3.25 Removal of Free-Standing Water, C of C, Page 4, 10(d) . 91

14.3.26 Approval of the TRUPACT-II Packaging, C of C,

Page $4,11 \ldots \ldots \ldots \ldots \ldots \ldots \ldots \ldots \ldots \ldots \ldots \ldots$

15.0 HAZARDOUS MATERIALS TRANSPORTATION ACT . . . . . . . . . 93

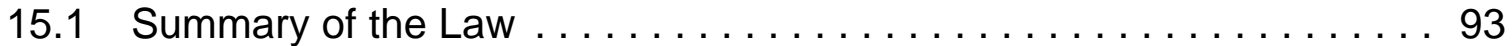

15.2 Compliance Status of the Regulatory Requirements . . . . . . . . 94

15.2.1 General Requirements, 49 CFR $\S 171.2 \ldots \ldots \ldots \ldots .94$

15.2.2 Hazardous Waste, 49 CFR $\S 171.3 \ldots \ldots \ldots \ldots \ldots . . . . .94$

15.2.3 Transitional Provisions for Implementing Requirements

Based on the United Nations Recommendations,

49 CFR $\S 171.14 \ldots \ldots \ldots \ldots \ldots \ldots$

15.2.4 Immediate Notice of Certain Hazardous Materials

Incidents and Detailed Hazardous Materials Incident

Reports, 49 CFR $\S \S 171.15$ through $171.16 \ldots \ldots \ldots 95$

15.2.5 Table of Hazardous Materials, 49 CFR $\S 172.101 \ldots . .99$

15.2.6 Shipping Papers, Subpart C, 49 CFR $\S \S 172.200$

through $172.205 \ldots \ldots \ldots \ldots \ldots \ldots \ldots \ldots \ldots \ldots$

15.2.7 Marking, Subpart D, 49 CFR $\S \S 172.300$ through

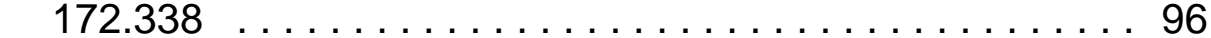

15.2.8 Labeling, Subpart E, 49 CFR $\S \S 172.400$ through

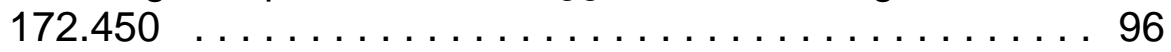

15.2.9 Placarding, Subpart F, 49 CFR $\S \S 172.500$ through

172.560

15.2.10 Emergency Response Information, Subpart G, 49 CFR

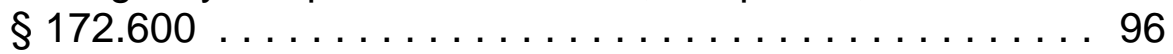

15.2.11 Training Requirements, Federal/State Relationship, and Applicability and Responsibility for Training and

Testing, Subpart H, 49 CFR §§ 172.700 through .702

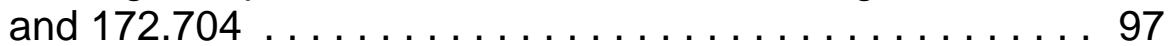

15.2.12 General Requirements for Shipments and Packaging, Subpart A, 49 CFR $\S \S 173.1$ through $173.12 \ldots \ldots \ldots . .98$

15.2.13 Preparation of Hazardous Materials for Transportation, Subpart B, 49 CFR $\S \S 173.21$ through $173.40 \ldots \ldots \ldots .98$

15.2.14 Definitions, Classification, and Packaging for Class 1

Materials, Subpart C, 49 CFR $\S \S 173.50$ through

173.63 
15.2.15 Definitions, Classification, Packaging Group

Assignments, and Exceptions for Hazardous Materials

other than Class 1 and Class 7, Subpart D, 49 CFR

$\S \S 173.115$ through $173.156 \ldots \ldots \ldots \ldots \ldots \ldots$

15.2.16 Non-Bulk Packaging Requirements for Hazardous

Materials other than Class 1 and Class 7, Subpart E,

49 CFR $\S \S 173.158$ through $173.229 \ldots \ldots \ldots \ldots \ldots .99$

15.2.17 Radioactive Materials, Subpart I, 49 CFR $\S \S 173.401$ through $173.476 \ldots \ldots \ldots \ldots \ldots \ldots \ldots$

15.2.18 Carriage by Aircraft, 49 CFR $175 \ldots \ldots \ldots \ldots \ldots .100$

15.2.19 Driver Training, 49 CFR $\S \S 177.800,177.816$, and 397,

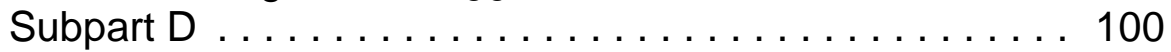

15.2.20 Specifications for Packagings, 49 CFR $178 \ldots \ldots \ldots \ldots$

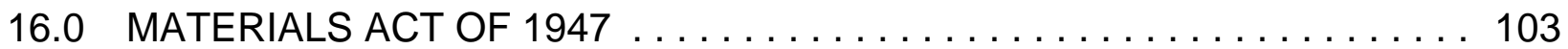

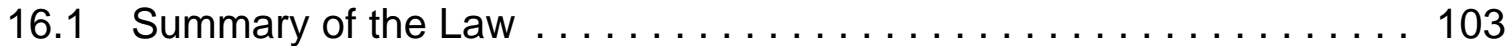

16.2 Compliance Status of the Regulatory Requirement .......... 103

16.2.1 Environmental Protection During Disposal of Mineral Material, 43 CFR $\S 3601.1-3 \ldots \ldots \ldots \ldots \ldots \ldots . \ldots 103$

17.0 FEDERAL LAND POLICY AND MANAGEMENT ACT $\ldots \ldots \ldots \ldots \ldots \ldots$

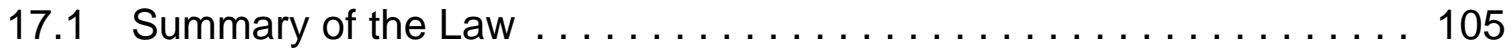

17.2 Compliance Status of the Regulatory Requirements $\ldots \ldots \ldots \ldots 106$

17.2.1 Resource Management Planning Guidance, 43 CFR

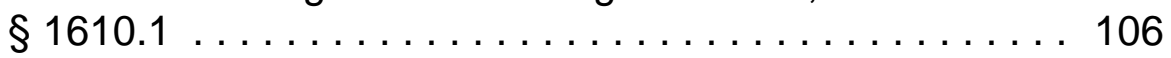

17.2.2 Public Participation, 43 CFR $\S 1610.2 \ldots \ldots \ldots \ldots \ldots 106$

17.2.3 Consistency of Management Plans, 43 CFR

106

17.2.4 Common Terms and Conditions of Right-of-Way

Reservations and Temporary-Use Permits, 43 CFR

$\S 2801.2(a) \ldots \ldots \ldots \ldots \ldots \ldots \ldots \ldots \ldots \ldots \ldots 10 \ldots$

17.2.5 Conditions to be Incorporated within all Right-of-Way

Reservations and Temporary-Use Permits, 43 CFR

$\S 2801.2(b) \ldots \ldots \ldots \ldots \ldots \ldots \ldots \ldots \ldots \ldots \ldots$

17.2.6 Requirements for Applications for Right-of-Way

Reservations and Temporary-Use Permits, 43 CFR

$\S 2802.2 \ldots \ldots \ldots \ldots \ldots \ldots$

17.3 Compliance Status of the Permit Conditions . . . . . . . . . 110

17.3.1 Common Conditions of the Right-of-Way Reservations . . 110

17.3.2 Right-of-Way Reservation No. NM 53809, Water

17.3.3 Right-of-Way Reservation No. NM 55676,

North Access Road ....................... 112

17.3.4 Right-of-Way Reservation No. NM 55699, Railroad . . . . 113

17.3.5 Right-of-Way Reservation No. NM 63136, Dosimetry

and Aerosol Sampling Sites ................ 115

17.3.6 Right-of-Way Reservation for Subsidence Monuments,

No. NM 65801 . . . . . . . . . . . . . . . . . . . . 116 
17.3.7 Right-of-Way Reservation for Two Survey Monuments,

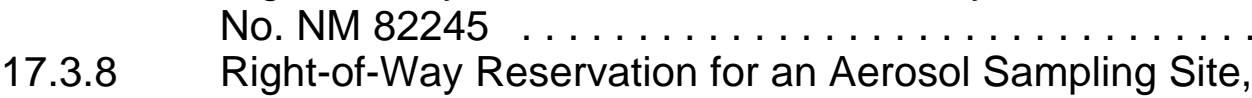
No. NM 77921 (NM 77860) . . . . . . . . . . . . . . 117

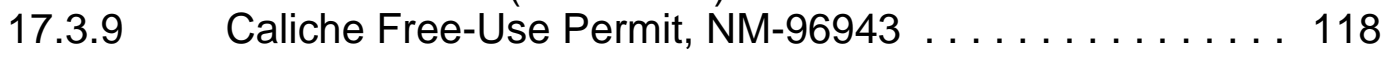

18.0 PUBLIC RANGELANDS IMPROVEMENT ACT $\ldots \ldots \ldots \ldots \ldots \ldots \ldots 121$

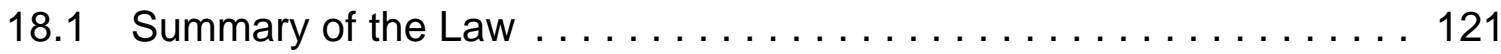

18.2 Compliance Status of the Regulatory Requirement . . . . . . . 122 18.2.1 Land Use Plans, 43 CFR $\S 4100.0$ through $4100.8 \ldots \ldots 122$

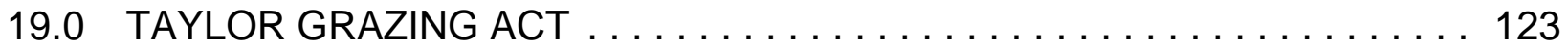

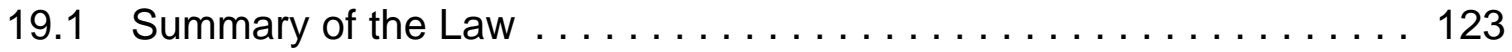

19.2 Compliance Status of the Regulatory Requirements . . . . . . . 123 19.2.1 Land Use Plans, 43 CFR $\S 4100.0$ through $4100.8 \ldots \ldots 124$

19.2.2 Allotment Management Plans, 43 CFR $\S 4120.2 \ldots \ldots .124$

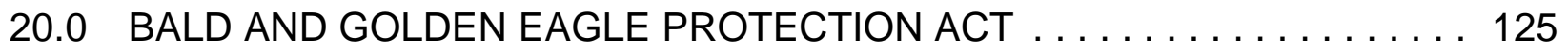

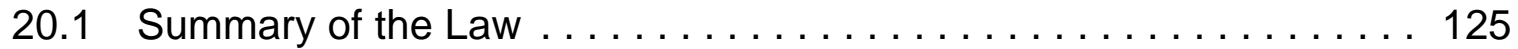

20.2 Compliance Status of the Regulatory Requirements ........... 125 20.2.1 Permit Application Procedures, 50 CFR $\S 13.11 \ldots \ldots .126$ 20.2.2 General Permit Requirements, 50 CFR $\S 22.11 \ldots \ldots .126$ 20.2.3 Permits to Take Golden Eagle Nests, 50 CFR $\S 22.25$. . 126

21.0 MIGRATORY BIRD TREATY ACT $\ldots \ldots \ldots \ldots \ldots \ldots \ldots \ldots \ldots \ldots \ldots \ldots \ldots$

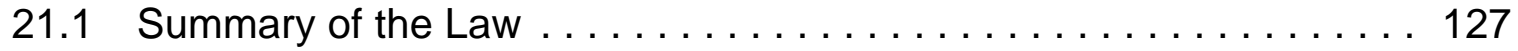

21.2 Compliance Status of the Regulatory Requirements . . . . . . . 128

21.2.1 Permit Application Procedures, 50 CFR $\S 13.11 \ldots \ldots .128$

21.2.2 Information Requirements for Permit Applications,

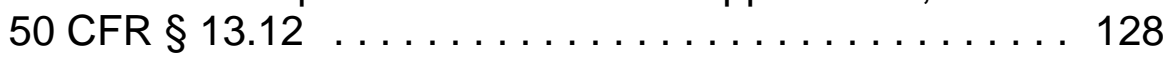

21.2.3 Display of Permit, 50 CFR $\S 13.44 \ldots \ldots \ldots \ldots \ldots \ldots 128$

21.2.4 Filing of Reports, 50 CFR $\S 13.45 \ldots \ldots \ldots \ldots \ldots \ldots$

21.2.5 Maintenance of Records, 50 CFR $\S 13.46 \ldots \ldots \ldots \ldots 129$

21.2.6 Inspection Requirement, 50 CFR $\S 13.47 \ldots \ldots \ldots \ldots 129$

21.2.7 Compliance with Permit Conditions, 50 CFR $\S 13.48 \ldots 129$

21.2.8 Acceptance of Liability, 50 CFR $\S 13.50 \ldots \ldots \ldots \ldots .130$

21.2.9 Compliance with Applicable Migratory Bird Hunting

Regulations, 50 CFR 20, Subpart C . .......... 130

21.2.10 Application for Banding or Marking Permit, 50 CFR

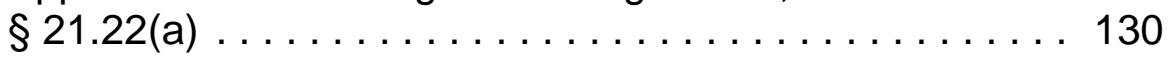

21.2.11 Additional Permit Conditions, 50 CFR $\S 21.22$ (c) . . . . 130

21.2.12 Term of Permit, 50 CFR $\S 21.22$ (d) $\ldots \ldots \ldots \ldots \ldots \ldots 131$

21.2.13 Special-Purpose Permits, 50 CFR $\S 21.27 \ldots \ldots \ldots \ldots 131$

21.2.14 Falconry Permits, 50 CFR $\S 21.28 \ldots \ldots \ldots \ldots \ldots \ldots 131$

21.2.15 Depredation Permits, 50 CFR $\S 21.41 \ldots \ldots \ldots \ldots . \ldots 131$

22.0 ENDANGERED SPECIES ACT $\ldots \ldots \ldots \ldots \ldots \ldots \ldots \ldots \ldots \ldots \ldots \ldots \ldots \ldots \ldots$

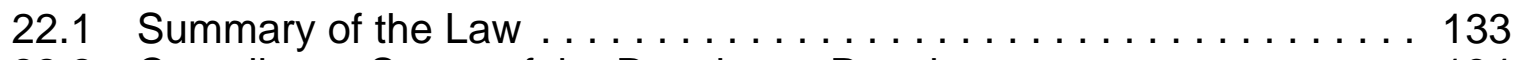

22.2 Compliance Status of the Regulatory Requirements . . . . . . . 134 
22.2.1 Permit Application Procedures, 50 CFR $\S 13.11 \ldots \ldots .134$

22.2.2 Application for Endangered or Threatened Species

Permit, 50 CFR $\S \S 17.22$ (a)(1), 17.32, 17.52,

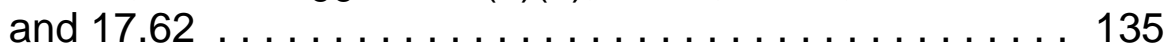

22.2.3 Biological Assessment of Impacts on Recognized

Species, 50 CFR $\S 402.12 \ldots \ldots \ldots \ldots \ldots \ldots \ldots 135$

22.2.4 Formal Consultation with the FWS Regarding Impacts

on Recognized Species, 50 CFR $\S 402.14$. . . . . . . 135

23.0 NATIONAL HISTORIC PRESERVATION ACT . . . . . . . . . . . . . . . 137

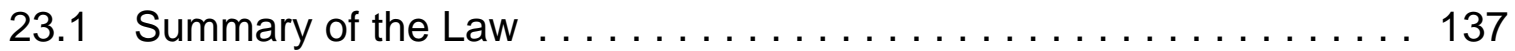

23.2 Compliance Status of the Regulatory Requirements . . . . . . . 138

23.2.1 Assessment of Effects on Historic Properties, 36 CFR

$\S 800.5 \ldots \ldots \ldots \ldots \ldots \ldots \ldots \ldots \ldots \ldots \ldots$

23.2.2 Development of a Plan for the Treatment of Historical

Property Discovered During a Federal Agency

Undertaking, 36 CFR $\S 800.11 \ldots \ldots \ldots \ldots \ldots \ldots . \ldots 139$

23.2.3 Application for Permits and Information Collection, 43 CFR $\S 7.5 \ldots \ldots \ldots \ldots \ldots \ldots \ldots \ldots \ldots \ldots$

24.0 NEW MEXICO ENVIRONMENTAL IMPROVEMENT ACT $\ldots \ldots \ldots \ldots \ldots 141$

24.1 Summary of the Law . . . . . . . . . . . . . . . . . . . 141

24.2 Compliance Status of the Law $\ldots \ldots \ldots \ldots \ldots \ldots \ldots \ldots \ldots \ldots$

25.0 NEW MEXICO HAZARDOUS WASTE ACT . . . . . . . . . . . . . . 143

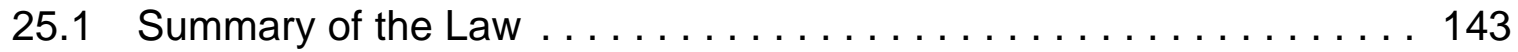

25.2 Compliance Status of Regulatory Requirements ........... 145

25.2.1 Compliance with the Hazardous Waste Regulatory

Requirement ...................... 145

25.2.2 Compliance with Standards Applicable to Generators

of Hazardous Waste, 20 NMAC 4.1, Subpart III, § 300 . . 145

25.2.3 Compliance with Standards Applicable to Transporters of Hazardous Waste, 40 CFR 263 (20 NMAC 4.1,

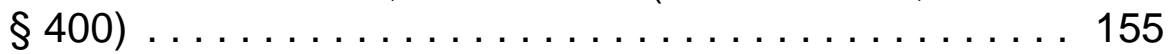

25.2.4 Compliance with the Regulatory Requirements for

TSDFs, 40 CFR 264 (20 NMAC 4.1, Subpart V, § 500) . . 157

25.2.5 Compliance with the Hazardous/Mixed Waste Permit

Program, 40 CFR 270 (20 NMAC 4.1, §§ 900

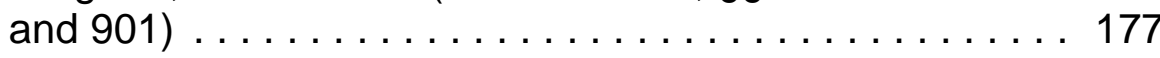

25.2.6 Compliance with the Universal Waste Management

Regulations under 20 NMAC Subpart X, § 1000

(40 CFR 273) . . . . . . . . . . . . . . . . . . . . . 179

25.2.7 Compliance with the UST Regulatory Requirements under 20 NMAC, Chapter $5 \ldots \ldots \ldots \ldots \ldots \ldots 181$

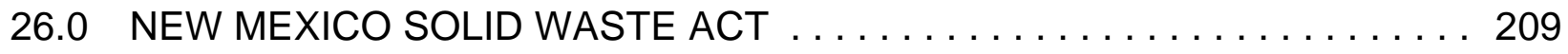

26.1 Summary of the Law . . . . . . . . . . . . . . . . . 209

26.2 Compliance Status of the Regulatory Requirements . . . . . . . . 209 
26.2.1 Applicability of Regulations, 20 NMAC 9.1, § 106.A . . . 209

26.2.2 General Requirements for Processing and Disposal of

Solid Waste, 20 NMAC 9.1, § $106 \ldots \ldots \ldots \ldots \ldots . .209$

26.2.3 Prohibited Acts, 20 NMAC 9.1, § $108 \ldots \ldots \ldots \ldots \ldots \ldots 210$

26.2.4 Exemptions, 20 NMAC 9.1, § 108c. . . . . . . . . . 210

26.2.5 Record Keeping and Annual Reports, 20 NMAC 9.1,

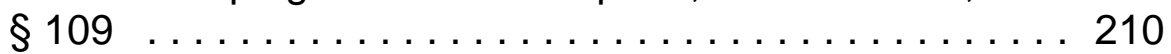

26.2.6 Entry by Department, Availability of Records,

20 NMAC $9.1, \S 111 \ldots \ldots \ldots \ldots \ldots \ldots \ldots \ldots .211$

26.2.7 Permit Application Requirements, 20 NMAC 9.1,

$\S \S 201,202,209,210 \ldots . . \ldots 211$

26.2.8 Solid Waste Facility Operation, 20 NMAC 9.1, $\S \S 401,403 \ldots \ldots \ldots \ldots \ldots \ldots \ldots \ldots \ldots \ldots \ldots \ldots \ldots \ldots \ldots$

26.2.9 Asbestos Waste, 20 NMAC 9.1, § $705 \ldots \ldots \ldots \ldots \ldots 211$

26.2.10 Landfill Closure and Postclosure Requirements,

20 NMAC 9.1, Subpart V

26.2.11 Operator Certification, 20 NMAC 9.1, Subpart VI . . . . 212

26.2.12 Storage and Containment of Infectious Waste, 20 NMAC $9.1, \S 706(C) \ldots \ldots \ldots \ldots \ldots \ldots \ldots 212$

26.2.13 Infectious Waste Treatment, Storage, and Disposal

Facilities, 20 NMAC 9.1, § 706(D) . . . . . . . . . . 213

26.2.14 Treatment and Disposal of Infectious Waste, 20 NMAC 9.1, $706(E) \ldots \ldots \ldots \ldots \ldots \ldots \ldots 213$

26.2.15 Infectious Waste Transporters, 20 NMAC 9.1,

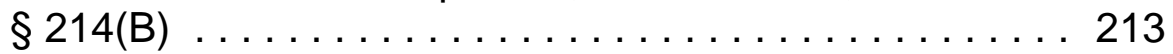

26.2.16 Manifest Requirements, 20 NMAC 9.1, § $712 \ldots \ldots \ldots 214$

27.0 NEW MEXICO GROUND WATER PROTECTION ACT . . . . . . . . . . 215

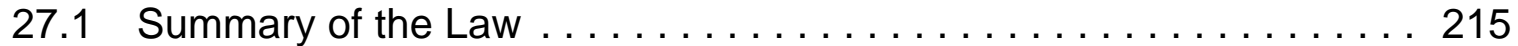

27.2 Compliance Status of the Regulatory Requirement ........... 215

27.3 Corrective Action for Spills/Releases From USTs, NMED-92-1 . . . . 215

28.0 NEW MEXICO AIR QUALITY CONTROL ACT . . . . . . . . . . . . . . . 217

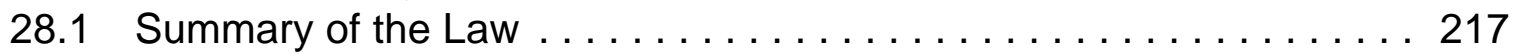

28.2 Compliance Status of the Regulatory Requirements . . . . . . . 217

28.2.1 Sampling Equipment, 20 NMAC $2.1 \ldots \ldots \ldots \ldots 217$

28.2.2 Excess Emissions During Malfunction, Start-Up,

28.2.3 Controlling Emissions Leaving New Mexico,

20 NMAC $2.8 \ldots \ldots \ldots \ldots \ldots \ldots \ldots \ldots \ldots \ldots . \ldots \ldots$

28.2.4 Oil-Burning Equipment--Particulate Matter,

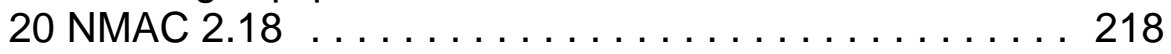

28.2.5 Oil-Burning Equipment--Nitrogen Dioxide,

20 NMAC $2.34 \ldots \ldots \ldots \ldots \ldots \ldots \ldots . \ldots \ldots$

28.2.6 Regulations to Control Open Burning, 20 NMAC $2.60 \ldots 218$

28.2.7 Regulations to Control Smoke and Visible Emissions,

20 NMAC $2.61 \ldots \ldots \ldots \ldots \ldots \ldots \ldots \ldots \ldots \ldots \ldots$

28.2.8 Compliance Plan, 20 NMAC 2.70.300 . . . . . . . 219 
28.2.9 Semiannual Operating Permit Reports and Progress

Reports on the Compliance Plan, 20 NMAC 2.70.302 . . 219

28.2.10 Permits, 20 NMAC $2.72 \ldots \ldots \ldots \ldots \ldots \ldots \ldots \ldots . . \ldots 220$

28.2.11 Permit Fees, 20 NMAC $2.75 \ldots \ldots \ldots \ldots \ldots \ldots \ldots .220$

28.2.12 National Emission Standards for Hazardous Air

Pollutants, 20 NMAC $2.78 \ldots \ldots \ldots \ldots \ldots \ldots$

28.2.13 Stack Height Requirements, 20 NMAC $2.80 \ldots \ldots \ldots .220$

28.3 Compliance Status of Permit Conditions . . . . . . . . . . . . . 220

28.3.1 Permit for Backup Diesel Generators, Permit

No. 310-M-2 . . . . . . . . . . . . . . . . . . . . . . 221

29.0 NEW MEXICO WATER QUALITY ACT . . . . . . . . . . . . . . . . . . . 227

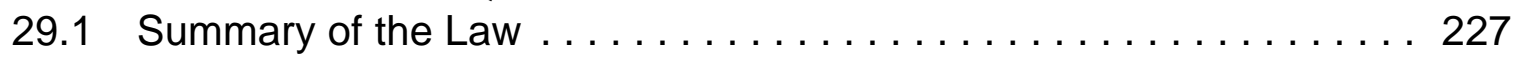

29.2 Compliance Status of the Regulatory Requirements . . . . . . . 227

29.2.1 Notice of Intent to Discharge, 20 NMAC 6.2, § 1-201 . . 227

29.2.2 Filing of Plans and Specifications - Sewerage

Systems, 20 NMAC 6.2, § 1-202 . . . . . . . . . 228

29.2.3 Notification of Discharge - Removal, 20 NMAC 6.2,

$\S 1-203 \ldots \ldots \ldots \ldots \ldots . \ldots \ldots \ldots . \ldots 228$

29.2.4 General Requirements, 20 NMAC 6.2, § 2-101 ....... 228

29.2.5 Discharge Plan Required, 20 NMAC 6.2, § 3-104 . . . . 229

29.2.6 Application for Discharge Plan Approval, 20 NMAC 6.2,

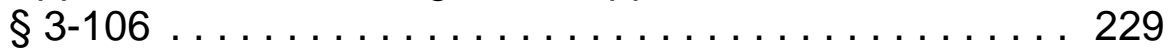

29.2.7 Monitoring, Reporting, and other Requirements,

Public Notice and Participation, 20 NMAC 6.2, § 3-108 .. 229

29.2.9 Director Approval, Disapproval, Modification, or

Termination of Proposed Discharge Plans,

20 NMAC 6.2, § 3-109 ................. 229

29.2.10 Water Quality Standards for Interstate and Intrastate

Streams in New Mexico, 20 NMAC $6.1 \ldots \ldots \ldots . .230$

29.2.11 Utility Operator Certification, 20 NMAC $7.4 \ldots \ldots \ldots 230$

29.3 Compliance Status of the Permit Requirements ............. 230

29.3.1 Requirements for Reporting Discharge Volumes,

Water Sources, and Quarterly Reports, DP-831

Conditions for Approval (CA) $1 \ldots \ldots \ldots \ldots \ldots \ldots .231$

29.3.2 Requirement for Water Quality Analysis Submitted

with Quarterly Report, DP-831 CA 2 . . . . . . . . 231

29.3.3 Requirement for Reporting Volume and Origin of

Miscellaneous Nonhazardous Discharges,

DP-831 CA 3

29.3.4 Authorization to Discharge, DP-831 Specific

Requirement $1 \ldots \ldots \ldots \ldots \ldots \ldots \ldots \ldots \ldots 232$

29.3.5 Authorization to Discharge, DP-831 Specific

Requirement $2 \ldots \ldots \ldots \ldots \ldots \ldots \ldots \ldots \ldots 232$

29.3.6 Authorization to Discharge, DP-831 Specific

Requirement $3 \ldots \ldots \ldots \ldots \ldots \ldots \ldots \ldots \ldots . \ldots \ldots 2$ 
29.3.7 Maintenance of Berms, DP-831 Specific

Requirement $4 \ldots \ldots \ldots \ldots \ldots \ldots \ldots \ldots \ldots 232$

29.3.8 Contingency Plan Required, DP-831 Specific

Requirement $5 \ldots \ldots \ldots \ldots \ldots \ldots \ldots \ldots 232$

29.3.9 Facility Closure Plan Required, DP-831 Specific

Requirement $6 \ldots \ldots \ldots \ldots \ldots \ldots \ldots \ldots 233$

29.3.10 General Requirement, Monitoring and Reporting,

DP-831 . . . . . . . . . . . . . . . . . . . 233

29.3.11 General Requirement, Record Keeping, DP-831 . . . . . 233

29.3.12 General Requirement, Inspection and Entry, DP-831 . . 233

29.3.13 General Requirement, Duty to Provide Information,

DP-831 . . . . . . . . . . . . . . . . . . . . . . . 233

29.3.14 General Requirement, Spills, Leaks, and other

Unauthorized Discharges, DP-831 . . . . . . . . . 234

29.3.15 General Requirement, Retention of Records, DP-831 . . 234

29.3.16 General Requirement, Modifications and/or Amendments, DP-831 ................. 234

30.0 NEW MEXICO DRINKING WATER REGULATIONS . . . . . . . . . 237

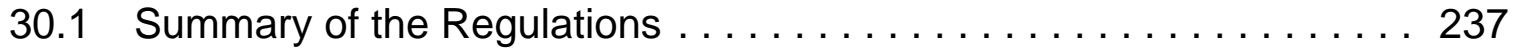

30.2 Compliance Status of the Regulatory Requirements . . . . . . . . 237

30.2.1 Maximum Contaminant Level for Total Coliform

Bacteria, 20 NMAC 7.1, \& 205(A) ............. 238

Cross-Connections, 20 NMAC 7.1, § 208(I) ......... 238

30.2.3 Certification of Sampling Personnel, 20 NMAC 7.1,

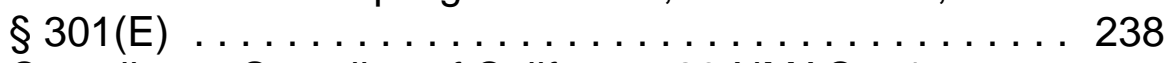

30.2.4 Compliance Sampling of Coliforms, 20 NMAC 7.1,

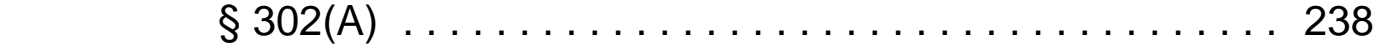

30.2.5 Laboratories, 20 NMAC 7.1, § $309 \ldots \ldots \ldots \ldots \ldots \ldots 239$

30.2.6 Sampling of Consecutive Public Water-Supply

Systems, 20 NMAC $7.1, \S 310 \ldots \ldots \ldots \ldots \ldots 239$

30.2.7 Reporting Requirements, 20 NMAC 7.1, § 401(A) . . . . 240

30.2.8 Record Maintenance, 20 NMAC 7.1, § 403(A) . . . . . . 240

31.0 NEW MEXICO HAZARDOUS CHEMICALS INFORMATION ACT . . . . . 241

31.1 Summary of the Law . . . . . . . . . . . . . . . . . 241

31.2 Compliance Status of the Regulatory Requirements . . . . . . . . . 241

31.2.1 Notice of Extremely Hazardous Substance,

$\S 74-4 \mathrm{E}-5(\mathrm{~A})(1) \quad \ldots \ldots \ldots \ldots \ldots \ldots \ldots \ldots \ldots \ldots \ldots \ldots \ldots$

31.2.2 Notice of Release of Chemical Substance(s),

$\S 74-4 \mathrm{E}-5(\mathrm{~A})(2) \quad \ldots \ldots \ldots \ldots \ldots \ldots \ldots \ldots \ldots \ldots \ldots \ldots \ldots \ldots \ldots$

31.2.3 Hazardous Material Inventory, § 74-4E-5(A)(3) . . . . . 242

31.2.4 Toxic Chemical Release Inventory, § 74-4E-5(A)(4) . . . 242

32.0 NEW MEXICO EMERGENCY MANAGEMENT ACT $\ldots \ldots \ldots \ldots \ldots \ldots 243$

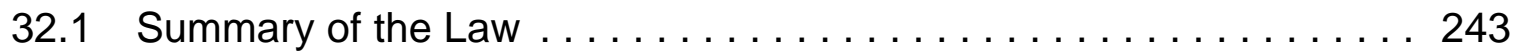

32.2 Compliance Status of the Regulatory Requirements . . . . . . . 243 
32.2.1 State Police Emergency Response Officer; Procedure for Notification; Cooperation of other State Agencies

and Local Governments, § 74-4B-5 . . . . . . . . . . . . 243

32.2.2 Clean-Up, $\S 74-4 B-10 \ldots \ldots \ldots \ldots \ldots \ldots \ldots . \ldots \ldots$

33.0 NEW MEXICO PREHISTORIC AND HISTORIC SITES PRESERVATION

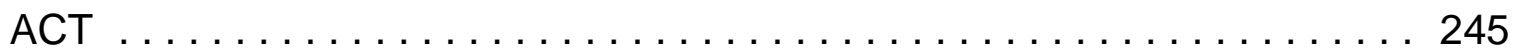

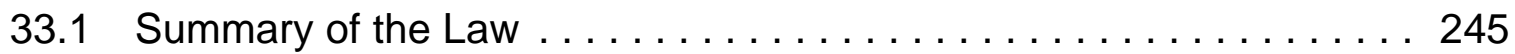

33.2 Compliance Status of the Regulatory Requirements . . . . . . . 245

34.0 NEW MEXICO STATE IMPLEMENTATION OF THE FEDERAL LAND

POLICY AND MANAGEMENT ACT $\ldots \ldots \ldots \ldots \ldots \ldots \ldots \ldots \ldots . \ldots 247$

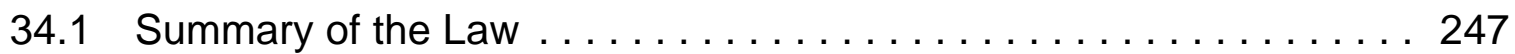

34.2 Compliance Status of the Regulatory Requirements . . . . . . . . 247

34.2.1 Application Requirements and Fees, SLO Rule 10.006 . . 247

34.2.2 Conditions, SLO Rule $10.009 \ldots \ldots \ldots \ldots \ldots \ldots \ldots .248$

34.2.3 Damage Bond, SLO Rule $10.010 \ldots \ldots \ldots \ldots \ldots \ldots .248$

34.2.4 Survey Plat, SLO Rule $10.011 \ldots \ldots \ldots \ldots \ldots \ldots .248$

34.2.5 Construction Reports, SLO Rule $10.012 \ldots \ldots \ldots \ldots .248$

34.2.6 Affidavit of Completion, SLO Rule $10.013 \ldots \ldots \ldots .249$

34.2.7 Renewal of Right-of-Way Reservations, SLO

Rule 10.017 ... . . . . . . . . . . . . . . . . . . 249

34.2.8 Reclamation and Restoration, SLO Rule 10.019 . . . . . 249

34.3 Compliance Status of the Permit Conditions ............... 249

34.3.1 Disposal of Brush and Other Debris, Term/Condition 3 .. 250

34.3.2 Depth of Pipelines, Term/Condition 4 . . . . . . . . . 250

34.3.4 Purpose of Right-of-Way, Term/Condition $6 \ldots \ldots \ldots 250$

34.3.5 Existing Rights, Term/Condition $7 \ldots \ldots \ldots \ldots \ldots 250$

34.3.6 Leases for Mineral Resources, Term/Condition 8 . . . . 251

34.3.7 Compliance with all Applicable Regulations and

Requirements, Term/Condition $9 \ldots \ldots \ldots \ldots \ldots 251$

34.3.8 Non-Use of the Right-of-Way, Term/Condition $10 \ldots . .251$

34.3.9 Protection and Preservation of Natural Environmental

Conditions, Term/Condition $13 \ldots \ldots \ldots \ldots \ldots . \ldots 251$

34.3.10 Reclamation of All Disturbed Areas,

Term/Condition $14 \ldots \ldots \ldots \ldots \ldots \ldots \ldots 252$

35.0 NEW MEXICO STATE IMPLEMENTATION OF THE BALD AND

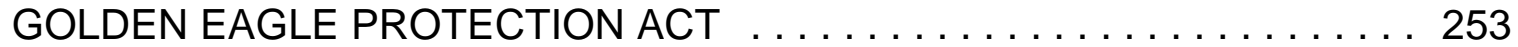

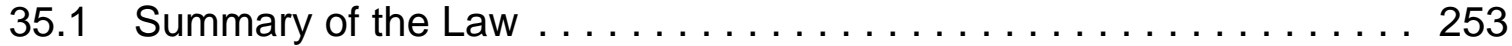

35.2 Compliance Status of the Regulatory Requirements $\ldots \ldots \ldots \ldots 253$

36.0 NEW MEXICO WILDLIFE CONSERVATION ACT, IMPLEMENTING THE

ENDANGERED SPECIES ACT $\ldots \ldots \ldots \ldots \ldots \ldots \ldots \ldots \ldots \ldots \ldots \ldots \ldots$

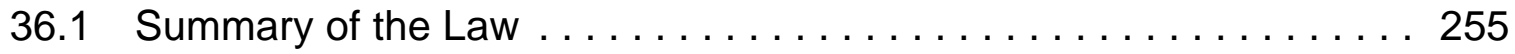

36.2 Compliance Status of the Regulatory Requirements . . . . . . . 256

36.2.1 Recognition of State-Listed Endangered Wildlife,

Regulation 19 NMAC 33.1 
36.2.2 Report of Unpermitted Removal, Capture, or Destruction of Endangered Species, Regulation 19 NMAC 33.2 . . . . . . . . . . . . . . . . . . . . 257

36.2.3 Permit Application and Requirements to Conduct Activities Authorized Under Regulation 19 NMAC 36.2 .. 257

36.2.4 Year-End Reports, Regulation 19 NMAC $36.2 \ldots \ldots \ldots .258$

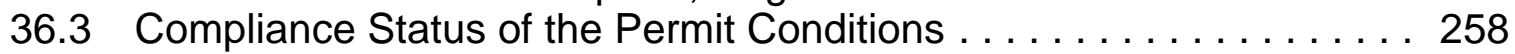

36.3.1 Permit No. $1894 \ldots \ldots \ldots \ldots \ldots \ldots \ldots \ldots \ldots \ldots$

36.3.2 Permit No. $1961 \ldots \ldots \ldots \ldots \ldots \ldots \ldots \ldots \ldots \ldots$

37.0 NEW MEXICO PESTICIDE CONTROL ACT . . . . . . . . . . . . . . . 261

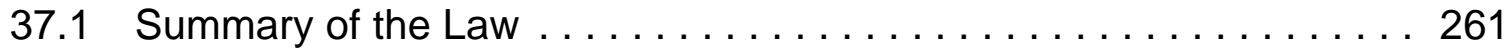

37.2 Compliance Status of the Regulatory Requirements . . . . . . . . 261

37.2.1 Storage of Pesticides and Disposal of Pesticide

Wastes, Section 5 of Regulatory Order No. 4 ...... 261

37.2.2 License Classification, Section 6 of Regulatory Order

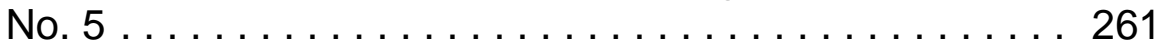

37.2.3 Protective Equipment, Section 10 of Regulatory Order

No. $5 \ldots \ldots \ldots \ldots \ldots \ldots \ldots \ldots \ldots 262$

37.2.4 Application of Pesticides, Section 11 of Regulatory

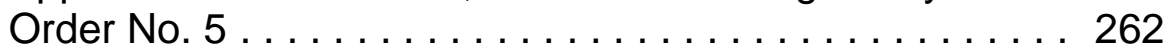

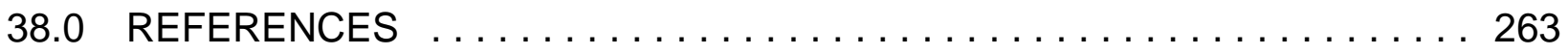

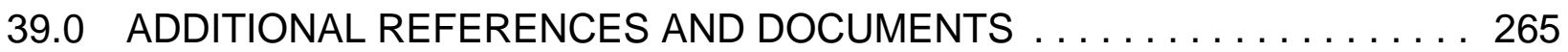

APPENDIX A - INDEX OF REQUIREMENTS BY TECHNICAL SUBJECT

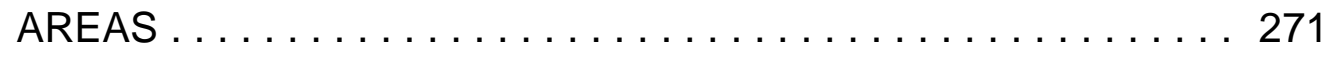

APPENDIX B - NATIONAL EMISSIONS STANDARDS FOR HAZARDOUS AIR POLLUTANTS FOR RADIONUCLIDES OTHER THAN RADON FROM DEPARTMENT OF ENERGY FACILITIES REPORT . . . . . . . . . . . . . . . . . . . . . 291 
This page intentionally left blank. 


\section{ACRONYMS AND ABBREVIATIONS}

AEA

AHERA

ALARA

BECR

BLM

BMP

BTU

C of $\mathrm{C}$

CAA

CAAA

CAO

CCA

CEQ

CERCLA

CFC

CFR

$\mathrm{CH}$

CWA

CY

DOE

DOT

DP

EA

EDE

EIS

EPA

EPCRA

FEIS

FIFRA

FLPMA

FR

FWS

GET

gpd

GWPA

HAP

HCIA
Atomic Energy Act

Asbestos Hazard Emergency Response Act

as low as reasonably achievable

Biennial Environmental Compliance Report

Bureau of Land Management

best management practice

British thermal unit

Certificate of Compliance

Clean Air Act

Clean Air Act Amendments of 1990

Carlsbad Area Office

Compliance Certification Application

Council on Environmental Quality

Comprehensive Environmental Response, Compensation, and Liability Act

chlorofluorocarbon

Code of Federal Regulations

contact-handled

Clean Water Act

calendar year

U.S. Department of Energy

U.S. Department of Transportation

Discharge Plan

environmental assessment

effective dose equivalent

Environmental Impact Statement

U.S. Environmental Protection Agency

Emergency Planning and Community Right-to-Know Act

Final Environmental Impact Statement

Federal Insecticide, Fungicide, and Rodenticide Act

Federal Land Policy and Management Act

Federal Register

(U.S.) Fish and Wildlife Service

General Employee Training

gallons per day

Ground Water Protection Act

hazardous air pollutant

Hazardous Chemicals Information Act 
HMTA

HSWA

HWA

IATA

ICAO

ICV

LEPC

LMP

LOV

LWA

MAP

MOC

MOU

$\mathrm{mg} / \mathrm{L}$

mrem

MSDS

NAAQS

NEPA

NESHAPS

NHPA

NMAC

NMDG\&F

NMED

NMSA

$\mathrm{NOI}$

NPDES

NRC

NSPS

NuPac

OCA

OCV

ODS

PAAA

PCB

pCi/L

PEIS

ppm

PPP

PSD

Pub. L.
Hazardous Materials Transportation Act

Hazardous and Solid Waste Amendments of 1984

Hazardous Waste Act

International Air Transport Association

International Civil Aviation Organization

inner containment vessel

Local Emergency Planning Committee (or Coordinator)

Land Management Plan

Letter of Violation

(Waste Isolation Pilot Plant) Land Withdrawal Act

Mitigation Action Plan

management and operating contractor

Memorandum of Understanding

milligrams per liter

millirem

Material Safety Data Sheet

National Ambient Air Quality Standard

National Environmental Policy Act

National Emission Standards for Hazardous Air Pollutants

National Historic Preservation Act

New Mexico Administrative Code

New Mexico Department of Game and Fish

New Mexico Environment Department

New Mexico Statutes Annotated

Notice of Intent

National Pollutant Discharge Elimination System

(U.S.) Nuclear Regulatory Commission

New Source Performance Standards

Nuclear Packaging Inc.

outer containment assembly

outer containment vessel

ozone-depleting substance

Price-Anderson Amendments Act of 1988

polychlorinated biphenyl

picocuries per liter

Programmatic Environmental Impact Statement

parts per million

Pollution Prevention Plan

Prevention of Significant Deterioration

Public Law 


$\begin{array}{ll}\text { QA } & \text { quality assurance } \\ \text { QAP } & \text { Quality Assurance Program } \\ \text { QAPD } & \text { Quality Assurance Program Description } \\ \text { RCRA } & \text { Resource Conservation and Recovery Act } \\ \text { RH } & \text { remote-handled } \\ \text { ROD } & \text { Record of Decision } \\ \text { RQ } & \text { reportable quantity } \\ & \\ \text { SAA } & \text { Satellite Accumulation Area } \\ \text { SAR } & \text { Safety Analysis Report } \\ \text { SARA } & \text { Superfund Amendments and Reauthorization Act of 1986 } \\ \text { SARP } & \text { Safety Analysis Report for Packaging } \\ \text { SDWA } & \text { Safe Drinking Water Act } \\ \text { SEIS } & \text { Supplemental Environmental Impact Statement } \\ \text { SERC } & \text { State Emergency Response Commission } \\ \text { SHPO } & \text { State Historic Preservation Officer (or Office) } \\ \text { SIC } & \text { Standard Industrial Classification } \\ \text { SLO } & \text { State Land Office } \\ \text { SPCC } & \text { Spill Prevention, Control, and Countermeasures Plan } \\ \text { SWB } & \text { standard waste box } \\ \text { SWDA } & \text { Solid Waste Disposal Act } \\ \text { SWMU } & \text { Solid Waste Management Unit } \\ & \\ \text { TDOP } & \text { ten-drum overpack } \\ \text { TDS } & \text { total dissolved solids } \\ \text { tpy } & \text { tons per year } \\ \text { TRANSCOM } & \text { Transportation Tracking and Communications System } \\ \text { TRAMPAC } & \text { TRUPACT-II Authorized Methods for Payload Control } \\ \text { TRU } & \text { transuranic } \\ \text { TRUCON } & \text { TRUPACT-II content codes } \\ \text { TRUPACT-II } & \text { Transuranic Package Transporter Model II } \\ \text { TSCA } & \text { Toxic Substances Control Act } \\ \text { TSDF } & \text { Treatment, Storage, and Disposal Facility } \\ & \\ \text { UST } & \text { underground storage tank } \\ \text { USTR } & \text { Underground Storage Tank Regulation } \\ \text { VOC } & \text { volatile organic compound } \\ \text { WAC } & \text { Waste Acceptance Criteria } \\ \text { WIPP } & \text { Waste Isolation Pilot Plant } \\ & \end{array}$


This page intentionally left blank. 


\section{$1.0 \quad$ INTRODUCTION}

This Biennial Environmental Compliance Report (BECR) documents environmental regulatory compliance at the Waste Isolation Pilot Plant (WIPP), a facility designed for the safe disposal of transuranic (TRU) radioactive waste, for the reporting period of April 1, 1998, to March 31, 2000. As required by the WIPP Land Withdrawal Act (LWA) (Public Law [Pub. L.] 102-579, and amended by Pub. L. 104-201), the BECR documents U.S. Department of Energy (DOE) Carlsbad Area Office's (hereinafter the "CAO") compliance with applicable environmental protection laws and regulations implemented by agencies of the federal government and the state of New Mexico.

An issue was identified in the $1998 \mathrm{BECR}$ relating to a potential cross-connection between the fire-water systems and the site domestic water system. While the CAO and its managing and operating contractor (hereinafter the "MOC") believe the site was always in compliance with cross-connection control requirements, hardware and procedural upgrades were implemented in March 1999 to strengthen its compliance posture. Further discussion of this issue is presented in section 30.2.2 herein.

During this reporting period WIPP received two letters and a compliance order alleging violation of certain requirements outlined in section 9(a)(1) of the LWA. With the exception of one item, pending a final decision by the New Mexico Environment Department (NMED), all alleged violations have been resolved without the assessment of fines or penalties. Additional information is provided below.

In August 1999, the CAO received a Letter of Violation from the NMED Hazardous and Radioactive Materials Bureau regarding three concerns identified during a compliance evaluation inspection of the facility conducted in July. These three concerns were as follows:

- A label was missing on a hazardous waste container in a satellite accumulation area (SAA). The MOC immediately marked the container and moved it to the less-than-90-day accumulation area. The CAO responded on September 9,1999, by notifying the NMED that the specific incident had been corrected and that additional training of affected hazardous waste management personnel was being conducted to ensure proper labeling of containers.

- There was insufficient aisle space in the less-than-90-day accumulation area. The MOC immediately increased the aisle spacing to at least two feet in order to meet NMED recommendations. The CAO responded on September 9, 1999, by notifying NMED that the specific incident had been corrected and that the weekly inspection procedure had been changed to incorporate the recommended aisle spacing.

- $\quad$ There was an issue relating to management of water from the Exhaust Shaft Catch Basin in the Underground Facility. The CAO responded on September 9, 1999, and again on November 12, 1999. The CAO and 
the NMED are continuing to address the NMED's concerns regarding the basin. When this issue is resolved, the NMED will issue a final determination and the resolution will be discussed in the next BECR.

On November 30, 1999, the NMED issued an Administrative Compliance Order alleging that the MOC had improperly characterized waste previously disposed of at WIPP. After addressing this concern with the NMED, the Compliance Order was dismissed and no fines or penalties were assessed.

Non-mixed TRU waste shipments began on March 26, 1999. Shipments continued through November 26, 1999, the effective date of the Waste Isolation Pilot Plant Hazardous Waste Facility Permit (NM4890139088-TSDF). No shipments regulated under the Hazardous Waste Facility Permit were received at WIPP during this BECR reporting period.

\subsection{Background of the Waste Isolation Pilot Plant}

The WIPP project was authorized by the DOE National Security and Military Applications of Nuclear Energy Authorization Act of 1980 (Pub. L. 96-164). This legislation mandated that the DOE provide a research and development facility to demonstrate the safe disposal of radioactive waste resulting from U.S. defense activities and programs. TRU waste is radioactive waste that contains alpha-emitting radionuclides of atomic number greater than 92 , with half-lives longer than 20 years, and which are present in concentrations greater than 100 nanocuries per gram of waste.

In January 1981, the DOE announced its decision to proceed with a phased development of WIPP, located in Eddy County in southeastern New Mexico, 26 miles east of the city of Carlsbad. The decision called for WIPP to be built to accommodate 6.2 million cubic feet of contact-handled $(\mathrm{CH})$ TRU waste and 0.25 million cubic feet of remote-handled $(\mathrm{RH})$ TRU waste. The WIPP LWA limited the total WIPP capacity to 6.2 million cubic feet of transuranic waste.

After completing a site and preliminary design validation phase, the construction phase at WIPP began in 1983. At present, surface and underground facilities to support waste handling and disposal operations have been constructed. The largest surface structure is the Waste Handling Building, which includes areas for the receipt, inventory, inspection, and transfer of waste to the underground. The WIPP underground facility, which is 2,150 feet below the land surface in a 2,000-foot-thick bedded salt formation, consists of four shafts, the waste disposal area, an equipment and maintenance facility, and connecting tunnels. Panel 1, consisting of seven waste disposal rooms, is being utilized for disposal of TRU and will also be utilized for disposal of TRU mixed waste. Mining in Panel 2, also to consist of seven rooms, is in progress and is expected to be complete by October 1, 2000. Because of the natural phenomenon of salt creep, which causes room closure, additional rooms will be mined on an as-needed basis. 
Originally, the construction phase was to be followed by the pilot plant phase. Following the preparation of the Final Supplement Environmental Impact Statement (SEIS, DOE 1990a) in 1990, the DOE decided that the construction phase was to be followed by a test phase, during which tests with TRU waste were to be conducted underground at WIPP. On October 21, 1993, the DOE announced its decision not to conduct TRU waste tests underground at the WIPP facility, but rather to conduct enhanced laboratory tests at the Los Alamos National Laboratory.

The Waste Isolation Pilot Plant Disposal Phase Final Supplemental Environmental Impact Statement ([SEIS-II] DOE, 1997) was issued in September 1997. The SEIS-II analyzed the environmental impacts of disposal phase operations of WIPP in light of additional information and changed circumstances since 1990, and also assessed alternatives for disposing of TRU waste at WIPP.

The Record of Decision (ROD) for the SEIS-II was issued January 23, 1998 (DOE, 1998). The selected alternative from the SEIS-II analysis was the disposal of defenserelated TRU waste meeting the requirements in the Waste Acceptance Criteria for the Waste Isolation Pilot Plant (WAC) (DOE, 1996) up to the limits allowed by law and to transport waste to WIPP by truck with the option of using rail in the future.

The receipt and disposal of the first TRU waste shipment in March 1999 initiated the disposal phase. The disposal phase will be followed by closure as a hazardous waste disposal site that includes the decontamination and decommissioning phase for all support structures.

More detailed information on the background of the WIPP project can be found in the DOE's Final Environmental Impact Statement, Waste Isolation Pilot Plant (FEIS; DOE, 1980); the DOE's 1981 ROD to the FEIS (DOE, 1981); the 1990 SEIS; the 1990 ROD to the SEIS (DOE, 1990b), the SEIS-II (DOE, 1997); and the 1998 ROD to the SEIS-II (DOE, 1998).

\subsection{Biennial Environmental Compliance Report under the WIPP Land Withdrawal Act}

This BECR provides the documentation required by the 1992 LWA. The LWA specifies that:

The Secretary shall, not later than two years after the date of the enactment of this Act, and biennially thereafter, submit documentation of continued compliance with the laws, regulations and permit requirements described in paragraph (1) to the Administrator, and, with the law described in paragraph $(1)(C)$, to the state $[\S 9(a)(2)]$.

Paragraph (1) requires that WIPP comply with Subpart A of 40 Code of Federal Regulations (CFR) 191; the Clean Air Act; the Solid Waste Disposal Act; the Safe Drinking Water Act; the Toxic Substances Control Act; the Comprehensive 
Environmental Response, Compensation, and Liability Act (CERCLA); "all other applicable federal laws pertaining to public health and safety or the environment;" and "all regulations promulgated, and all permit requirements" under these laws.

\subsection{Regulatory Requirements Hierarchy}

The first step in documenting regulatory compliance is the identification of all applicable regulatory requirements. This section describes the interrelationships among laws, regulations, and permit conditions and identifies the origins of the detailed regulatory requirements discussed in this report.

\subsubsection{Federal/State Laws}

Laws result from legislative processes at either the federal, state, or local level. This report will:

- $\quad$ Summarize the purpose of each relevant law
Discuss its applicability to WIPP
Document compliance by the DOE at WIPP

\subsubsection{Implementing Regulations}

Once a law is enacted, it is implemented by an agency that develops appropriate implementing regulations. At the federal level, these regulations are first published in the Federal Register (FR in citations) as "proposed rules" for comment from interested groups and individuals. The implementing agency then responds to the comments and prepares the "final rules." The final regulations are also published in the Federal Register. They are then codified in the CFR.

New Mexico agencies use a similar process of promulgating regulations by publishing proposed and final rules in the New Mexico Register and codifying them in the New Mexico Administrative Code (NMAC). Many of the state's environmental laws are based on similar federal statutes. New Mexico has been authorized by federal agencies to administer and enforce some of its own regulatory programs in lieu of the federal program, providing the state regulations are at least as stringent as the federal requirements.

Local laws or ordinances that apply to WIPP are limited to those under the authority of the Eddy County Commission, Eddy County, New Mexico. Zoning ordinances are the only local laws or ordinances applicable to WIPP. As these do not affect the facility's ability to protect human health and the environment, they are not included in this report.

This report identifies specific requirements of federal and state implementing regulations that apply to the WIPP facility. In some cases where implementing regulations have not been promulgated or where a particular statute requirement is not covered by the implementing regulations, this report identifies specific requirements directly from the statute. 
The WIPP LWA is not considered to be environmental legislation, although many aspects of the LWA impact regulations and laws "pertaining to public health and safety or the environment." Consequently, and at the suggestion of the state of New Mexico, a section has been added to this BECR addressing compliance with the LWA.

The WIPP LWA states that emplacement of TRU waste underground for disposal at WIPP may commence upon the completion of several requirements. The last of these is "the 30-day period beginning on the date on which the (DOE) Secretary notifies Congress that the requirements of section 9(a)(1) have been met [section 7(b)(3)]." The following chapters address compliance with the requirements of section 9(a)(1). Congress was first notified in May 1998. Disposal operations at WIPP then commenced on March 26, 1999.

\subsubsection{Permit Conditions}

A number of federal and state implementing regulations include the issuance of permits. Permits allow the regulatory agency to set conditions that must be met by the operators of a facility to meet the statutory goals and to provide timely reporting to the regulatory agency. This report identifies site-specific permit conditions that apply to WIPP.

\section{$1.4 \quad$ Regulatory Compliance at WIPP}

The DOE and its MOC are fully committed to conducting operations at WIPP in a way that achieves and demonstrates compliance with applicable regulations and permit conditions and which protects public health and the environment. Both organizations aggressively pursue compliance with the regulations and continuously assess their achievement of this compliance.

The primary means for maintaining compliance with environmental regulations are through the employment of knowledgeable, trained individuals and through management accountability. Throughout this document it is noted that procedures and manuals are in place to guide and direct WIPP personnel in the performance of specific jobs which have or could have a direct impact on the compliance status in given operational situations. These procedures and manuals are intended to supplement personnel training, education, and qualifications and to promote the operation of the WIPP facility in a safe and environmentally sound manner. Therefore these documents are continually evaluated and revised to assure they are current with respect to both regulatory and operational changes. For this reason, specific procedures and manuals are not referenced in the body of this document. In addition, a number of reports (especially those reports which are a result of regulatory requirements) are referenced throughout the document. Due to the continual update and revision requirements for reports of this nature, they are referenced only by the report title or by the citation that requires their submittal, rather than by document numbers. 


\subsubsection{Compliance Assurance}

Compliance includes a wide range of activities, ranging from the preparation of plans, procedures, reports, or permit applications to hands-on actions such as record keeping, monitoring, sampling and analysis, performing assessments or audits, and housekeeping.

There are three programs to assess WIPP programs and activities which impact on WIPP's environmental compliance status. These are the Environmental Compliance Assessment Program, the quality assurance (QA) programs, and programs established under the CAO Quality Assurance Program Description (QAPD).

The Environmental Compliance Assessment Program provides a comprehensive system to appraise compliance with applicable environmental laws and regulations, and identifies environmentally sound corrective action measures for any identified findings or observations. The assessments are used to identify and eliminate deficiencies that could lead to the following unacceptable events:

- $\quad$ Permit violations

- $\quad$ Regulatory noncompliance

- $\quad$ Safety and health risks to WIPP site workers and/or the general public

- Spills, releases, or discharges of environmental pollutants

Complementing the Environmental Compliance Assessment Program are the $\mathrm{CAO}$ and MOC QA programs. Quality assurance program surveillances, audits, and assessments of activities at WIPP are designed to verify compliance with procedural requirements and determine the adequacy and effectiveness of those activities.

Elements of these oversight activities include:

- $\quad$ Monitoring work in progress

- Documenting compliance or noncompliance with established requirements and procedures

- Identifying actual and potential conditions adverse to quality

- Obtaining timely corrective action commitments from cognizant managers

- $\quad$ Providing notification to responsible managers of the status and performance of work under assessment

- Verifying timely implementation of corrective actions

\subsection{Organization of and Reporting Period for the Report}

The organization of and reporting period for the BECR are discussed in the following subsections. 


\subsubsection{Organization of the Report}

This report organizes the pertinent regulatory requirements into fifteen sections, each corresponding to a federal or state agency authorized to administer regulatory programs. Each law that is relevant to the WIPP facility is addressed in a separate chapter contained in the administering agency's section. For example, the first section addresses regulatory programs administered by the U.S. Environmental Protection Agency (EPA). There are ten chapters in this section corresponding to the ten applicable laws administered by the EPA.

Each of the following chapters summarizes a law and its implementing regulations and briefly describes its applicability to WIPP. The requirements of the law and the CAO's compliance with the requirements are summarized in the text .

The WIPP facility is subject to oversight by a number of regulatory agencies. The scope of the BECR chapters includes the documentation of occasions in which WIPP may have received a letter of violation by a regulatory agency.

Appendix $A$ indexes the specific requirements in terms of their technical subject areas (for example, waste management requirements, water quality requirements, historic preservation requirements, etc.). Appendix 39 is a report of dose monitoring results required by 40 CFR 191, Subpart A.

\subsubsection{Reporting Period}

This is the fourth BECR to be issued as a result of the WIPP LWA. This BECR addresses the CAO's compliance status for the reporting period of April 1, 1998, through March 31, 2000. 
This page intentionally left blank. 


\subsection{RESOURCE CONSERVATION AND RECOVERY ACT AND SOLID WASTE DISPOSAL ACT}

\subsection{Summary of the Law}

The Resource Conservation and Recovery Act (RCRA; 42 United States Code [U.S.C.] $\S \S 6901$ et seq.) is a statute designed to provide "cradle-to-grave" control of hazardous waste by imposing management requirements on generators and transporters of hazardous wastes and on the owners and operators of treatment, storage, and disposal facilities (TSDF).

The RCRA was initiated in 1965 when Congress enacted the Solid Waste Disposal Act (Pub. L. 89-72; 42 U.S.C. §§ 3251 et seq.). This act dealt with solid waste disposal and gave the states the responsibility for developing solid waste management plans. In 1970, Congress passed the Resource Recovery Act (Pub. L. 91-12) to provide the EPA with funding for resource recovery programs. The Resource Conservation and Recovery Act of 1976 (Pub. L. 94-580) amended the Solid Waste Disposal Act and incorporated the intent of the Resource Recovery Act. A number of minor amendments were added during the next few years. The Hazardous and Solid Waste Amendments of 1984 (HSWA; Pub. L. 98-616) reauthorized RCRA, expanded its scope significantly, and altered many of its provisions. The term "RCRA" will be used throughout this document to refer to the reauthorized law as amended.

There are two major objectives of the RCRA. The first is to promote the protection of human health and the environment and to conserve material and energy resources. This objective is to be accomplished through such means as ensuring that hazardous waste management practices are conducted so as to protect human health and the environment, minimize the generation of hazardous waste, prohibit open dumping on the land, and require existing open dumps to be converted to facilities that pose no danger to the environment or human health. The second RCRA objective is to set national policy to reduce or eliminate the generation of hazardous waste as expeditiously as possible and to ensure that any hazardous waste generated be treated, stored, or disposed of so as to minimize the present and future threat to human health and the environment.

The EPA implements RCRA primarily through the 40 CFR 260 through 282 series: 40 CFR 260 through 279 consist of requirements and standards pertaining to hazardous waste; 40 CFR 280 through 282 pertain to the management of underground storage tanks (USTs) containing petroleum products or hazardous chemicals.

Congress intended for the RCRA program to be implemented by the states. Consequently, the EPA has defined a process through which states may apply for and receive authorization to administer the RCRA program. New Mexico received authorization for the base RCRA program in January 1985 and for its mixed waste program in July 1990. The EPA granted authorization for the HSWA program to the state of New Mexico in a notice that appeared in the Federal Register on October 17, 1995 (effective date: January 2, 1996). New Mexico administers its 
program through Chapters 4 and 5 of Title 20 of the New Mexico Administrative Code (20 NMAC 4.1, 4.2, 4.3, and Chapter 5). By virtue of this authorization, New Mexico has primary responsibility for permitting, implementation, and enforcement for most aspects of the RCRA program. The DOE has received a hazardous waste facility permit from the NMED. The federal RCRA requirements are presented in this chapter; the state RCRA-related requirements are incorporated in Chapter 25 herein, under the NMED.

The Land Withdrawal Act, as amended, exempted waste designated by the Secretary of Energy for disposal at WIPP from the treatment standards of the Solid Waste Disposal Act (42 U.S.C. $\S 6924[\mathrm{~m}]$ ). By virtue of this exclusion, the CAO is no longer required to demonstrate compliance with the Land Disposal Restrictions of 40 CFR 268 for waste shipped to WIPP for storage and disposal.

One section of the RCRA governs the management of USTs. This portion of the RCRA and the regulations specified under 40 CFR 280 and 281 address USTs containing petroleum products or hazardous chemicals. (Requirements for tanks containing hazardous wastes are specified under Subpart J of 40 CFR 264 and 265.) Requirements for UST management pertain to the design, construction, installation, and operation of USTs as well as notification and corrective action requirements in the event of a release and actions required for out-of-service USTs.

The NMED was authorized by the EPA to regulate UST. Therefore, the state UST requirements and the compliance status for each requirement are presented in Chapter 25 herein of this report.

\subsection{Status of Compliance with the Regulatory Requirements}

This section provides information on RCRA requirements and the EPA's regulations implementing this act.

\subsubsection{Compliance with the Resource Conservation and Recovery Act}

Nearly all of the requirements specified in RCRA are covered in more detail in the implementing regulations. The exception is $\S 3016$ of the act, which requires each federal agency to provide a biennial inventory of its TSDF.

2.2.1.1 Inventory of Federal Hazardous Waste Facilities, $\S 3016$

Each federal agency shall compile, publish, and submit to the EPA Administrator (and the state, if its hazardous waste program has been authorized by the EPA) an inventory of each site which the agency owns or operates at which hazardous waste is stored, treated, or disposed of at any time. The inventory shall be submitted every 2 years beginning January 31, 1986. 
The CAO files its hazardous waste inventory report (Form 0336-EPA-B1) for WIPP with the EPA and the NMED in even-numbered years as required by RCRA § 3016 . The CAO transmitted the latest report, the 2000 Inventory of Federal Hazardous Waste Activities at Currently Owned or Operated Federal Facilities--WIPP, to the EPA before the due date.

\subsubsection{Compliance with the Land Disposal Restrictions, 40 CFR 268}

The WIPP Land Withdrawal Amendments Act of 1996 (Pub. L. 104-201) exempts waste designated by the Secretary of Energy for disposal at WIPP from the Land Disposal restrictions. Regulations implementing portions of the RCRA for which the state of New Mexico is authorized are found in Chapter 25 herein. 
This page intentionally left blank. 


\subsection{COMPREHENSIVE ENVIRONMENTAL RESPONSE, COMPENSATION, AND LIABILITY ACT}

\subsection{Summary of the Law}

The Comprehensive Environmental Response, Compensation, and Liability Act (CERCLA; 42 U.S.C. §§ 9601 et seq.), or "Superfund," and the Superfund Amendments and Reauthorization Act of 1986 (SARA) establish a comprehensive federal strategy for responding to, and establishing liability for, releases of hazardous substances from a facility to the environment. The Emergency Planning and Community Right-to-Know Act was enacted as a stand-alone portion under SARA, Title III. It is described in further detail in Chapter 4 herein.

Any spills of reportable quantities of hazardous substances must be reported to the National Response Center under the provisions of $\S 103$ of CERCLA, "Notification Requirements Respecting Released Substances," and the implementing regulations in 40 CFR 302, "Designation, Reportable Quantities, and Notification." Because WIPP is not a CERCLA remediation site and is not expected to become one, most of the requirements of this act do not apply.

The MOC is responsible for reporting and managing any release of hazardous substances at WIPP as defined in $\S 101$ of CERCLA, "Definitions," in quantities equal to or greater than the reportable quantities outlined in $\S 102$, "Designation of Additional Hazardous Substances and Establishment of Reportable Released Quantities; Regulations," and specified in 40 CFR 302. In the event of a release of a hazardous substance to the environment in an amount that meets or exceeds the reportable quantity $(R Q)$ for that substance, a notification of the release will be made to the appropriate agencies by MOC personnel as required by Part 103 of CERCLA.

Section 120(c) of CERCLA, "Federal Agency Hazardous Waste Compliance Docket," establishes a docket that provides information regarding federal facilities that manage hazardous waste or from which hazardous substances may be or have been released. This is information to be submitted to the EPA by federal agencies under Part 103 of CERCLA or under $\S \S 3005,3010$, or 3016 of the RCRA. Facilities listed under the docket must prepare a Preliminary Assessment and submit it to the EPA within 18 months of the date of publication in the Federal Register. If deemed necessary, a site inspection report is also due to the EPA within the same time frame.

Under 40 CFR 300, "National Oil and Hazardous Substances Pollution Contingency Plan," the organizational structures and procedures are provided for preparing for and responding to discharges of oil and releases of hazardous substances, pollutants, and contaminants. The National Oil and Hazardous Substances Pollution Contingency Plan is required by Part 105 of the CERCLA. 


\subsection{Compliance Status of the Regulatory Requirements}

\subsubsection{Designation of Hazardous Substances, 40 CFR $\S 302.4$}

The elements and compounds and hazardous wastes appearing in Table 302.4 are designated as hazardous substances. A solid waste, as defined in 40 CFR 261.2, which is not excluded from regulation as a hazardous waste under 40 CFR 261.4(b), is a hazardous substance if it exhibits any of the characteristics identified in 40 CFR 261.20 through 261.24.

Listed and characteristic hazardous substances at the WIPP site have been identified.

\subsubsection{Determination of Reportable Quantities, 40 CFR § $\mathbf{3 0 2 . 5}$}

The quantity listed in the column "Final $R Q$ " for each substance in Table 302.4 or in Appendix B to Table 302.4 is the RQ for that substance.

Reportable quantities listed in Table 302.4 and Appendix 39 to $\S 302.4$ are used for reporting purposes at WIPP. The listed $R Q$ is used to determine if releases of pure materials or hazardous constituents in mixtures are reportable.

\subsubsection{Notification Requirements, 40 CFR § 302.6(a)}

Any release of a hazardous substance in a quantity equal to or exceeding the $R Q$ determined in 40 CFR $\S 302.5$ in any 24-hour period shall immediately be reported to the National Response Center at (800) 424-8802.

During this reporting period, there were no releases in excess of any reportable quantities.

\subsubsection{Releases of Mixtures or Solutions, 40 CFR $\S 302.6(b)(1)(i)$ and (ii)}

If the quantity of all hazardous constituents of the mixture or solution is known, notification is required where reportable quantities or more of any hazardous constituent is released. If the quantity of one or more of the hazardous constituents of the mixture or solution is unknown, notification is required where the total amount of the mixture or solution released equals or exceeds the reportable quantities for the hazardous constituent with the lowest $R Q$.

The reportable releases of hazardous constituents in mixtures are determined and reported as required in $\S \S 302.5$ and 302.6(a) of 40 CFR. During this reporting period, 
there were no releases of mixtures or solutions that exceeded the reportable quantities of any hazardous constituents.

\subsubsection{Notification of Releases of Radionuclides, 40 CFR § 302.6(b)(2)}

Radionuclides are subject to these notification requirements only in the following circumstances:

- $\quad$ The identity and quantity (in curies) of each radionuclide in a released mixture or solution is known and the sum of the ratios (quantity released in curies/ $R Q$ for the radionuclide) for each radionuclide in the mixture or solution is equal to or greater than 1.

- The identity of each radionuclide in a released mixture or solution is known but the quantity released (in curies) of one or more of the radionuclides is unknown and the total quantity (in curies) of the mixture or solution is equal to or greater than the lowest quantity of any individual radionuclide in the mixture or solution.

- The identity of one or more radionuclides in a released mixture or solution is unknown and the total quantity (in curies) released is equal to or greater than either 1 curie or the lowest $R Q$ of any known individual radionuclide in the mixture or solution, whichever is lower.

There have been no releases of radionuclides at the WIPP facility.

\subsubsection{Notification of the Release of Heavy Metals, 40 CFR § 302.6(d)}

Except for releases of radionuclides, notification of the release of a $R Q$ of solid particles of antimony, arsenic, beryllium, cadmium, chromium, copper, lead, nickel, selenium, silver, thallium, or zinc is not required if the mean diameter of the particles released is larger than 100 micrometers.

There have been no releases of heavy metals from the WIPP facility. 
This page intentionally left blank. 


\subsection{EMERGENCY PLANNING AND COMMUNITY RIGHT-TO-KNOW ACT}

\subsection{Summary of the Law}

Title III of the SARA, otherwise known as the Emergency Planning and CommunityRight-to-Know Act of 1986 (EPCRA; 42 U.S.C. §§ 11001 et seq.), authorizes a nationwide program of emergency planning as protection against accidents involving hazardous chemicals and extremely hazardous substances. The act also requires a comprehensive body of information about hazardous substances to be submitted to various state and local groups. Under Subtitle A, "Emergency Planning and Notification," facilities are required to make various notifications to the State Emergency Response Commission (SERC) and the Local Emergency Planning Committee (LEPC). These include notification of applicability under EPCRA, designation of a facility Emergency Coordinator, and notification of extremely hazardous substance releases to the environment. Subtitle B, "Reporting Requirements," requires the submittal of information such as inventories of specific hazardous chemicals used or stored within a facility to the SERC, LEPC, and the fire department that has jurisdiction over the facility. Within Subtitle B, the following sections outline specific reporting requirements:

(1) section 311, "Material Safety Data Sheets," directs the submission of a Material Safety Data Sheet (MSDS) for each hazardous chemical present or a list of hazardous chemicals present that require an MSDS; (2) section 312, "Emergency and Hazardous Chemical Inventory Forms," directs the annual submission of an inventory of hazardous chemicals present during the preceding year; and (3) section 313, "Toxic Chemical Release Forms," outlines requirements for facilities to submit a toxic chemical release report to the EPA and the resident state if toxic chemicals are used at that facility in excess of established threshold amounts.

The regulations under 40 CFR 355, "Emergency Planning and Notification," established the list of extremely hazardous substances, the threshold planning quantities, and facility notification responsibilities necessary for the development and implementation of state and local emergency response plans.

The regulations of 40 CFR 370, "Hazardous Chemical Reporting: Community Right-toKnow," established reporting requirements that provide the public with vital information on the hazardous chemicals in their communities, with the intent of ensuring enhanced community awareness of chemical hazards and facilitating the development of state and local emergency response plans.

In order to inform the public and surrounding communities of releases of toxic chemicals, 40 CFR 372, "Toxic Chemical Release Reporting: Community Right-toKnow," established requirements for the submission of information relating to the release of toxic chemicals under section 313 . 


\subsection{Compliance Status of the Requlatory Requirements}

\subsubsection{Emergency Planning, 40 CFR § 355.30(a)}

The requirements of this section apply to any facility at which there is present any extremely hazardous substance [as defined in 40 CFR 355] equal to or in excess of its threshold planning quantity.

The WIPP facility is subject to the emergency planning requirements because it uses sulphuric acid, which has a threshold planning quantity of 1,000 pounds. Sulphuric acid used at the WIPP facility is generally contained in lead-acid batteries. Small amounts are in the liquid form.

\subsubsection{Emergency Planning Notification, 40 CFR § 355.30(b)}

The owner or operator of a facility shall notify the Commission that it is subject to the emergency planning requirements.

The DOE notified the SERC that the WIPP facility is subject to emergency planning requirements prior $t$ the October 17,1990 , regulated deadline. The MOC submitted the latest revised chemical inventory list to the state in August 1999.

\subsubsection{Facility Emergency Coordinator, 40 CFR § 355.30(c)}

The facility shall designate a facility representative who will participate in the local emergency planning process as a facility emergency response coordinator.

The MOC appointed a WIPP representative to the LEPC, which began in 1994. The LEPC meets once a month. Emergency Management is responsible for WIPP's emergency response and preparedness programs at the WIPP facility.

\subsubsection{Provision of Information, 40 CFR $\S 355.30(d)$}

The owner or operator of a facility will inform the LEPC of any changes occurring at the facility that may be relevant to emergency planning.

The $\mathrm{CAO}$, or its $\mathrm{MOC}$, provides information to the LEPC regarding changes at the facility which may be relevant to emergency planning.

The last notification was made with the latest update of the Waste Isolation Pilot Plant Emergency Management Program (WP 12-9), September 24, 1999. 


\subsubsection{Emergency Release Notification, 40 CFR $§ 355.40$}

The owner or operator of a facility shall immediately notify the community emergency coordinator for the LEPC of any area that is likely to be affected by the release and the SERC of any state likely to be affected by the release.

There have been no releases of extremely hazardous substances from the WIPP facility.

\subsubsection{Material Safety Data Sheet Reporting, 40 CFR § 370.21}

The owner or operator of a facility shall submit a material safety data sheet (MSDS) for each hazardous chemical present at the facility according to the minimum threshold schedule to the committee, the commission, and the fire department with jurisdiction over the facility. In lieu of the submission of an MSDS, the owner or operator may submit a list of hazardous chemicals for which an MSDS is required.

On August 18, 1999, the CAO submitted an updated list of hazardous chemicals which are present at the WIPP facility in amounts that exceed the threshold planning quantities.

\subsubsection{Inventory Reporting, 40 CFR $§ 370.25$}

The owner or operator of a facility shall submit an inventory form to the SERC, LEPC, and the fire department with jurisdiction over the facility for hazardous chemicals at the facility during the preceding calendar year by March 1 of each year.

The CAO provide a timely submittal of Tier II Emergency and Hazardous Chemical Inventory reports to the SERC, LEPC, and the fire departments that maintain Memorandums of Understanding (MOU) with the CAO regarding the WIPP facility.

\subsubsection{Reporting Requirements and Schedule for Reporting, 40 CFR $\S 372.30$}

For each toxic chemical known by the owner or operator to be manufactured, processed, or otherwise used in excess of an applicable threshold quantity at its covered facility for a calendar year, the owner or operator must submit to the EPA and to the state a completed EPA Form $R$.

During this reporting period, the WIPP facility was exempt from Form $\mathrm{R}$ reporting under 40 CFR $\S 372.38$, "Exemptions." Products in excess of the threshold quantity were either contained in enclosed systems or fell under the Motor Vehicle Use exemption. 
This page intentionally left blank. 


\subsection{ATOMIC ENERGY ACT AND THE ENVIRONMENTAL PROTECTION AGENCY}

\subsection{Summary of the Law}

The Atomic Energy Act (AEA) of 1954, as amended (AEA; 42 U.S.C. §§ 2011 et seq.), initiated a national program for research, development, and use of atomic energy for both national defense and domestic civilian purposes.

The authority of the EPA to establish generally applicable standards for the protection of the public and the environment from radiation is derived from the AEA, as amended; Reorganization Plan No. 3 of 1970; and the Nuclear Waste Policy Act (NWPA) (Public Law 97-425). The protection standards found in 40 CFR 191 apply to both spent nuclear fuel and high-level radioactive waste as defined by the NWPA, and to TRU waste, which contains more than 100 nanocuries per gram of waste of alpha-emitting TRU isotopes with half-lives greater than 20 years. The standards of 40 CFR 191 consist of three subparts: Subpart A; "Environmental Standards for Management and Storage," Subpart B; "Environmental Standards for Disposal," and Subpart C; "Environmental Standards for Groundwater Protection."

Subpart A, "Standards for Management and Storage," sets the operational term requirements limiting annual doses to members of the public from management and storage operations at disposal facilities operated by the DOE and not regulated by either the U.S. Nuclear Regulatory Commission (NRC) or by agreement states. The annual dose equivalent, from all sources, to any member of the public in the general environment may not exceed 25 millirem (mrem) to the whole body and 75 mrem to any critical organ.

The EPA audits the DOE's compliance with Subpart A of 40 CFR 191. Since these regulations were promulgated by the EPA, they are discussed in this chapter rather than in Chapter 13 herein, Atomic Energy Act and the DOE. Because Subpart A only contains environmental performance standards, implementation details are left to the responsible agency. The EPA issued guidance for implementation of Subpart A, which includes methods for dose calculation, modeling, and reporting. The DOE has issued a compliance implementation plan that adopts the EPA's guidance and outlines the 40 CFR 191 compliance program.

The EPA has certification authority for Subparts B and C of 40 CFR 191. As required by the WIPP LWA in section 8(d)(2), the EPA certified on May 18, 1998 (FR Volume 63, Number 95, pp. 27353) that the WIPP facility was in compliance with 40 CFR 191, Subparts $B$ and $C$. This certification decision was made after careful consideration and evaluation of the DOE's Compliance Certification Application (CCA). The CCA was submitted to the EPA on October 29, 1996, as specified in the WIPP LWA section $8(d)(1)$, and demonstrates compliance with the provisions of Subparts B and C. 


\subsection{Compliance Status with the Regulatory Requirements}

The compliance status of each of the applicable requirements is summarized in the text under section 5.2.1 below for the environmental radiation protection disposal standards.

\subsubsection{Radiation Protection Standards, 40 CFR 191}

The requirements of 40 CFR 191, "Environmental Radiation Protection Standards for Management and Disposal of Spent Nuclear Fuel, High-Level, and Transuranic Radioactive Waste," apply to WIPP as of March 26, 1999, when the first shipment of TRU waste was received and emplaced for permanent disposal.

\subsubsection{Standards, 40 CFR $\S 191.03(b)$ (Subpart A)}

The combined annual dose equivalent to any member of the public shall not exceed 25 mrem to the whole body and 75 mrem to any critical organ.

Environmental monitoring samples have shown no releases of radionuclides that may affect the public. The MOC has conducted periodic confirmatory sampling since receipt of waste began in March 1999. Results of the MOC monitoring program demonstrate compliance with the $40 \mathrm{CFR} \S 191.03$ standards. Monitoring results for the period of January 1, 1999, to December 31, 1999, can be found in Appendix B to this report.

\subsubsection{Containment Requirements 40 CFR $§ 191.13$}

The disposal systems for spent nuclear fuel or high-level or TRU radioactive waste shall be designed to provide a reasonable expectation that the cumulative releases to the accessible environment for 10,000 years shall have a likelihood of less than one chance in ten of exceeding the quantities calculated according to Table I and less than one chance in 1,000 of exceeding ten times the quantities calculated in accordance with Table I.

These requirements were addressed in the DOE application for certification. The EPA certified the DOE's compliance in 1998.

\subsubsection{Individual Protection Requirements, 40 CFR $\S 191.15$}

Disposal systems for waste and any associated radioactive material shall be designed to provide a reasonable expectation that, for 10,000 years after disposal, undisturbed performance of the disposal system shall not cause the annual committed effective dose (calculated in accordance with Appendix $B$ of this Part) to exceed 5 mrems. 
These requirements were addressed in the DOE application for certification. The EPA certified the DOE's compliance in 1998.

\subsubsection{Disposal Standards, 40 CFR $\S 191.24$}

Disposal systems for waste and any associated radioactive material shall be designed to provide a reasonable expectation that, for 10,000 years after disposal, undisturbed performance of the disposal system shall not cause annual committed effective dose (calculated in accordance with Appendix B of this Part) to exceed 15 mrems.

These requirements were addressed in the DOE application for certification. The EPA certified the DOE's compliance in 1998.

\subsubsection{WIPP Compliance Certification Criteria, 40 CFR 194}

The WIPP LWA requires the EPA to establish criteria by which to certify that the DOE will comply with the radioactive waste disposal standards of 40 CFR 191, Subparts B and C. The EPA issued these criteria on February 9, 1996 (61 FR 5224 through 5245). The DOE submitted its application for certification on October 29, 1996. The EPA conducted two public hearings regarding the DOE's application and certified the DOE's compliance on May 18, 1998 (61 FR 27353 through 27406).

Since certification, the DOE has complied with the reporting requirements of the certification. These reporting requirements were established so the EPA will be notified in a timely manner in the event of a change that may affect the WIPP certification. No such changes have occurred. The DOE has also implemented monitoring programs designed to detect substantial and deleterious deviations from the basis used for certification. No such deviations have occurred. 
This page intentionally left blank. 


\subsection{CLEAN AIR ACT}

\subsection{Summary of the Law}

The Clean Air Act (CAA), as amended, establishes a national regulatory strategy and program to protect and enhance air quality in the United States. The CAA includes a number of standards, requirements, and permit programs to protect the quality of air in attainment areas (areas in which air pollutant emissions do not exceed the appropriate standards) and to improve it in nonattainment areas (areas that do not meet the national primary or secondary ambient air-quality standard for an air pollutant).

Congress enacted the Clean Air Act Amendments of 1990 (CAAA; Pub. L. 101-549) on November 15, 1990.

\subsubsection{Title I, Air Pollution Prevention and Control}

Title I of the CAA contains requirements and standards for a number of programs that govern air pollutant emissions from stationary sources. These include the National Ambient Air Quality Standards (NAAQS), the New Source Performance Standards (NSPS), the National Emission Standards for Hazardous Air Pollutants (NESHAPs), the Prevention of Significant Deterioration (PSD) program, and requirements for nonattainment areas. Most of these programs are requirements for proposed new construction or for modifications of existing sources. In addition, Titles VII and IX of the CAAA established provisions relating to enforcement and requirements for CAA-related research programs, respectively.

\subsubsection{National Ambient Air Quality Standards}

This program was established by Title I of the CAA (and revised by Title I of the CAAA) for the six "criteria" pollutants: sulfur dioxide, particulate matter, carbon monoxide, ozone, nitrogen dioxide, and lead. These standards establish the maximum levels of each pollutant allowed in the air within a particular area. The federal NAAQS are specified in 40 CFR $\S \S 50.4$ through 50.12 , and the program is implemented under 40 CFR 51. The EPA has authorized the NMED to administer the NAAQS program. The federal NAAQS were superseded by the New Mexico Ambient Air Quality Standards for the six criteria pollutants. Therefore, the two backup diesel electrical power supply generators at WIPP are regulated under New Mexico regulations, and compliance with these regulations is discussed in Chapter 28 herein under the New Mexico Air Quality Control Act.

After consultation with the NMED Air Quality Bureau, a determination was made that the CAO was required to obtain a permit under 20 NMAC 2.72 for the operation of two backup diesel electrical power supply generators at WIPP. A state permit is required when criteria pollutants exceed the state threshold levels of 10 pounds per hour or 25 tons per year (tpy). For compliance status with the state permit programs, see Chapter 28 herein. 


\subsubsection{New Source Performance Standards}

The NSPS program regulates emissions from operating facilities and specifies emission standards and test methods for analyzing the emissions. This program, which was initiated by section 111 of the CAA and is implemented by 40 CFR 60, "Standards of Performance for New Stationary Sources," specifies standards of performance for air pollutant emissions from different types of facilities and equipment. Pollutants that are regulated under the NSPS include sulfur dioxide, nitrogen oxides, particulate matter, visible emissions (opacity), carbon monoxide, volatile organic compounds (VOC), and lead. Since the EPA has authorized the NMED to administer the NSPS program, the NMED requirements supersede the federal requirements. Therefore, emissions from the backup generators at WIPP are regulated under the state program, which is discussed in Chapter 28 herein.

\subsubsection{National Emission Standards for Hazardous Air Pollutants}

Hazardous air pollutant emissions are regulated under section 112 of the CAA (Title III of the CAAA) as implemented by 40 CFR 61, "National Emission Standards for Hazardous Air Pollutants." Before the CAA was amended in 1990, Subpart A of NESHAPs listed only eight hazardous air pollutants (HAP). These pollutants are asbestos, benzene, beryllium, coke oven emissions, inorganic arsenic, mercury, radionuclides, and vinyl chloride. The CAAA (§ 301) added 181 HAPs, bringing the list of HAPs regulated under Subpart A to 189. De minimis levels for all the HAPs have been proposed under section $112(\mathrm{~g})$ as referenced by the proposed rule "Hazardous Air Pollutants: Proposed Regulations Governing Constructed, Reconstructed or Modified Major Sources," dated April 1, 1994 (59 FR 15504).

In 1997, the Air Emissions Inventory Report for Calendar Year 1996 was completed (Westinghouse Waste Isolation Division, 1997). This inventory report was developed to calculate maximum potential hourly and annual emissions of criteria pollutants, the regulated NESHAPs pollutants, and the New Mexico toxic air pollutants specified under 20 NMAC 2.72 and 2.78. Emission estimates were used to determine if the CAO is required to obtain air permits for WIPP under state regulations. The air emissions inventory for calendar year 1998, scheduled for completion in 1999, was postponed until 2000. Operations during calendar year 1998 were essentially identical to operations during calendar year 1996. The decision was made to conduct air emissions inventory after the operational status of WIPP changed. The inventory for calendar year 1999 will be completed in 2000 and will be reported in the next BECR.

Based on the inventory calculations, WIPP operations are significantly below the 10-tpy emission limit for any individual HAP or the 25-tpy limit for combined HAPs emissions established in Subpart A. Thus, there are no NESHAPs Subpart A permitting or reporting requirements for WIPP at this time. However, 40 CFR $\S 61.09(\mathrm{a})(1)$ required that the EPA be notified of WIPP's anticipated date of initial start-up of the source no more than 60 days or less than 30 days before that date. This notification was made on February 23, 1999, with the actual start-up date being March 26, 1999. The 15-day notice of actual start-up was submitted March 26, 1999. 
The inventory will be updated for calendar year 1999 to evaluate regulatory changes and to monitor the use of HAPs and toxic air pollutants at the site. The WIPP Chemical Inventory Database is used to evaluate chemical use at the site. Using chemical and material inventory data, MOC personnel evaluate potential replacement chemicals and minimize the use of materials regulated under NESHAPs as much as possible.

With regard to radionuclide emissions at WIPP, Subpart $\mathrm{H}$ of NESHAPs applies due to the nature of wastes to be received at WIPP. Subpart H of 40 CFR 61, "National Emission Standards for Emissions of Radionuclides Other Than Radon from Department of Energy Facilities," pertains to non-radon radionuclide emissions from DOE facilities. The NESHAPs for radionuclides is an effective dose equivalent (EDE) of 10 mrem per year to any member of the public. A NESHAPs application must be filed if the anticipated EDE will exceed 1 percent of the standard. The DOE and the EPA have agreed that WIPP will be regulated under NESHAPs through the completed closure of WIPP (see the final NESHAPs MOU between the EPA and the DOE, draft 6 , dated May 16, 1995).

Analyses for the expected levels of radionuclide emissions were performed and reported in a data package submitted to the EPA (i.e., the NESHAPs data package). The emissions were calculated to be less than 1 percent of the allowable EDE of 10 mrem per year to any one member of the public. In the current WIPP Safety Analysis Report (SAR), doses from radionuclide emissions anticipated from the WIPP facility under normal operations were calculated to be undetectable. An emissions sampling system was installed to comply with NESHAPs and to meet periodic confirmatory measurement requirements (see section 6.2.2 herein). Emissions sampling test results are used to verify compliance with Subpart $\mathrm{H}$.

\subsubsection{Prevention of Significant Deterioration Program}

The PSD program, like many of the other programs under the CAA, is designed for proposed new construction or the modification of existing facilities. It pertains to any proposed new or modified facility to be located in an attainment area, particularly if the facility could impact the air quality in a national park, wilderness area, monument, seashore, or other areas of special national or regional natural, recreational, scenic, or historic value. Because WIPP does not emit over 100 tpy of any criteria pollutant, WIPP is not categorized as a major source, and the PSD program does not apply.

\subsubsection{Title II, Emission Standards for Mobile Sources}

Although most of the requirements under the CAA pertain to stationary sources, the requirements under Title II of the CAA and the CAAA pertain to mobile sources and establish standards for motor vehicles and fuel. Many of these requirements are aimed at automobile manufacturers and petroleum companies (e.g., Part A of Title II, "Motor Vehicle Emission and Fuel Standards"). Federal agency fleets are covered in $\S 248$ of the CAA. Federal agencies that operate fleets in nonattainment areas for ozone and/or carbon monoxide are required to use clean-fuel vehicles and must use clean alternative fuels when operating in the nonattainment area. Indeed, the DOE published its new 
Alternative Fuel Transportation Program (10 CFR 490) in the Federal Register on March 14, 1996. However, since it must be adopted only by federal agencies that operate a fleet with at least 20 light-duty vehicles in a metropolitan statistical area or a consolidated metropolitan statistical area with a 1980 population of at least 250,000 people, these new regulations do not apply to Carlsbad, which is the closest population center to WIPP. In addition, most of the requirements for federal agency fleets under Title II are not applicable to WIPP because this facility is not located in a nonattainment area. Regulations (61 FR 3832, 40 CFR 80) make the purchaser/consumer of gasoline products or his/her agent liable for using gasoline containing lead (i.e., more than 0.05 gram of lead per gallon) or lead additives for highway use after December 31, 1995. This new provision is now incorporated into this chapter (see section 6.2.3.3 herein). Regulations were also promulgated for diesel fuel; however, they impact vehicles/ equipment using diesel fuel used on highways and do not impact non-road vehicles and equipment. Therefore, they are not applicable to WIPP because the diesel fuel dispensed at this facility is used only in non-road vehicles and equipment, such as the backup diesel generators and underground mining equipment.

\subsubsection{Title III, General Provisions}

Title III of the CAA provides general provisions for the administration of the CAA and pertains to all titles. The provisions of Title III include administration, federal procurement, suits, audits, and air quality monitoring and modeling. It does not add additional programs. Title III of the CAA (Title VIII of the CAAA) also requires that the EPA perform a comprehensive analysis of the impact of the CAAA.

\subsubsection{Title IV, Acid Deposition Control}

Title IV of both the CAA and the CAAA is aimed primarily at utilities and power plants that emit large quantities of sulfur dioxide and/or nitrogen oxides. It seeks to reduce emissions of sulfur dioxide and nitrogen oxides to decrease the acid rain problem in the United States. It is not applicable to WIPP.

\subsubsection{Title V, Permits}

Most of the other permitting programs under the CAA are designed primarily for proposed new construction or the modification of existing facilities. Title $V$ of both the CAA and the CAAA, as promulgated in 40 CFR 70, "State Operating Permit Programs," identifies the operating permit requirements for major stationary sources. Those facilities required by the state or by the EPA to have an operating permit will be expected to submit an operating permit application, a compliance plan, and periodic compliance reports.

The EPA promulgated final approval of the state of New Mexico operating permit program and it became effective on January 27, 1997. The state's program was established as "Operating Permits" and "Operating Permit Emission Fees" in 20 NMAC 2.70 and 2.71, respectively. The operating permit program is now discussed in Chapter 28 herein, the New Mexico Air Quality Control Act. 
The federal program (40 CFR 70 ) regulates and requires permits for both area and major sources. Major-source emission thresholds are used to determine which facilities require operating permits for both area and major sources under 40 CFR 70 and 20 NMAC 2.70 and 2.71. The inventory was also used to determine if WIPP is a major source as defined in 40 CFR 70 and 20 NMAC 2.71. A facility is considered a "major source" and is required to obtain an operating permit if the facility emits at least 100 tpy of criteria pollutants, 10 tpy of any single HAP, or 25 tpy of any combination of HAPs. Based on inventory emission calculations, WIPP is not a major source and is not currently required to obtain a federal CAA operating permit.

\subsubsection{Title VI, Stratospheric Ozone Protection}

Title VI of both the CAA and the CAAA places restrictions on and phases out the use of ozone-depleting chemicals, particularly chlorofluorocarbons (CFC). It is implemented by 40 CFR 82, "Protection of Stratospheric Ozone." These regulations are designed to phase out the use of Class I and Class II substances. Class I substances are CFCs, halons, carbon tetrachloride, methyl chloroform, hydrobromofluorocarbons, and methyl bromide. Class II substances are hydrochlorofluorocarbons, which generally have a lower ozone-depleting potential than do CFCs. The production of most Class I substances was prohibited as of January 1, 1996 (methyl bromide will be prohibited as of January 1, 2001, as indicated in 58 FR 69235). Proposed legislation indicates that, effective January 1, 2010, the use of Class II substances will be prohibited unless the substance has been used, recovered, and recycled; is used and entirely consumed in producing other chemicals; or is used as a refrigerant in appliances manufactured prior to January 1, 2020 (58 FR 15014). By January 1, 2030, the manufacture of all Class II substances will also be prohibited (58 FR 65018).

Implementing regulations pertaining to labeling requirements and the use and disposal of Class I substances during the service, repair, or disposal of appliances and industrial process refrigeration were published in the Federal Register. Recycling equipment registrations and training certifications were received from all WIPP refrigerant recycling contractors. Effective February 16, 1993, prohibition of the distribution or sale of any Class I substance identified as nonessential was implemented. Nonessential products include safety horns, wall-mounted alarms, CFC-containing cleaning fluids for electronic or photographic equipment, and CFC-containing aerosol products or other pressurized dispensers.

Most of the requirements pertaining to ozone-depleting substances (ODS) such as CFCs are applicable primarily to manufacturers of the chemicals, products containing the chemicals, or products in which ODSs are used during the manufacturing process. However, these regulations are applicable to WIPP in that these products will no longer be available after the time specified in the regulations. Therefore, replacement products must be found. Any container in which Class I or Class II substances (including waste) will be transported must have a warning label as required by 40 CFR § 82.106, "Warning Statement Requirements." However, the WIPP WAC requires that each generator site document that all aerosol cans included in the waste packages intended for disposal at WIPP were punctured (because the WAC allows no 
pressurized containers to be transported in the Transuranic Package Transporter Model II [TRUPACT-II] containers) and that all such containers are empty. Therefore, wastes destined for WIPP will not include containers with Class I or Class II substances, and the labeling requirements for Class I and Class II substances are not applicable to TRU wastes destined for WIPP.

\subsection{Compliance Status with the Regulatory Requirements}

\subsubsection{Control of Pollution from Federal Facilities, CAA § 118}

Each department of the executive, legislative, and judicial branches of the federal government having jurisdiction over any property or facility or engaged in any activity resulting in or that may result in the discharge of air pollutants and each employee thereof is subject to and must comply with all federal, state, interstate, and local requirements respecting the control and abatement of air pollution in the same manner and to the same extent as any nongovernmental entity.

The DOE complies with all federal and state requirements pertaining to the release of air pollutants that apply to WIPP. Compliance with federal and state air-quality requirements are described in this chapter and in Chapter 28 herein, respectively.

\subsubsection{National Emission Standards for Hazardous Air Pollutants, 40 CFR 61, Subpart H}

The NESHAPS for radionuclides other than radon from DOE facilities is EDE of $10 \mathrm{mrem} / \mathrm{year}$ to any member of the public.

Subpart H, "National Emission Standards for Emissions of Radionuclides Other Than Radon from Department of Energy Facilities," of 40 CFR 61 requires that facilities owned or operated by the DOE that emit any radionuclides other than radon-222 and radon-220 into the air are subject to this regulation.

Based on the May 1995 Memorandum of understanding Between the U.S. Environmental Protection Agency and the U.S. Department of Energy Concerning the Clean Air Act Emission Standards for Radionuclides 40 CFR 62 Including Subparts H. I, $Q$, and $T$, WIPP is subject to the emissions standard that specifies that no member of the public may receive an EDE of $10 \mathrm{mrem} /$ year in any year. In May 1994, modeling was performed for NESHAPs compliance using the CAP-88 code, which resulted in an estimated EDE of 4.04E-04 mrem/year. These calculated values are well below 1 percent of the regulatory limit of $10 \mathrm{mrem} /$ year. In November 1995, the DOE issued the WIPP SAR (DOE, 1995). The SAR and current amendments indicate that normal operations at WIPP are not expected to entail any releases of airborne radioactive materials, thus the EDE to the public would be undetectable. Since no source term currently exists at WIPP that could cause normal operations to exceed the 1 percent emission limit, only periodic confirmatory measurement as allowed by 40 CFR $\S 61.93$ 
will be required to comply with Subpart $\mathrm{H}$. The MOC will reassess the requirements as future operations dictate.

\subsubsection{NESHAPs Prestart-Up Notification, 40 CFR § 61.09(a)(1)}

The EPA will be notified of planned start-up between 30 and 60 days prior to start-up.

On February 23, 1999, the DOE submitted prestart-up notification letters to the EPA Administrator and to the EPA Region VI office to inform them of the impending start-up of WIPP, scheduled for late March 1999. The actual start-up date was March 26, 1999. These letters met the time frame requirements for notification.

\subsubsection{NESHAPs Poststart-Up Notification, 40 CFR $\S$ 61.09(a)(2)}

The EPA will be notified of actual start-up of WIPP within 15 days after that date.

On March 26, 1999, notification letters of actual start-up were submitted to the EPA. These letters met the time frame requirements for notification of actual start-up.

6.2.2.3 Emissions Monitoring and Test Procedures, 40 CFR § 61.93(a),(b)

Compliance with the standards shall be determined and EDE values calculated using EPA-approved sampling procedures and computer models. Radionuclide emissions shall be made at all release points which have a potential to discharge radionuclides into the air in quantities which could cause an EDE in excess of one percent of the standard. For other release points, periodic confirmatory measurements shall be made to verify the low emissions.

A single-point, anisokinetic sampling technology is employed at the WIPP for performing required periodic confirmatory measurements. This technology accurately measures potential emissions in the WIPP mine atmosphere. This technology is not an EPA standard reference sampling method as defined in NESHAPs; however, since the DOE is not a major emitter (i.e., WIPP's calculated emissions are less than 1 percent of the 10-mrem standard), WIPP is not required to use a reference sampling method, and thus not required to obtain approval to use an alternative sampling method. This position is reflected in the MOU. The CAP88-PC computer assessment model, and accepted EPA method, is used to estimate the EDE.

6.2.2.4 NESHAPs Quality Assurance Program Plan, 40 CFR $\S 61.93(b)$ and Appendix B, Method 114, Section 4.10

A NESHAPs Quality Assurance Program is required for facilities subject to Subpart $H$ of NESHAPS. 
The Periodic Confirmatory Measurement Protocol for the Waste Isolation Pilot Plant (DOE/WIPP 97-2238), was completed in 1997.

\title{
6.2.2.5 NESHAPs Annual Report, 40 CFR $\S 61.94$
}

A NESHAPs annual report must be submitted by June 30th for facilities subject to Subpart H of NESHAPs.

The DOE will file a NESHAPs report by June 30 every year as long as the facility is subject to these regulations. The report is for the previous calendar year. Therefore, the first report will be submitted in June 2000, a copy of which will be appended to this BECR as Appendix B.

\subsubsection{Record Keeping Requirements, 40 CFR $\S 61.95$}

\begin{abstract}
All facilities must maintain records documenting the source of input parameters, including the results of all measurements upon which they are based, the calculations and/or analytical methods used to derive values for input parameters, and the procedure used to determine the EDE. This documentation should be sufficient to allow an independent auditor to verify the accuracy of the determination made concerning the facility's compliance with the standard. These records must be kept at the site of the facility for at least five years and, upon request, be made available for inspection by the EPA Administrator or his/her authorized representative.
\end{abstract}

Monitoring for airborne radioactive emissions has been performed at WIPP since 1988. Two emission monitoring stations are available to sample exhaust from underground operations. All applicable records are maintained on site for at least five years and are available for examination if requested by the EPA Administrator or an authorized representative. The results of the measurements, supporting calculations, analytical methods, and procedure used to determine the EDE are all included in the records.

\subsubsection{NESHAPs Application for Radionuclides, 40 CFR $\S 61.96$}

The submittal of a NESHAPs application is required prior to construction or modification of any DOE facility that will emit radionuclides to the air.

Under NESHAPs if the estimated annual EDE is less than 1 percent of the standard, no application is required. Since the estimated EDE for WIPP is well below this number, no application was required for compliance with Subpart $\mathrm{H}$ of NESHAPs at WIPP. The MOC will reassess the NESHAPs application requirements as future facility modifications dictate. 
6.2.2.8 Prevention of Accidental Releases, CAA, $\S 112(r)$

A risk management plan/hazard assessment must be prepared, if applicable.

The list of regulated substances for accidental release prevention under $\S 112(r)$ of the CAA and the threshold quantities for these substances have been finalized in 40 CFR 68, "Chemical Accident Prevention Provisions." In order to comply with Subpart B of 40 CFR 68, two documents were used to determine whether emissions from WIPP exceed the regulatory threshold level of any of the chemicals listed in the final rule. The two documents are the Air Emissions Inventory Report Calendar Year 1996 for WIPP and the WIPP Tier II Emergency and Hazardous Chemical Inventory Report required under the EPCRA. It was found that, of the 162 substances and gases listed in the final rule, none at WIPP meet or exceed the final threshold levels. Therefore, WIPP is not currently required to develop a risk management plan to evaluate accidental releases from the site.

\subsubsection{State Operating Permit Programs, 20 NMAC 2.70 and 2.71}

The requirements for operating permits include a provision that state programs must provide for permitting of "any source, including an area source (i.e., a source of the pollutant that is not a major source), subject to a standard or other requirement under $\S 112$ of the [Clean Air] Act." (See section 70.3[a][3], which is the section on NESHAPs.) Based on emission calculations in the 1996 inventory, emissions at WIPP are below "major source" and NESHAPs emission limits. Thus, the permitting and reporting requirements contained in 20 NMAC 2.70 and 2.71 are not applicable at this time. The inventory will be updated for calendar year 1999 to evaluate regulatory changes and to monitor the use of HAPs and toxic air pollutants (defined in 20 NMAC 2.72 and 2.78) at the site. The WIPP Chemical Inventory Database is used to evaluate chemical use at the site. Using chemical and material inventory data, WIPP personnel evaluated potential replacement chemicals to minimize the use of materials regulated under the NESHAPs and toxic air pollutant programs.

Since the state has an operating permit program in place, the applicable state requirements for an operating permit program are discussed in Chapter 28 herein. However, federal requirements for an operating permit program and those still under development are summarized here.

\subsubsection{Operating Permit Application, 40 CFR § 70.3(a)(3)}

The state may require the submittal of operating permit applications from area sources under NESHAPS.

Based on the 1996 WIPP inventory, HAP emissions from the facility are below current operating permit threshold levels, and an operating permit is not required for WIPP. Submittal of an application is not applicable at this time. The state does not currently require the submittal of operating permit applications from area sources under 


\section{Waste Isolation Pilot Plant Biennial Environmental Compliance Report}

DOE/WIPP 99-2171

NESHAPs and is awaiting the EPA's decision on emission thresholds from area sources that will trigger the need for an area source to submit such an application.

In addition, the EPA has not yet defined "major source" with respect to radionuclides. Until such a definition is provided, or until the EPA specifies the quantity of radionuclide emissions released from a facility that will trigger the need to submit an operating permit application (as a major or an area source), no operating permit is needed for WIPP based on radionuclide emissions alone.

6.2.3.2 Reporting Information about Gasoline Represented as Being Unleaded at the Request of the EPA, $40 \mathrm{CFR} \S 80.7$

If the Administrator, the Regional Administrator, or a delegate has reason to believe that a violation of the CAA or its implementing regulations with respect to the use of prohibited fuel (e.g., leaded) has occurred, he/she may require that any wholesale purchaser/ consumer report information regarding receipt, transfer, delivery, or sale of gasoline represented to be unleaded and to allow the reproduction of such information at all reasonable times. The purchaser/consumer is also required to provide any other information to the EPA representative as requested to enable him/her to ensure that the purchaser/consumer acted in compliance with the applicable provisions of the CAA and the implementing regulations.

No instances are known to have occurred in which prohibited fuel was used at WIPP.

6.2.3.3 Prohibition against Dispensing Gasoline Containing Lead or Lead Additives, 40 CFR $\S 80.22$

After December 31, 1995, no person shall dispense or supply any gasoline produced with the use of lead additives or that contains more that 0.05 gram of lead per gallon, nor shall he/she supply or dispense gasoline represented to be unleaded unless it meets the criteria specified in 40 CFR 80.2(g) or allow gasoline other than unleaded to be dispensed into any motor vehicle that is equipped with a gasoline tank filler inlet designed for the introduction of unleaded gasoline.

There are no known instances in which the gasoline dispensed at WIPP has contained lead in concentrations exceeding 0.05 gram per gallon.

\subsubsection{Liability for Violations, 40 CFR $\S 80.23$}

In any case in which a wholesale purchaser-consumer or his/her employee or agent introduces gasoline other than unleaded into a motor vehicle equipped with a gasoline tank filler inlet designed 
for the introduction of unleaded gasoline, only the wholesale purchaser-consumer shall be deemed in violation.

There are no known instances in which a violation of these regulations has occurred at WIPP.

\subsubsection{Protection of Stratospheric Ozone, 40 CFR 82}

A number of requirements have been imposed that relate to CFCs and other ODSs. Most of these requirements pertain directly to manufacturers; however, because of the planned phaseout of these materials, the regulations will also impact users of these materials.

6.2.4.1 Restrictions on Repairing and Servicing Motor Vehicle Air Conditioners, $40 \mathrm{CFR} \S 82.40$

Effective August 13, 1992, no person repairing or servicing motor vehicles for consideration may perform any service on a motor vehicle air conditioner involving the refrigerant for the air conditioner without using approved refrigerant recycling equipment and unless he/she has been properly trained and certified by a technician certification program approved by the Administrator.

No government vehicles are serviced, repaired, or maintained by WIPP employees. All equipment owned or used by the vendors that service these vehicles has been approved, and all the service technicians who perform such work are certified to work on motor vehicle air conditioners.

6.2.4.2 Prohibition of Nonessential Class I Ozone-Depleting Substances, 40 CFR §§ 82.64(c) and 82.104(a)

Nonessential Class I ODSs are being phased out and will no longer be sold or distributed in the United States as of January 17, 1994. The Class I ODSs currently consist of the CFCs, halons, carbon tetrachloride, and methyl chloroform.

A list of the ODSs used at WIPP is included in the current WIPP emissions inventory. The major ODSs used at WIPP was methyl chloroform (i.e., 1,1,1-trichloroethane). According to the estimated emissions based on the 1993, 1994, and the 1996 HAPs inventories, use of this material at WIPP has been eliminated (based on estimated emissions of $0.67 \mathrm{lb} / \mathrm{hr}$ in 1993 versus $0.027 \mathrm{lb} / \mathrm{hr}$ in $1994 \mathrm{and} 0 \mathrm{lb} / \mathrm{hr}$ in 1996). As WIPP personnel continue to define the actual use of products containing ODSs, waste minimization personnel will continue to recommend substitute products to reduce ODS emissions from WIPP. 
6.2.4.3 Ban on Nonessential Products Containing Class I Substances, $40 \mathrm{CFR} \S 82.66$

The following products that release a Class I substance were identified as being nonessential and are subject to the prohibitions specified under 40 CFR $\S 82.64$ :

- Personal safety horns;

- Wall-mounted alarms used in factories or other work areas;

- Any plastic flexible or packaging foam product which is manufactured with or contains a CFC;

- Any aerosol product or other pressurized dispenser that contains a CFC including but not limited to household, industrial, automotive, and pesticide uses except lubricants, coatings, or cleaning fluids for electrical or electronic equipment that contain no CFCs other than CFC-11, CFC-12, or CFC-113 for solvent purposes; and

- Document preservation sprays that contain no other CFCs than CFC-113.

The deadlines set under 40 CFR $\S 82.64$ pertain to selling or distributing nonessential products. However, the items have been listed because no purchase of nonessential products may be made by government entities after October 24, 1994. An inventory of ODSs on site, dated June 1995, was reviewed. No personal safety horns, wallmounted alarms, or plastic flexible or packaging foam was listed on the inventory list.

A number of aerosol products appear on the WIPP inventory of products used at the site. Substitute products are being investigated.

A number of cleaning fluids used at the site are listed on the inventory list. The 1996 Air Emissions Inventory shows that substitute products are being identified and are replacing ODSs, and that the use of 1,1,1-trichloroethane (the ODSs with the greatest use at WIPP) was reduced to zero.

No document preservation sprays are used at WIPP.

6.2.4.4 Federal Procurement Requirements, 40 CFR $\S 82.84$

Each department, agency, and instrumentality of the United States shall conform its procurement regulations to the requirements and policies of Title VI of the CAA by October 24, 1994. Each such regulation shall provide, at a minimum, the following: 
- In place of Class I or Class II substances, or of products made with or containing such substances, safe alternatives identified under 42 U.S.C. $\S 7671$ (k) (or products made with or containing such alternatives) shall be substituted to the maximum extent practicable.

- $\quad$ Consistent with the phaseout schedules for ODSs, no purchase shall be made of Class II substances, or products containing Class II substances, for the purpose of any use prohibited under 42 U.S.C. $\S 7671(d)(c)$.

- All active or new contracts involving the performance of any service or activity subject to 42 U.S.C. $\S 7671(\mathrm{~g})$ or $7671(\mathrm{~h})$ or regulations promulgated thereunder include, or be modified to include, a condition requiring the contractor to ensure compliance with all requirements of those sections and regulations.

- No purchase shall be made of products whose sale is prohibited under 42 U.S.C. $\S 7671(h)$, except when they will be used by persons certified under $\S 609$ to service vehicles, and no purchase shall be made of nonessential products as defined under 42 U.S.C. § 7671(i).

- $\quad$ Proper labeling under 42 U.S.C. $\S 7671(j)$ shall be a specification for the purchase of any product subject to that section.

For agencies subject to the Federal Acquisition Regulation, 48 CFR 1, amendment of the Federal Acquisition Regulation, consistent with this subpart, shall satisfy the requirement of this section.

A comparison of the inventory lists prepared to date $(1993,1994$, and 1996) indicates that efforts are being made to identify substitute products to replace ODSs. Requests for the procurement of any new chemicals at WIPP are screened by personnel in one of the environment, safety, and/or health organizations before the chemicals are ordered to assure that the applicable regulations are being met.

6.2.4.5 Reporting Requirements, 40 CFR $\S 82.86$

No later than one year after October 22, 1993, each agency, department, and instrumentality of the United States shall certify to the Office of Management and Budget (OMB) that its procurement regulations have been amended in accordance with this section. 
Certification by the GSA [General Services Administration] that the Federal Acquisition Regulation has been amended in accordance with this section shall constitute adequate certification for purposes of all agencies subject to the Federal Acquisition Regulation.

The procurement regulations, which became effective on October 24, 1994, were amended as required, and a report to that effect was made to the Office of Management and Budget. (See also the response to section 6.2.4.4 above.)

6.2.4.6 Labeling of Products and Containers Containing Class I or Class II OzoneDepleting Substances, 40 CFR 82, Subpart E

Warning statements are required on containers of and products containing or manufactured with certain ODSs.

Federal procurement regulations require that proper labeling be a specification for the purchase of any product. The CAO requires that all chemicals purchased for use at WIPP, including those containing an ODS, be properly labeled.

\subsubsection{Applicability, 40 CFR $\S 82.102$}

These requirements apply to substances designated as Class I or Class II substances as of February 11, 1993, beginning on May 15, 1993. The requirements of this subpart apply to the following containers and products except those products manufactured prior to May 15, 1993, provided that the manufacturer submits documentation to the EPA upon request showing that the product was manufactured prior to that date. The requirements apply to:

- All containers in which a Class I or Class II substance is stored or transported,

- All products containing a Class I substance, or

- All products directly manufactured with a process that uses a Class I substance, unless otherwise exempted.

Beginning on January 1, 2015, or one year after any determination between May 15, 1993, and January 1, 2015, if suitable substitute products or manufacturing processes are found, the requirements of this subpart shall apply to the following:

- All products containing a Class II substance or 
- All products manufactured with a process that uses a Class II substance

Federal procurement regulations require that proper labeling shall be a specification for the purchase of any product. The CAO requires any chemical products to be used at WIPP, including those containing ODSs be properly labeled as a prerequisite for purchase.

6.2.4.8 Required Warning Statements, 40 CFR § 82.106

Unless otherwise exempted by this subpart, each container or product identified in $\S 82.102(a)$ or (b) shall bear the following warning statement, meeting the requirements of this subpart for placement and form:

"WARNING: Contains [or Manufactured with, if applicable] [insert name of substance], a substance which harms public health and environment by destroying ozone in the upper atmosphere."

Exemptions from the warning label requirement include:

- Products in which trace quantities of a controlled substance remain as a residue or impurity

- Waste containing controlled substances or blends of controlled substances bound for discard

- Products that are manufactured using methyl chloroform or CFC-113 by persons who can demonstrate and certify a 95-percent reduction in overall usage from their 1990 calendar year usage of methyl chloroform or CFC-113 as solvents during a 12-month period ending within 60 days of such certification or during the most recently completed calendar year

- $\quad$ Products that are otherwise not subject to the requirements of this subpart that are being repaired using a process that uses a controlled substance.

Federal procurement regulations require that proper labeling be a specification for the purchase of any product. Proper labeling is now one of the specifications used in the purchase of products containing an ODS at WIPP. 
6.2.4.9 Placement of Warning Statement and Prohibition on Removal of the Label Bearing the Warning Statement, 40 CFR $\S \S 82.108$ and 82.112

The warning statement shall be "clearly legible and conspicuous." The manner in which the label may be placed on the container is described. Removal of the label bearing the warning statement is prohibited. When purchasers of the product cannot view it at the time of purchase, the promotional printed material prepared for display or distribution may contain the warning statement or the statement may be placed such that it is clearly legible and conspicuous at the time of product delivery so that the purchaser may return the product.

The warning statement is primarily the responsibility of the manufacturer. The prohibition on removing the label bearing the warning statement applies primarily to the manufacturer and subsequent wholesalers. However, the purchaser also has the obligation to review products being ordered to avoid the procurement of all but essential ODS-containing materials. Furthermore, the purchaser is obliged to maintain the label on the container. It is CAO policy that warning labels not be removed or tampered with. If a label is damaged and becomes unreadable, it is replaced.

\subsubsection{Prohibitions, 40 CFR § 82.124(a)(4)}

On or after May 15, 1993, no person may modify, remove, or interfere with any warning statement required by this subpart, except as described in $\S 82.112$.

Every appliance and product containing CFCs should have a label from the manufacturer. It is CAO policy that warning labels not be removed or tampered with. If a label is damaged and becomes unreadable, it is replaced.

6.2.4.11 Service, Maintenance, and Repair of Appliances Using Refrigerants, 40 CFR $\S 82.150$

This subpart applies to any person servicing, maintaining, or repairing appliances except for motor vehicle air conditioners. This subpart also applies to persons disposing of appliances, including motor vehicle air conditions. In addition, this subpart applies to refrigerant reclaimers, appliance owners, and manufacturers of appliances and recycling and recovery equipment.

Although no WIPP employees service, maintain, or repair appliances, these regulations apply to WIPP because the facility owns appliances and is responsible for the disposal of appliances. The CAO policy is that WIPP appliances will be sold intact or refrigerants must be removed from all appliances by a certified recycling contractor. 
6.2.4.12 Prohibitions Regarding Maintenance, Service, Repair, or Disposal of Appliances, 40 CFR § 82.154

Prohibitions are specified for persons who maintain, service, repair, or dispose of appliances who may vent or otherwise release into the environment any Class I or Class II substance used as refrigerant in such equipment. De minimis releases associated with good faith attempts to recycle or recover refrigerants are not subject to this prohibition. No person may dispose of appliances except for small appliances, motor vehicle air conditioners, and motor vehicle air conditioner-like appliances unless the required practices described in 40 CFR $\$ 82.156$ are observed and equipment that is certified for that type of appliance is used. Prohibitions are also specified regarding recycling or recovery equipment.

Prohibitions also exist for the sale of Class I or Class II substances consisting wholly or in part of used refrigerants.

It is a violation of this subpart to accept a signed statement pursuant to 40 CFR 82.156(f)(2) if the person knew or had reason to know that such a signed statement is false.

No WIPP employees service, repair, or maintain appliances on site. Before appliances are disposed of, refrigerant is evacuated by a certified contractor. No recycling or recovery equipment is owned by the facility. Only small appliances have been disposed of by WIPP personnel since the regulation took effect on July 13, 1993. All contractors have submitted a signed statement to the EPA that ensures compliance with and knowledge of applicable regulations and is included in the equipment certification form. Recycling and reclamation of appliances containing refrigerants used at WIPP are owned by certified contractors. No recycling or reclamation appliances have been altered since their certification.

No Class I or II substances are sold or distributed from WIPP.

\subsubsection{Required Practices, 40 CFR $\S 82.156$}

Effective July 13, 1993, any person opening appliances other than motor vehicle air conditioners must evacuate the refrigerant to a system receiver or to a recovery or recycling machine as specified. At least one piece of certified, self-contained recovery equipment must be available at his/her place of business.

Leaks in appliances containing refrigerant must be repaired as specified. 
The contractors have indicated that this is done and work orders verify that this requirement is met. All recovery equipment owned/used by the contractors at WIPP is certified. All maintenance, service, and repair on applicable appliances is performed by one of the certified contractors, who have verified on the equipment certification form that they have complied with these regulations.

All equipment owned/used by the contractors at WIPP is self-contained. All applicable requirements of this section are being met.

No leaks were detected in the refrigeration units on site during this reporting period.

\subsection{Compliance Status of Permit Conditions}

Currently, only the permit for the backup diesel electrical power supply generators is required for WIPP under the CAA. This permit is discussed in Chapter 28 herein. 


\subsection{FEDERAL WATER POLLUTION CONTROL ACT OF 1972 ("CLEAN WATER ACT")}

\subsection{Summary of the Law}

The Federal Water Pollution Control Act of 1972 (33 U.S.C. $\S \S 1251$ et seq.) is usually referred to as the "Clean Water Act" (CWA). The major program under this act is the National Pollutant Discharge Elimination System (NPDES). This program, discussed in $\S 402$ of the CWA, regulates the discharge of pollutants into navigable waters of the United States. The regulations implementing the NPDES that are relevant to the WIPP project are found in 40 CFR 122, "EPA Administered Permit Programs: The National Pollutant Discharge Elimination System," which contains definitions and basic application requirements, standard permit conditions, and monitoring and reporting requirements for the NPDES program. However, because there are no point-source discharges into navigable waters from WIPP, the facility is not required to obtain a standard NPDES permit.

In 1990, an NPDES storm water permit program was added to the CWA (§ 402[p]) to govern the discharge of pollutants into precipitation runoff. The EPA has determined that the NPDES storm water regulations found in 40 CFR $\S 122.26$ are applicable to WIPP because a potential exists for storm water runoff to contact regulated pollutants. The NPDES storm water permit program involves three types of permits: general, individual, and group. To obtain a permit, a facility submits either a Notice of Intent (NOI) for a general permit, an individual application for an individual permit, or an application as part of a group of applicants for a group permit. The EPA planned to cover most industrial discharges under general permits and issued the Final NPDES General Permits for Storm Water Discharges Associated with Industrial Activity in the Federal Register on September 9, 1992. These general permits cover facilities that discharge effluents associated with industrial activities in 11 states, including New Mexico, that do not have authorized NPDES programs.

Of the other regulations that implement the NPDES program, only 40 CFR $\S 122.21$, "NPDES Permit Assessment for Sewage Sludge," and 40 CFR 459, "Photographic Point Source Category," could apply to WIPP. In order to meet the requirements of 40 CFR $\S 122.21(\mathrm{c})(2)$, the DOE filed an NPDES sewage sludge information package with EPA Region VI, requesting a determination as to whether the facility will be required to obtain an NPDES sewage sludge discharge permit. Based on the determination made by the Regional Director, the DOE may be required to submit an $\mathrm{NOI}$ to obtain a sludge-discharge permit. Information submitted to the EPA was reviewed to determine whether the facility is a "treatment works treating domestic sewage." If it is, the EPA will notify the DOE when a "sludge only" application must be submitted. WIPP is exempt from regulation under 40 CFR 459 because photographic wastes are collected and transported off site to a licensed facility for disposal.

Another implementing regulation under the CWA applicable to the WIPP project is 40 CFR 112, "Oil Pollution Prevention," which includes criteria and guidelines for the 
preparation and implementation of a facility's Spill Prevention, Control, and Countermeasures (SPCC) Plan (WP 02-EC.09).

\subsection{Compliance Status of the Regulatory Requirements}

\subsubsection{SPCC Plan Requirements, 40 CFR $\$ 112.3$}

Requirements for the preparation and implementation of SPCC plans are specified under the "Oil Pollution Prevention" regulations of 40 CFR 112.

The WIPP SPCC Plan was issued in November 1988. The revised plan was issued in April 1999.

\subsubsection{Amendment of the SPCC Plan by the Owner/Operator, 40 CFR $\S 112.5$}

Requirements for amending SPCC plans by the owners/operators of a facility are specified under the "Oil Pollution Prevention" regulations of 40 CFR 112.

The WIPP SPCC Plan undergoes an annual review and is revised as needed to reflect changes in facility activities and emergency equipment.

\subsubsection{Notification of Discharge of a Reportable Quantity, 40 CFR § 117.21}

Any discharge of a designated hazardous substance in quantities equal to or exceeding in any 24-hour period the $R Q$ shall immediately be reported to the appropriate agency of the United States Government.

During this reporting period there were no releases exceeding the $R Q$ of any designated hazardous substance.

\subsubsection{NPDES Permit Requirement, 40 CFR § 122.1(b)(1)}

The NPDES program requires permits for the discharge of pollutants from any point source into waters of the United States.

There are no point-source discharges into navigable water from WIPP. Therefore, the facility is not required to obtain a standard NPDES permit.

\subsubsection{NPDES Permit Assessment, 40 CFR § 122.21(c)(2)}

Any "treatment works treating domestic sewage" commencing operations after the promulgation of an applicable standard for sewage sludge use or disposal shall submit an application to the 
director at least 180 days prior to the date proposed for commencing operations.

The WIPP stabilization sewage lagoon began operating in June 1985. Sludge was disposed of in 1993 during the facility expansion. This expansion included the construction of two new, lined evaporation ponds and the subsequent draining and lining of the primary evaporation pond. All sludges were removed from the primary evaporation pond prior to the installation of the synthetic liner. This was the first removal of sludge in the 9-year operation of the facility, and it is anticipated that sludge removal will be necessary approximately twice prior to final facility closure.

Consultation with the NMED Surface Water Bureau and the EPA Region VI Water Management Division provided a determination for land disposal of the sewage sludges. Dried sludges were removed from the primary evaporation pond and mixed with top soils at a reclamation site near the construction landfill. Sludges were used as a soil additive to implement the best management practices (BMP) identified in the WIPP NPDES Storm Water Pollution Prevention Plan (PPP) (WP 02-EC.10).

\subsubsection{Requirement for NPDES Permit for Storm Water Discharges, 40 CFR § 122.26(a)}

Storm water discharges are regulated by the EPA under the NPDES program. The EPA requires an NPDES permit for facilities that could discharge contaminated storm water runoff to waters of the United States.

The WIPP site is regulated by NPDES Storm Water Multi-Sector General Permit No. NMR05A225.

Evaluation of NPDES storm water compliance options for WIPP began in July 1991. On April 2, 1992, the EPA published the final NPDES Application Deadlines, General Permit Requirements and Reporting Requirements for Storm Water Discharges Associated with Industrial Activity, which established the new general permit rules for minimal sampling and analytical requirements. The EPA published the Final NPDES General Permits for Storm Water Discharges Associated with Industrial Activity (hereafter referred to as the "NPDES General Permits") in the Federal Register on September 9, 1992. These general permits established NOI requirements, prohibitions, requirements to develop and implement storm water pollution prevention plans, and requirements to conduct site inspections for facilities with discharges that are authorized by the permit. In addition, these permits established monitoring requirements for certain classes of facilities.

With the expiration of the original general permit on September 9, 1997, an NOI was submitted August 29, 1997, to the EPA to request coverage under storm water discharges associated with industrial activity under an NPDES Multi-Sector General Permit. Permit No. NMRO5A225 was issued to the DOE on February 23, 1998, for a period of five years. 
This requirement is addressed in the WIPP NPDES Storm Water PPP. No sampling was required for the submittal of the NPDES General Permits NOI.

The NPDES storm water rules require compliance sampling of discharges resulting from any storm event that is greater than 0.1 inch in magnitude. WIPP uses personnel use BMPs such as retention basins designed to contain two consecutive 24-hour storm events, the covering of material storage areas, and the reclamation of disturbed sites to eliminate storm water contact with regulated pollutants. By design, complete compliance sampling is required only if a storm event results in a discharge from a retention basin. If sampling is required, it will be conducted as required by the NPDES General Permits.

\subsubsection{Application Requirement for Storm Water Discharges Associated with Industrial Activity, 40 CFR § 122.26(c)}

The implementing regulations in Part 122 require the submittal of an application for a storm water NPDES permit.

This requirement was superseded by the issuance of the EPA's Final NPDES General Permits for Storm Water Discharges Associated with Industrial Activity (57 FR 41236, September 9,1992), which replaces the requirement for the submittal of an application with the filing of an NOI for obtaining a general permit. This was again superseded by 60 FR 50804 issued September 29, 1995, EPA Final NPDES Storm Water Multi Sector General Permit for Industrial Activities.

\subsection{Compliance Status of Permit Conditions}

Specific conditions and their compliance status under the EPA's Final NPDES General Permits for Storm Water Discharges Associated with Industrial Activity were published in the Federal Register on September 9, 1992. All applicable requirements are specified in Part IV and Appendix B of the NPDES General Permits.

\subsubsection{Notice of Intent to File for a General Permit, IV(A) and Appendix B, II(A)}

In the EPA's NPDES General Permit, a provision was made that a facility should file an NOI to file for a general storm water discharge permit rather than submit a formal application for the permit.

The NOI to obtain an NPDES Storm Water Multi-Sector General Permit was submitted to the EPA on August 23, 1997. The EPA issued a general permit to WIPP on February 23, 1998 (No. NMR05A225). 


\subsubsection{Notice of Termination, $\operatorname{IV}(\mathbf{A})(4)$}

A facility may submit a Notice of Termination if no storm water discharges will be released.

Although the $\mathrm{CAO}$ and its MOC have implemented BMPs that are designed to make WIPP a zero-discharge facility, this requirement currently is not applicable because the facility has the potential to discharge storm water that could contact regulated pollutants. If the CAO can demonstrate that the storm water discharges at WIPP can be contained effectively, a Notice of Termination may be filed as specified under Condition IV $(A)(4)$ of the NPDES General Permits. If the Notice of Termination is approved by the EPA, coverage of WIPP under the NPDES General Permits for Storm Water Discharges Associated with Industrial Activity will cease.

\subsubsection{Prohibition on Non-Storm Water Discharges, IV(B)(1) and Appendix B, III(A)}

The EPA prohibits the release of non-storm water discharges under the storm water discharge NPDES permit.

All non-storm water discharges at WIPP are either air conditioner condensate discharges or fire water testing discharges, both of which are exempt from general permit rules. Air compressor condensate discharges are collected, characterized, and disposed of in accordance with applicable regulations.

\subsubsection{Releases of Reportable Quantities of Hazardous Substances and Oil, IV(B)(2) and Appendix B, III(B)}

Releases of reportable quantities of hazardous substances and oil must be reported.

There were no spills exceeding an $R Q$ during this reporting period.

The WIPP Storm Water PPP addresses the actions that must be taken in the event of a reportable spill, including notification to the National Response Center. If the notification to the National Response Center is made in reference to a release from BMPs (retention basins, etc.), the Storm Water PPP must be modified within 14 days to provide a description of the release; the circumstances leading to, and the date of, the release; measures to prevent recurrence and to respond to such releases; and notification to the EPA.

\subsubsection{Storm Water Pollution Prevention Plan, IV(C) and Appendix B, Part IV}

Regulated facilities with a general permit must have prepared and implemented a storm water pollution prevention plan. 
The WIPP Storm Water PPP describes how the BMPs and other requirements of the NPDES storm water regulations are being implemented at WIPP. Requirements addressed include the identification of a pollution prevention team, the potential pollution sources, and past spills and leaks.

\subsubsection{Pollution Prevention Team, IV(C)(1) and Appendix B, IV(D)(1)}

A pollution prevention team is required for permitted facilities. This team must be addressed in the facility's Storm Water PPP.

The WIPP Pollution Prevention Team is composed of representatives from organizations within the MOC who are knowledgeable about the facility and its operations and who will provide structure and direction to the storm water management program. The members of the Pollution Prevention Team and their functional area responsibilities are identified in the Storm Water PPP.

\subsubsection{Identification of Potential Pollution Sources, IV(C)(2) and Appendix B, $\operatorname{IV}(D)(2)$}

Potential sources of pollution must be identified at the permitted facility.

A site inspection was conducted in 1994 to identify improper connections into either the WIPP sewage system or storm water diversion swales. The inspection revealed eight areas that could contribute pollutants to storm water runoff. These eight areas are identified and discussed in the Storm Water PPP.

As described in the Storm Water PPP, three different material inventories were used to complete the materials inventory assessment: the WIPP Stores Stock Inventory, the MSDS Inventory, and the Hazardous Air Pollutants Inventory. Several site walkarounds were then conducted to examine material storage practice and to identify the operations and storage areas with the potential to come into contact with storm water.

Non-storm water discharges, described in the Storm Water PPP, are discussed in section 7.3.3 above. An identification of potential risks from discharges was not performed because all non-storm water discharges are either exempted, contained, or not regulated.

\subsubsection{Site Assessments, IV(C)(2) and Appendix B, IV(D)}

A site assessment for storm water discharge sources must be included in a facility's Storm Water PPP.

A summary of the site assessment is provided in the Storm Water PPP. This summary identifies the potential pollutant sources that require additional controls or BMPs to ensure compliance with the requirements. (See also section 7.3 .7 above.) 


\subsubsection{Measures and Controls, IV(C)(3) and Appendix B, IV(D)(3)}

Measures and controls (including record keeping and internal reporting) must be addressed in the Storm Water PPP.

The measures and controls for discharges are described in the Storm Water PPP. BMPs and implementation of these practices are specified for eight management areas (identified in section 7.3.7 above) and the solid waste management units (SWMU) located in the rest of the 16-section withdrawal area. Included in the discussion are sections on good housekeeping, maintenance, and visual inspections; the WIPP SPCC Plan; management of runoff and of sediment and erosion controls; employee training; compliance reporting; annual site compliance evaluations; and record keeping.

\subsubsection{Comprehensive Site Compliance Evaluations, IV(C)(4) and Appendix B, IV(D)(4)}

Comprehensive site compliance evaluations are mandatory for a permitted facility and must be discussed in the facility's Storm Water PPP.

Comprehensive site inspections are discussed in the Storm Water PPP. The initial internal site assessment is described, as is the periodic site compliance evaluation. The CWA Coordinator is responsible for conducting quarterly site compliance evaluations. The NPDES program, including site operation and materials management, is reviewed annually. In addition, the NPDES storm water permit program is evaluated periodically as part of the WIPP Environmental Compliance Assessment Program. The Storm Water PPP is reviewed quarterly to reflect changes in compliance strategy, regulations, team members, etc.

During the inspections, material handling and storage areas and other potential sources of pollution are visually inspected for evidence of actual or potential pollutant discharges. Guidelines for housekeeping, maintenance, and visual inspections are provided in an MOC manual. Self-assessments are conducted by MOC personnel in accordance with a WIPP procedure which outlines the requirements for evaluating good housekeeping practices and making visual inspections. In addition, MOC personnel conduct quarterly walk-arounds to assess compliance with the storm water regulations at the site and develop corrective action plans to mitigate any issues that may arise from these assessments.

\subsubsection{Requirements for Storage, Processing, and Handling Areas for EPCRA § 313 "Water Priority Chemicals," IV(D)(1) and Appendix B, IV(D)(7)}

The EPA specifies requirements for storage, processing, and handling areas for EPCRA § 313 "water priority chemicals." 
This section is not applicable because the CAO has not been required to submit a report for WIPP under $\S 313$ of EPCRA during this reporting period due to certain exemptions (see Chapter 4 herein).

\subsubsection{Enclosure or Covering of Outdoor Salt Piles, IV(D)(2) and Appendix B, IV(D)(8)}

The EPA's NPDES General Permit requires that outdoor salt piles be enclosed or covered. This requirement applies only to storage pile runoff discharged to waters of the United States.

The outdoor salt piles at WIPP are situated on a compacted, caliche liner which eliminates potential discharge to waters of the United States. Any storm water runoff is diverted to the caliche-lined evaporation basin. Storm water that collects in the evaporation basin usually evaporates within 24 hours. Furthermore, the moisture contained in the mined salt quickly forms a hard crust over the surface of the pile, which reduces wind-borne particulates. As rain falls on the salt pile, this protective crust becomes thicker, which further reduces salt particulate discharges. Because no waters are diverted to waters of the United States, enclosure of the salt piles is not required.

\subsubsection{Notification to Municipal Large and Medium Separate Storm Water Systems, IV(D)(3) and Appendix B, IV(D)(5)}

The NPDES General Permits require that the permitted facility notify the owners/operators of any municipal large and medium separate storm water systems that service the facility in the event of a discharge.

This requirement is not applicable at WIPP because storm water is not discharged through a large or medium separate storm water system.

\subsubsection{Monitoring and Reporting Requirements, IV(E) and Appendix B, Part IV and $\mathrm{XI}(\mathrm{C})(\mathrm{vi})$}

Monitoring and reporting requirements required are described in the NPDES General Permits and differ for different types of facilities.

As discussed in the Storm Water PPP, all regulated storm water discharges are or will be contained within retention basins or controlled by practices such as diversion berms, reclamation, or material covers. Therefore, the need for compliance sampling at WIPP is not anticipated.

As indicated by the Storm Water PPP, a Discharge Monitoring Report is required only if a discharge has occurred. In the event of a discharge, the Discharge Monitoring Report, along with sampling results, will be submitted to the EPA on the appropriate Discharge Monitoring Report form by October 28 of the appropriate year. 


\subsection{SAFE DRINKING WATER ACT}

\subsection{Summary of the Law}

The Safe Drinking Water Act of 1974 (SDWA; 42 U.S.C. $\S \S 300 f$ et seq.), as amended, provides the regulatory strategy for protecting public water supply systems and underground sources of drinking water. As defined in the implementing regulations in 40 CFR 141, "National Primary Drinking Water Regulations," these systems provide water for human consumption, have at least 15 connections, or regularly serve at least 25 people.

The SDWA also protects underground sources of drinking water from underground injection of contaminated fluids. Underground injection, defined as "subsurface emplacements of fluids by well injections" in $\S 1421(\mathrm{~d})$ of the SDWA, is governed by the Underground Injection Control program described in Subpart C of 40 CFR 144.

The EPA delegated authority for ensuring compliance with the SDWA's National Primary Drinking Water Standards by approving the NMED's Drinking Water Regulations (DWR). These regulations now occupy section 7.1 of 20 NMAC. (See Chapter 30 herein, New Mexico Drinking Water Regulations.)

\subsection{Compliance Status of the Regulatory Requirements}

The WIPP LWA specifically requires compliance with the SDWA.

The NMED has authority to administer the SDWA in New Mexico. The state compliance criteria and general operating requirements for owners and operators of water supply systems are described in 20 NMAC 7.1. These regulations and the compliance status at WIPP are covered in Chapter 30 herein.

\subsubsection{State Program Requirements, 40 CFR § 142.4}

All applicable requirements in this section are covered in the state program for the SDWA. (See Chapter 30 herein, which addresses the New Mexico Drinking Water Regulations.)

\subsubsection{Underground Injection Control, 40 CFR 144}

The EPA has established a number of requirements for facilities that dispose of wastes by means of underground injection.

None of the hazardous waste currently generated at WIPP is injected underground, nor will TRU waste be disposed by underground injection at WIPP. Therefore, the EPA's requirements for Underground Injection Control do not apply to WIPP. 
This page intentionally left blank. 


\section{$9.0 \quad$ TOXIC SUBSTANCES CONTROL ACT}

\subsection{Summary of the Law}

The Toxic Substances Control Act (TSCA; 15 U.S.C. §§ 2601 et seq.) regulates the production, use, distribution, and disposal of new, potentially toxic chemical substances. TSCA requires that tests be conducted on new chemical substances so that risks can be understood and addressed before the chemical substances are released into commerce.

The act applies primarily to commercial manufacturers, importers, and processors of toxic chemicals. WIPP is not a manufacturer or a processor of chemical products; therefore, most of the provisions of TSCA do not apply. However, three sections of this act pertain to existing commercial toxic substances, rather than to the development of new chemicals. These sections deal with asbestos, indoor radon abatement, and polychlorinated biphenyls (PCB).

\subsubsection{Asbestos Hazard Emergency Response Act of 1986}

Because of the potential for serious health hazards associated with asbestos, Congress amended TSCA in 1986 by adding Title II, the Asbestos Hazard Emergency Response Act (AHERA). The AHERA requires the EPA to establish a comprehensive regulatory framework of inspection, management, planning, operations and maintenance activities, and appropriate abatement responses for controlling asbestos-containing materials in schools. Under AHERA, the EPA promulgated its "AHERA-in-Schools Rule" on October 17, 1987. The 1988 AHERA amendments provided additional time for local educational agencies to submit asbestos management plans to the state governors and begin implementation of these plans.

Under AHERA, the EPA was also required to conduct a study to determine the extent of danger to human health posed by asbestos in public and commercial buildings and the means to respond to such danger. This study has been submitted to Congress. At the present time, the EPA does not recommend a regulatory program modeled on AHERA for public and commercial buildings. Therefore, the requirements of TSCA §§ 201 et seq. are not applicable to the WIPP facility.

\subsubsection{Indoor Radon Abatement}

The Title III TSCA amendment, Indoor Radon Abatement, was added to address the national long-term goal "with respect to radon levels in buildings, that the air within the buildings in the United States should be as free of radon as the ambient air outside of buildings." One of the goal-driven requirements that Title III sets forth in $\S 309$, "Study of Radon in Federal Buildings," directs each federal department or agency that owns a federal building to conduct a study to determine the extent of radon contamination in such buildings. The CAO has responded to this requirement. 


\subsubsection{Polychlorinated Biphenyls}

Section 6(e) of TSCA, Polychlorinated Biphenyls, directed the EPA to phase out PCB manufacture and use according to a mandated timetable. This timetable directed the EPA to promulgate rules for the disposal and marking of PCBs within six months of the enactment of TSCA: by one year after the passage of this act, no one was allowed to manufacture, process, distribute, or use any PCBs in the United States except in "a totally enclosed manner." Furthermore, unless the EPA did not find any unreasonable risk of injury to public health or the environment, no one was allowed to manufacture PCBs at all after two years, or to distribute them after two and one-half years after TSCA's passage.

The regulations in 40 CFR 761, "Environmental Protection Agency Regulations for Manufacturing, Processing, Distribution in Commerce, and Use Prohibitions for Polychlorinated Biphenyls under the Toxic Substances Control Act," implement the PCB provisions of TSCA. This part applies to all parties who manufacture, process, distribute in commerce, use, or dispose of PCBs or PCB items. The purpose of these regulations is to establish prohibitions of, and requirements for, the manufacture, processing, distribution in commerce, use, disposal, storage, and marking of PCBs and PCB items. DOE policy now prohibits the use of PCB items or equipment in DOEinstalled equipment at facilities such as WIPP. However, prior to the enactment of TSCA prohibiting PCBs, these chemicals were used in fluids of electrical systems across the country, including DOE sites. Therefore, surveys were done at DOE sites to identify any PCBs or PCB-containing equipment and to eliminate the fluids and equipment in accordance with EPA standards. Requirements for storage and disposal of PCBs were also established under TSCA (e.g., see 40 CFR § 761.60, "Disposal Requirements," and 40 CFR § 761.65, "Storage for Disposal").

\subsection{Compliance Status of the Regulatory Requirements}

The text provides more detail on the compliance status of each requirement.

\subsubsection{Study of Radon in Federal Buildings, TSCA, § 309}

Each federal agency that owns a building must conduct a study of radon contamination in the building(s).

The DOE conducted an indoor radon study in response to this requirement and submitted the findings in Results of the U.S. Department of Energy Indoor Radon Study (DOE, 1990e). Radon concentrations measured were less than $1.0 \mathrm{pCi} / \mathrm{l}$. These concentrations are below the $4 \mathrm{pCi} / \mathrm{l}$ level at which the EPA recommends further testing of indoor radon. 


\subsubsection{Prohibition of PCBs, 40 CFR $\S 761.20$}

No person may use any PCB or any PCB item regardless of concentration in any way other than in a totally enclosed manner within the United States.

The DOE has conducted surveys of electrical equipment, such as transformers, that could house PCB-containing fluids. Any equipment containing PCBs was identified and replaced by non-PCB-containing equipment. All PCB-containing equipment identified was disposed of in accordance with the regulations described in section 9.2.3 below.

\subsubsection{Disposal Requirements for PCBs, 40 CFR $\S 761.60$}

In most circumstances, PCBs must be incinerated as required by 40 CFR $\S 761.70$ or placed in chemical-waste landfills that meet the requirements of $40 \mathrm{CFR} \S 761.75$ and that have been approved as a landfill for PCBs by the EPA.

Any DOE equipment identified at WIPP that contained PCB fluids was decontaminated as described in the regulations and disposed of as required.

Disposal of PCBs in concentrations greater than or equal to 50 parts per million (ppm) is prohibited by the WIPP Hazardous Waste Facility Permit. Furthermore a disposal authorization from the EPA may be required. The source and nature of the inventory of PCBs comingled TRU waste is greatly varied and no single regulatory scheme addresses the PCB waste found in the DOE inventory. Currently, the CAO plans to work with EPA Region 6 to develop a disposal authorization that will allow for PCB disposal in the underground repository and will be protective of human health and the environment. 
This page intentionally left blank. 
10.0 FEDERAL INSECTICIDE, FUNGICIDE, AND RODENTICIDE ACT

\subsection{Summary of the Law}

The Federal Insecticide, Fungicide, and Rodenticide Act (FIFRA; 7 U.S.C. §§ 136 et seq.) authorizes the EPA to regulate the registration, certification, use, storage, disposal, transportation, and recall of pesticides. Section 18 of FIFRA authorizes the EPA to exempt state and federal agencies from any provision of the act if emergency conditions requiring an exemption were determined to exist. Exemption of Federal and State Agencies for Use of Pesticides under Emergency Conditions, provides guidelines for urgent, nonroutine situations that require the use of pesticides and for which exemptions may be authorized. Sections 19(a) and 25(a) of FIFRA authorize the EPA to establish regulations and procedures regarding the disposal or storage of packages and containers of pesticides and the disposal or storage of excess amounts of such pesticides. FIFRA provides for Regulations for the Acceptance of Certain Pesticides and Recommended Procedures for the Disposal and Storage of Pesticides and Pesticides Containers, established procedures for the acceptance, disposal, or storage of packages and containers of pesticides and for the acceptance, disposal, or storage of packages and containers of pesticides and for the disposal or storage of excess amounts of such pesticides. The standards of FIFRA are considered mandatory for DOE facilities. All uses and applications of restricted-use pesticides at WIPP are conducted only by commercial pesticide applicators who are under contract with the MOC and are required to meet federal and state standards. (See also Chapter 37 herein.)

\subsection{Compliance Status of the Regulatory Requirements}

The two major requirements of FIFRA and the compliance status of each are summarized in the text.

\subsubsection{Registration of Pesticide Products, 40 CFR $\S 152.15$}

No person may distribute or sell any pesticide product that is not registered under FIFRA. The pesticide must be registered if the person who distributes or sells the substance knows that it will be used as a pesticide.

Restricted-use pesticides are neither stored at WIPP, nor are they applied by WIPP personnel. All applications of restricted-use pesticides are conducted according to existing contract(s) negotiated with licensed pesticide applicators, and the MOC safety and regulatory compliance personnel review all pesticide application contracts before they are awarded. The DOE requires that any pesticide contractor be licensed with the state as a certified pesticide applicator and submit a list of pesticides used and their respective EPA numbers to the MOC prior to awarding the contract. The current agreement requires that the applicator perform scheduled quarterly applications and respond to unscheduled "special situations" such as occurrences of wasp swarming and ant infestation. Before an application is performed, the contractor submits 
information consisting of the application date, location, method of application, the generic pesticide name, and an MSDS for review by the MOC, which confirms that adequate protective equipment is available and that the pesticides to be used are not on the EPA restricted-pesticide list. After the application, the contractor must submit such information to the MOC as the type and amount of pesticide used and the dilution factor.

General-use wasp and hornet pesticides used on site by WIPP personnel are properly registered with the state of New Mexico.

\subsubsection{Storage and Disposal of Pesticides and Containers, 40 CFR § 156.10}

The directions for use shall include specific directions for the storage and disposal of pesticides and their containers.

The general-use wasp and hornet pesticides are stored according to label instructions. Used, empty cans are discarded by WIPP personnel into SAA containers and managed as hazardous waste.

Because WIPP personnel do not use, store, or dispose of restricted-use pesticides on site, the majority of these requirements are not applicable. All restricted-use pesticide applications are made by licensed contractors, who are responsible for storing and disposing of pesticides off-site.

The WIPP site is inspected periodically by the New Mexico Department of Agriculture, Division of Agriculture and Environmental Services Bureau of Pesticide Management. The purpose of an inspection is to determine compliance with FIFRA, as amended, and/or the New Mexico Pesticide Control Act. The inspection may include an overview of the site warehouse, where consumer product pesticides are stored, and records pertaining to pesticides applied by the site pest control subcontractor. The site was inspected in March of 1995 and February of 1996. A Notice of Pesticide Inspection is generated following each inspection. No violations were noted.

Applications of restricted-use pesticides at WIPP are performed by commercial, statelicensed applicators. The DOE requires applicators under contract to comply with the requirements of the New Mexico Pesticide Control Act and the implementing regulations set forth by the New Mexico State University Board of Regents. More information on the state requirements is provided in Chapter 37 herein. 


\section{$11.0 \quad$ NOISE CONTROL ACT OF 1972}

\subsection{Summary of the Law}

In the Noise Control Act of 1972 (42 U.S.C. $\S \S 4901$ et seq.), the EPA declared its policy of promoting an environment for all Americans that is free from noise that jeopardizes public health or welfare. According to the act's policy clause in § 2(a)(3), the primary responsibility for noise control is vested in state and local governments. Federal regulation is deemed essential only for commercial noise sources requiring national uniformity of treatment (e.g., aircraft noise). However, federal agencies are directed to carry out the programs within their control in a manner that furthers the act's policy. Each agency having jurisdiction over any property or facility, or engaged in any activity resulting or which may result in the emission of noise, shall comply with federal, state, interstate, and local requirements regarding the control and abatement of environmental noise to the fullest extent consistent with their authority." Facilities under the DOE are required to comply with the Occupational Safety and Health Administration regulations that address occupational noise exposure standards under 29 CFR 1910, "Occupational Safety and Health Standards."

The regulations under 29 CFR $\S 1910.95$, "Occupational Noise Exposure," define the permissible noise exposure levels to which employees may be subjected. The regulations also include requirements for the development and implementation of a monitoring program, the establishment and maintenance of an audiometric testing program, the measurement of noise, the provision of personal hearing protection equipment when necessary, and the administration of a hearing conservation program.

\subsection{Compliance Status of the Regulatory Requirement}

The following summarizes the applicable requirement and its compliance status.

\subsubsection{Compliance with Hearing Protection Standards, 29 CFR § 1910.95}

Employers must take measures to protect the hearing of employees.

The DOE administers a full program in accordance with the Noise Control Act and implementing regulations. Program activities include the following: a hearing conservation program; an audiometric testing program; administrative and engineering controls (e.g., noise mufflers in the area of underground exhaust fans, posted signs); noise measurement (e.g., sound meters, dosimetry); and the provision of personal hearing protection equipment (e.g., ear plugs, ear muffs). Furthermore, the DOE maintains contract with a certified occupational medicine or health physician; requires hearing protection training for WIPP employees; and developed procedures such as the Hearing Conservation Program. The WIPP Industrial Hygiene Program Safety Manual and the Occupational Health Manual and their implementing procedures address the requirements and activities conducted under this program. 
This page intentionally left blank. 
12.0 NATIONAL ENVIRONMENTAL POLICY ACT

\subsection{Summary of the Law}

The National Environmental Policy Act (NEPA; 42 U.S.C. $\S \S 4321$ et seq.) is a comprehensive legislative and public policy statement on protection of the environment. NEPA requires that the federal government use all practicable means to consider potential environmental impacts as part of the decision-making process prior to the initiation of new projects and activities. NEPA dictates that the public be allowed to review and comment on proposed projects with the potential to significantly affect the environment.

\subsection{Compliance Status of the Regulatory Requirements}

12.2.1 Provision of Environmental Information to Public Officials and Private Citizens, 40 CFR 1500 through 1508

Environmental information must be made available to the public before decisions are made and actions are taken and must include a detailed statement on environmental impacts of major federal actions significantly affecting the quality of the human environment.

The NEPA created the Council on Environmental Quality (CEQ). The CEQ, contained within the Executive Branch of the government, is the agency charged by Congress to advise the President and to review federal programs in light of national environmental policy. The CEQ's regulations in 40 CFR 1500 through 1508 implement NEPA § 102(2). These regulations outline specific requirements for the early integration of the NEPA process, the preparation of EISs or environmental assessments (EAs), public review and solicitation of comments on EISs, decisions with respect to an EIS or EA, and implementation of the decisions. The NEPA regulations also instruct federal agencies to interpret and administer their own specific directives (such as regulations, plans, or orders) to implement the CEQ NEPA regulations within their agency. General directives to federal agencies include considering the impacts of actions in decisions, providing necessary data for decisions, informing the public, and soliciting public input in the decision process.

\section{$12.3 \quad$ U.S. Department of Energy Compliance with NEPA}

\subsubsection{Summary of the Law}

Pursuant to 40 CFR $\S 1507.3$, the DOE first codified its own NEPA regulations on April 24, 1992, as 10 CFR 1021, National Environmental Policy Act Compliance. The DOE NEPA Rule underscored the DOE's intent to conform with the CEQ regulations. The DOE NEPA Rule was amended on July 9, 1996, to make the implementation of NEPA more efficient and effective. Subpart D of the DOE NEPA Rule was further modified on December 6, 1996, to revise and expand its listing of Categorical 
Exclusions contained in Subpart D, Appendices A through D. Categorical Exclusions are categories of actions which do not individually or cumulatively have a significant effect on the human environment and which are exempt from requirements to prepare an EA or an EIS. The expanded listing has provided a much clearer understanding of the DOE's views regarding the actions that potentially have a significant impact on human health and the environment.

The implementing procedures in 10 CFR 1021 detail requirements for the preparation and circulation of NEPA documents, including EISs, supplemental EISs, RODs, Mitigation Action Plans (MAP), and EAs. The DOE requires that a MAP be prepared for the implementation of any commitments made in an EIS/ROD or supplement for mitigation of environmental impacts associated with an action. A MAP is also required of any Finding of No Significant Impact to an EA that contains mitigative actions prior to initiating the proposed action.

Subpart D, "Typical Classes of Actions," of this part lists typical types of actions that require NEPA documentation and those which are typically categorically excluded from the need to prepare an EIS or an EA. Classes of actions that the DOE has determined do not individually or cumulatively have a significant effect on the human environment are categorical exclusions. The classes of actions identified in Subpart D are:

(1) "Categorical Exclusions Applicable to General Agency Actions," such as routine administrative actions; (2) "Categorical Exclusions Applicable to Specific Agency Actions," such as installation of data-processing equipment; (3) "Classes of Actions That Normally Require EAs but Not Necessarily EISs," such as field demonstration projects for wetlands mitigation; and (4) "Classes of Actions That Normally Require EISs," such as the siting, construction, and operation of a facility, such as WIPP, for the disposal of TRU waste.

The DOE issues various types of directives (e.g., orders and policy statements) to establish or change policies, organizations, methods, standards, or procedures. The DOE has issued DOE Order $451.1 \mathrm{~A}$, as well as regulations and guidelines contained within 10 CFR 1021, to ensure that practical and auditable methods are used to demonstrate compliance with NEPA at DOE facilities. The DOE provides periodic revisions and supplements to its guidance and orders.

\subsubsection{Implementing DOE's NEPA Regulations at WIPP, 10 CFR 1021}

DOE's regulations implement NEPA (10 CFR 1021) supplement and clarify the requirements contained in 40 CFR 1500 through 1508. The DOE regulations add a requirement for Mitigation Action Plans and Supplement Analyses. They also delineate specific categorical exclusions for DOE facilities.

Pursuant to the requirements of NEPA, the DOE published the FEIS for WIPP in 1980 (DOE, 1980). The FEIS analyzed and compared the environmental impacts of various alternatives for demonstrating the safe disposal of TRU waste resulting from national defense activities. 
Based on the environmental analyses in the FEIS, the DOE published a ROD to the FEIS in 1981 to proceed with the phased development of the WIPP facility (DOE, 1981). This ROD noted that the FEIS would be supplemented, as appropriate, if new environmental data resulted from the site and preliminary design validation program or from other WIPP activities. A number of mitigation commitments were specified in the ROD.

Changes addressed in the 1990 Final Supplement Environmental Impact Statement (SEIS) (DOE, 1990a) included alterations in the composition of the waste inventory, the transportation of waste to WIPP, conducting a test phase at WIPP, and management of mixed waste (TRU waste with hazardous constituents). The DOE published an ROD to the SEIS in 1990 (DOE, 1990b).

The DOE issued the Mitigation Action Plan for the Records of Decision for the Waste Isolation Pilot Plant (DOE/WIPP 91-030) on July 10, 1991. This document addresses the mitigative commitments stated in the RODs to the 1980 FEIS and the 1990 SEIS and discusses mitigative actions, organizations responsible for implementing these actions, and the status of each commitment. No new mitigation commitments were identified in the ROD for the SEIS-II. The Annual Mitigation Report is prepared on an annual basis to track the status of each commitment not yet closed.

In October 1993, the DOE decided not to conduct the full range of test phase experiments at WIPP and moved toward the implementation of waste disposal operations. This was based on a determination that TRU waste experiments could be adequately performed at a lower cost in aboveground laboratories as part of the ongoing experimental program. However, a commitment was made in the SEIS-I ROD to prepare a second SEIS (SEIS-II) prior to beginning disposal operations at WIPP.

In addition to the DOE's 1990 ROD commitment to prepare SEIS-II, regulatory and statutory changes, as well as changes in the TRU waste inventory and waste acceptance criteria, had occurred since the SEIS-I was issued. New hydrologic and geologic information was used in the development of WIPP performance assessment and the evaluation of the facility's ability to isolate waste. All these factors formed the basis for a second Supplemental Environmental Impact Statement.

On August 23, 1995, the DOE issued a Notice of Intent to prepare WIPP's second SEIS for the disposal phase. Some of the information analyzed in the SEIS-II includes the identification of additional generator sites, changes in known waste volume and form, acquisition of new data from the experimental program, and changes to the WAC. In September 1997, the DOE published the SEIS-II (DOE/EIS-0026-S-2, Volumes 1 through 3). The SEIS-II takes into account all of the changing circumstances since 1990 that might result in potential environmental impacts from WIPP disposal and closure operations.

Some of the changes that have occurred since the issuance of the 1990 SEIS-I include the identification of additional TRU waste generator sites, changes in TRU waste volumes and waste forms, and changes in the compliance status of previously disposed 
TRU wastes. Other major changes discussed in the SEIS-II include the passage of the amended WIPP Land Withdrawal Act, the acquisition of new data from experimental programs, the issuance of the DOE's Final Waste Management Programmatic Environmental Impact Statement (WM PEIS), changes in the Planning Basis Waste Acceptance Criteria, and changes in regulations applicable to WIPP.

On January 16, 1998, the DOE issued the ROD for the SEIS-II. The SEIS-II ROD was prepared in coordination with the ROD for the DOE's WM PEIS ROD. The SEIS-II ROD describes the DOE's decision to select the preferred alternative to dispose of TRU wastes generated by defense-related activities at WIPP. This decision was based on the DOE's analysis of alternatives described in the SEIS-II.

\subsubsection{Operational Compliance with NEPA at WIPP}

Day-to-day operational compliance with NEPA at WIPP is achieved through implementation of the National Environmental Policy Act Compliance Plan (WP 02-EC.08) and the NEPA compliance procedure. These documents describe the roles and responsibilities of both the DOE NEPA Compliance Officer and the MOC NEPA Coordinator to evaluate the impacts of proposed projects at the site. Activities that have undergone NEPA review are tracked on the NEPA Compliance Database. The NEPA compliance procedure also establishes a program to screen proposed actions against existing NEPA documents to determine whether such actions are within the scope of existing WIPP programmatic NEPA documentation. The initial screening of proposed actions is completed by the MOC NEPA Coordinator. The DOE NEPA Compliance Officer is responsible for making the final determination whether proposed actions are outside the scope of existing documentation, and makes a determination whether the proposed action is included in existing WIPP programmatic NEPA documentation or is categorically excluded. If the action is not covered by WIPP programmatic NEPA documentation or is not categorically excluded, the Compliance Officer submits a recommendation to the appropriate official as delineated by DOE Order 451.1A regarding the need to prepare a Supplemental Analysis, Environmental Assessment, or Environmental Impact Statement to address the proposed action. 


\subsection{ATOMIC ENERGY ACT AND THE U.S. DEPARTMENT OF ENERGY}

\subsection{Summary of the Law}

The Atomic Energy Act of 1954 as amended (AEA; 42 U.S.C. $\S \S 2011$ et seq.) established a national program for research, development, and use of atomic energy for national defense and civilian purposes. Section 161 of the AEA authorized the Atomic Energy Commission to establish rules, regulations, and orders to govern any activity regulated under the AEA to protect health and minimize hazards to life or property. Activities included standards and restrictions pertaining to the design, location, and operation of facilities.

The Atomic Energy Commission has been succeeded by three organizations: The Energy Research Development Agency and subsequently the DOE for national defense and the NRC for domestic civilian purposes (see Chapter 14 herein for the compliance status of NRC-related requirements). Thus, the AEA and subsequent reorganization acts gave the DOE its authority to develop policies, issue orders, and promulgate regulations that address environmental, safety, and health protection aspects of radioactive waste and nuclear materials. Limits on radioactivity levels in transuranic ${ }^{1}$ (TRU) waste to be disposed of at WIPP are set in section 7 of the WIPP LWA. The radioactive constituents of the TRU waste to be shipped to the WIPP are regulated under the AEA by the DOE. This is done by a system of orders, notices, directives, and policies which carries out the AEA mandate to implement effective and consistent programs to protect the public, the environment, and workers from adverse consequences from DOE operations.

\subsection{Compliance Status with the Regulatory Requirements}

As indicated in the previous section, the DOE uses a system of orders, notices, directives, and policies to implement its programs under the AEA and to ensure compliance with the requirements of the AEA. An assessment process is in place to assure compliance with environmental safety and health related orders. The compliance status for each of the DOE orders that are relevant to the management of TRU waste at WIPP are noted.

${ }^{1}$ The AEA defined "transuranic waste" as

. . material contaminated with elements that have an atomic number greater than 92, including neptunium, plutonium, americium, and curium, and that are in concentrations greater than 10 nanocuries per gram, or in such other concentrations as the Nuclear Regulatory Commission may prescribe to protect the public health and safety (AEA, § 11[ee]).

In 1982, TRU waste was redefined as having a half life greater than 20 years and a concentration greater than 100 nanocuries per gram of waste. Wastes with concentrations of radioactivity that are less than 100 nanocuries per gram of waste are classified as low-level waste. 


\subsubsection{DOE Order 151.1, Comprehensive Emergency Management System}

This order establishes requirements for emergency planning, categorization, preparedness, response, notification, public protection, and readiness assurance activities. The applicable requirements of this order are implemented through the WIPP Emergency Management Manual; Emergency Response Manual; Training Manual; Emergency Readiness Assurance Plan; RCRA Contingency Plan (Attachment F of the Hazardous Waste Facility Permit); and WIPP Records Management Program (15-PR).

\subsubsection{DOE Order 225.1A, Accident Investigations}

The objective of this order is to prescribe requirements for conducting investigations of certain accidents occurring at DOE operations and sites; prevent the recurrence of such accidents; and contribute to improved environmental protection and safety and health of DOE employees, contractors, and the public. This order is implemented through the Root Cause Analysis procedure.

\subsubsection{DOE Order 231.1, Environment, Safety and Health Reporting}

The objective of this order is to ensure collection and reporting of information on environment, safety and health that is required by law or regulation to be collected, or that is essential for evaluating DOE operations and identifying opportunities for improvement needed for planning purposes within the DOE. The order specifies the reports that must be filed, the persons or organizations responsible for filing the reports, the recipients of the reports, the format in which the reports must be prepared, and the schedule for filing the reports. The order was approved on September 30, 1985, and is implemented at the WIPP through the WIPP Environmental Monitoring Plan (99-2194); Annual Site Environmental Report (DOE/WIPP 99-2225); Site-Generated, Non-Radioactive Hazardous Waste Management Plan (WP 02-RC.01); WIPP Hazardous Waste Permit Reporting and Notifications Compliance Plan (WP 02-PC.03); WIPP Radiation Safety Manual (WP 12-5); Dosimetry Program (WP 12-3); Fire Protection Program (WP 12-FP.01); and MOC procedures.

\subsubsection{DOE Order 232.1A, Occurrence Reporting and Processing of Operations Information}

This order is to establish and maintain a system for reporting operations information related to DOE-owned and DOE-leased facilities, in order to identify the root causes of unusual, off-normal and emergency occurrences and to provide for appropriate corrective action. This order is implemented through the WIPP Emergency Management Program; Management of Hazardous Materials Plan (WP 02-EC.04); Radiation Safety Manual; Fire Protection Program (WP 12-FP.01); Exposure Control Plan (WP 15-HS.01); and MOC procedures. 


\subsubsection{DOE Order 414.1A, Quality Assurance}

This order provides DOE policy, sets forth principles, and assigns responsibilities for establishing, implementing, and maintaining programs of plans and actions to ensure quality achievement in DOE programs. This order is fully implemented through the cited MOC and CAO QA programs.

\subsubsection{DOE Order 420.1, Facility Safety}

This order specifies requirements for nuclear safety, criticality safety, fire protection, and natural phenomena hazards mitigation. The requirements are implemented through the WIPP SAR.

\subsubsection{DOE Order 435.1, Radioactive Waste Management}

The objective of this order is to ensure that all DOE radioactive waste is managed in a manner that is protective of workers and the public. Requirements in this order that overlap with the LWA do not apply to the operation of WIPP or the disposal of waste therein.

\subsubsection{DOE Order 440.1A, Worker Protection Management for DOE Federal Contractor Employees}

This order establishes the framework for a worker protection program that will reduce or prevent injuries, illnesses, and accidental losses by providing DOE federal and contractor workers with a safe and healthful workplace. This MOC implementing documents are the Radiation Safety Manual; Industrial Safety Program (WP 12-IS.01); WIPP Industrial Hygiene Program (WP 12-IH.02); Fire Protection Program (WP 12-FP.01); Occupational Health Program Plan (WP 15-HS.02); and MOC procedures.

\subsubsection{DOE Order 451.1A, National Environmental Policy Act Compliance Program}

This order is implemented by the CAO and the MOC for site activities covered in the NEPA Compliance Plan. Further discussion of this requirement can be found in Chapter 12 of this BECR. This order replaced Order 451.1, which, in turn, replaced Order 5440.1E.

\subsubsection{DOE Order 460.1A, Packaging and Transportation Safety}

This order establishes requirements for the packaging and transportation of hazardous materials, hazardous substances, and hazardous wastes. Requirements for portions of this order are addressed in the TRUPACT-II SARP and the TRUPACT-II C of C and are implemented through the Waste Isolation Division Transportation Program (WP 06-1). 


\subsubsection{DOE Order 460.2, Departmental Materials Transportation and Packaging Management}

This order establishes DOE policies and requirements for materials transportation and packaging operations including traffic management, for other than intrabuilding and intrasite transfers. This order also establishes administrative procedures for the certification and use of radioactive and other hazardous materials packaging by the DOE. Requirements of the order are contained in the TRUPACT-II Safety Analysis Report for Packaging (SARP) and the TRUPACT-II Certificate of Compliance (C of C). The order is implemented through the Transportation Program (WP 06-1).

\subsubsection{DOE Order 5400.1, General Environmental Protection Program}

This order establishes environmental protection program requirements, authorities, and responsibilities for DOE operations for assuring compliance with federal, state, and local environmental protection laws and regulations, executive orders, and internal DOE policies. In addition to MOC procedures, this order is implemented through the WIPP Groundwater Monitoring Program (WP 02-1); the WIPP Meteorological Quality Assurance Plan (WP 02-EM.01); the WIPP Environmental Monitoring Plan (99-2194); and the annual Site Environmental Report (99-2225).

\subsubsection{DOE Order 5400.5, Radiation Protection of the Public and the Environment}

This order along with portions of Order 231.1, establishes standards and requirements for operations of the DOE and its contractors with respect to protecting members of the public and the environment against undue risk from radiation. Activities and analyses describing compliance with the applicable requirements of this order are cited in the WIPP Safety Analysis Report. Monitoring activities to document compliance with the order are described in the WIPP ALARA [as low as reasonably achievable] Program Manual, the Environmental Monitoring Plan, the WIPP Records Management Program (15-PR), and the WIPP Radiation Safety Manual (WP 12-5).

\subsubsection{DOE Order 5480.4, Environmental Protection, Safety and Health Protection Standards (portions)}

This order specifies and provides requirements for the application of the mandatory environmental protection, safety, and health standards applicable to all DOE and contractor operations, contains a listing of those standards, and identifies the sources of the mandatory and reference standards. The standards are implemented through the RCRA Contingency Plan; the WIPP Transportation Program, and the Site-Generated, Non-Radioactive Hazardous Waste Management Plan (WP 02-RC.01). Portions of this order have been replaced by DOE Order 440.1A, "Worker Protection Management for DOE Federal and Contractor Employees." 


\subsubsection{DOE Order 5480.21, Unreviewed Safety Questions}

This order provides the definition and basis for determining the existence of an Unreviewed Safety Question. The applicable requirements of this order, approved on December 24, 1991, are implemented through the WIPP SAR.

\subsubsection{DOE Order 5480.22, Technical Safety Requirements}

This order defines Technical Safety Requirements and states the requirements to have them prepared for DOE nuclear facilities and to delineate the criteria, content, scope, format, approval process, and reporting requirements of these documents and their revisions. The applicable requirements of this order are implemented through the WIPP SAR and WIPP Technical Safety Requirements.

\subsubsection{DOE Order 5480.23, Nuclear Safety Analysis Reports}

This order establishes uniform requirements for the preparation and review of safety analyses of DOE operations which include identification of hazards, their elimination, or control, assessment of the risk, and documented management authorization of the operation. The applicable requirements of this order, approved on March 10, 1994, are implemented through the WIPP SAR.

\subsubsection{DOE Order 5484.1, Environmental Protection, Safety and Health Protection Information Reporting Requirements}

This order along with portions of Orders 0225.1 and 0231.1 establish requirements and procedures for reporting information having environmental protection, safety, or health significance for DOE operations. The orders are implemented through the Root Cause Analysis Investigation Procedure, Dosimetry Program Manual, and Incident Investigation and Reporting Summaries.

\subsubsection{DOE Order 5530.4, Aerial Measuring System}

This order establishes DOE policy for the DOE Aerial Measuring System Program.

This program is scheduled and performed as needed. The initial background aerial gamma survey of the WIPP site and surrounding area is documented in the EG\&G/EM Survey Report, AMO-8809.

Two additional gamma surveys have been conducted since the initial background survey.

\subsubsection{DOE Order 6430.1A, General Design Criteria}

This order provides general design criteria for use in the acquisition of the DOE's facilities and establishes responsibilities and authorities for the development and maintenance of these criteria. Pursuant to this order, all DOE facilities are to be 
designed and constructed to be reasonable and adequate for their intended purpose and consistent with health, safety, security, and environmental protection requirements. This order is implemented through the Industrial Safety Program (WP 12-IS.01) and the WIPP Emergency Management Program.

\subsection{Other Regulations - 10 CFR 830 Series}

The DOE has issued other regulations in the $10 \mathrm{CFR}$ series that are intended to protect public health, safety, and the environment. On December 14, 1993, the DOE published 10 CFR 835, "Occupational Radiation Protection." These regulations became effective on January 13,1994 . A number of programs are in place at WIPP to meet the requirements of 10 CFR 835 . These regulations describe occupational exposure limits resulting from normal activities for employees.

The DOE published proposed regulations entitled "Radiation Protection of the Public and the Environment" (10 CFR 834) in the Federal Register on March 25, 1993. These regulations will become applicable to WIPP when they are issued in final form.

The DOE has promulgated additional regulations, 10 CFR 830, "Nuclear Safety Management," which were published in the Federal Register on April 5, 1994.

\subsubsection{Taking Action(s) Inconsistent with the Requirements of 10 CFR 830, 10 CFR § 830.4(a)}

No person shall take or cause to be taken any action inconsistent with the requirements of this part or any program, plan, schedule, or other process established by this part.

No person at the WIPP facility is known to have taken action (or caused to take action) that is inconsistent with the requirements of 10 CFR 830 or with any of the program, plan, schedule, or other process established by these regulations.

\subsubsection{Implementation and Compliance with Requirements of 10 CFR 830, 10 CFR § 830.4(b)}

The contractor responsible for the design, construction, operation, or decommissioning of the facility is responsible for implementing and complying with the requirements of this part.

The MOC has implemented and is complying with the requirements of 10 CFR 830 in the MOC's QAPD(WP 13-1). The manager of the MOC's Quality Assurance Department is responsible for verifying effective implementation of the QAPD and for ensuring that an internal self- assessment of the quality program is performed annually. 


\subsubsection{Plan or Program Required by This Part as the Basis for Determining Compliance, 10 CFR § 830.4(c)}

If a section of this part expressly requires a plan, program, or implementation plan (approved by DOE), the provisions of the plan or program will be the basis used to determine compliance with the relevant nuclear safety requirements in the section.

This part specifies that a Quality Assurance Program (QAP) will be developed and implemented (10 CFR $\S 830.120[a[] i i]$-[iii]). This required QAP is described in the MOC's QAPD. The provisions of this QAP provide the basis used to determine compliance with the relevant nuclear safety requirements in the section. The MOC's QAPD was last updated in March 2000.

\subsubsection{Records to Substantiate Compliance, 10 CFR $\S 830.6$}

Complete and accurate records will be maintained as needed to substantiate compliance with the requirements of this part.

The MOC personnel maintain complete and accurate records as necessary to substantiate compliance with the requirements of this part. Record keeping requirements are described in more detail in Chapter 4 of the QAPD.

\subsubsection{Use of a Graded Approach, 10 CFR § 830.7}

Where indicated in a subpart, a graded approach will be utilized to comply with the requirements. When such an approach is applied, the bases for selecting an action shall be documented.

According to 10 CFR $\S 830.120$ (b)(1), the criteria of 10 CFR $\S 830.120$ (c) shall be applied using a graded approach. Risk factors and the graded approach to QA are discussed in section 1.5.1.2 of the QAPD. Assignment of a specific quality code to an item or activity is commensurate with the associated risk classification; the resulting levels of control provide effective program management and incorporate due regard for the health and safety of the public and plant personnel, complexity, consequences of failure, environmental impacts, cost, and the safe and reliable operation of WIPP and the TRU transport packaging program.

The MOC has also issued a procedure to implement the graded approach to the application of the criteria described in 10 CFR $\S 830.120$ (c).

A graded approach of quality measures to software $Q A$ requirements is also described in the QAPD. The extent to which specific programmatic controls are implemented will be appropriate to the specific application and will also be sufficient to ensure the quality of the software for its intended use. Several criteria are described that are to be considered in the software evaluation process. 
13.3.6 Development and Implementation of Contractor's QAP To Be Approved by the DOE and Conduct of Work in Accordance with 10 CFR § 830.120(a) and 10 CFR § 830.120(c)

The contractor responsible for the DOE nuclear facility shall develop a QAP and submit it to DOE for approval. After the QAP has been approved by DOE, the contractor must implement it and must conduct its work in accordance with the criteria described in 10 CFR $\S 830.120(c)$.

The MOC developed a QAP as described in the QAPD. Quality-related work is conducted in accordance with the criteria specified in 10 CFR $\S 830.120$ (c)and described in the QAPD. The DOE approved the QAPD March 22, 2000.

\subsubsection{Application of the Appropriate QA Criteria in the QAP and Annual Submittal of Substantive Changes in the QAP to the DOE, 10 CFR § 830.120(b)}

The contractor shall develop a QAP by applying the QA criteria described in 10 CFR $\S 830.120$ (c) and indicating how the criteria will be satisfied. The contractor will use a graded approach in applying the criteria and shall use appropriate standards where applicable to develop and implement the QAP. Within 180 days after May 5, 1994, the contractor shall submit the current QAP to DOE, along with an implementation plan, for approval. Substantive changes made to the QAP over the previous year shall be submitted annually to DOE for review.

The MOC has developed a QAP as described in the QAPD using the criteria specified in 10 CFR $\S 830.120$ (c) (see section 13.2.8 below). The QAPD includes a discussion of how the criteria of paragraph (c) of 10 CFR $\S 830.120$ are met.

The QAPD was submitted to the DOE, and the DOE approved it in January 1995. Several substantive changes have been made to the QAPD since that time; each time, the changes were submitted to and approved by the DOE.

\subsubsection{QA Criteria To Be Included in the QAP, 10 CFR $\S 830.120$ (c)}

A written $Q A P$ shall be developed. The $Q A$ criteria to be included in the QAP are specified and include the management program, personnel training and qualification, quality improvement, documents, and records. The QA criteria also must address performance (i.e., work processes, design, procurement, inspection, and acceptance testing) and assessment (i.e., management assessment and independent assessment). 
The MOC developed and implemented the QAPD to comply with the requirement to prepare a written QAP. The management program is described in subsection 1.1 of this document. As required, the organization structure, functional responsibilities and authorities, and interfaces are described in the QAPD and includes a description of planning considerations.

Personnel training and qualifications are described in subsection 1.2. Subsection 1.3 pertains to quality improvement and includes a description of the requirements and responsibilities for ensuring that appropriate methods are used to enhance quality, to detect and prevent quality problems, and to take corrective actions when necessary when "conditions adverse to quality" have been detected.

Requirements pertaining to documents and records are described in subsections 1.4 and 1.5 of the QAPD. The discussion in subsection 1.4 addresses the preparation, review, and approval of documents. The discussion in subsection 1.5 deals with the generation; classification; indexing; receipt; storage; preservation, disposition,; retrieval; and correction of information in quality records.

Section 2, Performance Quality Assurance Requirements, of the QAPD encompasses the general area of performance QA requirements. Work processes are addressed in subsection 2.1, including work, implementing procedures; item identification and control; special processes; and handling, storage, and shipping. Subsection 2.2, Design Control, presents a discussion of the design control requirements, including design input, process, analyses, interfaces, verification, and change. Subsection 2.3, Procurement, describes the requirements pertaining to procurement planning, documents, evaluation of supplier performance, and commercial grade items. Subsection 2.4, Inspection and Testing, provides information pertaining to the requirements and responsibilities for the inspection of Quality Code 1, 2, and 3 items or activities affecting the quality of those items to verify conformance to specified criteria. This subsection also describes requirements and responsibilities for the control of measuring and test equipment.

Section 3, Assessment Requirements, is comprised of two subsections: Management Assessment (subsection 3.1) and Independent Assessment (subsection 3.2).

Subsection 3.1 describes how managers should assess their management processes and identify, correct, and track problems that impede achievement of the organization's objectives. Subsection 3.2 describes how independent assessments are planned and conducted to evaluate compliance with the applicable QA requirements and the implementing procedures, as well as to evaluate the effectiveness of the overall quality program.

Section 4, Sample Control and Quality Assurance Requirements, deals with sample control and identification; handling, storing, and shipping samples; disposition of nonconforming samples; and environmental data operation samples.

Section 5 addresses QA requirements for scientific investigations. 
Section 6 deals with requirements for software.

This discussion of the organization of the QAPD is based on Revision 186 of this document. This new revision was approved by the MOC on March 14, 2000; CAO approval was obtained on March 22, 2000.

\subsubsection{Occupational Dose Limits for General Employees, 10 CFR § 835.202(a)}

The occupational dose received by general employees shall be controlled such that the a total EDE of 5 rem (0.05 sievert), a dose equivalent of $15 \mathrm{rem}$ ( 0.15 sievert) to the lens of the eye, the sum of the deep dose equivalent for external exposures and the committed dose equivalents to any other organs and tissues of 50 rem ( 0.5 sievert), and a shallow dose equivalent of 50 rem ( 0.5 sievert) to the skin or to any extremity shall not be exceeded.

WIPP policy sets control limits to ensure that no MOC workers achieve doses that exceed these limits. Personnel dosimetry results to date have shown that no employees have exceeded any radiological dose of concern.

\subsection{Nuclear Safety Noncompliance and the Price-Anderson Amendments Act of 1988}

Congress passed the Price-Anderson Act in 1957 as an amendment to the AEA of 1954. The purpose of the Price-Anderson Act is threefold: (1) to promote growth and development of nuclear energy through increased private industry participation, (2) to protect the public, and (3) to ensure compensation should a nuclear event occur that damages and/or injures members of the public by providing funds for recovery operations. These penalties could only be imposed by the NRC. However, the NRC only regulated nuclear operations in the private sector.

The Price-Anderson Amendments Act (PAAA) of 1988 allowed the DOE to impose civil and criminal penalties on its contractors, subcontractors, and employees for violating any nuclear safety rule or order issued by the Secretary of Energy. The DOE has the authority to either reduce or not impose the base civil penalty of up to $\$ 110,000$ per violation per day, if the MOC promptly identifies the violation and reports it to the DOE. Conversely, the DOE will not mitigate the base civil penalty if the MOC does not promptly identify and report nuclear safety violations. The MOC uses the Noncompliance Tracking System, a centralized data base, to report and track reportable PAAA nuclear safety noncompliance events that are reportable under the PAAA. Procedures are in place at WIPP to assist personnel in determining and reporting noncompliance issues. To date there have been no nuclear noncompliance issues at WIPP. 


\subsection{ATOMIC ENERGY ACT AND THE U.S. NUCLEAR REGULATORY COMMISSION}

\subsection{Summary of the Law}

As discussed in Chapter 13 herein, the AEA of 1954 as amended (AEA; 42 U.S.C. $\S \S 2011$ et seq.) gives the NRC its authority to develop policies, issue orders, and promulgate regulations that address environmental, safety, and health protection aspects of radioactive waste and nuclear materials in the civilian sector. Regulations promulgated by the NRC under the AEA appear in 10 CFR and establish standards for the management of nuclear material and the protection of the public against radiation. Additional NRC requirements apply to the licensing, packaging, preparation, and transportation of radioactive materials.

\subsection{Compliance Status of the Regulatory Requirements}

As intended by the AEA, the DOE is generally exempted from the regulatory authority of the NRC. The only portion of the NRC's implementing regulations that applies to WIPP is 10 CFR 71, "Packaging and Transportation of Radioactive Material." These regulations pertain to the NRC's certification of packaging such as the TRUPACT-II shipping container designed to transport $\mathrm{CH}$ TRU wastes from the generator sites to WIPP. The shipping container for transporting $\mathrm{RH}$ TRU waste to WIPP is the $\mathrm{RH}-72 \mathrm{~B}$ cask. The RH-72B SARP was approved by the NRC and a $C$ of $C$ was issued on March 3, 1999. A SARP for the HALFPACT has also been submitted to the NRC for review and issuance of $\mathrm{a} C$ of $\mathrm{C}$.

Notification was made on July 20,1999, 1999 to the NRC concerning a missing vent port plug cover on a TRU-waste shipment. The absence of the vent port cover did not compromise the integrity of the TRUPACT-II containment boundary. Assessment teams were dispatched to the TRU-waste shipper sites to ensure procedural compliance.

\subsubsection{General License, 10 CFR $§ 71.12$}

A general license is issued to any licensee of the NRC to transport licensed material in a package for which a license, certificate of compliance, or other approval has been issued by the NRC.

A general license is not required for WIPP. However, each type of packaging to be used to transport either $\mathrm{CH}$ or $\mathrm{RH}$ TRU waste is required to have a $\mathrm{C}$ of $\mathrm{C}$.

The TRUPACT-II container has been approved for use in transporting CH TRU waste under the general license provisions of 10 CFR $\S 71.12 \mathrm{C}$ of C No. 9218, Revision 11, dated December 28, 1999). The DOE is registered with the NRC as a user. The NRC's reissuance of Revision 11 of $C$ of $C$ No. 9218 confirms that the TRUPACT-II 
packaging design continues to meet the applicable requirements of $10 \mathrm{CFR} \S 71.12$. The reissued TRUPACT-II C of C will expire on June 30, 2004.

\subsubsection{Contents of Application and Package Description/Evaluation, 10 CFR § 71.31 through 71.39}

The required contents of an application are described. The application must include a package description/evaluation and description of the packaging and proposed contents as described in 10 CFR $\S 71.33$ and must demonstrate that the package meets the appropriate NRC standards. In addition, the QA program for the design, fabrication, assembly, testing, maintenance, repair, modification, and use of the package must be described, along with established codes and standards. Any additional information requested by the NRC must be provided.

The SARP for the TRUPACT-II packaging describes the design, specifications, and safety evaluation in accordance with the NRC's requirements (DOE, 1989a). The NRC's reissuance of Revision 11 of $C$ of $C$ No. 9218 confirms that the TRUPACT-II is in compliance with all applicable requirements of 10 CFR $\S \S 71.31$ through 71.39.

\subsubsection{Demonstration of Compliance, 10 CFR $\S 71.41$}

The tests specified in 10 CFR $\S \S 71.71$ and 71.73 must be performed on the package to demonstrate compliance under normal conditions and hypothetical accident conditions, respectively.

Section 1.2 of the TRUPACT-II SARP describes the analysis and testing to demonstrate compliance with both normal and hypothetical accident conditions of transport. The NRC's reissuance of $C$ of $C$ No. 9218 (Revision 11) confirms that the TRUPACT-II continues to meet the applicable requirements of $10 \mathrm{CFR} \S 71.41$.

\subsubsection{Standards for All Packages, 10 CFR $\S \S 71.43$ and 71.45}

Standards for all packages must be met. These include general standards such as size, seals and fastening devices, materials and construction of the package, valves, temperature, and prohibition of continuous venting during transport as well as lifting and tie-down standards.

Sections 2.4 and 2.5 of the TRUPACT-II SARP describe the packaging features, including tie-downs. The NRC's reissuance of C of C No. 9218 (Rev. 11) confirms that the TRUPACT-II continues to meet the applicable requirements of 10 CFR $\S \S 71.43$ and 71.45 . 


\title{
14.2.5 External Radiation Standards for All Packages, 10 CFR $§ 71.47$
}

\begin{abstract}
A package must be designed and prepared for shipment so that the radiation level at any external surface of the package does not exceed 200 millirem per hour and the transport index does not exceed 10.
\end{abstract}

Section 5.0 of the TRUPACT-II SARP discusses the fact that the TRUPACT-II has no special shielding; the contents are limited to those which will produce less than 200 millirem per hour at the surface of the payload containers. The NRC's reissuance of C of C No. 9218 (Rev. 11) confirms that the TRUPACT-II continues to meet the applicable requirements of $10 \mathrm{CFR} \S 71.47$.

\subsubsection{Additional Requirements for Type B Packages, 10 CFR $\S 71.51$}

Type B packages must be designed, constructed, and prepared for shipment so as to prevent loss or disposal of radioactive material, significant increase in external radiation levels, or substantial reduction in the effectiveness of the packaging during normal transport. In addition, release of krypton-85 may not exceed 10,000 curies in 1 week, release of other radioactive material may not exceed a total amount $A_{2}$ in 1 week, and no external radiation dose rate may exceed 1 rem per hour at 1 meter from the external surface of the package during hypothetical accident conditions. Compliance with these requirements must not be predicated upon the use of filters or of a mechanical cooling system.

Section 4.0 of the TRUPACT-II SARP discusses containment design and an acceptance criterion (a leak rate of less than $1 \times 10^{-7}$ standard cubic centimeters per second). The NRC's reissuance of C of C No. 9218 (Rev. 11) confirms that the TRUPACT-II continues to meet the applicable requirements of $10 \mathrm{CFR} \S 71.51$.

\subsubsection{Requirements for All Fissile Material Packages, 10 CFR $\S \mathbf{7 1 . 5 5}$ through 71.61}

All packages used to ship fissile material must be designed and constructed in accordance with 10 CFR $\S \$ 71.41$ through 71.51 . In addition, each package must be designed and constructed and its contents so limited that the contents will remain subcritical during normal and accident transportation conditions and that the packaging will remain effective during normal transportation conditions. Specific standards for fissile material packages are described in 10 CFR $\$ 71.59$. 
Section 6.0 of the TRUPACT-II SARP discusses criticality; the contents are controlled to limit the amount of fissile material that may be shipped. Fissile classes have been replaced with a Criticality Transport Index. The Transport Index for the TRUPACT-II is 0.0 . The NRC's reissuance of $C$ of $C$ No. 9218 (Rev. 11) confirms that the TRUPACT-II continues to meet the applicable requirements of $10 \mathrm{CFR} \S \S 71.55$ through 71.61 .

\subsubsection{Special Requirements for Plutonium Shipments, 10 CFR § 71.63}

Plutonium in excess of 20 curies per package must be shipped as a solid and must be packaged in a separate inner container placed within outer packaging that meets the requirements of 10 CFR $\S \S 71.41$ through 71.77. In addition, the restrictions limiting plutonium under normal and accident conditions must be met.

Section 1.2 of the TRUPACT-II SARP describes the double containment feature of the TRUPACT-II. The NRC's reissuance of C of C No. 9218 (Rev. 11) confirms that the TRUPACT-II continues to meet the applicable requirements of $10 \mathrm{CFR} \S 71.63$.

\subsubsection{Tests under Normal Conditions of Transport, 10 CFR $\S 71.71$}

The behavior of each package design under tests and conditions simulating normal transportation conditions must be evaluated. The tests include thermal insulation for both heated and cold conditions, increased and reduced external pressure, vibration, water spray, free drop, corner drop, compressive loading, and penetration.

Section 2.6 of the TRUPACT-II SARP describes the analyses and/or tests performed to demonstrate compliance with the normal conditions of transport. The NRC's reissuance of $C$ of C No. 9218 (Rev. 11) confirms that the TRUPACT-II continues to meet the applicable requirements of 10 CFR $\S 71.71$.

\subsubsection{Tests under Hypothetical Accident Conditions, 10 CFR $\S 71.73$}

Evaluation of a package for hypothetical accident conditions is based upon the sequential application of tests in the order specified to determine their cumulative effect on a package or array of packages. Tests include free drop, puncture, thermal, and immersion as specified in 10 CFR $\S 71.73$.

Section 2.7 of TRUPACT-II SARP describes the analyses and/or tests performed to demonstrate compliance with the hypothetical accident conditions of transport. The NRC's reissuance of Revision 11 of $C$ of C No. 9218 confirms that the TRUPACT-II continues to meet the applicable requirements of $10 \mathrm{CFR} \S 71.73$. 


\title{
14.2.11 Compliance with Operating Controls and Procedures, 10 CFR $§ 71.81$
}

\begin{abstract}
A licensee who is subject to this part and who transports MRClicensed material must comply with requirements of the general provisions (71.00 through 71.6a), operating controls and procedures (71.81 through 71.99$)$, and $Q A$ requirements (71.10 through 71.137).
\end{abstract}

Sections 7.0, 8.0, and 9.0 of the TRUPACT-II SARP describe acceptance and maintenance, operating instructions, and QA. The NRC's reissuance of Revision 11 of C of C No. 9218 confirms that the TRUPACT-II continues to meet the applicable requirements of $10 \mathrm{CFR} \S 71.81$. NRC-licensed material will not be shipped to WIPP.

\subsubsection{Assumptions Regarding Unknown Properties, 10 CFR $§ 71.83$}

When the isotopic abundance, mass, concentration, degree of irradiation, degree of moderation, or other relevant property of fissile material in a package is not known, the fissile material will be packaged as if the unknown properties have credible values that will cause the maximum nuclear reactivity.

Section 6.0 of the TRUPACT-II SARP assumes the worst case for the criticality assumptions; Appendix 1.3.7 limits the amount of fissile material that may be shipped in the TRUPACT-II packaging. The NRC's reissuance of Revision 11 of C of C No. 9218 confirms that the TRUPACT-II continues to meet the applicable requirements of 10 CFR $\S 71.83$.

\subsubsection{Preliminary Determination of Integrity of Packaging, Pressure Testing, and Marking, 10 CFR $§ 71.85$}

Prior to the first use of any packaging for shipment of NRClicensed material, the licensee shall verify the structural integrity of the containment system by conducting a pressure test and shall mark the package appropriately as specified by 10 CFR $\S$ 71.85 .

Prior to the first use of any TRUPACT-Il packaging for the shipment of TRU waste, the integrity of the packaging will be ensured; pressure testing will be conducted as required; and the packagings will be marked with the TRUPACT-II model number, gross weight, and package identification number assigned by the NRC. Section 8.1 of the TRUPACT-II SARP describes preliminary determinations. NRC-licensed material will not be shipped to WIPP. 


\subsubsection{Routine Determinations Prior to Each Shipment, 10 CFR § 71.87}

Prior to each shipment of NRC-licensed material, the licensee must ensure that the package and its contents satisfy the applicable requirements of this part and the license. These routine determinations include appropriateness and integrity of packaging; closure devices; liquid containment; pressure relief devices; loading and closure procedures; moderator/neutron absorbers, if appropriate; lift/tie-down devices; external radiation levels (on external surfaces of the package and around vehicle); and accessible package surface temperatures.

Routine MOC procedures and operating and maintenance instructions are in place to ensure that these requirements are met. Section 8.0 of the TRUPACT-II SARP describes routine determinations. NRC-licensed material will not be shipped to WIPP.

\subsubsection{Special Opening Instructions, 10 CFR § 71.89}

Any special opening instructions must be sent or otherwise made available to the consignee prior to delivery of a package.

The TRUPACT-II Operating and Maintenance Instructions Manual provides instructions for preparation, use, operation, inspection, and maintenance of the TRUPACT-II shipping package. WIPP personnel are also responsible for training personnel at the generator sites in these methods and performing assessments and audits to ensure that WIPP-generated methods are being applied correctly at the generator sites.

\subsubsection{Maintenance of Records, 10 CFR $\$ 71.91$}

A record of each shipment of NRC-licensed material must be kept
at least 3 years after shipment. The records to be kept include
identification of the packaging by model number, verification of
integrity of the packaging, coolant information, type and quantity
of NRC-licensed material, specific information regarding irradiated
fissile material, date of shipment, any special controls, name and
address of transferee and of recipient, and results of the
determinations required by 10 CFR $\S 71.87$. Records
demonstrating the quality of packaging must also be retained.

The TRUPACT-II Operating and Maintenance Instruction Manual provides instructions to all users of the TRUPACT-II to meet records retention requirements. Retention times are also identified for each record. Records are retained at the working location and submitted to the WIPP records center for safe and retrievable storage. NRC-licensed material will not be shipped to WIPP. 


\subsubsection{NRC Inspections and Tests, 10 CFR § 71.93}

The licensee or certificate holder shall allow the NRC to inspect the NRC-licensed material, packaging, premises, and facilities in which the material or packaging is used, provided, constructed, listed, stored, or shipped; perform (and allow the NRC to perform) tests deemed necessary by the NRC; and notify the NRC at least 45 days prior to the fabrication of a package to be used to ship $N R C$-licensed material that exceeds the allowed heat load (5 kilowatts) or the maximal normal operating pressure (15 poundsper-square-inch gauge).

The DOE has allowed, and will continue to allow, the NRC to inspect and/or conduct tests, or will perform those tests deemed necessary by the NRC, on TRU waste transportation packages. The TRUPACT-II C of $\mathrm{C}$ requires the DOE to meet Subpart $\mathrm{G}$ requirements (see sections 14.2.11 through 14.2.19 herein). Currently, there are twelve TRUPACT-II packages in production. NRC-licensed material will not be shipped to WIPP.

\subsubsection{Reports Regarding Decreased Effectiveness or Defects with Safety Significance, 10 CFR § 71.95}

Within 30 days, the licensee will report the following to the NRC:

(1) any instance in which there was decreased effectiveness of any authorized packaging during use and (2) details of any defects with safety significance in packaging after first use and the means used to prevent recurrence.

The packaging maintenance program is defined and detailed in a the MOC procedure that addresses such topics as control of material, spare parts, and nonconformance reports. Maintenance records are maintained by the TRUPACT-II maintenance engineer. No conditions causing decreased effectiveness have occurred to date. An audit of the TRUPACT-II maintenance program, conducted in March 2000 by the MOC, determined that all the programmatic requirements for maintaining the TRUPACT-II packagings were being met adequately.

\subsubsection{Advance Notification of Shipment of Nuclear Waste, 10 CFR $\S 71.97$}

Advance written notification of a shipment of nuclear waste will be provided to the governor of any state to be traversed by the shipment. Notification must be provided at least 7 days or 4 days before the beginning of the 7-day period during which departure of the shipment is expected if notification is by mail or by messenger, respectively. The information required by $10 \mathrm{CFR} \S$ 71.97(d) will be provided. It should be noted that a revised list of governors' designees was published in the Federal Register on 
June 30, 1995 (60 FR 34306). The annually updated list will be published in the Federal Register every year around June 30.

Advance notification to state officials is made in writing and using the Transportation Tracking and Communications System (TRANSCOM) satellite tracking system. Operations personnel and designated state officials are notified regarding WIPP shipments and other selected high-visibility shipments. State officials designated for receipt of this information have been provided with the requisite TRANSCOM computer software and have been trained in its use. In addition, the DOE will provide the officials with a year-long schedule of proposed shipments of TRU waste to WIPP, with updates every six months.

\subsubsection{NRC Quality Assurance Requirements, 10 CFR $\S \S 71.101$ through 71.137}

Subpart H of 10 CFR 71 (\$§ 71.101 through 71.137) established the NRC QA requirements for packagings. The $Q A$ requirements pertain to design, purchase, fabrication, handling, shipping, storage, cleaning, assembly, inspections, testing, operation, maintenance, repair, and modification of components of packaging that are important for safety. The requirements address the licensee's QA organization (\$ 71.103); QA program (\$ 71.105); package design control (\$ 71.107); procurement document control (\$ 71.109); instructions, procedures, and drawings (\$ 71.111); document control (\$ 71.113); control of purchased material, equipment, and services (\$ 71.115); identification and control of material parts and components $(\S$ 71.117); control of special processes (\$ 71.119); internal inspections (\$ 71.121); test control (\$ 71.123); control of measuring and test equipment (\$ 71.125); handling, storage, and shipping control (\$ 71.127); inspection test and operating status (§ 71.129); nonconforming materials, parts, or components (\$ 71.131); corrective action ( $\$ 71.133) ;$ QA records (\$ 71.135); and audits (§ 71.137).

The Quality Assurance Plan for Procurement, Use, Maintenance and Repair of TRUPACT-II has addressed the 18 criteria specified within Annex 2 of the NRC's Regulatory Guide 7.10, promulgated by the Office of Nuclear Regulatory Research. The title of this document is Establishing Quality Assurance Programs for Packaging Used in the Transport of Radioactive Material. The NRC has inspected MOC's QA program and found that it meets the requirements of 10 CFR 71, Subpart $\mathrm{H}$.

The MOC conducted an audit regarding the transportation, receipt, and maintenance of the TRUPACT-II packagings in March 2000. The overall audit results indicated that all the programmatic requirements in these three areas were being administered adequately. 


\subsection{Compliance Status of the Certificate of Compliance}

The NRC has issued C of C No. 9218 to the DOE for the TRUPACT-II container and registered the DOE as a user. A number of conditions are specified in the $C$ of $C$. The conditions from the latest revision of the $C$ of $C$ (Revision 11, dated December 28, 1999) are summarized in the text.

\subsubsection{Overall Specifications for the TRUPACT-II, C of C, Page 1, 5(2), Paragraph 1}

The TRUPACT-II consists of an unvented, 1/4-inch-thick stainless steel inner containment vessel (ICV) positioned within an outer containment assembly (OCA).

The OCA is an unvented 1/4-inch-thick stainless steel outer containment vessel (OCV) with a 10-inch-thick layer of polyurethane foam and a 1/4- to 3/8-inch-thick outer stainless steel shell.

The package is a right circular cylinder with outside dimensions of about 94 inches in diameter and 122 inches in height.

The TRUPACT-II packaging is composed of the ICV positioned within the OCA. As shown in the drawings in Appendix 1.3.2 of the TRUPACT-II SARP and discussed in section 1.2.1.1 of that document, the ICV is unvented and is fabricated primarily of 1/4-inch Type 304 stainless steel. The OCA is also unvented and is bounded by a 1/4to 3/8-inch-thick Type 304 stainless steel shell. Within the outer shell of the OCA is the OCV, which has a 3/16-inch-thick Type 304L stainless steel shell. Between the inner shell of the OCA and the outer shell of the OCV is a layer of polyurethane foam to provide insulation and absorb energy; this layer is up to 9-13/16 inches thick.

The configuration of the TRUPACT-II packaging is that of a right cylinder with domed heads. The OCA is 94-3/8 inches in diameter and 121-3/4 inches high (see section 1.2.1.1.1 of the TRUPACT-II SARP).

\subsubsection{Overall Weight, C of C, Page 1, 5(2), Paragraph 1}

The package weighs no more than 19,250 lbs when loaded, with the maximal allowable contents of 7,265 lbs.

According to the TRUPACT-II SARP, the maximum gross shipping weight of the TRUPACT-II package is $19,250 \mathrm{lbs}$. The maximal payload weight is $7,265 \mathrm{lbs}$. 


\subsubsection{Outer Containment Assembly of the TRUPACT-II, C of C, Page 1, 5(2), Paragraph 2}

The OCA has a domed lid that is secured to the OCA's cylindrical body with a locking-ring mechanism.

The OCV containment seal is provided by a butyl rubber O-ring (bore seal).

The OCV is equipped with a seal test port and a vent port.

As shown and described in the TRUPACT-II SARP, the OCA has a domed lid that is secured to the body of the OCA with a locking ring assembly. The containment O-ring is made of butyl rubber. The location of the OCV seal test port and the vent port are shown in Appendix 1.3.2 of the TRUPACT-II SARP (Sheet 2 of Drawing 2077-500SNP).

\subsubsection{Inner Containment Vessel of the TRUPACT-II, C of C, Page 1, 5(2), Paragraph 3}

The ICV is a right cylinder with two domed heads. Its outside dimensions are approximately 73 inches in diameter and 98 inches high.

The lid is secured to the ICV body with a locking ring.

The ICV containment seal is provided by a butyl rubber O-ring (bore seal).

The ICV is equipped with a seal test port and vent port. Honeycombed aluminum spacer sections are placed in the top and bottom domed heads of the ICV during shipping. The cavity available for the contents is a cylinder of approximately 73 inches in diameter and 75 inches in height.

The ICV is a right cylinder with domed heads. According to the TRUPACT-II SARP, the ICV has a maximal external diameter of 76-5/16 inches, a minimal external diameter of 73-1/8 inches, and an overall external length of 99 inches when the lid is installed on the body of the ICV. The lid is secured to the body with a locking ring. Two main O-rings are enclosed between the mating lid and body of the OCV: the upper main O-ring is made of butyl rubber and serves a containment function; the lower (test) seal is made of neoprene or ethylene propylene and allows a vacuum to be established on the exterior side of the containment O-ring for helium and pressure-rise leakage-rate testing.

The locations of the ICV seal test port and the vent port are shown in Appendix 1.3.2 of the TRUPACT-II SARP (Sheet 3 of Drawing 2077-500SNP). The upper and lower aluminum spacer assemblies are shown on Sheet 6 of this same set of drawings in Appendix 1.3.2 of the SARP. 
A cylindrical cavity is available for the contents to be placed in the ICV. The dimensions of the cavity are a minimal and maximal diameter of 72-7/16 and 73-7/8 inches (section 1.2.1.1.2 of the TRUPACT-II SARP) and a height of 74-5/8 inches (Appendix 1.3.2 of the SARP, Drawing 2077-500SNP, Sheet 2).

\subsubsection{Drawings Showing Construction of TRUPACT-II, C of C, Page 2, 5(a)(3), Paragraph 1}

The packaging is constructed in accordance with Nuclear Packaging Inc. (NuPac) drawing 2077-500SNP, Sheets 1-11 (Rev. N).

The 11 sheets of Drawing 2077-500SNP are included in the TRUPACT-II SARP. The TRUPACT-II packages are constructed in accordance with these drawings.

\subsubsection{Drawings Showing Position of Contents in TRUPACT-II, C of C, Page 2, 5(a)(3), Paragraph 2}

The contents are positioned within the packaging in accordance with NuPac drawings 2077-007SNP (Rev. C) and 2077-008SNP, Sheets 1 and 2 (Rev. C).

NuPac Drawings 2077-007SNP (one sheet) and 2077-008SNP (two sheets) are included in Appendix 1.3.8 of the TRUPACT-II SARP. The drum assemblies or standard waste boxes (SWB) are positioned within the package as shown in these drawings.

\subsubsection{Physical Form of Allowable Material and Receptacles, C of C, Page 2, 5(b)(1)}

Only dewatered, solid, or solidified TRU and tritium-contaminated materials and wastes are allowed. They must be packaged in 55-gallon drums, SWBs, pipe overpacks, or ten-drum overpacks (TDOP).

According to section 3.2.1.2 of the WAC, standard 55-gallon drums, SWBs, TDOPs, and pipe overpacks are authorized for shipping $\mathrm{CH}$ TRU wastes in TRUPACT-II packaging. The physical form of the $\mathrm{CH}$ TRU waste comprising the TRUPACT-II payload is restricted to solid or solidified material. Liquid waste is prohibited from the payload except for residual amounts in well-drained containers. (See also section 2 of Appendix 1.3.7 to the TRUPACT-II SARP.) 


\subsubsection{Prohibition of Explosives, Corrosives, Nonradioactive Pyrophorics, and Pressurized Containers, C of C, Page 2, 5(b)(1)}

Explosives, corrosives, nonradioactive pyrophorics, and pressurized containers are prohibited.

Sections 3.5.1 and 3.5.4 of the WAC prohibit the acceptance of explosives, corrosives, or pressurized vessels at WIPP. The WAC requires that any nonradioactive pyrophoric materials must be rendered safe by mixing them with chemically stable materials (e.g., concrete, glass) or by processing them to remove their hazardous properties; thus, they will be rendered nonpyrophoric prior to shipment to WIPP. (See also section 4 of Appendix 1.3 to the TRUPACT-II SARP.)

Corrosive wastes are prohibited on two counts. They are prohibited on the basis of the definition of corrosive waste used in the WAC (i.e., aqueous materials with a pH less than or equal to 2 or greater than or equal to 12.5). Furthermore, since corrosive wastes are aqueous by definition, they are prohibited as freestanding liquids (see section 14.3.10 below).

\subsubsection{Restriction of Radioactive Pyrophorics, C of C, Page 2, 5(b)(1)}

Radioactive pyrophorics must not exceed 1 percent by weight within a waste container.

Section 3.5.1 of the WAC restricts pyrophoric forms of radionuclides to less than 1 percent by weight of the waste in each waste container. If radioactive pyrophorics are present they shall be generally dispersed in the waste. (See also section 4 of Appendix 1.3.7 to the TRUPACT-II SARP.)

\subsubsection{Restriction of Free Liquids, C of C, Page 2, 5(b)(1)}

Free liquids must not exceed 1 percent by volume within a payload container.

Section 3.4.1 of the WAC stipulates that liquid waste will not be accepted for disposal at WIPP and that the total liquid in a waste container will not equal or exceed 1 volume percent of the payload container. (See also section 2 of Appendix 1.3.7 to the TRUPACT-II SARP.)

\subsubsection{Restriction of Flammable Organics, C of C, Page 2, 5(b)(1)}

Flammable organics are limited to $500 \mathrm{ppm}$ in the headspace of any waste package.

Section 3.6.4 of the WAC limits the total concentration of potentially flammable VOCs to $500 \mathrm{ppm}$ in the headspace of a waste package; this value includes error measurement. (See also section 5 of Appendix 1.3.7 to the TRUPACT-II SARP). 


\subsubsection{Maximal Allowable Weight, C of C, Page 2, 5(b)(2), Paragraph 1}

Contents must not exceed 7,265 pounds including shoring and secondary containers.

Section 3.2.2 of the WAC specifies the following weight limits for waste package assemblies transported in the TRUPACT-II package:

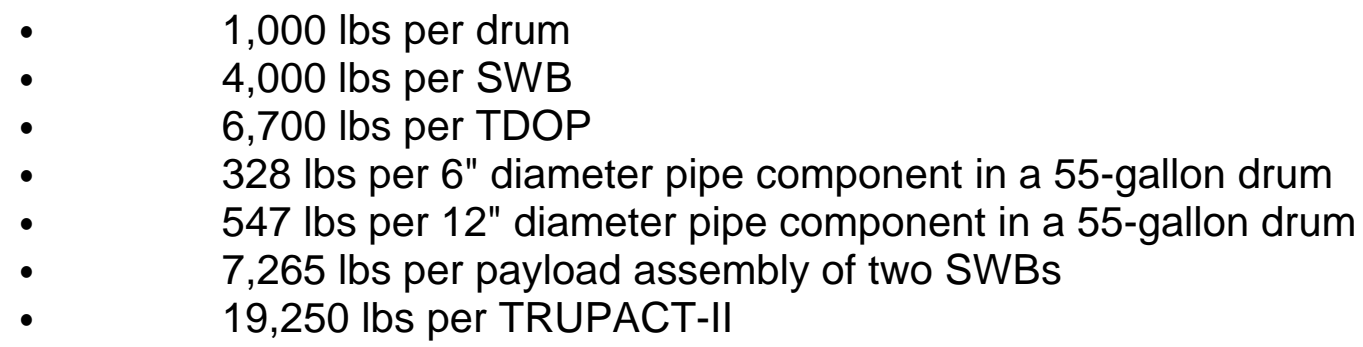

14.3.13 Maximum Number of Payload Containers Per Package and Authorized Configurations, C of C, Page 2, 5(b)(2), Paragraph 2

The maximum number of payload containers per package and authorized packaging configurations are:

- 14, 55-gallon drums

- 14, pipe overpacks (each in a 55-gallon drum)

- 2 SWBs

- 2 SWBs, each containing one bin

- 2 SWBs, each containing up to four 55-gallon drums

- 1 TDOP

- 1 TDOP containing ten 55-gallon drums

- 1 TDOP containing up to six 85-gallon drums

- 1 TDOP containing one SWB

- 1 TDOP containing one bin within an SWB

- 1 TDOP containing four 55-gallon drums within an SWB

According to the WAC (section 3.2.1), the authorized loading configurations for shipment in the TRUPACT-II package are limited to those as specified in Appendix 1.3.7 of the TRUPACT-II SARP.

\subsubsection{Amount of Allowable Fissile Material, C of C, Page 2, 5(b)(2), Paragraph 3}

Fissile material must not exceed 325 grams Pu-239 equivalent, with no more than 200 grams Pu-239 equivalent per 55-gallon drum or 325 grams Pu-239 equivalent per SWB (for Pu-239 equivalent, see Appendix 1.3.7 of the TRUPACT-II SARP). 


\section{Waste Isolation Pilot Plant Biennial Environmental Compliance Report}

DOE/WIPP 99-2171

Section 3.3.2 of the WAC specifies that the fissile radionuclide content of $\mathrm{CH}$ TRU waste packages will not exceed the following values, in Pu-239 fissile-gram equivalents:

- 200 grams per pipe overpack

- 200 grams per 55-gallon drum

- $\quad 325$ grams per SWB

- $\quad 325$ grams per TDOP

The sum of the fissile equivalents of all waste packages in the entire payload of a TRUPACT-II, including two times the error may not exceed 325 (see the calculation methods described in Appendix 1.3.7 of the TRUPACT-II SARP).

\subsubsection{Allowable Decay Heat, C of C, Page 2, 5(b)(2)}

Decay heat per payload must not exceed the values given in Appendix 1.3.7, Table 5-6.

According to section 3.6.2 of the WAC, the decay heat within each payload container plus the measurement error shall be less than or equal to the decay heat limit specified in Table 5-6 of Appendix 1.3.7 in the TRUPACT-II SARP. The total decay heat from all containers in a TRUPACT-II shall be less than 40 watts.

\subsubsection{Criticality Transport Index, C of C, Page 3, 5(c)}

Fissile Class has been replaced by the Criticality Transport Index.

The $\mathrm{C}$ of $\mathrm{C}$ identified the TRUPACT-II as a fissile material packaging. Therefore, the requirements specified in 10 CFR $\S 71.59$ must be met. The Transport Index for TRUPACT-II is 0.0 and meets the requirements of 10 CFR $\S 71.59$.

\subsubsection{Restrictions of Form, Properties, and Other Parameters, C of C, Page 3, 6}

The physical form, chemical properties, chemical compatibility, configuration of the payload containers and contents, isotopic inventory, fissile content, decay heat, weight and center of gravity, and radiation dose rate must be determined and limited in accordance with the TRUPACT-II Authorized Methods for Payload Control (TRAMPAC) (TRUPACT-II SARP, Appendix 1.3.7).

The methods for determining and controlling the physical form of the wastes are visual examination, radiography, acceptable knowledge, and sampling (SARP, Appendix 1.3.7, section 1). The chemical properties of the waste (SARP, Appendix 1.3.7, section 4) are determined by the allowable chemical constituents within a given waste type and are restricted so that all the payload containers are safe for handling and transport. Chemical compatibility (SARP, Appendix 1.3.7, section 4; see 
also SARP Appendix 2.10.12) within the waste and between the waste and the packaging ensures that no chemical process will occur that might pose a threat to the safe transport of the payload in the TRUPACT-II package. The configuration of the payload container and content is controlled as described in section 6 of the SARP's Appendix 1.3.7. This section also describes specifications for filter vents and preshipping venting and aspiration requirements.

The isotopic inventory for each payload container and the fissile content are discussed in section 3 of the TRAMPAC. Decay heat is discussed in section 5 of the TRAMPAC.

The allowable weights for individual payload containers and for the total payload are presented in section 2 of the TRAMPAC, along with methods of determining and controlling weight. The methods for determining the center of gravity of the loaded TRUPACT-II package are also described in this section for 55-gallon drums and for SWBs.

External radiation dose rates are presented in section 3 of the TRAMPAC. These rates may not exceed 200 mrem per hour at the surface of the payload container and 10 mrem per hour at 2 meters. (See also section 5.0 of the TRUPACT-II SARP.)

\subsubsection{Shipping Category Designations, C of C, Page 3, 7}

Each drum and SWB must be assigned a shipping category in accordance with section 5 of the TRAMPAC or tested for gas generation to determine the actual rate of gas generation and hydrogen concentration prior to shipment in accordance with Attachment 2.0 to Appendix 1.3.7 of the TRUPACT-II SARP.

Section 1.2.3.2 of the TRUPACT-II SARP discusses the payload shipping categories developed specifically for the TRUPACT-II package. The primary difference among the categories is their potential for gas generation and internal bagging configuration. For waste with an adequate margin of safety, an analytical prediction suffices. Wastes without such a margin of safety require testing as described in section 1.2.3.3.12 and Attachment 2.0 to Appendix 1.3.7 of the TRUPACT-II SARP.

\subsubsection{Labeling Requirements, C of C, Page 3, 8}

Each drum and SWB must be labeled to indicate its shipping category. All drums and SWBs within a package must be of the same shipping category.

As described in section 3.4.4 of the WAC, each waste package will be labeled with the shipping category after all payload parameters have been verified. (See also section 6 of Appendix 1.3.7 to the TRUPACT-II SARP.) 


\subsubsection{Preshipment Venting or Aspirating Requirements, C of C, Page 3, 9}

Each drum, SWB, or TDOP must be equipped with filtered vents prior to shipment in accordance with Appendix 1.3.5 to the TRUPACT-II SARP. Drums not equipped with filtered vents during storage must be aspirated before shipment.

Section 3.6.5 of the WAC stipulates that all payload containers that have been stored in an unvented condition, must be aspirated for a specific length of time. (See also section 25.5 of Appendix 1.3.5 to the TRUPACT-II SARP.)

\subsubsection{Requirements of Subpart G of 10 CFR 71, C of C, Page 3, 10}

Compliance with the requirements of Subpart G of 10 CFR 71 is required.

Subpart G invokes Subpart H, Quality Assurance. Compliance is discussed in section 14.2.20 herein.

\subsubsection{Preparation of Packages for Shipment and Operations, C of C, Page 3, 10(a)}

Each package must be prepared for shipment and operated in accordance with procedures described in Chapter 7, "Operating Procedures," of the TRUPACT-II SARP.

Chapter 7 of the TRUPACT-II SARP contains procedures for loading and unloading the TRUPACT-II container and for preparing an empty packaging for transport. In addition, the payload assembly criteria are presented in section 6 of Appendix 1.3.7 to the TRUPACT-II SARP. Compliance is incorporated into WIPP TRUPACT-II unloading procedures.

\subsubsection{Testing and Maintenance of Packages, C of C, Page 4, 10(b)}

Each package must be tested and maintained in accordance with procedures described in Chapter 8, Acceptance Tests and Maintenance Program, of the TRUPACT-II SARP.

The required acceptance tests and the maintenance program are included in Chapter 8 of the TRUPACT-II SARP. The acceptance tests are those tests that must be performed prior to the first use of the TRUPACT-II and that include visual inspection and structural, pressure, leakage, component, and thermal acceptance tests. (No shielding is provided in the TRUPACT-II container; therefore, shielding integrity tests are not appropriate.) The maintenance program consists of procedures and tests used to ensure the continuation of proper performance of the TRUPACT-II packaging. It comprises structural and pressure tests; leak tests and subsystems maintenance of fasteners; the ICV; the OCA; seal areas and grooves; and valves, rupture discs, and 
gaskets on the containment vessel. No shielding or thermal inspections or tests are necessary to ensure continued performance of the TRUPACT-II container.

Personnel from the MOC Quality Assurance Department performed an audit in March 2000 on compliance with applicable regulations with respect to the training requirements and procedures relating to maintenance of the TRUPACT-II packagings. The audit team concluded that all the programmatic requirements for the maintenance of the TRUPACT-II packagings were being met.

\subsubsection{Leak Testing, C of C, Page 4, 10(c)}

Prior to each shipment, lid and vent port seals on inner and outer containment vessels must be leak tested in accordance with Appendix 7.4.2 of the TRUPACT-II SARP.

The assembly verification leak test and other leak tests that must be performed on the TRUPACT-II package are described in Appendix 7.4.2 of the TRUPACT-II SARP. All such mandatory tests will be run on each package prior to shipment.

\subsubsection{Removal of Free-Standing Water, C of C, Page 4, 10(d)}

All free-standing water must be removed from the ICV cavity and the OCV cavity before shipment.

The operating procedures of Chapter 7 of the TRUPACT-II SARP include instructions for inspecting for freestanding water and removing it from the package. These procedures must be used for loading the TRUPACT-II container.

\subsubsection{Approval of the TRUPACT-II Packaging, C of C, Page 4, 11}

The TRUPACT-II packaging must be approved for use under general license provisions of 10 CFR § 71.12.

See section 14.2.1 above. 
This page intentionally left blank. 


\subsection{HAZARDOUS MATERIALS TRANSPORTATION ACT}

\subsection{Summary of the Law}

The Hazardous Materials Transportation Act (HMTA; 49 U.S.C. $\S \S 1801$ et seq.), as amended, is the major transportation-related statute that affects the DOE. The objective of the HMTA is "to improve the regulatory and enforcement authority of the Secretary of Transportation to protect the Nation adequately against risks to life and property which are inherent in the transportation of hazardous materials in commerce." The HMTA provides for safe intra- and interstate transportation of hazardous materials (including nuclear materials).

The Federal Hazardous Materials Transportation Law (Pub. L. 103-429) was reauthorized on October 31, 1994. This public law, which amends the HMTA, required the U.S. Department of Transportation (DOT) to set standards for designating routes for the transportation of hazardous materials that are required to be placarded, establish regulations on training standards for all hazardous materials transportation workers, issue safety permits to motor carriers for certain hazardous materials, and perform a railroad transportation safety study for certain highly radioactive materials. The DOT is also required to participate in international forums dealing with recommendations or legislation relating to mandatory standards and requirements pertaining to the transportation of hazardous materials, and to consult with interested agencies to facilitate consistency in international law with respect to hazardous materials transportation. In addition, the Hazardous Materials Transportation Uniform Safety Act requires registration and an annual registration fee for shippers and carriers of certain hazardous materials such as radioactive materials and establishes planning and training grants to the states for developing, improving, and implementing emergency plans.

In the Second Modification to the Agreement for Consultation and Cooperation, dated August 4, 1987, the DOE agreed to comply with all applicable DOT regulations and any applicable corresponding regulations of the NRC. The following regulations are applicable to WIPP.

Title 49 CFR 171, "General Information, Regulations, and Definitions," sets forth the DOT requirements that are applicable to the transportation of hazardous materials and the packaging used in the transportation of those materials.

Title 49 CFR 172, "Hazardous Materials Table, Special Provisions, Hazardous Materials Communications Requirements and Emergency Response Information and Training Requirements," lists and classifies the materials the DOT has designated as hazardous for the purpose of transportation and describes the communications regulations that apply when those materials are shipped.

In 49 CFR 173, "Shippers - General Requirements for Shipments and Packagings," the DOT defines hazardous material classes for the purpose of transportation; establishes requirements in preparing materials for shipment; sets forth inspection, testing, and retesting responsibilities concerning containers built, repaired, or conditioned for use in 
the transportation of hazardous materials; sets forth requirements for transporting radioactive materials; classifies materials having more than one hazard; and describes criteria for instructing those responsible for preparing hazardous materials for shipment.

In 49 CFR 175, "Carriage by Aircraft," the DOT prescribes additional requirements to those in 49 CFR 171, 172, and 173 concerning the transportation of hazardous material by air. Title 49 CFR $\S 171.11$ is the interface between DOT and International Air Transportation Association (IATA) and the International Civil Aviation Organization (ICAO). This allows air shipments to be made under IATA/ICAO regulations that are not in conflict with DOT regulations. All air shipments from WIPP are in compliance with DOT and IATA/ICAO regulations.

In 49 CFR 177, "Carriage by Public Highway," the DOT sets forth requirements to promote the uniform enforcement of law to minimize danger to life and property in the transportation of hazardous materials by public highway.

Title 49 CFR 178, "Specifications for Packagings," describes manufacturing and testing specifications for packaging and containers used for the transportation of hazardous materials.

\subsection{Compliance Status of the Regulatory Requirements}

The text gives more detail on the compliance status of regulatory requirements under HMTA.

\subsubsection{General Requirements, 49 CFR § 171.2}

General requirements regarding the offering or acceptance of hazardous material for transportation in commerce are described.

Material to be shipped must be properly classified, described, packaged, marked, labeled, and in condition for shipment.

General requirements for the shipment of hazardous material are addressed in the Transportation Program, which identifies the organizations and positions responsible for ensuring compliance with the HMTA. The completion and certification of several worksheets (e.g., Shipping Request, Shipment Worksheet for Ground Transportation, and Shipment Worksheet for Air Transportation) ensures compliance through careful documentation of all required actions.

\subsubsection{Hazardous Waste, 49 CFR $§ 171.3$}

Requirements for the shipment of hazardous wastes include the preparation of manifests or other shipping papers, motor vehicle placarding, waste packaging, marking and labeling, and identification numbers for the generators and the transporters. 
Manifests, marking and placarding, and other labeling requirements are addressed in the Transportation Program. Completion of step-by-step worksheets and checklists ensure the proper execution of these tasks in shipping hazardous wastes from WIPP to an off-site Treatment, Storage, and Disposal Facility (TSDF).

\subsubsection{Transitional Provisions for Implementing Requirements Based on the United Nations Recommendations, 49 CFR § 171.14}

Provides an orderly transition to the new requirements incorporated as part of a comprehensive revision to this subchapter based on the United Nations' Recommendations.

Prescribed methods are included in the Transportation Program that address the shipment of nonradioactive hazardous materials.

\subsubsection{Immediate Notice of Certain Hazardous Materials Incidents and Detailed Hazardous Materials Incident Reports, 49 CFR §§ 171.15 through 171.16}

Section 171.15 specifies the requirements of immediate notification by each carrier who transports certain hazardous materials (including hazardous wastes) and is involved in a hazardous material incident during the course of transportation. Section 171.16 specifies the requirements for the submission of a written hazardous materials incident report by the carrier.

Requirements for transportation emergency notifications are specified in the Transportation Program. This program and MOC procedures address reportable incident and reporting requirements, including the identification of organizations and other entities that receive reports. During this reporting period there were no hazardous materials incidents as defined in these regulations.

\subsubsection{Table of Hazardous Materials, 49 CFR $§ 172.101$}

The Hazardous Materials Table designates all materials listed as hazardous for the purpose of transporting those materials.

These requirements are covered in the Transportation Program and apply to any "... material, including its mixtures and solutions that ... is listed in Table 172.101 and/or in appendices to 49 CFR $\S 172.101$, 'List of Hazardous Substances and Reportable Quantities."'

\subsubsection{Shipping Papers, Subpart C, 49 CFR $\S \S 172.200$ through 172.205}

This subpart describes the requirements for the provision of shipping papers by persons who offer hazardous material for 
transportation. The shipping papers must include a description of the hazardous material and a shipper's certification. A "bill of lading" or "hazardous waste manifest" may be used depending on the commodity being shipped.

Requirements concerning shipping papers, including manifests for hazardous waste and bills of lading for hazardous materials, are described in MOC procedures. Each required record is identified and defined by forms attached to these procedures.

\subsubsection{Marking, Subpart D, 49 CFR $\S 172.300$ through 172.338}

Marking requirements for the transportation of hazardous materials or substances are described in this subpart.

According to $\mathrm{MOC}$ procedure, the transportation engineer marks the shipment in accordance with either Subpart D of 49 CFR 172 or the International Air Transport Association (IATA) 7.1.

\subsubsection{Labeling, Subpart E, 49 CFR $§ ~ 172.400$ through 172.450}

This subpart describes the requirements for the labeling of packages or containment devices by persons who offer hazardous material for transport.

According to MOC procedures, the transportation engineer labels the shipment in accordance with either Subpart E of 49 CFR 172 or IATA 7.2. The driver's responsibility in maintaining the labels is stated in the Transportation Program.

\subsubsection{Placarding, Subpart F, 49 CFR $\S \S 172.500$ through 172.560}

This subpart describes the requirements for the placarding of hazardous material by persons who offer hazardous material for transport.

According to an MOC procedure, the transportation engineer ensures that the vehicle that will transport hazardous materials or waste from WIPP is properly placarded, if necessary.

\subsubsection{Emergency Response Information, Subpart G, 49 CFR § 172.600}

This subpart describes the requirements for the provision of emergency response information during transportation and at facilities where hazardous materials are loaded for transportation, stored incidental to transportation, or otherwise handled during any phase of transportation. 
According to an MOC procedure, the transportation engineer delivers the shipping papers and the DOT Emergency Response Guides for the particular shipment materials to the driver and releases the shipment. These procedures specify driver actions to be taken in the event of an incident during transportation.

The MOC addresses on-site emergency response in its procedures and waste management plans. The transportation engineer provides the Central Monitoring Room with copies of transportation documentation. The Central Monitoring Room is a 24-hour emergency contact for all shipments of hazardous waste or materials.

\title{
15.2.11 Training Requirements, Federal/State Relationship, and Applicability and Responsibility for Training and Testing, Subpart H, 49 CFR $\S 172.700$ through .702 and 172.704
}

\begin{abstract}
Prescribes minimal training requirements for the transportation of hazardous materials and specifies requirements that hazardous materials employers and employees as established by DOT must meet to ensure that their hazardous materials employees are trained in a systematic program. The following requirements are included: states may impose more stringent training requirements under certain conditions; the training curriculum must include general awareness and familiarization, hazardous material recognition and identification, function-specific topics, and safety and emergency response information; and current hazardous materials employee training records must be maintained and contain specific training documentation including certification of training.
\end{abstract}

WIPP employees who are responsible for coordinating the transportation of hazardous materials must attend the Hazardous Material Transportation Course. Through this training program, hazardous materials employees become familiar with the applicable hazardous material regulations, are able to recognize and identify hazardous materials, are knowledgeable of function-specific hazardous material regulations, and are knowledgeable of emergency response information and hazardous material communications requirements. The MOC provides each hazardous materials employee at WIPP with initial and recurrent training in accordance with established schedules. New employees, or employees who change job functions and are required to attend the training, must do so within 90 days. Until completion of their training, they may work under the direct supervision of another certified hazardous materials employee. The MOC maintains records of current training, inclusive of the preceding three years. The training records are maintained in accordance with existing requirements. 


\subsubsection{General Requirements for Shipments and Packaging, Subpart A, 49 CFR §§ 173.1 through 173.12}

This subpart includes the requirements for preparing hazardous materials for shipment by air, highway, rail, or water and definitions and classifications of hazardous materials for transportation purposes.

The MOC procedures encompass the requirements of these sections. WIPP shipments are evaluated and authorized by an MOC transportation engineer to ensure these requirements are met.

\subsubsection{Preparation of Hazardous Materials for Transportation, Subpart B, 49 CFR §§ 173.21 through 173.40}

This subpart describes the general requirements for the preparation of hazardous materials for transportation. The shipper's responsibilities are described and include the hazard classification and description of hazardous material and the determination that the packaging or container is an authorized packaging and that it has been manufactured, assembled, and marked properly.

According to MOC procedures, the MOC's National TRU Programs Shipping Coordination Section is responsible for ensuring that materials are packaged, marked, and labeled in accordance with $49 \mathrm{CFR}$. Personnel packaging hazardous materials must be familiar with the packaging requirements for these materials, commensurate with the complexity of the packaging and the degree, nature, and quantity of hazard.

\subsubsection{Definitions, Classification, and Packaging for Class 1 Materials, Subpart C, 49 CFR $\S 173.50$ through 173.63}

Definitions, classifications, and requirements for packaging of Class 1 materials (explosives) are described.

In December 1999, Class 1 material was shipped from WIPP. The Class 1 material consisted of misfired cartridges or power devices used in hand-held fastening guns.

15.2.15 Definitions, Classification, Packaging Group Assignments, and Exceptions for Hazardous Materials other than Class 1 and Class 7, Subpart D, 49 CFR §§ 173.115 through 173.156

Definitions, classifications, packing group assignments, and exceptions for hazardous materials, including flammable, nonflammable, poisonous and nonpoisonous gases, flammable liquids and solids, and toxic material are specified. 
Applicable MOC procedures include worksheets for ground and air shipments. Actions required for the classification and packaging of hazardous materials other than Class 1 are included in these worksheets.

\subsubsection{Non-Bulk Packaging Requirements for Hazardous Materials other than Class 1 and Class 7, Subpart E, 49 CFR §§ 173.158 through 173.229}

Non-bulk packaging requirements for hazardous materials other than Class 1 and Class 7 materials are described. Specific requirements are described in 49 CFR $\S 173.158$ through 173.198 for nitric acid; wet batteries; corrosive nonexplosive smoke bombs; chemical kits; gallium; hydrogen fluoride; mercury; smokeless powder for small arms; aircraft hydraulic power unit fuel tanks; paint, paint-related material, adhesives and ink; refrigerating machines; liquid pyrophoric materials; barium azide; nitrocellulose-based film; highway or rail fuses; lithium batteries and cells; matches; pyrophoric solids, metals, or alloys; white or yellow phosphorus; certain Group 1 poisonous materials; mixtures of bromoacetone, methyl bromide, chloropicrin, and methyl chloride or of chloropicrin and methyl chloride or of chloropicrin and compressed gas; hydrogen cyanide; infectious substances; and nickel carbonyl.

An MOC procedure directs the transportation engineer to classify each shipment using the information provided in the shipping request by completing a shipment worksheet. If required, the requester and/or the transportation engineer obtain additional information to classify the shipment properly. Based on this information the transportation engineer determines the packaging requirements.

\subsubsection{Radioactive Materials, Subpart I, 49 CFR $\S 173.401$ through 173.476}

This subpart sets forth requirements for the transportation of radioactive materials by carriers and shippers and includes requirements for package design, package testing, empty radioactive materials packaging, and NRC-approved packages.

The WAC, SARP, and TRAMPAC programs control the generation, packaging, and shipment of radioactive waste to WIPP. These documents also define how packaging requirements are determined, including verification that the quantity and form of material to be shipped meet the requirements of the $\mathrm{C}$ of $\mathrm{C}$ and/or tested parameters of the intended package. More detail is provided in Chapter 14 herein under the NRC's regulations implementing transportation requirements under the AEA. 


\subsubsection{Carriage by Aircraft, 49 CFR 175}

This part describes requirements that must be observed with respect to the transportation of hazardous materials in air craft. Included are provisions relating to unacceptable hazardous materials shipments; acceptance and inspection of shipments; discrepancy reports; notification of the pilot in command; shipping papers; keeping and replacement of labels; reporting hazardous materials incidents; quantity limitation; orientation, securing, and location of cargo containing hazardous materials; compatibility of packages; damaged shipments; and specific regulations applicable according to the classification of the material, including special limitations and requirements for Class 7 (i.e., radioactive) materials.

An MOC procedure provides guidance for shipping hazardous materials by air. Hazardous materials shipped by air from WIPP are in accordance with the IATA, ICAO, and 49 CFR $\S 171.11$. There were no air shipments of hazardous materials during this reporting period.

\subsubsection{Driver Training, 49 CFR $\S \S 177.800,177.816$, and 397, Subpart D}

These sections set forth requirements for training, including the following: a carrier may not transport or cause to be transported hazardous material by motor vehicle unless each of its hazardous materials employees has received the appropriate specialized training. Each of the carrier's hazardous materials drivers must have the appropriate state-issued commercial driver's license with the proper endorsement. Drivers transporting Class 7 (radioactive) materials must have received written training within the previous two years and must have in his/her immediate possession a certificate of training that includes a proper statement of authentication.

All transportation of radioactive waste has been by contract carrier. The carrier's employees are properly trained, and their records include all certification information. The carrier's drivers all possess a commercial driver's license with a hazardous material endorsement, and each is trained and certified to transport highway route controlledquantity radioactive materials. Each driver has a properly authenticated training certificate in his or her possession.

\subsubsection{Specifications for Packagings, 49 CFR 178}

This part contains prescribed manufacturing and testing specifications and inspection requirements for packaging and for containers used for the transportation of hazardous materials. 
WIPP QA procedures define the methodology by which specified criteria are verified. The TRUPACT-II container has been developed to transport CH TRU waste to WIPP from the generator sites. The WAC requires Type A packagings, and UN-packagings, which are equivalent to Type A packagings, for WIPP disposal. The MOC's transportation engineers use an MOC procedure worksheet to specify the performanceoriented packaging necessary to satisfy these requirements for each shipment of hazardous materials from WIPP. 
This page intentionally left blank. 


\subsection{MATERIALS ACT OF 1947}

\subsection{Summary of the Law}

The Materials Act of 1947 (30 U.S.C. §§ 601 et seq.) establishes policy that directs the Bureau of Land Management (BLM) to prescribe rules and regulations for the disposal of mineral material resources (including, but not limited to, sand, stone, gravel, pumice, cinders, and clay) on public lands under the BLM's jurisdiction at fair market value while ensuring that adequate measures are taken to protect the environment and to minimize damage to public health and safety during the authorized removal of such minerals. Under the act, no mineral material shall be disposed of if the Secretary of the Interior determines that the aggregate damage to public lands and resources would exceed the benefits to be derived from the proposed sale or free use of the material.

The policy of the Materials Act of 1947 is addressed in the 1992 LWA. In the LWA, the DOE was given authority and responsibility for the management of the withdrawn land at WIPP and the disposal of mined salt consistent with the Materials Act of 1947, the LWA, and other applicable laws such as the Federal Land Policy and Management Act and the Public Rangelands Improvement Act (see Chapters 18 and 19 herein, respectively). Furthermore, the LWA directs the DOE to produce a WIPP land management plan to address the disposal of salt tailings in accordance with the Materials Act of 1947. The regulations in 43 CFR 3600, "Mineral Materials Disposal: General," implement the Materials Act of 1947 and establish procedures for the disposal of mineral material resources.

\subsection{Compliance Status of the Regulatory Requirement}

The text provides more detail on the compliance status under the Materials Act of 1947 requirement.

\subsubsection{Environmental Protection During Disposal of Mineral Material, 43 CFR § 3601.1-3}

Authorized land managers must take steps to prevent unnecessary or undue environmental degradation resulting from mineral material disposal operations.

Salt from the underground mining operations at WIPP is brought to the surface and stored in the salt pile just north of the surface facilities. This salt storage pile has the capacity to store the two million tons of material projected to be excavated during the lifetime of the WIPP project. There is also an inactive salt storage pile at WIPP. This salt pile is a result of the site and preliminary design validation phase.

According to the planned actions addressed in the WIPP Land Management Plan (LMP) (CAO/WIPP 93-004), excess salt tailings extracted from within the withdrawal area will be disposed of in accordance with the requirements of $\S \S 2$ and 3 of the Materials Act of 1947. These requirements specify that if the appraised value of the 
salt exceeds $\$ 1,000$, disposal will be performed by the highest responsible qualified bidder by competitive bidding and publication of notice of the proposed disposal as described in $\S 2$ of the Materials Act. If the appraised value of the salt is $\$ 1,000$ or less, it may be disposed of at the discretion of the DOE. Any money received from the disposal of the salt will be disposed of in the same manner as money received from the sale of public lands (Materials Act, $\S 3$ ). 


\subsection{FEDERAL LAND POLICY AND MANAGEMENT ACT}

\subsection{Summary of the Law}

One of the objectives of the Federal Land Policy and Management Act (FLPMA; 43 U.S.C. $\S \S 1701-1782$ ) is to ensure that:

... public lands be managed in a manner that will protect the quality of scientific, scenic, historical, ecological, environmental, air and atmospheric, water resource, and archeological values; that, where appropriate, will preserve and protect certain public lands in their natural condition; that will provide food and habitat for fish and wildlife and domestic animals; and that will provide for outdoor recreation and human occupancy and use.

Title II under FLPMA, Land Use Planning; Land Acquisition and Disposition, directs the Secretary of the Interior to prepare and maintain an inventory of all public lands and to develop and maintain, with public involvement, land-use plans regardless of whether subject public lands have been classified as withdrawn, set aside, or otherwise designated. Under Title V, Rights-of-Way, the Secretary of the Interior is authorized to grant, issue, or renew rights-of-way over, upon, under, or through public lands.

The policy and commitment of the FLPMA are addressed in the 1992 LWA. The LWA gave the DOE authority and responsibility for the management of the withdrawn land consistent with FLPMA, the LWA, and other applicable laws such as the Public Rangelands Improvement Act and the Taylor Grazing Act (see also Chapters 18 and 19 herein, respectively). Furthermore, the LWA directed the DOE to produce a WIPP land management plan to provide for grazing, hunting and trapping, wildlife habitat, the disposal of salt tailings, and mining, consistent with the applicable implementing regulations of FLPMA, as appropriate.

A process was established in the implementing regulations of 43 CFR 1600, "Planning, Programming, Budgeting," for the development, approval, maintenance, amendment, and revision of resource management plans for public lands administered by the BLM. This part states that the objective of resource management planning is to guide and control future management actions and the development of subsequent more detailed and limited scope plans for resources and uses consistent with the principles of Title II of FLPMA. To the extent it is consistent with WIPP's mission, the DOE must develop and maintain a land management plan consistent with the processes and requirements for resource management plans as described in these regulations.

Other regulations implementing FLPMA established procedures for the orderly and timely processing of applications, grants, permits, amendments, assignments, and terminations for rights-of-way and permits over, upon, under, or through public lands. In particular, 43 CFR 2800, "Rights-of-Way, Principles and Procedures," provides guidelines for the use of right-of-way and temporary-use permit areas and establishes requirements for the submission and processing of right-of-way grant/reservation and 
temporary-use permit applications. These regulations remain applicable to WIPP because of the necessity to establish rights-of-way for the construction and phased operation of this facility.

\subsection{Compliance Status of the Regulatory Requirements}

The text provides more detail on the compliance status of each FLPMA requirement. It should be noted that the LWA has limited the DOE's compliance with FLPMA, and other applicable law to the extent such compliance is consistent with the LWA and with WIPP-related uses of the withdrawn land. As such, it is up to the Secretary of Energy, in consultation with the Secretary of the Interior, to determine applicability as necessary and appropriate.

\subsubsection{Resource Management Planning Guidance, 43 CFR § 1610.1}

Guidance in preparing resource management plans may be provided to the District and Area BLM Managers by the Director and state Director of the BLM.

The WIPP LMP was prepared for the DOE by its MOC with considerable input from the $\mathrm{BLM}$. No changes to the plan occurred during this BECR reporting period.

\subsubsection{Public Participation, 43 CFR § 1610.2}

The public shall be provided an opportunity to review and comment on land management plans.

Public meetings were held in Carlsbad and Hobbs, New Mexico, and members of the public were given 30 days to review and comment on the WIPP LMP. A copy of the draft plan was also sent to the Governor's Radioactive Waste Consultation Task Force, the State Land Office, the Environmental Evaluation Group, and the NMED for their review. The comments obtained were incorporated, as appropriate, into the final document.

\subsubsection{Consistency of Management Plans, 43 CFR § 1610.3-2}

Land-use plans shall be consistent with the purposes, policies, and programs of federal laws and regulations that apply to public lands.

As a requirement of the LWA, the WIPP LMP was developed for the withdrawal area consistent with FLPMA. The plan was drafted by the DOE and its MOC in consultation with the BLM and the state of New Mexico and was submitted to Congress in October 1993. 


\subsubsection{Common Terms and Conditions of Right-of-Way Reservations and Temporary-Use Permits, 43 CFR § 2801.2(a)}

By accepting a right-of-way reservation or a temporaryuse permit, the applicant agrees and consents to comply with the following terms and conditions in addition to those terms and conditions that are specified in the reservation(s) or permit(s). The common terms and conditions are:

- To comply with all applicable state and federal laws and the implementing regulations to the extent practicable;

- To protect employees and applicants for employment who will be or are involved in the construction, operation, maintenance, and termination of the authorized use against discrimination because of race, creed, color, sex, or national origin and to ensure that all subcontracts include an identical provision;

- To rebuild and repair roads, fences, and established trails that may be destroyed or damaged by the construction, operation, or maintenance of the project and to build and maintain suitable crossings for existing roads and significant trails that intersect the project; and

- To prevent and suppress fires on or in the immediate vicinity of the right-of-way areas.

Compliance with all applicable state and federal laws and their implementing regulations is discussed throughout this document. (See the specific regulations and the compliance status section of each for more detailed information.)

The DOE and its contractors have a nondiscrimination policy in effect for their employees and for hiring. In addition, contracts and subcontracts awarded by the DOE and by its contractors include such a nondiscrimination clause.

Any roads, fences, or established trails destroyed or damaged by the construction, operation, or maintenance of any of the structures for which the CAO has received a right-of-way reservation or temporary-use permit for WIPP are repaired as required.

The MOC maintains fire-fighting equipment at WIPP. Some WIPP emergency response personnel are trained in fire-fighting methods. The CAO has an agreement with the Carlsbad Fire Department to provide fire-fighting services at WIPP if necessary. 


\subsubsection{Conditions to be Incorporated within all Right-of-Way Reservations and Temporary-Use Permits, 43 CFR § 2801.2(b)}

All right-of-way reservations and temporary-use permits must contain requirements to ensure:

- Restoration, revegetation, and curtailment of land erosion;

- Compliance with applicable air- and water-quality standards;

- Protection of scenic, aesthetic, cultural, and environmental values as well as federal property and public health and safety;

- $\quad$ Protection of the interests of local inhabitants who rely on the fish, wildlife, and biota of the area for subsistence;

- Maintenance and operation of facilities on the prescribed location in a manner that is consistent with the reservation or permit; and

- Compliance with any state standards for public health and safety; environmental protection; and siting, construction, operation, and maintenance that are more stringent than the federal standards.

Each area that is the subject of a right-of-way reservation will be reclaimed and revegetated as described in the LMP.

Compliance with applicable air- and water-quality standards is discussed in Chapters 6 through 8,28 , and 29 of this report. (See these chapters for more specific information pertaining to the air- and water-quality standards.)

Protection of scenic, aesthetic, cultural, and environmental values was addressed in the FEIS and the SEIS. A second SEIS was prepared to address disposal of TRU waste at WIPP; the Land Management Plan; and the Joint Powers Agreement with the state of New Mexico. Any changes in previous values or the potential impact of WIPP operations on those values will be addressed in this document.

The people who live in the vicinity of the WIPP facility are ranchers. There are no local inhabitants who rely on fish and wildlife of the area for subsistence. Various chapters in this report and the LMP describe activities that protect these interests.

Each "facility" (road, pipeline, railroad, etc.) is maintained and operated in accordance with the stipulations provided in the respective right-of-way reservation. (See section 17.3 below for more specific information.) Standards or permit conditions imposed by the state are being met. 


\subsubsection{Requirements for Applications for Right-of-Way Reservations and Temporary-Use Permits, 43 CFR § $\mathbf{2 8 0 2 . 2}$}

Parties seeking a right-of-way reservation or temporary-use permit involving the use of public lands shall file an application for the reservation or permit with either the Area Manager, the District Manager, or the State Director having jurisdiction over the affected public lands.

To date, several right-of-way reservations and land-use permits have been granted to the DOE. The following are examples of WIPP reservations and permits.

Right-of-way Reservation No. NM 53809 for a water pipeline was granted on August 17, 1983, and is still active. This Reservation is held in perpetuity. (See section 17.3.2 below.)

Right-of-way Reservation No. NM 55676 for the north access road at WIPP was granted on August 24, 1983, and is still active. This Reservation is held in perpetuity. (See section 17.3.3 below.)

Right-of-way Reservation No. NM 55699 for the railroad spur at WIPP was granted on September 27, 1983, and is still active. This Reservation is held in perpetuity. (See section 17.3.4 below.)

Right-of-way Reservation No. NM 63136 for dosimetry and aerosol sampling sites was granted on July 31,1986 , and is still active. This Reservation is held in perpetuity. (See section 17.3.5 below.)

Right-of-way Reservation No. NM 65801 for seven subsidence monuments was granted on November 7, 1986, and is still active. This Reservation is held in perpetuity. (See section 17.3.6 below.)

Right-of-way Reservation No. NM 77921 for an aerosol sampling site was granted on August 18, 1989, and is still active. The permit expires August 18, 2019. (See section 17.3.8 below.)

Free-Use Caliche Permit No. NM-96943 was renegotiated on January 9, 1997, and is extended to April 9, 2000. This permit will be allowed to expire and the area will undergo reclamation in accordance with mining plans. (See section 17.3 .9 below.)

A right-of-way permit for a high-volume air sampler has also been issued to WIPP. Because the permit was issued by the New 
Mexico Commissioner of Public Lands, it is discussed in more detail in section 34.3 herein.

\subsection{Compliance Status of the Permit Conditions}

The following text provides more detail on the compliance status of each right-of-way reservation or temporary-use permit awarded to WIPP by the BLM.

\subsubsection{Common Conditions of the Right-of-Way Reservations}

Several conditions are common to all the right-of-way reservations awarded to WIPP by the BLM. These common conditions are:

(1) That the subject of the reservation be under the control and jurisdiction of the DOE;

(2) That right of access and use is reserved to DOE personnel and those authorized by DOE and to BLM personnel and their authorized permittees, licensees, and leasees;

(3) That any products or resources on lands within the right-ofway remain under the jurisdiction of the issuing agency;

(4) That all applicable regulations under 43 CFR 2800 be followed; and

(5) That seeding requirements received mutual concurrence of the BLM and DOE.

The subjects of each of the right-of-way reservations are under the control and jurisdiction of the DOE. Right of access and use of these structures is reserved to the DOE and the BLM and their authorized personnel.

In October 1992, the WIPP LWA was passed. This legislation transferred administrative responsibility for WIPP lands from the U.S. Department of the Interior to the DOE. These lands were also withdrawn from all forms of entry, appropriation, and disposal under the public land laws, including the mineral leasing laws (subject to existing, valid rights).

The applicable portions of 43 CFR 2800 and the compliance status of each are described in sections 17.2.4 through 17.2.6 above.

Reclamation of disturbed areas is an ongoing activity at WIPP and is performed as described in the LMP. Seeding is conducted in accordance with the requirements for the BLM Roswell District. 


\subsubsection{Right-of-Way Reservation No. NM 53809, Water Pipeline}

The conditions specified for the water pipeline right-of-way reservation are described in this section, along with the compliance status of each condition.

The reservation was awarded on August 17, 1983, and extends to perpetuity.

17.3.2.1 Preconstruction and Construction Conditions for the Water Pipeline, section 13 and Standard Stipulation Nos. 1, 2, 5, 6, 8

Preconstruction notification and conditions for construction (e.g., minimization of blading and clearing of vegetation; protection of scenic values; permits; livestock barriers) were specified in the right-of-way reservation and in the Standard Stipulations for Pipeline and Underground Cable Rights of Way in the Roswell District, BLM.

All conditions were met when the water pipeline was constructed.

\subsubsection{Livestock Water, Section 13.E}

The DOE has agreed to provide water access (taps) off the waterline for livestock in the area. The DOE will also provide water meters and all necessary materials, equipment, and labor to install new water troughs in the four sections specified.

The DOE installed water taps on the water pipeline for use by ranchers.

\subsubsection{Road Construction, Standard Stipulation No. 3}

Roads will not be constructed where terrain features allow vehicles to maneuver without the aid of such construction. All vehicular traffic and construction activities will be confined to the authorized right-of-way.

No roads have been constructed where the terrain allows vehicles to maneuver adequately. All traffic is confined to the authorized right-of-way.

17.3.2.4 Gates or Cattle Guards on Public Lands, Standard Stipulation No. 7

Gates or cattle guards on public lands will not be locked or closed to the public.

Gates and cattle guards on public lands are not locked and remain open to the public. 


\subsubsection{Right-of-Way Reservation No. NM 55676, North Access Road}

The conditions specified for the North Access Road right-of-way reservation are described in this section, along with the compliance status of each condition. Since the road was built approximately ten years ago, the conditions required for its construction are not discussed individually. This reservation was awarded on August 24, 1983, and extends to perpetuity.

\subsubsection{Polychlorinated Biphenyls, Standard Stipulation No. 2}

Any PCB shall be used in a totally enclosed manner in accordance with the provisions of the Toxic Substances Control Act. Any release of PCB in excess of the $R Q$ shall be reported as required under the Comprehensive Environmental Response, Compensation, and Liability Act, with a copy of any report required by the federal or state agency being provided to the Authorized Officer within five working days of the occurrence of the spill or release.

As described in Chapter 9 herein, all PCB-containing equipment and fluids have been removed from the WIPP site and have been disposed of in accordance with the regulations. No PCBs are allowed on site. No release or spill of PCBs or PCBcontaining fluids is known to have ever occurred at WIPP. Therefore, these conditions do not apply at WIPP.

If an incident involving PCBs were to happen on a right-of-way within the WIPP boundary, the New Mexico State Police would respond and provide the proper notifications.

17.3.3.2 Standard Stipulations for the Construction of Overhead Electric Distribution Lines, Standard Stipulation Nos. 3 through 5

Upon DOE's request, BLM authorized the DOE to install an auxiliary electrical line and 10-13 poles along the right-of-way for the North Access Road. This authorization was accompanied by standard stipulations for overhead electrical distribution lines in the Roswell District. The standard stipulations for the construction of power lines included a prohibition of clearing or blading of the right-of-way unless agreed to in writing by the Authorized Officer, construction of the power lines to ensure the safety of raptors, and minimization of damage to existing fences and other improvements on public lands.

All stipulations for the construction of power lines were met. 
17.3.3.3 Posting of BLM Serial Number, Standard Stipulation No. 6

The BLM serial number assigned to this authorization (i.e., NM 55676) shall be posted in a permanent, conspicuous manner where the power line crosses roads and at all serviced facilities. Numbers must be at least 2 inches high and will be affixed to the pole nearest the road crossing and at the facilities served.

The BLM Serial Number (NM 55676) is posted as required.

17.3.3.4 Actions Required upon Abandonment, Relinquishment, or Expiration of Right-of-Way Reservation, Terms/Conditions, Nos. 7 and 8

Upon cancellation, relinquishment, or expiration of the reservation, the holder of the reservation will comply with those abandonment procedures prescribed by the BLM Authorized Officer. All surface structures (poles, lines, transformers, etc.) will be removed within 180 days of abandonment, relinquishment, or termination of use of the reservation or of the use of the serviced facility or facilities. This will not apply where the power line extends service to an active adjoining facility or facilities.

These conditions will be met upon termination of the reservation or abandonment of the site by the DOE.

\subsubsection{Fencing, Amendment (April 22, 1988)}

The DOE requested that it be allowed to install fencing on the east and west sides of the WIPP North Access Road for a distance of 12.125 miles to allow for a safe travel route when entering or leaving the site via Highway 62/180. The BLM allowed this installation, subject to the BLM fencing standards.

The BLM fencing standards were met in installing the fence along the North Access Road.

\subsubsection{Right-of-Way Reservation No. NM 55699, Railroad}

The conditions specified for the railroad right-of-way reservation are described in this section, and the compliance status of each condition is given. Since the railroad spur at WIPP was constructed a number of years ago, the conditions pertaining to the construction of the spur are not discussed individually.

This right-of-way reservation was awarded on September 27, 1983, and extends to perpetuity. 
17.3.4.1 Preconstruction and Construction Requirements for the Railroad Spur, Standard Stipulation Nos. 1 through 4, 7 through 9, and 11

The preconstruction and construction conditions for the railroad spur were listed in the "Special Stipulation for WIPP Railroad Access." These conditions include preconstruction notification and a prework conference, notification of any anticipated changes, notification of grazing permittees or lessees prior to entering public lands on grazing allotments, barriers and fences for livestock, road or stock trail crossings, mitigation of cultural resources, and installation of fences.

Agreement was reached among members of the BLM, the DOE, and the Army Corps of Engineers with respect to the DOE's meeting all preconstruction and construction requirements.

17.3.4.2 Reseeding upon Completion of Construction, Standard Stipulation No. 5

The right-of-way must be reseeded upon completion of railroad construction according to BLM seeding requirements for the Roswell District.

The right-of-way was reseeded upon completion of railroad construction in accordance with the BLM seeding requirements for the Roswell district.

17.3.4.3 Abandonment of the Site, Standard Stipulation No. 6

If the WIPP is abandoned for any reason, the railroad bed will be ripped and returned as much as possible to its original terrain.

The area will be reseeded as discussed in section 17.3.4.2 above.

If the site is abandoned, these actions will be conducted. Until such time, these conditions are not applicable.

\subsubsection{Access to Water for Livestock, Standard Stipulation No. 10}

The DOE will provide a water tap and a livestock watering facility in one section, a livestock drinker and related pipeline in a second section, and a water pipeline to tie into an existing water tub in a third. This action is separate and apart from the railroad reservation and will be implemented after completion of the Cooperative Agreement among the DOE, the BLM, and the rancher.

Water taps and related equipment have been provided by the DOE. (See also section 17.3.2.2 above.) 
17.3.4.5 Removal of Caliche and/or other Mineral Material, Standard Stipulation No. 12

The grantee and its subcontractor will remove caliche and/or other mineral material from BLM-approved sites only. The DOE will submit a pit development and rehabilitation plan to the BLM for its approval before removing any caliche.

An application for a free-use caliche permit was submitted to the BLM by the DOE. The permit was awarded by the BLM. (See also section 17.3.9 below.)

17.3.4.6 Application for Free-Use Permits, Standard Stipulation No. 13

The DOE will sign applications for BLM free-use permits for the borrowing of caliche, sand, gravel, and other construction materials in quantities that may be reasonably required for this project.

The DOE submitted an application to the BLM for a free-use permit for caliche. The permit was granted by the BLM. (See also section 17.3.9 below.)

17.3.4.7 Notification of the BLM Regarding the Access Road Parallel to the Railroad, Amendment

An access road parallel to the railroad was deemed necessary. Since the existing access road, constructed in conjunction with the railroad, is located within 75 feet of the railroad centerline (i.e., within the railroad right-of-way), no new right-of-way was required. However, notification to the BLM was needed.

The BLM was notified as specified.

\subsubsection{Right-of-Way Reservation No. NM 63136, Dosimetry and Aerosol Sampling Sites}

The conditions specified for the right-of-way reservation for the aerosol sampling sites are described in this section, along with the compliance status of each condition. The reservation was awarded on July 31, 1986, and amended in August 1988. The reservation is to remain in effect for 25 years (i.e., until July 31, 2011).

17.3.5.1 Establishment of Dosimeter Stations and Air Samplers, Attachment A

The reservation allowed the installation of 21 thermoluminescent dosimeters and four aerosol sampling stations at 20 and two locations, respectively. The DOE and its operating contractor are technically and financially responsible for the installation, maintenance, and operation of these monitoring systems. 
Air samplers have been installed, and MOC personnel operate and maintain the monitoring system. The environmental dosimetry program that used the thermoluminescent dosimeters was discontinued in 1990 on the basis of two studies performed: one internally; the other by University of Michigan personnel for the Environmental Evaluation Group. Both studies concluded that the environmental dosimetry program could be discontinued because it is much less sensitive than other sampling programs used at WIPP.

\subsubsection{Air Monitoring and Data Collection Site, Amendment \\ Right-of-way reservation No. 63136 was modified to allow an air monitoring and data collection site.}

An instrumentation trailer ( 8 feet by 16 feet), a 10 -meter-tall meteorological tower, and various environmental monitoring instruments were installed as agreed to between the $\mathrm{DOE}$ and the BLM. The installation required clearing an area of vegetation, constructing a concrete foundation for the trailer and tower, burying instrumentation wires, and constructing an access road. The 0.25 -acre area was enclosed by a chainlink security fence as specified in the request to amend the right-of-way reservation.

\subsubsection{Right-of-Way Reservation for Subsidence Monuments, No. NM 65801}

No unique conditions were specified for the right-of-way reservation for seven geological subsidence monuments. Therefore, only the common conditions described in section 17.3.1 above apply and have been met.

The right-of-way reservation was awarded on November 7, 1986. It is to be held in perpetuity.

\subsubsection{Right-of-Way Reservation for Two Survey Monuments, No. NM 82245}

The conditions of the right-of-way reservation for two survey monuments are described in this section, along with the compliance status of each condition.

The reservation was granted on December 13,1989 . It has a 30 -year term and is renewable.

\subsubsection{Construction and Maintenance of the Monuments, 1}

The monuments will be constructed and maintained in accordance with the details specified in the application submitted on December 4, 1989.

Two concrete survey monuments were installed on the right-of-way. The monuments are approximately 18 inches in diameter and 36 inches deep. Installation of the monuments was performed as described in the application. 
17.3.7.2 Security and Maintenance of the Monuments, 3

The DOE is responsible for the security and maintenance of the monuments.

The DOE is responsible for the security of the monuments. The MOC maintains the monuments under contractual authority from the DOE.

\subsubsection{Rehabilitation of the Land, 5}

Upon cancellation or termination of this reservation, the DOE will rehabilitate the land. All structures, improvements, debris, etc., will be removed. All disturbed surfaces will be reseeded in accordance with BLM specifications using Seed Mixture 2.

Upon cancellation or termination of this right-of-way reservation, the DOE will ensure that the land is rehabilitated as specified. All structures, improvements, and debris will be removed and all disturbed surfaces reseeded with pure live seed (Seed Mixture 2) containing no weeds as specified in the BLM Seeding Requirements in the Roswell District. Until the reservation is canceled or terminated, these conditions are not applicable.

\subsubsection{Right-of-Way Reservation for an Aerosol Sampling Site, No. NM 77921 (NM 77860)}

The conditions for the right-of-way reservation for an aerosol sampling site are discussed in this section, along with the compliance status of each condition. Right-of-way reservation No. NM 77921 was granted on August 18, 1989. (It was originally granted as No. NM 77860, but the number had already been issued and was subsequently changed.) The reservation was made for a 30 -year term and is renewable.

\subsubsection{Construction, Operation, and Maintenance, 1}

The facility will be constructed, operated, and maintained in accordance with the details specified in the application submitted on July 31, 1989.

The application (dated July 13,1989 ) specified that a 6 -foot metallic stand would be positioned on an existing concrete pad, an electrical hookup would be made to an existing power line, and a chain-link security fence would be emplaced. It also indicated that the monitoring station would be used throughout the life of the project and would be operated throughout each year of the project. These conditions have been met. 
17.3.8.2 Security and Operation of the Aerosol Sampling Station, 3

The DOE will be responsible for the security and day-to-day operation of the facility.

The DOE is responsible for the security of the aerosol sampling station, and MOC personnel operate and maintain the station under contractual authority from the DOE.

\subsubsection{Rehabilitation of the Land Occupied by the Aerosol Sampling Station, 5}

The conditions specified (and the response to the conditions) are identical to those described in section 17.3.7.3 above. See this section for specific information pertaining to rehabilitation of the land upon cancellation or termination of a right-of-way reservation.

\subsubsection{Use of the Abandoned Concrete Slab}

A concrete slab was present at the location of the right-of-way land. The slab had been owned by the El Paso Natural Gas Company. Cognizant MOC personnel requested the use of the slab for radiation monitoring. El Paso Natural Gas Company personnel stated that the slab could be used if their personnel in Jal, New Mexico, were notified prior to initiating construction and if the BLM gave its consent.

Discussions were held with personnel from the El Paso Natural Gas Company. No additional conditions were specified, and notifications were made as requested by El Paso Natural Gas.

The BLM's issuance of this right-of-way reservation constitutes its implied approval of use of the concrete slab.

\subsubsection{Caliche Free-Use Permit, NM-96943}

The conditions specified under this permit are discussed in this section, and the compliance status of each condition is given. The Caliche Free Use Permit was renegotiated January 9, 1997, and extended to April 9, 2000. This permit will be allowed to expire. Reclamation contingencies still apply.

17.3.9.1 Reclamation of the Caliche Borrow Pit

Upon completion of its withdrawal of caliche from the caliche borrow pit, the DOE will perform reclamation and other closure activities, including reseeding, as specified under the permit. 
WIPP and BLM personnel have agreed that the only closure activity to be performed by the DOE is to recontour the slope of the withdrawal area to a 3:1 slope. The DOE is solely responsible for caliche pit reclamation. 
This page intentionally left blank. 


\subsection{PUBLIC RANGELANDS IMPROVEMENT ACT}

\subsection{Summary of the Law}

Congress has recognized that vast segments of public rangelands produce less than their potential for livestock, wildlife habitat, recreation, forage, and water and soil conservation benefits. The 1978 Public Rangelands Improvement Act (43 U.S.C. $\S \S 1901$, et seq.) was enacted to address the concerns that such rangelands could remain in such an unsatisfactory condition and that some areas could decline further under existing levels of management.

With the passage of this act, Congress reaffirmed a national policy and commitment to:

$\bullet$

•

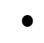

Inventory and identify current public rangeland conditions and trends;

Manage, maintain, and improve the condition of public rangelands so that they become as productive as is feasible; and

Continue the policy of protecting wild free-roaming horses and burros while facilitating the removal and disposal of excess wild free-roaming horses and burros that pose a threat to themselves, their habitat, and other rangeland values.

This policy and commitment are echoed in other statutes that address public land use and management. One such act, FLPMA, directs the Secretary of the Interior to prepare and maintain an inventory of all public lands and to develop and maintain landuse plans with public involvement regardless of whether the public lands have been classified as withdrawn, set aside, or otherwise designated (see Chapter 17 herein). Another statute, the LWA, transferred jurisdiction over, and statutory authority and responsibility for, the management of the withdrawn lands at WIPP from the Department of the Interior to the DOE. Section 4 of the LWA, Establishment of Management Responsibilities, directs the DOE to conduct the management of grazing consistent with such laws as the Public Rangelands Improvement Act, the Taylor Grazing Act (Chapter 19 herein), the LWA, and other applicable laws such as Title IV, "Range Management," of the FLPMA (Chapter 17 herein).

The implementing regulations under Subchapter D, Range Management, 43 CFR 4100, "Grazing Administration - Exclusive of Alaska," provide uniform guidance for the administration of grazing on public lands. The objectives of these regulations include the following: orderly use, improvement, and development; enhancement of productivity by prevention of overgrazing and soil deterioration; and provision of inventory and categorization of public rangelands on the basis of range conditions and trends. The regulations specify that grazing on administered public lands must be managed in accordance with applicable land-use plans. These plans must set forth program constraints and the general management practices needed to achieve the management objectives. 


\subsection{Compliance Status of the Regulatory Requirement}

The text discusses the compliance status of the Public Rangelands Improvement Act requirements in more detail.

\subsubsection{Land Use Plans, 43 CFR $§ 4100.0$ through 4100.8}

Grazing on administered public lands shall be managed under the principle of multiple use and sustained yield and must be in accordance with the applicable land-use plan.

As addressed in the WIPP LMP, the DOE's intent is to continue current rangemanagement practices with no immediate changes. Grazing will continue on the withdrawn lands as it has since the inception of the WIPP project. Range-management plans include (1) continued management of two affected grazing allotments under multiple-use management and sustained yield; (2) continued vegetative monitoring, which will include collecting data on actual livestock use, wildlife use, and degree of use of key forage species; and (3) continued monitoring studies to determine range condition and trends. In accordance with the LMP, the BLM will administer all range management activities. 


\subsection{TAYLOR GRAZING ACT}

\subsection{Summary of the Law}

Although the United States does not and cannot hold property for private or personal purposes, it controls public lands under constitutional grant, acting through Congress. Control over public lands is in the hands of Congress; with this power, Congress may prohibit or fix the terms under which public lands may be used.

The Taylor Grazing Act of 1934 (43 U.S.C. §§ 315 et seq.) was enacted by Congress for the purpose of establishing a means for federal management of public lands used for grazing. The intent of Congress was to aid the livestock industry by defining grazing rights and to protect these rights by regulation. This act is intended to prohibit injury to public grazing lands from unregulated grazing and directs the orderly use of and improvement to public grazing lands by establishing grazing districts and a grazing permit system.

The LWA withdrew public lands and transferred jurisdiction over WIPP site lands from the Department of the Interior to the DOE. As a result of the LWA, the DOE was given statutory authority and responsibility for the management of the withdrawn land consistent with FLPMA (see Chapter 17 herein), the LWA, and other applicable laws such as the Taylor Grazing Act. Under the LWA, the DOE may allow grazing to continue where it was established before the enactment of the LWA, consistent with the applicable implementing regulations of the Taylor Grazing Act such as 43 CFR 4100, "Grazing Administration - Exclusive of Alaska," although the BLM continues to administer the grazing permit program and collects the grazing fee. The WIPP withdrawal area affects two grazing allotments (i.e., land designated and managed for the grazing of livestock).

The implementing regulations of 43 CFR 4100 provide uniform guidance for the administration of grazing on public lands, exclusive of Alaska. The objectives of these regulations are as follows: orderly use, improvement, and development of public grazing lands; enhancement of grazing land productivity by the prevention of overgrazing and soil deterioration; stabilization of the livestock industry dependent upon the public range; and provision of inventory and categorization of public rangelands on the basis of range conditions and trends. These objectives must be consistent with land-use plans, multiple-use, sustained yield, environmental values, and other general objectives as stated by the Taylor Grazing Act.

\subsection{Compliance Status of the Regulatory Requirements}

The text gives more detail on the compliance status of each requirement under the Taylor Grazing Act. 


\subsubsection{Land Use Plans, 43 CFR $\$ 4100.0$ through 4100.8}

Grazing on public lands shall be managed under the principles of multiple use and sustained yield in accordance with applicable land-use plans.

In accordance with the LMP, the BLM will ensure that range management activities are carried out under the authority of the Taylor Grazing Act of 1934, FLPMA (Chapter 17 herein), and the Public Rangelands Improvement Act (Chapter 19 herein). The principles of multiple use and sustained yield are basic to the management of these activities. The DOE's intent is to continue current management practices with no immediate changes in current operations. (See also section 18.2.1 herein.)

\subsubsection{Allotment Management Plans, 43 CFR § 4120.2}

An allotment management plan shall be prepared in careful and considered consultation, cooperation, and coordination with BLM personnel, the landowners involved, the district grazing advisory board, and any other affected interests.

The WIPP withdrawal area affects two grazing allotments administered by the BLM: the Livingston Ridge and Antelope Ridge. Portions of both allotments lie within the withdrawal area. No formal grazing system has been implemented for the Livingston Ridge; however, a recent review by the BLM of actual-use data indicates that there is pasture rotation, with some pastures being rested for at least a portion of the growing season. The Antelope Ridge allotment is leased to a livestock rancher; in consultation with the BLM, an allotment management plan has been developed for this allotment. The plan includes a five-pasture rotation system, with some pastures being rested for full years and others receiving growing season rest. WIPP is contained within an area of 300 acres within the Antelope Range allotment that is posted against trespass and fenced to prevent grazing. The 277 -acre DOE Exclusive Use Area and 23 additional acres set aside for reclamation sites, storage yards, etc., are the only portions of the withdrawal area not currently used for livestock activity. 


\subsection{BALD AND GOLDEN EAGLE PROTECTION ACT}

\subsection{Summary of the Law}

The Bald and Golden Eagle Protection Act (16 U.S.C. § 668-668d) makes it unlawful to take (i.e., capture, kill, or destroy), possess, molest, or disturb bald eagles (Haliaeetus leucocephalus) and golden eagles (Aquila chrysaetos), alive or dead, their nests, or their eggs anywhere in the United States. A permit must be obtained from the Department of the Interior to relocate any nest that interferes with resource development or recovery operations. The Bald and Golden Eagle Protection Act is implemented by several parts under 50 CFR, Subchapter B, "Taking, Possession, Transportation, Sale, Purchase, Barter, Exportation, and Importation of Wildlife and Plants." These implementing regulations are found in 50 CFR $\S \S 13,17,21$, and 22.

The regulations in 50 CFR 13, "General Permit Procedures," provide uniform rules, conditions, and procedures for the application for, and the issuance, denial, suspension, revocation, and general administration of, all permits issued pursuant to 50 CFR Subchapter B. The provisions in this part are in addition to other regulations, such as the Migratory Bird Treaty Act (Chapter 21 herein) and the Endangered Species Act (Chapter 22 herein), and apply to all permits issued under these regulations, including 50 CFR $\S \S 17,21$, and 22.

The regulations of 50 CFR 17, "Endangered and Threatened Wildlife and Plants," which also implement the Endangered Species Act and are discussed in Chapter 22 herein, could apply to WIPP because of the potential for the presence of the endangered bald eagle. The regulations in this part outline permit requirements for activities involving endangered wildlife and identify those species of wildlife and plants recognized as endangered or threatened with extinction.

The purpose of the regulations in 50 CFR 21, "Migratory Bird Permits," is to supplement the general permit regulations of Part 13 of Subchapter B with respect to permits for the taking, possession, transportation, sale, purchase, barter, importation, exportation, and banding or marking of migratory birds. Section 21.22 of 50 CFR 21 outlines the requirements and procedures for the permits needed to band or mark bald and golden eagles. The requirements under 50 CFR 21 are discussed in Chapter 21 herein.

The purpose of the regulations in 50 CFR 22, "Eagle Permits," is to govern the taking, possession, and transportation of bald and golden eagles for scientific, educational, and depredation-control purposes and for the religious purposes of Indian tribes. The import, export, purchase, sale, and or barter of bald or golden eagles, their parts, nests, or eggs are not permitted by any regulation of Subchapter B.

\subsection{Compliance Status of the Regulatory Requirements}

The text provides more detail on the compliance status of the Bald and Golden Eagle Protection Act requirements. 


\subsubsection{Permit Application Procedures, 50 CFR § 13.11}

Applicants must submit separate applications for each permit on prescribed forms and must follow prescribed forwarding instructions.

At present, no bald or golden eagles are nesting on the WIPP site; however, individual eagles overwinter on WIPP lands. Overwintering eagles are provided considerations during determinations of all land-use actions. WIPP personnel will file an application for an eagle permit as required if the need for such a permit is perceived. Other permit requirements under 50 CFR 13, which would become applicable were a need to arise to disturb or relocate a bald or golden eagle, are discussed in Chapter 21 herein.

\subsubsection{General Permit Requirements, 50 CFR § 22.11}

No person shall take, possess, or transport any bald or golden eagle, living or dead, or the parts, nest, or eggs of such birds except as authorized under terms of a valid issued permit.

WIPP personnel will apply for a permit and will comply with the permit conditions if such a permit is ever needed.

\subsubsection{Permits to Take Golden Eagle Nests, 50 CFR § 22.25}

Persons desiring to take golden eagle nests during a resourcedevelopment or recovery operation must file a permit application in accordance with prescribed procedures. The nests may be taken only when they are inactive.

At present, no golden eagles are nesting on the WIPP site. If it becomes necessary to move or remove a golden eagle nest, a permit application will be filed. All permit conditions will be met, and the nest(s) will be moved only when inactive. 


\subsection{MIGRATORY BIRD TREATY ACT}

\subsection{Summary of the Law}

The Migratory Bird Treaty Act (16 U.S.C. $§ \S 703$ through 712 ) is intended to protect birds that have common migratory flyways between the United States and Canada, Mexico, Japan, and Russia. The act makes it unlawful "at any time, by any means or in any manner, to pursue, hunt, take, capture, kill, or attempt to take, capture, or kill . . . any migratory bird, any part, nest, or eggs of any such bird" unless specifically authorized by the Secretary of the Interior by direction or through regulations permitting and governing these actions. Although WIPP is not located within a major migration corridor, there is the potential for migratory birds to be present on WIPP lands.

The regulations in 50 CFR 13, "General Permit Procedures," provide uniform rules, conditions, and procedures for the application for and the issuance, denial, suspension, revocation, and general administration of all permits issued pursuant to $50 \mathrm{CFR}$ Subpart B, Taking, Possession, Transportation, Sale, Purchase, Barter, Exportation, and Importation of Wildlife and Plants. The provisions in this part are in addition to other regulations, including 50 CFR 17, 21, and 22, and apply to all permits issued under these regulations.

The regulations of 50 CFR 17, "Endangered and Threatened Wildlife and Plants," also implement the Migratory Bird Treaty Act and could apply to WIPP because of the potential for the presence of migratory endangered and threatened species of birds at WIPP. These regulations, discussed in Chapter 22 herein, outline the requirements for permits for activities involving endangered wildlife and identify those species of wildlife which are recognized as endangered or threatened with extinction.

Under the Migratory Bird Treaty Act, the DOE is required to consult annually with the U.S. Fish and Wildlife Service (FWS) with respect to impacts on migratory game birds ${ }^{2}$ and crows resulting from the hunting activities permitted on WIPP lands. Hunting privileges for the public within the withdrawal area will continue, except for the areas that are posted against trespass. These hunting activities, whether conducted out of or within the withdrawal area, are subject to regulations implementing the Migratory Bird Treaty Act (i.e., 50 CFR 20, "Migratory Bird Hunting"1), which regulate the harvest of migratory birds by specifying the mode of harvest, hunting seasons, possession limits, and so on. Furthermore, because certain migratory birds that have been federally recognized and listed as endangered or threatened, such as bald eagles and peregrine falcons, could be present on WIPP lands, the Bald and Golden Eagle Protection Act (Chapter 20 herein) and the Endangered Species Act (Chapter 22 herein) may also apply, along with their implementing regulations.

\footnotetext{
$2{ }^{1}$ Migratory game birds are migratory birds that belong to the following families: Anatidae (ducks, geese, brant, and swans); Columbidae (doves and pigeons); Gruidae (little brown cranes); Rallidae (rails, coots, and gallinules); and Scolopacidae (woodcock and snipe).
} 
The regulations in 50 CFR 21, "Migratory Bird Permits," supplement the general permit regulations of Part 13 of this subchapter with respect to permits for the taking, possession, transportation, sale, purchase, barter, importation, exportation, and banding or marking of migratory birds. The portion that is relevant to WIPP is $\S 21.22$, which outlines the requirements and procedures for obtaining permits to band or mark birds. Part 21 also provides certain exceptions to the permit requirements for public, scientific, or educational institutions and establishes depredation orders that provide limited exceptions to the Migratory Bird Treaty Act.

The purpose of the regulations in 50 CFR 22, "Eagle Permits," is to govern the taking, possession, and transportation of bald and golden eagles for scientific, educational, and depredation-control purposes and for the religious purposes of Indian tribes. Compliance with these regulations is discussed in Chapter 20 herein.

\subsection{Compliance Status of the Regulatory Requirements}

The compliance status of each of the applicable regulatory requirements under the Migratory Bird Treaty Act is summarized in the following text.

\subsubsection{Permit Application Procedures, 50 CFR § 13.11}

Applicants must submit a separate application on the prescribed form for each permit and must follow the prescribed forwarding instructions.

The prescribed information has been submitted to the FWS.

\subsubsection{Information Requirements for Permit Applications, 50 CFR § 13.12}

Applicants must provide current information such as organizational affiliation, reason(s) for the permit application, and certification of familiarity with 50 CFR 13.

The prescribed permit applications and supporting information have been submitted to the FWS.

\subsubsection{Display of Permit, 50 CFR $§ 13.44$}

Any permit issued under 50 CFR 13 will be displayed for inspection upon the request of the Director, his/her agent, or any other person that relies upon the existence of the permit.

The permits are permanently displayed on the door of the freezer in which tissue samples are held at WIPP. 


\subsubsection{Filing of Reports, 50 CFR $\S 13.45$}

Recipients of a permit may be required to file reports of the activities conducted under the permit. Any such report must be filed by March 31 for the preceding calendar year ending December 31 or for any portion of the year during which the permit was in force.

Annual reports are submitted to the FWS.

\subsubsection{Maintenance of Records, 50 CFR $\S 13.46$}

From the date of issuance of a permit, the recipient of the permit must maintain complete and accurate records of any taking, possession, transportation, sale, purchase, barter, exportation, or importation of plants obtained from the wild or wildlife covered under the permit. The records must be kept current and must include the names and addresses of any persons involved in the transfer of the plant or wildlife as well as the date of the transaction and any other appropriate information. The records must be legible or reproducible and written in English and must be maintained for 5 years from the date of expiration of the permit.

All applicable records are held for at least five years from the date of expiration of the permit.

\subsubsection{Inspection Requirement, 50 CFR § 13.47}

Any person holding a permit under this subpart shall allow the Director's agent to enter his/her premises at any reasonable hour to inspect any wildlife or plant held or to inspect, audit, or copy any permits, books, or records required under Subpart $B$.

The Director's agent has not yet requested such an inspection. Should an inspection be requested, full cooperation will be given.

\subsubsection{Compliance with Permit Conditions, 50 CFR § 13.48}

Any person holding a permit under this subpart or acting under the authority of the permittee must comply with all conditions of the permit and with all applicable laws and regulations governing the permitted activity.

Conditions described in the permit have been met. See also section 21.2.12 below. 


\subsubsection{Acceptance of Liability, 50 CFR $\S 13.50$}

Any person holding a permit under Subpart B assumes all liability and responsibility for the conduct of any activity conducted under the authority of the permit.

The MOC personnel responsible for the management of the permits granted under Subpart B at WIPP are fully aware of their liabilities and assume responsibility for their activities.

\subsubsection{Compliance with Applicable Migratory Bird Hunting Regulations, 50 CFR 20, Subpart C}

Hunters of migratory game birds must comply with open-season requirements, including the avoidance of prohibited hunting methods.

Hunting privileges for the public will continue within the withdrawal area, except in areas posted against trespass, in accordance with applicable hunting regulations.

\subsubsection{Application for Banding or Marking Permit, 50 CFR § 21.22(a)}

Persons intending to capture migratory birds for banding or marking must have obtained a permit acquired in accordance with prescribed permit regulations.

All appropriate permits are maintained as the need arises.

\subsubsection{Additional Permit Conditions, 50 CFR § 21.22(c)}

In addition to the general permit conditions described in 50 CFR 13 [see sections 21.2.1 through 21.2.8 above], the following conditions will be met:

- Only official numbered leg bands issued by the Fish and Wildlife Service will be used to band migratory birds.

- All traps or nets used to capture migratory birds for banding or marking will have a tag attached with the name and address of the permittee and the permit number.

- $\quad$ The holder of a permit may salvage birds killed or found dead. All such dead birds salvaged under the authority of a banding or marking permit must be donated and transferred to a public, scientific, or educational institution at least every six months or within 60 days of the expiration or revocation of 
the permit unless a special permit that authorizes possession

for a longer period of time has been issued.

- $\quad$ The permittees must keep accurate records of their operations and must file reports as required.

The additional permit conditions are met at WIPP.

\subsubsection{Term of Permit, 50 CFR § 21.22(d)}

The term of a banding or marking permit shall not exceed three years from the date of issuance or renewal. The expiration date is designated on the permit unless the permit has been amended or revoked.

All appropriate permits are maintained as the need arises.

\subsubsection{Special-Purpose Permits, 50 CFR § 21.27}

Permits may be issued for special-purpose activities related to migratory birds or their parts, nests, or eggs that are otherwise outside the scope of the standard permits of this part.

No special-purpose permits have been needed at WIPP to date. Should such a permit become necessary, all appropriate requirements will be met as specified under this section.

\subsubsection{Falconry Permits, 50 CFR § 21.28}

A falconry permit is required before any person may take; possess; transport; sell; purchase; barter; or offer to sell, purchase, or barter raptors for falconry purposes.

No falconry activities are anticipated at WIPP. Therefore, this permit is not applicable.

\subsubsection{Depredation Permits, 50 CFR § 21.41}

A depredation permit is required before any person may take, possess, or transport migratory birds for depredation control.

No need for a depredation permit to control migratory birds is anticipated at WIPP. Therefore, this permit does not apply. 
This page intentionally left blank. 


\subsection{ENDANGERED SPECIES ACT}

\subsection{Summary of the Law}

The Endangered Species Act (16 U.S.C. §§ 1531 et seq.) was enacted in 1973 to prevent the extinction of certain species of animals and plants. This act provides strong measures to help alleviate the loss of species and their habitats and places restrictions on a wide range of activities involving endangered and threatened animals and plants to help ensure their continued survival. With limited exceptions, this act prohibits activities that could potentially impact these protected species unless authorized by a permit from the FWS. Under section 1536 of the act and the implementing regulations in 50 CFR 402, "Interagency Cooperation--Endangered Species Act, as Amended," the EPA is prohibited from authorizing activities likely to jeopardize the continued existence of any threatened or endangered species or its critical habitat. A biological assessment and "formal consultation," followed by the issuance of a "biological opinion" by the FWS, may be required for any species that is determined to be in potential jeopardy.

The DOE consulted with the FWS in 1979 to determine the presence of threatened or endangered species at or near the WIPP site. At that time, the FWS listed the Lee pincushion cactus (Coryphantha sneedi var. Leel), the black-footed ferret (Mustela nigripes), the American peregrine falcon (Falco peregrinus anatum), and the bald eagle (Haliaeetus leucocephalus) as threatened or endangered species that could occur on lands within or outlying the WIPP site. However, no critical habitat for endangered species was identified at WIPP. In 1989, the DOE again consulted with the FWS to update the list of threatened and endangered species. The agency has advised the DOE that the list of species provided in 1979 is still valid.

During 1989, the DOE consulted with the New Mexico Department of Game and Fish (NMDG\&F) regarding the state-listed endangered species in the vicinity of WIPP. Based on NMDG\&F Regulation 657, dated January 9, 1988, the NMDG\&F listed seven birds and one reptile in one of two endangerment categories that occur or are likely to occur at the site.

During 1995, the FWS transmitted the April 24, 1995, updated list of threatened and endangered species (to include Notice of Review) for Eddy and Lea Counties, New Mexico. Inclusive were approximately 18 species that occur or are likely to occur on WIPP lands. Accordingly, the list was distributed to pertinent WIPP departments for consideration and incorporation into applicable documents. The DOE currently operates under the assumption that activities associated with the operation of WIPP will have no impact on any threatened or endangered species. Considerations pertaining to protected species are implemented in accordance with this management plan, during the deliberation and administration of projects conducted on WIPP lands.

To ensure that WIPP environmental protection programs are current in their consideration of sensitive and protected species, the 1996 Waste Isolation Pilot Plant Threatened and Endangered Species Survey (DOE/WIPP 97-2228) was conducted 
from August to November 1996. No Threatened or Endangered species were found within the WIPP LWA boundaries during the 1996 survey.

The regulations in 50 CFR 13, "General Permit Procedures," provide uniform rules, conditions, and procedures for the application for and the issuance, denial, suspension, revocation, and general administration of all permits issued pursuant to $50 \mathrm{CFR}$ Subchapter B, "Taking, Possession, Transportation, Sale, Purchase, Barter, Exportation, and Importation of Wildlife and Plants." The provisions in this part are in addition to other regulations and apply to all permits issued under them, including 50 CFR 17, 21, and 22.

The regulations of 50 CFR 17, "Endangered and Threatened Wildlife and Plants," implement the Endangered Species Act as well as the Bald and Golden Eagle Protection Act (see Chapter 20 herein) and could apply to WIPP because of the potential for the presence of the endangered animal and plant species identified above. The regulations in this part outline the requirements for permits for activities involving endangered wildlife and identify those species of wildlife and plants recognized as endangered or threatened with extinction.

Other federal regulations which implement the Endangered Species Act and which apply to WIPP include the implementing regulations in 50 CFR 21 and 22 . The purpose of the regulations in 50 CFR 21, "Migratory Bird Permits," is to supplement the general permit regulations of Part 13 of Subchapter B with respect to permits for the taking, possession, transportation, sale, purchase, barter, importation, exportation, and banding or marking of migratory birds, including those listed as threatened or endangered. Compliance with these regulations is discussed in Chapter 21 herein.

The regulations in 50 CFR 22, "Eagle Permits," govern the taking, possession, and transportation of the endangered bald eagle for scientific, educational, and depredationcontrol purposes and for the religious purposes of Indian tribes. Requirements under these regulations are discussed in Chapter 20 herein.

\title{
22.2 Compliance Status of the Regulatory Requirements
}

The text gives more detail on the compliance status of each requirement under the Endangered Species Act.

\subsubsection{Permit Application Procedures, 50 CFR § 13.11}

\author{
Applicants must submit separate applications for each permit on \\ prescribed forms and must follow prescribed forwarding \\ instructions.
}

No activities involving endangered species are conducted at WIPP; therefore, no permit is required. Other requirements related to permits under 50 CFR 13, which would become applicable only if activities involving endangered species were initiated, are summarized and discussed in Chapter 21 herein. 


\title{
22.2.2 Application for Endangered or Threatened Species Permit, 50 CFR $\S \S 17.22$ (a)(1), 17.32, 17.52, and 17.62
}

Applicants for permits for using endangered or threatened species of wildlife or plants for scientific purposes, enhancement of propagation or survival, or for incidental taking must submit an application as prescribed.

To date, taking endangered or threatened wildlife or plants for these purposes, which would require a permit from the FWS, has not been necessary. It is not expected that such a permit will be needed in the future.

\subsubsection{Biological Assessment of Impacts on Recognized Species, 50 CFR § 402.12}

\begin{abstract}
A biological assessment may be required to determine whether construction activities will jeopardize the continued existence of endangered species or the critical habitat of any such species.
\end{abstract}

On May 29, 1980, the FWS determined that construction of WIPP would have no adverse impacts on recognized endangered or threatened species. In addition, no critical habitat for terrestrial endangered species has been identified at the WIPP site. Consequently, no biological assessment has been required for WIPP.

\subsubsection{Formal Consultation with the FWS Regarding Impacts on Recognized Species, 50 CFR § 402.14}

Formal consultation with the FWS to determine whether construction activities will jeopardize the continued existence of endangered species or its critical habitat is required.

On May 29, 1980, the FWS determined that construction of WIPP would have no adverse impacts on recognized endangered or threatened species. In addition, no critical habitat for terrestrial endangered species has been identified at the WIPP site. Consequently, no formal consultation has been required for WIPP. 
This page intentionally left blank. 


\subsection{NATIONAL HISTORIC PRESERVATION ACT}

\subsection{Summary of the Law}

The National Historic Preservation Act (NHPA; 16 U.S.C. $\S \S 470$ et seq.) was enacted to protect the nation's cultural resources in conjunction with the states, local governments, Indian tribes, and private organizations and individuals. The policy of the federal government includes (1) providing leadership in preserving the prehistoric and historic resources of the nation; (2) administering federally owned, administered, or controlled prehistoric resources for the benefit of present and future generations; (3) contributing to the preservation of nonfederally owned prehistoric and historic resources; and (4) assisting state and local governments and the National Trust for Historic Preservation in expanding and accelerating their historic preservation programs and activities. The act also established the National Register of Historic Places (National Register). At the state level, the State Historic Preservation Officer (SHPO) coordinates the state's participation in implementing the NHPA.

Section 106 of NHPA requires that a federal agency head who has jurisdiction over a federal, federally assisted, or federally licensed undertaking take into account the effects of the agency's undertaking on historic properties included in or eligible for the National Register. Furthermore, the "section 106 process" requires that the federal agency head afford the Advisory Council on Historic Preservation (the Council) a reasonable opportunity to comment on the undertaking prior to initiating the undertaking. Through the section 106 process, the Council seeks to accommodate historic preservation concerns with the needs of federal undertakings. The Council encourages this accommodation through consultation among the federal agency, the SHPO, and other interested parties during the early stages of planning.

The NHPA has been amended by two acts. The Archaeological and Historic Preservation Act (16 U.S.C. $\S \S 469$ et seq.) directs federal agencies to recover and preserve historic and archaeological data that would otherwise be lost as a result of federal construction or program activities. This statute applies to known cultural resources on the WIPP lands or those which may be recorded in the future.

The other act amending the NHPA is the Archaeological Resources Protection Act (16 U.S.C. $\S \S 470$ aa et seq.). This statute sets forth the requirements for obtaining a permit from the Department of the Interior for the excavation or removal of archaeological resources from public or Indian lands. The act's implementing regulations in 43 CFR 7, "Protection of Archaeological Resources," establish uniform definitions, standards, and procedures to be followed by all federal land managers in providing protection for archaeological resources located on public lands. The statute and regulations apply to known cultural resources on WIPP lands or those that may be recorded in the future.

The NHPA's implementing regulations in 36 CFR 800, "Protection of Historic and Cultural Properties," contain provisions for the development of a treatment plan by a 
federal agency that identifies historic properties likely to be discovered during the implementation of an undertaking and how they will be managed.

Since 1976, cultural resource investigations have recorded 60 archaeological sites and 91 isolated occurrences within the 16-square-mile WIPP site boundary. The exact number of sites within the WIPP site boundary was confirmed with the completion of a comprehensive archaeological database created in July 1994. During the creation of the database some inconsistencies were discovered with regard to the number of archaeological sites, eligible and ineligible for inclusion in the National Register, reported to exist within the WIPP land withdrawal area. Some sites previously included as "WIPP archaeological sites" are located within the outer perimeters of WIPP's Control Zone IV. When the WIPP site was configured to the present 16-section square, much of Control Zone IV reverted to the management of the Department of the Interior. Therefore, the archaeological sites located in those areas are no longer the responsibility of the DOE.

In 1997, the DOE officially entered into a Joint Powers Agreement with agencies from the state of New Mexico. One of the participating agencies is the SHPO. Commitments by both respective agencies are established in the agreement with regard to notification time lines. In addition, the agreement reiterates the DOE obligation to manage cultural resources in accordance with sections 106 and 110 of the National Historic Preservation Act, the Archaeological Resource Protection Act, Native American Graves Protection and Repatriation Act, and applicable DOE orders.

\subsection{Compliance Status of the Regulatory Requirements}

The text summarizes the regulatory requirements and their compliance status under the NHPA.

\subsubsection{Assessment of Effects on Historic Properties, 36 CFR $\S 800.5$}

In consultation with the SHPO, the federal agency official with jurisdiction over an undertaking is responsible for assessing the effect of an undertaking on affected historic properties, obtaining the SHPO's concurrence when the effect is not considered adverse, and notifying and submitting summary documentation to the Council.

The DOE submitted documentation to the New Mexico SHPO describing excavation activities and the avoidance of any potential historical sites. A determination of No Adverse Effect from WIPP activities on historic properties was made by the SHPO in May 1980. This determination was applicable for the primary construction activities associated with the development of WIPP. Similar documentation was submitted to the Council. Since the 1980 determination, the DOE has evaluated minor construction activities in previously undisturbed areas for potential impacts to cultural resources. New surface disturbing activities are evaluated by a licensed, permitted archaeologist and approval is obtained from the SHPO prior to allowing the action to proceed. 


\subsubsection{Development of a Plan for the Treatment of Historical Property Discovered During a Federal Agency Undertaking, 36 CFR § 800.11}

After a determination by the federal agency official presiding over an undertaking that the potential for the discovery of historical property exists, the agency official may develop a plan for the treatment of such properties if discovered and include this plan in any documentation prepared to comply with 36 CFR $\S 800.5$.

A mitigation plan describing excavation activities at WIPP and the avoidance of historical sites was submitted to the New Mexico SHPO. A determination of No Adverse Effect from WIPP activities on cultural resources was made by the SHPO in May 1980. A similar mitigation plan was submitted to the Council. The Council concurred that the WIPP Mitigation Action Plan is appropriate to protect cultural resources.

The WIPP LMP also outlines objectives and planned actions for the management of cultural resources within the withdrawal area.

\subsubsection{Application for Permits and Information Collection, 43 CFR $§ 7.5$}

Any person proposing to excavate and/or remove archaeological resources from public lands and to carry out activities associated with such excavation and/or removal shall apply for a permit for the proposed work and shall not begin the proposed work until a permit has been issued.

Avoidance of known archaeological sites is the primary mitigation measure used at WIPP. During this reporting period no archaeological sites were excavated. 
This page intentionally left blank. 


\subsection{NEW MEXICO ENVIRONMENTAL IMPROVEMENT ACT}

\subsection{Summary of the Law}

The enactment of the New Mexico Environmental Improvement Act (EIA; §§ 74-1-1 through 74-1-10 NMSA [New Mexico Statutes Annotated] 1978) created the Environmental Improvement Board (EIB) to promulgate regulations and standards to protect health and safety and the environment. The Environmental Improvement Act also created the Environmental Improvement Division, now known as the NMED. The act directs the NMED to assume responsibility for environmental management and protection to demonstrate that environmental policy provides optimal health, safety, social, and economic well-being for the people of New Mexico. In carrying out its responsibilities, the NMED is directed to maintain, develop, and enforce regulations and standards in areas including water supply, liquid waste, air quality, radiation control, health and safety, hazardous wastes, and underground storage tanks. Many of these regulations and standards are applicable to WIPP. These include the Hazardous Waste Act and the implementing hazardous waste management and USTRs, the Solid Waste Act, the Ground Water Protection Act, the Air Quality Control Act, the Water Quality Act, and Water Supply Regulations.

\subsection{Compliance Status of the Law}

The DOE will continue to comply with all applicable New Mexico environmental regulations and standards as demonstrated in the following chapters. 
This page intentionally left blank. 


\subsection{NEW MEXICO HAZARDOUS WASTE ACT}

\subsection{Summary of the Law}

The purpose of the Hazardous Waste Act (HWA; §§ 74-4-1 through 74-4-14 NMSA 1978 ) is to ensure the maintenance of the quality of New Mexico's environment; to confer optimal health, safety, comfort, and economic and social well being on its inhabitants; and to protect the proper utilization of its lands. The HWA established the program for hazardous waste management and control in the state of New Mexico. Since its initial enactment in 1977, it has been amended substantially several times to make its provisions more consistent with the 1980 and 1984 amendments to RCRA (see Chapter 2 herein). The major provisions of the HWA were taken directly from Subtitles C ("Hazardous Waste Management") and I ("Regulation of Underground Storage Tanks") of the RCRA.

On January 11, 1985, New Mexico received authorization from the EPA to administer the base federal hazardous waste program, effective January 25, 1985. Additional authorizations that expanded the scope of the initial authorization were granted by the EPA and became effective on April 10, 1990; July 25, 1990; December 4, 1992; August 23, 1994; December 21, 1994; April 25, 1995; and January 2, 1996.

On January 2, 1996, the EPA provided an additional Final Authorization of State Hazardous Waste Management Program Revisions in the state of New Mexico. With this authorization the state was provided regulatory authority to implement the 1984 HSWA. The EPA published this final authorization in accordance with the requirements of 40 CFR $\S 271.21(\mathrm{~b})(3)$. With this authorization the EPA determined that the revisions to the New Mexico hazardous waste program met the requirements of section 3006(b) of the RCRA by demonstrating that the state program was equivalent to and consistent with the federal program, and that the state program provided adequate enforcement authority to implement the revised HSWA authority under RCRA.

Section 74-4-4.E of the HWA allows the Environmental Improvement Board to adopt federal hazardous waste management regulations by reference after public notice and public hearing. On January 11, 1991, New Mexico adopted the entire body of 40 CFR 260 through 266, and 268 through 270 of the EPA's regulations implementing Subtitle $\mathrm{C}$, with only a few substitutions and minor exceptions. With regard to the management of mixed waste, on July 11, 1990, the EPA published its acceptance of New Mexico's revised hazardous waste program, effective July 25, 1990. This authorization allows New Mexico to regulate the hazardous constituents of mixed waste under the revised HWA. The only exception to this authorization are regulatory changes made by the EPA subsequent to the authorization. Therefore, this authorization allows the state to regulate the hazardous constituents of the mixed waste to be sent to WIPP unless changes in the federal regulations have been made and not adopted by NMED.

On July 23, 1992, New Mexico submitted an application for additional program approvals. The EPA published an immediate final rule on October 5, 1992, in which the 


\section{Waste Isolation Pilot Plant Biennial Environmental Compliance Report}

DOE/WIPP 99-2171

decision was made to grant final authorization to New Mexico for the additional program modifications. The final authorization became effective on December 4, 1992.

Subsequent applications and approvals were done July 10, 1995, and January 21 , 1996.

Included in this section is a brief summary of the requirements of a set of implementing regulations, recently adopted by the NMED, for the management of "universal waste" (40 CFR 273), which apply to three post-consumer use wastes. The universal waste regulations established management requirements for spent batteries, recalled and unused pesticides, and mercury-containing thermostats. These regulations allow these items to be regulated as universal waste rather than hazardous waste. Under this program there is no requirement to notify the EPA of universal waste handling activities (40 CFR $\S 273.12$ ) or to track shipments of universal waste (40 CFR $\S 273.19$ ). In 1996, the state of New Mexico adopted these regulations into 20 NMAC 4.1, Subpart X. The adoption of these regulations was documented in the New Mexico Register, Vol. VII, No. 23, December 14, 1996. The WIPP site is a small-quantity handler of universal waste. The MOC manages nickel cadmium and lithium batteries at WIPP under these regulations. The WIPP site typically does not generate pesticide waste and rarely generates thermostat waste. Spent lead acid batteries sent for recycling are not managed under these regulations, instead the exemption located in 40 CFR $\S 266.80$ (20 NMAC 4.1 Subpart VII) is applied. Waste characterization and hazardous waste determinations have been completed for spent lead acid batteries as required by 40 CFR 261 and $\S 262.11$.

Regulations were promulgated with respect to organic emissions from containers, tanks, and surface impoundments. These regulations are found in 40 CFR Subpart CC - Air Emission Standards for Tanks, Surface Impoundments, and Containers. These regulations were implemented where applicable (40 CFR $\S 265.1080$ ) at WIPP during the reporting period. The regulations apply only to wastes containing VOCs above 500 ppm by weight that are stored in 90-day accumulation areas in containers greater than $0.1 \mathrm{~m}^{3}$ (26.4 gallons). Implementation of these regulations is required in the 90-day accumulation area per

40 CFR $\S 262.34(\mathrm{a})(1)(\mathrm{i})$. Implementation is not required in WIPP SAAs per 40 CFR $\S 262.34(\mathrm{c})(1)$. WIPP implements "Container Level 1 controls" by using only DOT-approved containers for storing all organic waste in the 90-day accumulation area at WIPP. Furthermore, the size of containers used for storing organic waste at WIPP is limited to $<0.46 \mathrm{~m}^{3}$. The MOC keeps containers appropriately closed in accordance with 40 CFR $\S 265.1087$ (c)(3). During the reporting period, organic waste was stored only in Level 1, DOT-approved containers.

The state's Hazardous Waste Management Regulations are applicable to WIPP in two different areas. First, WIPP is a generator of hazardous waste and is thus required to comply with the generator requirements of 40 CFR 262 (20 NMAC 4.1, Subpart III). As long as site generated hazardous wastes are sent to a permitted off-site TSDF within 90 days, no permit is required for the accumulation and storage of hazardous wastes. Second, WIPP is a disposal and storage facility for TRU mixed waste, which mandates that WIPP receive a hazardous waste facility operating permit. The permit for the 
disposal phase was issued by the NMED on October 27, 1999. Underground storage tanks are regulated under the New Mexico Underground Storage Tank Regulations (USTR), codified as 20 NMAC 5.

The New Mexico USTRs differ somewhat from the federal regulations specified in 40 CFR 280. These state regulations are also discussed in detail in this chapter (see section 25.2.7 below). The UST section includes the results of the environmental compliance assessment that was performed for the UST program at WIPP.

\subsection{Compliance Status of Regulatory Requirements}

\subsubsection{Compliance with the Hazardous Waste Regulatory Requirement}

The New Mexico requirement pertaining to hazardous waste management that differs from the federal regulations is summarized in the text.

\subsubsection{Compliance With Other Regulations, 20 NMAC 4.1, § 1101}

Compliance with the Hazardous Waste Management Regulations does not relieve a person of the obligation to comply with other applicable state and federal regulations.

Compliance with the other federal and state regulations pertaining to environmental protection that apply to WIPP is discussed in the other chapters of this BECR.

\subsubsection{Compliance with Standards Applicable to Generators of Hazardous Waste, 20 NMAC 4.1, Subpart III, § 300}

The following summarizes the applicable regulatory requirements and compliance status for hazardous waste generators under Subpart III of 20 NMAC 4.1, which corresponds to the federal implementing regulations of 40 CFR 262. Because New Mexico adopts the federal implementing regulations by reference, the citations given are from the federal regulations (40 CFR 262). The compliance status of WIPP to each requirement of Subpart III is summarized in the text.

\subsubsection{Hazardous Waste Determination, 40 CFR § 262.11 (20 NMAC 4.1, § 300) \\ The generator of solid waste is required to determine whether the waste is hazardous as defined under 40 CFR 261.}

Hazardous waste is currently generated from maintenance, construction, and laboratory operations at WIPP. This waste is characterized through knowledge of the materials and processes that generated the waste and/or waste sampling and analysis. 
25.2.2.2 EPA Identification Number, 40 CFR $\S 262.12$ (20 NMAC 4.1, § 300)

An EPA identification number is required for each generator of hazardous waste. In addition, a generator must not offer waste to transporters or TDSFs that have not received an EPA identification number. In addition, a generator must not offer waste to transporters or TSD facilities that have not received an EPA identification number.

The DOE has obtained a generator identification number for WIPP. The EPA identification number for WIPP is NM4890139088. The DOE does not utilize transporters or TDSFs that do not have an EPA identification number.

The MOC does not utilize transporters or TSD facilities that do not have an EPA identification number.

25.2.2.3 Manifest Requirements, 40 CFR § 262.20 (20 NMAC 4.1, § 300)

Compliance with the manifest requirements is mandatory for shipping hazardous waste off site. One of the requirements is that the generator have a waste minimization program in place.

Hazardous waste generated at WIPP is manifested prior to shipment to an off-site disposal facility. Records are maintained in the operating files at the WIPP facility for five years. Processes are in place that address these requirements. The MOC is responsible for implementing these processes. A waste minimization program, found in the WIPP Pollution Prevention Program Plan (WP 02-EC.11) is in place.

\subsubsection{Acquisition of Manifests, 40 CFR $\S 262.21$ (20 NMAC 4.1, § 300)}

The generator must obtain a manifest from the appropriate source.

The MOC obtains a manifest from consignment states which require a manifest. If the consignment state does not require a specific manifest, a uniform hazardous waste manifest is used. The current revision of EPA form 8700-22 is used at WIPP.

25.2.2.5 Number of Copies, 40 CFR § 262.22 (20 NMAC 4.1, § 300)

The manifest shall consist of sufficient copies to provide two for the generator and one each for the transporter and owner or operator of the designated facility.

The manifests used at WIPP contain the required number of copies to fulfill this requirement. The manifest form currently used contains six copies. 
25.2.2.6 Use of the Manifest, 40 CFR $\S 262.23$ (20 NMAC 4.1, § 300)

The generator must sign the manifest certification by hand, obtain the handwritten signature of the initial transporter and date of acceptance on the manifest, and retain one copy. The generator must give the transporter the remaining copies of the manifest. Other requirements of this regulation pertain to shipments by water, rail, or to a designated facility in an authorized state which has not yet obtained authorization to regulate that particular waste as hazardous.

The MOC hazardous waste management and transportation procedures address compliance with applicable parts of this regulation. Hazardous waste generated at WIPP is sent to TSDFs in states authorized to regulate that particular hazardous waste.

25.2.2.7 Packaging Requirements, 40 CFR § 262.30 (20 NMAC 4.1, § 300)

EPA and DOT packaging requirements must be met before shipping hazardous waste off site.

The MOC transportation and shipping procedures address these requirements. The $\mathrm{MOC}$ is responsible for proper packaging of all hazardous waste shipped from the site.

25.2.2.8 Labeling Requirements, 40 CFR § 262.31 (20 NMAC 4.1, § 300)

EPA and DOT labeling requirements must be met before shipping hazardous waste off site.

The MOC hazardous waste management and transportation procedures address these requirements.

25.2.2.9 Marking Requirements, 40 CFR § 262.32 (20 NMAC 4.1, § 300)

EPA and DOT marking requirements must be met before shipping hazardous waste off site.

The MOC hazardous waste management and transportation procedures address these requirements.

25.2.2.10 Placarding Requirements, 40 CFR § 262.33 (20 NMAC 4.1, § 300)

EPA and DOT placarding requirements must be met before shipping hazardous waste off site.

The MOC hazardous waste management and transportation procedures address these requirements. 
25.2.2.11 Accumulation Time, 40 CFR § 262.34(a) (20 NMAC 4.1, § 300)

Accumulation time for large quantity generators is limited to 90day storage of hazardous wastes for a non-permitted facility.

Waste is accumulated in containers in SAAs and subsequently moved to the hazardous waste storage area at WIPP. At this point, the 90-day storage requirement comes into effect. Applicable MOC procedures address requirements for hazardous wastes generated at WIPP and shipped off site to an approved TSDF. Records that document compliance with the 90-day storage requirement are maintained at WIPP.

25.2.2.12 Compliance with Subpart I of 40 CFR 265, 40 CFR $\S 262.34(a)(1)(i)$ (20 NMAC 4.1, § 300)

Compliance with Subpart I of 40 CFR 265 is required for waste placed in containers. The requirements of this subpart pertain to the condition of containers, compatibility of waste with the containers, closing containers during storage, inspections, the location of containers holding ignitable or reactive waste, the segregation of incompatible wastes, and air emission standards.

The MOC hazardous waste management procedures that address compliance with Subpart I of 40 CFR 265 are in place. These procedures provide for weekly inspections of containers, including container condition and container/waste compatibility, and segregation of incompatible wastes. The hazardous waste storage area is located more than 50 feet from the WIPP property line for compliance with the requirements for ignitable or reactive waste (40 CFR $\S 265.176$ ).

The air emissions requirements of Subpart AA and BB are not applicable to WIPP. Subpart CC did not apply to WIPP during this BECR reporting period, except as discussed in section 25.1 above, but may be applicable in the future.

25.2.2.13 Accumulation of Hazardous Wastes, 40 CFR $\S$ 262.34(a)(1)(ii) (20 NMAC $4.1 \S 300)$

Except as provided in paragraphs (d), (e), and (f) of this section, a generator may accumulate hazardous waste on site for 90 days or less without a permit or without having interim status, provided that the waste is placed in tanks, and the generator complies with Subpart J of 40 CFR 265, except § 265.197(c) and § 265.200.

On July 19, 20, and 21, 1999, the NMED conducted an inspection of WIPP regarding generator and interim status. Based on their review, WIPP was issued a LOV (NM4890139088 dated August 17, 1999) related to managing water from the Exhaust Shaft catch basin in the Underground Facility. The CAO responded on September 9, 1999, and again on November 12, 1999. The CAO and the NMED are working to appropriately address the NMED's concerns. 
25.2.2.14 Compliance with Subpart W of 40 CFR 265, 40 CFR $\S 262.34(a)(1)(i i i)$ (20 NMAC 4.1, § 300)

Compliance with Subpart W of 40 CFR 265 for wastes placed on drip pads is required.

Drip pads are not used at WIPP for hazardous waste accumulation. Therefore, this requirement does not apply.

25.2.2.15 Marking with Date of Initial Accumulation, 40 CFR $\S 262.34(a)(2)$ (20 NMAC 4.1, § 300)

Each container of hazardous waste must be clearly marked with the date of the initial accumulation of the waste, and the label must be visible for inspection.

The accumulation date listed on the Request for Disposal (RFD) is the initial accumulation date and is placed on the container when it enters the temporary storage area to await transport off site.

25.2.2.16 Marking as Hazardous Waste, 40 CFR § 262.34(a)(3) (20 NMAC 4.1, § 300)

Each hazardous waste container in the less-than-90-day storage area must be labeled or marked as hazardous waste.

Each hazardous waste container in the less-than-90-day storage area is clearly labeled as a hazardous waste as described in MOC procedures. Weekly inspections are performed to verify proper labeling of containers.

25.2.2.17 Compliance with Emergency Response, Training, and Waste Analysis Plan Requirements, 40 CFR § 262.34(a)(4) (20 NMAC 4.1, § 300)

Compliance with Subparts $C$ (preparedness and prevention) and $D$ (contingency plans and emergency procedures) of $40 \mathrm{CFR}$ 265 and with 40 CFR § 265.16 (personnel training) and $\S 268.7(a)(4)$ (waste analysis plan for prohibited waste under the land disposal restrictions) is required. In addition the requirements of 40 CFR $\S 265.111$ (closure performance standard) and 40 CFR $\S 265.114$ (disposal or decontamination of equipment, structures, and soils) must be met.

The CAO complies with this requirement through the RCRA Contingency Plan, various emergency response procedures, formal personnel training, and operation, maintenance, and testing of emergency equipment.

40 CFR 265, Subpart C, Preparedness and Prevention: WIPP is maintained and operated to minimize the possibility of fire, explosions, or any unplanned release of 
hazardous waste to the environment. Inspections of waste handling areas and equipment are conducted periodically in accordance with MOC procedures. Any corrective actions needed are initiated via spill management procedures and action requests.

Attachment $E$ of the Hazardous Waste Facility Permit is the is the Prevention and Preparedness Plan. This Plan describes internal and external communications systems, emergency equipment, and water for fire control. It also addresses aisle space requirements; preventive procedures, structures, and equipment; and prevention of reaction of ignitable, reactive, and incompatible wastes.

The following communication and alarm systems are available at the WIPP site: one-way communication by the public address system and its intercom phones and paging channels; local and facility-wide alarm systems, pagers and plectron; and two-way communication using an intra-plant telephone system, mine phones, and portable two-way radios. Inspection procedures are in place for the communication and alarm systems and the fire protection equipment. These procedures include provisions for testing and maintenance to ensure that equipment will be operable in an emergency. Spill control and decontamination equipment is inspected weekly, and the results are recorded on inspection sheets as defined in Attachment $D$ (Inspections) to the Hazardous Waste Facility Permit. Adequate aisle space is maintained in the hazardous waste storage area at WIPP to allow for potential emergency response activities.

The WIPP Emergency Management Section provides regional ambulance and emergency medical services. In addition, the DOE has established Memoranda of Understanding (MOU) with off-site emergency response agencies for fire fighting, medical assistance, and law enforcement. An example is the mutual aid agreement between Hobbs and the DOE that provides for mutual ambulance, medical, fire, rescue, and hazardous material response services. All outside agencies with which MOUs have been made have received copies of the RCRA Contingency Plan and the Waste Isolation Pilot Plant Emergency Management Program.

40 CFR 265, Subpart D, Contingency Plan and Emergency Procedures: The RCRA Contingency Plan was provided to outside emergency response agencies. The Plan defines responsibilities, provides guidance for the coordination of activities, and minimizes hazards to human health and the environment from fires, explosions, or any sudden or non-sudden release of hazardous waste or hazardous waste constituents. The RCRA Contingency Plan describes actions that must be taken in response to fires, explosions, or any unplanned sudden or non-sudden release of hazardous waste or hazardous waste constituents to air, soil, or water. It lists agreements with local authorities; lists names, addresses, and phone numbers of persons qualified to act as Emergency Coordinators; provides a list of emergency equipment at the facility; and includes an evacuation plan. As stated in the plan, the RCRA Emergency Coordinator has the authority to commit the resources necessary to respond to an emergency. 
Copies of the Plan have been provided to all outside agencies with which WIPP has agreements for assistance in an emergency situation. The MOC has the distribution list for the plan and is responsible for updating the copies.

The plan will be reviewed and permit modifications will be submitted if necessary whenever applicable regulations are revised; if the plan fails in an emergency; if the facility changes in a way that materially increases the potential for fires, explosions, or releases of hazardous waste or hazardous waste constituents, or changes the response necessary in an emergency; or if the list of RCRA Emergency Coordinators or the list of emergency equipment changes.

The TRU mixed waste handling areas at the WIPP facility do not include tank storage or treatment of hazardous waste as defined by the regulations. At the WIPP facility, tanks are used to store water and petroleum fuels only. The petroleum tanks store diesel and unleaded gasoline. Underground storage tanks are subject to the New Mexico Underground Storage Tank Regulations.

A RCRA Emergency Coordinator is on site 24 hours a day, 7 days a week. The coordinator is responsible for coordinating all emergency response measures. The primary RCRA Emergency Coordinator is the on duty Facility Shift Manager. Emergency Coordinators are thoroughly familiar with. The plan has provisions that meet the emergency procedure requirements such as communication of an emergency situation to employees, notification of the appropriate agency if assistance is needed, identification of hazardous materials, assessment of hazards, and notification of any incident that requires implementation of the Contingency Plan.

40 CFR 265.16, Personnel Training: Formal training at WIPP is conducted in accordance with the MOC training program. Training includes General Employee Training (GET), other classroom training, and on-the-job training. Classroom training is conducted by certified instructors. Certification requirements are established in an MOC procedure. The GET course provides detailed training in such areas as communications, alarm systems, and emergency response. section $\mathrm{H}-1 \mathrm{~b}(1)$ of Attachment $\mathrm{H}$ (Personnel Training) to the Hazardous Waste Facility Permit requires all personnel to attend GET within 30 days of employment. All MOC employees must take annual GET refresher training. Other classroom training is offered for personnel in selected job categories that involve the management of hazardous waste, such as maintenance and waste operations. Annual refreshers are provided. Maintenance personnel are trained to provide repair and replacement services. Inspections are a part of job-specific training and emergency response personnel training. WIPP employees involved in managing site-generated, nonradioactive waste, or TRU mixed waste will receive the Hazardous Waste Worker course. This course provides job specific training required to safely receive, transfer, or handle waste at the facility. Review and update of the Hazardous Waste Worker topics are provided annually.

The MOC DOC maintains a listing of all hazardous waste management job titles, the names of employees assigned by job title to hazardous waste management jobs, and 
job descriptions that identify RCRA-related duties. Records on active and inactive personnel are kept at the facility in accordance with MOC procedures.

\section{CFR § 268.7(a)(4), Waste Analysis for Treating Prohibited Wastes in Tanks or} Containers: This requirement for a waste analysis plan for the treatment of wastes prohibited from land disposal in tanks or containers is not applicable to WIPP as WIPP-generated hazardous waste is neither treated nor land disposed at this facility.

40 CFR § 265.111, 40 CFR § 265.114, Closure Performance Standard and Disposal or Decontamination of Equipment, Structures, and Soils: The requirements of these regulations are addressed in the Closure Plan, which is Attachment I of the Hazardous Waste Facility Permit. In accordance with the Closure Plan, closure will be deemed complete when all hazardous waste and hazardous waste residues have been removed from the storage units, all equipment and structures associated with the operation of the units have been decontaminated, the panels and facility are closed, and unit closure certification has been submitted to and approved by the NMED.

\subsubsection{Extension of Storage Period, 40 CFR § 262.34(b) (20 NMAC 4.1, § 300)}

The 90-day storage period may be extended due to unforeseen, temporary, and uncontrollable circumstances.

Applicable MOC procedures provide instruction for the shipment of hazardous waste off site prior to the 90-day deadline. An extension of the storage period was not required during this reporting period; however, procedures exist if a request for an extension is needed.

25.2.2.19 Restrictions and Requirements, 40 CFR § 262.34(c)(1) (20 NMAC 4.1, $\S 300)$

There are a number of restrictions and requirements for SAAs. These include the limit of 55 gallons of hazardous or 1 quart of acutely hazardous waste (listed in 40 CFR $\S 261.33[e]$ ) and the requirement that the $S A A$ be located at or near the point of generation of the waste under the control of the operator.

The MOC SAA management procedure addresses how inspections are conducted to verify that the 55-gallon limit per SAA is not exceeded. None of the SAAs have a capacity that exceeds 55 gallons, and no SAA for acutely hazardous waste have been established at WIPP. The SAAs are located at or near the points of generation of the hazardous waste, and are under the control of the operator generating the waste. In addition, this procedure defines the requirements for placing waste in an SAA, and defines the responsibilities of the waste generator. 
25.2.2.20 Compliance with 40 CFR $\S 265.171,265.172$, and 265.173(a), 40 CFR § 262.34(c)(1)(i) (20 NMAC 4.1, § 300)

Requirements for hazardous waste generators from 40 CFR 265 pertain to the condition of the containers (\$265.171), compatibility of the waste with the container (\$ 265.172), and the necessity to keep the containers closed when not actually adding waste to or removing it from the containers (\$ 265.173[a]). In addition, a container holding hazardous waste must not be opened, handled, or stored in a manner that could rupture the container or cause it to leak.

The MOC SAA procedures and weekly inspections ensure that containers used to hold hazardous waste in SAAs are in good condition. If a container is found to be damaged, it is repaired, or the waste is removed and transferred to another container. This procedure addresses waste/container compatibility, and the requirement that containers be closed except when waste is being added or removed. This procedure also addresses the requirement that containers not be opened, handled, or stored in a manner that could cause the container to rupture or leak by requiring that containers be inspected before and after transportation from the SAA to the staging area. Weekly inspections confirm that this requirement is being met. No special liners are used in the waste containers.

25.2.2.21 Labeling of Container as "Hazardous Waste," 40 CFR $\S 262.34$ (c)(1)(ii) (20 NMAC 4.1, § 300)

Labeling of each hazardous waste container as "hazardous waste" is required.

On July 19, 20, and 21, 1999, the NMED conducted an inspection of WIPP regarding generator and interim status. Based on their review, WIPP was issued a LOV (NM4890139088 dated August 17,1999) related to a missing label on a hazardous waste container in a SAA. The MOC immediately marked and moved the container to the 90-day accumulation area. The CAO responded on September 9, 1999, notifying the state that the specific incident had been corrected and that additional training was being conducted with affected hazardous waste management personnel to ensure proper labeling.

Applicable MOC procedures are in place, and weekly inspections are conducted to verify that each container of hazardous waste is clearly labeled as hazardous waste.

25.2.2.22 Management of Waste, 40 CFR § 262.34(c)(2) (20 NMAC 4.1, § 300)

If waste accumulates in one of the SAAs in excess of the 55-gallon or 1-quart limit, the container(s) containing the excess waste must be marked with the date on which excess waste 
began accumulating, and excess accumulation wastes must be moved to the 90-day storage area within 3 days.

There were no excess accumulations in the SAAs during this BECR reporting period. Procedures and weekly inspections ensure that all waste in an SAA is moved to the less-than-90-day storage area before excess amounts are accumulated.

\subsubsection{Record Keeping Requirements, 40 CFR § 262.40 (20 NMAC 4.1, § 300) \\ Manifests, test results, waste analyses, biennial reports, and exception reports must be kept on site for at least three years.}

Required records are maintained by the MOC on site for a minimum of five years after which they may be retained onsite until closure or microfiched and stored indefinitely. Although 20 NMAC $4.1 \S 300$ requires that manifests and their associated records be maintained for only three years, DOE DOC procedures dictate that manifest records will be maintained onsite for five years. Waste analyses and reports supporting Land Disposal Restrictions (LDR) must be kept on file five years (40 CFR § 268.7[a][7]). WIPP's five-year retention period is designed to assure that manifest and associated LDR records are kept together, and that LDR records are retained onsite the required five-year period. Note: on May 12, 1997, the EPA changed this LDR documentation retention period to three years. However, New Mexico has not yet adopted this change in the 20 NMAC 4.1 regulations.

25.2.2.24 Generator-Biennial Report, 40 CFR § 262.41 (20 NMAC 4.1, § 300)

Each generator of hazardous waste that ships the waste off site to an approved TSDF must file a report to the EPA by March 1 of every even-numbered year, including a description of the results of waste minimization efforts.

The MOC prepares this report in accordance with specific instructions provided by the NMED to respond to these requirements. The most recent report was submitted in February 2000.

\subsubsection{Exception Reporting, 40 CFR § 262.42 (20 NMAC 4.1, § 300) \\ Exception reporting is required if a copy of the manifest is not returned to the generator within 45 days of the date of acceptance of the hazardous waste by the transporter.}

The MOC hazardous waste management procedures address exception reporting. An exception report was filed on February 2, 2000 for waste that was shipped on December 15, 1999. The waste was received at the designated facility 43 days after shipment. The manifest was received by the MOC 47 days after the waste was shipped. 
25.2.2.26 Additional Reporting, 40 CFR $\S 262.43$ (20 NMAC 4.1, § 300)

The Administrator, as he or she deems necessary, may require generators to furnish additional reports concerning the quantities and disposition of wastes identified or listed in 40 CFR 261.

No additional reports have been requested to date.

25.2.2.27 Special Requirements for Generators of Between 100 and 1,000 Kilograms per month, 40 CFR § 262.44 (20 NMAC 4.1, § 300)

A generator of greater than 100 kilograms but less than 1000 kilograms of hazardous waste in a calendar month is subject to only . . . record keeping; . . . exception reporting; and . . . additional reporting.

The WIPP site is currently categorized as a large quantity generator (over 1,000 kilograms in any calendar month); therefore, this regulation is not applicable.

\subsubsection{Compliance with Standards Applicable to Transporters of Hazardous Waste, 40 CFR 263 (20 NMAC 4.1, § 400)}

The standards and requirements specified under 40 CFR 263 will become applicable when the generator sites begin shipping TRU mixed wastes to WIPP. The DOE and its MOC conduct assessments or audits to review WIPP compliance with requirements of applicable federal regulations, DOE orders, and DOE Albuquerque Operations Office $(\mathrm{AL})$ Directives that pertain to hazardous waste transportation activities.

A summary of the requirements for transporters of hazardous or mixed wastes and the compliance status of each requirement is provided in the text.

25.2.3.1 Compliance with Department of Transportation Regulations, 40 CFR § 263.10(a) (20 NMAC 4.1, § 400)

Transporters of hazardous/mixed waste must comply with all applicable DOT regulations.

Cast Transportation, Inc. has been contracted to transport TRU waste to WIPP from the generator sites. The Cast Transportation Management Plan (dated June 22, 1995) incorporates the applicable DOT regulations from the 49 CFR.

Any transporter hired to ship TRU and TRU mixed waste from the generator sites to WIPP must comply with the DOT regulations. 
25.2.3.2 EPA Identification Number, 40 CFR $\S 263.11$ (20 NMAC 4.1, § 400)

The transporter must have an EPA identification number from the EPA Administrator.

Cast Transportation Inc. has been contracted to transport TRU and TRU mixed waste from the generator sites to WIPP. Their EPA identification number is COD 980953269. Any transporter hired to ship TRU and TRU mixed waste to WIPP must have an EPA identification number.

25.2.3.3 Compliance with the Manifest System and with Record Keeping Requirements, 40 CFR § 263.20-263.22 (20 NMAC 4.1, § 400)

The transporter must comply with all relevant manifest and record keeping requirements.

The Cast Transportation Management Plan indicates that it will comply with requirements of the manifest system. Any transporter hired to ship TRU mixed waste to WIPP must comply with these requirements. Applicable records are maintained by both the MOC National TRU Waste Programs.

25.2.3.4 Immediate Action after Hazardous Waste Discharges, 40 CFR $\S 263.30$ (20 NMAC 4.1, § 400)

The transporter will take appropriate immediate action in the event of a discharge of hazardous waste during transportation.

The Cast Transportation Management Plan addresses actions that will be undertaken to protect human health and the environment. Any transporter that ships TRU mixed waste to WIPP must have these capabilities. WIPP has not yet received any TRU mixed waste shipments; therefore; no hazardous waste discharges have occurred.

25.2.3.5 Discharge Cleanup, 40 CFR $\S 263.31$ (20 NMAC 4.1, § 400)

A transporter must clean up any hazardous waste discharge that occurs during transportation or must take any action(s) required by federal, state, or local officials to render the discharge nonhazardous to human health and the environment.

In the event of a hazardous waste constituent discharge during transportation, cleanup activities will be undertaken, as required. Any transporter of TRU waste to WIPP must be capable of ensuring adequate cleanup of any hazardous or mixed waste released to the environment during a transportation incident or accident. No waste discharges have occurred. 


\subsubsection{Compliance with the Regulatory Requirements for TSDFs, 40 CFR 264 (20 NMAC 4.1, Subpart V, § 500)}

An operating permit for WIPP was issued on October 27,1999. Applicable requirements of a permitted RCRA disposal facility are described in this section.

25.2.4.1 Applicability, 40 CFR § 264.10 (20 NMAC 4.1, § 500)

The regulations in Subpart $B$ apply to owners and operators of all hazardous waste facilities, except as $\S 264.1$ provides otherwise.

The portions of Subpart B applicable to WIPP are identified in $\S \S 264.11$ through 264.18 as discussed in sections 25.2.4.2 through 25.2.4.9 below.

25.2.4.2 EPA Identification Number, 40 CFR § 264.11 (20 NMAC 4.1, § 500)

Each TSDF must have an EPA identification number.

The EPA identification number for WIPP is NM4890139088.

25.2.4.3 Required Notices, 40 CFR $\S 264.12$ (b) (20 NMAC $4.1 \S 500)$

The owner or operator of a facility that receives waste from an offsite source must inform the generator that the appropriate permits are in place and waste will be accepted.

On January 12, 2000 the DOE/CAO sent notification to all applicable generators that a permit had been received. DOE will retain a copy of the notification in the operating record, as required by Permit Condition II.B.2. Notifications (of waste acceptance) are made to the generator upon a review of each waste stream profile for compliance with the permit and completeness of the profile.

25.2.4.4 General Waste Analysis, 40 CFR § 264.13 (20 NMAC 4.1, § 500)

A detailed chemical and physical analysis of a representative sample of the wastes is required before a TSDF may treat, store, or dispose of waste. The owner/operator of the TSDF must inspect and, if necessary, analyze the waste received to ensure that it matches the identity of the waste described in the accompanying manifest. The owner/operator must follow a written waste analysis plan to ensure compliance with these requirements.

General waste analysis is addressed in Module II and Attachments B, B1, B2, B3, B4, B5 and B6 of the Hazardous Waste Facility Permit. Characterization methods consist of acceptable knowledge; visual examination; radiography; headspace gas sampling and analysis and sampling and analysis of homogeneous waste forms. 


\subsubsection{Security, 40 CFR $\S 264.14$ (20 NMAC $4.1 \S 500)$}

Security measures are required to prevent the possibility of unknowing and/or unauthorized entry by persons or livestock onto the active portion of the facility. A 24-hour surveillance system or barrier is required, and the facility must be posted.

Security requirements are contained in Attachment C (Security) of the Hazardous Waste Facility Permit. The WIPP Property Protection Area is enclosed within an 8-foothigh chain-link fence, and 24-hour surveillance is conducted by guards trained to prevent unauthorized entry onto the facility. Signs with the legend "Danger-Unauthorized Personnel Keep Out" in both English and Spanish are posted. The perimeter fence, gates, and signs are inspected daily for evidence of tampering or structural damage in accordance with a WIPP procedure.

25.2.4.6 General Inspection Requirements, 40 CFR § 264.15 (20 NMAC 4.1, § 500)

The owner/operator must inspect the facility for malfunctions, deterioration, operator errors, and discharges that cause actual or potential releases of hazardous constituents to the environment or a threat to human health. A written schedule must be developed and followed for inspecting all monitoring, safety, and emergency equipment; security devices; and operating/structural equipment needed to prevent, detect, or respond to environmental or human health hazards. The inspections must be recorded in an inspection log or summary and kept for at least three years.

The MOC implements inspection procedures for all monitoring, safety, and emergency equipment; security devices; and operating and structural equipment. Written schedules (Attachments D and D1 of the Hazardous Waste Facility Permit ) that indicate the frequency of routine inspections have been developed.

Cognizant individuals develop procedures that outline the types of problems that will be examined during inspections of equipment and systems and each organization responsible for inspections maintains its own inspection information. Completed inspection sheets include a signature, date and time of inspection; observations made; and the date and nature of any repairs or other remedial actions. Inspection documentation is maintained in the operating record for at least three years.

25.2.4.7 Personnel Training, 40 CFR $\S 264.16$ (20 NMAC 4.1, § 500)

Personnel training must be provided to facility personnel within six months of their employment or new assignment; personnel must not work in unsupervised positions until the training has been completed. The training program must be designed to ensure that facility personnel can respond effectively to an 
emergency. The training program must teach personnel those hazardous waste management procedures that are relevant to the positions in which they are employed. The program must be directed by a person trained in hazardous waste management procedures. The job title for each position at the facility that is related to hazardous waste management, the name of the employee filling the position, a written description of the training required, and records that document that the training and/or job experience has been completed are also required. These records must be kept until closure for current personnel and for at least three years for former employees.

Training requirements are specified in Attachments $\mathrm{H}, \mathrm{H} 1$, and $\mathrm{H} 2$ of the Hazardous Waste Facility Permit. Formal training is conducted in accordance with a training manual. The training includes General Employee Training (GET) for all WIPP employees, other classroom training, and on-the-job training. WIPP training is conducted by certified instructors.

General Employee Training provides training in such areas as communications, alarm systems, and emergency response. An MOC procedure requires all personnel to attend GET within 30 days of employment. Personnel are required to take GET refresher annually. Other classroom training is offered for personnel in certain job categories. Annual refresher courses are provided. Maintenance personnel are trained to provide repair and replacement services. Inspections are a part of job-specific training and emergency response personnel training. WIPP employees involved in managing site-generated, nonradioactive waste, or TRU mixed waste receive the Hazardous Waste Worker course. This course provides job specific training required to safely receive, transfer or handle waste at the facility. Review and update of the Hazardous Waste Worker topics are provided annually.

The MOC maintains a listing of all hazardous waste management job titles, names of employees assigned by job title to hazardous waste management jobs, and job descriptions that identify RCRA duties. Records on active and inactive personnel are kept at the WIPP facility for the specified time periods.

25.2.4.8 General Requirements for Ignitable, Reactive, or Incompatible Wastes, 40 CFR § 264.17 (20 NMAC 4.1, § 500)

Precautions must be taken to prevent accidental ignition or reaction of ignitable or reactive waste. Any mixture or commingling of incompatible wastes must be conducted so that it does not generate extreme heat or pressure, fire or explosion, violent reaction; does not produce uncontrolled toxic airborne materials; does not produce uncontrolled flammable fumes or gases; does not damage the structural integrity of the device or facility; or does not threaten human health or the environment. 
WIPP is precluded from accepting ignitable, corrosive, or reactive waste as specified in Module II and Permit Attachment B1 (Waste Analysis Plan) of the Hazardous Waste Facility Permit. In the analysis of the compatibility of the waste categories with each other and with waste containers, backfill, and other facility materials, no incompatibilities were identified.

25.2.4.9 Location Standards, 40 CFR § 264.18 (20 NMAC 4.1, § 500)

Facilities where disposal of hazardous waste will be conducted must not be located near a fault as listed in 40

CFR § 270.14(b)(ii). Facilities in a 100-year floodplain must be designed, constructed, operated, and maintained to prevent washout by a 100-year flood. no hazardous waste may be emplaced in such structures as a salt-bed formation or an underground mine except at the DOE Waste Isolation Pilot Plant in New Mexico.

Eddy County is not listed as a political jurisdiction in which compliance with 40 CFR § 264.18(a) must be demonstrated. Therefore, it can be assumed that the WIPP facility is in compliance with this requirement. The Preparedness and Prevention Plan states that the WIPP site does not lie within a 100-year floodplain. Therefore, there are no requirements for flood-protection. However, drainage and diversion structures have been constructed such that surface and subsurface structures will not be affected by a probable maximum precipitation event. WIPP is specifically identified in the regulation as the only facility of this type that may be used for the placement of hazardous waste.

25.2.4.10 Maintenance and Operation of Facility, 40 CFR $\S 264.31$ (20 NMAC 4.1, $\S 500)$

Facilities must be designed, constructed, maintained, and operated to minimize the possibility of fire, explosions, or any unplanned release of hazardous constituents to air, soil, or surface water that could threaten human health or the environment.

All waste handling facilities are designed, constructed, maintained, and operated so as to minimize the possibility of a fire, explosion, or any unplanned sudden or non-sudden release of hazardous waste or hazardous waste constituents which could threaten human health or the environment. General facility conditions for maintenance and operation of the WIPP are stated in Module II of the Hazardous Waste Facility Permit. Preventive procedures, structures, and equipment are specified in the Preparedness and Prevention Plan. An inspection schedule for equipment instrumental in preventing, detecting, or responding to environmental or human health hazards is given in Attachment D (Inspections) of the Hazardous Waste Facility Permit. 
25.2.4.11 Required Equipment, 40 CFR § 264.32 (20 NMAC 4.1, § 500)

All facilities must be equipped with an internal communications or alarm system for immediate emergency instruction; devices to summon external emergency assistance; fire extinguishers and fire-control, spill-control, and decontamination equipment; and water or foam equipment, sprinklers, or water-spray systems.

The intraplant communication systems, designed to provide immediate emergency instructions to facility personnel, include communication by the public address system and its intercom phones and paging channels, an intraplant telephone system, mine phones, pagers and plectron, portable two-way radios, and local and facility-wide alarm systems. The procedures for notifying facility personnel in RCRA Contingency Plan.

There are various alarm systems used at the WIPP facility. The public address system has two alarm tones in use, a yelp and a gong. Its signals are produced in the master PA console by a tone generator and are transmitted sitewide over the paging channel of the system, overriding its normal use.

Whenever TRU mixed wastes are handled, two persons, at a minimum, are involved in the operation. The Waste Handling Building contains readily accessible telephones and public address stations throughout. The mine phones are the main means of communication underground, although the public address system is also available.

Underground communication and alarm systems are arranged to meet the requirements of 30 CFR 57 which regulates the operation of underground mines and are imposed by the Mine Safety and Health Administration. Telephones or other twoway communication equipment with instructions for their use are provided for communications from underground to the surface. Alarm systems capable of promptly warning every person underground are provided and maintained in operating condition. If persons are assigned to work areas beyond the warning capabilities of the system, provisions will be made to alert them in a proper manner to provide for their safe evacuation. Typically, these provisions include a flashing light capable of being easily seen.

The external communication systems, designed to provide two-way communication with outside agencies or for summoning emergency assistance from off site, include the commercial telephone system and two-way radios.

The Preparedness and Prevention Plan specifies preventive procedures, structures, and equipment. The RCRA Contingency Plan describes the capabilities and locations of the fire-suppression equipment and systems.

The primary function of the WIPP facility water system is to supply water for domestic use and fire protection. Water is furnished by the Double Eagle Water Company, owned by the city of Carlsbad. 
At the WIPP facility, the water enters a pair of 180,000-gallon, aboveground storage tanks located adjacent to the pump house. These tanks are 32 feet in diameter and are constructed of welded steel. Of the 360,000-gallon total capacity, at least 180,000 gallons are dedicated to fire suppression and are sufficient to handle the maximum credible fire. Separate sets of pumps fort the domestic water and fire-water systems are provided in the pump house.

25.2.4.12 Testing and Maintenance of Equipment, 40 CFR $\S 264.33$ (20 NMAC 4.1, $\S 500)$

All facility communications or alarm systems and fire-control, spillcontrol, and decontamination equipment must be tested and maintained as needed to ensure its proper operation during an emergency.

Equipment instrumental in preventing, detecting, or responding to environmental or human health hazards, such as alarm systems, fire protection equipment, and decontamination equipment are tested and maintained to assure its proper operation in a time of emergency. Alarms, spill control, and decontamination equipment are inspected weekly and the results recorded on an inspection form as defined in Attachment D-1 (Inspection Sheets, Logs, and Instructions for Systems/Equipment Requiring Inspection) of the Hazardous Waste Facility Permit.

25.2.4.13 Access to Communications or Alarm Systems, 40 CFR $\S 264.34$ (20 NMAC 4.1, § 500)

Immediate access to a communications or internal alarm system is required for all personnel involved when handling hazardous waste. If just one employee is ever on the premises during operations, he/she must have immediate access to a device (e.g., telephone) for summoning external emergency assistance.

The following communication and alarm systems are available at the WIPP site: the public address system and its intercom phones and paging channels, an intra-plant telephone system, mine phones, local and facility-wide alarm systems, pagers and plectron, and portable two-way radios. The Preparedness and Prevention Plan specifies preventive procedures, structures, and equipment, and the RCRA Contingency Plan provides an inspection schedule for this equipment and describes the location of alarms, telephones, etc. Alarms and telephones are strategically placed in and adjacent to hazardous and TRU waste management facilities. There is more than one employee at the site at all times.

25.2.4.14 Required Aisle Space, 40 CFR § 264.35 (20 NMAC 4.1, § 500)

Aisle space must be maintained to allow the unobstructed movement of personnel and of fire-protection, spill-control, and 
decontamination equipment to any area of facility operation unless aisle space is not needed for these purposes.

Module III and the Preparedness and Prevention Plan of the Hazardous Waste Facility Permit and MOC procedures call for maintaining appropriate aisle space for all stored waste in the Waste Handling Building, waste storage areas, and the 90-day storage area. Painted lines are provided in the Waste Handling Building and the 474 Building to assure proper aisle space is maintained.

No aisle spacing will be maintained in the Hazardous Waste Disposal Units as per Attachment M2 (Geologic Repository) of the Hazardous Waste Facility Permit.

\subsubsection{Arrangements with Local Authorities, 40 CFR $\S 264.37$ (20 NMAC 4.1, $\S 500)$}

Arrangements with local authorities must be made for the provision of emergency services if needed. Requirements include familiarizing the local authorities with the layout of the facility, properties of hazardous waste to be handled, possible evacuation routes, and other information needed for emergency responses.

The RCRA Contingency Plan addresses this requirement. The DOE has established MOUs with appropriate off-site emergency response agencies for fire fighting, medical assistance, and law enforcement. Examples include an MOU with the Carlsbad Medical Center Emergency Radiological Treatment Center for WIPP, which provides for the treatment of radiologically contaminated personnel, and a mutual aid agreement between Hobbs and the DOE, which provides for mutual ambulance, medical, fire, rescue, and hazardous material response services. Outside agencies with which MOUs have been made have received copies of the RCRA Contingency Plan and the WIPP Emergency Management Program. WIPP personnel provide regional fire and emergency services to residences and local businesses.

25.2.4.16 Purpose and Implementation of the Contingency Plan, 40 CFR $\S 264.51$ (20 NMAC 4.1, §500)

Each owner/operator must have a contingency plan for his or her TSDF. The contingency plan must be designed to minimize hazards to human health or the environment from fires, explosions, or unplanned releases of hazardous waste or hazardous constituents to the environment. The provisions of the plan must be carried out whenever a fire, explosion, or release of hazardous waste or hazardous constituents could threaten human health or the environment.

The RCRA Contingency Plan defines responsibilities; provides guidance for coordination of activities; and minimizes hazards to human health and the environment 
from fires, explosions, or any unplanned release of hazardous waste or hazardous waste constituents.

25.2.4.17 Content of the Contingency Plan, 40 CFR $\S 264.52$ (20 NMAC 4.1, § 500)

The contingency plan must describe the actions to be taken by facility personnel in response to fires, explosions, or any unplanned releases of hazardous waste or hazardous constituents to the environment. The plan must describe arrangements agreed to by local authorities and emergency response units and must list the current names, addresses, and phone numbers (work and home) of all Emergency Coordinators. All emergency equipment must be listed, along with the location, description, and capabilities of all equipment. An evacuation plan for facility personnel must be included.

The RCRA Contingency Plan describes actions that must be taken in response to fires, explosions, or any unplanned or sudden or non-sudden release of hazardous waste or hazardous waste constituents to air, soil, or water, and describes agreements with local authorities. It also lists the names, addresses, and phone numbers of persons qualified to act as Emergency Coordinators, provides a list of emergency equipment at the facility, and includes an evacuation plan.

The RCRA Contingency Plan also describes the agreements between WIPP and local police and fire departments, hospitals, contractors, and state and local emergency response teams. An evacuation plan for WIPP personnel is also included in the RCRA Contingency Plan.

25.2.4.18 Copies of the Contingency Plan, 40 CFR $\S 264.53$ (20 NMAC 4.1, 5500 )

Copies of the contingency plan and all revisions to the plan must be maintained at the facility and submitted to all local police and fire departments, hospitals, and state and local emergency response teams that may be called upon to provide emergency services.

Copies of the RCRA Contingency Plan are maintained at WIPP. A copy of the attachment is maintained at document locations accessible to emergency responders and on WIPP network where it is available to all WIPP personnel. The MOC maintains a distribution list for, and is responsible for submitting permit modifications to update, the RCRA Contingency Plan. Copies of the attachment have been provided to each outside agency with which the CAO has agreements for assistance in an emergency situation. 
25.2.4.19 Amendment of Contingency Plan, 40 CFR § 264.54 (20 NMAC 4.1, § 500)

The contingency plan must be reviewed and immediately revised, if necessary, whenever applicable regulations are revised; the plan fails in an emergency; the facility changes in a way that increases the potential for fire, explosions, or release of hazardous waste; or the list of Emergency Coordinators or emergency equipment changes.

The RCRA Contingency Plan will be reviewed and the Permit modified if necessary whenever applicable regulations are revised; the plan fails in an emergency; the facility changes in a way that materially increases the potential for fires, explosions, or releases of hazardous waste or hazardous waste constituents or changes the response necessary in an emergency; the list of Emergency Coordinators changes; or the list of emergency equipment changes.

\subsubsection{Emergency Coordinator, 40 CFR § 264.55 (20 NMAC 4.1, § 500)}

At least one employee (on the facility premises or on call) must be designated as the Emergency Coordinator, with the responsibility for coordinating all emergency response measures. The Emergency Coordinator must be familiar with the contingency plan, all operations and activities at the facility, the location and characteristics of waste handled, location of all facility records, and the facility layout. The Emergency Coordinator must have the authority to commit the resources needed to carry out the contingency plan.

An Emergency Coordinator is on site at the WIPP facility 24 hours a day, 7 days a week, and is responsible for coordinating all emergency response measures. The primary Emergency Coordinator is the Facility Shift Manager. The FSM is the coordinator who will be on duty at the time of any incident that requires implementation of the RCRA Contingency Plan.

Persons qualified to act as the Emergency Coordinator are listed in the RCRA Contingency Plan. These employees have the requisite experience and authority to perform their role as Emergency Coordinator.

\subsubsection{Emergency Procedures, 40 CFR § 264.56 (20 NMAC 4.1, § 500)}

In the event of an imminent or actual emergency situation, the Emergency Coordinator or designee must notify facility personnel via internal alarms or communications systems and must notify state or local agencies if their help is needed. A release, fire, or explosion mandates that the Emergency Coordinator obtain appropriate information, assess possible hazards, make any notifications required, prevent the spread or reoccurrence of the 
incident, monitor if necessary, recover waste, prevent handling of incompatible waste in the area, ensure emergency equipment is cleaned up and fit for use after the event, and record details regarding the incident in the facility's operating record. The owner or operator must note specific information about any incident that requires the contingency plan to be implemented. This information must be recorded in the facility's operating record. A written report must be submitted to the Regional EPA office and the NMED within 15 days of the incident. The SERC must be contacted rather than the NMED in the event of any spill incident that may endanger human health or the environment.

WIPP Emergency Coordinators are thoroughly familiar with the RCRA Contingency Plan. The attachment has provisions that meet the emergency procedure requirements such as communicating information about the emergency to employees, notifying appropriate agencies to obtain assistance, identifying hazardous materials, assessing hazards, and making the necessary notifications. The appropriate agencies include the Local Emergency Planning Committee (LEPC), the Carlsbad Police Department, the Carlsbad Fire Department, and the Eddy County Sheriff.

The Facility Shift Manager is responsible for coordinating the cleanup of spills. Disposal of the waste resulting from cleanup is the responsibility of the MOC.

All equipment used in an emergency will be thoroughly decontaminated before being placed back in service. If decontamination is not possible, equipment will be disposed of according to MOC procedures, and replaced. All emergency equipment listed in the RCRA Contingency Plan is kept clean and fit for its intended use.

As described in the RCRA Contingency Plan, a daily log is maintained in the Central Monitoring Room at WIPP. The Facility Shift Manager signs into the log before beginning his or her duty shift. All incidents, regardless of whether or not they activate the RCRA Contingency Plan, are recorded in the Central Monitoring Room log, along with routine maintenance activities.

The RCRA Contingency Plan addresses the requirement that the SERC and the NMED be notified in the event of a spill that would endanger human health or the environment.

\subsubsection{Use of Manifest System, 40 CFR § 264.71 (20 NMAC 4.1, § 500)}

If a facility receives hazardous waste or hazardous constituents accompanied by a manifest, the owner or operator or designee must sign and date each copy of the manifest to certify receipt of the waste, note any significant discrepancies in the manifest, return at least one copy of the manifest to the transporter, send a copy of the manifest to the generator within 30 days, and retain a copy of the manifest for at least three years. 
The MOC waste management procedures and transportation procedures provide guidance on the proper management and retention of hazardous waste manifests. These procedures provide instructions for receiving, surveying, and inspecting TRUPACT-II containers at WIPP, which includes proper disposition of the hazardous waste. Further, generator sites are required to provide a manifest for shipments of TRU mixed waste. This requirement will become applicable when WIPP facility begins receiving TRU mixed waste shipments.

\subsubsection{Manifest Discrepancies, 40 CFR § 264.72 (20 NMAC 4.1, § 500) \\ Manifest discrepancies are differences between the quantity or type of hazardous waste designated in the manifest and that actually received. Upon discovering a significant discrepancy, the owner or operator must try to reconcile the discrepancy with the generator or transporter. If not resolved within 15 days, the owner or operator must notify the Regional Administrator.}

The MOC waste management procedures and transportation procedures provide instruction and guidance for handling manifest discrepancies. The generator will be notified of all discrepancies, and the discrepancies will be recorded in the "remarks" section of the appropriate form. If the discrepancies cannot be resolved within 15 days, they will be reported in writing to the NMED.

\subsubsection{Operating Record, 40 CFR § 264.73 (20 NMAC 4.1, § 500)}

The owner/operator must keep a written operating record at the facility. Information relating to the type and amount of hazardous waste, its location and quantity at each location, cross references to specific manifest documents and records and the results of waste analyses, summary reports and details of all incidents requiring implementation of the contingency plan, records and results of inspections, monitoring and analytical data and any corrective actions taken, and closure cost estimates must be included. In addition, information on the annual certification of a waste minimization program and records pertaining to an off-site treatment, land disposal, or storage facility must be kept in the operating record.

Module II, General Facility Conditions, of the Hazardous Waste Facility Permit establishes, and the MOC complies with, the above requirements for maintaining the written operating record.

25.2.4.25 Availability, Retention, and Disposition of Records, 40 CFR $\S 264.74$ (20 NMAC 4.1, § 500)

All records required under this part, including plans, must be retained and made available for inspection by EPA designees. 
The retention period for all records required under this part is automatically extended during the course of any unresolved enforcement action or as requested by the Administrator. Records of waste disposal locations and quantities must be submitted to the appropriate agencies upon closure of the facility.

The Permit establishes requirements for maintaining a written operating record. The MOC implementation includes provisions for furnishing all records upon request to the EPA and the NMED, as well as provisions for submitting a copy of waste emplacement locations and quantities to appropriate state and federal regulators. In the event of an enforcement action, records will be retained for the duration of the action.

\subsubsection{TSDF Biennial Report, 40 CFR § 264.75 (20 NMAC 4.1, § 500) \\ The owner or operator of a TSDF must submit a copy of a biennial report to the Regional Administrator by March 1 of each even-numbered year using EPA Form 8700-13B.}

The MOC will begin submitting TRU mixed waste data for the TSDF biennial report once TRU mixed was is received at WIPP.

25.2.4.27 Unmanifested Waste Report, 40 CFR § 264.76 (20 NMAC 4.1, § 500)

A report must be submitted to the Regional Administrator for any hazardous waste accepted for treatment, storage, or disposal that is not accompanied by a hazardous waste manifest.

As stated in the Permit Attachment B (Waste Analysis Plan) and in the WAC, a hazardous waste manifest shall be transmitted with each shipment of TRU mixed waste to WIPP. Therefore, no mixed waste will be accepted that is not accompanied by a hazardous waste manifest. No TRU mixed waste shipments were received at WIPP during the reporting period.

25.2.4.28 Additional Reports, 40 CFR § 264.77 (20 NMAC 4.1, § 500)

Additional reports required of the owner or operator of a TSDF by the Regional Administrator are reports relating to releases, fire, or explosions; groundwater contamination and monitoring data; facility closure; and air emissions under Subparts $A A$ and $B B$ of this part.

Additional reports will be submitted as specified in Module I of the Hazardous Waste Facility Permit. Whenever it becomes necessary to partially or finally close WIPP, the DOE will notify the NMED, in writing, at least 60 days prior to the date on which such closure will commence, as specified by DOC MOC procedure. Subparts AA and BB do not apply at WIPP; therefore, no reporting is required at WIPP under these subparts. 
Subpart CC did not apply to WIPP, except as discussed in section 25.1 above, during this reporting period.

25.2.4.29 Applicability [of the Groundwater Monitoring System], 40 CFR $\S 264.90$ (20 NMAC 4.1, § 500)

A groundwater monitoring system is required by the owner or operator of a surface impoundment, landfill, or land treatment facility used to manage hazardous waste. All or part of the groundwater monitoring requirements may be waived if the owner/operator can demonstrate that there is no potential for migration of liquid from the facility via the uppermost aquifer to water supply wells or to surface water. The demonstration, in writing, must be certified by a qualified geologist or geotechnical engineer.

A groundwater detection monitoring program is required by Attachment $L$ (WIPP Groundwater Detection Monitoring Program Plan) of the Hazardous Waste Facility Permit. This program has been implemented.

25.2.4.30 Required Programs, 40 CFR $\S 264.91$ (20 NMAC 4.1, § 500)

The owner or operator must institute a detection monitoring program. The Regional Administrator will specify in the facility permit the specific elements of the program.

Attachment $L$ of the Hazardous Facility Waste Permit is the WIPP Groundwater Detection Monitoring Plan.

25.2.4.31 Groundwater Protection Standard, 40 CFR § 264.92 (20 NMAC 4.1, § 500)

The owner or operator must comply with conditions specified in the facility permit that are designed to ensure that hazardous constituents detected in the groundwater do not exceed concentration limits under 40 CFR $\S 264.94$.

Sampling, monitoring, and analytical requirements for the groundwater monitoring system are contained in the WIPP Groundwater Detection Monitoring Plan.

25.2.4.32 Hazardous Constituents, 40 CFR § 264.93 (20 NMAC 4.1, § 500)

The Regional Administrator will specify in the facility permit the hazardous constituents to which the groundwater protection standard applies.

The NMED has specified the target analytes for WIPP groundwater monitoring program. These are in Module V, Table V.D., in the Hazardous Waste Facility Permit. 
25.2.4.33 Concentration Limits, 40 CFR $§ 264.94$

The Regional Administrator will specify in the facility permit concentration limits in the groundwater for hazardous constituents.

The NMED included background water quality for the identified parameters and constituents in the Hazardous Waste Facility Permit upon receipt of background quality reports filed in April 1998 (see section 25.2.4.36.4 below).

25.2.4.34 Point of Compliance, 40 CFR § 264.95 (20 NMAC 4.1 § 500)

The Regional Administrator will specify in the facility permit the point of compliance at which the groundwater protection standard applies and at which monitoring must be conducted.

The point of compliance is specified in section V.B of the Hazardous Waste Facility Permit.

25.2.4.35 Compliance Period, 40 CFR § 264.96 (20 NMAC $4.1 \S 500$ )

The Regional Administrator will specify in the permit the compliance period during which the groundwater protection standard applies.

The compliance period will begin with emplacement of TRU mixed waste and will continue through the postclosure phase as specified in the Preparedness and Prevention Plan.

25.2.4.36 General Groundwater Monitoring Requirements, 40 CFR $\S 264.97$ (20 NMAC $4.1 \S 500)$

25.2.4.36.1 The groundwater monitoring system must consist of a sufficient number of wells installed at appropriate locations and depths to yield groundwater samples from the uppermost aquifer.

The number of wells and the well locations are identified in Module V, Table V.C.1 in the Hazardous Waste Facility Permit.

25.2.4.36.2 The groundwater monitoring program must include consistent sampling and analysis procedures. The groundwater monitoring program must include sampling and analytical methods that are appropriate for groundwater sampling and that accurately measure hazardous constituents in groundwater samples.

The sampling and analysis procedures are addressed in section V.E and the Preparedness and Prevention Plan of the Hazardous Waste Facility Permit. 
25.2.4.36.3 The groundwater monitoring program must include a determination of the groundwater surface elevation each time groundwater is sampled.

Groundwater surface elevations are obtained before sampling activities occur, as specified in section V.G. and the Preparedness and Prevention Plan of the Hazardous Waste Facility Permit.

25.2.4.36.4 Data on each hazardous constituent specified in the permit will be collected from background wells and wells at the compliance point. The number and kinds of samples collected to establish background shall be appropriate for the form of statistical test employed. Groundwater monitoring data, including actual levels of constituents must be maintained in the facility operating record. The Regional Administrator will specify in the permit when the data must be submitted for review.

Statistical procedures are specified in the Preparedness and Prevention Plan.

Groundwater monitoring results for required parameters and hazardous constituents were reported in April 1998. Monitoring data is maintained in the facility operating record in accordance with Module V of the Hazardous Waste Facility Permit.

\subsubsection{Detection Monitoring Program, 40 CFR § 264.98 (20 NMAC $4.1 \S 500$ )}

25.2.4.37.1 The Regional Administrator will specify the parameters or constituents to be monitored in the facility permit.

The parameters and constituents to be monitored are listed in Table V.D. of the Hazardous Waste Facility Permit

25.2.4.37.2 The Regional Administrator will specify the frequencies for collecting samples and conducting statistical tests to determine whether there is statistically significant evidence of contamination for any parameter or hazardous constituent specified in the permit.

The sampling frequency is specified in section V.E.1 and in Table L-2 of the Hazardous Waste Facility Permit.

25.2.4.37.3 The owner or operator must determine the groundwater flow rate and direction at least annually.

Groundwater flow rate and direction will be determined at least annually as specified in section V.H. of the Hazardous Waste Facility Permit. 
25.2.4.37.4 The owner or operator must determine whether there is statistically significant evidence of contamination for any chemical parameter or hazardous constituent specified in the permit.

Statistical analysis methods are specified in the WIPP Groundwater Detection Monitoring Plan. For each sampling event, comparisons will be made between the groundwater quality and the background groundwater quality using the specified statistical methods in accordance with section V.I. of the Hazardous Waste Facility Permit.

25.2.4.37.5 If the owner or operator determines there is statistically significant evidence of contamination, additional reporting and sampling are required. In addition, a permit modification to establish a compliance monitoring program and submittal of additional information are required.

The MOC will respond to any statistically significant contamination events as specified in the Hazardous Waste Facility Permit, Module V, Condition V.J. 3.

25.2.4.38 Corrective Action for Solid Waste Management Units, 40 CFR § 264.101

25.2.4.38.1 Corrective action will be specified in the permit in accordance with this section and Subpart $S$ of this part. The permit will contain schedules of compliance for such corrective action (where such corrective action cannot be completed prior to issuance of the permit) and assurances of financial responsibility for completing such corrective action.

There are 18 SWMUs identified in the Module VII of Hazardous Waste Facility Permit. Fifteen of the SWMUs require a RCRA Facility Investigation, while the remaining three do not. In addition there are eight Areas of Concern included in the Hazardous Waste Facility Permit.

The SWMUs and AOCs are described in the Technical Support Document, Exclusion/Inclusion of Solid Waste Management Units and Areas of Concern, Permit Module VII Correction Action for Solid Waste Management Units (TSD) (NMED, 1999b). The permit requires submittal of a Facility Work Plan and a RCRA Facility Investigation or Sampling and Analysis Plan. The Facility Work Plan was submitted to NMED on February 24, 2000. The Sampling and Analysis Plan (in lieu of a RCRA Facility Investigation) is being completed, but was not required to be submitted during this BECR reporting period. The Hazardous Waste Facility Permit includes the schedule for compliance in Table 1 to Module VII.

25.2.4.39 Applicability of the Closure/Postclosure Requirements, 40 CFR $\S 264.110$ (20 NMAC 4.1, § 500)

Closure and postclosure requirements apply to the owners and operators of all hazardous and mixed-waste management facilities. 


\section{Waste Isolation Pilot Plant Biennial Environmental Compliance Report}

DOE/WIPP 99-2171

The DOE has prepared a closure plan and a postclosure plan for WIPP. These are included in the Hazardous Waste Facility Permit as Attachment I (Closure Plan) and Attachment J (Post-Closure Plan).

25.2.4.40 Closure Performance Standard, 40 CFR § 264.111 (20 NMAC 4.1, § 500)

A closure performance standard is required to minimize the need for further maintenance; to control, minimize, or eliminate the post-closure escape of hazardous waste, hazardous constituents, leachate, contaminated runoff, or hazardous waste decomposition products to the environment; and to comply with the other closure requirements of this subpart.

In accordance with the Closure Plan in the Hazardous Waste Facility Permit, closure will be deemed complete when all hazardous waste and hazardous waste residues have been removed from the storage units, all equipment and structures associated with the operation of the units have been decontaminated, the panels and facility are closed, and unit closure certification has been submitted to and approved by the NMED.

25.2.4.41 Closure Plan; Amendment of Plan, 40 CFR § 264.112 (20 NMAC 4.1, § 500)

The owner/operator of a hazardous or mixed-waste management facility must have a written closure plan. The plan must identify the steps necessary to perform partial and/or final closure of the facility. The plan may be amended as needed. The owner or operator must notify the Regional Director in writing prior to the date on which closure will begin.

The CAO has prepared a written closure plan to satisfy the RCRA closure requirements. The NMED has incorporated this plan into the Hazardous Waste Facility Permit as the Closure Plan. The plan addresses the required steps for closure.

Should it become necessary to amend the WIPP closure plan, the DOE will submit a written notification of, or request for, a permit modification describing any change in operation, facility design, or storage/disposal designs that affect the closure plan.

25.2.4.42 Time Allowed for Closure, 40 CFR § 264.113 (20 NMAC 4.1, § 500)

Within 90 days after receipt of the final volume of hazardous mixed waste at a hazardous waste management unit or facility, the owner or operator must treat, remove, or dispose of all hazardous/mixed wastes on site in accordance with the approved closure plan. Partial or final closure activities must be complete in accordance with the approved closure plan within 180 days of receipt of the final volume of waste. An extension of time may be allowed if the owner/operator can demonstrate 
that the activities required will take longer than the allotted time period and has taken and will continue to take all steps necessary to prevent threats to human health and the environment from the unclosed but nonoperational facility.

The time allowed for closure is addressed in the Hazardous Waste Facility Permit.

25.2.4.43 Disposal or Decontamination of Equipment, Structures, and Soils, 40 CFR § 264.114 (20 NMAC 4.1, § 500)

During the partial and final closure periods, all contaminated equipment, structures, and soils must be properly disposed of or decontaminated. By removing all hazardous constituents during closure, the owner/operator may become a mixed or hazardous waste generator and must handle all such waste in accordance with the requirements of 40 CFR 262.

The regulatory requirements for the disposal or decontamination of equipment, structures, and soils are addressed in MOC procedures, and are broken down into four subsections. These include the removal of hazardous waste residues; the decontamination of equipment, structures, and soils; personnel decontamination; and sampling and QA.

25.2.4.44 Certification of Closure, 40 CFR $\S 264.115$ (20 NMAC 4.1, § 500)

Within 60 days of the completion of closure of each landfill unit and within 60 days of completion of final closure, the owner/operator must submit a certification that the hazardous or mixed waste unit has been closed in accordance with the specifications in the approved closure plan. The certification must be sent to the Regional Administrator by registered mail and must be signed by the owner/operator and by an independent registered professional engineer.

The DOE will submit the Certification of Closure to the Secretary of the NMED within 60 days of completion of panel closure and final closure activities.

25.2.4.45 Survey Plat, 40 CFR $\S 264.116$ (20 NMAC 4.1, § 500)

The owner/operator must submit a survey plat to the Regional Administrator and the authority with jurisdiction over local land use no later than the submittal of the certification of closure. The survey plat must indicate the location and dimensions of landfill cells or other hazardous waste disposal units with respect to permanently surveyed benchmarks. The plat must be prepared and certified by a professional land surveyor. 
The survey plat will be submitted to the NMED following closure. The survey plat will indicate the location and dimensions of hazardous waste disposal units with respect to permanently surveyed benchmarks. The plat will be prepared and certified by a professional land surveyor and will contain a prominently displayed note that states the DOE's obligation to restrict disturbance of the hazardous waste disposal unit.

25.2.4.46 Postclosure Care and Use of Property, 40 CFR $\S 264.117$ (20 NMAC 4.1, $\S 500)$

Postclosure care for each hazardous/mixed-waste unit must begin after completion of closure and continue for 30 years after that date. All postclosure care must be performed in accordance with the postclosure plan for the facility.

Postclosure care and use of property will be performed in accordance with the PostClosure Plan.

25.2.4.47 Postclosure Plan; Amendment of Plan, 40 CFR § 264.118 (20 NMAC 4.1, $\S 500)$

The owner/operator of a hazardous or mixed waste disposal unit must have a written postclosure plan. The plan, approved by the Regional Administrator or designee, may be amended subject to the Regional Administrator's approval.

The Post-Closure Plan is Attachment $\mathrm{J}$ of the Hazardous Waste Facility Permit.

25.2.4.48 Postclosure Notices, 40 CFR § 264.119 (20 NMAC 4.1, § 500)

A record of the type, location, and quantity of hazardous/mixed wastes disposed of within each unit must be submitted to the NMED and the authority with jurisdiction over local land use no later than 60 days after submittal of the certification of closure. Within the same time frame, the owner/operator must also record a notation in the deed to the facility that the facility has been used to manage hazardous/mixed wastes and that the record of type, location, and quantity of waste disposal has been filed; the owner/operator must also certify that this notation has been recorded as required.

The DOE will submit to the NMED and to Eddy County within 60 days after certification of final closure, a Registered Professional engineer's certification. The DOE will also assure that this notification is properly recorded in the deed to the facility. 
25.2.4.49 Certification of Completion of Postclosure Care, 40 CFR $\S 264.120$ (20 NMAC 4.1, § 500)

Within 60 days of the completion of postclosure of each landfill unit and within 60 days of completion of final postclosure, the owner/operator must submit a certification that the hazardous or mixed-waste unit has been closed in accordance with the specifications in the approved postclosure plan. The certification must be sent to the NMED Secretary by registered mail and must be signed by the owner/operator and by an independent registered professional engineer.

The DOE will notify the NMED within 60 days after completion of postclosure care, with a Registered professional engineer's certification that the postclosure care period was performed in accordance with the Post-Closure Plan.

25.2.4.50 Cost Estimate for Closure, 40 CFR § 264.142 (20 NMAC 4.1, § 500)

The owner/operator must provide a detailed written estimate of the cost of closing the facility.

The closure and postclosure cost estimate is included in the Hazardous Waste Facility Permit, Attachment K (Financial Requirements).

25.2.4.51 Financial Assurance for Closure, 40 CFR § 264.143 (20 NMAC 4.1, § 500)

The owner/operator of each facility must establish financial assurance for closure of the facility.

The NMED has required that the MOC comply with the RCRA financial assurance provisions. The MOC has provided for a trust fund to meet this requirement.

25.2.4.52 Cost Estimate for Post-Closure Care, 40 CFR $\S 264.144$ (20 NMAC 4.1, $\S 500)$

The owner/operator of each TSDF must provide a detailed written cost estimate for postclosure monitoring and maintenance of the facility.

The closure and postclosure cost estimate is included in the Hazardous Waste Facility Permit Attachment K (Financial Requirements). 
25.2.4.53 Financial Assurance for Post-Closure Care, 40 CFR $\S 264.145$ (20 NMAC 4.1, § 500)

The owner/operator of a hazardous or mixed waste disposal unit must establish financial assurance for postclosure care of the disposal unit(s).

The NMED has required that the MOC comply with the RCRA financial assurance provisions. The MOC has provided for a trust fund to meet this requirement.

25.2.4.54 Use of a Mechanism for Financial Assurance of Both Closure and Post-Closure Care, 40 CFR § 264.146 (20 NMAC 4.1, § 500)

The owner/operator may satisfy the requirements for financial assurance by using a mechanism such as a trust fund, security bond, letter of credit, etc.

The NMED has required that the MOC comply with the RCRA financial assurance provisions. The MOC has chosen a trust fund as the specific mechanism for satisfying these requirements.

25.2.4.55 Liability Requirements, 40 CFR § 264.147 (20 NMAC 4.1, § 500)

An owner/operator of a TSDF must demonstrate financial responsibility for bodily injury and property damage from accident occurrences arising from operations of the TSDF.

The NMED has required that the MOC comply with the RCRA liability requirements. The liability coverage amounts are included in the Hazardous Waste Facility Permit.

\subsubsection{Compliance with the Hazardous/Mixed Waste Permit Program, 40 CFR 270 (20 NMAC 4.1, §§ 900 and 901)}

The requirements of 40 CFR 270 pertain to general Hazardous Waste Facility permitting requirements for TSDFs and include provisions for submitting applications, standard permit conditions, monitoring and reporting requirements, and modifying permits. The compliance status of each applicable requirement is summarized in the text below.

25.2.5.1 Purpose and Scope of the Hazardous Waste Facility Permit Program Regulations, 40 CFR § 270.1 (20 NMAC 4.1, § 900)

The purpose and scope of the Hazardous Waste Facility Permit program regulations are defined, and the regulations are summarized. 
The DOE submitted a Hazardous Waste Facility Permit application to the EPA and to the NMED for the disposal phase. In May and August 1998, the NMED issued drafts of the Hazardous Waste Facility Permit for WIPP. The DOE submitted comments both drafts. Hearings on the draft permit and final permit issuance occurred in February and March 1999, respectively.

25.2.5.2 Signatories to Permit Applications and Reports, 40 CFR $\S 270.11$ (20 NMAC 4.1, § 900)

Signatories to permit applications shall be by a senior executive officer with responsibility for overall operations for a federal agency and/or a responsible corporate officer for a corporation. Reports and plans required by permits (e.g., the annual waste minimization plan) and other information requested shall be signed by a duly authorized representative. Any person signing one of these documents is required to make the certification statement specified in 40 CFR $\S 270.11(d)$.

The requirement is incorporated into the Hazardous Waste Facility Permit in Module I, section IE. Signatory requirement and apportionment of the signatory authority were discussed in Part A to the Permit Application.

25.2.5.3 Conditions Applicable to all Permits, 40 CFR $\S 270.30$ (20 NMAC 4.1, $\S 900)$

Conditions applicable to all permits are specified and include duty to comply, duty to reapply, minimization of releases, proper operation and maintenance, permit actions, property rights, duty to provide information, inspection and entry, monitoring and records, signatory requirements, and reporting requirements.

The general permit conditions are incorporated into the Module I of the Hazardous Waste Facility Permit.

25.2.5.4 Requirements for Recording and Reporting of Monitoring Results, 40 CFR § 270.31 (20 NMAC 4.1, § 900)

Requirements for recording and reporting monitoring results will be specified in the Hazardous Waste Facility Permit.

The requirements for recording and reporting monitoring results are incorporated into the Hazardous Waste Facility Permit. 
25.2.5.5 Permit Modification at the Request of the Permittee, 40 CFR $\S 270.42$ (20 NMAC 4.1, §§ 900 and 901)

After a Hazardous Waste Facility Permit has been finalized, the permittee may request that it be modified. Three classes of modifications are identified in Appendix I to 40 CFR $\$ 270.42$.

Class 1, the least significant of the permit modifications, covers minor modifications such as the correction of typographical errors; changes to conform with agency guidelines or regulations; or procedural changes that increase the frequency of monitoring, reporting, sampling, or maintenance activities. Class 1 modifications require notification of the Director within 7 days after the change has been made; all persons on the facility mailing list must be notified within 90 calendar days after the change is put into effect or after the request, whichever applies.

Class 2 modifications are more extensive and significant and apply to changes needed to allow timely response to common variations in the types and quantities of wastes managed, technological advancements, and changes in the regulations (e.g., changes in emergency procedures or removal of equipment from the emergency equipment list). They require that the permittee submit a modification request to the Director, announce a 60-day comment period, notify all persons on the facility mailing list, publish the notice in a major local newspaper of general circulation, and hold a public meeting.

Class 3 modifications are the most significant and potentially impactive and substantially alter the facility or its operation (e.g., extending the closure period or a final compliance date; creating a new landfill or other type of unit or increasing the capacity of a preexisting one). The notification and other requirements are similar to those for Class 2 modifications.

The DOE has notified the NMED of several Class 1 modifications since issuance of the Hazardous Waste Facility Permit.

\subsubsection{Compliance with the Universal Waste Management Regulations under 20 NMAC Subpart X, § 1000 (40 CFR 273)}

25.2.6.1 Standards for Universal Waste, Small Quantity Handlers, 40 CFR 273, Subpart B (20 NMAC 4.1,Subpart X)

Small-quantity handlers are those who accumulate less than 5,000 kilograms of universal waste at any one time. 
WIPP is a small quantity handler of universal waste.

25.2.6.2 Prohibitions, 40 CFR $\S 273.11$

Universal waste is not to be disposed of or diluted or treated to render it less hazardous (except in the possible case of releases from universal waste).

Universal waste is not treated. Universal waste is shipped off site to a permitted TSDF.

25.2.6.3 Waste Management, 40 CFR $\S 273.13$

Universal waste must be properly contained so as to prevent releases and must lack evidence of leakage, spillage, etc.

Universal waste is managed similarly to hazardous waste at WIPP. It is contained, stored in the hazardous waste accumulation area and inspected weekly for evidence of spillage or leakage.

\subsubsection{Labeling/Marking, 40 CFR § 273.14}

Universal waste must be labeled or marked appropriately (e.g., universal waste batteries).

Universal waste is only managed in the WIPP hazardous waste storage area and is marked according to 40 CFR $\S 273.14$

25.2.6.5 Accumulation Time Limits, 40 CFR $\S 273.15$

A small-quantity universal waste handler may accumulate universal waste for up to one year from the date the waste was generated. A log, inventory or labeling/marking should be used to show the date that each item of universal waste was placed in the universal waste collection container in a specific accumulation area.

The MOC logs the date universal waste enters the hazardous waste storage area at WIPP and marks the container with the date that the waste was first placed into the container.

25.2.6.6 Employee Training, 40 CFR $\S 273.16$

Employees who handle or are responsible for managing universal waste should be provided with the appropriate information needed with respect to proper handling and 
appropriate emergency procedures for the type of universal waste being managed at the facility.

The handlers of universal waste and those responsible for its management are trained hazardous waste workers. This training applies to universal waste as well.

25.2.6.7 Responses to Releases, 40 CFR $\S 273.17$

All releases of universal wastes and residues from such wastes must be contained immediately; any material resulting from the release must be assessed to determine if it is hazardous waste; if so, it must be managed in compliance with all applicable $R C R A$ regulations.

No releases of universal waste occurred during the reporting period. Any such releases of universal waste will be characterized and managed similarly to releases of hazardous waste utilizing the same procedures and processes in place for hazardous waste.

25.2.6.8 Off-Site Shipments, 40 CFR $\S 273.18$

A small-quantity universal waste generator may send its universal waste only to another universal waste handler, a destination facility, or a foreign destination.

Universal waste is shipped to an off-site permitted TSDF.

\subsubsection{Compliance with the UST Regulatory Requirements under 20 NMAC, Chapter 5}

This section of the report will examine the New Mexico UST requirements as they pertain to WIPP. Compliance status is summarized in the text below.

25.2.7.1 Applicability, 20 NMAC 5.1, § 103; 40 CFR $\S 280.10$

Any owner or operator of an UST that contains a hazardous substance or petroleum product must meet the standards set by the New Mexico Environmental Improvement Board (EIB) in the New Mexico Underground Storage Tank Regulations (USTRs).

There are two 8,000-gallon USTs at WIPP; one contains unleaded gasoline, and the other contains diesel fuel.

25.2.7.2 Existing Tanks, 20 NMAC 5.2, § 200

The owner of any UST must register such tank or tanks with the Underground Storage Tank section of the NMED within three 
months after April 14, 1988, the effective date of this Part II as first adopted, except that any owner who has filed the form of notice entitled "Notification for Underground Storage Tanks," prescribed by the EPA and described in 40 CFR 280, is not required to register a tank for which a notice has been filed, provided that the information provided is still current.

Registration becomes effective upon receipt of the first year's annual fee described in sections 25.2.7.10 and 25.2.7.11 below. Registration must by renewed annually by payment of the annual fee until the permanent closure of the tank.

Both USTs at WIPP are registered with the UST Bureau of the NMED.

25.2.7.3 Transfer of Ownership, 20 NMAC 5.2, § 201

If ownership of the UST system changes, the new owner must re-register the tank with the division within 30 days of ownership transfer, using a form provided by the division.

This section is not applicable since ownership of the tanks has not been transferred.

25.2.7.4 New UST System, 20 NMAC 5.2, § 202

The owner must notify the division in writing at least 30 days before any new tank or UST system is installed and must register any new tank or UST system with the division prior to placing it in service.

No new UST systems were installed during this reporting period.

25.2.7.5 Substantially Modified UST Systems, 20 NMAC 5.2, § 203

When an existing UST system is substantially modified or replaced, the owner must notify the division in writing of such modification or replacement at least 30 days prior to the modification or replacement. Emergency repairs or replacements are exempt from these notification requirements.

No UST systems were substantially modified during this reporting period.

25.2.7.6 Notification of Spill or Release, 20 NMAC 5.2, § 204

Notice of any known or suspected release from a UST system, any spill, or any other emergency situation must be given to the NMED by telephone within 24 hours. The owner or operator making the report shall provide the information specified under section 204(A). 
Written notice describing the spill, release, or suspected release and any investigation or follow-up action taken or to be taken must be mailed or delivered to the NMED within seven days of the incident. The written notice shall verify the prior oral notification as to each of the items of information listed in subsection $A$ and provide any appropriate additions or corrections to the information contained in the prior oral notification.

No releases from USTs have occurred during this reporting period. However, if this should occur, MOC procedures discuss the requirements for the proper handling of spills and releases.

25.2.7.7 Emergency Repairs and Tank Replacement, 20 NMAC 5.2, § 205

Immediate repairs or replacement of an UST system may be made in the event an emergency situation presents a threat to the public health, provided notice is given to the NMED

No such emergency repair or replacement of a UST system was necessary during this reporting period.

25.2.7.8 Application Forms, 20 NMAC 5.2, § 206

All USTs must be registered on application forms provided by the NMED unless the EPA form (Notification for Underground Storage Tanks) has been submitted to the NMED and all information contained therein is still accurate. An application submitted by a municipal, state, or other public facility must be signed by either a principal executive officer, ranking elected official, or other duly authorized employee.

The New Mexico UST registration form is used to register the USTs at WIPP. It is submitted annually to the NMED.

25.2.7.9 Registration Certificate, 20 NMAC 5.2, § 207

Upon submittal of a complete registration application or the EPA form and payment of the annual fee, the NMED shall issue a validated registration certificate which is current and valid and must be displayed on the premises of the UST system at all times. In the event that any information provided on the registration form or the EPA form changes or is no longer accurate, the change must be reported to the NMED on the appropriate form within 30 days. 
The current registration certificate from the NMED is displayed in Facility Operations at the WIPP facility.

25.2.7.10 Payment of Fee, 20 NMAC 5.3, $§ 300$

An annual per-tank fee shall be paid to the NMED no later than July 31 for each current calendar year or portion of a year that a tank is in use. A tank shall be deemed "in use" until notice is received by the NMED that the tank has been removed or otherwise permanently closed in a manner acceptable to the division.

The annual fee for a new tank placed in service after July 31 for any calendar year after 1989 shall be paid within 30 days after the tank is placed in service. The annual fees shall be designated to the Hazardous Waste and Underground Storage Tank Fund.

The annual fee per UST at WIPP is paid by July 31 for each calendar year

25.2.7.11 Amount of Fee, 20 NMAC 5.3, § 301

The annual fee for each UST is $\$ 100.00$ per tank.

The annual fee paid for each UST at WIPP is $\$ 100$, or $\$ 200$ for both tanks.

25.2.7.12 Late Payment Penalties, 20 NMAC 5.3, § 302

In the event that the annual fee is not paid when due, a late fee of $\$ 5.00$ or 5 percent of the unpaid fee, whichever is greater, and interest charges at the rate of 1.5 percent per month shall be imposed and shall accumulate until the annual fee and all accrued late fees and interest charges are paid.

No late payment penalties have been incurred.

25.2.7.13 Performance Standards for Tanks in New UST Systems, 20 NMAC 5.4 $\S 400 ; 40$ CFR $\S 280.20$ (a)

Each tank must be properly designed and constructed, and any portion underground must be protected from corrosion by a nationally recognized association or independent testing laboratory as specified. Each tank must be constructed of fiberglass-reinforced plastic; steel, with cathodic protection; or steel-fiberglass-reinforced-plastic composite. The tank may be constructed of metal without additional corrosion protection if 
the conditions apply as described in section 400(4) of 20 NMAC 5.4.

The tanks are designed and constructed of fiberglass-reinforced plastic in accordance with Underwriters Laboratories Standard 1316, Standard for Glass-Fiber-Reinforced Plastic Underground Storage Tanks for Petroleum Products, and with the American Society for Testing and Materials Standard D4021-86, Standard Specification for Glass-Fiber-Reinforced Polyester Underground Petroleum Storage Tanks.

25.2.7.14 Design and Construction of Piping, 20 NMAC 5.4, § 400(B); 40 CFR $\S 280.20(b)$

The piping that routinely contains regulated substances and is in contact with the ground must be properly designed, constructed, and protected from corrosion in accordance with a code of practice developed by a nationally recognized association or independent testing laboratory as specified. The piping is constructed of fiberglass-reinforced plastic; or steel, with cathodic protection; or metal without additional corrosion protection measures provided that the piping is installed at a noncorrosive site and records are maintained that demonstrate the noncorrosivity of the site for the remaining life of the piping. The piping construction and corrosion protection are determined by the implementing agency to be designed to prevent the release or threatened release of any stored regulated substance in a manner that is no less protective of human health and the environment.

The piping is constructed of fiberglass-reinforced plastic as designed by the Xerxes Corporation in accordance with the appropriate standards.

25.2.7.15 Spill Prevention Equipment, 20 NMAC 5.4, § 400(C); 40 CFR $\S 280.20$ (c)(1)(i)

Owners and operators must use spill prevention equipment that will prevent the release of product to the environment when the transfer hose is detached from the fill pipe (for example, a spill catchment basin).

WIPP's UST system uses a spill catchment basin.

25.2.7.16 Overflow Prevention Equipment, 20 NMAC 5.4, § 400(C)(1)(b); 40 CFR $\S 280.20$ (c)(1)(ii)

Overfill-prevention equipment must be used that will automatically shut off flow into the tank when the tank is no more than 95 percent full; alert the transfer operator when the 
tank is no more than 90 percent full by restricting the flow into the tank or triggering a high-level alarm; or restrict the flow 30 minutes prior to overfilling, alert the operator with a high-level alarm one minute before overfilling, or automatically shut off flow into the tank so that none of the fittings located on top of the tank is exposed to product due to overfilling. Owners and operators may use alternative equipment if it is determined by the implementing agency to be no less protective of human health and the environment than the equipment specified above or if the UST system is filled by transfers of no more than 25 gallons at one time.

The Model 310 extractor vent valve is used to automatically shut off the flow into the tank when the tank is no more than 95 percent full. This valve is a permanent part of the system.

25.2.7.17 Installation of Tanks and Piping, 20 NMAC 5.4, § 400(D); 40 CFR § 280.20 (d)

All tanks and piping must be properly installed in accordance with a code of practice developed by a nationally recognized association or independent testing laboratory and in accordance with the manufacturer's instructions.

The installer (Cline Pump Co.) certified on the NMED application that the methods used to install the tanks and piping comply with the requirements. Cline Pump has supplied the CAO with copies of qualified certification.

25.2.7.18 Certificate of Installation, 20 NMAC 5.4, § 400(E); 40 CFR § 280.20(e)

All owners and operators must ensure that one or more of the specified methods of certification, testing, or inspection was used to demonstrate compliance with section 25.2.7.17 above by providing a certification of compliance on the UST notification form required by 20 NMAC 5.2. The allowable methods of certification for the installer are: certification by the tank and piping manufacturers; certification or licensing by the implementing agency; inspection and certification of the installation by a registered professional engineer with education and experience in UST system installation, inspection and approval by the implementing agency, or the presence of a representative from the UST Bureau of the NMED at the installation; completion of all work listed on the manufacturer's installation checklists; or compliance with another method for ensuring compliance with this section that is determined by the 
implementing agency to be no less protective of human health and the environment.

Cline Pump Company is certified by the NMED. The installation of the new systems was inspected and approved by an NMED representative who was present during the installation.

25.2.7.19 Upgrading Existing UST Systems, 20 NMAC 5.4, § 401(A); 40 CFR § 280.21(a)

All existing UST systems must be upgraded to meet the new performance standards, the requirements described in sections 25.2.7.20 through 25.2.7.22 below, or the closure requirements described in sections 25.2.7.66 through 25.2.7.73 below by December 22, 1998.

The UST system meets the new performance standards; therefore, upgrading is not appropriate at this time. A March 11, 1998, compliance inspection by the NMED UST Bureau confirmed that WIPP meets all December 1998 compliance standards.

25.2.7.20 Tank Upgrading Requirements, 20 NMAC 5.4, § 401(B); 40 CFR $\S 280.21$ (b)

Steel tanks must be upgraded to have an interior lining and/or cathodic protection.

The new tanks are constructed of fiberglass-reinforced plastic and are not constructed of steel. Therefore this requirement is not applicable.

25.2.7.21 Piping Upgrading Requirements, 20 NMAC 5.4, § 401(C); 40 CFR § 280.21 (c)

Metal piping that routinely contains regulated substances and is in contact with the ground must be cathodically protected.

The piping for the UST system at WIPP is made of double-walled fiberglassreinforced plastic. Therefore this requirement is not applicable.

25.2.7.22 Spill and Overfill Prevention Equipment, 20 NMAC 5.4, § 401(D); 40 CFR § $280.21(d)$

To prevent spilling and overfilling associated with the transfer of product to the UST system, all existing UST systems must comply with the new UST system spill and overfill prevention equipment requirements specified in 20 NMAC 5.4, section $400(C)$. 
Spill and overfill prevention equipment has been incorporated into the UST system as described in sections 25.2.7.15, 25.2.7.16, and 25.2.7.17 above.

25.2.7.23 Certificate of Compliance and Notification Requirements, 20 NMAC 5.4, $\S 402 ; 40$ CFR $\S 280.22$

In the registration application required by 20 NMAC 5.2, all owners and operators of new UST systems must certify compliance with the installation requirements of USTR section 400(e), cathodic protection requirements for steel tanks and piping under sections 400(a) and (b), financial responsibility under 20 NMAC 5.9, and release detection under sections 601 and 602. The owners and operators must also ensure that the installer certifies that the methods used to install the tanks and piping comply with the requirements in section 400 (d).

The notification requirements pertain to the person who sells a tank intended to be used as an UST.

As outlined in the registration form, the certification requirements were met. The cathodic protection requirements are not applicable since neither the tank nor the piping is made of steel. The financial responsibility requirements are not applicable because WIPP is a federal facility. The notification requirements apply only to the person who sold the tank to be used as an UST and therefore do not apply to WIPP.

25.2.7.24 Spill and Overfill Control, 20 NMAC 5.5, § 500 (A); 40 CFR § 280.30

Owners and operators must ensure that any releases due to spilling or overfilling do not occur, that the volume available in the tank is greater than the volume of product to be transferred to the tank before the transfer is made, and that the transfer operation is monitored constantly to prevent overfilling and spilling. Any spills or overfills must be reported, cleaned up, and investigated in accordance with 20 NMAC, Chapter 5, sections 204 and 703.

The new tanks are equipped with spill and overfill protection equipment. Applicable MOC procedures are in place that govern the transfer of product to the tanks and that specify requirements for reporting, cleaning up, and investigating spills or overfills.

25.2.7.25 Operation and Maintenance of Corrosion Protection, 20 NMAC 5.5, $\S 501(\mathrm{~A}) ; 40 \mathrm{CFR} \S 280.31(\mathrm{a})$

All corrosion protection systems must be operated and maintained to continuously provide corrosion protection to the metal components of that portion of the tank and piping that 
routinely contain regulated substances and are in contact with the ground.

The corrosion protection consists of rubber boots around the metal fittings.

25.2.7.26 Inspections of Cathodic Protection System, 20 NMAC 5.5, § 501(B); 40 CFR $\S 280.31$ (b)

All UST systems equipped with cathodic protection systems must be inspected for proper operation by a qualified cathodic protection tester in accordance with requirements regarding the frequency of inspections and specific inspection criteria.

Cathodic protection is required only for steel tanks and metal parts. The metal fittings in the UST system are protected by rubber boots. Therefore, cathodic protection is not required.

25.2.7.27 Inspections of Impressed-Current Cathodic Protection Systems, 20 NMAC 5.5, § 501(C); 40 CFR § 280.31(c)

All UST systems with impressed-current cathodic protection systems must be inspected every 60 days to ensure that the equipment is running properly.

No cathodic protection systems are required for fiberglass-reinforced plastic systems.

25.2.7.28 Records of Operation of the Cathodic Protection System, 20 NMAC 5.5, $\S 501(\mathrm{D}) ; 40 \mathrm{CFR} \S 280.31(\mathrm{~d})$

For UST systems using cathodic protection, records of the operation of the cathodic protection system must be maintained in accordance with 40 CFR 280.34 to demonstrate compliance with the performance standards in this section. These records must provide the results of inspections.

No cathodic protection is required for fiberglass-reinforced plastic UST systems.

Therefore, this requirement does not apply.

25.2.7.29 Compatibility, 20 NMAC 5.5, § 502; 40 CFR § 280.32

Owners and operators must use an UST system made of or lined with materials that are compatible with the substance stored in the UST system.

Fiberglass-reinforced plastic is compatible with unleaded gasoline and diesel fuel. 
25.2.7.30 Repairs Allowed, 20 NMAC 5.5, § 503(A); 40 CFR § 280.33(a)

Repairs to UST systems must be properly conducted in accordance with a code of practice developed by a nationally recognized association or an independent testing laboratory.

No major repairs were required during this reporting period.

25.2.7.31 Repairs to Fiberglass-Reinforced Plastic Tanks, 20 NMAC 5.5, § 503(B); 40 CFR § 280.33(b)

Repairs to fiberglass-reinforced plastic tanks may be made by the manufacturer's authorized representatives or in accordance with a code of practice developed by a nationally recognized association or an independent testing laboratory.

No major repairs were required during this reporting period.

25.2.7.32 Repairs of Pipe Sections and Fittings, 20 NMAC 5.5, § 503(C); 40 CFR § $280.33(\mathrm{c})$

Metal pipe sections and fittings that have released product as a result of corrosion or other damage must be replaced.

Fiberglass pipes and fittings may be repaired in accordance with the manufacturer's specifications.

No repairs to pipes or fittings were performed during this reporting period.

25.2.7.33 Tightness Testing After Repairs, 20 NMAC 5.5, § 503(D); 40 CFR $\S 280.33(d)$

Repaired tanks and piping must be tightness tested in accordance with 20 NMAC 5.6, sections 603(d) and 604(b) within 30 days after the date of the completion of the repair except as provided in this section.

No repairs to tanks or piping were required during this reporting period.

25.2.7.34 Testing of Repaired Cathodically Protected UST System, 20 NMAC 5.5, $\S 503(\mathrm{E}) ; 40$ CFR § 280.33(e)

Within six months following the repair of any cathodically protected UST system, the cathodic protection system must be tested in accordance with 20 NMAC 5.5, sections 501(b) and (c) to ensure that it is operating properly.

The WIPP UST system does not require cathodic protection. 
25.2.7.35 Records of all Repairs, 20 NMAC 5.5, § 503(F); 40 CFR § 280.33(f)

UST system owners and operators must maintain records of each repair for the remaining operating life of the UST system to demonstrate compliance with the requirements of this section.

No repairs were performed on the USTs during this reporting period. However, when UST system repairs are necessary, the records will be maintained at WIPP for the life of the UST system.

25.2.7.36 Reporting, 20 NMAC 5.5, § 504(A); 40 CFR § 280.34(a)

Owners and operators must submit the following information to the NMED: registration of all UST systems, including certification of installation for new UST systems ( 20 NMAC 5.2); reports of all releases (including suspected releases, spills, and overfills) and confirmed releases; corrective actions planned or taken; and a notification before permanent closure or change in service.

The applicable information in this requirement has been submitted to the NMED. Spill, overfill, and release reporting requirements are addressed by MOC procedures.

25.2.7.37 Record Keeping Requirements, 20 NMAC 5.5, § 504(B); 40 CFR § 280.34(b)

Owners and operators must maintain the following information: a corrosion expert's analysis of site corrosion potential if corrosion protection equipment is not used, documentation of operation of corrosion protection equipment, documentation of UST system repairs, recent compliance with release detection requirements, and the results of the site investigation required prior to permanent closure.

Rubber boots are placed around steel joints of the UST system. The rubber boots are considered adequate to meet the corrosion protection requirements since the tank and piping consist of fiberglass-reinforced plastic. Metal flex elbow fittings are contained within the rubber boots, which separate them from contact with the ground.

Applicable MOC procedures specify the retention time for records of UST system repairs.

An MOC procedure addresses the retention of monitoring results. Correspondence WD 93:00280 contains the tank closure form as an attachment. 
25.2.7.38 Availability and Maintenance of Records, 20 NMAC 5.5, § 504(C); 40 CFR $\S 280.34(c)$

The applicable records must be kept either at the UST site and immediately available for inspections by the NMED or at a readily available alternative site and be provided to the NMED upon request.

The UST records are maintained at the WIPP site and are readily available to NMED inspectors.

25.2.7.39 Inspections, Monitoring, and Testing of USTs, 20 NMAC 5.5, § 505(A)

Any owner or operator of an UST shall, upon the request of the director or authorized NMED representatives, furnish information relating to the UST(s), conduct monitoring or testing, and allow the NMED representative to have access to the USTS and to copy all records relating to such tanks at all reasonable times. NMED officers, employees, or representatives will be allowed to inspect the UST system(s) and obtain samples of their contents and to conduct monitoring or testing of the tanks and its associated equipment or the surrounding soils, air, surface water, or groundwater.

NMED personnel are allowed to inspect the UST systems at any reasonable time. They are also allowed to sample the contents of the USTs. Monitoring or testing of the tanks and associated equipment and contents or the surrounding soils, air, or surface or groundwater may also be performed.

25.2.7.40 Inspections of UST Installations, Repairs or Modifications, or Removals or System Closures, 20 NMAC 5.5, § 505(C)

The owner and operator must allow the Director or authorized NMED representatives to be present at and inspect all UST system installations, replacements, repairs, substantial modifications, installations of leak detection systems, and UST system closures. To ensure that the inspector has an opportunity to be present during the steps in these procedures which are important to the prevention of releases, the owner or operator must give the NMED oral notice of the dates on which critical junctures in the installation, repair, substantial modification, or closure of the UST system are to take place. Oral notice must be given at least 24 hours in advance of the commencement of the procedure. The inspector may require that critical junctures be performed from Monday through Friday during regular business hours. 
A representative of the NMED UST Bureau was present at the installation of the UST systems on February 10, 1992.

25.2.7.41 General Requirements for all UST Systems, 20 NMAC 5.6, § 600(A); 40 CFR $\S 280.40(a)$

Owners and operators of new and existing UST systems must provide a method, or combination of methods, of release detection that can detect a release from any portion of the tank and the connected underground piping that routinely contains product; is installed, calibrated, operated, and maintained in accordance with the manufacturer's instructions, including routine maintenance and service checks for operability or running condition; meets the performance requirements; and must be capable of detecting the leak rate or quantity specified for that method in the corresponding section of the rule with a probability of detection of 0.95 and a probability of false alarm of 0.05 .

The UST system uses interstitial monitoring to detect releases. There are sensors between the walls at the lowest end of the piping and tank. Interstitial monitoring is adequate because it can detect a release through the inner wall in any portion of the double-walled tank and/or piping that regularly contains product. The system is equipped with an alarm that will sound in the event of a leak into the interstitial area. In addition, MOC personnel compile a weekly leak report to assure correct operations of the leak detection system. Calibration and maintenance of the leak detection system is done by a certified UST repairman.

25.2.7.42 Notification of Releases, 20 NMAC 5.6, § 600(B); 40 CFR § 280.40(b)

When a release detection method operated in accordance with the performance standards in 20 NMAC 5.6, sections 603 and 604 indicates that a release may have occurred, owners and operators must notify the NMED in accordance with 20 NMAC 5.2, section 204, and 20 NMAC 5.7.

No releases or suspected releases have occurred with the current UST system during this reporting period.

25.2.7.43 Schedule for Required Release Detection, 20 NMAC 5.6, § 600(C); 40 CFR $\S 280.40$ (c)

Owners and operators of all UST systems must comply with the release-detection requirements of this part by December 22 of the year listed in the schedule in 40 CFR $\$ 280.40$ (c). 
The current UST systems were installed on February 10, 1992. The current systems meet the release-detection requirements of this part.

25.2.7.44 Failure to Comply with Release-Detection Requirements, 20 NMAC 5.6, $\S 600(\mathrm{D}) ; 40$ CFR $\S 280.40(\mathrm{~d})$

Any existing UST system that cannot apply a release-detection method that complies with the requirements of this part must complete the closure procedures for the system by the date indicated in 20 NMAC 5.6, section 600(c)

The current UST system at WIPP uses a release-detection method that complies with the requirements of this part. Therefore, section USTR 600(d) does not apply to the WIPP UST systems.

25.2.7.45 Requirements for Tanks of Petroleum UST Systems, 20 NMAC 5.6, $\S 601(\mathrm{~A}) ; 40$ CFR § 280.41(a)

Tanks must be monitored at least every 30 days for releases using one of the methods listed in 20 NMAC 5.6, section 603 except that UST systems that meet the performance standards and the monthly inventory control requirements may use tank tightness testing at least every five years until December 22, 1998 , or until ten years after the tank is installed or upgraded, whichever is later; UST systems that do not meet the performance standards may use monthly inventory controls and annual tank tightness testing until December 22, 1998, when the tank must be upgraded or permanently closed; and tanks with a capacity of 550 gallons or less may use weekly tank gauging.

The interstitial monitoring system meets the release-detection requirement. Should the interstitial system become inoperable, monthly inventory controls will be used. In this contingency situation, tank tightness testing will be performed every five years.

25.2.7.46 Requirements for Piping of Petroleum UST Systems, 20 NMAC 5.6, $\S 601(\mathrm{~B}) ; 40$ CFR $\S 280.41(\mathrm{~b})$

Underground piping that routinely contains regulated substances must be monitored for releases in a manner that meets the requirements for pressurized or suction piping.

See section 25.2.7.48 below, which specifies the requirements for suction piping as used in the UST systems at WIPP. 
25.2.7.47 Requirements for Pressurized Piping, 20 NMAC 5.6, § 601(B)(1); 40 CFR $\S 280.41(b)(1)$

Underground piping that conveys regulated substances under pressure must be equipped with an automatic line leak detector and have an annual line-tightness test or have monthly monitoring conducted.

This requirement is not applicable since the current UST system operates under suction piping.

25.2.7.48 Requirements for Suction Piping, 20 NMAC 5.6, § 601(B)(2); 40 CFR § 280.41 (b)(2)

Underground piping that conveys regulated substances under suction must either have a line tightness test conducted at least every three years in accordance with 20 NMAC 5.6, section 604(B), or use a monthly monitoring method conducted in accordance with 20 NMAC 5.6, section 604(C). No release detection is required for suction piping that is designed and constructed to meet the following standards: the below-grade piping operates at less than atmospheric pressure; the below-grade piping is sloped so that the contents of the pipe will drain back into the storage tank if the suction is released; only one check valve is included in each suction line; the check valve is located directly below and as close as practical to the suction pump; and a method is provided that allows compliance with this section to be readily determined.

No release detection is required on the piping since the system was designed and constructed to meet each of the above requirements.

25.2.7.49 Requirements for Hazardous Substance UST Systems, 20 NMAC 5.6, $\S 602 ; 40$ CFR § 280.42

A number of release-detection requirements are specified for UST systems that contain hazardous substances.

There are no UST systems at WIPP that contain hazardous substances. Therefore, these requirements do not apply to this facility.

25.2.7.50 Methods of Release Detection for Tanks, 20 NMAC 5.6, § 603; 40 CFR $\S 280.43$

A number of requirements for the acceptable release-detection methods are specified. The release-detection methods described are: inventory control, manual tank gauging, tank- 
tightness testing, automatic tank gauging, vapor monitoring, groundwater monitoring, interstitial monitoring, and other methods.

The MOC uses interstitial monitoring to meet this requirement.

25.2.7.51 Inventory Control, 20 NMAC 5.6, § 603(A); 40 CFR § 280.43(a)

Product inventory control (or another test of equivalent performance) must be conducted monthly to detect a release of at least 1.0 percent of flow-through plus 130 gallons on a monthly basis in the following manner: inventory volume measurements for regulated substance inputs, withdrawals, and the amount still remaining in the tank are recorded each operating day; the equipment used is capable of measuring the level of product over the full range of the tank's height to the nearest one-eighth of an inch; the regulated substance inputs are reconciled with delivery receipts by measurement of the tank inventory volume before and after delivery; deliveries are made through a drop tube that extends to within 1 foot of the tank bottom; product dispensing is metered and recorded within the local standards for meter calibration or an accuracy of 6 cubic inches for every five gallons of product withdrawn; and the measurement of any water level in the bottom of the tank is made to the nearest one-eighth of an inch at least once a month.

Inventory control is a "contingency" method used only if the interstitial monitoring system fails. An MOC procedure addresses the requirements for using this method if this situation arises. Compliance with the requirement for a drop tube extending to within one foot of the tank bottom has been verified through discussions with the installing organization. The stick reading can measure to the nearest one-eighth of an inch.

25.2.7.52 Manual Tank Gauging, 20 NMAC 5.6, § 603(B); 40 CFR § 280.43(b)

Manual tank gauging must meet the following requirements: tank liquid level measurements are taken at the beginning and ending of a period of at least 36 hours during which no liquid is added to or removed from the tank; level measurements are based on an average of two consecutive stick readings at both the beginning and ending of the period; the equipment used is capable of measuring the level of product over the full range of the tank's height to the nearest one-eighth of an inch; a leak is suspected and subject to the requirements of 20 NMAC 5.7 if 
the variation between beginning and ending measurements exceeds the weekly or monthly standards in the table provided.

This requirement is not applicable since the UST system uses interstitial monitoring as the primary method of release detection.

25.2.7.53 Tank Tightness Testing, 20 NMAC 5.6, § 603(C); 40 CFR § 280.43(c)

Tank tightness testing (or another test of equivalent performance) must be capable of detecting a 0.1-gallon-perhour leak rate from any portion of the tank that routinely contains product while accounting for the effects of thermal expansion or contraction of the product, vapor pockets, tank deformation, evaporation or condensation, and the location of the water table.

Tank tightness testing is not required for the WIPP USTs. If the interstitial monitoring method fails, tank tightness testing will be performed every five years as part of the inventory control method.

25.2.7.54 Automatic Tank Gauging, 20 NMAC 5.6, § 603(D); 40 CFR § 280.43(d)

Equipment for automatic tank gauging that tests for the loss of product and conducts inventory control must meet the following requirements: the automatic product level monitor test can detect a 0.2-gallon-per-hour leak rate from any portion of the tank that routinely contains product, and inventory control (or another test of equivalent performance) is conducted in accordance with the requirements of 20 NMAC 5.6, section 603(a).

Automatic tank gauging is not used at WIPP; therefore, this method is not applicable.

25.2.7.55 Vapor Monitoring, 20 NMAC 5.6, § 603(E); 40 CFR § 280.43(e)

Testing or monitoring for vapors within the soil gas of the excavation zone must meet the following requirements: the materials used as backfill are sufficiently porous (e.g., gravel, sand, crushed rock) to readily allow diffusion of vapors from releases into the excavation area; the stored regulated substance (e.g., gasoline), or a tracer compound placed in the tank system, is sufficiently volatile to result in a vapor level that is detectable by the monitoring devices located in the excavation zone in the event of a release from the tank; the measurement of vapors by the monitoring device is not rendered inoperative by the groundwater, rainfall, soil moisture, or other known interferences so that a release could go 
undetected for more than 30 days; the level of background contamination in the excavation zone will not interfere with the method used to detect releases from the tank; the vapor monitors are designed and operated to detect any significant increase in concentration above background of the regulated substance stored in the tank system, a component or components of that substance, or a tracer compound placed in the tank system; in the UST excavation zone, the site is assessed to establish the number and positioning of monitoring wells that will detect releases within the excavation zone from any portion of the tank that routinely contains product; and monitoring wells are clearly marked and secured to avoid unauthorized access and tampering.

This method is not applicable to the WIPP USTs because there have been no released from the USTs.

25.2.7.56 Groundwater Monitoring, 20 NMAC 5.6, § 603(F); 40 CFR § 280.43(f)

Testing or monitoring for liquids in the groundwater must meet the following requirements: the regulated substance stored is immiscible in water and has a specific gravity of less than 1; groundwater is never more than 20 feet from the ground surface, and the hydraulic conductivity of the soil(s) between the UST system and the monitoring wells or devices is not less than $0.01 \mathrm{~cm} / \mathrm{sec}$ (e.g., the soil should consist of gravels, coarse to medium sands, coarse silts, or other permeable materials); the slotted portion of the monitoring well casing must be designed to prevent the migration of natural soils or filter pack into the well and to allow the entry of regulated substances on the water table into the well under both high and low groundwater conditions; monitoring wells shall be sealed from the ground surface to the top of the filter pack; monitoring wells or devices intercept the excavation zone or are as close to it as is technically feasible; the continuous monitoring devices or manual methods used can detect the presence of at least one-eighth of an inch of free product on top of the groundwater in the monitoring wells; within and immediately below the UST system excavation zone, the site is assessed to ensure compliance with the first five requirements of this section and to establish the number and positioning of the monitoring wells or devices that will detect releases from any portion of the tank that routinely contains product; and monitoring wells are clearly marked and secured to avoid unauthorized access and tampering. 
The requirements of this section are not applicable to WIPP. The regulations require that tanks be monitored for releases using one of several methods. The MOC utilizes interstitial monitoring at WIPP to meet the requirement.

25.2.7.57 Interstitial Monitoring, 20 NMAC 5.6, § 603(G); 40 CFR § 280.43(g)

Interstitial monitoring between the UST system and a secondary barrier immediately around or beneath it may be used, but only if the system is designed, constructed, and installed to detect a leak from any portion of the tank that routinely contains product and also meets one of the following requirements: for double-walled UST systems, the sampling or testing method can detect a release through the inner wall in any portion of the tank that routinely contains product; for UST systems with a secondary barrier within the excavation zone, the sampling or testing method used can detect a release between the UST system and the secondary barrier; the secondary barrier around or beneath the UST system consists of artificially constructed material that is sufficiently thick and impermeable (at least $10^{-6}$ $\mathrm{cm} / \mathrm{sec}$ for the regulated substance stored) to direct a release to the monitoring point and permit its detection; the barrier is compatible with the regulated substance stored so that a release from the UST system will not cause a deterioration of the barrier, allowing a release to pass through undetected; for cathodically protected tanks, the secondary barrier must be installed so that it does not interfere with the proper operation of the cathodic protection system; the groundwater, soil moisture, or rainfall will not render the testing or sampling method used inoperative so that a release could go undetected for more than 30 days; the site is assessed to ensure that the secondary barrier is always above the groundwater and is not located in a 25-year flood plain, unless the barrier and monitoring designs are for use under such conditions; monitoring wells are clearly marked and secured to avoid unauthorized access and tampering; and, for tanks with an internally fitted liner, an automated device can detect a release between the inner wall of the tank and the liner, and the liner is compatible with the substance stored.

The interstitial monitoring system is the primary method of release detection for the UST system. The as-built engineering drawings verify that this method can detect a release through the inner wall in any portion of the tank that routinely contains product. 
25.2.7.58 Other Methods of Detecting Releases, 20 NMAC 5.6, § 603(H); 40 CFR $\S 280.43(\mathrm{~h})$

Any other method may be used if it can detect a 0.2-gallon-perhour leak rate or a release of 150 gallons within a month with a probability of detection of 0.95 and a probability of false alarm of 0.05 , and it has been approved by the NMED.

The MOC does not use any methods of release detection other than the ones described in section 25.2.7.57 above.

25.2.7.59 Methods of Release Detection of Piping, 20 NMAC 5.6, § 604; 40 CFR $\S 280.44$

Each method of release detection for piping used to meet the requirements of 20 NMAC 5.6, section 601, must be conducted in accordance with specific requirements for automatic line leak detectors, line tightness testing, or applicable tank methods.

Since the system meets the requirements of 20 NMAC 5.6, section 601(B), line leak detectors are not required.

25.2.7.60 Release Detection Record Keeping, 20 NMAC 5.6, § 605; 40 CFR $\S 280.45$

All UST system owners and operators must maintain records in accordance with 20 NMAC 5.5, section 504, that demonstrate compliance with all applicable requirements in 20 NMAC 5.6. All written performance claims pertaining to any release detection system used, and the manner in which these claims have been justified or tested by the equipment manufacturer or installer, must be maintained for five years, or for another reasonable period of time determined by the NMED, from the date of installation. The results of any sampling, testing, or monitoring must be maintained for at least one year, or for any reasonable period of time determined by the NMED, except that the results of tank tightness testing conducted in accordance with 20 NMAC 5.6, section 603(C), must be retained until the next test is conducted. Written documentation of all calibration, maintenance, and repair of release-detection equipment permanently located on site must be maintained for at least one year after the servicing work has been completed or for any reasonable time period determined by the NMED. Any schedules of required calibration and maintenance provided by the release-detection equipment manufacturer must be retained for five years from the date of installation. 
The MOC purchasing group maintains the manufacturer's equipment and performance claims records. The Records Inventory and Disposition Schedule (RIDS) discusses the maintenance of these records. The RIDS adequately addresses the record retention requirements of this section. According to the manufacturer of the tanks, no calibration or maintenance is required for the current configuration. However, if modifications are made, these functions will need to be performed.

25.2.7.61 Reporting of Suspected Releases, 20 NMAC 5.7, § 700; 40 CFR § 280.50

Owners and operators of UST systems must report suspected releases to the NMED within 24 hours and follow the procedures in 20 NMAC 5.7, section 702, for any of the following conditions:

- The discovery by owners and operators or others of released regulated substances at the UST site or in the surrounding area

- Unusual operating conditions

- Monitoring results from a release detection method that indicate that a release may have occurred unless the monitoring device is found to be defective and is immediately repaired and subsequent monitoring does not confirm the initial results or, in the case of inventory control, a second month of data does not confirm the initial result.

No releases or suspected releases have occurred from the current UST system during this reporting period. An MOC procedure outlines the required steps above should a suspected release occur.

25.2.7.62 Investigation of Off-Site Impacts, 20 NMAC 5.7, § 701; 40 CFR § 280.51

When required by the NMED, owners and operators of UST systems must follow the procedures in 20 NMAC 5.7, section 702, to determine if the UST system is the source of offsite impacts.

The NMED has not requested off-site impact information.

25.2.7.63 Release Investigation and Confirmation Steps, 20 NMAC 5.7, § 702; 40 CFR § 280.52

Unless corrective action is initiated in accordance with 20 NMAC 5.12 and 5.13, owners and operators must immediately investigate and confirm all suspected releases of 
regulated substances that require reporting under 20 NMAC 5.7, section 700, within seven days using a system test and/or a site check as described in more detail in this part of the regulations. If a leak in the UST system is found to exist, the system must be repaired, replaced, or upgraded as needed.

Applicable MOC procedures indicate the appropriate testing, investigating, reporting, and corrective action to be taken if a release of regulated substances is suspected. There were no leaks in the WIPP USTs during this reporting period.

25.2.7.64 Reporting and Cleanup of Large Spills and Overfills, 20 NMAC 5.7, $\S 703(\mathrm{~A}) ; 40 \mathrm{CFR} \S 280.53(\mathrm{a})$

Owners and operators of UST systems must contain and immediately clean up a spill or overfill and report it to the NMED within 24 hours. Corrective action must be initiated in accordance with 20 NMAC 5.2, section 204. If a spill or overfill of a petroleum product results in a release to the environment that exceeds 25 gallons [or a hazardous substance spill results in a release to the environment that equals or exceeds its $R Q$ under CERCLA (40 CFR 302), corrective action must be initiated in accordance with 20 NMAC 5.12 or 5.13 .

There were no large spills or overfills with the WIPP USTs during this reporting period. Applicable MOC procedures address the requirements with respect to petroleum UST systems (i.e., as specified in 20 NMAC 5.12). No hazardous substances are contained in UST systems at WIPP; therefore, USTR Part XIII does not apply.

25.2.7.65 Reporting and Cleanup of Small Spills and Overfills, 20 NMAC 5.7, $\S 703(\mathrm{~B}) ; 40 \mathrm{CFR} \S 280.53(\mathrm{~b})$

Owners and operators of UST systems must contain and immediately clean up a spill or overfill of a petroleum product that is less than 25 gallons and a spill or overfill of a hazardous substance that is less than the $R Q$. If cleanup cannot be accomplished within 24 hours, owners and operators must immediately notify the implementing agency.

Small spills and overfills have been properly contained and cleaned up. Applicable MOC procedures address this requirement with respect to petroleum UST systems. No UST systems are used to contain hazardous substances at WIPP.

25.2.7.66 Temporary Closure, 20 NMAC 5.8, § 800; 40 CFR $\S 280.70$

When an UST system is temporarily closed, owners and operators must continue operation and maintenance of corrosion protection in accordance with 20 NMAC 5.5, 
section 501, and any release detection in accordance with 20 NMAC 5.6, 5.7, 5.12, 5.13, and section 204 of NMAC 5.2 must be complied with if a release is suspected or confirmed. However, release detection is not required as long as the UST system is empty. When an UST system is temporarily closed for three months or more, the vent lines must be left open and functioning, and all other lines, pumps, manways, and ancillary equipment must be capped and secured.

Documentation of the original tank closures was submitted to NMED. No temporary closure took place.

25.2.7.67 Permanent Closure and Changes in Service, 20 NMAC 5.8, § 801(A); 40 CFR $\S 280.71(a)$

At least 30 days before beginning either permanent closure or a change in service, owners and operators must notify the NMED unless such action is in response to corrective action.

The closure documentation for the old UST systems was submitted to the NMED within the 30-day requirement for beginning permanent closure.

25.2.7.68 Permanent Closure of a Tank, 20 NMAC 5.8, § 801(B); 40 CFR $\S 280.71(b)$

To permanently close a tank, the owners and operators must empty and clean it by removing all liquids and accumulated sludges. The tanks must be either removed from the ground or filled with an inert solid material.

The closure documentation for the old UST system is maintained at the WIPP site. These USTs were emptied, cleaned, and removed from the ground as required.

25.2.7.69 Change in Service, 20 NMAC 5.8, § 801(C); 40 CFR § 280.71(c)

Before a change in service in which the use of a UST system is continued for the storage of a nonregulated substance, owners and operators must empty and clean the tank by removing all liquid and accumulated sludge and conduct a site assessment in accordance with 20 NMAC 5.8, section 802.

There was no change in service for the old UST system.

25.2.7.70 Assessing the Site, 20 NMAC 5.8, § 802(A); 40 CFR § 280.72(a)

Before permanent closure or a change in service is completed, owners and operators must measure for the presence of a 
release where contamination is most likely to be present at the UST site as required under this subsection.

The UST site was assessed prior to permanent closure of the old UST system. The closure documentation for the old UST systems is maintained at the WIPP site.

25.2.7.71 Corrective Action, 20 NMAC 5.8, § 802(B); 40 CFR $\S 280.72(b)$

If contaminated soils, contaminated groundwater, or free product as a liquid or vapor are discovered, owners and operators must begin corrective action in accordance with 20 NMAC 5.12 or 5.13 .

The MOC has procedures in place which address the required actions to take if a release or suspected release is identified. See section 25.2.7.80 below for further information.

25.2.7.72 Applicability to Previously Closed UST Systems, 20 NMAC 5.8, § 803; 40 CFR $\S 280.73$

When directed by the NMED, the owner and operator of an UST system permanently closed before December 22, 1988, must assess the excavation zone and close the UST system if releases from the UST may pose a current or potential threat to human health and the environment.

No UST systems at WIPP were permanently closed before December 22, 1988.

25.2.7.73 Closure Records, 20 NMAC 5.8, § 804; 40 CFR § 280.74

Owners and operators must maintain records in accordance with 20 NMAC 5.5, section 504, that demonstrate compliance with closure requirements under this part. The results of the excavation zone assessment required in 20 NMAC 5.8, section 802, must be maintained for at least three years after completion of permanent closure or change in service.

A tank closure for the old UST systems was submitted to NMED. The records are maintained at WIPP.

25.2.7.74 Applicability of Financial Responsibility, 20 NMAC 5.9, § 900; 40 CFR $\S 280.90$

State and federal government entities whose debts and liabilities are the debts and liabilities of a state or the United States are exempt from the requirements of 20 NMAC 5.9, "Financial Responsibility." 
As the owner of WIPP, the DOE is exempt from the financial responsibility requirements of this part.

25.2.7.75 Informal Review, 20 NMAC 5.10, § 1000

Any owner or operator of an UST who disagrees with a decision made by NMED personnel pursuant to the USTRs may have the decision reviewed by submitting a written request for informal review to the NMED. The request must be postmarked within 15 days of the date of the decision. The grounds for the petitioner's objection must be specified.

This provision has not been invoked at WIPP.

25.2.7.76 Review by the Secretary on Written Memoranda, 20 NMAC 5.10, $\S 1001(A)$

Within 20 days after the NMED has made a determination under 20 NMAC 5.10, section 1000, the petitioner may appeal the determination to the NMED Secretary by requesting a review on written memoranda in writing. The grounds for the objection to the determination must be specified. The request must be accompanied by all written information, documentation, and arguments that the petitioner wants the Secretary to consider.

This provision has not been invoked at WIPP.

25.2.7.77 Compliance With Other Regulations, 20 NMAC 5.1, § 108 Compliance with the USTRs does not relieve a person of the obligation to comply with other applicable state and federal regulations.

Compliance with the other applicable federal and state regulations is discussed elsewhere in this document (see Chapters 2 through 37 herein, respectively).

25.2.7.78 Construction, 20 NMAC 5.1, § 109

The USTRs shall be liberally construed to effectuate the purpose of the New Mexico Hazardous Waste Act.

The USTRs are liberally construed to effectuate the purpose of the New Mexico HWA with respect to the sections in this act that pertain to managing UST systems containing hazardous (i.e., regulated) substances. 
25.2.7.79 Severability, 20 NMAC 5.1, § 110

If any part, section, or application of the USTRs is held invalid, the remainder (or its application to other situations or persons) shall not be affected.

No action is required.

25.2.7.80 Cleanup Requirements for Releases from Petroleum UST Systems, 20 NMAC 5.12, § $1200(A)$

All releases must be cleaned up through soil remediation, ground- and surface-water remediation, and any other appropriate procedures in a manner protective of health, public welfare, and the environment.

No releases occurred from the WIPP USTs during this reporting period.

25.2.7.81 Additional Corrective Action Requirements for Petroleum UST Systems, 20 NMAC 5.12, §§ 1200(B)-1222

Additional corrective action requirements specify types of releases, notification and reporting requirements, types of actions required for remediation and reclamation involving specific releases, and provisions for monitoring.

No releases have occurred during this reporting period. However, MOC procedures are in place to address them should corrective actions involving petroleum USTs become necessary in the future.

25.2.7.82 Corrective Action for Hazardous Substance UST Systems, 20 NMAC 5.13, $\S \S 1300$ through 1320

Requirements for corrective actions for hazardous substance UST systems are specified in this part of 20 NMAC Chapter 5.

There are no hazardous substance UST systems at WIPP. Therefore, 20 NMAC 5.13 (sections 1300 through 1320) do not apply to WIPP.

25.2.7.83 Certification of Tank Installers, 20 NMAC 5.14, §§ 1400 through 1417

Certification by the NMED is required for all individuals and companies that install or repair UST systems in New Mexico. Certification is based on field experience, training, and a written and an on-site examination. 
Documentation of certification of the contractor that installed the new UST systems at WIPP is retained at WIPP.

25.2.7.84 Priorities, 20 NMAC 5.15, § 1505

NMED priorities for corrective action at sites contaminated by releases of regulated substances from USTs are established in this section.

If a release is detected from the UST systems at WIPP, the action to be taken by the NMED will depend on the extent and nature of the release.

See section 25.2.7.85 below for the requirements for a minimum site assessment.

25.2.7.85 Minimum Site Assessment, 20 NMAC 5.15, § 1508

Owners and operators are strictly liable for the NMED's costs of taking corrective action at a site unless the owner or operator has conducted a minimum site assessment as required by these regulations. To complete such an assessment, the owner and operator must report, investigate, and confirm the release pursuant to 20 NMAC 5.7 and determine the immediate extent, magnitude, and impact of contamination by conducting investigations and reporting to the NMED (20 NMAC 5.12, sections 1203 through 1206). The owner or operator shall include with the report of the on-site investigation a copy of any insurance policies which are in effect on the date of the report and any policies in existence at the time the release may have occurred. The NMED shall notify the owner or operator of any inadequacies in the report within 30 days of its receipt of the onsite investigation report. The owner or operator shall, within 15 days of such notice of inadequacy, modify the report and resubmit it to the NMED for review and written approval. If the modified report does not meet the requirements of 20 NMAC 5.12, section 1205, the owner and operator shall be deemed not to have conducted a minimum site assessment.

No releases have occurred during this reporting period. However, if a minimum site assessment is deemed necessary in the future, it will be prepared and submitted to meet the requirements specified. The transmittal of insurance policies is not required for a federal facility; therefore, the report would not be accompanied by a copy of such policies.

25.2.7.86 Certification of Contractors, 20 NMAC 5.16

Provisions are contained in 20 NMAC 5.16 for the qualification of firms performing corrective action on sites where payment or 
reimbursement from the Corrective Action Fund will be sought. It addresses education, experience, examination, continuing education and certification requirements for certified scientists.

This requirement is not applicable to WIPP. The Ground Water Protection Act prohibits expenditures from the Corrective Action Fund for federally owned and operated sites.

25.2.7.87 Corrective Action Fund Payment and Reimbursement, 20 NMAC 5.17

The regulation establishes procedures for the reimbursement or payment from the Corrective Action Fund for corrective actions.

This requirement is not applicable to WIPP. The Ground Water Protection Act prohibits expenditures from the Corrective Action Fund for federally owned and operated sites. 


\subsection{NEW MEXICO SOLID WASTE ACT}

\subsection{Summary of the Law}

With the enactment of the Solid Waste Act in 1990, the New Mexico Legislature authorized and directed the establishment of a comprehensive and integrated solid waste management program at both the state and local levels. This legislation directs the planning and regulation of the reduction, storage, collection, transportation, and disposal of solid waste and authorizes the establishment of a system of permits for the construction, operation and, if applicable, closure and postclosure maintenance of solid waste facilities.

The Solid Waste Act is implemented by the New Mexico Solid Waste Management Regulations (SWMR). The SWMR are contained within section 9.1 of Title 20 NMAC. These regulations are applicable to WIPP because of infectious wastes generated at the facility. A construction debris landfill is operational at the site but is exempt under $\S 108$ of the SWMR.

\subsection{Compliance Status of the Regulatory Requirements}

The text summarizes the applicable requirements and their compliance status under the Solid Waste Act.

\subsubsection{Applicability of Regulations, 20 NMAC 9.1, § 106.A}

Subpart 106.A. specifies that all solid waste shall be processed or disposed of in accordance with the regulations.

A construction debris landfill is operational at the WIPP site. The construction landfill is on property owned by the DOE and receives nonhazardous material generated on the property from construction activities; no hazardous wastes or materials are allowed. The landfill is thus covered by the exemption found in $\S 108$ of the SWMR. Infectious wastes are generated at the facility and meet the applicable requirements of $\S 706$ of the SWMR.

\subsubsection{General Requirements for Processing and Disposal of Solid Waste, 20 NMAC 9.1, § 106}

All solid waste must be processed or disposed of by means in accordance with Environmental Improvement Board regulations, including recycling, composting, transformation, or landfilling. Generators of solid waste must provide containers for the solid waste except for construction and demolition debris, yard refuse, and white goods.

The construction landfill receives waste generated by construction activities at the site and is covered by the $\S 108$ exemption of the regulations. The requirements and 
rules of operation for the landfill are described in a WIPP procedure that provides guidelines for the operation of the construction landfill in a manner that is protective of human health and the environment and ensures compliance with applicable local, state, and federal laws and regulations. Infectious waste generated at the site is shipped off-site for disposal.

\subsubsection{Prohibited Acts, 20 NMAC 9.1, § 108}

Subpart 108 specifies prohibited acts including the following: disposal of solid waste in places other than a permitted solid waste facility; disposal of regulated waste such as special waste, hazardous waste, radioactive materials, and petroleum waste; disposal of bulk liquids; and disposal of any solid wastes that are known to be harmful to the environment or hazardous to public health or safety.

The following wastes are excluded from the WIPP landfill:

- $\quad$ Radioactive materials
- $\quad$ Hazardous or other regulated materials, including petroleum products
- $\quad$ Any recyclable materials as determined by the MOC
Municipal Solid Waste

Construction debris that may be disposed of in the landfill is material generally considered to be non-water-soluble and nonhazardous in nature and includes timbers, pipes, excavation soil (if not contaminated with hazardous materials/wastes), concrete, packing materials, sheet metal, glass, and wood.

\subsubsection{Exemptions, 20 NMAC 9.1, § 108c.}

This Part does not apply to disposal of construction and demolition debris or yard refuse by a person in possession of property if the material was generated on the property and if the disposal of the solid waste does not violate any provision of this Part.

WIPP's landfill falls within this exemption; thus, the DOE is not required to obtain a landfill permit for construction debris generated and disposed on the WIPP site.

26.2.5 Record Keeping and Annual Reports, 20 NMAC 9.1, § 109

Operators of solid waste facilities shall make and maintain records during the active life of the facility. Operators shall submit annual reports to the Secretary of the NMED within 45 days after each anniversary date of any permit or other approval given. 
The construction landfill is covered by the $\S 108$ exemption found in the SWMR. Although the landfill is exempt from record keeping requirements, records for the landfill are maintained. Records are found on the MOC construction debris disposal form, which requires the name, company, date, description and estimated volume of debris, and signatures of the landfill user and of the landfill custodian. No permit is required. Therefore, an annual report is not necessary.

\subsubsection{Entry by Department, Availability of Records, 20 NMAC 9.1, § 111}

The Secretary or any authorized representative, employee or agent of the Department may enter any solid waste facility at any reasonable times for the purpose of making an inspection.

The NMED will be provided access to the facility any time it wishes to conduct an inspection.

26.2.7 Permit Application Requirements, 20 NMAC 9.1, §§ 201, 202, 209, 210

Any person seeking a permit to construct, operate, or modify a solid waste facility must file an application.

Chapter 20 of NMAC 9.1, 108 provides an exemption for this site, because the regulations do not apply to disposal of construction and demolition debris if the material is generated on the property and the disposal of the solid waste does not violate any provision of the regulations. This landfill is exempted from permit application requirements because it receives construction debris only and because it is located at the same site where the construction debris is generated. Therefore, a permit is not required for this landfill.

\subsubsection{Solid Waste Facility Operation, 20 NMAC 9.1, §§ 401, 403}

A solid waste facility must be operated so that it does not cause a public nuisance or create a potential hazard to public health or welfare.

The landfill is covered by the $\S 108$ exemption contained in the SWMR. In order to ensure compliance with the SWMR, the construction landfill is operated according to $\mathrm{MOC}$ procedures that ensure protection of public health and welfare.

\subsubsection{Asbestos Waste, 20 NMAC 9.1, § 705}

Section 705 of 20 NMAC 9.1 specifies a number of requirements for transportation and disposal of asbestos waste, including transporter and labeling requirements.

A permit for the transportation of asbestos-containing TRU waste within the state has been obtained by the commercial carrier carrying dedicated loads to WIPP. 
Disposal authorization for emplacement of asbestos-containing TRU waste is pending from the NMED. Notices have been sent to the Hazardous and Radioactive Waste Bureau, the Solid Waste Bureau, and the Air Quality Bureau.

\subsubsection{Landfill Closure and Postclosure Requirements, 20 NMAC 9.1, Subpart V}

Subpart $V$ of 20 NMAC 9.1 specifies a number of landfill closure and postclosure requirements including the installation of a final cover, preparing and implementing a land-use plan, a schedule for completing all closure work, an approved postclosure care and monitoring plan, and annual reports.

This landfill is exempted from these requirements because it receives construction debris only and because it is located at the same site (i.e., WIPP) where the construction debris is generated. Therefore, closure and postclosure requirements are not applicable.

\subsubsection{Operator Certification, 20 NMAC 9.1, Subpart VI}

Subpart VI of 20 NMAC 9.1 provides requirements for operator certification: certification of operators is required as of January 31, 1994. The amount and type of personnel training and experience are specified for landfills and for other types of facilities.

This landfill is exempted from these requirements because it receives construction debris only and because it is located at the same site (i.e., WIPP) where the construction debris is generated. Therefore, operator certification is not required.

\subsubsection{Storage and Containment of Infectious Waste, 20 NMAC 9.1, § 706(C)}

Subpart 706(C) specifies infectious waste storage and containment requirements, including waste segregation; specifications for container integrity; container labeling and marking; and storage and containment area access, integrity, and marking.

The following practices are ongoing at WIPP:

- $\quad$ Access to the infectious waste collection and storage area is limited to trained medical personnel.

- $\quad$ Special containers are easily identifiable through the use of enclosed redlined biohazard bags. 
- $\quad$ All sharps are sealed in containers that are leak-proof, puncture-proof, and tamper-proof. These containers are then enclosed in plastic biohazard bags.

- $\quad$ All containment bags are clearly identifiable with red lining as specified by 29 CFR $\S 1910.145(f)(4)$.

- No infectious waste containers are reused.

- $\quad$ Storage and containment areas are in an enclosed, clearly marked environment.

- No compaction or grinding devices are used to reduce the volume of infectious waste.

26.2.13 Infectious Waste Treatment, Storage, and Disposal Facilities, 20 NMAC 9.1, § 706(D)

Section 706(D) specifies operational requirements for infectious waste treatment, storage, and disposal facilities. Included is a requirement for the preparation and maintenance of a management plan that identifies the type of waste generated or handled; the segregation, packaging, labeling, collection, storage, and transportation procedures to be implemented; the treatment or disposal methods to be used; the transporter and disposal facility to be used; and the person responsible for the management of the infectious waste.

The MOC Transportation Manual and the Occupational Health Manual address the operational requirements for infectious waste as specified in this part.

\subsubsection{Treatment and Disposal of Infectious Waste, 20 NMAC 9.1, § 706(E)}

Several methods are specified for the treatment and disposal of infectious waste. These methods include controlled incineration, heat sterilization, discharge to a sewage treatment system, and landfilling.

The method of treatment and disposal is incineration or steam sterilization at an offsite facility. Transportation is provided by an off-site subcontractor.

\subsubsection{Infectious Waste Transporters, 20 NMAC 9.1, § 214(B)}

Transporters of infectious waste shall register with the NMED, submit a description of the solid waste facilities used, submit a contingency plan to the Secretary, and carry a copy of the plan and appropriate cleanup kits in the vehicle. 
Transportation of infectious waste generated at WIPP is accomplished by an off-site contractor that meets the requirements.

\title{
26.2.16 Manifest Requirements, 20 NMAC 9.1, § 712
}

\begin{abstract}
A manifest must accompany each shipment of infectious waste. Each manifest must include information on the waste generator, transporter, waste treatment facility, the type of waste, and any special instructions.
\end{abstract}

Medical waste shipments are accompanied by a shipment manifest that includes the required information. 


\subsection{NEW MEXICO GROUND WATER PROTECTION ACT}

\subsection{Summary of the Law}

The Ground Water Protection Act (GWPA; § 74-6B NMSA 1978) was enacted in 1990 in response to the threat facing public health and safety and the environment from pollution of groundwater resources from leaking USTs. The purpose of this act includes the provision of substantive direction that allows the state of New Mexico to take corrective action at sites contaminated by leakage from USTs.

The GWPA is implemented by the regulations of the NMED, NMED-92-1, Ground Water Protection Act Corrective Action Fund Regulations. These regulations provide guidelines for the payment or reimbursement of the costs of a minimum site assess ment and corrective action and specify the requirements for owners or operators of leaking USTs.

The GWPA is also implemented by the GWPA regulations, which are provided in the New Mexico USTRs as Part XV. These regulations are discussed in Chapter 25 herein. The CAO has installed two USTs at WIPP that meet the state's standards and requirements for USTs. Procedures are in place for routine operations regarding the tanks and for dealing with any spills or releases from the UST systems. Two sections in Chapter 25 herein (sections 25.2.7.84 and 25.2.7.85) deal specifically with the applicable New Mexico GWPA regulations.

\subsection{Compliance Status of the Regulatory Requirement}

The below text summarizes the general regulatory requirement and its compliance status under the implementing regulation of the New Mexico GWPA. See also sections 25.2.7.84 and 25.2.7.85 herein for the applicable portions of the GWPA Regulations.

\subsection{Corrective Action for Spills/Releases from USTs, NMED-92-1}

The owners or operators of USTs that release a regulated substance must take appropriate corrective action. The NMED will reimburse certain costs associated with performing a minimum site assessment and other corrective actions taken for spills or releases from USTs.

The CAO will take appropriate corrective actions if a regulated substance is released from a UST at WIPP. 
This page intentionally left blank. 


\subsection{NEW MEXICO AIR QUALITY CONTROL ACT}

\subsection{Summary of the Law}

The New Mexico Air Quality Control Act (§§ 74-2-1 through 74-2-22 NMSA 1978), based primarily on the CAA (see Chapter 6 herein), is not generally more stringent than the CAA except in areas of air pollution prevention that have not been preempted by the CAA and are not precluded by the limiting provisions of the Air Quality Control Act. The Air Quality Control Act was formerly implemented by the Air Quality Control Regulations and is now implemented by Chapter 2 of Title 20 of the NMAC.

Under 40 CFR 70, operating permits are required for both area and major sources. The NMED will implement the federal requirements under 20 NMAC 2.70 and 2.71 which describe the fee structure for the operating permit program. At this time, emission limits for area sources have not been established, and major source emission thresholds are being used to determine which facilities require operating permits under 20 NMAC 2.70.

\subsection{Compliance Status of the Regulatory Requirements}

The text summarizes the compliance status of the requirements in Chapter 2 of Title 20 of the NMAC that are potentially applicable to WIPP. It should be noted that 20 NMAC 2.70 and 2.71 will deal with the state operating permit program and that the EPA has granted approval for the NMED's operating permit program. Therefore, a brief discussion of WIPP's compliance status with respect to 20 NMAC 2.70 is included in this chapter.

\subsubsection{Sampling Equipment, 20 NMAC 2.1}

Sampling equipment on stacks or other openings through which emissions are released to the atmosphere will be used as required.

The sampling equipment required for measuring emissions from the WIPP backup diesel generators was specified by the state in $\S 3(b)$ of the permit. Sampling ports, safe sampling platforms, safe access to sampling platforms, and utilities for sampling and testing equipment have been provided. A 0.25 -inch stainless steel sampling line adjacent to the sampling ports, which extends down to within 4 feet above ground level, has been installed as required by the permit. This sampling line provides access for future audits by the NMED.

\subsubsection{Excess Emissions During Malfunction, Start-Up, Shutdown, or} Scheduled Maintenance, 20 NMAC 2.7

Excess emissions during malfunction, start-up, shutdown, or scheduled maintenance must be minimized. 
Special attention is paid during start-up, shutdown, scheduled maintenance, and any malfunction of the generators to ensure that emissions are minimized. The release of excess emissions is unlikely, however, because a redundant system is in place, and the second backup generator will be used, as appropriate, to reduce potential emissions. If excess emissions occur, reporting will be performed as required by 20 NMAC 2.7. No problems were detected during this reporting period.

\subsubsection{Controlling Emissions Leaving New Mexico, 20 NMAC 2.8}

Emissions leaving New Mexico must not exceed the standards and regulations of the receiving state.

Emissions calculations and modeling that have been completed reveal that the emissions do not exceed the NAAQs.

\subsubsection{Oil-Burning Equipment--Particulate Matter, 20 NMAC 2.18}

Standards have been established for particulate-matter emissions from oil-burning equipment with a rated heat capacity exceeding 250 million British thermal units (BTU) per hour.

No oil-burning equipment at WIPP exceeds this rated heat capacity. The rated heat capacity of each of the generators is only 139.6 million BTU per hour.

\subsubsection{Oil-Burning Equipment--Nitrogen Dioxide, 20 NMAC 2.34}

Standards have been established for nitrogen dioxide emissions from oil-burning equipment with a rated heat capacity of 1012 BTU per hour.

No oil-burning equipment at WIPP exceeds this rated heat capacity. The rated heat capacity of each of the two generators is only 139.6 million BTU per hour (i.e., $1.4 \mathrm{x}$ 108 BTU/hour).

\subsubsection{Regulations to Control Open Burning, 20 NMAC 2.60}

Open burning is allowed for the instruction and training of firefighting and rescue personnel when a permit is obtained from the NMED.

The open-burning permit was canceled in October 1995 and will not be renewed. Firefighter live-fire training is no longer conducted at WIPP.

\subsubsection{Regulations to Control Smoke and Visible Emissions, 20 NMAC 2.61}

No person owning or operating stationary combustion equipment shall permit, cause, or allow visible emissions from 
stationary combustion equipment to equal or exceed an opacity

of 20 percent. No emissions of smoke with an opacity greater

than 30 percent shall be released into the open air for any

period greater than 10 seconds from any diesel-powered

vehicle operating below 8,000 feet mean sea level. Opacity

emissions shall be determined using Method 9 described in

Appendix A of 40 CFR 60 (minimum time period for taking

opacity reading: 10 minutes).

Opacity measurements are not required for the backup diesel generators because no opacity measurements are specifically required under the permit (see section 28.3.1 below). However, opacity testing has been performed on the generators and was found to be less than the 20 percent opacity limit.

Other diesel equipment is present on site that does not require a permit under 20 NMAC 2.72 because this equipment represents such a small source of emissions. The inventory on the equipment was submitted to the NMED with the permit application for the backup generators. The emissions from the diesel equipment fall well below the permit thresholds.

\subsubsection{Compliance Plan, 20 NMAC 2.70.300}

Submittal of a compliance plan is required as part of the operating permit application for 40 CFR 70 sources.

Based on the 1996 WIPP Air Emissions Inventory, HAPs and other pollutant emissions from the facility are below current operating permit threshold levels; therefore, an operating permit is not required for WIPP. If a determination is made at a later date that an operating permit application is required for the facility, a compliance plan will be part of the application as specified.

\subsubsection{Semiannual Operating Permit Reports and Progress Reports on the Compliance Plan, 20 NMAC 2.70.302}

Semiannual operating permit reports and progress reports on the compliance plan will be filed, if applicable.

Based on the 1996 WIPP Air Emissions Inventory, HAP emissions from the facility are below current operating permit threshold levels, and an operating permit is not required for WIPP. The CAO will be required to submit these reports if and when WIPP is considered to be subject to the operating permit program. 


\subsubsection{Permits, 20 NMAC 2.72}

A permit is required for facilities that emit criteria pollutants or toxic air pollutants at rates that meet or exceed the threshold levels specified in 20 NMAC 2.72.

The permit was issued by the NMED on December 7, 1993. (See section 28.3.1 below.)

\subsubsection{Permit Fees, 20 NMAC 2.75}

Permit fees must be paid with the submittal of a permit application.

The only permit required at WIPP under 20 NMAC 2 is for the diesel generators. (See also section 28.3.1 below.) The permit fee for the diesel generators $(\$ 10,100)$ was submitted with the permit application in July 1993.

\subsubsection{National Emission Standards for Hazardous Air Pollutants, 20 NMAC 2.78}

NESHAPs requirements must be met.

The state is authorized to administer the NESHAPs program except for radionuclide emissions. Therefore, the EPA regulates these emissions under Subpart $\mathrm{H}$ of 40 CFR 61 (see Chapter 6 herein).

In 1997, WIPP completed an emission inventory for chemicals used during 1994 (WID, 1997). The inventory included calculations of the maximal potential hourly and annual emissions of criteria pollutants, the chemicals regulated under the NESHAPs program, and the New Mexico TAPs specified under 20 NMAC 2.78 and Part III of 20 NMAC 2.72. Based on the Air Emissions inventory calculations, WIPP operations are significantly below the 10-tpy emission limit for any individual HAP or the 25-tpy limit for combined HAPs emissions established in Subpart A of NESHAPs. Thus, WIPP does not have any NESHAPs Subpart A permitting or reporting requirements.

\subsubsection{Stack Height Requirements, 20 NMAC 2.80}

Stack height requirements must be met.

WIPP meets the requirement for stack height. The state has approved the MOC calculations and modeling.

\subsection{Compliance Status of Permit Conditions}

Only one permit issued under the NMAC is now in place at WIPP. The permit for the backup diesel generators, which was issued to WIPP on December 7, 1993, is in 
place. The permit conditions and the compliance status of each are provided in the text.

\subsubsection{Permit for Backup Diesel Generators, Permit No. 310-M-2}

The conditions specified by Air Quality Permit No. 310-M-2 for the backup diesel generators at WIPP are described in this section.

\subsubsection{Construction and Operation, Condition 1}

The plant (i.e., the diesel generators) shall be constructed and operated as described in the permit application dated June 18, 1993, and with the air quality monitoring information that was submitted on September 22, 1993, unless modified by the conditions of this permit. The facility consists of two Caterpillar diesel generators with a rated capacity of 1500 horsepower. Only one Caterpillar diesel engine may operate at one time, and the sum of hours of operation for both engines shall not exceed 480 hours per year. Changes in plans, specification, and other representations provided in the application documents shall not be made if they change the method of emissions control or in the character of the emissions or if they would increase the discharge of emissions. Any such proposed change must be submitted as a proposal revision or modification of the permit in accordance with the condition described in section 28.3.1.4 below.

The equipment described in the permit is being operated in accordance with the terms and conditions of the permit.

\subsubsection{Emission Rates, Condition 2}

The NMED has specified maximal emission rates for nitrogen oxide, carbon monoxide, sulfur dioxide, and particulate matter. The rates specified are in terms of pounds per hour and tons per year from each engine and from the facility (i.e., both engines).

The emissions were established during emissions testing in 1992. The amounts of emissions were based upon calculations for the equipment installed. The equipment is operated and maintained in accordance with the manufacturer's specification.

Currently the only requirement the permit specifies is that the equipment be operated less than 480 hours per year. 
28.3.1.3 Compliance Test Methods, Conditions 3-4

Initial compliance tests for all four pollutants described for Condition 2 [section 28.3.1.2 above] are required for one of the diesel generators. Compliance tests may be reimposed if noncompliance is indicated or if the tests were technically unsatisfactory. The tests shall be conducted within 60 days after achieving the maximal production rate at which the generator will normally be operated. If the maximal production rate does not occur within 120 days of source start-up, the tests must be conducted no later than 180 days after the initial start-up of the source.

The tests shall be conducted in accordance with EPA Reference Methods 1-4, Method 5 (particulate matter), Method 6 (sulfur dioxide), Method 8 (A-E) (nitrogen dioxide), and Method 10 (carbon monoxide) contained in 40 CFR 60, Appendix A, and with the requirements of 40 CFR 60.8(f). The oxygen in the stack gas shall be determined by using EPA Method 3.

The NMED shall be notified of the date and time of compliance testing at least 30 days before the planned test date so that the NMED may have an observer present during testing. The permittee will arrange a pretest meeting with the NMED at least 30 days prior to the anticipated test date and shall observe the pretesting and testing procedures described in detail under this condition. These requirements include submitting a written test protocol to the NMED at least 1 week prior to the testing date for approval and providing appropriate equipment and access to the NMED observer for sampling. Several parameters (i.e., engine revolutions per minute, exhaust static pressure, exhaust manifold temperature, fuel consumption, and horsepower as indicated by kilowatt output) shall be monitored and recorded during the test and the results included with the test report. Flow straighteners shall be installed where necessary to prevent cyclonic flow in the stack. The tests shall be conducted at 90 percent of full load or greater and at additional loads as specified by NMED personnel at the test or pretest meeting.

Two copies of the compliance test report must be submitted to the NMED within 30 days after completion of testing.

Compliance with these conditions was achieved and reported in the compliance test report, Emission Sampling Report, Backup Diesel Generator, that was submitted to the NMED Air Quality Bureau on March 6, 1994, and approved on May 12, 1994. 
28.3.1.4 Revisions and Modifications, Condition 5

Any future changes shall be preceded by the submittal of a permit application to the NMED in accordance with 20 NMAC 2.72. No modifications shall be made prior to the issuance of the revised permit.

There have been no revisions or modifications to the equipment or its operation during this reporting period.

28.3.1.5 Notification to Subsequent Owners, Condition 6

If there is any change in control or ownership of the diesel generators, the permittee shall notify the succeeding owner of the permit and its conditions and shall notify the NMED of the change in ownership within 15 days of the change.

There has been no change in ownership or control of the permitted equipment during this reporting period.

28.3.1.6 Right to Access Property and Review Records, Condition 7

The NMED will be given the right to enter the facility at all reasonable times to verify the terms and conditions of the permit. Upon receipt of a verbal or written request from any authorized representative of the NMED, the company will produce any records or information necessary to demonstrate that the terms and conditions of the permit are being met.

Upon request, NMED representatives will be allowed entry to the site and will be provided with appropriate records and information. No NMED personnel requested entry to the site to verify the terms and conditions of the permit for the diesel generators within this reporting period.

28.3.1.7 Posting of the Permit, Condition 8

A copy of the permit will be posted and in view of the plant site at all times. It will be made available to NMED personnel for inspection upon request.

A copy of the permit is posted at the WIPP facility.

\subsubsection{Record Keeping, Condition 9}

DOE will maintain an operational log in which the date, time, and hours of operation will be recorded for each engine. The records will be maintained on site for at least two years from the 
time of recording and will be made available to NMED personnel upon request.

Completion and maintenance of operational logs are carried out as prescribed by MOC procedures. Central Monitoring Room logs contain information about the diesel generators. The run times for the generators are recorded automatically by the Central Monitoring System. The records are maintained on site for at least two years.

28.3.1.9 Reporting, Condition 10

The permittee will notify the NMED in writing or provide the NMED with the following information:

- The anticipated date of the initial start-up of each new or modified emission source at least 30 days prior to that date

- The actual date of the initial start-up of each new or modified source within 15 days after the start-up date

- $\quad$ The date when each new or modified source reaches the maximal production rate at which it will operate within 15 days after that date

- Any change of operators within 15 days after the change

- Any necessary update or correction no more than 60 days after the operator knows or should have known of the condition necessitating the update or correction of the permit

Notice of the initial start-up of each source was submitted to the Air Quality Bureau in December 1993. Subsequent reports will be filed as needed.

28.3.1.10 Permit Cancellations (Permit, p.8)

The NMED will cancel the permit automatically if any source ceases operation for at least five years or if the construction or modification of a source is not initiated within two years from the date of issuance of if work on construction or modification is suspended for a total of one year.

If the generator ceases operation for at least five years and is to be reactivated, a new permit application will be filed. The generators will not be operated until the permit has been issued. 
28.3.1.11 Notice of Intent and Emission Inventory (Permit, Page 8)

Requirements related to Notice of Intent and emission inventory are contained in 20 NMAC 2.73.

See Section 28.3.1.11.1 below, which pertains to compliance with 20 NMAC 2.73.

28.3.1.11.1 Annual Emission Inventory, 20 NMAC 2.73

An annual emission inventory is required annually for any stationary source permitted under 20 NMAC 2.72 (except for those sources that are permitted only for toxic air pollutant emissions). Other sources that are required to file an annual emission inventory are those that must file a Notice of Intent under 20 NMAC 2.73 or that emit in excess of 1 ton of lead or 10 tons of total suspended particulates, particulate matter with an aerodynamic diameter of $10 \mu$ or less (i.e., $P M_{10}$ ), sulfur dioxide, nitrogen dioxide, carbon monoxide, or volatile organic compounds (VOCs) in any calendar year including and subsequent to 1990.

Emission testing for the diesel generators was performed in February 1994 and reported to the NMED as part of the original permit package. There have been no further requirements or NMED requests for emission testing to date. 
This page intentionally left blank. 


\subsection{NEW MEXICO WATER QUALITY ACT}

\subsection{Summary of the Law}

With the enactment of the New Mexico Water Quality Act ( 74-6-1 through 74-6-17 NMSA 1978), a mechanism was provided at the state level to establish waterquality standards that are consistent with the CWA. The state act created the Water Quality Control Commission and directed the commission, as the state's waterpollution-control agency for all purposes of the CWA, to adopt a comprehensive water quality management program and water quality standards. The New Mexico Water Quality Control Commission Regulations include water-quality standards for ground and surface water and regulations regarding discharges to surface-water courses and groundwater.

Pursuant to the regulations of $\S 3-109$, "Director Approval, Disapproval, Modification, or Termination of Proposed Discharge Plans," the Discharge Plan (DP in citations) submitted by the DOE for the discharge of 23,000 gallons per day (gpd) of sewage effluent and up to $1,500 \mathrm{gpd}$ of nonhazardous brine water from WIPP was approved in 1992. On August 28, 1995, the MOC submitted a request to the NMED requesting a minor amendment to DP-831 increasing the amount of nonhazardous brine for disposal to 2,000 gpd. On October 4, 1995, the NMED approved the amendment to the Discharge Plan.

A modification request was submitted to the NMED for the use of the $\mathrm{H}-19$ Evaporation Pond for disposal of up to $8,000 \mathrm{gpd}$ of miscellaneous nonhazardous waters generated at the site. The modification was approved July 3, 1997.

Title 20 NMAC 7.4 defines public water supply systems and public wastewater facilities. Under these definitions, and because of the size of the population served, WIPP is classified as a Class 1 public wastewater facility and a Class 2 public water supply system. Since these systems require certified operators, the WIPP facility employs operators and supervisors certified to the requirements of Subpart II of this Part.

\subsection{Compliance Status of the Regulatory Requirements}

The following text provides the regulatory requirements and their compliance status under the New Mexico Water Quality Act.

\subsubsection{Notice of Intent to Discharge, 20 NMAC 6.2, § 1-201}

Any party intending to make a new water contaminant discharge or to alter the character or location of an existing water contaminant discharge, unless the discharge is being made or will be made into a community sewer system or subject to the Liquid Waste Disposal Regulations adopted by the New Mexico Environmental Improvement Board, shall file a notice 
with the Water Pollution Control Bureau of the New Mexico

Environment Department (NMED).

Notices of intent to discharge have been filed as required.

29.2.2 Filing of Plans and Specifications - Sewerage Systems, 20 NMAC 6.2, $\S 1-202$

Any party proposing to construct a sewerage system or proposing to modify any sewerage system in a manner that will change the quantity or quality of the discharge from the system substantially must file plans and specifications for the construction or modification with the Water Pollution Control Bureau of the NMED.

Sewage system plans and specifications were included in the transmittal of the Discharge Plan application to the NMED.

\subsubsection{Notification of Discharge - Removal, 20 NMAC 6.2, § 1-203}

Requirements for reporting, notifications, and corrective action with respect to any discharge from any facility of oil or other water contaminant, in such quantity as may with reasonable probability injure or be detrimental to human health, animal or plant life, or property, or unreasonably interfere with the public welfare or the use of property are specified.

In the event of an unauthorized discharge of oil or other potentially harmful water contaminants, notification and reporting will be performed and corrective action taken according to the WIPP environmental incident reporting procedure. The discharge will be reported to the Chief of the Groundwater Bureau of the NMED within 24 hours. A written report will be submitted within seven days, as required under this regulation.

\subsubsection{General Requirements, 20 NMAC 6.2, § 2-101}

General discharge limitations and sampling/analytical requirements for the discharge of effluents to a watercourse must be met.

These limitations and requirements are specified in the NMED's Discharge Plan Approval DP-831. The discharge limitations and the sampling/analytical requirements are met. Reports are submitted quarterly to the NMED. 


\subsubsection{Discharge Plan Required, 20 NMAC 6.2, § 3-104}

No party shall cause or allow effluent or leachate to discharge so that it may move directly or indirectly into groundwater unless the discharge meets the requirements of a discharge plan approved by the Director. When a plan has been approved, discharges must be consistent with the terms and conditions of the plan.

All discharges are consistent with the terms and conditions of the discharge plan approved July 3, 1997.

\subsubsection{Application for Discharge Plan Approval, 20 NMAC 6.2, § 3-106}

Any party who intends to begin discharging any listed water contaminants or any toxic pollutant so that they may move directly or indirectly into groundwater must submit a Discharge Plan as required.

All discharges are consistent with the terms and conditions of the discharge plan. The NMED approved the discharge plan on July 3, 1997. It will expire on July 3, 2002.

29.2.7 Monitoring, Reporting, and other Requirements, 20 NMAC 6.2, § 3-107

Requirements include notifying the NMED of any facility expansion, production increase, or process modifications that would result in the discharge of water contaminants.

Monitoring reports are filed quarterly according to the following schedule: January 31 , April 30, July 31, and October 31 of each year.

29.2.8 Public Notice and Participation, 20 NMAC 6.2, § 3-108

Within 30 days of filing of a proposed discharge plan, or modification or renewal of an approved discharge plan, the NMED must ensure that the public and affected governmental agencies are notified.

The NMED made public notice of the Discharge Plan on January 15, 1997. No comments were received from the public.

29.2.9 Director Approval, Disapproval, Modification, or Termination of Proposed Discharge Plans, 20 NMAC 6.2, § 3-109

If the monitoring data submitted indicate that these regulations are being or may be violated or that the standards in 
20 NMAC 6.2, § 3-102, "Standards for Ground Water of $10,000 \mathrm{mg} / \mathrm{L}$ [milligrams/liter] TDS [total dissolved solids] Concentration or Less," are being or will be exceeded in groundwater at any place of withdrawal for the present or reasonably foreseeable future due to the discharge, it may be necessary to modify the Discharge Plan.

If the monitoring data submitted indicate that the Discharge Plan conditions or the standards are being or will be exceeded, the plan may be reviewed and revised, as appropriate.

\subsubsection{Water Quality Standards for Interstate and Intrastate Streams in New Mexico, 20 NMAC 6.1}

The state has set a number of water-quality standards for interstate and intrastate streams in New Mexico.

The water-quality standards for interstate and intrastate streams in New Mexico do not apply to WIPP because there are no streams, either intermittent or permanent, that will be affected by WIPP.

\subsubsection{Utility Operator Certification, 20 NMAC 7.4}

The state requires that operators of public water supply systems and public wastewater facilities be certified to the educational and experience requirements of Subpart II of Part 4.

Under these regulations, WIPP is considered a public water supply system. WIPP is classified as a Class 2 public water supply system because of the population served, 501 to 5,000 .

WIPP is also considered a Class 1 public wastewater facility because of the population served and the treatment process being raw wastewater lagoons.

Since these systems at WIPP require certified operators, the MOC's Facility Operations Section employs operators and supervisors certified to the section's requirements. All operators undergo recertification and training every three years; training and certification records are maintained by the MOC at the WIPP facility.

\subsection{Compliance Status of the Permit Requirements}

The following text summarizes the specific and general requirements from the Discharge Plan for WIPP and their compliance status. 


\subsubsection{Requirements for Reporting Discharge Volumes, Water Sources, and Quarterly Reports, DP-831 Conditions for Approval (CA) 1}

The WIPP shall measure the volume of sewage effluent discharged to the facultative lagoon system and the volumes of nonhazardous brine water individually discharged to the north evaporation cell and the $\mathrm{H}-19$ evaporation pond. The origins of all waters discharged to the north evaporation cell and the $\mathrm{H}-19$ evaporation pond shall be specifically described and reported. Reports of the volumes and water sources will be submitted to NMED by January 31, April 30, July 31, and October 31 of each year.

The reporting of discharge volumes and water sources required by the NMED Discharge Plan Approval DP-381 has been conducted as required. The results have been submitted in the quarterly Discharge Monitoring Reports required by the Discharge Plan.

\subsubsection{Requirement for Water Quality Analysis Submitted with Quarterly} Report, DP-831 CA 2

WIPP shall sample and analyze the inflow to the facultative lagoon system for nitrate as nitrogen (NO3-N); total Kjeldahl nitrogen; TDS, plutonium 238, 239/240; americium 241; uranium 234, 235, 238; strontium 90; and gross alpha particle activity (including radium 226, but excluding radon and uranium). WIPP shall sample and analyze the north evaporation pond (Pond $B$ ), the south evaporation pond (Pond $\mathrm{C}$ ), and the $\mathrm{H}-19$ evaporation pond for TDS; plutonium 238, 239/240; americium 241; uranium 234; 235,238; strontium 90; and gross alpha particle activity. If gross alpha activity is greater than $15 \mathrm{pCi} / \mathrm{L}$ then additional samples for radioactivity, as combined radium 226 and radium 228, will be collected and analyzed within 30 days of the initial analysis. Reports of the analysis shall be submitted to NMED by January 31, April 30, July 31, and October 31 of each year.

Water quality analyses for these analytes have been submitted with the quarterly reports.

\subsubsection{Requirement for Reporting Volume and Origin of Miscellaneous Nonhazardous Discharges, DP-831 CA 3}

The CAO shall notify NMED of the volume and origin of all wastewater to be discharged that is derived from miscellaneous nonhazardous sources. 
The volume and origin of all wastewater discharged derived from miscellaneous nonhazardous sources has been submitted with the quarterly reports.

\subsubsection{Authorization to Discharge, DP-831 Specific Requirement 1}

WIPP is authorized to discharge up to 23,000 gpd of sewage effluent to the 5 synthetically lined lagoons for solids settling and evaporation. WIPP can also discharge up to 100 gallons per year of neutralized acid solution to the lagoons.

The discharge volumes of the sewage effluent and the discharge volumes and $\mathrm{pH}$ of the neutralized acid solution are measured, recorded, and reported quarterly. Discharges have been maintained below permit limits.

\subsubsection{Authorization to Discharge, DP-831 Specific Requirement 2}

WIPP is authorized to discharge up to 2,000 gpd of nonhazardous brine water to the synthetically lined north evaporation cell.

The discharge volumes are measured, recorded, and reported quarterly. Discharges have been below permit levels.

\subsubsection{Authorization to Discharge, DP-831 Specific Requirement 3}

WIPP is authorized to discharge up to 8,000 gpd of nonhazardous brine water to the synthetically lined $\mathrm{H}-19$ evaporation pond.

The discharge volumes are measured, recorded, and reported quarterly. Discharges have been maintained below permit limits.

\subsubsection{Maintenance of Berms, DP-831 Specific Requirement 4 \\ WIPP will maintain all berms surrounding the facultative lagoon system to protect against storm water run-on and runoff}

The berms are inspected and maintained to protect against storm water run-on and runoff.

29.3.8 Contingency Plan Required, DP-831 Specific Requirement 5

WIPP will implement the RCRA Contingency Plan, dated

December 16, 1996, in the event of a failure of the waste water treatment and disposal system. 
The RCRA Contingency Plan will be implemented as described in Part 17 of the NMED Ground Water Discharge Permit Application dated December 16, 1996.

\subsubsection{Facility Closure Plan Required, DP-831 Specific Requirement 6}

WIPP will implement the closure plan, dated December 16, 1996, when the facility is decommissioned.

The closure plan will be implemented as described in Part 19 of the NMED Ground Water Discharge Permit Application dated December 16, 1996.

\subsubsection{General Requirement, Monitoring and Reporting, DP-831}

Monitoring and reporting shall be as specified in the discharge plan and supplements thereto.

Monitoring is conducted and reports are submitted to the NMED quarterly as specified in the Discharge Plan.

\subsubsection{General Requirement, Record Keeping, DP-831}

The discharger shall maintain at the facility, a written record of groundwater and wastewater quality analyses at the facility. The information shall be recorded and made available to the NMED upon request.

Monitoring, reporting, and record-keeping requirements are met as specified in the Discharge Plan.

\subsubsection{General Requirement, Inspection and Entry, DP-831}

The discharger shall allow the NMED Secretary or his authorized representative, upon the presentation of credentials, to enter the discharger's facility during regular business hours or at other reasonable times under the conditions of this discharge plan.

NMED personnel are allowed on site to conduct inspections, sampling, and monitoring during normal business hours. NMED personnel performed an inspection of the facility in January 2000.

\subsubsection{General Requirement, Duty to Provide Information, DP-831}

The discharger shall furnish to the NMED, within a reasonable time frame specified by the NMED, any relevant information which it may request to determine whether cause exists for 
modifying, terminating, and/or renewing this discharge plan or to determine compliance with this plan. The discharger shall furnish to the NMED, upon request, copies of records required to be kept by this Discharge Plan.

No requests have been received from the NMED to provide information relevant to the Discharge Plan. Similarly, the NMED has not requested copies of the records to be maintained under the terms of the Discharge Plan.

\subsubsection{General Requirement, Spills, Leaks, and other Unauthorized Discharges, DP-831}

Any unauthorized discharges must be reported to the NMED and remediated as required. This requirement applies to all seeps, spills, and/or leaks discovered from the sewerage lagoons or that may directly or indirectly leave the boundaries of the WIPP site.

Any spills, leaks, and other unauthorized discharges will be reported to the NMED and remediated in accordance with MOC procedures. No such unauthorized discharges have occurred during this reporting period.

\subsubsection{General Requirement, Retention of Records, DP-831}

The discharger shall retain records of all monitoring information, including all calibration and maintenance records, copies of all reports required by this discharge plan, and records of all data used to complete the application for this discharge plan, for a period of at least five years from the date of the sample collection, measurement, report, or application.

All monitoring information, analytical results, monitoring reports, and data used to complete the discharge plan application will be retained for at least five years.

\subsubsection{General Requirement, Modifications and/or Amendments, DP-831}

The discharger must notify the NMED of any modifications or additions to the applicant's wastewater disposal system, including any increase in wastewater flow rate and wastewater storage and disposal management changes to the system as approved under this discharge plan. The discharger shall obtain the NMED's approval, as a discharge plan modification, prior to any increase in the quantity or concentration of constituents in the wastewater above those approved in this plan. 
If any modifications or additions to the wastewater disposal system are planned for WIPP that would increase the quantity and/or the concentration of constituents in the waste water above those approved in the discharge plan, the NMED will be notified. No work will be initiated until the NMED approves the modification or addition. 
This page intentionally left blank. 
30.0 NEW MEXICO DRINKING WATER REGULATIONS

\subsection{Summary of the Regulations}

Like the SDWA, the New Mexico Drinking Water Regulations (DWR), section 7.1 of Title 20 NMAC, provide a regulatory strategy for protecting public water-supply systems within the state. This section identifies the various categories of water-supply systems and establish operating requirements for each system. It also establishes the maximum contaminant levels for water-supply systems and implement monitoring and analytical requirements for each system.

The DWRs were formerly implemented by the New Mexico Water Supply Regulations, Part III. They are now implemented by Chapter 7 of Title 20 of the NMAC.

\subsection{Compliance Status of the Regulatory Requirements}

The NMED notified WIPP on September 9, 1992, that the WIPP water supply system is considered a public water supply and classified the system as a nontransient, noncommunity water supply for reporting and testing under the requirements of the SDWA. The DOE has corresponded with the NMED since the original letter of September 9, 1992, which identified WIPP as a nontransient, noncommunity water supply system, to obtain a determination of the specific SDWA sampling requirements for the site. This direction was requested because WIPP obtains raw water from the Double Eagle Water Line, which is owned and operated by the city of Carlsbad.

On March 11, 1994, the NMED Carlsbad Field Office provided specific direction on the type of SDWA sampling required for the WIPP water supply system. The letter references Part III, § 310, of the New Mexico DWR, which states:

When a public water system supplies water to one or more other public water supply systems, the Department may modify the compliance sampling requirements imposed by the regulations to the extent that the interconnection of the systems justifies treating them as a single system for compliance sampling purposes.

The NMED went on to determine that "since the Carlsbad Municipal Public Water Supply (WSS206-08) provides WIPP with its water and since Carlsbad already tests the various constituents at each Double Eagle well field source, WIPP is exempted from taking these samples." The NMED then determined that WIPP is required to obtain point-of-use system samples, including lead, copper, and total coliform bacteria.

The specific requirements that are applicable to WIPP and the compliance status of each are provided in the text. 


\subsubsection{Maximum Contaminant Level for Total Coliform Bacteria, 20 NMAC 7.1, § 205(A)}

The maximum contaminant level for total coliform bacteria is based on the presence or absence of total coliforms in a sample rather than on coliform density. For a system that collects fewer than 40 samples per month, the system is in compliance with the total coliform maximum contaminant level if no more than one sample collected during the month is total coliform positive.

Analyses for total coliform bacteria (i.e., Escherichia coli) are performed at WIPP on a monthly basis. The laboratory submits the results to WIPP and to the NMED. To date, coliforms have remained below the maximum contaminant level

\subsubsection{Cross-Connections, 20 NMAC 7.1, § 208(I)}

No physical connection between a public water supply and any water-supply source not regulated by the NMED is allowed unless the public water-supply system is protected by a backflow prevention device that has been reviewed by the NMED and is listed by an appropriate listing agency.

The MOC maintains a cross-connection control program. In July 1997, an Environmental Compliance Assessment (ECA-97-007) was conducted to evaluate the site cross-connection control system at WIPP. During this assessment a potential cross-connection between the fire water systems and the site domestic water system was noted. The corrective actions were completed in March 1999.

\subsubsection{Certification of Sampling Personnel, 20 NMAC 7.1, § 301(E)}

All persons who collect compliance samples for water-supply samples must possess a current Sampling Certificate issued by the Secretary of the NMED. Sampling Certificates are issued only to persons who have successfully completed an approved training course and have passed an examination that is administered periodically by the NMED. Sampling Certificates are valid for 3 years.

All WIPP personnel involved with water-supply sampling to ensure compliance with the DWR have completed the New Mexico water-sampling training course and have current Sampling Certificates.

\subsubsection{Compliance Sampling of Coliforms, 20 NMAC 7.1, § 302(A)}

Public water-supply systems must collect total coliform samples at sites that are representative of water throughout the 
distribution system according to their approved written sampling plan.

The minimal number of samples required per month is based on the population served by the system. Only one sample per month is required by a water-supply system that serves an average daily population of 25 to 1,000 .

Samples are collected from sites that are representative of water throughout the distribution system. This technique is covered in the MOC procedures for coliform sampling of WIPP drinking water.

Fewer than 1,000 people are served by the water-supply system at WIPP. Therefore, at least one sample is collected per month for total coliform bacteria analysis.

\subsubsection{Laboratories, 20 NMAC 7.1, § 309}

Compliance samples may be considered only if they have been analyzed by a laboratory that is acceptable to the NMED.

Lead and copper samples are analyzed by the Scientific Laboratory Division of the NMED and the soil, water, and air testing laboratory of New Mexico State University. Both laboratories are accepted by the NMED.

\subsubsection{Sampling of Consecutive Public Water-Supply Systems, 20 NMAC 7.1,} § 310

When a public water-supply system provides water to one or more other public water-supply systems, the NMED may modify the compliance sampling requirements imposed by these regulations. Any modified compliance sampling shall be conducted in accordance with the schedule specified by the NMED.

The water-supply system at WIPP receives its water from the public water-supply system of the city of Carlsbad. Carlsbad is responsible for all well-source sampling. Therefore, the NMED has modified the compliance sampling requirements for WIPP and requires sampling only for lead, copper, and total coliform bacteria.

Per the requirements set forth in 20 NMAC 7.1, Subpart X, § 1001(c)(1), "the lead action level is exceeded if the concentration of lead in more than 10 percent of tap water samples collected during any monitoring period conducted in accordance with $\S 1007$ is greater than $0.015 \mathrm{mg} / \mathrm{L}$."

Per the requirements set forth in 20 NMAC 7.1, Subpart X, § 1001(c)(2), "the copper action level is exceeded if the concentration of copper in more than 10 percent of tap 
water samples collected during any monitoring period conducted in accordance with $\S 1007$ is greater than $1.3 \mathrm{mg} / \mathrm{L}$."

The CAO requested, the NMED granted, reduced monitoring status at WIPP. Because of reduced monitoring status for lead and copper, sampling frequency was reduced from ten samples annually to ten samples every three years. Total coliform bacteria sampling is unaffected by this action and samples are collected once a month as required by the NMED. The first triennial compliance sampling was conducted on July 13,1999. The results were below action levels and were reported to the NMED on August 18, 1999.

\subsubsection{Reporting Requirements, 20 NMAC 7.1, § 401(A)}

Unless a shorter period is specified, the water supplier shall provide a copy of the results and data required to the appropriate NMED field office within 10 days after analysis.

Analytical reports for lead and copper are submitted to the appropriate NMED field office within 10 days of their receipt by MOC personnel and directly by the laboratory. The analytical laboratory that analyzes total coliform bacteria sends a copy of the results and data directly to WIPP and to the appropriate NMED field office.

\subsubsection{Record Maintenance, 20 NMAC 7.1, § 403(A)}

A water supplier shall retain the appropriate records on or near the premises of the public water-supply system. Records of bacteriological and chemical analyses shall be kept for at least five and ten years, respectively. The information that must be retained includes the date, place, and time of sampling; the name of the person who collected the sample; identification of the sample; date of analysis and name of the laboratory and person who performed the analysis; the analytical method used; and the results of the analysis.

All applicable records pertaining to the sampling and analysis and the analytical results are maintained as quality records by the MOC. 


\subsection{NEW MEXICO HAZARDOUS CHEMICALS INFORMATION ACT}

\subsection{Summary of the Law}

The New Mexico Hazardous Chemicals Information Act (HCIA; §§ 74-4E-1 through 74-4E-9 NMSA 1978) was enacted to ensure that current information on the nature and location of hazardous chemicals is available to LEPCs, emergency responders, and the public as required by SARA Title III. The HCIA created the SERC and directs facility owners or operators to notify the New Mexico Department of Public Safety under certain conditions, including the presence of extremely hazardous substances at or above a specified quantity at a facility and the release of any chemical substance that has occurred at or above reportable quantities determined by the state. The $\mathrm{HClA}$ specifies reports to be submitted to the state, including toxic chemical release and hazardous material inventory reports.

\subsection{Compliance Status of the Regulatory Requirements}

The text provides more detail for each applicable requirement and its compliance status under the HCIA.

\subsubsection{Notice of Extremely Hazardous Substance, § 74-4E-5(A)(1)}

Facility owners or operators must notify the state safety department that an extremely hazardous substance, at or above the threshold planning quantity, is present at a facility.

The CAO submits a list of hazardous chemicals to the SERC, the LEPC, and all local fire departments with which WIPP maintains an MOU whenever additional substances are received or if significant new information is received about an item for which a list was provided. A revised list of hazardous chemicals was submitted to these organizations in August 1999. The listing comprised extremely hazardous substances present in amounts equal to or greater than the Threshold Planning Quantity or 500 pounds, whichever is less, and all substances classified as hazardous under the Occupational Safety and Health Act Hazard Communication Standard with site inventories equal to or greater than 10,000 pounds.

\subsubsection{Notice of Release of Chemical Substance(s), § 74-4E-5(A)(2)}

Facility owners or operators must notify the state safety department of the release of a chemical substance when the release is at or above the $R Q$ of the substance.

During this reporting period, there were no releases or spills at WIPP that exceeded a $\mathrm{RQ}$. 


\subsubsection{Hazardous Material Inventory, § 74-4E-5(A)(3)}

Facility owners or operators must submit to the state an inventory form containing Tier II information on or before March 1 of each year.

The CAO submitted the Emergency and Hazardous Chemical Inventory Report (Tier II Report) in February 1999 and February 2000 to the SERC, the LEPC, and all local fire departments.

\subsubsection{Toxic Chemical Release Inventory, § 74-4E-5(A)(4)}

Facility owners or operators employing at least 10 employees and with a covered Standard Industrial Classification (SIC) code must submit a toxic chemical release form on or before July 1 of each year to the state safety department.

WIPP's SIC code, 4953, is a covered SIC code. However, during this reporting period WIPP was exempt from submitting a Toxic Chemical Release Inventory report because the use of toxic chemicals at WIPP fell under the exemptions described in 40 CFR § 372.38, "Exemptions." 
32.0 NEW MEXICO EMERGENCY MANAGEMENT ACT

\subsection{Summary of the Law}

The New Mexico Emergency Management Act (EMA; §§ 74-4B-1 through 74-4B-14 NMSA 1978) was enacted to ensure the adequacy of hazardous material emergency management capabilities in the state to protect the health and safety of New Mexico citizens and the environment. The act delineates those state agencies that are responsible for responding to hazardous material accidents and providing control and management of such accidents. Furthermore, the act provides for the formulation of a comprehensive hazardous materials emergency management plan.

\subsection{Compliance Status of the Regulatory Requirements}

The text provides more detail on the compliance status of each requirement under the Emergency Management Act.

32.2.1 State Police Emergency Response Officer; Procedure for Notification; Cooperation of other State Agencies and Local Governments, § 74-4B-5

State Police Emergency Response Officers shall be designated, trained, and available to answer an emergency response call from the first responder. The responsibilities of these officers and of the State Police Emergency Response Center are described. Any driver of a vehicle carrying hazardous materials involved in an accident which may cause injury to persons or property or any owner, shipper, or carrier of hazardous materials involved in an accident who has knowledge of such accident or any owner or person in charge of any building, premises, or facility where such an accident occurs shall immediately notify the New Mexico State Police Division of the Public Safety Department by the quickest means of communication available.

Should an accident involving hazardous materials occur, the New Mexico State Police Division of the Public Safety Department will be notified by the driver, owner, shipper, or carrier of the waste as outlined in an MOC procedure and the Carrier Management Plan. In the event of an accident involving a TRUPACT-II container, contact to the Central Monitoring Room operator will be made through TRANSCOM. The Central Monitoring Room operator will then contact the state police and other appropriate agencies.

WIPP personnel will contact the SERC in the event of a spill that could endanger human health or the environment. The SERC will, in turn, contact the NMED if their assistance is needed. 


\subsubsection{Clean-Up, § 74-4B-10}

Nothing in the Emergency Management Act shall be construed to relieve hazardous materials owners, shippers, or carriers of their responsibilities and liability in the event of an accident. Such persons shall assist the state as requested in responding to an accident and are responsible for restoring the scene of the accident to the satisfaction of the state.

The DOE Radiological Assistance Team will take responsibility for site remediation of any occurrences involving TRUPACT-II containers, whether on-site or off-site. The Radiological Assistance Team will clean up the accident scene to the affected state's satisfaction. 
33.0 NEW MEXICO PREHISTORIC AND HISTORIC SITES PRESERVATION ACT

\subsection{Summary of the Law}

The provisions of the Congressional National Historic Preservation Act are furthered by law in the state of New Mexico. The act currently in place is the New Mexico Prehistoric and Historic Sites Preservation Act (§§ 18-8-1 through 18-8-8 NMSA 1978). The purpose of this act is the acquisition, stabilization, restoration, or protection of significant prehistoric and historic sites by the state of New Mexico and corporations. This act is administered by the SHPO in consultation with the Cultural Properties Review Committee.

The Prehistoric and Historic Sites Preservation Act is implemented by Historic Preservation Division Rule 89-2, which established procedures for acquiring, stabilizing, restoring, or protecting significant prehistoric and historic sites. Rule 89-2 also established procedures and guidelines to evaluate alternatives to programs and projects requiring the use of land from significant prehistoric and historic sites and to determine whether all possible planning has been implemented to preserve and protect such sites. Detailed requirements for a long-term management plan for any site acquired, stabilized, restored, or protected are included under this rule.

\subsection{Compliance Status of the Regulatory Requirements}

WIPP is bound by the New Mexico statutes and regulations regarding cultural properties in accordance with edicts provided by the SHPO. WIPP personnel contract for archeological surveys and consult with the SHPO each time an action is proposed that would impact a previously undisturbed area. Detailed instructions for compliance with applicable cultural resource management requirements are contained in the LMP.

Prior to the issuance of the LWA, the BLM was responsible for archaeological resource management on the WIPP site and served as the DOE's liaison with the SHPO. Following the issuance of the LWA, the BLM continued to serve in this capacity until July 19, 1994, when the Memorandum of Understanding Between the DOE and the Department of the Interior was finalized. At that time, the CAO began communicating directly with the SHPO regarding archeological concerns at WIPP.

There were no SHPO approvals requested for surface disturbing activities during this reporting period. 
This page intentionally left blank. 


\subsection{NEW MEXICO STATE IMPLEMENTATION OF THE FEDERAL LAND POLICY AND MANAGEMENT ACT}

\subsection{Summary of the Law}

The FLPMA was enacted to ensure that "public lands be managed in a manner that will protect the quality of scientific, scenic, historical, ecological, environmental, air and atmospheric, water resource, and archeological values; that, where appropriate, will preserve and protect certain public lands in their natural condition; that will provide food and habitat for fish and wildlife and domestic animals; and that will provide for outdoor recreation and human occupancy and use." Under the FLPMA, the Secretary of the Interior is authorized to grant, issue, or renew rights-of-way over, upon, under, or through public lands.

The spirit and purpose of the congressional legislation to protect and preserve the quality of public lands is furthered by law in the state of New Mexico. In 1912, the New Mexico Legislature created the State Land Office (SLO) and directed that the Office's executive officer, the Commissioner of Public Lands (the Commissioner), execute jurisdiction over, and provide for the management, care, control, and disposition of, public lands owned and subsequently acquired by the state. The Commissioner was authorized to grant rights-of-way and easements over, upon, or across state lands for highways, power lines, mining, or other purposes. The Commissioner's authority related to rights-of-way and easements is currently promulgated in New Mexico Statute 19-7-57.

The regulation of right-of-way and easement grants is addressed in the SLO's Rule 10, Relating to Easements and Rights-of-Way, which outlines the requirements for applying for and maintaining a right-of-way grant.

\subsection{Compliance Status of the Regulatory Requirements}

The text provides more detail for applicable requirements under SLO Rule 10 and the compliance status of each requirement.

\subsubsection{Application Requirements and Fees, SLO Rule 10.006}

Written application for right-of-way grants (reservations) shall be made upon the proper forms. The application shall be made under oath and be accompanied by the payment of appropriate fees. The application will contain a legal description of the lands to be crossed and a plat [see section 34.2.4 below].

The proper application form and the fees required were submitted as required. The application included the legal description of the lands to be crossed and a survey plat.

Permit No. RW-22789 was issued for a high-volume air sampler for the period of October 3, 1985, through October 3, 2020. 


\subsubsection{Conditions, SLO Rule 10.009}

The minimum width of a right-of-way or easement granted under these rules shall be 30 feet.

As described in the application and survey plat, the right-of-way covers a 40 -foot-wide strip of land.

\subsubsection{Damage Bond, SLO Rule 10.010}

The applicant must file a bond with the Commissioner before the right-of-way may be issued. The bond must compensate the state or other appropriate party for any damage done to improvements or other property. The Commissioner may waive this requirement if the applicant is a governmental agency that is prohibited from posting a security bond, the applicant is not immune to suit or is otherwise required by law to pay such damages, or meets other conditions specified.

The DOE is a governmental agency. As such a damage bond is not required.

\subsubsection{Survey Plat, SLO Rule $\mathbf{1 0 . 0 1 1}$}

Specific requirements for the survey plat are described in SLO Rule 10.011

A survey plat was included in the application. The plat met all requirements specified in SLO Rule 10.011.

\subsubsection{Construction Reports, SLO Rule $\mathbf{1 0 . 0 1 2}$}

The holder of a right-of-way shall notify the Commissioner immediately in the event that any historic or prehistoric ruin, monument, or artifact of historical, archeological, or scientific value is discovered upon the right-of-way. The holder of the right-of-way shall refrain from further disturbing the area until the Commissioner has been notified and inspection and clearance have been performed by the proper authorities if deemed necessary by the Commissioner.

No ruins, monuments, or artifacts of historical, archeological, or scientific value were discovered upon the right-of-way. 


\subsubsection{Affidavit of Completion, SLO Rule 10.013}

Upon the completion of construction of any right-of-way, the applicant shall promptly file an affidavit of completion with the Commissioner. Failure to file such an affidavit in accordance with this section shall subject the right-of-way to cancellation in accordance with the provisions of these rules.

The DOE submitted an Affidavit of Completion to the SLO certifying the completion of construction and the location of the high-volume air sampler.

\subsubsection{Renewal of Right-of-Way Reservations, SLO Rule 10.017}

An application may be submitted for a renewal of the reservation prior to the expiration date of any right-of-way.

Permit No. RW-22789 (see section 34.3 below) was granted for a term of 35 years. If the right-of-way will still be needed after the expiration date, an application will be submitted as required.

\subsubsection{Reclamation and Restoration, SLO Rule $\mathbf{1 0 . 0 1 9}$}

Any person who enters upon state land to survey or construct a right-of-way shall take all steps necessary to preserve and protect the natural environmental conditions of the land, including reclaiming disturbed areas by leveling or terracing and revegetation. Revegetation shall include the establishment of suitable grasses and forbs. The grantee of any right-of-way shall consult with the Commissioner's designee regarding reclamation prior to undertaking same and shall abide by all directives of the designee.

The DOE will ensure that all reclamation and revegetation activities requested by the Commissioner or by his/her designee will be performed. Until these activities have been initiated, these requirements do not apply to WIPP.

\subsection{Compliance Status of the Permit Conditions}

The Commissioner granted Right-of-Way Permit No. RW-22789 to WIPP for a highvolume air sampler. The term of the permit is 35 years (October 3, 1985, through October 3, 2020). The text summarizes the applicable permit conditions and the compliance status of each condition. 


\subsubsection{Disposal of Brush and Other Debris, Term/Condition 3}

In clearing the right-of-way, the grantee agrees to dispose of brush and other debris so as not to interfere with the movement of livestock of state grazing lessees.

All brush and other debris were disposed of appropriately.

\subsubsection{Depth of Pipelines, Term/Condition 4}

All pipelines placed on the right-of-way lands under this permit must be buried at least 20 inches deep.

This right-of-way was not obtained for a pipeline. Therefore, this condition is not applicable.

\subsubsection{Prevention of Destruction or Injury to Improvements or Livestock, Term/Condition 5}

The grantee agrees to carefully avoid causing destruction or injury to any improvements or livestock lawfully upon the premises, to close all gates immediately after passing through them, and to make prompt payment of all reasonable and just damages for any injury or destruction arising from constructing or maintaining the right-of-way.

The DOE carefully avoids causing destruction or injury to any improvements or livestock that are lawfully upon the premises. Gates are closed as soon as possible.

\subsubsection{Purpose of Right-of-Way, Term/Condition 6}

The right-of-way granted is for the sole purpose of providing egress from and ingress to a high-volume air sampler. The right-of-way may not be used for any other purpose and may not be reassigned by the grantee.

The right-of-way granted under this permit is used only for the high-volume air sampler.

\subsubsection{Existing Rights, Term/Condition 7}

The rights granted under Permit RW-22789 are subject to valid existing rights.

No existing leases or rights-of-way of record are known. 


\subsubsection{Leases for Mineral Resources, Term/Condition 8}

The Commissioner reserves the right to execute leases for oil and gas, coal and minerals; to sell or dispose of same; and to grant rights-of-way and easements related to such leasing.

The land subject to the conditions of Permit RW-22789 (i.e., T 19 S, R 27 E, section 13) is not part of the land that was withdrawn from the Department of the Interior and transferred to the DOE under the LWA (i.e., several sections under T $22 \mathrm{~S}, \mathrm{R} 31 \mathrm{E}$ ). Therefore, this term remains applicable although no action is required by WIPP personnel.

\subsubsection{Compliance with all Applicable Regulations and Requirements, Term/Condition 9}

The grantee and its employees, agents, and contractors shall fully comply with all laws, regulations, and requirements of any governmental authority or agency in all matters that affect the premises and operations pertaining to such issues as conservation, sanitation, aesthetics, pollution, cultural properties, fire, or ecology.

This BECR addresses compliance with all such laws, regulations, and requirements at WIPP.

\subsubsection{Non-Use of the Right-of-Way, Term/Condition 10}

If the right-of-way granted is not used for a period that exceeds one year without the prior written permission of the Commissioner, the right-of-way will be considered abandoned. Non-use for shorter periods will require that the grantee prove that there was no intent to abandon the right-of-way.

The right-of-way is used periodically to collect samples and to maintain the sampler.

\subsubsection{Protection and Preservation of Natural Environmental Conditions, Term/Condition 13}

The grantee agrees to preserve and protect the natural environmental conditions of the land encompassed in this permit and to take such reclamation or corrective actions necessary to protect the land from pollution, erosion, or other forms of environmental degradation.

The land encompassed in this permit is being preserved and protected. In addition, a contemporary reclamation program and a corresponding long-range plan have been 
implemented at WIPP. When the right-of-way for the high-volume air sampler is to be reclaimed, WIPP personnel will use the best acceptable reclamation practices. (See also section 34.3.10 below.)

\subsubsection{Reclamation of All Disturbed Areas, Term/Condition 14}

The grantee agrees to reclaim all disturbed areas by grading, leveling, or terracing and to landscape these areas at its own expense. Landscaping will include the planting of native grasses, shrubs, or other vegetation so as to return disturbed areas to their natural state and prevent erosion caused by water and/or wind.

The seed mixes to be used to revegetate the area will reflect those species which are indigenous to the vicinity, with priority given to those species of plants that are conducive to soil stabilization and to the needs of livestock and wildlife. (See also section 34.3.9 above.) This section is not applicable to WIPP during this reporting period. 
35.0 NEW MEXICO STATE IMPLEMENTATION OF THE BALD AND GOLDEN EAGLE PROTECTION ACT

\subsection{Summary of the Law}

The Bald and Golden Eagle Protection Act makes it unlawful to take (i.e., capture, kill, or destroy), possess, molest, or disturb living or dead bald eagles (Haliaeetus leucocephalus) or golden eagles (Aquila chrysaetos), their parts, their nests, or their eggs anywhere in the United States. A permit must be obtained from the Department of the Interior to relocate any nest that interferes with resource development or recovery operations. In addition, a permit may be obtained that authorizes taking, possessing, or transporting eagles or their parts, nests, or eggs.

Chapter 17 of the New Mexico statutes establishes rules and regulations to protect raptors. In particular, § 17-2-14, "Hawks, vultures and owls, taking, possessing, trapping, destroying, maiming or selling prohibited; exception by permit; penalty," authorizes the Director of the Department of Game and Fish to issue permits to allow any person to take, possess, trap, ensnare, or destroy any bird protected by this section. Permits may be granted for several purposes, including scientific purposes, in accordance with the law and the State Game Commission's regulations. In addition, §§ 17-2-37 through 17-2-46 of the Wildlife Conservation Act also further the purpose of the Bald and Golden Eagle Protection Act with respect to the bald eagle as an endangered species (see Chapter 37 herein).

\subsection{Compliance Status of the Regulatory Requirements}

At present, no bald or golden eagles are nesting on the WIPP site; however, individual eagles are frequently observed overwintering in the area. Therefore, a permit regarding bald or golden eagles is not required. If it becomes necessary, a permit application will be submitted, and all applicable permit requirements will be met. 
This page intentionally left blank. 


\subsection{NEW MEXICO WILDLIFE CONSERVATION ACT, IMPLEMENTING THE ENDANGERED SPECIES ACT}

\subsection{Summary of the Law}

The federal Endangered Species Act was enacted in 1973 to prevent the extinction of many species of animals and plants. The act provides strong measures to help alleviate the loss of species and their habitats. It places restrictions on a wide range of activities involving endangered and threatened animals and plants to help ensure their continued survival. With limited exceptions, the act prohibits activities using these protected species unless authorized by a permit from the FWS.

The intent of the Congressional endangered species legislation is furthered in the New Mexico Wildlife Conservation Act, which was enacted to protect the state's rare animals in 1974 (the New Mexico Endangered Plant Species Act [9-10-10 NMSA] protects rare plants). The current sections of the state's Wildlife Conservation Act reside in §§ 17-2-37 through 17-2-46 NMSA 1978. The Wildlife Conservation Act directs that endangered species of wildlife that are indigenous to New Mexico should be managed and maintained and, to the extent possible, their numbers enhanced within the carrying capacity of the habitat. The state is directed to assist in the management of endangered and threatened species of wildlife, including those which are federally listed.

Protection under the Wildlife Conservation Act extends to native species, of crustaceans, mollusks, fish, amphibians, reptiles, birds, and mammals that are listed by the State Game Commission in regulation 19 NMAC 33.1.

Section 17-2-41, "Endangered Species," states that "except as otherwise provided in this act, it is unlawful to take, possess, transport, export, process, sell or offer for sale, or ship" any species or subspecies of wildlife that appears on the following lists:

(1) wildlife indigenous to the state determined to be endangered within the state as set forth by regulations of the Game Commission of the state of New Mexico (the Commission) and (2) the federal lists of endangered species as set forth in the Endangered Species Act to the extent that such lists are adopted by regulations of the Commission. Section 17-2-38L defines "take" to include harass, hunt, capture, or kill.

In section 17-2-42, "Management Programs," the Director of the State Department of Game and Fish is directed to perform the following: (1) establish programs deemed necessary by the Commission for the management of endangered species; (2) work with federal and state entities or with private individuals in the administration and management of programs for the management of endangered species; (3) authorize by permit the taking, possession, transportation, or shipment of species deemed to need management for purposes including scientific and educational; and (4) authorize by permit the removal, capture, and destruction of endangered species where necessary to prevent damage to property or to protect human health. 
The intent of the congressional legislation protecting migratory birds under the Migratory Bird Treaty Act is also addressed in Chapter 17 of the New Mexico statutes. In particular, § 17-2-3 NMSA, "Protected wildlife species and game fish defined," specifies that all of the migratory bird family Anatidae (waterfowl) is protected. Section 17-2-14 NMSA addresses the protection of hawks, vultures, and owls. Section 17-2-13 NMSA protects many species of songbirds. The hunting, taking, capturing, killing, or possession or the attempt to hunt, take, capture, or kill these species is regulated by the Commission.

The Commission's Regulation 19 NMAC 33.1, "Governing the Removal, Capture or Destruction of Endangered Species," was adopted in 1975. This regulation specifies that any person who does not possess a permit and who removes, captures, or destroys any wildlife species classified as threatened or endangered by Commission regulations, must report any such incident to the NMDG\&F.

The Commission's Regulation 19 NMAC 33.1, "List of Threatened and Endangered Species," lists threatened and endangered wildlife in the state. The regulation was last amended in 1996. It includes seven species of wild cats as "restricted species," by adoption of the federal list of endangered species.

The amended listing of threatened and endangered wildlife of New Mexico includes a number of endangered or threatened species that could be found at WIPP and were specified in the FEIS (DOE, 1980) or the SEIS (DOE, 1990a). These include two species of reptiles (Western Ribbon Snake, Sand Dunes Lizard) and five species of birds (Aplomado falcon, Peregrine falcon, Bald eagle, Baird's sparrow, Varied bunting).

The Commission's Regulation 19 NMAC 36.2, "Regulation for the Taking and Possession of Protected Wildlife for Scientific and Educational Purposes," contains the requirements for obtaining and using state permits and authorizations for taking and possessing wildlife for scientific and educational purposes. Permits and authorizations are issued to individuals rather than to parties or organizations; however, a permittee may have qualified subpermittees. "Protected wildlife" is defined as all wild species of mammals, birds, reptiles, amphibians, and fishes and endangered mollusks and crustaceans taken by a nonresident of New Mexico, or as pikas, marmots, and game, fur-bearing, and endangered mammals; all birds except rock doves, European starlings, and house sparrows; horned lizards if sacrificed, retained, and/or transported out of state; endangered reptiles; bullfrogs and endangered amphibians; game and endangered fishes; and endangered mollusks and crustaceans taken by a resident.

\subsection{Compliance Status of the Regulatory Requirements}

The text provides a summary for each applicable requirement and its compliance status under the state of New Mexico's Game and Fish Code (Chapter 17 NMSA). It should be noted that a number of these requirements apply to WIPP because of the 
potential for the occurrence of recognized protected, endangered or threatened species on WIPP lands.

\subsubsection{Recognition of State-Listed Endangered Wildlife, Regulation 19 NMAC 33.1}

The state-listed threatened and endangered species that could be present at WIPP and/or affected by WIPP activities must be identified.

In 1989, the DOE consulted with the NMDG\&F regarding the state-listed endangered species in the vicinity of the WIPP site. At that time, the department communicated to the DOE their opinion of which state-listed endangered species "occur or are likely to occur at the WIPP site." The species identified were listed in Regulation No. 657, dated January 9, 1988, and included the following species: Mississippi kite, bald eagle, peregrine falcon, least tern, willow flycatcher, Bell's vireo, Baird's sparrow, and the sand dunes lizard. The NMDG\&F subsequently concurred that proposed WIPP activities would probably have no significant impacts on state-listed species in the area. Regulation No. 682 was updated on November 30, 1990, with Amendment No. 1 issued on July 25, 1991. Regulation 682 was replaced by 19 NMAC 33.1 which was last amended in 1996. This list does not include the Mississippi kite. The CAO received the most recent list of threatened and endangered species delineated by county and currently uses this list when considering land-use proposals.

\subsubsection{Report of Unpermitted Removal, Capture, or Destruction of Endangered Species, Regulation 19 NMAC 33.2}

Persons without an authorized state permit who remove, capture, or destroy a state-listed endangered species must provide detailed information on such incident(s) to the state Game and Fish Department within 30 days.

No incidents requiring reports occurred during the reporting period. Several permits and authorizations have been issued for various activities involving the taking of wildlife that are neither endangered nor threatened. These permits and authorizations specify that endangered wildlife shall not be taken during these activities (see section 36.3 below).

\subsubsection{Permit Application and Requirements to Conduct Activities Authorized Under Regulation 19 NMAC 36.2}
A person must complete and submit a permit or authorization application; after receipt of the permit, permittees and subpermittees must comply with written permit requirements.

To date, two permits have been issued. More detail on these permits is provided in section 36.3 below. 


\subsubsection{Year-End Reports, Regulation 19 NMAC 36.2}

An annual report is generally required for permits issued by the Department of Game and Fish. The permits must be filed by March 31.

Annual reports are submitted that describe the activities conducted under each permit issued by the NMDG\&F.

\subsection{Compliance Status of the Permit Conditions}

The text provides a summary of the conditions imposed by the NMDG\&F for each of the two permits issued and the compliance status of each permit condition.

\subsubsection{Permit No. 1894}

Permit No. 1894 authorizes the permittee and subpermittees specified to use live traps, trotlines, and nets (except gill nets) to obtain specimens and to salvage dead, injured, or otherwise incapacitated vertebrates. The authorized MOC personnel may take up to 30 specimens of quail, 50 channel/flathead catfish, and unprotected vertebrates as needed in Eddy and Lea counties. Nonlethal methods must be used to take the catfish. Any endangered or threatened species salvaged must be reported to the NMDG\&F within 14 days. WIPP is the ultimate disposition location for all specimens retained under this permit.

Permit No. 1894 is issued annually. No gill nets have been used to obtain specimens. The allowable number of channel/flathead catfish is 50 specimens. Methods used to capture the catfish are not lethal to these fish or to other aquatic vertebrates. No endangered or threatened species have been salvaged.

\subsubsection{Permit No. 1961}

Permit No. 1961 authorizes the designated permittee and subpermittees to live-capture, band, and release all protected species of birds except for waterfowl, eagles, resident gallinaceous game birds, and endangered or threatened species. Salvage of any dead, injured, or otherwise incapacitated members of an endangered or threatened species must be reported to the NMDG\&F within 14 days. The ultimate disposition of all protected wildlife that is not released is to the Carnegie Museum of Natural History, New Mexico State University, or the University of Arizona. 
Permit No. 1961 is issued annually. The ultimate disposition of any protected species allowable under this permit resides in the Carnegie Museum of Natural History, New Mexico State University, or the University of Arizona, as specified in the permit. 
This page intentionally left blank. 


\subsection{NEW MEXICO PESTICIDE CONTROL ACT}

\subsection{Summary of the Law}

The Pesticide Control Act (§§ 76-4-1 through 76-4-30 NMSA 1978) is administered and enforced by the New Mexico State Department of Agriculture under the direction of the Board of Regents of New Mexico State University, Las Cruces, New Mexico. This act provides for the registration, labeling, distribution, storage, transportation, application, use, and disposal of pesticides and pesticide-related devices. It also provides for the licensing of pesticide dealers, consultants, applicators, and operators of pesticide apparatus and imposes penalties to protect the environment and the public health and welfare.

The Pesticide Control Act is implemented by two regulatory orders of the Board of Regents of New Mexico State University. Regulatory Order No. 4, "Regulatory Orders of the Board of Regents of New Mexico State University" (dated September 16, 1978), describes state requirements for the storage of pesticides and the disposal of pesticide wastes. Regulatory Order No. 5, "Definitions, Licensing, Equipment Inspection, Record Keeping of Pesticides by Regulated Applicants" (dated November 2, 1979), describes requirements for licensing and for applying pesticides in New Mexico and applies to all activities involving the distribution and use of pesticides in the state.

\subsection{Compliance Status of the Regulatory Requirements}

The compliance status of each of the major requirements of the implementing regulations of the Pesticide Control Act is provided in the text.

\subsubsection{Storage of Pesticides and Disposal of Pesticide Wastes, Section 5 of Regulatory Order No. 4}

Requirements for storing pesticides and for disposing of pesticide wastes and pesticide containers are described in section 5 of Regulatory Order No. 4 to the New Mexico Pesticide Control Act.

All restricted-use pesticides are brought on site by the contractor who has been hired to apply them. Storage and disposal of restricted-use pesticides and their containers are the responsibility of the contractors who are licensed by the state and knowledgeable of applicable requirements (see also section 10.2.2 herein). Generaluse pesticides are properly stored at WIPP in accordance with the product label. Used, empty aerosol cans are managed as hazardous waste.

\subsubsection{License Classification, Section 6 of Regulatory Order No. 5}

There are 17 categories of licenses granted by the state of New Mexico. Each one represents the type and scope of the 
specific certification examinations that must be taken by commercial, noncommercial, and public applicators and by pestmanagement consultants for their licenses.

The contractor who applies pesticides at WIPP is licensed under the following categories:

$\begin{array}{ll}- & \text { 3A - Ornamental Pest Control } \\ \text { - } & \text { 3B - Turf Pest Control } \\ \text { - } & \text { 7A - Structural Pest Control } \\ \text { - } & \text { 7D - Rodent Control }\end{array}$

37.2.3 Protective Equipment, Section 10 of Regulatory Order No. 5

All licensed certified applicators must make available properly decontaminated protective equipment which is in proper working order and must advise their employees of its use to meet the safety requirements of the pesticide labeling.

The MOC is not a certified applicator. All pesticide application is done by subcontractors. All pesticide application contracts are reviewed and approved by the MOC before the contract is awarded. Provisions in the contract require that the MOC approve the use of all pesticides prior to application on site. In addition, the contractor is required to submit records of the date of application, specific location, application method, quantity applied, and weather conditions at time of application.

Personal protective equipment is supplied by the contractor.

\subsubsection{Application of Pesticides, Section 11 of Regulatory Order No. 5}

A licensed certified applicator shall apply only those pesticides registered for use in New Mexico under his/her license application. Any person who applies pesticides must follow the directions, rates, and precautions that are stated on the approved label and labeling. Restricted-use pesticides shall be applied only by licensed certified applicators or persons under their direct supervision.

The MOC reviews the application methods and pesticides to be used by the contractor before the application to ensure that the method is appropriate and that no pesticides on the EPA's restricted list will be used.

A copy of the contractor's current license is maintained by the MOC. 


\subsection{REFERENCES}

EG\&G/EM, 1989. An Aerial Radiological Survey of the Waste Isolation Pilot Plant and Surrounding Area, AMO-8809, June.

New Mexico Environment Department, 1999a. Waste Isolation Pilot Plant Hazardous Waste Facility Permit, NM4890139088-TSDF, October 27.

New Mexico Environment Department, 1999b. Technical Support Document, Exclusion/Inclusion of Solid Waste Management Units and Areas of Concern, Permit Module VII Corrective Action for Solid Waste Management Units. Waste Isolation Pilot Plant EPA No. NM4890139088, October.

U.S. Department of Energy, 1980. Final Environmental Impact Statement, Waste Isolation Pilot Plant, DOE/EIS-0026, 2 Vols., October.

U.S. Department of Energy, 1981. Record of Decision for the Final Environmental Impact Statement, Waste Isolation Pilot Plant, Federal Register 46(18): 9162 through 9164, January 28.

U.S. Department of Energy, 1990a. Final Supplement, Environmental Impact Statement, Waste Isolation Pilot Plant, DOE/EIS-0026-FS, 13 Vols., January.

U.S. Department of Energy, 1990b. Record of Decision for the Supplement Environmental Impact Statement, Waste Isolation Pilot Plant, Federal Register 55(121): 25689 through 25692, June 22.

U.S. Department of Energy, 1990c. Results of the U.S. Department of Energy Indoor Radon Study, DOE/ID/12584-75, 2 Vols., August.

U.S. Department of Energy, 1995. Emergency Planning, Response, and Recovery Roles and Responsibilities for TRU-Waste Transportation Incidents, DOE/CAO 94-1039, January.

U.S. Department of Energy, 1996a. Compliance Certification Application, DOE/WIPP 96-2184, October.

U.S. Department of Energy, 1996b. 1996 WIPP Threatened and Endangered Species Survey, DOE/WIPP 97-2228, November.

U.S. Department of Energy, 1997a. Final Supplemental Environmental Impact Statement, Waste Isolation Pilot Plant, DOE/EIS-0026-S-2, 3 volumes, September 1997.

U.S. Department of Energy, 1998. Record of Decision for the Supplemental Environmental Impact Statement, Waste Isolation Pilot Plant, 63 FR 3623-3629, January 23, 1998. 
U.S. Department of Energy, 1999a. Waste Acceptance Criteria for the Waste Isolation Pilot Plant, DOE/WIPP-069, Rev. 7, November.

U.S. Department of Energy, 1999. Waste Isolation Pilot Plant Safety Analysis Report, DOE/WIPP 95-2065, Rev. 4, December.

U.S. Department of Energy, 1999b. Safety Analysis Report for the TRUPACT-II Shipping Package, Rev. 18, August 1999.

U.S. Department of Energy, 2000. Implementation Plan for 40 CFR 191, Subpart A, DOE/WIPP 00-3121, Rev. 1, March.

U.S. Environmental Protection Agency, 1992a. Final NPDES General Permits for Storm Water Discharges Associated with Industrial Activity, Federal Register 57(175): 41236-41342, September 9.

U.S. Environmental Protection Agency, 1992b. National Pollutant Discharge Elimination System Application Deadlines, General Permit Requirements and Reporting Requirements for Storm Water Discharges Associated with Industrial Activity, Federal Register 57(64):11394, April 2.

U.S. Environmental Protection Agency, 1995. Final National Pollutant Discharge Elimination System Storm Water Multi-Sector General Permit for Industrial Activities, Federal Register 60(189):50803 through 51319, September 29.

U.S. Environmental Protection Agency, 1998. Criteria for the Certification and Recertification of the Waste Isolation Pilot Plant's Compliance with the Disposal Regulations: Certification Division, Federal Register 63(95): 27353 through 27406, May 18.

U.S. Environmental Protection Agency, 1998. National Pollutant Discharge Elimination System Storm Water Multi-Sector General Permit issued for use in the State of New Mexico, NMR05A225, February 23.

Westinghouse Electric Corporation Waste Isolation Division, 1997. Air Emissions Inventory Report Calendar Year 1996 for WIPP. 


\subsection{ADDITIONAL REFERENCES AND DOCUMENTS}

Anand, N. K., and A.R. McFarland. Particle Penetration through CAM-Sampler Aerosol Transport Lines, College Station, Texas, April, 1988.

Donovan, K. S. Letter, Manifest Exception Reporting, to D. Brinkerhoff, Santa Fe, NM, February 2, 2000.

IT Corporation. Emission Sampling Report, Backup Diesel Generator, March 24, 1994.

New Mexico Environment Department. Assessment of Solid Waste Management Units at the Waste Isolation Pilot Plant, the WIPP RCRA Facility Assessment, NMED/DOE/AIP 94/1, May, 1994.

New Mexico Environment Department. HRMB Standard Operating Procedures Manual, March, 1998.

U.S. Environmental Protection Agency, Notice Proposing to Grant a Conditional Variance to the Department of Energy Waste Isolation Pilot Plant (WIPP) for Land Disposal Restrictions, Federal Register 55(67): 13068 through 13094, April 6, 1990.

Newton, G. J., K. J. Shenk, Y. F. Su, H-C Yeh, M. D. Hoover, and B. B. Boecker, 1987. Aerosol Studies for Evaluation of 'Isokinetic' Sampling at the Waste Isolation Pilot Plant: Phase I, Measurement in the 14-ft Diameter Exhaust Shaft, Lovelace Inhalation Toxicology Research Institute, Albuquerque, New Mexico, July 30 .

Shariff, M.F., Letter, "TRUPACT II Shipping Package Application, Docket No. 71-9218," to C.R. Chappell, Rockville, MD, July 20, 1999.

NOTE: The following documents are current as of March 31, 2000. There is no guarantee that they are either applicable or current after March 31, 2000.

\begin{tabular}{|l|l|c|}
\hline \multicolumn{1}{|c|}{ Document No. } & \multicolumn{1}{|c|}{ Document Title } & Rev. No. \\
\hline WP 02-EC.02 & Special Waste Management Plan & 0 \\
\hline WP 02-EC.04 & Management of Hazardous Materials Plan & 2 \\
\hline WP 02-EC.05 & $\begin{array}{l}\text { Quality Assurance Project Plan for WIPP Site Effluent and } \\
\text { Hazardous Materials Sampling }\end{array}$ & 0 \\
\hline WP 02-EC.06 & WIPP Site Effluent and Hazardous Materials Sampling Plan & 1 \\
\hline WP 02-EC.08 & National Environmental Policy Act Compliance Plan & 1 \\
\hline WP 02-EC.09 & WIPP Spill Prevention, Control, and Countermeasures Plan & 1 \\
\hline WP 02-EC.10 & $\begin{array}{l}\text { WIPP National Pollutant Discharge Elimination System Storm } \\
\text { Water Pollution Prevention Plan }\end{array}$ & 0 \\
\hline WP 02-EC.11 & Waste Isolation Pilot Plant Pollution Prevention Program Plan & 0 \\
\hline WP 02-EC0 & Environmental Management System Implementation Document & 3 \\
\hline WP 02-EC1001 & Characterization Sampling, Shipping, and Documentation & 2 \\
\hline
\end{tabular}




\section{Waste Isolation Pilot Plant Biennial Environmental Compliance Report DOE/WIPP 99-2171}

\begin{tabular}{|c|c|c|}
\hline Document No. & Document Title & Rev. No. \\
\hline WP 02-EC3201 & Environmental Compliance Assessment Program & 2 \\
\hline WP 02-EC3506 & Environmental Incident Reporting & 1 \\
\hline WP 02-EC3801 & NEPA Compliance & 1 \\
\hline WP 02-1 & WIPP Groundwater Monitoring Program Plan & 5 \\
\hline WP 02-EM1001 & Sewage Lagoon Sampling & 1 \\
\hline WP 02-EM1005 & Groundwater Serial Sample Analysis & 1 \\
\hline WP 02-EM1009 & Soil Sampling for Radiological Analysis & 0 \\
\hline WP 02-EM1011 & Biotic Sampling & 0 \\
\hline WP 02-EM1012 & Airborne Particulate Sampling & 2 \\
\hline WP 02-EM1014 & Groundwater Level Measurement & 0 \\
\hline WP 02-EM1016 & Request to Discharge to Evaporation Ponds & 0 \\
\hline WP 02-EM1017 & Surface Water and Sediment Sampling for Radiological Analysis & 0 \\
\hline WP 02-EM1019 & Vegetation Sampling & 0 \\
\hline WP 02-PC.02 & Delaware Basin Drilling Surveillance Plan & 0 \\
\hline WP 02-PC.03 & $\begin{array}{l}\text { WIPP Hazardous Waste Permit Reporting and Notifications } \\
\text { Compliance Plan }\end{array}$ & 2 \\
\hline WP 02-PC3001 & WIPP Hazardous Waste Facility Permit Screening & 0 \\
\hline WP 02-PC3002 & $\begin{array}{l}\text { RCRA Permit Change - Screening Approval and Modification } \\
\text { Processing }\end{array}$ & 1 \\
\hline WP 02-RC.01 & $\begin{array}{l}\text { Site-Generated, Non-Radioactive Hazardous Waste Management } \\
\text { Plan }\end{array}$ & 0 \\
\hline WP 02-RC.04 & RCRA Training Documentation & 0 \\
\hline WP 06-HM3108 & Request for Disposal & 3 \\
\hline WP 02-RC3109 & Hazardous Waste Accumulation Area Inspection & 0 \\
\hline WP 02-RC3502 & Used Oil Management & 0 \\
\hline WP 04-AD3008 & Shift Operating Logs & 2 \\
\hline WP 04-AD3027 & TSR Violation Reporting and Recovery Plan & $O A$ \\
\hline WP 04-CO & Conduct of Operations & 3 \\
\hline WP 04-MD3003 & Control of Operator Aids & 0 \\
\hline WP 04-PC3017 & Essential Plant Communication Systems Testing & 1 \\
\hline WP 04-AU1026 & Self-Rescuer Inspection & 0 \\
\hline WP 04-CA4001 & Compressed Air System Alarm Response & 1 \\
\hline WP 04-CM1002 & TRANSCOM: Routine Operations for the CMRO & 1 \\
\hline WP 04-CM1301 & Public Address System Console Operation & 1 \\
\hline WP 04-CM2002 & $\begin{array}{l}\text { Central Monitoring Room Operator's Actions for Transportation } \\
\text { Irregularities }\end{array}$ & 3 \\
\hline WP 04-EM1301 & Surface Seismic Monitoring System Operation & 1 \\
\hline WP 04-EM1302 & Quarterly Operational Test of Surface Seismic Monitoring System & 1 \\
\hline WP 04-EM1601 & Underground Seismic Monitoring System Operation & 2 \\
\hline WP 04-EM4200 & Station A (Skid A-3) Alarm Response Procedure & 2 \\
\hline WP 04-FP1201 & Site Fire Water Supply System Operations & 3 \\
\hline WP 04-GC1201 & Sewage Lagoon System Operation & 3 \\
\hline WP 04-HO4002 & Salt Hoist Alarm Response & 2 \\
\hline WP 04-HO4003 & Waste Handling Hoist Alarm Response & 1 \\
\hline WP 04-HO4010 & Mine Hoist Emergency Responses & 2 \\
\hline WP 05-TM3001 & TRUPACT-II Maintenance Program & 3 \\
\hline WP 05-WH1001 & TRUPACT-II Loading & 3 \\
\hline WP 05-WH1011 & $\mathrm{CH}$ Waste Processing & 7 \\
\hline WP 05-WH1036 & Site-Derived Mixed Waste Handling & 1 \\
\hline WP 05-WH1083 & TRUPACT-II Operations & 2 \\
\hline
\end{tabular}




\section{Waste Isolation Pilot Plant Biennial Environmental Compliance Report DOE/WIPP 99-2171}

\begin{tabular}{|c|c|c|}
\hline Document No. & Document Title & Rev. No. \\
\hline WP 05-WH1101 & Surface Transuranic Mixed Waste Handling Area Inspections & 3 \\
\hline WP 05-WH1683 & TRUPACT-II Loading/Unloading Using Mobile Loading Unit & 1 \\
\hline WP 05-WH1810 & Underground Transuranic Mixed Waste Disposal Area Inspections & 4 \\
\hline WP 05-WH3015 & Site Derived Mixed Waste Management & 1 \\
\hline WP 05-WH4401 & Waste Handling Operator Event Response & 1 \\
\hline WP 06-1 & $\begin{array}{l}\text { Westinghouse Electric Corporation Waste Isolation Division } \\
\text { Transportation Program }\end{array}$ & 4 \\
\hline WP 06-108 & Construction Landfill Operation & 1 \\
\hline WP 06-HM3107 & Transportation: 24-Hour Emergency Response & 1 \\
\hline WP 06-HM3111 & Return of TRU Waste to the Generator & 2 \\
\hline WP 05WA.01 & WIPP Waste Information System Data Management Plan & \\
\hline WP 05WA.02 & WIPP Waste Information System Program & \\
\hline WP 08-NT3101 & Shipment of Non-Radioactive Hazardous Materials & 0 \\
\hline WP 08-NT3102 & Shipment of Hazardous Materials by Air & 0 \\
\hline WP 08-NT3103 & Shipment of Non-Radioactive Hazardous Waste & 0 \\
\hline WP 08-NT3110 & Shipment of Radioactive Materials & 0 \\
\hline WP 09-CN3007 & $\begin{array}{l}\text { Engineering and Design Document Preparation and Change } \\
\text { Control }\end{array}$ & 8 \\
\hline WP 09-CN3018 & Design Verification & 1 \\
\hline WP 09-CN3023 & Design Classification Determination & 0 \\
\hline WP 09-DC.01 & Construction Management Manual & 2 \\
\hline WP 09-TM1001 & TRUPACT-II Upper Main O-Ring Seal Batch Test & 1 \\
\hline WP EA10-2-8-0 & Job Hazard Analysis Checklist & 0 \\
\hline WP 10-WC.01 & Cross-Connection Control Program & 0 \\
\hline WP 10.WC.02 & Predictive Maintenance Program & 0 \\
\hline WP 10-WC3008 & Facility Inspections & $3 \mathrm{~A}$ \\
\hline WP 10-WC3009 & Aerosol Can Puncturing & 1 \\
\hline WP 12-3 & Dosimetry Program & 9 \\
\hline WP 12-DS1361 & $\begin{array}{l}\text { Bioassay Scheduling, Sampling, Shipping, and Analysis Results } \\
\text { Receipt }\end{array}$ & 1 \\
\hline WP 12-DS1366 & Calculation of Internal Dose and Internal Dose Assessment & 0 \\
\hline WP 12-DS3304 & Radiation Work Restriction & 1 \\
\hline WP 12-4 & WIPP Radiological Assistance Plan & 2 \\
\hline WP 12-ES3918 & Reporting Occurrences in Accordance with DOE Order 232.1A & 1 \\
\hline WP 12-9 & Waste Isolation Pilot Plant Emergency Management Program & 13 \\
\hline WP 12-ER3002 & Emergency Operations Center (EOC) Activation & 1 \\
\hline WP 12-ER3903 & Event Recovery & 1 \\
\hline WP 12-ER3904 & Categorization and Classification of Operational Emergencies & $1 \mathrm{~A}$ \\
\hline WP 12-ER4901 & Severe Weather Response & 1 \\
\hline WP 12-ER4902 & Hazardous Material Spill and Release Response & 4 \\
\hline WP 12-ER4903 & Radiological Event Response & 1 \\
\hline WP 12-ER4905 & Security Emergency Response & 1 \\
\hline WP 12-ER4906 & Surface Medical Emergency & 1 \\
\hline WP 12-ER4907 & Site Evacuation & 1 \\
\hline WP 12-ER4908 & Surface Fire Response & 1 \\
\hline WP12-ER4910 & Earthquake/Seismic Response & 1 \\
\hline WP 12-ER4911 & Underground Fire Response & 1 \\
\hline WP 12-ER4912 & Underground Medical Emergency Response & 1 \\
\hline WP 12-FP.01 & Fire Protection Program & $1 \mathrm{~A}$ \\
\hline
\end{tabular}




\section{Waste Isolation Pilot Plant Biennial Environmental Compliance Report DOE/WIPP 99-2171}

\begin{tabular}{|c|c|c|}
\hline Document No. & Document Title & Rev. No. \\
\hline WP 12-FP3002 & Hot Work Permits & 0 \\
\hline WP 12-5 & Waste Isolation Pilot Plant Radiation Safety Manual & 4 \\
\hline WP 12-HP1225 & Calibration of Continuous Air Monitors & 1 \\
\hline WP 12-HP2001 & Abnormal Radiological Conditions & 0 \\
\hline WP 12-HP3000 & Operational Health Physics (OHP) Administration & 1 \\
\hline WP 12-HP3125 & Instructions for Completing NESHAP Compliance Report & 4 \\
\hline WP 12-HP3200 & Radioactive Material Control & 4 \\
\hline WP 12-HP3300 & Radiation Exposure Control & 1 \\
\hline WP 12-HP3400 & Contamination Control & 4 \\
\hline WP 12-HP3500 & Airborne Radioactivity & 6 \\
\hline WP 12HP3700 & Radiological Event Reporting & 0 \\
\hline WP 12-HP4000 & Emergency Radiological Control Responses & 1 \\
\hline WP 12-IH.01 & WIPP Chemical Hygiene Plan & 2 \\
\hline WP 12-IH.02 & Waste Isolation Pilot Plant Industrial Hygiene Program & 1 \\
\hline WP 12-IS.01 & Industrial Safety Program & 3 \\
\hline WP 12-IS1006 & Airborne Contaminant Sampling & 1 \\
\hline \begin{tabular}{|l} 
WP 12-NS.01 \\
\end{tabular} & Changes to the WIPP Safety Analysis Report & 1 \\
\hline WP 12-NS3003 & Safety Analysis Calculation & 0 \\
\hline WP 12-2 & WIPP ALARA Program Manual & 3 \\
\hline WP 12-RC.0-1 & $\begin{array}{l}\text { Quality Assurance Project Plan for Sampling Emissions of } \\
\text { Radionuclides to the Ambient Air at the Waste Isolation Pilot Plant }\end{array}$ & 5 \\
\hline WP 12-RL1009 & $\begin{array}{l}\text { Gross Alpha and Gross Beta Activity in Air Filter, Soil, Water, } \\
\text { Sludge, and Biota }\end{array}$ & 0 \\
\hline WP 12-RL1400 & Radiochemistry Laboratory Waste Management & 0 \\
\hline WP 12-SA3130 & Reporting Occupational Injuries and Illnesses & 1 \\
\hline WP 12-VC.01 & Confirmatory Volatile Organic Compound Monitoring Plan & 2 \\
\hline WP 12-VC.02 & $\begin{array}{l}\text { VOC Monitoring Quality Assurance Project Plan for Volatile } \\
\text { Organic Compound Monitoring } \\
\end{array}$ & 2 \\
\hline WP 13-QA1080 & TRUPACT-II Assembly Verification Leak Tests & 0 \\
\hline WP 13-QA1082 & TRUPACT-II Container Integrity Leak Test & 1 \\
\hline WP 13-QA3003 & Corrective Actions Program & 3 \\
\hline \begin{tabular}{|l|l|} 
WP 14-TR.01 \\
\end{tabular} & WIPP Training Program & 3 \\
\hline WP 15-MD3100 & Lessons Learned Program & 1 \\
\hline WP 15-MD3102 & Event Investigation and Root Cause Analysis & 1 \\
\hline WP 15-HS.01 & Exposure Control Plan & 0 \\
\hline WP 15-HS.02 & Occupational Health Program Plan & 1 \\
\hline WP 15-PR & WIPP Records Management Program & 2 \\
\hline WP 15-PR.01 & WIPP Emergency Operating Records Protection Program Plan & 0 \\
\hline WP 15-PR3006 & $\begin{array}{l}\text { Records Inventory and Disposition System Schedule Review and } \\
\text { Approval }\end{array}$ & 0 \\
\hline WP 15-RA.01 & Price Anderson Program & 3 \\
\hline WP 15-RA3003 & External Oversight Activities & 3 \\
\hline DOE/WIPP 91-030 & $\begin{array}{l}\text { Mitigation Action Plan for the Records of Decision for the Waste } \\
\text { Isolation Pilot Plant }\end{array}$ & $7 / 10 / 91$ \\
\hline DOE/WIPP 93-004 & Waste Isolation Pilot Plant Land Management Plan & $1 / 10 / 00$ \\
\hline DOE/WIPP 93-1001 & TRUPACT-II Operating and Maintenance Instructions & 4 \\
\hline DOE/CAO 94-1007 & Recovery Guide for TRU Waste Packaging & $\begin{array}{l}\text { Oct. } \\
1997\end{array}$ \\
\hline DOE/CAO 94-1051 & Federal Employee Occupational Safety and Health Program & 2 \\
\hline DOE/WIPP 97-2238 & Periodic Confirmatory Measurement Protocol for the Waste & 4 \\
\hline
\end{tabular}


Waste Isolation Pilot Plant Biennial Environmental Compliance Report DOE/WIPP 99-2171

\begin{tabular}{|l|l|c|}
\hline \multicolumn{1}{|c|}{ Document No. } & \multicolumn{1}{|c|}{ Document Title } & Rev. No. \\
\hline & Isolation Pilot Plant & \\
\hline DOE/CAO 98-2276 & Integrated Safety Management System Description & 1 \\
\hline DOE/WIPP 99-2194 & Environmental Monitoring Plan & Sept. \\
& & 1999 \\
\hline DOE/WIPP 99-2225 & 1998 Site Environmental Report & Oct. \\
& & 1999 \\
\hline DOE/WIPP 99-2286 & Reporting Implementation Plan & Dec. \\
& & 1999 \\
\hline DOE/WIPP 00-2001 & WIPP Facility Work Plan for SWMUs and Areas of Concern & 0 \\
\hline DOE/WIPP 00-3121 & Implementation Plan for 40 CFR 191, Subpart A & 1 \\
\hline
\end{tabular}


This page intentionally left blank. 


\section{Waste Isolation Pilot Plant Biennial Environmental Compliance Report}

DOE/WIPP 99-2171

\section{APPENDIX A - INDEX OF REQUIREMENTS BY TECHNICAL SUBJECT AREAS}

\begin{tabular}{|c|c|c|}
\hline CITATION & REQUIREMENT & $\begin{array}{c}\text { BECR } \\
\text { SECTION }\end{array}$ \\
\hline \multicolumn{3}{|c|}{ Air Quality Legislation } \\
\hline CAA, § 112(r)(6)(K) & Prevention of accidental releases & 6.2.2.8 \\
\hline CAA, § 118 & Control of pollution from federal facilities & 6.2.1 \\
\hline 40 CFR 60 & New Source Performance Standards & 6.1.1 \\
\hline 40 CFR 61 & $\begin{array}{l}\text { National Emission Standards for Hazardous Air } \\
\text { Pollutants (NESHAPs) } \\
\end{array}$ & 6.1.1 \\
\hline 40 CFR $\S 61.09(a)(1)$ & EPA notification under NESHAPs, prestart-up & 6.2 .2 .1 \\
\hline 40 CFR $\S 61.09(a)(2)$ & EPA notification under NESHAPs, poststart-up & 6.2.2.2 \\
\hline 40 CFR $\S 61.93(a),(b)$ & Emissions monitoring and test procedures & 6.2.2.3 \\
\hline \begin{tabular}{|l|}
40 CFR $\S 61.93(\mathrm{~b})$ and \\
Appendix B, Method $114, \S 4.10$ \\
\end{tabular} & NESHAPs Quality Assurance Project Plan & 6.2.2.4 \\
\hline 40 CFR $\S 61.94$ & NESHAPs annual report & 6.2.2.5 \\
\hline $40 \mathrm{CFR} \S 61.95$ & Record-keeping requirements & 6.2.2.6 \\
\hline $40 \mathrm{CFR} \S 61.96$ & NESHAPs application for radionuclides & 6.2.2.7 \\
\hline 40 CFR 70 & State Operating Permit Programs & 6.2 .3 \\
\hline 40 CFR 80 & Emissions Standards for Mobile Sources & 6.1 .2 \\
\hline 40 CFR $\S 80.7$ & $\begin{array}{l}\text { Reporting info about gasoline represented to be } \\
\text { unleaded if requested by the EPA }\end{array}$ & 6.2 .3 .2 \\
\hline 40 CFR $\S 80.22$ & $\begin{array}{l}\text { Prohibition against dispensing gasoline with lead or } \\
\text { lead additives }\end{array}$ & 6.2.3.3 \\
\hline $40 \mathrm{CFR} \S 80.23$ & Liability for violations & 6.2.3.4 \\
\hline 40 CFR 82 & Stratospheric Ozone Protection & \begin{tabular}{|l|}
6.1 .6 \\
6.2 .4 \\
\end{tabular} \\
\hline 40 CFR $\S 82.40$ & $\begin{array}{l}\text { Restrictions on repairing and servicing motor vehicle } \\
\text { air conditioners }\end{array}$ & 6.2.4.1 \\
\hline 40 CFR § 82.54(c), 82.104(a) & $\begin{array}{l}\text { Prohibition of nonessential Class I ozone-depleting } \\
\text { substances }\end{array}$ & 6.2 .4 .2 \\
\hline 40 CFR $\S 82.66$ & $\begin{array}{l}\text { Ban on nonessential products containing Class I } \\
\text { substances }\end{array}$ & 6.2 .4 .3 \\
\hline $40 \mathrm{CFR} \S 82.84$ & Federal procurement requirements & 6.2.4.4 \\
\hline $40 \mathrm{CFR} \S 82.86$ & Reporting requirements & 6.2.4.5 \\
\hline 40 CFR § 82, Subpart E & $\begin{array}{l}\text { Labeling of products and containers containing } \\
\text { Class I or Class II ODSs }\end{array}$ & 6.2 .4 .6 \\
\hline 40 CFR $\S 82.102$ & Applicability & 6.2.4.7 \\
\hline 40 CFR $\S 82.106$ & Required warning statements & 6.2.4.8 \\
\hline 40 CFR $\S 82.108,82.112$ & $\begin{array}{l}\text { Placement of warning statement and prohibition of } \\
\text { removal of the label bearing the warning statement }\end{array}$ & 6.2 .4 .9 \\
\hline 40 CFR $\S 82.124(a)(4)$ & Prohibitions & 6.2.4.10 \\
\hline $40 \mathrm{CFR} \S 82.150$ & $\begin{array}{l}\text { Service, maintenance, and repair of appliances } \\
\text { using refrigerants }\end{array}$ & 6.2 .4 .11 \\
\hline 40 CFR $\S 82.154$ & $\begin{array}{l}\text { Prohibitions regarding maintenance, service, repair, } \\
\text { or disposal of appliances }\end{array}$ & 6.2.4.12 \\
\hline
\end{tabular}




\section{Waste Isolation Pilot Plant Biennial Environmental Compliance Report}

DOE/WIPP 99-2171

\begin{tabular}{|c|c|c|}
\hline CITATION & REQUIREMENT & $\begin{array}{l}\text { BECR } \\
\text { SECTION }\end{array}$ \\
\hline 40 CFR $\S 82.156$ & Required practices & 6.2.4.13 \\
\hline 20 NMAC 2 & New Mexico Air Quality Control Regulations & 28.1 \\
\hline 20 NMAC 2.60 & Regulations to control open burning & 28.2 .6 \\
\hline 20 NMAC 2.61 & Regulations to control smoke and visible emissions & 28.2 .7 \\
\hline 20 NMAC 2.18 & Oil-burning equipment -- particulate matter & 28.2 .4 \\
\hline 20 NMAC 2.34 & Oil-burning equipment -- nitrogen dioxide & 28.2 .5 \\
\hline 20 NMAC 2.75 & Permit fees & 28.2 .11 \\
\hline 20 NMAC 2.70 & $\begin{array}{l}\text { Compliance Plan as part of operating permit } \\
\text { application }\end{array}$ & 28.2 .8 \\
\hline 20 NMAC 2.70 & $\begin{array}{l}\text { Semiannual operating permit reports and progress } \\
\text { reports on Compliance Plan }\end{array}$ & 28.2 .9 \\
\hline 20 NMAC 2.72 & Permits & 28.2 .10 \\
\hline 20 NMAC 2.73 & Annual emission inventory & 28.3.1.11.1 \\
\hline 20 NMAC 2.80 & Stack height requirements & 28.2 .13 \\
\hline 20 NMAC 2.78 & $\begin{array}{l}\text { NESHAPs - radionuclides } \\
\text { NESHAPs - other HAPs }\end{array}$ & 28.2.12 \\
\hline 20 NMAC 2.7 & $\begin{array}{l}\text { Excess emissions during malfunction, start-up, } \\
\text { shutdown, or scheduled maintenance }\end{array}$ & 28.2 .2 \\
\hline 20 NMAC 2.8 & Controlling emissions leaving New Mexico & 28.2 .3 \\
\hline 20 NMAC 2.1 & Sampling equipment & 28.2 .1 \\
\hline $\begin{array}{l}\text { Air Quality Permit No. 310-M-2, } \\
\text { Condition } 1\end{array}$ & Construction and Operation & 28.3 .1 .1 \\
\hline Condition 2 & Emission rates & 28.3.1.2 \\
\hline Conditions 3-4 & Compliance test methods & 28.3.1.3 \\
\hline Condition 5 & Revisions and modifications & 28.3.1.4 \\
\hline Condition 6 & Notification to subsequent owners & 28.3 .1 .5 \\
\hline Condition 7 & Right to access property and review records & 28.3.1.6 \\
\hline Condition 8 & Posting of the permit & 28.3.1.7 \\
\hline Condition 9 & Record keeping & 28.3.1.8 \\
\hline Condition 10 & Reporting & 28.3.1.9 \\
\hline Additional Condition, p. 8 & Permit cancellations & 28.3.1.10 \\
\hline Additional Condition, p. 8 & Notice of intent and emission inventory & 28.3.1.11 \\
\hline \multicolumn{3}{|c|}{ Environmental Protection Legislation } \\
\hline$\S \S 74-1-1$ through $74-1-10$ & New Mexico Environmental Improvement Act & 24.1 \\
\hline 10 CFR 1021 & Implementing DOE's NEPA Regulations & 12.3.2 \\
\hline 29 CFR 1910 & Occupational Safety and Health Standards & 11.1 \\
\hline 29 CFR $\S 1910.95$ & Compliance with hearing protection standards & 11.2 .1 \\
\hline
\end{tabular}




\section{Waste Isolation Pilot Plant Biennial Environmental Compliance Report}

DOE/WIPP 99-2171

\begin{tabular}{|c|c|c|}
\hline CITATION & REQUIREMENT & \begin{tabular}{|l} 
BECR \\
SECTION
\end{tabular} \\
\hline 40 CFR 141 & $\begin{array}{l}\text { National Primary Drinking Water Regulations } \\
\text { Implementation }\end{array}$ & 8.1 \\
\hline 40 CFR $\S 142.4$ & State program requirements & $\begin{array}{l}8.2 .1 \text { and } \\
\text { Chapter } 30\end{array}$ \\
\hline 40 CFR 144 & Underground Injection Control Program & 8.1 \\
\hline 40 CFR 144 & Underground injection control & 8.2 .2 \\
\hline 40 CFR 300 & $\begin{array}{l}\text { National Oil and Hazardous Substances } \\
\text { Pollution Contingency Plan }\end{array}$ & 3.1 \\
\hline 40 CFR 302 & $\begin{array}{l}\text { Designation, Reportable Quantities, and } \\
\text { Notification }\end{array}$ & 3.1 \\
\hline $40 \mathrm{CFR} \S 302.4$ & Designation of hazardous substances & 3.2 .1 \\
\hline $40 \mathrm{CFR} \S 302.5$ & Determination of reportable quantities & 3.2 .2 \\
\hline 40 CFR $\S 302.6(a)$ & Notification requirements & 3.2 .3 \\
\hline 40 CFR $\S 302.6(b)(1)$ & Releases of mixture or solutions & 3.2 .4 \\
\hline 40 CFR $\S 302.6(b)(2)$ & Notification of releases of radionuclides & 3.2 .5 \\
\hline 40 CFR $\S 302.6(d)$ & Notification of the release of heavy metals & 3.2 .6 \\
\hline 40 CFR § 355 & Emergency Planning and Notification & 4.1 \\
\hline 40 CFR 355.30(a) & Emergency planning & 4.2 .1 \\
\hline 40 CFR $355.30(b)$ & Emergency planning notification & 4.2 .2 \\
\hline $40 \mathrm{CFR} \S 355.30(\mathrm{c})$ & Facility Emergency Coordinator & 4.2 .3 \\
\hline 40 CFR $\S 355.30(d)$ & Provision of information & 4.2 .4 \\
\hline 40 CFR $\S 355.40$ & Emergency release notification & 4.2 .5 \\
\hline 40 CFR 370 & $\begin{array}{l}\text { Hazardous Chemical Reporting: Community } \\
\text { Right-to-Know }\end{array}$ & 4.1 \\
\hline 40 CFR $\S 370.21$ & Material Safety Data Sheet reporting & 4.2 .6 \\
\hline 40 CFR $\S 370.25$ & Inventory reporting & 4.2 .7 \\
\hline 40 CFR 372 & $\begin{array}{l}\text { Toxic Chemical Release Reporting: Community } \\
\text { Right-to-Know }\end{array}$ & 4.1 \\
\hline 40 CFR 1500-1508 & $\begin{array}{l}\text { Provision of Environmental Information to } \\
\text { Public Officials and Private Citizens } \\
\end{array}$ & 12.2 .1 \\
\hline \begin{tabular}{|l} 
§§ 74-4B-1 - 74-4B-14, NMSA \\
1978 \\
\end{tabular} & New Mexico Emergency Management Act & 32.1 \\
\hline$\S 74-4 \mathrm{~B}-5$ & $\begin{array}{l}\text { State Police Emergency Response Officer; } \\
\text { procedure for notification; cooperation with other } \\
\text { State agencies and local governments }\end{array}$ & 33.2 .1 \\
\hline$\S 74-4 \mathrm{~B}-10$ & Clean-Up & 33.2 .2 \\
\hline \multicolumn{3}{|c|}{ Hazardous Substance Legislation } \\
\hline TSCA, Title II & $\begin{array}{l}\text { Asbestos Hazard Emergency Response Act } \\
\text { (AHERA) }\end{array}$ & 9.1 .1 \\
\hline TSCA, Title III & Indoor Radon Abatement & 9.1 .2 \\
\hline TSCA Title III, § 309 & Study of Radon in Federal Buildings & 9.2 .1 \\
\hline $40 \mathrm{CFR} \S 152.15$ & Registration of pesticide products & 10.2 .1 \\
\hline 40 CFR $\S 156.10$ & Storage and disposal of pesticides and containers & 10.2 .2 \\
\hline
\end{tabular}




\begin{tabular}{|c|c|c|}
\hline CITATION & REQUIREMENT & \begin{tabular}{|c|} 
BECR \\
SECTION \\
\end{tabular} \\
\hline 40 CFR 761 & Polychlorinated Biphenyls & 9.1 .3 \\
\hline 40 CFR $\S 761.20$ & Prohibition of PCBs & 9.2 .2 \\
\hline 40 CFR $\S 761.60$ & Disposal requirements for PCBs & 9.2 .3 \\
\hline $\mathrm{HCIA} \S 74-4 \mathrm{E}$ & $\begin{array}{l}\text { New Mexico Hazardous Chemicals Information } \\
\text { Act (HCIA) }\end{array}$ & 31.1 \\
\hline $\mathrm{HCIA} \S 74-4 \mathrm{E}-5(\mathrm{~A})(1)$ & Notice of Extremely Hazardous Substance(s) & 31.2 .1 \\
\hline $\mathrm{HCIA} \S 74-4 \mathrm{E}-5(\mathrm{~A})(2)$ & Notice of Release of Chemical Substance(s) & 31.2 .2 \\
\hline $\mathrm{HCIA} \S 74-4 \mathrm{E}-5(\mathrm{~A})(3)$ & Hazardous Material Inventory & 31.2 .3 \\
\hline $\mathrm{HCIA} \S 74-4 \mathrm{E}-5(\mathrm{~A})(4)$ & Toxic Chemical Release Inventory & 31.2 .4 \\
\hline Regulatory Order No. 4 & $\begin{array}{l}\text { New Mexico Pesticide Control Act: Regulatory } \\
\text { Order of the Board of Regents of New Mexico } \\
\text { State University }\end{array}$ & 37.1 \\
\hline Section 5 & $\begin{array}{l}\text { Storage of pesticides and disposal of pesticide } \\
\text { wastes }\end{array}$ & \begin{tabular}{|l|}
37.2 .1 and \\
10.2 .2 \\
\end{tabular} \\
\hline Regulatory Order No. 5 & $\begin{array}{l}\text { New Mexico Pesticide Control Act: Definitions, } \\
\text { Licensing, Equipment Inspections, Record } \\
\text { Keeping of Pesticides by Regulated Applicators }\end{array}$ & 37.1 \\
\hline Section 6 & License classifications & 37.2 .2 \\
\hline Section 10 & Protective equipment & 37.2 .3 \\
\hline Section 11 & Application of pesticides & 37.2 .4 \\
\hline \multicolumn{3}{|c|}{ Historic Preservation Legislation } \\
\hline 36 CFR 800 & Protection of Historic and Cultural Properties & 23.1 \\
\hline 36 CFR $\S 800.5$ & Assessment of effects on historic properties & 23.2 .1 \\
\hline 36 CFR § 800.11 & $\begin{array}{l}\text { Development of plan for treatment of historical } \\
\text { property }\end{array}$ & 23.2 .2 \\
\hline 43 CFR $\S 7.5$ & Application for permits and information collection & 24.2 .3 \\
\hline §§ 18-8-1 through 18-8-8 & $\begin{array}{l}\text { New Mexico Prehistoric and Historic Sites } \\
\text { Preservation Act }\end{array}$ & 33.1 \\
\hline \multicolumn{3}{|c|}{ Land Management Legislation } \\
\hline 43 CFR 3600 & Mineral Materials Disposal: General & 16.1 \\
\hline 43 CFR § 3601.1-3 & $\begin{array}{l}\text { Environmental protection during disposal of mineral } \\
\text { materials }\end{array}$ & 16.2 .1 \\
\hline 43 CFR 1600 & Planning, Programming, Budgeting & 17.2 .1 \\
\hline 43 CFR $\S 1610.1$ & Resource management planning guidance & 17.2 .1 \\
\hline 43 CFR $\S 1610.2$ & Public participation & 17.2 .2 \\
\hline 43 CFR § 1610.3-2 & Consistency of management plans & 17.2 .3 \\
\hline 43 CFR 2800 & Rights-of-Way, Principles and Procedures & 17.1 \\
\hline 43 CFR § 2801.2(a) & $\begin{array}{l}\text { Common terms and conditions of right-of-way } \\
\text { reservations and temporary-use permits }\end{array}$ & 17.2 .4 \\
\hline 43 CFR § 2801.2(b) & $\begin{array}{l}\text { Conditions to be incorporated within all right-of-way } \\
\text { reservations and temporary-use permits }\end{array}$ & 17.2 .5 \\
\hline
\end{tabular}




\begin{tabular}{|c|c|c|}
\hline CITATION & REQUIREMENT & $\begin{array}{c}\text { BECR } \\
\text { SECTION } \\
\end{array}$ \\
\hline 43 CFR $\S 2802.2$ & $\begin{array}{l}\text { Requirements for applications for right-of-way } \\
\text { reservations and temporary-use permits }\end{array}$ & 17.2 .6 \\
\hline CC 1 & $\begin{array}{l}\text { Common Conditions (CC) of the Right-of-Way } \\
\text { Reservations }\end{array}$ & 17.3 .1 \\
\hline CC 1 & Control and jurisdiction of DOE & 17.3 .1 \\
\hline CC 2 & Right of access and use & 17.3 .1 \\
\hline CC 3 & $\begin{array}{l}\text { Products or resources on lands within the right-of- } \\
\text { way }\end{array}$ & 17.3 .1 \\
\hline CC 4 & Compliance with 43 CFR $\S 2800$ & 17.3 .1 \\
\hline CC 5 & BLM seeding requirements for BLM Roswell District & 17.3 .1 \\
\hline Sec. 13; Standard Stipulations & $\begin{array}{l}\text { Right-of-Way Reservation No. NM 53809, Water } \\
\text { Pipeline }\end{array}$ & 17.3 .2 \\
\hline $\begin{array}{l}\text { Sec. 13; Standard } \\
\text { Stipulations } 1,2,5,6,8\end{array}$ & $\begin{array}{l}\text { Preconstruction and construction conditions for the } \\
\text { water pipeline }\end{array}$ & 17.3 .2 .1 \\
\hline Sec. $13 \mathrm{E}$ & Livestock Water & 17.3.2.2 \\
\hline Standard Stipulation 3 & Road construction & 17.3.2.3 \\
\hline Standard Stipulation 7 & Gates or cattle guards on public lands & 17.3.2.4 \\
\hline Sec. 13; Standard Stipulations & $\begin{array}{l}\text { Right-of-Way Reservation No. NM 55676, } \\
\text { North Access Road }\end{array}$ & 17.3 .3 \\
\hline Standard Stipulation 2 & Polychlorinated biphenyls & 17.3.3.1 \\
\hline $\begin{array}{l}\text { Standard Stipulations } 3 \\
\text { through5 } \\
\end{array}$ & $\begin{array}{l}\text { Standard Stipulations for the construction of } \\
\text { overhead electric distribution lines }\end{array}$ & 17.3.3.2 \\
\hline Standard Stipulation 6 & Posting of BLM serial number & 17.3.3.3 \\
\hline Terms/Conditions 7 and 8 & $\begin{array}{l}\text { Actions required upon abandonment, } \\
\text { relinquishment, or expiration of right-of-way } \\
\text { reservation }\end{array}$ & 17.3.3.4 \\
\hline Amendment (April 22, 1988) & Fencing & 17.3.3.5 \\
\hline Sec. 13; Standard Stipulations & $\begin{array}{l}\text { Right-of-Way Reservation No. NM 55699, } \\
\text { Railroad }\end{array}$ & 17.3 .4 \\
\hline $\begin{array}{l}\text { Standard Stipulations } 1 \text { through } \\
4,7 \text { through } 9,11\end{array}$ & $\begin{array}{l}\text { Preconstruction and construction requirements for } \\
\text { railroad spur }\end{array}$ & 17.3 .4 .1 \\
\hline Standard Stipulation 5 & Reseeding upon completion of construction & 17.3.4.2 \\
\hline Standard Stipulation 6 & Abandonment of the site & 17.3.4.3 \\
\hline Standard Stipulation 10 & Access to water for livestock & 17.3.4.4 \\
\hline Standard Stipulation 12 & Removal of caliche and/or other mineral material & 17.3.4.5 \\
\hline Standard Stipulation 13 & Application for free-use permits & 17.3.4.6 \\
\hline Amendment & $\begin{array}{l}\text { Notification of BLM regarding the access road } \\
\text { parallel to the railroad }\end{array}$ & 17.3.4.7 \\
\hline Sec. 13; Standard Stipulations & $\begin{array}{l}\text { Right-of-Way Reservation No. NM 63136, } \\
\text { Dosimetry and Aerosol Sampling Sites }\end{array}$ & 17.3 .5 \\
\hline Attachment A & $\begin{array}{l}\text { Establishment of dosimeter stations and air } \\
\text { samplers }\end{array}$ & 17.3.5.1 \\
\hline
\end{tabular}




\begin{tabular}{|c|c|c|}
\hline CITATION & REQUIREMENT & \begin{tabular}{|c|} 
BECR \\
SECTION \\
\end{tabular} \\
\hline Amendment & Air monitoring and data collection site & 17.3.5.2 \\
\hline Sec. 13; Standard Stipulations & $\begin{array}{l}\text { Right-of-Way Reservation for Subsidence } \\
\text { Survey Monuments, No. NM } 65801\end{array}$ & 17.3 .6 \\
\hline Sec. 13; Standard Stipulations & $\begin{array}{l}\text { Right-of-Way Reservation for Two Survey } \\
\text { Monuments, No. NM } 82245 \\
\end{array}$ & 17.3.7 \\
\hline$\# 1$ & Construction and maintenance of the monuments & 17.3.7.1 \\
\hline \#3 & Security and maintenance of the monuments & 17.3.7.2 \\
\hline$\# 5$ & Rehabilitation of the land & 17.3.7.3 \\
\hline Sec. 13; Standard Stipulations & $\begin{array}{l}\text { Right-of-Way Reservation No. NM 77921, } \\
\text { Aerosol Sampling Site } \\
\end{array}$ & 17.3 .8 \\
\hline$\# 1$ & Construction, operation, and maintenance & 17.3.8.1 \\
\hline \#3 & Security and operation of aerosol sampling station & 17.3.8.2 \\
\hline$\# 5$ & $\begin{array}{l}\text { Rehabilitation of the land occupied by the aerosol } \\
\text { sampling station }\end{array}$ & 17.3.8.3 \\
\hline $\begin{array}{l}\text { Letter from El Paso Natural Gas } \\
\text { Company }\end{array}$ & Use of the abandoned concrete slab & 17.3 .8 .4 \\
\hline Sec. 13; Standard Stipulations & Caliche Free-Use Permit No. NM-96943 & 17.3 .9 \\
\hline Attachment 2, Reclamation & Reclamation of caliche borrow pit & 17.3.9.1 \\
\hline 43 CFR 4100 & Grazing Administration - Exclusive of Alaska & $18.1,19.1$ \\
\hline 43 CFR § 4100.0-8 & Land-use plans & $\begin{array}{ll}\text { 18.2.1 } \\
19.2 .1\end{array}$ \\
\hline 43 CFR $\S 4120.2$ & Allotment management plans & 19.2 .2 \\
\hline $\begin{array}{l}\text { New Mexico State Land Office } \\
\text { (SLO) Rule No. } 10 \\
\end{array}$ & Relating to Easements and Rights-of-Way & 34.1 \\
\hline SLO Rule 10.006 & Application requirements and fees & 34.2 .1 \\
\hline SLO Rule 10.009 & Conditions & 34.2 .2 \\
\hline SLO Rule 10.010 & Damage bond & 34.2 .3 \\
\hline SLO Rule 10.011 & Survey plat & 34.2 .4 \\
\hline SLO Rule 10.012 & Construction reports & 34.2 .5 \\
\hline SLO Rule 10.013 & Affidavit of completion & 34.2 .6 \\
\hline SLO Rule 10.017 & Renewal of right-of-way reservations & 34.2 .7 \\
\hline SLO Rule 10.019 & Reclamation and restoration & 34.2 .8 \\
\hline RW 22789 & $\begin{array}{l}\text { Permit No. RW-22789 for a High-Volume Air } \\
\text { Sampler }\end{array}$ & 34.3 \\
\hline Term/Condition \#3 & Disposal of brush and other debris & 34.3 .1 \\
\hline Term/Condition \#4 & Depth of pipelines & 34.3 .2 \\
\hline Term/Condition \#5 & $\begin{array}{l}\text { Prevention of destruction or injury to improvements } \\
\text { or livestock }\end{array}$ & 34.3 .3 \\
\hline Term/Condition \#6 & Purpose of right-of-way & 34.3 .4 \\
\hline Term/Condition \#7 & Existing rights & 34.3 .5 \\
\hline Term/Condition \#8 & Leases for mineral resources & 34.3 .6 \\
\hline
\end{tabular}




\begin{tabular}{|c|c|c|}
\hline CITATION & REQUIREMENT & \begin{tabular}{|c|} 
BECR \\
SECTION \\
\end{tabular} \\
\hline Term/Condition \#9 & $\begin{array}{l}\text { Compliance with all applicable regulations and } \\
\text { requirements }\end{array}$ & 34.3 .7 \\
\hline Term/Condition \#10 & Non-use of the right-of-way & 34.3 .8 \\
\hline Term/Condition \#13 & $\begin{array}{l}\text { Protection and preservation of natural environmental } \\
\text { conditions }\end{array}$ & 34.3 .9 \\
\hline Term/Condition \#14 & Reclamation of all disturbed areas & 34.3 .10 \\
\hline \multicolumn{3}{|c|}{ Radiation Protection Legislation } \\
\hline 10 CFR 71 & $\begin{array}{l}\text { Packaging and Transportation of Radioactive } \\
\text { Material }\end{array}$ & 14.2 \\
\hline 10 CFR $\S 71.12$ & General license & 14.2 .1 \\
\hline 10 CFR $\S 71.31$ through 71.39 & $\begin{array}{l}\text { Contents of application and package description } \\
\text { evaluation }\end{array}$ & 14.2 .2 \\
\hline 10 CFR $\S 71.41$ & Demonstration of compliance & 14.2 .3 \\
\hline 10 CFR $\S 71.43$ and 71.45 & Standards for all packages & 14.2 .4 \\
\hline 10 CFR $\S 71.47$ & External radiation standards for all packages & 14.2 .5 \\
\hline 10 CFR $\S 71.51$ & Additional requirements for Type B packages & 14.2 .6 \\
\hline 10 CFR $\S 71.55-71.61$ & Requirements for all fissile material packages & 14.2 .7 \\
\hline $10 \mathrm{CFR} \S 71.63$ & Special requirements for plutonium shipments & 14.2 .8 \\
\hline 10 CFR $\S 71.71$ & Tests under normal conditions of transport & 14.2 .9 \\
\hline 10 CFR $\S 71.73$ & Tests under hypothetical accident conditions & 14.2 .10 \\
\hline 10 CFR $\S 71.81$ & Compliance with operating controls and procedures & 14.2.11 \\
\hline 10 CFR $\S 71.83$ & Assumptions regarding unknown properties & 14.2 .12 \\
\hline 10 CFR $\S 71.85$ & $\begin{array}{l}\text { Preliminary determinations of integrity of packaging, } \\
\text { pressure testing, and marking }\end{array}$ & 14.2 .13 \\
\hline 10 CFR $\S 71.87$ & Routine determinations prior to each shipment & 14.2 .14 \\
\hline 10 CFR $\S 71.89$ & Special opening instructions & 14.2.15 \\
\hline 10 CFR $\S 71.91$ & Maintenance of records & 14.2 .16 \\
\hline $10 \mathrm{CFR} \S 71.93$ & NRC inspections and tests & 14.2 .17 \\
\hline 10 CFR $\S 71.95$ & $\begin{array}{l}\text { Reports regarding decreased effectiveness or } \\
\text { defects with safety significance }\end{array}$ & 14.2 .18 \\
\hline 10 CFR $\S 71.97$ & Advance notification of shipment of nuclear waste & 14.2 .19 \\
\hline $\begin{array}{l}\text { 10 CFR § } 71.101 \text { through } \\
71.137\end{array}$ & NRC quality assurance requirements & 14.2 .20 \\
\hline $\mathrm{C}$ of $\mathrm{C}$ & TRUPACT-II Certificate of Compliance & 14.3 \\
\hline C of $\mathrm{C}$, p. $1,5(2)$, para. 1 & Overall specifications for the TRUPACT-II & 14.3 .1 \\
\hline C of $\mathrm{C}$, p. $1,5(2)$, para. 1 & Overall weight & 14.3.2 \\
\hline C of $C$, p. $1,5(2)$, para. 2 & Outer containment assembly of the TRUPACT-II & 14.3 .3 \\
\hline C of C, p. $1,5(2)$, para. 3, ICV & Inner containment vessel of the TRUPACT-II & 14.3.4 \\
\hline C of C, p. $2,5(a)(3)$, para. 1 & Drawings showing construction of TRUPACT-II & 14.3 .5 \\
\hline C of $C$, p. $2,5(a)(3)$, para. 2 & $\begin{array}{l}\text { Drawings showing position of contents in } \\
\text { TRUPACT-II }\end{array}$ & 14.3 .6 \\
\hline
\end{tabular}




\begin{tabular}{|c|c|c|}
\hline CITATION & REQUIREMENT & \begin{tabular}{|c|} 
BECR \\
SECTION \\
\end{tabular} \\
\hline C of C, p. 2, 5(b)(1) & Physical form of allowable material and receptacles & 14.3 .7 \\
\hline C of $C, p .2,5(b)(1)$ & $\begin{array}{l}\text { Prohibition of explosives, corrosives, nonradioactive } \\
\text { pyrophorics, and pressurized containers }\end{array}$ & 14.3 .8 \\
\hline C of C, p. 2, 5(b)(1) & Prohibition of radioactive pyrophorics & 14.3 .9 \\
\hline C of C, p. 2, 5(b)(1) & Restriction of free liquids & 14.3 .10 \\
\hline C of C, p. 2, 5(b)(1) & Restriction of flammable organics & 14.3 .11 \\
\hline C of $C$, p. $2,5(b)(2)$, para. 1 & Maximum allowable weight & 14.3 .12 \\
\hline C of $C$, p. $2,5(b)(2)$, para. 2 & $\begin{array}{l}\text { Maximum number of payload containers per } \\
\text { package and authorized configurations }\end{array}$ & 14.3 .13 \\
\hline C of C, p. $2,5(b)(2)$, para. 3 & Amount of allowable fissile material & 14.3 .14 \\
\hline C of C, p. 2, 5(b)(2), para. 4 & Allowable decay heat & 14.3 .15 \\
\hline C of $C, p .3,5(c)$ & Criticality transport Index & 14.3.16 \\
\hline C of C, p. 3,6 & $\begin{array}{l}\text { Restrictions of form, properties, and other } \\
\text { parameters }\end{array}$ & 14.3 .17 \\
\hline C of C, p. 3,7 & Shipping category designations & 14.3 .18 \\
\hline C of C, p. 3,8 & Labeling requirements & 14.3 .19 \\
\hline C of C, p. 3,9 & Preshipment venting or aspirating requirements & 14.3 .20 \\
\hline $\mathrm{C}$ of $\mathrm{C}, \mathrm{p} .3,10$ & Requirements of Subpart G of 10 CFR 71 & 14.3 .21 \\
\hline C of $C, p .3,10(a)$ & $\begin{array}{l}\text { Preparation of packages for shipment and } \\
\text { operations }\end{array}$ & 14.3 .22 \\
\hline C of $C, p .4,10(b)$ & Testing and maintenance of packaging & 14.3 .23 \\
\hline C of C, p. $4,10(\mathrm{c})$ & Leak testing & 14.3 .25 \\
\hline C of $C, p .4,10(d)$ & Removal of free-standing water & 14.3 .26 \\
\hline C of $C$, p. 4,11 & Approval of TRUPACT-II packaging & 14.3 .27 \\
\hline 10 CFR 830 & Nuclear Safety Management & 13.3 \\
\hline 10 CFR $\S 830.4(a)$ & Taking action(s) inconsistent with requirements & 13.3 .1 \\
\hline $10 \mathrm{CFR} \S 830.4(\mathrm{~b})$ & Implementation and compliance with requirements & 13.3 .2 \\
\hline 10 CFR $\S 830.4(c)$ & $\begin{array}{l}\text { Plan or program required by this part as the basis } \\
\text { for determining compliance }\end{array}$ & 13.3 .3 \\
\hline $10 \mathrm{CFR} \S 830.6$ & Records to substantiate compliance & 13.3 .4 \\
\hline $10 \mathrm{CFR} \S 830.7$ & Use of a graded approach & 13.3 .5 \\
\hline $\begin{array}{l}10 \text { CFR § 830.120(a) and } \\
\S 830.120(c)\end{array}$ & $\begin{array}{l}\text { Development and implementation of contractor's } \\
\text { QAP to be approved by the DOE and conduct of } \\
\text { work }\end{array}$ & 13.3 .6 \\
\hline 10 CFR $\S 830.120(b)$ & $\begin{array}{l}\text { Application of the appropriate QA criteria in the QAP } \\
\text { and annual submittal of substantive changes in the } \\
\text { QAP to the DOE }\end{array}$ & 13.3 .7 \\
\hline 10 CFR $\S 830.120(\mathrm{c})$ & QA criteria to be included in the QAP & 13.3 .8 \\
\hline 40 CFR 191 & $\begin{array}{l}\text { Environmental Radiation Protection Standards } \\
\text { for Management and Disposal of Spent Nuclear } \\
\text { Fuel, High-Level, and Transuranic Radioactive } \\
\text { Waste }\end{array}$ & 5.2 .1 \\
\hline
\end{tabular}




\section{Waste Isolation Pilot Plant Biennial Environmental Compliance Report}

DOE/WIPP 99-2171

\begin{tabular}{|c|c|c|}
\hline CITATION & REQUIREMENT & $\begin{array}{c}\text { BECR } \\
\text { SECTION } \\
\end{array}$ \\
\hline 40 CFR $\S 191.03(b)$ & Standards & 5.2.1.1 \\
\hline 40 CFR $\S 191.13$ & Containment requirements & 5.2.1.2 \\
\hline 40 CFR $\S 191.15$ & Individual protection requirements & 5.2 .1 .3 \\
\hline 40 CFR $\S 191.24$ & Disposal standards & 5.2 .1 .4 \\
\hline \multicolumn{3}{|c|}{ Plant and Animal Preservation Legislation } \\
\hline 50 CFR 13 & General Permit Procedures & $\begin{array}{l}\text { 20.1, 21.1, } \\
\text { and 22.1 }\end{array}$ \\
\hline 50 CFR $\S 13.11$ & Permit application procedures & $\begin{array}{l}\text { 20.2.1, } \\
21.2 .1 \text {, anc } \\
22.2 .1\end{array}$ \\
\hline 50 CFR $\S 13.12$ & Information requirements for permit applications & 21.2 .2 \\
\hline 50 CFR $\S 13.44$ & Display of permit & 21.2 .3 \\
\hline 50 CFR $\S 13.45$ & Filing of reports & 21.2 .4 \\
\hline $50 \mathrm{CFR} \S 13.46$ & Maintenance of records & 21.2 .5 \\
\hline $50 \mathrm{CFR} \S 13.47$ & Inspection requirement & 21.2 .6 \\
\hline 50 CFR $\S 13.48$ & Compliance with permit conditions & 21.2 .7 \\
\hline 50 CFR $\S 13.50$ & Acceptance of liability & 21.2 .8 \\
\hline 50 CFR 17 & Endangered and Threatened Wildlife and Plants & 22.1 \\
\hline $\begin{array}{l}50 \text { CFR } \S 17.22,17.32,17.52, \\
\text { and } 17.62\end{array}$ & Application for permit & 22.2 .2 \\
\hline 50 CFR 20 & Migratory Bird Hunting & 21.1 \\
\hline 50 CFR $\S 20$, Subpart C & $\begin{array}{l}\text { Compliance with applicable migratory bird hunting } \\
\text { regulations }\end{array}$ & 21.2 .9 \\
\hline 50 CFR 21 & Migratory Bird Permits & 21.1 \\
\hline 50 CFR $\S 21.22(a)$ & Application for banding or marking permit & 21.2 .10 \\
\hline 50 CFR $\S 21.22(\mathrm{c})$ & Additional permit conditions & 21.2 .11 \\
\hline 50 CFR $\S 21.22(d)$ & Term of permit & 21.2 .12 \\
\hline 50 CFR $\S 21.27$ & Special-purpose permits & 21.2 .13 \\
\hline $50 \mathrm{CFR} \S 21.28$ & Falconry permits & 21.2 .14 \\
\hline $50 \mathrm{CFR} \S 21.41$ & Depredation permits & 21.2 .15 \\
\hline 50 CFR 22 & Eagle Permits & 20.1 \\
\hline $50 \mathrm{CFR} \S 22.11$ & General permit requirements & 20.2 .2 \\
\hline $50 \mathrm{CFR} \S 22.25$ & Permits to take golden eagle nests & 20.2 .3 \\
\hline 50 CFR 402 & $\begin{array}{l}\text { Interagency Cooperation - Endangered Species } \\
\text { Act, as Amended }\end{array}$ & 22.1 \\
\hline 50 CFR $\S 402.12$ & $\begin{array}{l}\text { Biological assessment of impacts on recognized } \\
\text { species }\end{array}$ & 22.2 .3 \\
\hline 50 CFR $\S 402.14$ & $\begin{array}{l}\text { Formal consultation with the FWS regarding } \\
\text { impacts on recognized species }\end{array}$ & 22.2 .4 \\
\hline §§ 17-2-37 through 17-2-46 & New Mexico Wildlife Conservation Act & $\begin{array}{l}35.1 \text { and } \\
36.1\end{array}$ \\
\hline
\end{tabular}




\begin{tabular}{|c|c|c|}
\hline CITATION & REQUIREMENT & \begin{tabular}{|c|} 
BECR \\
SECTION \\
\end{tabular} \\
\hline Regulation 19 NMAC 33.1 & Recognition of state-listed endangered wildlife & 36.2 .1 \\
\hline Regulation 19 NMAC 33.2 & $\begin{array}{l}\text { Report of unpermitted removal, capture, or } \\
\text { destruction of endangered species }\end{array}$ & 36.2 .2 \\
\hline Regulation 19 NMAC 36.2 & $\begin{array}{l}\text { Permit application and requirements to conduct } \\
\text { activities }\end{array}$ & 36.2 .3 \\
\hline Regulation 19 NMAC 36.2 & Year-end reports & 36.2 .4 \\
\hline NMDG\&F permits & $\begin{array}{l}\text { New Mexico Department of Game and Fish } \\
\text { Permits }\end{array}$ & 36.3 \\
\hline Permit No. 1894 & $\begin{array}{l}\text { Live trapping; catfish, and unprotected species; } \\
\text { nonlethal methods for catfish; report for salvaging } \\
\text { endangered or threatened vertebrates }\end{array}$ & 36.3 .1 \\
\hline Permit No. 1961 & $\begin{array}{l}\text { Authorization for live capture and banding of } \\
\text { protected birds, reporting of salvaged endangered } \\
\text { or threatened wildlife, and disposition of wildlife }\end{array}$ & 36.3 .2 \\
\hline \multicolumn{3}{|c|}{ Waste Management Legislation } \\
\hline RCRA § 3016 & Inventory of Federal hazardous waste facilities & 2.2.1.1 \\
\hline 20 NMAC 4.1, § 1101 & $\begin{array}{l}\text { Compliance with the Hazardous Waste } \\
\text { Regulatory Requirements }\end{array}$ & 25.2 .1 \\
\hline $\begin{array}{l}40 \text { CFR } 262 \text { (20 NMAC } 4.1 \text {, } \\
\S 300)\end{array}$ & $\begin{array}{l}\text { Compliance with Standards Applicable to } \\
\text { Generators of Hazardous Waste }\end{array}$ & 25.2 .2 \\
\hline 40 CFR $\S 262.11$ & Hazardous waste determination & 25.2 .2 .1 \\
\hline 40 CFR $\S 262.12$ & EPA identification number & 25.2 .2 .2 \\
\hline 40 CFR $\S 262.20$ & Manifest requirements & 25.2 .2 .3 \\
\hline 40 CFR $\S 262.21$ & Acquisition of manifests & 25.2 .2 .4 \\
\hline 40 CFR $\S 262.22$ & Number of copies & 25.2 .2 .5 \\
\hline 40 CFR $\S 262.23$ & Use of the manifest & 25.2 .2 .6 \\
\hline 40 CFR $\S 262.30$ & Packaging requirements & 25.2 .2 .7 \\
\hline 40 CFR $\S 262.31$ & Labeling requirements & 25.2 .2 .8 \\
\hline 40 CFR $\S 262.32$ & Marking requirements & 25.2 .2 .9 \\
\hline 40 CFR $\S 262.33$ & Placarding requirements & 25.2 .2 .10 \\
\hline 40 CFR § 262.34(a) & Accumulation time & 25.2 .2 .11 \\
\hline 40 CFR $\S 262.34(a)(1)(i)$ & Compliance with Subpart I of 40 CFR 265 & 25.2 .2 .12 \\
\hline 40 CFR $\S 262.34(a)(1)(i i)$ & Accumulation of hazardous wastes & 25.2.2.13 \\
\hline 40 CFR § 262.34(a)(1)(iii) & Compliance with Subpart W of 40 CFR $\S 265$ & 25.2 .2 .14 \\
\hline 40 CFR $\S 262.34(a)(2)$ & Marking with the date of initial accumulation & 25.2 .2 .15 \\
\hline 40 CFR $\S 262.34(a)(3)$ & Marking as hazardous waste & 25.2.2.16 \\
\hline 40 CFR $\S 262.34(a)(4)$ & $\begin{array}{l}\text { Compliance with emergency response, training, and } \\
\text { waste analysis plan requirements }\end{array}$ & 25.2 .2 .17 \\
\hline 40 CFR § 262.34(b) & Extension of storage period & 25.2 .2 .18 \\
\hline 40 CFR $\S 262.34(c)(1)$ & Restrictions and requirements & 25.2 .2 .19 \\
\hline 40 CFR $\S 262.34(c)(1)(i)$ & $\begin{array}{l}\text { Compliance with } 40 \text { CFR } \S \S 265.171,265.172 \text {, and } \\
\text { 265.173(a) }\end{array}$ & 25.2 .2 .20 \\
\hline
\end{tabular}




\section{Waste Isolation Pilot Plant Biennial Environmental Compliance Report}

DOE/WIPP 99-2171

\begin{tabular}{|c|c|c|}
\hline CITATION & REQUIREMENT & $\begin{array}{c}\text { BECR } \\
\text { SECTION }\end{array}$ \\
\hline 40 CFR $\S 262.34(\mathrm{c})(1)(\mathrm{ii})$ & Labeling of container as "hazardous waste" & 25.2.2.21 \\
\hline 40 CFR $\S 262.34(\mathrm{c})(2)$ & Management of waste & 25.2 .2 .22 \\
\hline $40 \mathrm{CFR} \S 262.40$ & Record keeping requirements & 25.2.2.23 \\
\hline 40 CFR $\S 262.41$ & Generator-biennial report & 25.2.2.24 \\
\hline 40 CFR $\S 262.42$ & Exception reporting & 25.2 .2 .25 \\
\hline 40 CFR $\S 262.43$ & Additional reporting & 25.2 .2 .26 \\
\hline 40 CFR $\S 262.43$ & $\begin{array}{l}\text { Special requirements for generators of between } 100 \\
\text { and } 1,000 \text { kilograms per month }\end{array}$ & 25.2.2.27 \\
\hline $\begin{array}{l}40 \text { CFR } 263 \text { (20 NMAC } 4.1 \text {, } \\
\S 400)\end{array}$ & $\begin{array}{l}\text { Compliance with Standards Applicable to } \\
\text { Transporters of Hazardous Waste }\end{array}$ & 25.2 .3 \\
\hline 40 CFR $\S 263.10(a)$ & Compliance with DOT regulations & 25.2 .3 .1 \\
\hline 40 CFR $\S 263.11$ & EPA identification number & 25.2 .3 .2 \\
\hline 40 CFR $\S 263.20-263.22$ & $\begin{array}{l}\text { Compliance with the manifest system and record } \\
\text { keeping requirements }\end{array}$ & 25.2.3.3 \\
\hline $40 \mathrm{CFR} \S 263.30$ & Immediate action after hazardous waste discharges & 25.2.3.4 \\
\hline 40 CFR $\S 263.31$ & Discharge cleanup & 25.2.3.5 \\
\hline $\begin{array}{l}40 \text { CFR } 264 \text { (20 NMAC 4.1, } \\
\S 600)\end{array}$ & $\begin{array}{l}\text { Compliance with the Regulatory Requirements } \\
\text { for TSDFs. }\end{array}$ & 25.2 .4 \\
\hline 40 CFR $\S 264.10$ & Applicability & 25.2.4.1 \\
\hline 40 CFR $\S 264.11$ & EPA identification number & 25.2.4.2 \\
\hline 40 CFR § 264.12 & Required notices & 25.2 .4 .3 \\
\hline 40 CFR $\S 264.13$ & General waste analysis & 25.2.4.4 \\
\hline 40 CFR $\S 264.14$ & Security & 25.2 .4 .5 \\
\hline 40 CFR $\S 264.15$ & General inspection requirements & 25.2.4.6 \\
\hline 40 CFR $\S 264.16$ & Personnel training & 25.2.4.7 \\
\hline 40 CFR $\S 264.17$ & $\begin{array}{l}\text { General requirements for ignitable, reactive, or } \\
\text { incompatible wastes }\end{array}$ & 25.2 .4 .8 \\
\hline 40 CFR $\S 264.18$ & Location standards & 25.2 .4 .9 \\
\hline 40 CFR $\S 264.31$ & Maintenance and operation of facility & 25.2.4.10 \\
\hline 40 CFR $\S 264.32$ & Required equipment & 25.2.4.11 \\
\hline 40 CFR $\S 264.33$ & Testing and maintenance of equipment & 25.2.4.12 \\
\hline 40 CFR § 264.34 & Access to communications or alarm system & 25.2.4.13 \\
\hline 40 CFR $\S 264.35$ & Required aisle space & 25.2.4.14 \\
\hline 40 CFR $\S 264.37$ & Arrangements with local authorities & 25.2.4.15 \\
\hline 40 CFR $\S 264.51$ & $\begin{array}{l}\text { Purpose and implementation of the contingency } \\
\text { plan }\end{array}$ & 25.2.4.16 \\
\hline 40 CFR $\S 264.52$ & Content of the contingency plan & 25.2.4.17 \\
\hline 40 CFR $\S 264.53$ & Copies of contingency plan & 25.2.4.18 \\
\hline 40 CFR $\S 264.54$ & Amendment of contingency plan & 25.2.4.19 \\
\hline 40 CFR $\S 264.55$ & Emergency Coordinator & 25.2.4.20 \\
\hline
\end{tabular}




\section{Waste Isolation Pilot Plant Biennial Environmental Compliance Report}

DOE/WIPP 99-2171

\begin{tabular}{|c|c|c|}
\hline CITATION & REQUIREMENT & \begin{tabular}{|c|} 
BECR \\
SECTION \\
\end{tabular} \\
\hline 40 CFR $\S 264.56$ & Emergency procedures & 25.2 .4 .21 \\
\hline 40 CFR § 264.71 & Use of manifest system & 25.2 .4 .22 \\
\hline 40 CFR $\S 264.72$ & Manifest discrepancies & 25.2.4.23 \\
\hline 40 CFR § 264.73 & Operating record & 25.2 .4 .24 \\
\hline 40 CFR $\S 264.74$ & Availability, retention, and disposition of records & 25.2 .4 .25 \\
\hline 40 CFR $\S 264.75$ & TSDF biennial report & 25.2 .4 .26 \\
\hline $40 \mathrm{CFR} \S 264.76$ & Unmanifested waste report & 25.2 .4 .27 \\
\hline 40 CFR $\S 264.77$ & Additional reports & 25.2 .4 .28 \\
\hline 40 CFR $\S 264.90$ & Applicability of the groundwater monitoring system & 25.2 .4 .29 \\
\hline 40 CFR $\S 264.91$ & Required programs & 25.2 .4 .30 \\
\hline 40 CFR § 264.92 & Groundwater Protection Standard & 25.2 .4 .31 \\
\hline 40 CFR § 264.93 & Hazardous Constituents & 25.2 .4 .32 \\
\hline 40 CFR § 264.94 & Concentration Limits & 25.2 .4 .33 \\
\hline 40 CFR § 264.95 & Point of compliance & 25.4 .4 .34 \\
\hline 40 CFR § 264.96 & Compliance period & 25.4 .4 .35 \\
\hline 40 CFR $\S 264.97$ & General groundwater monitoring requirements & 25.4 .4 .36 \\
\hline 40 CFR $\S 264.98$ & Detection Monitoring Program & 25.2 .4 .37 \\
\hline 40 CFR $\S 264.101$ & $\begin{array}{l}\text { Corrective Action for Solid Waste Management } \\
\text { Units }\end{array}$ & 25.2.4.38 \\
\hline 40 CFR $\S 264.110$ & $\begin{array}{l}\text { Applicability of the closure/post-closure } \\
\text { requirements }\end{array}$ & 25.2.4.39 \\
\hline 40 CFR $\S 264.111$ & Closure performance standard & 25.2 .4 .40 \\
\hline 40 CFR $\S 264.112$ & Closure plan; amendment of plan & 25.2.4.41 \\
\hline $40 \mathrm{CFR} \S 264.113$ & Time allowed for closure & 25.2 .4 .42 \\
\hline 40 CFR $\S 264.114$ & $\begin{array}{l}\text { Disposal or decontamination of equipment, } \\
\text { structures, and soils }\end{array}$ & 25.2 .4 .43 \\
\hline 40 CFR $\S 264.115$ & Certification of closure & 25.2.4.44 \\
\hline 40 CFR $\S 264.116$ & Survey plat & 25.2 .4 .45 \\
\hline 40 CFR $\S 264.117$ & Postclosure care and use of property & 25.2.4.46 \\
\hline 40 CFR $\S 264.118$ & Postclosure plan; amendment of plan & 25.2.4.47 \\
\hline 40 CFR $\S 264.119$ & Postclosure notices & 25.2 .4 .48 \\
\hline 40 CFR $\S 264.120$ & Certification of completion of post-closure care & 25.2.4.49 \\
\hline 40 CFR $\S 264.142$ & Cost estimate for closure & 25.2 .4 .50 \\
\hline 40 CFR $\S 264.143$ & Financial assurance for closure & 25.2 .4 .51 \\
\hline 40 CFR $\S 264.144$ & Cost estimate for postclosure care & 25.2 .4 .52 \\
\hline 40 CFR $\S 264.145$ & Financial assurance for postclosure care & 25.2 .4 .53 \\
\hline 40 CFR $\S 264.146$ & $\begin{array}{l}\text { Use of a mechanism for financial assurance of both } \\
\text { closure and post-closure care }\end{array}$ & 25.2 .4 .54 \\
\hline 40 CFR $\S 264.147$ & Liability requirements & 25.2 .4 .55 \\
\hline
\end{tabular}




\section{Waste Isolation Pilot Plant Biennial Environmental Compliance Report}

DOE/WIPP 99-2171

\begin{tabular}{|c|c|c|}
\hline CITATION & REQUIREMENT & $\begin{array}{c}\text { BECR } \\
\text { SECTION }\end{array}$ \\
\hline 40 CFR § 265.1080 & $\begin{array}{l}\text { Air emission standards for tanks, surface } \\
\text { impoundment and containers }\end{array}$ & 25.1 \\
\hline 40 CFR 268 & Land Disposal Restrictions & 2.2 .2 \\
\hline $\begin{array}{l}40 \text { CFR } 270 \text { (20 NMAC 4.1, } \\
\S \S 900 \text { and } 901)\end{array}$ & $\begin{array}{l}\text { Compliance with the Hazardous/Mixed Waste } \\
\text { Permit Program }\end{array}$ & 25.2 .5 \\
\hline 40 CFR $\S 270.1$ & $\begin{array}{l}\text { Purpose and scope of the Hazardous Waste Facility } \\
\text { Permit program regulations }\end{array}$ & 25.2 .5 .1 \\
\hline 40 CFR $\S 270.11$ & Signatories to permit applications and reports & 25.2 .5 .2 \\
\hline 40 CFR $\S 270.30$ & Conditions applicable to all permits & 25.2 .5 .3 \\
\hline 40 CFR $\S 270.31$ & $\begin{array}{l}\text { Requirements for recording and reporting of } \\
\text { monitoring results }\end{array}$ & 25.2 .5 .4 \\
\hline 40 CFR $\S 270.42$ & Permit modification at the request of the permittee & 25.2 .5 .5 \\
\hline RCRA, § 3016 & Inventory of Federal Hazardous Waste Facilities & 2.2.1.1 \\
\hline 20 NMAC 9.1 & Solid Waste Management Regulations & 26.1 \\
\hline 20 NMAC 9.1, § 104(A) & Applicability of regulations & 26.2 .1 \\
\hline 20 NMAC $9.1, \S 106$ & $\begin{array}{l}\text { General requirements for processing and disposal } \\
\text { of solid waste }\end{array}$ & 26.2 .2 \\
\hline 20 NMAC 9.1, § 108 & Prohibited acts & 26.2 .3 \\
\hline 20 NMAC 9.1, § 108(C) & Exemptions & 26.2 .4 \\
\hline 20 NMAC $9.1, \S 109$ & Record keeping and annual reports & 26.2 .5 \\
\hline 20 NMAC $9.1, \S 111$ & Entry by department; availability of records & 26.2 .6 \\
\hline $\begin{array}{l}20 \text { NMAC } 9.1, \S \S 201,202,209, \\
210\end{array}$ & Permit application requirements & 26.2 .7 \\
\hline 20 NMAC 9.1, §§ 401, 403 & Solid waste facility operation requirements & 26.2 .8 \\
\hline 20 NMAC $9.1 \S 705$ & Asbestos waste & 26.2 .9 \\
\hline 20 NMAC 9.1, Subpart V & Landfill closure and postclosure requirements & 26.2 .10 \\
\hline 20 NMAC 9.1, Subpart VI & Operator certification & 26.2 .11 \\
\hline 20 NMAC $9.1, \S 706(C)$ & Storage and containment of infectious waste & 26.2 .12 \\
\hline 20 NMAC 9.1, § 706(D) & $\begin{array}{l}\text { Infectious waste treatment, storage, and disposal } \\
\text { facilities }\end{array}$ & 26.2 .13 \\
\hline 20 NMAC $9.1, \S 706(E)$ & Treatment and disposal of infectious waste & 26.2 .14 \\
\hline 20 NMAC 9.1, § 214(B) & Infectious waste transporters & 26.2 .15 \\
\hline 20 NMAC $9.1, \S 712$ & Manifest requirements & 26.2 .16 \\
\hline \multicolumn{3}{|c|}{ Underground Storage Tanks } \\
\hline 20 NMAC 5 & $\begin{array}{l}\text { New Mexico Underground Storage Tank } \\
\text { Regulations }\end{array}$ & 25.2 .7 \\
\hline 20 NMAC 5.1, § 103 & Applicability & 25.2 .7 .1 \\
\hline 20 NMAC 5.2, § 200 & Existing tanks & 25.2 .7 .2 \\
\hline 20 NMAC 5.2, § 201 & Transfer of ownership & 25.2 .7 .3 \\
\hline 20 NMAC 5.2, § 202 & New UST system & 25.2.7.4 \\
\hline 20 NMAC 5.2, § 203 & Substantially modified UST systems & 25.2 .7 .5 \\
\hline
\end{tabular}




\section{Waste Isolation Pilot Plant Biennial Environmental Compliance Report}

DOE/WIPP 99-2171

\begin{tabular}{|c|c|c|}
\hline CITATION & REQUIREMENT & $\begin{array}{c}\text { BECR } \\
\text { SECTION }\end{array}$ \\
\hline 20 NMAC 5.2, § 204 & Notification of spill or release & 25.2.7.6 \\
\hline 20 NMAC 5.2, § 205 & Emergency repairs and tank replacement & 25.2 .7 .7 \\
\hline 20 NMAC 5.2, § 206 & Application forms & 25.2.7.8 \\
\hline 20 NMAC 5.2, § 207 & Registration certificate & 25.2.7.9 \\
\hline 20 NMAC 5.3, § 300 & Payment of fee & 25.2.7.10 \\
\hline 20 NMAC 5.3, § 301 & Amount of fee & 25.2 .7 .11 \\
\hline 20 NMAC 5.3, § 302 & Late payment penalties & 25.2.7.12 \\
\hline 20 NMAC 5.4, § 400 & $\begin{array}{l}\text { Performance standards for tanks in new UST } \\
\text { systems }\end{array}$ & 25.2 .7 .13 \\
\hline 20 NMAC 5.4, § 400(B) & Design and construction of piping & 25.2.7.14 \\
\hline 20 NMAC 5.4, § 400(C) & Spill prevention equipment & 25.2 .7 .15 \\
\hline 20 NMAC 5.4, § 400(C)(b) & Overflow prevention equipment & 25.2.7.16 \\
\hline 20 NMAC 5.4, § 400(D) & Installation of tanks and piping & 25.2.7.17 \\
\hline 20 NMAC 5.4, § 400(E) & Certificate of installation & 25.2.7.18 \\
\hline 20 NMAC 5.4, § 401(A) & Upgrading existing UST systems & 25.2.7.19 \\
\hline 20 NMAC 5.4, § 401(B) & Tank upgrading requirements & 25.2.7.20 \\
\hline 20 NMAC 5.4, § 401(C) & Piping upgrading requirements & 25.2.7.21 \\
\hline 20 NMAC 5.4, § 401(D) & Spill and overfill prevention equipment & 25.2 .7 .22 \\
\hline 20 NMAC 5.4, § 402 & $\begin{array}{l}\text { Certification of compliance and notification } \\
\text { requirements }\end{array}$ & 25.2.7.23 \\
\hline 20 NMAC 5.5, §500(A) & Spill and overflow control & 25.2.7.24 \\
\hline 20 NMAC 5.5, § 501(A) & Operations and maintenance of corrosion protection & 25.2.7.25 \\
\hline 20 NMAC 5.5, § 501(B) & Inspections of cathodic protection system & 25.2.7.26 \\
\hline 20 NMAC 5.5, § 501(C) & $\begin{array}{l}\text { Inspections of impressed-current cathodic protection } \\
\text { systems }\end{array}$ & 25.2.7.27 \\
\hline 20 NMAC 5.5, § 501(D) & $\begin{array}{l}\text { Records of operation of the cathodic protection } \\
\text { system }\end{array}$ & 25.2.7.28 \\
\hline 20 NMAC 5.5, § 502 & Compatibility & 25.2.7.29 \\
\hline 20 NMAC 5.5, § 503(A) & Repairs allowed & 25.2.7.30 \\
\hline 20 NMAC 5.5, § 503(B) & Repairs to fiberglass-reinforced plastic tanks & 25.2.7.31 \\
\hline 20 NMAC 5.5, § 503(C) & Repairs of pipe sections and fittings & 25.2.7.32 \\
\hline 20 NMAC 5.5, § 503(D) & Tightness testing after repairs & 25.2.7.33 \\
\hline 20 NMAC 5.5, § 503(E) & $\begin{array}{l}\text { Testing of repaired cathodically protected UST } \\
\text { system }\end{array}$ & 25.2.7.34 \\
\hline 20 NMAC 5.5, § 503(F) & Records of all repairs & 25.2.7.35 \\
\hline 20 NMAC 5.5, § 504(A) & Reporting & 25.2.7.36 \\
\hline 20 NMAC 5.5, § 504(B) & Record keeping requirements & 25.2.7.37 \\
\hline 20 NMAC 5.5, § 504(C) & Availability and maintenance of records & 25.2.7.38 \\
\hline 20 NMAC 5.5, § 505(A) & Inspections, monitoring, and testing of USTs & 25.2.7.39 \\
\hline 20 NMAC 5.5, § 505(C) & $\begin{array}{l}\text { Inspections of UST installations, repairs or } \\
\text { modifications, or removals or system closures }\end{array}$ & 25.2.7.40 \\
\hline
\end{tabular}




\section{Waste Isolation Pilot Plant Biennial Environmental Compliance Report}

DOE/WIPP 99-2171

\begin{tabular}{|c|c|c|}
\hline CITATION & REQUIREMENT & $\begin{array}{c}\text { BECR } \\
\text { SECTION }\end{array}$ \\
\hline 20 NMAC 5.6, § 600(A) & General requirements for all UST systems & 25.2.7.41 \\
\hline 20 NMAC 5.6, § 600(B) & Notification of releases & 25.2 .7 .42 \\
\hline 20 NMAC 5.6, § 600(C) & Schedule for required release detection & 25.2.7.43 \\
\hline 20 NMAC 5.6, § 600(D) & $\begin{array}{l}\text { Failure to comply with release-detection } \\
\text { requirements }\end{array}$ & 25.2.7.44 \\
\hline 20 NMAC 5.6, § 601(A) & Requirements for tanks of petroleum UST systems & 25.2 .7 .45 \\
\hline 20 NMAC 5.6, § 601(B) & Requirements for piping of petroleum UST systems & 25.2.7.46 \\
\hline 20 NMAC 5.6, § 601(B)(1) & Requirements for pressurized piping & 25.2.7.47 \\
\hline 20 NMAC 5.6, § 601(B)(2) & Requirements for suction piping & 25.2.7.48 \\
\hline 20 NMAC 5.6, § 602 & $\begin{array}{l}\text { Requirements for hazardous substance UST } \\
\text { systems }\end{array}$ & 25.2.7.49 \\
\hline 20 NMAC 5.6, § 603 & Methods of release detection for tanks & 25.2 .7 .50 \\
\hline 20 NMAC 5.6, § 603(A) & Inventory control & 25.2 .7 .51 \\
\hline 20 NMAC 5.6, § 603(B) & Manual tank gauging & 25.2 .7 .52 \\
\hline 20 NMAC 5.6, § 603(C) & Tank tightness testing & 25.2 .7 .53 \\
\hline 20 NMAC 5.6, § 603(D) & Automatic tank gauging & 25.2 .7 .54 \\
\hline 20 NMAC 5.6, § 603(E) & Vapor monitoring & 25.2.7.55 \\
\hline 20 NMAC 5.6, § 603(F) & Groundwater monitoring & 25.2.7.56 \\
\hline 20 NMAC 5.6, § 603(G) & Interstitial monitoring & 25.2 .7 .57 \\
\hline 20 NMAC 5.6, § 603(H) & Other methods of detecting releases & 25.2.7.58 \\
\hline 20 NMAC 5.6, § 604 & Methods of release detection of piping & 25.2.7.59 \\
\hline 20 NMAC 5.6, § 605 & Release detection record keeping & 25.2.7.60 \\
\hline 20 NMAC 5.7, § 700 & Reporting of suspected releases & 25.2.7.61 \\
\hline 20 NMAC 5.7, § 701 & Investigations of off-site impacts & 25.2 .7 .62 \\
\hline 20 NMAC 5.7, § 702 & Release investigation and confirmation steps & 25.2 .7 .63 \\
\hline 20 NMAC 5.7, § 703(A) & Reporting and cleanup of large spills and overfills & 25.2 .7 .64 \\
\hline 20 NMAC 5.7, § 703(B) & Reporting and cleanup of small spills and overfills & 25.2.7.65 \\
\hline 20 NMAC 5.8, § 800 & Temporary closure & 25.2.7.66 \\
\hline 20 NMAC 5.8, § 801(A) & Permanent closure and changes in service & 25.2 .7 .67 \\
\hline 20 NMAC 5.8, § 801(B) & Permanent closure of a tank & 25.2.7.68 \\
\hline 20 NMAC 5.8, § 801(C) & Change in service & 25.2.7.69 \\
\hline 20 NMAC 5.8, § 802(A) & Assessing the site & 25.2.7.70 \\
\hline 20 NMAC 5.8, § 802(B) & Corrective action & 25.2.7.71 \\
\hline 20 NMAC 5.8, § 803 & Applicability to previously closed UST systems & 25.2.7.72 \\
\hline 20 NMAC 5.8, § 804 & Closure records & 25.2.7.73 \\
\hline 20 NMAC 5.9, § 900 & Applicability of financial responsibility & 25.2.7.74 \\
\hline 20 NMAC 5.10, § 1000 & Informal review & 25.2 .7 .75 \\
\hline 20 NMAC 5.10, § 1001 & Review by Secretary on written memoranda & 25.2 .7 .76 \\
\hline 20 NMAC 5.1, § 108 & Compliance with other regulations & 25.2.7.77 \\
\hline 20 NMAC 5.1, § 109 & Construction & 25.2.7.78 \\
\hline
\end{tabular}




\section{Waste Isolation Pilot Plant Biennial Environmental Compliance Report}

DOE/WIPP 99-2171

\begin{tabular}{|c|c|c|}
\hline CITATION & REQUIREMENT & $\begin{array}{l}\text { BECR } \\
\text { SECTION }\end{array}$ \\
\hline 20 NMAC 5.1, § 110 & Severability & 25.2 .7 .79 \\
\hline 20 NMAC 5.12, § 1200(A) & $\begin{array}{l}\text { Cleanup requirements for releases from petroleum } \\
\text { UST systems }\end{array}$ & 25.2 .7 .80 \\
\hline $\begin{array}{l}20 \text { NMAC 5.12, §§ 1200(B)- } \\
1222\end{array}$ & $\begin{array}{l}\text { Additional corrective action requirements for } \\
\text { petroleum UST systems }\end{array}$ & 25.2 .7 .81 \\
\hline 20 NMAC 5.13, §§ 1300-1320 & $\begin{array}{l}\text { Corrective action for hazardous substance UST } \\
\text { systems }\end{array}$ & 25.2.7.82 \\
\hline 20 NMAC 5.14, §§ 1400-1417 & Certification of tank installers and repairers & 25.2.7.83 \\
\hline 20 NMAC 5.15, § 1505 & Priorities & 25.2 .7 .84 \\
\hline 20 NMAC 5.15, § 1508 & Minimum site assessment & 25.2 .7 .85 \\
\hline 20 NMAC 5.16 & Certification of contractors & 25.2 .7 .86 \\
\hline 20 NMAC 5.17 & Corrective Action Fund payment and reimbursement & 25.2 .7 .87 \\
\hline \multicolumn{3}{|c|}{ Universal Waste Legislation } \\
\hline 40 CFR 273 & Universal Waste Regulations & 25.2 .6 \\
\hline 40 CFR $\S 273$, Subpart B & $\begin{array}{l}\text { Standards for Universal Waste, Small-Quantity } \\
\text { Handlers }\end{array}$ & 252.6 .1 \\
\hline 40 CFR $\S 273.11$ & Prohibitions & 25.2 .6 .2 \\
\hline 40 CFR $\S 273.13$ & Waste management & 25.2 .6 .3 \\
\hline 40 CFR $\S 273.14$ & Labeling/Marking & 25.2 .6 .4 \\
\hline 40 CFR $\S 273.15$ & Accumulation time limits & 25.2 .6 .5 \\
\hline 40 CFR $\S 273.16$ & Employee training & 25.2 .6 .6 \\
\hline 40 CFR $\S 273.17$ & Responses to releases & 25.2.6.7 \\
\hline 40 CFR $\S 273.18$ & Off-site shipments & 25.2 .6 .8 \\
\hline \multicolumn{3}{|c|}{ Waste Transportation Legislation } \\
\hline 49 CFR 171 & $\begin{array}{l}\text { General Information, Regulations, and } \\
\text { Definitions } \\
\end{array}$ & 15.1 \\
\hline 49 CFR $\S 171.2$ & General requirements & 15.2 .1 \\
\hline 49 CFR $\S 171.3$ & Hazardous waste & 15.2 .2 \\
\hline 49 CFR $\S 171.14$ & $\begin{array}{l}\text { Transitional provisions for implementing } \\
\text { requirements based on the United Nations } \\
\text { recommendations }\end{array}$ & 15.2 .3 \\
\hline 49 CFR $\S 171.15$ and .16 & $\begin{array}{l}\text { Immediate notice of certain hazardous materials } \\
\text { incidents and detailed hazardous materials incident } \\
\text { reports }\end{array}$ & 15.2 .4 \\
\hline 49 CFR 172 & $\begin{array}{l}\text { Hazardous Materials Table, Special Provisions, } \\
\text { Hazardous Materials Communication } \\
\text { Requirements and Emergency Response } \\
\text { Information Requirements }\end{array}$ & 15.1 \\
\hline 49 CFR $\S 172.101$ & Table of hazardous materials & 15.2 .5 \\
\hline $\begin{array}{l}49 \text { CFR } \S 172.200 \text { through } \\
172.205 \text {, Subpart C }\end{array}$ & Shipping papers & 15.2 .6 \\
\hline
\end{tabular}




\begin{tabular}{|c|c|c|}
\hline CITATION & REQUIREMENT & \begin{tabular}{|c|} 
BECR \\
SECTION \\
\end{tabular} \\
\hline $\begin{array}{l}49 \text { CFR § } 172.300 \text { through } \\
\text { 172.338, Subpart D } \\
\end{array}$ & Marking & 15.2 .7 \\
\hline $\begin{array}{l}\text { 49 CFR § } 172.400 \text { through } \\
172.450 \text {, Subpart E } \\
\end{array}$ & Labeling & 15.2 .8 \\
\hline $\begin{array}{l}\text { 49 CFR § } 172.500 \text { through } \\
172.560 \text {, Subpart F } \\
\end{array}$ & Placarding & 15.2 .9 \\
\hline 49 CFR $\S 172.600$, Subpart G & Emergency response information & 15.2 .10 \\
\hline $\begin{array}{l}\text { 49 CFR § } 172.700 \text { through } \\
\text { 172.704, Subpart H }\end{array}$ & $\begin{array}{l}\text { Training requirements, federal/state relationship, } \\
\text { and applicability and responsibility for training and } \\
\text { testing }\end{array}$ & 15.2 .11 \\
\hline 49 CFR 173 & $\begin{array}{l}\text { Shippers - General Requirements for Shipments } \\
\text { and Packagings }\end{array}$ & 15.1 \\
\hline $\begin{array}{l}49 \text { CFR § } 173.1 \text { through .12, } \\
\text { Subpart A }\end{array}$ & General requirements for shipments and packaging & 15.2 .12 \\
\hline $\begin{array}{l}49 \text { CFR } \S 173.21 \text { through } \\
\text { 173.40, Subpart B }\end{array}$ & $\begin{array}{l}\text { Preparation of hazardous materials for } \\
\text { transportation }\end{array}$ & 15.2 .13 \\
\hline $\begin{array}{l}\text { 49 CFR § } 173.50 \text { through } \\
\text { 173.63, Subpart C }\end{array}$ & $\begin{array}{l}\text { Definitions, classification, and packaging for Class } 1 \\
\text { materials }\end{array}$ & 15.2 .14 \\
\hline $\begin{array}{l}49 \text { CFR } \S 173.115 \text { th rough } \\
\text { 173.156, Subpart D }\end{array}$ & $\begin{array}{l}\text { Definitions, classification, packaging group } \\
\text { assignments, and exceptions for hazardous } \\
\text { materials other than Class } 1 \text { and Class } 7\end{array}$ & 15.2.15 \\
\hline $\begin{array}{l}\text { 49 CFR § } 173.158 \text { through } \\
\text { 173.229, Subpart E } \\
\end{array}$ & $\begin{array}{l}\text { Non-bulk packaging requirements for hazardous } \\
\text { materials other than Class } 1 \text { and Class } 7 \\
\end{array}$ & 15.2.16 \\
\hline $\begin{array}{l}49 \text { CFR § } 173.401 \text { through } \\
\text { 173.476, Subpart I } \\
\end{array}$ & Radioactive materials & 15.2 .17 \\
\hline 49 CFR 177 & Carriage by Public Highway & 15.1 \\
\hline 49 CFR 175 & Carriage by Aircraft & 15.2.18 \\
\hline $\begin{array}{l}49 \text { CFR § } 177.800,177.816, \\
\text { and 397, Subpart D } \\
\end{array}$ & Driver training & 15.2 .19 \\
\hline 49 CFR 178 & Specifications for Packagings & 15.1 \\
\hline 49 CFR 178 & Specifications for Packagings & 15.2 .20 \\
\hline \multicolumn{3}{|c|}{ Water Quality Legislation } \\
\hline 40 CFR 112 & Oil Pollution Prevention & 7.1 \\
\hline $40 \mathrm{CFR} \S 112.3$ & SPCC plan requirements & 7.2 .1 \\
\hline 40 CFR $\S 112.5$ & Amendment of SPCC plan by the owner/operator & 7.2 .2 \\
\hline $40 \mathrm{CFR} \S 117.21$ & Notification of discharge of $R Q$ & 7.2 .3 \\
\hline 40 CFR 122 & $\begin{array}{l}\text { EPA-Administered Permit Programs: the } \\
\text { National Pollutant Discharge Elimination System } \\
\text { (NPDES) }\end{array}$ & 7.1 \\
\hline 40 CFR $\S 122.1(b)(1)$ & NPDES permit requirement & 7.2 .4 \\
\hline 40 CFR $\S 122.21(\mathrm{c})(2)$ & NPDES permit assessment & 7.2 .5 \\
\hline 40 CFR $\S 122.26(a)$ & $\begin{array}{l}\text { Requirement for a NPDES permit for storm water } \\
\text { discharges }\end{array}$ & 7.2 .6 \\
\hline
\end{tabular}




\begin{tabular}{|c|c|c|}
\hline CITATION & REQUIREMENT & \begin{tabular}{|c|} 
BECR \\
SECTION \\
\end{tabular} \\
\hline 40 CFR § 122.26(c) & Application requirement for storm water discharges & 7.2 .7 \\
\hline IV(A); Appendix B, II(A) & Notice of Intent to file for general permit & 7.3 .1 \\
\hline $\mathrm{IV}(\mathrm{A})(4)$ & Notice of Termination & 7.3 .2 \\
\hline IV(B)(1); Appendix B, III(A) & Prohibition on non-storm water discharges & 7.3.3 \\
\hline IV(B)(2); Appendix B, III(B) & $\begin{array}{l}\text { Releases of reportable quantities of hazardous } \\
\text { substances and oil }\end{array}$ & 7.3 .4 \\
\hline IV(C); Appendix B, Part IV & Storm water pollution prevention plan & 7.3 .5 \\
\hline $\mathrm{IV}(\mathrm{C})(1)$; Appendix B, IV(D)(1) & Pollution prevention team & 7.3 .6 \\
\hline IV(C)(2)Appendix B, IV(D)(2) & Identification of potential pollution sources & 7.3 .7 \\
\hline IV(C)(2); Appendix B, IV(D) & Site assessments & 7.3 .8 \\
\hline IV(C)(3); Appendix B, IV(D)(3) & Measures and controls & 7.3 .9 \\
\hline IV(C)(4); Appendix B, IV(D)(4) & Comprehensive site compliance evaluations & 7.3.10 \\
\hline $\mathrm{IV}(\mathrm{D})(1) ;$ Appendix B, IV(D)(7) & $\begin{array}{l}\text { Requirements for storage, processing, and handling } \\
\text { areas for EPCRA § } 313 \text { "water priority chemicals" }\end{array}$ & 7.3 .11 \\
\hline IV(D)(2); Appendix B, IV (D)(8) & Enclosure or covering of outdoor salt piles & 7.3.12 \\
\hline IV(D)(3); Appendix B, IV(D)(5) & $\begin{array}{l}\text { Notification to municipal large and medium separate } \\
\text { storm water systems }\end{array}$ & 7.3 .13 \\
\hline $\begin{array}{l}\text { IV(E); Appendix B, Part IV and } \\
\text { XI(C)(Vi) }\end{array}$ & Monitoring and reporting requirements & 7.3 .14 \\
\hline NMED 92-1 & $\begin{array}{l}\text { New Mexico Environment Department 92-1, } \\
\text { Ground Water Protection Act Corrective Action } \\
\text { Fund Regulations }\end{array}$ & 27.1 \\
\hline NMED 92-1 & Corrective actions for spills/releases from USTs & 27.3 \\
\hline DP-831 & \begin{tabular}{|l} 
New Mexico Discharge Plan for the WIPP, \\
DP-831
\end{tabular} & 29.3 \\
\hline $\begin{array}{l}\text { DP-831 Condition for } \\
\text { Approval \#1 }\end{array}$ & $\begin{array}{l}\text { Requirement for reporting discharge volumes, water } \\
\text { sources, and quarterly reports }\end{array}$ & 29.3 .1 \\
\hline DP-831 CA \#2 & $\begin{array}{l}\text { Requirement for water quality analysis submitted } \\
\text { with quarterly report }\end{array}$ & 29.3 .2 \\
\hline DP-831 CA \#3 & $\begin{array}{l}\text { Requirement for reporting volume and origin of } \\
\text { miscellaneous nonhazardous discharges }\end{array}$ & 29.3 .3 \\
\hline DP-831 Specific Requirement 1 & Authorization to discharge & 29.3 .4 \\
\hline DP-831 Specific Requirement 2 & Authorization to discharge & 29.3 .5 \\
\hline DP-831 Specific Requirement 3 & Authorization to discharge & 29.3 .6 \\
\hline DP-831 Specific Requirement 4 & Maintenance of berms & 29.3 .7 \\
\hline DP-831 Specific Requirement 5 & Contingency plan required & 29.3 .8 \\
\hline DP-831 Specific Requirement 6 & Facility closure plan required & 29.3 .9 \\
\hline DP-831 General Requirement & Monitoring and reporting & 29.3 .10 \\
\hline DP-831 General Requirement & Record keeping & 29.3.11 \\
\hline DP-831 General Requirement & Inspection and entry & 29.3.12 \\
\hline DP-831 General Requirement & Duty to provide information & 29.3.13 \\
\hline
\end{tabular}




\begin{tabular}{|c|c|c|}
\hline CITATION & REQUIREMENT & $\begin{array}{l}\text { BECR } \\
\text { SECTION }\end{array}$ \\
\hline DP-831 General Requirement & Spills, leaks, and unauthorized discharges & 29.3 .14 \\
\hline DP-831 General Requirement & Retention of records & 29.3 .15 \\
\hline DP-831 General Requirement & Modifications and/or amendments & 29.3 .16 \\
\hline 20 NMAC 6.1 & $\begin{array}{l}\text { Water quality standards for interstate and } \\
\text { intrastate streams in New Mexico } \\
\end{array}$ & 29.2.10 \\
\hline 20 NMAC 6.2 & $\begin{array}{l}\text { New Mexico Water Quality Control Commission } \\
\text { Regulations }\end{array}$ & 29.1 \\
\hline 20 NMAC $6.2,1-201$ & Notice of Intent to discharge & 29.2 .1 \\
\hline 20 NMAC $6.2,1-202$ & $\begin{array}{l}\text { Filing of plans and specifications--sewerage } \\
\text { systems }\end{array}$ & 29.2 .2 \\
\hline 20 NMAC $6.2,1-203$ & Notification of discharge - removal & 29.2 .3 \\
\hline 20 NMAC $6.2,2-101$ & General requirements & 29.2 .4 \\
\hline 20 NMAC $6.2,3-104$ & Discharge plan required & 29.2 .5 \\
\hline 20 NMAC $6.2,3-106$ & Application for discharge plan approval & 29.2 .6 \\
\hline 20 NMAC $6.2,3-107$ & Monitoring, reporting, and other requirements & 29.2 .7 \\
\hline 20 NMAC $6.2,3-108$ & Public notice and participation & 29.2 .8 \\
\hline 20 NMAC 6.2, 3-109 & $\begin{array}{l}\text { Director approval, disapproval, modification, or } \\
\text { termination of proposed discharge plans }\end{array}$ & 29.2 .9 \\
\hline 20 NMAC 7.1 & New Mexico Water Supply Regulations (WSR) & 30.1 \\
\hline 20 NMAC 7.1, § 205(A) & $\begin{array}{l}\text { Maximum Contaminant Level for total coliform } \\
\text { bacteria }\end{array}$ & 30.2 .1 \\
\hline 20 NMAC $7.1, \S 208(I)$ & Cross connections & 30.2 .2 \\
\hline 20 NMAC $7.1, \S 301(E)$ & Certification of sampling personnel & 30.2 .3 \\
\hline 20 NMAC $7.1, \S 302(A)$ & Compliance sampling of coliforms & 30.2 .4 \\
\hline 20 NMAC $7.1, \S 309$ & Laboratories & 30.2 .5 \\
\hline 20 NMAC $7.1, \S 310$ & $\begin{array}{l}\begin{array}{l}\text { Sampling of consecutive public water-supply } \\
\text { systems }\end{array} \\
\end{array}$ & 30.2 .6 \\
\hline 20 NMAC $7.1, \S 401(\mathrm{~A})$ & Reporting requirements & 30.2 .7 \\
\hline 20 NMAC $7.1, \S 403(\mathrm{~A})$ & Record maintenance & 30.2 .8 \\
\hline 20 NMAC 7.4 & Utility Operator Certification & 29.2.11 \\
\hline
\end{tabular}


This page intentionally left blank. 


\section{APPENDIX B - NATIONAL EMISSIONS STANDARDS FOR HAZARDOUS AIR POLLUTANTS FOR RADIONUCLIDES OTHER THAN RADON FROM DEPARTMENT OF ENERGY FACILITIES REPORT}

\section{REPORT SUMMARY}

This report summarizes the WIPP facility compliance with the standard established by 40 CFR 191, Subpart A (and satisfies the reporting requirements within 40 CFR 61, Subpart H, National Emissions Standards for Hazardous Air Pollutants for Radionuclides Other Than Radon from Department of Energy Facilities) for 1999. All laboratory data, calculation results, and modeling results presented herein cover, at a minimum, the period of time January 1, 1999, through the last day of the year (December 1999).

The CAP88-PC version 2.0 dose assessment computer model was used to estimate the doses(s) reported in this report. Attachments 1 and 2 are copies of the output data from CAP88-PC. Calculations made using the above referenced code indicate that the effective dose equivalent (EDE) resulting from normal operations conducted at this facility is $2.23 \mathrm{E}-6$ millirem (mrem) per year to the maximally exposed individual resident, and the maximum critical organ dose is $3.88 \mathrm{E}-5 \mathrm{mrem}$ per year to this exposed individual. Calculations also indicate that the EDE resulting from normal operations conducted at this facility is $3.05 \mathrm{E}-5 \mathrm{mrem}$ per year to the maximally exposed individual at the fence line, and the maximum critical organ dose to the individual at the fence line is $5.31 \mathrm{E}-4$ mrem per year. All of these values are in compliance with the requirements of the $\$ 191.03(b)$ standard.

\section{Facility Name and Location}

Facility:

Waste Isolation Pilot Plant

Facility Location: $\quad 26$ Miles SE of Carlsbad, New Mexico, 88221

\section{Radioactive Materials Used}

The waste managed at the WIPP contains transuranic (TRU) radionuclides. The TRU radionuclides with the highest potential to deliver a dose to an off-site receptor are ${ }^{238} \mathrm{Pu},{ }^{239} \mathrm{Pu},{ }^{240} \mathrm{Pu}$, and ${ }^{241} \mathrm{Am}$. Operations at the WIPP facility do not involve handling any loose radioactive material. All waste containers are sealed at the wastegenerating facilities and remain sealed during the disposal operation. Removable contamination on the exterior surfaces of containers is restricted to minimal levels in accordance with DOE/WIPP-069, Waste Acceptance Criteria, and should not present a significant source of radionuclide release in airborne effluents. During normal operating conditions, there is essentially no potential for airborne emissions of radionuclides contained in the TRU waste managed at the WIPP facility. 
Small quantities (i.e., activities) of radioactive materials (mostly sealed sources) are used at the WIPP facility to calibrate and verify the operation of various radiation detection instrumentation. However, this source of radioactive materials does not have the potential to result in measurable off-site dose consequences.

\section{Description of Operations}

The WIPP facility is a TRU radioactive waste disposal facility owned by the U.S. Department of Energy (DOE) and operated by the Waste Isolation Division (WID) of Westinghouse Government Environmental Services Company. The principal operation of the WIPP facility involves the receipt of contact and planned receipt of remote handled TRU and TRU mixed waste and emplacement in the underground repository for disposal. Only waste that conforms with DOE/WIPP-069, Waste Acceptance Criteria, is accepted for placement in the WIPP facility. Administrative controls prohibit the waste containers from being opened once they are accepted at the WIPP.

\section{Emission Points}

The WIPP facility has three emission points, Stations A, B, and C, that may release airborne radionuclides to the environment. Station $A$ exhausts unfiltered air from the underground repository to the atmosphere. Station B exhausts high-efficiency particulate air (HEPA) filtered air from the underground repository to the atmosphere when in Filtration Mode of operation. When in filtration Mode, Stations A and B are mutually exclusive (i.e., when air is exhausted from one Station, none is exhausted from the other Station). Station A \& B Sample the same air when operated in the Maintenance Bypass, Reduced, or Minimum Mode. Station $C$ exhausts HEPA filtered air from the Waste Handling Building (WHB) to the atmosphere.

\section{Effluent Controls}

Radionuclide emissions from waste containers are controlled by carbon composite filter vents that must be fitted to all waste containers accepted at the WIPP facility. Each filter must exhibit filtering efficiencies of greater than 99 percent with 0.3 to 0.5 -micron particles of dioctyl phthalate (DOP) smoke (DOE 1989).

Air monitors are maintained at strategic locations in the WHB and in the underground repository to monitor the real-time levels of airborne radioactivity. Readouts from the underground air monitors are displayed in the Central Monitoring Room (CMR), a continuously occupied location from which WIPP facility operations are monitored. During normal conditions, the underground repository effluent does not pass through HEPA filtration units before being discharged to the environment. The WHB effluent, generated by aboveground waste handling operations, is subject to continuous HEPA filtration before being discharged to the environmental through Station C. Stations B 
and C HEPA filtration units are tested annually and exhibit filtering efficiencies greater than 99 percent for 0.3 to 0.5 micron particles (DOE 1995).

The WHB ventilation system maintains a negative pressure differential between the outside environment and the waste handling environment. This provides a secondary confinement barrier against the release of radionuclides to the environment, where the waste containers themselves are considered the primary barrier. A negative pressure differential ensures that any leaks in the WHB structure will result in an inleakage of outside air which precludes the release of airborne contamination inside the WHB to the environment.

The underground ventilation system is composed of four subsystems with a common air supply. This dividing of the air supply inhibits the spread of contamination in the unlikely event radioactive material becomes airborne. Separation of the subsystem air flows is maintained by the use of air locks until the flows are recombined at the exhaust shaft. A pressure differential is maintained between the subsystems to ensure that any air leakage flows from the non-nuclear areas (least contamination potential) to the radioactive materials areas (highest contamination potential).

The WIPP facility uses skid-mounted fixed air samplers (FASs) at each emission point to collect representative samples of airborne particulates. Each emission point FAS has two independent vacuum pumps; one vacuum pump supplies the vacuum and the other functions as a backup. In the event of an external power failure, an uninterruptible power supply provides sufficient power to all FASs for approximately 30 minutes. Diesel generators are available to supply electrical power should the electrical outage last longer than 30 minutes.

An approved and controlled operating procedure WP 12-HP1300 is used at the WIPP facility to ensure uniform methods are used to collect, package, and transport FAS filters. The use of such procedures provides a means for demonstrating quality assurance of air emission data. Station A FAS filters are collected as needed each working shift in order to assure a representative sample. Station B FAS filters are collected weekly and at the end of each underground effluent filtration event. Station C FAS filters are collected weekly. Filters from all three stations are typically analyzed for ${ }^{238} \mathrm{Pu},{ }^{239} \mathrm{Pu},{ }^{240} \mathrm{Pu}$, and ${ }^{241} \mathrm{Am}$. These four radionuclides account for approximately 98 percent of the potential dose (EDE) resulting from the WIPP facility air emissions (DOE/WIPP 95-2065, Safety Analysis Report). The FAS filters are also analyzed for beta activity if beta screening analysis indicates beta activity could contribute more than $0.01 \mathrm{mrem} / \mathrm{year}$.

\section{Distances to Nearest Receptors from Release Points}

The WIPP facility is located in a low population density area that has less than 30 permanent residents living within a 10-mile radius (DOE/WIPP 95-2065). The area surrounding the WIPP facility is used primarily for grazing and development of potash, oil, and gas resources. All land within the WIPP site boundary up to the "exclusive 
use area" is leased for grazing, which is the only significant agricultural activity in the vicinity of the WIPP facility. Development of the natural resources results in a transient (nonpermanent) population consisting primarily of workers at three potash mines and numerous oil and gas wells located within 10 miles of the WIPP facility.

In compliance with $40 \mathrm{CFR} 61$, Subpart $\mathrm{H}$, the nearest permanent residence, school, business or office is the Mills Ranch located $5.4 \mathrm{~km}$ away in the SSW sector. The nearest farm producing vegetables is $9.7 \mathrm{~km}$ in the NNW sector, milk (commercial) $80.0 \mathrm{~km}$ in NW sector and meat is $0.3 \mathrm{~km}$ in East sector (the site boundary).

\section{Input Data for CAP88-PC Dose Assessment Computer Model}

Listed below are the input parameters and file names of the data collected for the given reporting period. Attachment 1 contains the meteorological and population data collected at local residences. Attachment 2 contains similar data for persons at the fence line. Table 1, below, lists the properties for each emission point.

Meteorological Data File: $\quad$ 96-99.wnd (WIPP Site data 6/1/96 to 10/25/99)

Population Data File: WIPP99.pop (Population data for WIPP region)

Annual precipitation: $\quad \underline{33 \mathrm{~cm} / \mathrm{yr}}$ (Three-year average, 1996 to 1998)

Annual ambient temperature: $\quad \underline{17^{\circ} \mathrm{C}}$ (Three-year average, 1996 to 1998)

Lid height: $\quad \underline{1000 \mathrm{~m}}$

Agricultural Scenario: Local

Table 1 - Characteristics of WIPP's Emission Points

\begin{tabular}{|l|c|c|c|}
\hline \multicolumn{1}{|c|}{ Characteristics } & Station A & Station B & Station C \\
\hline Effective Station Height $(\mathrm{m})$ & 7.7 & 6.7 & 20.0 \\
\hline $\begin{array}{l}\text { Effective Station Diameter } \\
(\mathrm{m})\end{array}$ & 5.2 & 1.8 & 2.6 \\
\hline Station Area $\left(\mathrm{m}^{2}\right)$ & 21.2 & 2.6 & 6.8 \\
\hline Flow Rate $\left(\mathrm{ft}^{3} / \mathrm{min}\right)$ & $4.25 \times 10^{5}$ & $6.0 \times 10^{4}$ & $4.7 \times 10^{4}$ \\
\hline Flow Rate $\left(\mathrm{m}^{3} / \mathrm{min}\right)$ & $1.2 \times 10^{4}$ & 1699 & 1331 \\
\hline Exit Velocity $(\mathrm{m} / \mathrm{sec})$ & 9.4 & 10.8 & 3.3 \\
\hline Effective Exit Velocity $(\mathrm{m} / \mathrm{sec})$ & 6.7 & $\mathrm{NA}$ & $\mathrm{NA}$ \\
\hline Orientation & $45^{\circ}$ angle & vertical & vertical \\
\hline Shape & rectangle & round & square \\
\hline
\end{tabular}




\begin{tabular}{|l|c|c|c|}
\hline HEPA filtered & no & yes & yes \\
\hline
\end{tabular}

\section{Monitoring Results}

The monitoring activities at the WIPP involve two individual programs. The primary program is used to detect for the presence of radionuclides within the exclusive use area. The secondary program provides a method to determine if any radioactive material has extended beyond the boundary of the facility. These programs are known as radiological monitoring and environmental monitoring, respectively.

The radiological monitoring activities (as described above in the Effluent Controls section) involve the use of multiple sampling and monitoring techniques to quantify the amount of radioactive material released (if any) in both the waste stream in the underground area and also from the WHB. The annual summary of laboratory data from each filter collection point is summarized in Table 2.

Table 2 - Summary of Radionuclide Effluents from Underground Storage Areas

\begin{tabular}{|c|c|c|c|c|}
\hline Station & Radionuclide & $\begin{array}{c}\text { Activity Released } \\
\text { (Cl/YR) }\end{array}$ & $\begin{array}{c}\text { Particle Size } \\
\text { (um) }^{*}\end{array}$ & Class (D, W, Y)+ \\
\hline $\mathrm{A}$ & ${ }^{238} \mathrm{Pu}$ & $1.5 \mathrm{E}-08$ & 1 & w \\
\hline $\mathrm{A}$ & ${ }^{239 / 240} \mathrm{Pu}$ & $2.7 \mathrm{E}-08$ & 1 & w \\
\hline $\mathrm{A}$ & ${ }^{241} \mathrm{Am}$ & $2.6 \mathrm{E}-08$ & 1 & w \\
\hline $\mathrm{B}$ & ${ }^{238} \mathrm{Pu}$ & $1.4 \mathrm{E}-09$ & 1 & w \\
\hline $\mathrm{B}$ & ${ }^{239 / 240} \mathrm{Pu}$ & $8.8 \mathrm{E}-10$ & 1 & w \\
\hline $\mathrm{B}$ & ${ }^{241} \mathrm{Am}$ & $1.6 \mathrm{E}-9$ & 1 & w \\
\hline $\mathrm{C}$ & ${ }^{238} \mathrm{Pu}$ & $9 \mathrm{E}-09$ & 1 & w \\
\hline $\mathrm{C}$ & ${ }^{239 / 240} \mathrm{Pu}$ & $4.6 \mathrm{E}-09$ & 1 & w \\
\hline $\mathrm{C}$ & ${ }^{241} \mathrm{Am}$ & $6.4 \mathrm{E}-09$ & 1 & w \\
\hline
\end{tabular}

* Default values from CAP88-PC

$+\quad$ Assumed to yield upper bound dose estimates

The environmental monitoring involves sampling the air, soil, surface water, groundwater, and biological life throughout the area surrounding the WIPP site. A summary of the annual laboratory data from the environmental sampling activities for the calendar years 1998 and 1999 is presented in Table 3. A baseline inventory of the background radioactivity for these two calendar years can be found in the WIPP Site Environmental Report, which is produced annually. 


\section{Waste Isolation Pilot Plant Biennial Environmental Compliance Report}

DOE/WIPP 99-2171

Table 3 - Annual Summary of Environmental Monitoring Activities

\begin{tabular}{|c|c|c|c|c|c|c|c|c|c|}
\hline \multirow[b]{2}{*}{ Sample Matrix } & \multirow{2}{*}{$\begin{array}{c}\text { No. of } \\
\text { samples }\end{array}$} & Mean & 2SD & Mean & 2SD & Mean & 2SD & Mean & 2SD \\
\hline & & \multicolumn{2}{|c|}{ Gross alpha } & \multicolumn{2}{|c|}{ Gross beta } & \multicolumn{2}{|c|}{${ }^{241} \mathbf{A m}$} & \multicolumn{2}{|c|}{${ }^{238} \mathrm{Pu}$} \\
\hline Air $(\mathrm{Bq} / \mathrm{L})$ & 416 & $6.80 \mathrm{E}-08$ & $3.24 \mathrm{E}-08$ & $9.25 \mathrm{E}-07$ & $5.39 \mathrm{E}-09$ & $3.46 \mathrm{E}-08$ & $2.15 \mathrm{E}-06$ & $-3.63 \mathrm{E}-06$ & $1.28 \mathrm{E}-05$ \\
\hline Soil $(0-2 \mathrm{~cm})(\mathrm{Bq} / \mathrm{g}$ dry $)$ & 7 & $\mathrm{~N} / \mathrm{A}$ & $N / A$ & $\mathrm{~N} / \mathrm{A}$ & $\mathrm{N} / \mathrm{A}$ & $-1.38 \mathrm{E}-03$ & $1.28 \mathrm{E}-03$ & $1.37 \mathrm{E}-04$ & $5.14 \mathrm{E}-04$ \\
\hline Soil $(2-5 \mathrm{~cm})(\mathrm{Bq} / \mathrm{g}$ dry $)$ & 7 & $\mathrm{~N} / \mathrm{A}$ & $\mathrm{N} / \mathrm{A}$ & $\mathrm{N} / \mathrm{A}$ & $\mathrm{N} / \mathrm{A}$ & $-5.13 E-04$ & $2.97 \mathrm{E}-04$ & $-4.81 E-04$ & $3.20 \mathrm{E}-04$ \\
\hline Soil $(5-10 \mathrm{~cm})(\mathrm{Bq} / \mathrm{g}$ dry $)$ & 7 & $\mathrm{~N} / \mathrm{A}$ & $\mathrm{N} / \mathrm{A}$ & $\mathrm{N} / \mathrm{A}$ & $\mathrm{N} / \mathrm{A}$ & $-2.22 E-04$ & $2.96 \mathrm{E}-04$ & $-7.51 \mathrm{E}-04$ & 4.09E-04 \\
\hline Surface water $(\mathrm{Bq} / \mathrm{L})$ & 13 & $\mathrm{~N} / \mathrm{A}$ & $\mathrm{N} / \mathrm{A}$ & $\mathrm{N} / \mathrm{A}$ & $\mathrm{N} / \mathrm{A}$ & $-5.58 \mathrm{E}-04$ & $2.63 \mathrm{E}-04$ & $-1.34 \mathrm{E}-03$ & $2.23 \mathrm{E}-04$ \\
\hline Groundwater (Bq/L) & 14 & $\mathrm{~N} / \mathrm{A}$ & $\mathrm{N} / \mathrm{A}$ & $\mathrm{N} / \mathrm{A}$ & $\mathrm{N} / \mathrm{A}$ & $1.91 \mathrm{E}-02$ & $1.64 \mathrm{E}-02$ & $4.29 \mathrm{E}-03$ & $1.16 \mathrm{E}-02$ \\
\hline Sediments (Bq/g dry) & 13 & $\mathrm{~N} / \mathrm{A}$ & $\mathrm{N} / \mathrm{A}$ & $\mathrm{N} / \mathrm{A}$ & $\mathrm{N} / \mathrm{A}$ & 3.73E-04 & 7.48E-05 & $-1.48 \mathrm{E}-04$ & $1.08 \mathrm{E}-04$ \\
\hline Vegetation (Bq/g wet) & 7 & $\mathrm{~N} / \mathrm{A}$ & $\mathrm{N} / \mathrm{A}$ & $\mathrm{N} / \mathrm{A}$ & $\mathrm{N} / \mathrm{A}$ & $-5.74 E-05$ & $2.06 \mathrm{E}-03$ & $-2.09 E-05$ & $8.21 \mathrm{E}-06$ \\
\hline Beef & 0 & & & & & & & & \\
\hline Deer (Bq/g wet) & 3 & $\mathrm{~N} / \mathrm{A}$ & $\mathrm{N} / \mathrm{A}$ & $\mathrm{N} / \mathrm{A}$ & $\mathrm{N} / \mathrm{A}$ & $-5.98 \mathrm{E}-06$ & 4.05E-06 & 5.83E-07 & $1.98 \mathrm{E}-06$ \\
\hline Quail (Bq/g wet) & 1 & $\mathrm{~N} / \mathrm{A}$ & $\mathrm{N} / \mathrm{A}$ & $\mathrm{N} / \mathrm{A}$ & $\mathrm{N} / \mathrm{A}$ & $-2.05 E-05$ & $2.41 \mathrm{E}-05$ & $1.58 \mathrm{E}-06$ & 7.03E-06 \\
\hline Rabbit & 0 & & & & & & & & \\
\hline Fish (Bq/g wet) & 3 & $\mathrm{~N} / \mathrm{A}$ & $\mathrm{N} / \mathrm{A}$ & $\mathrm{N} / \mathrm{A}$ & $\mathrm{N} / \mathrm{A}$ & $-8.52 E-07$ & 4.19E-06 & $-6.67 \mathrm{E}-06$ & $2.84 \mathrm{E}-02$ \\
\hline
\end{tabular}

\begin{tabular}{|c|c|c|c|c|c|c|c|c|c|}
\hline \multirow[b]{2}{*}{ Sample Matrix } & \multirow{2}{*}{$\begin{array}{c}\text { No. of } \\
\text { samples }\end{array}$} & Mean & 2SD & Mean & 2SD & Mean & 2SD & Mean & 2SD \\
\hline & & \multicolumn{2}{|c|}{${ }^{239+240} \mathrm{Pu}$} & \multicolumn{2}{|c|}{${ }^{233+234} \mathbf{U}$} & \multicolumn{2}{|c|}{${ }^{235} \mathrm{U}$} & \multicolumn{2}{|c|}{${ }^{238} \mathbf{U}$} \\
\hline $\operatorname{Air}(\mathrm{Bq} / \mathrm{L})$ & 416 & $-4.01 E-07$ & $3.46 \mathrm{E}-06$ & $2.72 \mathrm{E}-06$ & 4.64E-06 & $3.43 E-08$ & $1.48 \mathrm{E}-06$ & $2.71 \mathrm{E}-06$ & 3.98E-06 \\
\hline Soil $(0-2 \mathrm{~cm})(\mathrm{Bq} / \mathrm{g}$ dry $)$ & 7 & $-2.70 \mathrm{E}-04$ & $3.36 \mathrm{E}-04$ & $8.41 \mathrm{E}-03$ & $6.79 \mathrm{E}-04$ & 8.67E-04 & $2.12 \mathrm{E}-04$ & 8.09E-03 & $6.05 \mathrm{E}-04$ \\
\hline Soil $(2-5 \mathrm{~cm})(\mathrm{Bq} / \mathrm{g}$ dry $)$ & 7 & $1.32 \mathrm{E}-04$ & $1.71 \mathrm{E}-04$ & $7.66 \mathrm{E}-03$ & $6.53 E-04$ & 8.99E-05 & 1.84E-04 & 7.77E-03 & $6.12 \mathrm{E}-04$ \\
\hline Soil $(5-10 \mathrm{~cm})(\mathrm{Bq} / \mathrm{g}$ dry $)$ & 7 & $-4.70 \mathrm{E}-04$ & $4.58 \mathrm{E}-04$ & $8.40 \mathrm{E}-03$ & $6.55 E-04$ & $1.74 \mathrm{E}-04$ & 1.40E-04 & $9.51 \mathrm{E}-03$ & $6.51 \mathrm{E}-04$ \\
\hline Surface water $(\mathrm{Bq} / \mathrm{L})$ & 13 & $-1.13 \mathrm{E}-03$ & $1.77 \mathrm{E}-04$ & $4.67 \mathrm{E}-02$ & $1.26 \mathrm{E}-03$ & $1.04 \mathrm{E}-03$ & $1.70 \mathrm{E}-04$ & $2.66 \mathrm{E}-02$ & $8.10 \mathrm{E}-04$ \\
\hline Groundwater (Bq/L) & 14 & $-3.50 \mathrm{E}-03$ & $7.95 \mathrm{E}-03$ & $1.69 \mathrm{E}+01$ & $4.15 \mathrm{E}-01$ & $1.41 \mathrm{E}-01$ & $1.79 \mathrm{E}-02$ & $2.98 \mathrm{E}+00$ & $9.41 \mathrm{E}-02$ \\
\hline Sediments (Bq/g dry) & 13 & $-6.26 \mathrm{E}-05$ & $6.30 \mathrm{E}-05$ & $1.94 \mathrm{E}-02$ & $4.14 \mathrm{E}-04$ & $7.51 \mathrm{E}-04$ & 8.06E-05 & 1.95E-02 & 3.94E-04 \\
\hline Vegetation (Bq/g wet) & 7 & $-7.62 \mathrm{E}-06$ & $7.86 \mathrm{E}-06$ & $1.38 \mathrm{E}-05$ & $2.79 \mathrm{E}-06$ & $7.40 \mathrm{E}-08$ & $9.73 \mathrm{E}-07$ & $1.74 \mathrm{E}-05$ & $2.38 \mathrm{E}-06$ \\
\hline Beef & 0 & & & & & & & & \\
\hline Deer (Bq/g wet) & 3 & $-8.63 \mathrm{E}-07$ & $1.15 \mathrm{E}-06$ & $2.10 \mathrm{E}-06$ & $3.34 \mathrm{E}-06$ & $-1.69 \mathrm{E}-07$ & 3.33E-07 & $6.04 \mathrm{E}-06$ & $3.45 \mathrm{E}-06$ \\
\hline Quail (Bq/g wet) & 1 & $0.00 \mathrm{E}+00$ & $1.48 \mathrm{E}-21$ & $-9.32 \mathrm{E}-05$ & $4.44 \mathrm{E}-05$ & $-9.18 E-05$ & $3.70 \mathrm{E}-05$ & $-8.07 E-05$ & 3.37E-05 \\
\hline
\end{tabular}




\section{Waste Isolation Pilot Plant Biennial Environmental Compliance Report}

DOE/WIPP 99-2171

\section{Table 3 - Annual Summary of Environmental Monitoring Activities}

\begin{tabular}{|c|c|c|c|c|c|c|c|c|c|}
\hline Rabbit & 0 & & & & & & & & \\
\hline Fish (Bq/g wet) & 3 & $-3.31 E-06$ & $3.10 \mathrm{E}-06$ & 9.02E-05 & $1.60 \mathrm{E}-05$ & $-1.03 \mathrm{E}-05$ & $6.61 \mathrm{E}-06$ & 7.09E-05 & $1.03 \mathrm{E}-05$ \\
\hline \multirow[b]{2}{*}{ Sample Matrix } & \multirow{2}{*}{$\begin{array}{c}\text { No. of } \\
\text { samples }\end{array}$} & Mean & 2SD & Mean & 2SD & Mean & 2SD & Mean & 2SD \\
\hline & & \multicolumn{2}{|c|}{${ }^{90} \mathrm{Sr}$} & \multicolumn{2}{|c|}{${ }^{60} \mathrm{Co}$} & \multicolumn{2}{|c|}{${ }^{137} \mathrm{Cs}$} & \multicolumn{2}{|c|}{${ }^{40} \mathrm{~K}$} \\
\hline Air $(\mathrm{Bq} / \mathrm{L})$ & 416 & $-7.82 \mathrm{E}-06$ & $2.19 \mathrm{E}-05$ & $4.62 \mathrm{E}-06$ & $2.03 \mathrm{E}-05$ & $1.10 \mathrm{E}-05$ & $2.13 \mathrm{E}-05$ & $1.17 \mathrm{E}-04$ & $2.24 \mathrm{E}-04$ \\
\hline Soil $(0-2 \mathrm{~cm})(\mathrm{Bq} / \mathrm{g}$ dry $)$ & 7 & 3.17E-04 & 5.37E-03 & & & $4.60 \mathrm{E}-03$ & $1.38 \mathrm{E}-03$ & $2.46 \mathrm{E}-01$ & 2.09E-02 \\
\hline Soil $(2-5 \mathrm{~cm})(\mathrm{Bq} / \mathrm{g}$ dry $)$ & 7 & $-5.29 E-04$ & 5.29E-03 & & & $6.08 \mathrm{E}-03$ & 1.73E-03 & $2.75 \mathrm{E}-01$ & $2.34 \mathrm{E}-02$ \\
\hline Soil $(5-10 \mathrm{~cm})(\mathrm{Bq} / \mathrm{g}$ dry) & 7 & $-4.02 E-03$ & $7.95 \mathrm{E}-03$ & & & $4.53 \mathrm{E}-03$ & $1.38 \mathrm{E}-03$ & $2.62 \mathrm{E}-01$ & $2.28 \mathrm{E}-02$ \\
\hline Surface water $(\mathrm{Bq} / \mathrm{L})$ & 13 & $4.23 \mathrm{E}-02$ & $9.44 \mathrm{E}-03$ & & & $1.53 \mathrm{E}-01$ & $5.40 \mathrm{E}-02$ & $1.13 \mathrm{E}+00$ & $1.25 \mathrm{E}+00$ \\
\hline Groundwater (Bq/L) & 14 & $1.46 \mathrm{E}+00$ & $5.88 \mathrm{E}-01$ & & & $6.45 \mathrm{E}+00$ & $1.10 \mathrm{E}+01$ & $3.12 \mathrm{E}+02$ & $1.24 \mathrm{E}+02$ \\
\hline Sediments (Bq/g dry) & 13 & $4.01 \mathrm{E}-03$ & 1.82E-03 & & & $6.15 \mathrm{E}-03$ & 5.92E-04 & $5.26 \mathrm{E}-01$ & 1.35E-02 \\
\hline Vegetation (Bq/g wet) & 7 & 4.64E-03 & $5.27 E-04$ & 6.07E-03 & 4.57E-03 & 3.67E-03 & $3.23 E-03$ & $4.07 E+00$ & $2.55 E-01$ \\
\hline Beef & 0 & & & & & & & & \\
\hline Deer (Bq/g wet) & 3 & $-2.16 \mathrm{E}-04$ & $1.11 \mathrm{E}-04$ & & & & & $1.41 \mathrm{E}-01$ & 4.62E-02 \\
\hline Quail (Bq/g wet) & 1 & 7.03E-04 & $6.66 \mathrm{E}-04$ & & & & & $1.38 \mathrm{E}-01$ & $2.63 E-02$ \\
\hline Rabbit & 0 & & & & & & & & \\
\hline Fish (Bg/g wet) & 3 & $4.84 \mathrm{E}-04$ & $1.67 \mathrm{E}-04$ & $-1.85 \mathrm{E}-04$ & $1.78 \mathrm{E}-03$ & $7.77 \mathrm{E}-04$ & $1.25 \mathrm{E}-03$ & $3.54 \mathrm{E}-01$ & $4.78 \mathrm{E}-02$ \\
\hline
\end{tabular}




\section{Waste Isolation Pilot Plant Biennial Environmental Compliance Report DOE/WIPP 99-2171}

\section{Construction and Modifications}

No construction or modifications were undertaken on the A, B, or C Sampling Stations during this period.

\section{Oath and Signature}

I certify under penalty of law that I have personally examined and am familiar with the information submitted herein, and based on my inquiry of those individuals immediately responsible for obtaining the information, I believe that the submitted information is true, accurate, and complete. I am aware that there are significant penalties for submitting false information including the possibility of fine and imprisonment (see 18 U.S.C. 1001).

Signed:

Date:

Title: 


\title{
Attachment 1 to Appendix B
}

\author{
C A P 88 - P C \\ Version 2.00 \\ Clean Air Act Assessment Package - 1988 \\ SYNOPSIS REPORT \\ Non-Radon Population Assessment \\ Apr 24, $2000 \quad 12: 45$ pm \\ Facility: Waste Isolation Pilot Project \\ Address: 26 Miles SE of Carlsbad, NM \\ City: Carlsbad \\ State: NM Zip: 88221 \\ Source Category: exempt DOE facility \\ Source Type: Stack \\ Emission Year: 1999
}

Comments: Run for 1999

Effective Dose Equivalent (mrem/year)

\subsection{E-06}

At This Location: 7500 Meters West Northwest

Dataset Name: 1999run

Dataset Date: $\quad$ Apr 24, 2000 12:44 pm

Wind File: C:ICAP88PC2IWNDFILESI96-99.WND

Population File: C:ICAP88PC2\POPFILESIWIPP99.POP 
Waste Isolation Pilot Plant Biennial Environmental Compliance Report DOE/WIPP 99-2171 
Apr 24, $2000 \quad 12: 45$ pm

SYNOPSIS

Page 1

MAXIMALLY EXPOSED INDIVIDUAL

Location of The Individual: $\quad 7500$ Meters West Northwest

Lifetime Fatal Cancer Risk: $\quad 1.14 \mathrm{E}-11$

ORGAN DOSE EQUIVALENT SUMMARY

\begin{tabular}{|c|c|c|}
\hline Organ & $\begin{array}{l}\text { Selected } \\
\text { Individual } \\
\text { (mrem/y) }\end{array}$ & $\begin{array}{c}\text { Collective } \\
\text { Population } \\
\text { (person-rem/y) }\end{array}$ \\
\hline $\begin{array}{l}\text { GONADS } \\
\text { BREAST } \\
\text { R MAR } \\
\text { LUNGS } \\
\text { THYROID } \\
\text { ENDOST } \\
\text { RMNDR }\end{array}$ & $\begin{array}{l}4.98 \mathrm{E}-07 \\
4.98 \mathrm{E}-08 \\
3.15 \mathrm{E}-06 \\
3.20 \mathrm{E}-07 \\
4.91 \mathrm{E}-08 \\
3.88 \mathrm{E}-05 \\
1.72 \mathrm{E}-06\end{array}$ & $\begin{array}{l}1.10 \mathrm{E}-06 \\
1.10 \mathrm{E}-07 \\
6.93 \mathrm{E}-06 \\
7.00 \mathrm{E}-07 \\
1.08 \mathrm{E}-07 \\
8.54 \mathrm{E}-05 \\
3.79 \mathrm{E}-06\end{array}$ \\
\hline EFFEC & 2.23E-06 & 4.91E-06 \\
\hline
\end{tabular}

FREQUENCY DISTRIBUTION OF LIFETIME FATAL CANCER RISKS

\begin{tabular}{|c|c|c|c|c|}
\hline Risk Range & $\begin{array}{c}\text { \# of } \\
\text { People }\end{array}$ & $\begin{array}{c}\text { \# of People } \\
\text { in This Risk } \\
\text { Range or Higher }\end{array}$ & $\begin{array}{c}\text { Deaths/Year } \\
\text { in This } \\
\text { Risk Range }\end{array}$ & $\begin{array}{c}\text { Deaths/Year } \\
\text { in This Risk } \\
\text { Range or Higher }\end{array}$ \\
\hline $1.0 \mathrm{E}+00$ TO $1.0 \mathrm{E}-01$ & 0 & 0 & $0.00 \mathrm{E}+00$ & $0.00 \mathrm{E}+00$ \\
\hline 1.0E-01 TO 1.0E-02 & 0 & 0 & $0.00 \mathrm{E}+00$ & $0.00 \mathrm{E}+00$ \\
\hline 1.0E-02 TO 1.0E-03 & 0 & 0 & $0.00 \mathrm{E}+00$ & $0.00 \mathrm{E}+00$ \\
\hline 1.0E-03 TO $1.0 \mathrm{E}-04$ & 0 & 0 & $0.00 \mathrm{E}+00$ & $0.00 \mathrm{E}+00$ \\
\hline 1.0E-04 TO $1.0 \mathrm{E}-05$ & 0 & 0 & $0.00 \mathrm{E}+00$ & $0.00 \mathrm{E}+00$ \\
\hline 1.0E-05 TO $1.0 \mathrm{E}-06$ & 0 & 0 & $0.00 \mathrm{E}+00$ & $0.00 \mathrm{E}+00$ \\
\hline LESS THAN 1.0E-06 & 78955 & 78955 & $3.56 \mathrm{E}-10$ & $3.56 \mathrm{E}-10$ \\
\hline
\end{tabular}


Apr 24, $2000 \quad 12: 45$ pm

SYNOPSIS

Page 2

RADIONUCLIDE EMISSIONS DURING THE YEAR 1999

\begin{tabular}{|c|c|c|c|c|c|c|}
\hline$\underline{\text { Nuclide }}$ & $\underline{\text { Class }}$ & $\underline{\text { Size }}$ & $\begin{array}{c}\text { Source } \\
\# 1 \\
\mathrm{Ci} / \mathrm{y} \\
\end{array}$ & $\begin{array}{c}\text { Source } \\
\# 2 \\
\mathrm{Ci} / \mathrm{y} \\
\end{array}$ & $\begin{array}{c}\text { Source } \\
\# 3 \\
\text { Ci/y } \\
\end{array}$ & $\begin{array}{c}\text { TOTAL } \\
\text { Ci/y }\end{array}$ \\
\hline $\begin{array}{l}\text { AM-241 } \\
\text { PU-238 } \\
\text { PU-239 }\end{array}$ & $\begin{array}{l}\text { W } \\
W \\
W\end{array}$ & $\begin{array}{l}1.00 \\
1.00 \\
1.00\end{array}$ & $\begin{array}{l}2.6 \mathrm{E}-08 \\
1.5 \mathrm{E}-08 \\
2.7 \mathrm{E}-08\end{array}$ & $\begin{array}{l}1.6 \mathrm{E}-09 \\
1.4 \mathrm{E}-09 \\
8.8 \mathrm{E}-10\end{array}$ & $\begin{array}{l}6.4 \mathrm{E}-09 \\
9.4 \mathrm{E}-09 \\
4.6 \mathrm{E}-09\end{array}$ & $\begin{array}{l}3.4 \mathrm{E}-08 \\
2.6 \mathrm{E}-08 \\
3.3 \mathrm{E}-08\end{array}$ \\
\hline \multicolumn{7}{|c|}{ SITE INFORMATION } \\
\hline & & \multicolumn{2}{|c|}{$\begin{array}{l}\text { Temperature: } \\
\text { Precipitation: } \\
\text { Mixing Height: }\end{array}$} & $\begin{array}{l}17 \text { degrees } \\
33 \mathrm{~cm} / \mathrm{y} \\
1000 \mathrm{~m}\end{array}$ & & \\
\hline
\end{tabular}

\section{SOURCE INFORMATION}

Source Number:

Stack Height $(\mathrm{m})$ :

Diameter $(m)$ :

Plume Rise

Momentum (m/s):

(Exit Velocity)

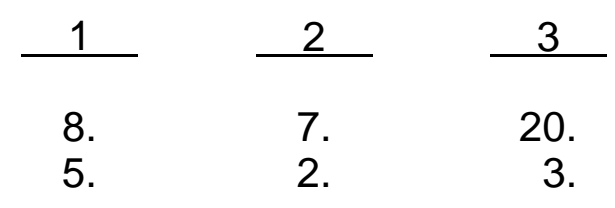

9.

11.

3.

\section{AGRICULTURAL DATA}

$\begin{array}{ccccc} & \text { Vegetable } & \text { Milk } & & \text { Meat } \\ \text { Fraction Home Produced: } & 1.000 & 1.000 & 1.000 \\ \text { Fraction From Assessment Area: } & 0.000 & 0.000 & 0.000 \\ \text { Fraction Imported: } & 0.000 & 0.000 & 0.000 \\ & & & \\ \text { Beef Cattle Density: } & 4.13 \mathrm{E}-02 & & \\ \text { Milk Cattle Density: } & 1.14 \mathrm{E}-03 & & \\ \text { Land Fraction Cultivated } & & & \end{array}$


Waste Isolation Pilot Plant Biennial Environmental Compliance Report DOE/WIPP 99-2171

for Vegetable Crops: $\quad 1.38 \mathrm{E}-03$ 
Apr 24, $2000 \quad 12: 45$ pm

SYNOPSIS

Page 3

POPULATION DATA

Distance $(\mathrm{m})$

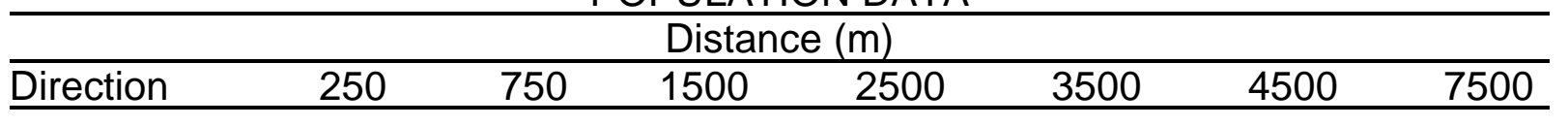

\begin{tabular}{rlllllll} 
N & 0 & 0 & 0 & 0 & 0 & 0 & 0 \\
NNW & 0 & 0 & 0 & 0 & 0 & 0 & 0 \\
NW & 0 & 0 & 0 & 0 & 0 & 0 & 0 \\
WNW & 0 & 0 & 0 & 0 & 0 & 0 & 6 \\
W & 0 & 0 & 0 & 0 & 0 & 0 & 0 \\
WSW & 0 & 0 & 0 & 0 & 0 & 0 & 0 \\
SW & 0 & 0 & 0 & 0 & 0 & 0 & 0 \\
SSW & 0 & 0 & 0 & 0 & 0 & 0 & 9 \\
S & 0 & 0 & 0 & 0 & 0 & 0 & 0 \\
SSE & 0 & 0 & 0 & 0 & 0 & 0 & 0 \\
SE & 0 & 0 & 0 & 0 & 0 & 0 & 0 \\
ESE & 0 & 0 & 0 & 0 & 0 & 0 & 0 \\
E & 0 & 0 & 0 & 0 & 0 & 0 & 0 \\
ENE & 0 & 0 & 0 & 0 & 0 & 0 & 0 \\
NE & 0 & 0 & 0 & 0 & 0 & 0 & 0 \\
NNE & 0 & 0 & 0 & 0 & 0 & 0 & 0 \\
\hline
\end{tabular}

\begin{tabular}{rrrrrrr}
\multicolumn{7}{c}{ Distance $(\mathrm{m})$} \\
\hline Direction & 15000 & 25000 & 35000 & 45000 & 55000 & 70000 \\
\hline N & 15 & 0 & 0 & 20 & 0 & 0 \\
NNW & 0 & 0 & 0 & 20 & 50 & 0 \\
NW & 40 & 0 & 0 & 0 & 20 & 7000 \\
WNW & 0 & 50 & 0 & 0 & 50 & 0 \\
W & 0 & 20 & 100 & 27000 & 20 & 5 \\
WSW & 0 & 0 & 0 & 1400 & 30 & 50 \\
SW & 0 & 0 & 0 & 0 & 0 & 0 \\
SSW & 0 & 0 & 0 & 20 & 25 & 23 \\
S & 0 & 0 & 3 & 4 & 0 & 25 \\
SSE & 0 & 0 & 4 & 6 & 0 & 125 \\
SE & 0 & 0 & 2 & 0 & 2 & 20 \\
ESE & 0 & 0 & 0 & 4 & 4 & 2060 \\
E & 0 & 0 & 4 & 5 & 1400 & 1400 \\
ENE & 0 & 0 & 0 & 0 & 0 & 14000 \\
NE & 0 & 0 & 0 & 0 & 0 & 14000 \\
NNE & 0 & 0 & 0 & 0 & 0 & 9914 \\
\hline
\end{tabular}




\author{
C A P $88-P$ C \\ Version 2.00 \\ Clean Air Act Assessment Package - 1988 \\ GENERAL DATA \\ Non-Radon Population Assessment \\ Apr 24, 2000 12:45 pm \\ Facility: Waste Isolation Pilot Project \\ Address: 26 Miles SE of Carlsbad, NM \\ City: Carlsbad \\ State: NM Zip: 88221 \\ Source Category: exempt DOE facility \\ Source Type: Stack \\ Emission Year: 1999 \\ Comments: Run for 1999 \\ Dataset Name: 1999run \\ Dataset Date: $\quad$ Apr 24, 2000 12:44 pm \\ Wind File: C:ICAP88PC2IWNDFILESI96-99.WND \\ Population File: C:ICAP88PC2\POPFILESIWIPP99.POP
}


Apr 24, $2000 \quad 12: 45$ pm

GENERAL

Page 1

VALUES FOR RADIONUCLIDE-DEPENDENT PARAMETERS

\begin{tabular}{ccccc}
\hline Nuclide & $\begin{array}{c}\text { Clearance } \\
\text { Class }\end{array}$ & $\begin{array}{c}\text { Particle } \\
\text { Size } \\
\text { (microns) }\end{array}$ & $\begin{array}{c}\text { Scavenging } \\
\text { Coefficient } \\
\text { (per second) }\end{array}$ & $\begin{array}{c}\text { Dry } \\
\text { Deposition } \\
\text { Velocity } \\
\text { (m/s) }\end{array}$ \\
\hline AM-241 & W & & & \\
PU-238 & W & 1.0 & $3.30 \mathrm{E}-06$ & $1.80 \mathrm{E}-03$ \\
PU-239 & W & 1.0 & $3.30 \mathrm{E}-06$ & $1.80 \mathrm{E}-03$ \\
& 1.0 & $3.30 \mathrm{E}-06$ & $1.80 \mathrm{E}-03$ \\
\hline
\end{tabular}

VALUES FOR RADIONUCLIDE-DEPENDENT PARAMETERS

COEFFICIENT

DECAY CONSTANT (PER DAY)

TRANSFER

-

\begin{tabular}{lccccc} 
Nuclide & Radioactive $^{(1)}$ & Surface & Water & Milk $^{(2)}$ & Meat $^{(3)}$ \\
\hline & & & & & \\
AM-241 & $0.00 \mathrm{E}+00$ & $5.48 \mathrm{E}-05$ & $0.00 \mathrm{E}+00$ & $4.00 \mathrm{E}-07$ & $3.50 \mathrm{E}-06$ \\
PU-238 & $0.00 \mathrm{E}+00$ & $5.48 \mathrm{E}-05$ & $0.00 \mathrm{E}+00$ & $1.00 \mathrm{E}-07$ & $5.00 \mathrm{E}-07$ \\
PU-239 & $0.00 \mathrm{E}+00$ & $5.48 \mathrm{E}-05$ & $0.00 \mathrm{E}+00$ & $1.00 \mathrm{E}-07$ & $5.00 \mathrm{E}-07$
\end{tabular}

FOOTNOTES: (1) Effective radioactive decay constant in plume; set to zero if less than $1.0 \mathrm{E}-2$

(2) Fraction of animal's daily intake of nuclide which appears in each $\mathrm{L}$ of milk (days/L)

(3) Fraction of animal's daily intake of nuclide which appears in each $\mathrm{kg}$ of meat (days $/ \mathrm{kg}$ ) 
Apr 24, $2000 \quad 12: 45$ pm

GENERAL

Page 3

VALUES FOR RADIONUCLIDE-DEPENDENT PARAMETERS

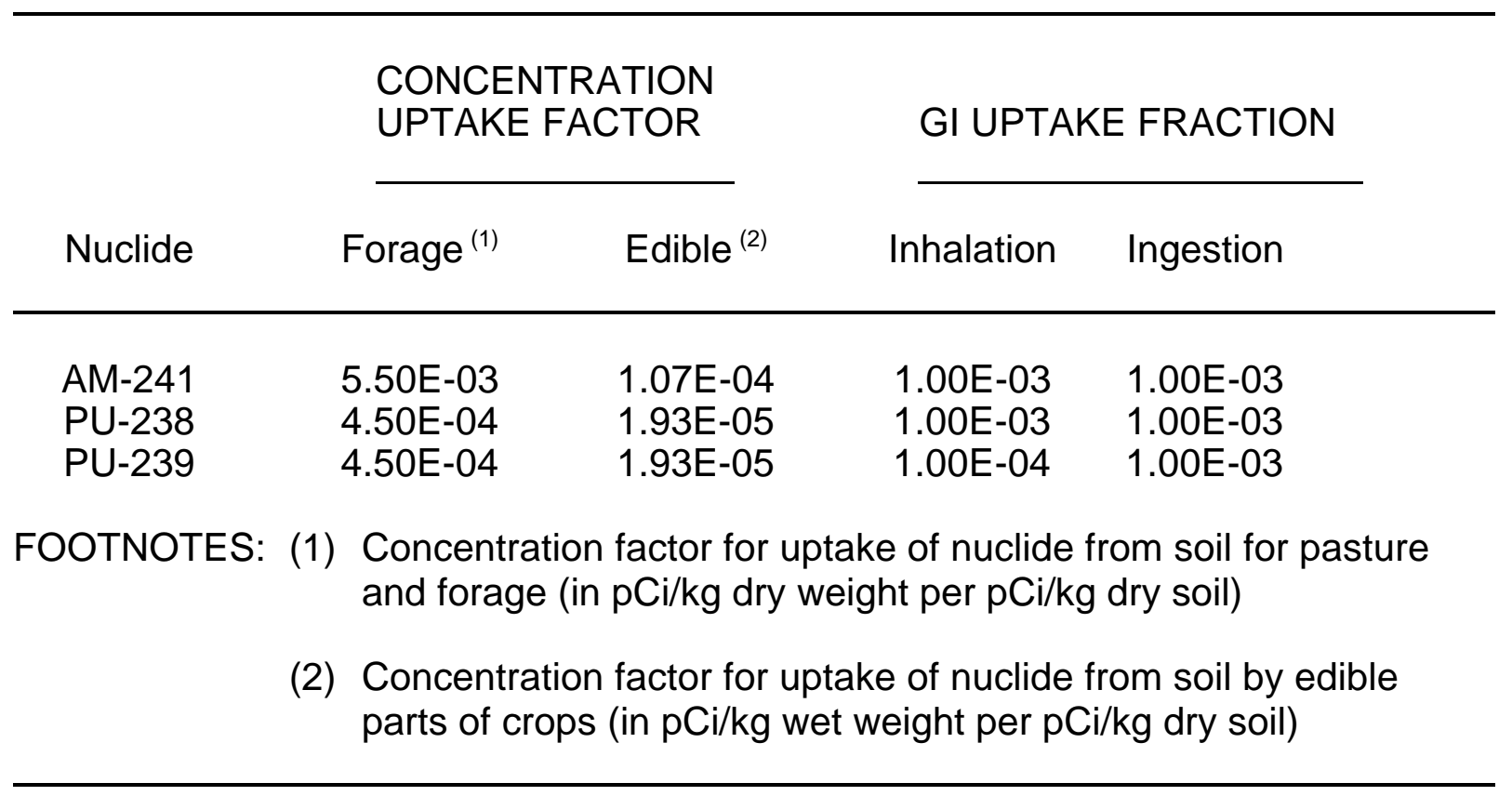


NUMBER OF BEEF CATTLE

\begin{tabular}{|c|c|c|c|c|c|c|c|}
\hline \multirow[b]{2}{*}{ Direction } & \multicolumn{6}{|c|}{ Distance (meters) } & \multirow[b]{2}{*}{7500} \\
\hline & 250 & 750 & 1500 & 2500 & 3500 & 4500 & \\
\hline $\mathrm{N}$ & 0 & 1 & 2 & 4 & 6 & 7 & 61 \\
\hline NNW & 0 & 1 & 2 & 4 & 6 & 7 & 61 \\
\hline W & 0 & 1 & 2 & 4 & 6 & 7 & 61 \\
\hline WNW & 0 & 1 & 2 & 4 & 6 & 7 & 61 \\
\hline & 0 & 1 & 2 & 4 & 6 & 7 & 61 \\
\hline WSW & 0 & 1 & 2 & 4 & 6 & 7 & 61 \\
\hline SW & 0 & 1 & 2 & 4 & 6 & 7 & 61 \\
\hline SSW & 0 & 1 & 2 & 4 & 6 & 7 & 61 \\
\hline$S$ & 0 & 1 & 2 & 4 & 6 & 7 & 61 \\
\hline SSE & 0 & 1 & 2 & 4 & 6 & 7 & 61 \\
\hline SE & 0 & 1 & 2 & 4 & 6 & 7 & 61 \\
\hline ESE & 0 & 1 & 2 & 4 & 6 & 7 & 61 \\
\hline $\mathrm{E}$ & 0 & 1 & 2 & 4 & 6 & 7 & 61 \\
\hline ENE & 0 & 1 & 2 & 4 & 6 & 7 & 61 \\
\hline $\mathrm{NE}$ & 0 & 1 & 2 & 4 & 6 & 7 & 61 \\
\hline NNE & 0 & 1 & 2 & 4 & 6 & 7 & 61 \\
\hline
\end{tabular}

Distance (meters)

\begin{tabular}{rcccccc} 
& \multicolumn{7}{c}{ Direction } & 15000 & 25000 & 35000 & 45000 & 55000 & 70000 \\
\cline { 2 - 7 } N & 243 & 405 & 568 & 730 & 892 & 2271 \\
NNW & 243 & 405 & 568 & 730 & 892 & 2271 \\
NW & 243 & 405 & 568 & 730 & 892 & 2271 \\
NW & 243 & 405 & 568 & 730 & 892 & 2271 \\
W & 243 & 405 & 568 & 730 & 892 & 2271 \\
WSW & 243 & 405 & 568 & 730 & 892 & 2271 \\
SW & 243 & 405 & 568 & 730 & 892 & 2271 \\
SSW & 243 & 405 & 568 & 730 & 892 & 2271 \\
S & 243 & 405 & 568 & 730 & 892 & 2271 \\
SSE & 243 & 405 & 568 & 730 & 892 & 2271 \\
SE & 243 & 405 & 568 & 730 & 892 & 2271 \\
ESE & 243 & 405 & 568 & 730 & 892 & 2271 \\
E & 243 & 405 & 568 & 730 & 892 & 2271 \\
ENE & 243 & 405 & 568 & 730 & 892 & 2271 \\
NE & 243 & 405 & 568 & 730 & 892 & 2271 \\
NNE & 243 & 405 & 568 & 730 & 892 & 2271
\end{tabular}


Waste Isolation Pilot Plant Biennial Environmental Compliance Report DOE/WIPP 99-2171 
Apr 24, $2000 \quad 12: 45$ pm

GENERAL

Page 5

NUMBER OF MILK CATTLE

\begin{tabular}{cccccccc}
\hline & \multicolumn{7}{c}{ Distance (meters) } \\
\cline { 2 - 8 } Direction & 250 & 750 & 1500 & 2500 & 3500 & 4500 & 7500 \\
\hline N & 0 & 0 & 0 & 0 & 0 & 0 & 2 \\
NNW & 0 & 0 & 0 & 0 & 0 & 0 & 2 \\
NW & 0 & 0 & 0 & 0 & 0 & 0 & 2 \\
WNW & 0 & 0 & 0 & 0 & 0 & 0 & 2 \\
W & 0 & 0 & 0 & 0 & 0 & 0 & 2 \\
WSW & 0 & 0 & 0 & 0 & 0 & 0 & 2 \\
SW & 0 & 0 & 0 & 0 & 0 & 0 & 2 \\
SSW & 0 & 0 & 0 & 0 & 0 & 0 & 2 \\
S & 0 & 0 & 0 & 0 & 0 & 0 & 2 \\
SSE & 0 & 0 & 0 & 0 & 0 & 0 & 2 \\
SE & 0 & 0 & 0 & 0 & 0 & 0 & 2 \\
ESE & 0 & 0 & 0 & 0 & 0 & 0 & 2 \\
E & 0 & 0 & 0 & 0 & 0 & 0 & 2 \\
ENE & 0 & 0 & 0 & 0 & 0 & 0 & 2 \\
NE & 0 & 0 & 0 & 0 & 0 & 0 & 2 \\
NNE & 0 & 0 & 0 & 0 & 0 & 0 & 2 \\
& & 0 & & 0 & & & \\
\hline
\end{tabular}

Distance (meters)

\begin{tabular}{rrrrrrl} 
Direction & 15000 & 25000 & 35000 & 45000 & 55000 & 70000 \\
\cline { 2 - 7 } N & 7 & 11 & 16 & 20 & 25 & 63 \\
NNW & 7 & 11 & 16 & 20 & 25 & 63 \\
NW & 7 & 11 & 16 & 20 & 25 & 63 \\
WNW & 7 & 11 & 16 & 20 & 25 & 63 \\
W & 7 & 11 & 16 & 20 & 25 & 63 \\
WSW & 7 & 11 & 16 & 20 & 25 & 63 \\
SW & 7 & 11 & 16 & 20 & 25 & 63 \\
SSW & 7 & 11 & 16 & 20 & 25 & 63 \\
S & 7 & 11 & 16 & 20 & 25 & 63 \\
SSE & 7 & 11 & 16 & 20 & 25 & 63 \\
SE & 7 & 11 & 16 & 20 & 25 & 63 \\
ESE & 7 & 11 & 16 & 20 & 25 & 63 \\
E & 7 & 11 & 16 & 20 & 25 & 63 \\
ENE & 7 & 11 & 16 & 20 & 25 & 63 \\
NE & 7 & 11 & 16 & 20 & 25 & 63 \\
NNE & 7 & 11 & 16 & 20 & 25 & 63
\end{tabular}


Waste Isolation Pilot Plant Biennial Environmental Compliance Report DOE/WIPP 99-2171 
Waste Isolation Pilot Plant Biennial Environmental Compliance Report DOE/WIPP 99-2171

Apr 24, $2000 \quad 12: 45$ pm

GENERAL

Page 6

AREA OF VEGETABLE CROP PRODUCTION $\left(\mathrm{M}^{* *} 2\right)$

\begin{tabular}{rccccccc}
\hline & \multicolumn{7}{c}{ Distance (meters) } \\
\cline { 2 - 7 } Direction & 250 & 750 & 1500 & 2500 & 3500 & 4500 & 7500 \\
\hline$N$ & $0.0 \mathrm{E}+00$ & $2.0 \mathrm{E}+02$ & $8.1 \mathrm{E}+02$ & $1.4 \mathrm{E}+03$ & $1.9 \mathrm{E}+03$ & $2.4 \mathrm{E}+03$ & $2.0 \mathrm{E}+04$ \\
NNW & $0.0 \mathrm{E}+00$ & $2.0 \mathrm{E}+02$ & $8.1 \mathrm{E}+02$ & $1.4 \mathrm{E}+03$ & $1.9 \mathrm{E}+03$ & $2.4 \mathrm{E}+03$ & $2.0 \mathrm{E}+04$ \\
NW & $0.0 \mathrm{E}+00$ & $2.0 \mathrm{E}+02$ & $8.1 \mathrm{E}+02$ & $1.4 \mathrm{E}+03$ & $1.9 \mathrm{E}+03$ & $2.4 \mathrm{E}+03$ & $2.0 \mathrm{E}+04$ \\
WNW & $0.0 \mathrm{E}+00$ & $2.0 \mathrm{E}+02$ & $8.1 \mathrm{E}+02$ & $1.4 \mathrm{E}+03$ & $1.9 \mathrm{E}+03$ & $2.4 \mathrm{E}+03$ & $2.0 \mathrm{E}+04$ \\
W & $0.0 \mathrm{E}+00$ & $2.0 \mathrm{E}+02$ & $8.1 \mathrm{E}+02$ & $1.4 \mathrm{E}+03$ & $1.9 \mathrm{E}+03$ & $2.4 \mathrm{E}+03$ & $2.0 \mathrm{E}+04$ \\
WSW & $0.0 \mathrm{E}+00$ & $2.0 \mathrm{E}+02$ & $8.1 \mathrm{E}+02$ & $1.4 \mathrm{E}+03$ & $1.9 \mathrm{E}+03$ & $2.4 \mathrm{E}+03$ & $2.0 \mathrm{E}+04$ \\
SW & $0.0 \mathrm{E}+00$ & $2.0 \mathrm{E}+02$ & $8.1 \mathrm{E}+02$ & $1.4 \mathrm{E}+03$ & $1.9 \mathrm{E}+03$ & $2.4 \mathrm{E}+03$ & $2.0 \mathrm{E}+04$ \\
SSW & $0.0 \mathrm{E}+00$ & $2.0 \mathrm{E}+02$ & $8.1 \mathrm{E}+02$ & $1.4 \mathrm{E}+03$ & $1.9 \mathrm{E}+03$ & $2.4 \mathrm{E}+03$ & $2.0 \mathrm{E}+04$ \\
S & $0.0 \mathrm{E}+00$ & $2.0 \mathrm{E}+02$ & $8.1 \mathrm{E}+02$ & $1.4 \mathrm{E}+03$ & $1.9 \mathrm{E}+03$ & $2.4 \mathrm{E}+03$ & $2.0 \mathrm{E}+04$ \\
SSE & $0.0 \mathrm{E}+00$ & $2.0 \mathrm{E}+02$ & $8.1 \mathrm{E}+02$ & $1.4 \mathrm{E}+03$ & $1.9 \mathrm{E}+03$ & $2.4 \mathrm{E}+03$ & $2.0 \mathrm{E}+04$ \\
SE & $0.0 \mathrm{E}+00$ & $2.0 \mathrm{E}+02$ & $8.1 \mathrm{E}+02$ & $1.4 \mathrm{E}+03$ & $1.9 \mathrm{E}+03$ & $2.4 \mathrm{E}+03$ & $2.0 \mathrm{E}+04$ \\
ESE & $0.0 \mathrm{E}+00$ & $2.0 \mathrm{E}+02$ & $8.1 \mathrm{E}+02$ & $1.4 \mathrm{E}+03$ & $1.9 \mathrm{E}+03$ & $2.4 \mathrm{E}+03$ & $2.0 \mathrm{E}+04$ \\
$\mathrm{E}$ & $0.0 \mathrm{E}+00$ & $2.0 \mathrm{E}+02$ & $8.1 \mathrm{E}+02$ & $1.4 \mathrm{E}+03$ & $1.9 \mathrm{E}+03$ & $2.4 \mathrm{E}+03$ & $2.0 \mathrm{E}+04$ \\
ENE & $0.0 \mathrm{E}+00$ & $2.0 \mathrm{E}+02$ & $8.1 \mathrm{E}+02$ & $1.4 \mathrm{E}+03$ & $1.9 \mathrm{E}+03$ & $2.4 \mathrm{E}+03$ & $2.0 \mathrm{E}+04$ \\
NE & $0.0 \mathrm{E}+00$ & $2.0 \mathrm{E}+02$ & $8.1 \mathrm{E}+02$ & $1.4 \mathrm{E}+03$ & $1.9 \mathrm{E}+03$ & $2.4 \mathrm{E}+03$ & $2.0 \mathrm{E}+04$ \\
NNE & $0.0 \mathrm{E}+00$ & $2.0 \mathrm{E}+02$ & $8.1 \mathrm{E}+02$ & $1.4 \mathrm{E}+03$ & $1.9 \mathrm{E}+03$ & $2.4 \mathrm{E}+03$ & $2.0 \mathrm{E}+04$ \\
& & & & & & & \\
\hline
\end{tabular}

Distance (meters)

\begin{tabular}{rcccccc} 
Direction & 15000 & 25000 & 35000 & 45000 & 55000 & 70000 \\
\cline { 2 - 7 }$N$ & & & & & & \\
$N$ & $8.1 \mathrm{E}+04$ & $1.4 \mathrm{E}+05$ & $1.9 \mathrm{E}+05$ & $2.4 \mathrm{E}+05$ & $3.0 \mathrm{E}+05$ & $7.6 \mathrm{E}+05$ \\
NNW & $8.1 \mathrm{E}+04$ & $1.4 \mathrm{E}+05$ & $1.9 \mathrm{E}+05$ & $2.4 \mathrm{E}+05$ & $3.0 \mathrm{E}+05$ & $7.6 \mathrm{E}+05$ \\
$N W$ & $8.1 \mathrm{E}+04$ & $1.4 \mathrm{E}+05$ & $1.9 \mathrm{E}+05$ & $2.4 \mathrm{E}+05$ & $3.0 \mathrm{E}+05$ & $7.6 \mathrm{E}+05$ \\
WNW & $8.1 \mathrm{E}+04$ & $1.4 \mathrm{E}+05$ & $1.9 \mathrm{E}+05$ & $2.4 \mathrm{E}+05$ & $3.0 \mathrm{E}+05$ & $7.6 \mathrm{E}+05$ \\
W & $8.1 \mathrm{E}+04$ & $1.4 \mathrm{E}+05$ & $1.9 \mathrm{E}+05$ & $2.4 \mathrm{E}+05$ & $3.0 \mathrm{E}+05$ & $7.6 \mathrm{E}+05$ \\
WSW & $8.1 \mathrm{E}+04$ & $1.4 \mathrm{E}+05$ & $1.9 \mathrm{E}+05$ & $2.4 \mathrm{E}+05$ & $3.0 \mathrm{E}+05$ & $7.6 \mathrm{E}+05$ \\
SW & $8.1 \mathrm{E}+04$ & $1.4 \mathrm{E}+05$ & $1.9 \mathrm{E}+05$ & $2.4 \mathrm{E}+05$ & $3.0 \mathrm{E}+05$ & $7.6 \mathrm{E}+05$ \\
SSW & $8.1 \mathrm{E}+04$ & $1.4 \mathrm{E}+05$ & $1.9 \mathrm{E}+05$ & $2.4 \mathrm{E}+05$ & $3.0 \mathrm{E}+05$ & $7.6 \mathrm{E}+05$ \\
S & $8.1 \mathrm{E}+04$ & $1.4 \mathrm{E}+05$ & $1.9 \mathrm{E}+05$ & $2.4 \mathrm{E}+05$ & $3.0 \mathrm{E}+05$ & $7.6 \mathrm{E}+05$ \\
SSE & $8.1 \mathrm{E}+04$ & $1.4 \mathrm{E}+05$ & $1.9 \mathrm{E}+05$ & $2.4 \mathrm{E}+05$ & $3.0 \mathrm{E}+05$ & $7.6 \mathrm{E}+05$ \\
SE & $8.1 \mathrm{E}+04$ & $1.4 \mathrm{E}+05$ & $1.9 \mathrm{E}+05$ & $2.4 \mathrm{E}+05$ & $3.0 \mathrm{E}+05$ & $7.6 \mathrm{E}+05$ \\
$\mathrm{ESE}$ & $8.1 \mathrm{E}+04$ & $1.4 \mathrm{E}+05$ & $1.9 \mathrm{E}+05$ & $2.4 \mathrm{E}+05$ & $3.0 \mathrm{E}+05$ & $7.6 \mathrm{E}+05$ \\
$\mathrm{E}$ & $8.1 \mathrm{E}+04$ & $1.4 \mathrm{E}+05$ & $1.9 \mathrm{E}+05$ & $2.4 \mathrm{E}+05$ & $3.0 \mathrm{E}+05$ & $7.6 \mathrm{E}+05$ \\
ENE & $8.1 \mathrm{E}+04$ & $1.4 \mathrm{E}+05$ & $1.9 \mathrm{E}+05$ & $2.4 \mathrm{E}+05$ & $3.0 \mathrm{E}+05$ & $7.6 \mathrm{E}+05$ \\
NE & $8.1 \mathrm{E}+04$ & $1.4 \mathrm{E}+05$ & $1.9 \mathrm{E}+05$ & $2.4 \mathrm{E}+05$ & $3.0 \mathrm{E}+05$ & $7.6 \mathrm{E}+05$
\end{tabular}



NNE
$8.1 \mathrm{E}+04$
$1.4 \mathrm{E}+05$
$1.9 \mathrm{E}+05$
$2.4 \mathrm{E}+05$
$3.0 \mathrm{E}+05$
$7.6 \mathrm{E}+05$

Apr 24, $2000 \quad$ 12:45 pm

GENERAL

Page 7

\section{VALUES FOR RADIONUCLIDE-INDEPENDENT PARAMETERS}

HUMAN INHALATION RATE

Cubic centimeters/hr

9.17E+05

SOIL PARAMETERS

Effective surface density ( $\mathrm{kg} / \mathrm{sq} \mathrm{m}$, dry weight)

(Assumes $15 \mathrm{~cm}$ plow layer)

2.15E+02

BUILDUP TIMES

For activity in soil (years)

For radionuclides deposited on ground/water (days)

$1.00 \mathrm{E}+02$

$3.65 \mathrm{E}+04$

DELAY TIMES

Ingestion of pasture grass by animals (hr)

Ingestion of stored feed by animals (hr)

$0.00 \mathrm{E}+00$

Ingestion of leafy vegetables by man (hr)

$2.16 \mathrm{E}+03$

Ingestion of produce by man (hr)

$3.36 \mathrm{E}+02$

Transport time from animal feed-milk-man (day)

$3.36 \mathrm{E}+02$

Time from slaughter to consumption (day)

$2.00 \mathrm{E}+00$

$2.00 \mathrm{E}+01$

WEATHERING

Removal rate constant for physical loss (per hr)

2.90E-03

CROP EXPOSURE DURATION

Pasture grass (hr)

Crops/leafy vegetables (hr)

$7.20 \mathrm{E}+02$

$1.44 \mathrm{E}+03$

AGRICULTURAL PRODUCTIVITY

Grass-cow-milk-man pathway (kg/sq m)

Produce/leafy vegetables for human consumption ( $\mathrm{kg} / \mathrm{sq} \mathrm{m}$ )

2.80E-01

7.16E-01

FALLOUT INTERCEPTION FRACTIONS

Vegetables

2.00E-01

Pasture

$5.70 \mathrm{E}-01$

GRAZING PARAMETERS

Fraction of year animals graze on pasture

4.00E-01 
Waste Isolation Pilot Plant Biennial Environmental Compliance Report DOE/WIPP 99-2171

Fraction of daily feed that is pasture grass

when animal grazes on pasture

4.30E-01 
VALUES FOR RADIONUCLIDE-INDEPENDENT PARAMETERS

ANIMAL FEED CONSUMPTION FACTORS

Contaminated feed/forage ( $\mathrm{kg} /$ day, dry weight)

$1.56 \mathrm{E}+01$

DAIRY PRODUCTIVITY

Milk production of cow (L/day)

$1.10 \mathrm{E}+01$

MEAT ANIMAL SLAUGHTER PARAMETERS

Muscle mass of animal at slaughter $(\mathrm{kg})$

$2.00 \mathrm{E}+02$

Fraction of herd slaughtered (per day)

DECONTAMINATION

Fraction of radioactivity retained after washing

for leafy vegetables and produce

5.00E-01

FRACTIONS GROWN IN GARDEN OF INTEREST

Produce ingested

Leafy vegetables ingested

$1.00 \mathrm{E}+00$

$1.00 \mathrm{E}+00$

INGESTION RATIOS:

IMMEDIATE SURROUNDING AREA/TOTAL WITHIN AREA

Vegetables

Meat

$1.00 \mathrm{E}+00$

Milk

$1.00 \mathrm{E}+00$

$1.00 \mathrm{E}+00$

MINIMUM INGESTION FRACTIONS FROM OUTSIDE AREA

(Actual fractions of food types from outside area can

be greater than the minimum fractions listed below.)

Vegetables

$0.00 \mathrm{E}+00$

Meat

$0.00 \mathrm{E}+00$

Milk

$0.00 \mathrm{E}+00$

HUMAN FOOD UTILIZATION FACTORS

Produce ingestion $(\mathrm{kg} / \mathrm{y})$

Milk ingestion (L/y)

Meat ingestion $(\mathrm{kg} / \mathrm{y})$

Leafy vegetable ingestion $(\mathrm{kg} / \mathrm{y})$

$1.76 \mathrm{E}+02$

$1.12 \mathrm{E}+02$

$8.50 \mathrm{E}+01$

$1.80 \mathrm{E}+01$

SWIMMING PARAMETERS

Fraction of time spent swimming

$0.00 \mathrm{E}+00$

Dilution factor for water $(\mathrm{cm})$

$1.00 \mathrm{E}+00$ 
Waste Isolation Pilot Plant Biennial Environmental Compliance Report DOE/WIPP 99-2171 


\author{
C A P 88 - P C \\ Version 2.00 \\ Clean Air Act Assessment Package - 1988 \\ WEATHER DATA \\ Non-Radon Population Assessment \\ Apr 24, 2000 12:45 pm
}

\author{
Facility: Waste Isolation Pilot Project \\ Address: 26 Miles SE of Carlsbad, NM \\ City: Carlsbad \\ State: NM Zip: 88221 \\ Source Category: exempt DOE facility \\ Source Type: Stack \\ Emission Year: 1999 \\ Comments: Run for 1999 \\ Dataset Name: 1999run \\ Date: $\quad$ Apr 24, 2000 12:44 pm \\ Wind File: C:ICAP88PC2IWNDFILES|96-99.WND \\ Population File: C:ICAP88PC2\POPFILESIWIPP99.POP
}


Waste Isolation Pilot Plant Biennial Environmental Compliance Report DOE/WIPP 99-2171

Apr 24, $2000 \quad$ 12:45 pm

WEATHER

Page 1

HARMONIC AVERAGE WIND SPEEDS (WIND TOWARDS)

\begin{tabular}{rcccccccc}
\hline \multicolumn{7}{c}{ Pasquill Stability Class } \\
\hline Dir & A & B & C & D & E & F & G & $\begin{array}{c}\text { Wind } \\
\text { Freq }\end{array}$ \\
\hline & & & & & & & & \\
N & 4.316 & 3.287 & 2.956 & 2.406 & 1.861 & 1.673 & 0.000 & 0.065 \\
NNW & 4.678 & 3.731 & 3.211 & 3.161 & 3.516 & 2.173 & 0.000 & 0.102 \\
NW & 4.702 & 3.763 & 3.472 & 3.928 & 4.246 & 2.813 & 0.000 & 0.162 \\
WNW & 4.365 & 3.707 & 3.448 & 3.428 & 3.790 & 3.166 & 0.000 & 0.142 \\
W & 4.490 & 3.680 & 3.132 & 3.718 & 3.432 & 2.539 & 0.000 & 0.074 \\
WSW & 4.374 & 3.449 & 3.466 & 3.733 & 3.465 & 2.200 & 0.000 & 0.045 \\
SW & 4.627 & 3.720 & 3.078 & 3.497 & 2.609 & 2.087 & 0.000 & 0.041 \\
SSW & 4.721 & 3.339 & 3.187 & 3.470 & 2.482 & 2.080 & 0.000 & 0.042 \\
S & 4.775 & 3.691 & 3.381 & 3.197 & 2.867 & 2.115 & 0.000 & 0.041 \\
SSE & 4.836 & 3.418 & 2.886 & 2.686 & 2.027 & 2.093 & 0.000 & 0.036 \\
SE & 4.289 & 3.306 & 2.614 & 2.097 & 2.529 & 1.709 & 0.000 & 0.033 \\
ESE & 4.031 & 2.793 & 2.376 & 1.864 & 2.207 & 1.737 & 0.000 & 0.033 \\
E & 5.485 & 3.338 & 2.777 & 2.521 & 3.483 & 2.097 & 0.000 & 0.054 \\
ENE & 4.690 & 2.966 & 2.700 & 2.247 & 2.937 & 2.120 & 0.000 & 0.048 \\
NE & 4.160 & 2.780 & 2.366 & 1.762 & 2.116 & 1.696 & 0.000 & 0.037 \\
NNE & 4.062 & 2.997 & 2.541 & 2.030 & 2.072 & 1.548 & 0.000 & 0.045 \\
& & & & & & & & \\
\hline
\end{tabular}

ARITHMETIC AVERAGE WIND SPEEDS (WIND TOWARDS)

\begin{tabular}{rccccccc}
\hline & \multicolumn{7}{c}{ Pasquill Stability Class } \\
\hline Dir & A & B & C & D & E & F & G \\
\hline & & & & & & & \\
N & 4.838 & 3.860 & 3.710 & 3.611 & 2.996 & 2.433 & 0.000 \\
NNW & 5.292 & 4.449 & 4.129 & 4.709 & 4.858 & 2.998 & 0.000 \\
NW & 5.366 & 4.460 & 4.444 & 5.514 & 5.410 & 3.574 & 0.000 \\
WNW & 4.915 & 4.409 & 4.249 & 4.871 & 5.008 & 3.921 & 0.000 \\
W & 5.255 & 4.337 & 4.276 & 5.534 & 5.176 & 3.740 & 0.000 \\
WSW & 5.230 & 4.496 & 4.532 & 5.878 & 5.119 & 3.221 & 0.000 \\
SW & 5.636 & 4.642 & 4.515 & 5.550 & 4.448 & 2.944 & 0.000 \\
SSW & 5.536 & 4.247 & 4.289 & 5.238 & 3.817 & 3.016 & 0.000 \\
S & 5.613 & 4.430 & 4.567 & 4.749 & 4.265 & 3.161 & 0.000 \\
SSE & 5.885 & 4.300 & 3.667 & 4.485 & 3.532 & 3.270 & 0.000 \\
SE & 4.968 & 3.927 & 3.526 & 3.644 & 4.203 & 2.832 & 0.000 \\
ESE & 4.831 & 3.371 & 3.247 & 3.745 & 3.902 & 2.869 & 0.000 \\
E & 7.011 & 5.066 & 4.827 & 5.533 & 5.517 & 3.479 & 0.000 \\
ENE & 5.812 & 4.244 & 4.082 & 4.305 & 4.550 & 3.319 & 0.000 \\
NE & 5.173 & 3.558 & 3.285 & 3.231 & 3.477 & 2.651 & 0.000 \\
NNE & 4.695 & 3.535 & 3.223 & 3.279 & 3.312 & 2.329 & 0.000
\end{tabular}


Waste Isolation Pilot Plant Biennial Environmental Compliance Report DOE/WIPP 99-2171 
Apr 24, $2000 \quad 12: 45$ pm

WEATHER

Page 2

FREQUENCIES OF STABILITY CLASSES (WIND TOWARDS)

Pasquill Stability Class

\begin{tabular}{rccccccc}
\hline Dir & $\mathrm{A}$ & $\mathrm{B}$ & $\mathrm{C}$ & $\mathrm{D}$ & $\mathrm{E}$ & $\mathrm{F}$ & $\mathrm{G}$ \\
\hline & & & & & & & \\
N & 0.4054 & 0.0755 & 0.0587 & 0.1246 & 0.1117 & 0.2241 & 0.0000 \\
NNW & 0.2905 & 0.0542 & 0.0464 & 0.1514 & 0.2004 & 0.2571 & 0.0000 \\
NW & 0.1586 & 0.0329 & 0.0305 & 0.1327 & 0.2805 & 0.3648 & 0.0000 \\
WNW & 0.0923 & 0.0241 & 0.0247 & 0.1107 & 0.2048 & 0.5434 & 0.0000 \\
W & 0.1172 & 0.0356 & 0.0355 & 0.1908 & 0.2368 & 0.3841 & 0.0000 \\
WSW & 0.1232 & 0.0350 & 0.0449 & 0.2430 & 0.2060 & 0.3480 & 0.0000 \\
SW & 0.1321 & 0.0361 & 0.0421 & 0.2354 & 0.1389 & 0.4154 & 0.0000 \\
SSW & 0.1417 & 0.0428 & 0.0490 & 0.2459 & 0.1306 & 0.3900 & 0.0000 \\
S & 0.1824 & 0.0547 & 0.0535 & 0.2204 & 0.1910 & 0.2980 & 0.0000 \\
SSE & 0.2230 & 0.0678 & 0.0568 & 0.2221 & 0.1631 & 0.2672 & 0.0000 \\
SE & 0.2240 & 0.0923 & 0.0930 & 0.2069 & 0.1481 & 0.2356 & 0.0000 \\
ESE & 0.2814 & 0.0879 & 0.0784 & 0.1877 & 0.1323 & 0.2324 & 0.0000 \\
E & 0.3832 & 0.0690 & 0.0683 & 0.1695 & 0.1526 & 0.1574 & 0.0000 \\
ENE & 0.4052 & 0.0835 & 0.0743 & 0.1602 & 0.1175 & 0.1593 & 0.0000 \\
NE & 0.4123 & 0.0933 & 0.0799 & 0.1439 & 0.1045 & 0.1660 & 0.0000 \\
NNE & 0.4284 & 0.0968 & 0.0704 & 0.1217 & 0.0919 & 0.1909 & 0.0000 \\
TOTAL & 0.2272 & 0.0528 & 0.0487 & 0.1635 & 0.1851 & 0.3228 & 0.0000 \\
& & & & & & & \\
\hline
\end{tabular}

\section{ADDITIONAL WEATHER INFORMATION}

Average Air Temperature: $\quad 17.0$ degrees C

Precipitation: $\quad 33.0 \mathrm{~cm} / \mathrm{y}$

Lid Height: 1000 meters

Surface Roughness Length: 0.010 meters

Height of Wind Measurements: 10.0 meters

Average Wind Speed: $\quad 4.411 \mathrm{~m} / \mathrm{s}$

Vertical Temperature Gradients:

STABILITY E $\quad 0.073 \mathrm{k} / \mathrm{m}$

STABILITY F $\quad 0.109 \mathrm{k} / \mathrm{m}$

STABILITY G $\quad 0.146 \mathrm{k} / \mathrm{m}$ 
Waste Isolation Pilot Plant Biennial Environmental Compliance Report DOE/WIPP 99-2171 


\author{
C A P $88-P$ C \\ Version 2.00 \\ Clean Air Act Assessment Package - 1988 \\ DOSE AND RISK CONVERSION FACTORS \\ Non-Radon Population Assessment \\ Apr 24, 2000 12:45 pm
}

Facility: Waste Isolation Pilot Project

Address: 26 Miles SE of Carlsbad, NM

City: Carlsbad

State: NM Zip: 88221

Source Category: exempt DOE facility

Source Type: Stack

Emission Year: 1999

Comments: Run for 1999

Dataset Name: 1999run

Dataset Date: Apr 24, 2000 12:44 pm

Wind File: C:ICAP88PC2IWNDFILESI96-99.WND

Population File: C:ICAP88PC2\POPFILESIWIPP99.POP 


\section{Waste Isolation Pilot Plant Biennial Environmental Compliance Report

Apr 24, $2000 \quad 12: 45$ pm

FACTOR

Page 1

\section{DOSE AND RISK FACTOR UNITS}

The units for each type of dose rate conversion factor are shown below, by pathway:

Pathway $\quad \underline{\text { Units }}$

Ingestion millirem/picoCurie

Inhalation millirem/picoCurie

Immersion millirem-cubic $\mathrm{cm} /$ microCurie-year

Surface millirem-square $\mathrm{cm} /$ microCurie-year

Risks for internal exposures (inhalation and ingestion) are the lifetime risk of premature death in a birth cohort of 100,000 people for a 1 picoCurie/year intake rate, where the average lifetime is 70.7565 years.

This is simplified to lifetime risk per 100,000 picoCuries.

The units for each type of risk conversion factor are shown below, by pathway:

Pathway $\quad \underline{\text { Units }}$

Ingestion lifetime risk/100,000 picoCuries

Inhalation lifetime risk/100,000 picoCuries

Immersion lifetime risk-cubic $\mathrm{cm} / 100,000$ picoCurie-years

Surface lifetime risk-square $\mathrm{cm} / 100,000$ picoCurie-years 


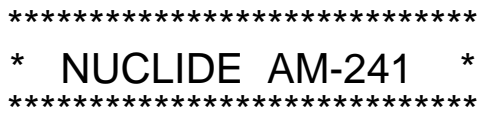

DOSE RATE CONVERSION FACTORS

\begin{tabular}{|c|c|c|c|c|}
\hline Organ & Ingestion & Inhalation & Air Immersion & Ground Surfac \\
\hline GONADS & $1.001 \mathrm{E}-03$ & $1.212 \mathrm{E}-01$ & $1.151 \mathrm{E}+08$ & $3.541 E+04$ \\
\hline BREAST & $9.709 \mathrm{E}-05$ & 1.176E-02 & $1.469 \mathrm{E}+08$ & $5.550 \mathrm{E}+04$ \\
\hline R MAR & 6.327E-03 & $7.663 \mathrm{E}-01$ & $3.737 \bar{E}+07$ & $1.077 \bar{E}+04$ \\
\hline LUNGS & $9.714 \mathrm{E}-05$ & 8.047E-02 & $6.919 \bar{E}+07$ & $2.009 \mathrm{E}+0$ \\
\hline THYROID & $9.703 \mathrm{E}-05$ & $1.175 \mathrm{E}-02$ & $1.099 \mathrm{E}+08$ & $3.175 \bar{E}+04$ \\
\hline ENDOST & $7.801 \mathrm{E}-02$ & $9.447 \mathrm{E}+00$ & $1.273 \mathrm{E}+08$ & $3.693 \mathrm{E}+04$ \\
\hline RMNDR & $3.508 \mathrm{E}-03$ & 4.176E-01 & $6.778 \mathrm{E}+07$ & $1.937 \mathrm{E}+04$ \\
\hline EFFEC & $4.430 \mathrm{E}-0$ & $5.428 \mathrm{E}-01$ & $9.104 \mathrm{E}+07$ & $2.875 \mathrm{E}+0$ \\
\hline
\end{tabular}

GENETIC EFFECT DOSE RATE CONVERSION FACTORS

$\begin{array}{lllll}\text { TESTES } & 9.208 \mathrm{E}-03 & 1.110 \mathrm{E}+00 & 3.452 \mathrm{E}+09 & 1.062 \mathrm{E}+06 \\ \text { OVARIES } & 9.232 \mathrm{E}-03 & 1.112 \mathrm{E}+00 & 1.521 \mathrm{E}+09 & 4.384 \mathrm{E}+05 \\ \text { AVERAGE } & 9.221 \mathrm{E}-03 & 1.111 \mathrm{E}+00 & 2.486 \mathrm{E}+09 & 7.504 \mathrm{E}+05\end{array}$

\section{RISK CONVERSION FACTORS}

\begin{tabular}{|c|c|c|c|c|}
\hline Cancer & Ingestion & Inhalation & Air Immersion & Ground Surface \\
\hline LEUKEMIA & 5.337E-04 & 6.457E-02 & $1.184 \mathrm{E}+01$ & $3.410 \mathrm{E}-03$ \\
\hline BONE & $3.433 \mathrm{E}-04$ & $4.152 \mathrm{E}-02$ & $2.253 \mathrm{E}+00$ & $6.535 \mathrm{E}-04$ \\
\hline THYROID & $1.062 \mathrm{E}-06$ & $1.283 \mathrm{E}-04$ & $4.998 \mathrm{E}+00$ & $1.444 \mathrm{E}-03$ \\
\hline BREAST & 7.158E-06 & 8.639E-04 & $5.751 \mathrm{E}+01$ & $2.174 \mathrm{E}-02$ \\
\hline LUNG & $9.643 \mathrm{E}-06$ & $2.284 \mathrm{E}-02$ & $3.429 \mathrm{E}+01$ & $9.960 \mathrm{E}-03$ \\
\hline STOMACH & 6.586E-06 & 7.140E-04 & $1.852 \mathrm{E}+01$ & 5.317E-03 \\
\hline BOWEL & $1.094 \mathrm{E}-05$ & $3.603 \mathrm{E}-04$ & $8.526 \mathrm{E}+00$ & $2.445 \mathrm{E}-03$ \\
\hline LIVER & $1.198 \mathrm{E}-03$ & $1.448 \mathrm{E}-01$ & $2.179 \mathrm{E}+01$ & $6.239 \mathrm{E}-03$ \\
\hline PANCREAS & $4.480 \mathrm{E}-06$ & $5.408 \mathrm{E}-04$ & $9.503 \mathrm{E}+00$ & $2.760 \mathrm{E}-03$ \\
\hline URINARY & $2.298 \mathrm{E}-\mathrm{C}$ & $2.773 \mathrm{E}-04$ & $8.681 \mathrm{E}+00$ & $2.479 \mathrm{E}-03$ \\
\hline OTHER & $5.479 \mathrm{E}-0$ & $6.614 \mathrm{E}-04$ & $1.162 \mathrm{E}+01$ & 3.376E-03 \\
\hline
\end{tabular}


Waste Isolation Pilot Plant Biennial Environmental Compliance Report DOE/WIPP 99-2171

AVERAGE

3.197E-10

3.843E-08

$6.464 \mathrm{E}+02$

$1.951 \mathrm{E}-01$ 


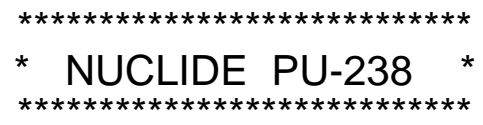

DOSE RATE CONVERSION FACTORS

\begin{tabular}{|c|c|c|c|c|}
\hline Organ & Ingestion & Inhalation & Air Immersion & Ground Surfac \\
\hline $\begin{array}{l}\text { GONADS } \\
\text { BREAST } \\
\text { R MAR } \\
\text { LUNGS } \\
\text { THYROID } \\
\text { ENDOST } \\
\text { RMNDR } \\
\text { EFFEC }\end{array}$ & $\begin{array}{l}\text { 8.603E-04 } \\
8.419 E-05 \\
5.485 E-03 \\
8.419 E-05 \\
8.419 E-05 \\
6.763 E-02 \\
3.085 E-03 \\
3.853 E-03\end{array}$ & $\begin{array}{l}1.041 \mathrm{E}-01 \\
1.020 \mathrm{E}-02 \\
6.641 \mathrm{E}-01 \\
7.893 \mathrm{E}-02 \\
1.020 \mathrm{E}-02 \\
8.189 \mathrm{E}+00 \\
3.666 \mathrm{E}-01 \\
4.726 \mathrm{E}-01\end{array}$ & $\begin{array}{l}4.218 E+05 \\
1.806 E+06 \\
5.291 E+04 \\
1.177 E+05 \\
1.709 E+05 \\
2.090 E+05 \\
8.732 E+04 \\
4.344 E+05\end{array}$ & $\begin{array}{l}7.548 E+02 \\
4.070 E+03 \\
4.514 E+01 \\
1.225 E+02 \\
1.510 E+02 \\
2.050 E+02 \\
7.659 E+01 \\
8.530 E+02\end{array}$ \\
\hline
\end{tabular}

GENETIC EFFECT DOSE RATE CONVERSION FACTORS

$\begin{array}{lllll}\text { TESTES } & 8.657 \mathrm{E}-03 & 1.043 \mathrm{E}+00 & 1.265 \mathrm{E}+07 & 2.264 \mathrm{E}+04 \\ \text { OVARIES } & 8.673 \mathrm{E}-03 & 1.045 \mathrm{E}+00 & 2.331 \mathrm{E}+06 & 2.087 \mathrm{E}+03 \\ \text { AVERAGE } & 8.665 \mathrm{E}-03 & 1.044 \mathrm{E}+00 & 7.492 \mathrm{E}+06 & 1.237 \mathrm{E}+04\end{array}$

\section{RISK CONVERSION FACTORS}

\begin{tabular}{|c|c|c|c|c|}
\hline$\underline{\text { Cancer }}$ & Ingestion & $\underline{\text { Inhalation }}$ & Air Immersion & Ground Surface \\
\hline LEUKEMIA & 4.695E-04 & 5.676E-02 & 1.676E-02 & 1.430E-05 \\
\hline BONE & 3.046E-04 & $3.681 \mathrm{E}-02$ & $3.700 \mathrm{E}-03$ & 3.628E-06 \\
\hline THYROID & $9.438 \mathrm{E}-07$ & $1.140 \mathrm{E}-04$ & 7.775E-03 & $6.866 \mathrm{E}-06$ \\
\hline BREAST & 6.493E-06 & 7.839E-04 & 7.072E-01 & 1.594E-03 \\
\hline LUNG & 8.684E-06 & 2.272E-02 & 5.833E-02 & 6.072E-05 \\
\hline STOMACH & 5.991E-06 & 6.480E-04 & 2.550E-02 & 1.840E-05 \\
\hline BOWEL & 1.016E-05 & 3.272E-04 & 1.083E-02 & $6.451 \mathrm{E}-06$ \\
\hline LIVER & 1.099E-03 & 1.327E-01 & 2.503E-02 & 9.235E-06 \\
\hline PANCREAS & 4.054E-06 & 4.895E-04 & 1.656E-02 & 1.864E-05 \\
\hline URINARY & 2.080E-06 & $2.511 \mathrm{E}-04$ & 1.007E-02 & 3.352E-06 \\
\hline OTHER & 4.959E-06 & 5.987E-04 & 2.026E-02 & 2.280E-05 \\
\hline
\end{tabular}

GENETIC EFFECT RISK CONVERSION FACTORS
AVERAGE
2.992E-10
3.604E-08
$1.948 \mathrm{E}+00$
3.216E-03 
Waste Isolation Pilot Plant Biennial Environmental Compliance Report DOE/WIPP 99-2171 


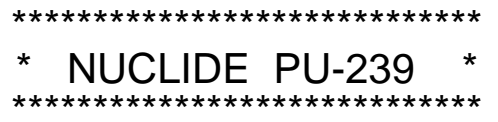

DOSE RATE CONVERSION FACTORS

\begin{tabular}{|c|c|c|c|c|}
\hline Organ & Ingestion & Inhalation & Air Immersion & Ground Surfac \\
\hline DNADS & $9.741 \mathrm{E}-04$ & $1.180 \mathrm{E}-01$ & $4.329 \mathrm{E}+05$ & $3.463 E+C$ \\
\hline REAST & $9.453 \mathrm{E}-05$ & $1.145 \mathrm{E}-02$ & $9.990 \mathrm{E}+05$ & $1.617 \mathrm{E}+0$ \\
\hline R MAR & $6.166 \mathrm{E}-03$ & 7.471E-01 & $1.950 \mathrm{E}+05$ & $5.587 E+0$ \\
\hline LUNGS & $9.453 \mathrm{E}-1$ & 7.609E-02 & $2.420 \mathrm{E}+05$ & $8.954 \mathrm{E}+01$ \\
\hline THYROID & $9.453 \mathrm{E}-05$ & 1.145E-02 & $3.385 E+05$ & $1.165 \mathrm{E}+0$ \\
\hline ENDOST & 7.593E-02 & $9.199 \mathrm{E}+00$ & $3.996 \mathrm{E}+05$ & $1.473 \mathrm{E}+0$ \\
\hline RMNDR & 3.399E-( & 4.054E-01 & $2.250 \mathrm{E}+05$ & $6.734 \mathrm{E}+0$ \\
\hline & $4.310 \mathrm{E}$ & $5.278 \mathrm{E}$ & $4.002 \mathrm{E}+05$ & $3.747 \bar{E}+0$ \\
\hline
\end{tabular}

GENETIC EFFECT DOSE RATE CONVERSION FACTORS

$\begin{array}{lllll}\text { TESTES } & 8.801 \mathrm{E}-03 & 1.061 \mathrm{E}+00 & 1.299 \mathrm{E}+07 & 1.039 \mathrm{E}+04 \\ \text { OVARIES } & 8.777 \mathrm{E}-03 & 1.058 \mathrm{E}+00 & 5.506 \mathrm{E}+06 & 1.798 \mathrm{E}+03 \\ \text { AVERAGE } & 8.789 \mathrm{E}-03 & 1.059 \mathrm{E}+00 & 9.246 \mathrm{E}+06 & 6.094 \mathrm{E}+03\end{array}$

\section{RISK CONVERSION FACTORS}

\begin{tabular}{|c|c|c|c|c|}
\hline Cancer & Ingestion & Inhalation & Air Immersion & Ground Surf \\
\hline LEUKEMIA & 5.183E-04 & $6.271 \mathrm{E}-02$ & $6.176 \mathrm{E}-02$ & $1.770 \mathrm{E}-\mathrm{C}$ \\
\hline BONE & $3.323 \mathrm{E}-04$ & $4.019 \mathrm{E}-02$ & 7.072E-03 & \\
\hline THYROID & 1.027E-06 & $1.242 \mathrm{E}-04$ & $1.540 \mathrm{E}-02$ & $5.301 \mathrm{E}-($ \\
\hline BRE & $6.868 \mathrm{E}$ & $8.298 \mathrm{E}-04$ & 3.913E-01 & $6.333 \mathrm{E}-0$ \\
\hline LUN & $9.263 \mathrm{E}-$ & 2.149E-02 & $1.200 \mathrm{E}-01$ & $4.439 \mathrm{E}-\mathrm{C}$ \\
\hline STOMACH & $6.254 \mathrm{E}-06$ & $6.858 \mathrm{E}-04$ & 6.736E-02 & $1.961 \mathrm{E}-0$ \\
\hline BOWEL & $9.813 \mathrm{E}-06$ & 3.457E-04 & $3.275 \mathrm{E}-02$ & 8.719E-0 \\
\hline LIVER & $1.148 \mathrm{E}-03$ & $1.387 \bar{E}-01$ & 7.186E-02 & $1.699 \mathrm{E}-0$ \\
\hline PANCREAS & $4.289 \mathrm{E}-1$ & $5.181 \mathrm{E}$ & 4.236E-02 & $1.502 \mathrm{E}-\mathrm{C}$ \\
\hline URINAR & $2.200 \mathrm{E}-$ & $2.658 \mathrm{E}-$ & $2.614 \mathrm{E}-02$ & $6.081 \mathrm{E}-0$ \\
\hline $\mathrm{OTHE}$ & $5.246 \mathrm{E}-0$ & $6.337 \mathrm{E}-0$ & $5.181 \mathrm{E}-02$ & $1.838 \mathrm{E}-0$ \\
\hline
\end{tabular}


Waste Isolation Pilot Plant Biennial Environmental Compliance Report DOE/WIPP 99-2171

$\begin{array}{llll}\text { AVERAGE } & 3.034 \mathrm{E}-10 \quad 3.656 \mathrm{E}-08 & 2.404 \mathrm{E}+00 \quad 1.584 \mathrm{E}-03\end{array}$ 


\author{
C A P $88-P$ C \\ Version 2.00 \\ Clean Air Act Assessment Package - 1988 \\ CONCENTRATION TABLES \\ Non-Radon Population Assessment \\ Apr 24, 2000 12:45 pm
Facility: Waste Isolation Pilot Project
Address: 26 Miles SE of Carlsbad, NM
City: Carlsbad
State: NM Zip: 88221
Source Category: exempt DOE facility
Source Type: Stack
Emission Year: 1999 \\ Comments: Run for 1999 \\ Dataset Name: 1999run \\ Dataset Date: $\quad$ Apr 24, 2000 12:44 pm \\ Wind File: C:ICAP88PC2IWNDFILESI96-99.WND \\ Population File: C:ICAP88PC2IPOPFILESIWIPP99.POP
}


Waste Isolation Pilot Plant Biennial Environmental Compliance Report DOE/WIPP 99-2171

Apr 24, $2000 \quad 12: 45$ pm

CONCENTRATIONS

Page 1

ESTIMATED RADIONUCLIDE CONCENTRATIONS

AT VARIOUS LOCATIONS IN THE ENVIRONMENT

\begin{tabular}{|c|c|c|c|c|c|c|}
\hline $\begin{array}{l}\text { Wind } \\
\text { Toward }\end{array}$ & $\begin{array}{l}\text { Distance } \\
\text { (meters) }\end{array}$ & Nuclide & $\begin{array}{c}\text { Air } \\
\text { Concentration } \\
(\mathrm{pCi} / \mathrm{m} 3)\end{array}$ & $\begin{array}{c}\text { Dry } \\
\text { Deposition } \\
\text { Rate } \\
\text { (pCi/cm2/s) }\end{array}$ & $\begin{array}{c}\text { Wet } \\
\text { Deposition } \\
\text { Rate } \\
\text { (pCi/cm2/s) }\end{array}$ & $\begin{array}{c}\text { Ground } \\
\text { Deposition } \\
\text { Rate } \\
\text { (pCi/cm2/s) }\end{array}$ \\
\hline $\mathrm{N}$ & 250 & AM-241 & 1.7E-09 & $3.1 \mathrm{E}-16$ & $8.9 \mathrm{E}-17$ & $4.0 \mathrm{E}-16$ \\
\hline $\mathrm{N}$ & 250 & PU-238 & $1.4 \mathrm{E}-09$ & $2.4 \mathrm{E}-16$ & $6.8 \mathrm{E}-17$ & $3.1 \mathrm{E}-16$ \\
\hline $\mathrm{N}$ & 250 & $\mathrm{~J}-239$ & 1.6E-09 & $2.9 \mathrm{E}-16$ & $8.5 \mathrm{E}-17$ & $3.7 \bar{E}-16$ \\
\hline $\mathrm{N}$ & 750 & AM-241 & $6.6 \mathrm{E}-10$ & $1.2 \mathrm{E}-16$ & 3.0E-17 & $1.5 \mathrm{E}-16$ \\
\hline $\mathrm{N}$ & 750 & PU-238 & $5.4 \mathrm{E}-10$ & $9.7 \mathrm{E}-17$ & $2.2 \mathrm{E}-17$ & $1.2 \mathrm{E}-16$ \\
\hline$N$ & 750 & PU-239 & $6.0 \mathrm{E}-10$ & $1.1 \mathrm{E}-16$ & $2.8 \mathrm{E}-17$ & $1.4 \mathrm{E}-16$ \\
\hline $\mathrm{N}$ & 1500 & AM-241 & $3.6 \mathrm{E}-10$ & $6.5 \mathrm{E}-17$ & $1.5 \mathrm{E}-17$ & $8.0 \mathrm{E}-17$ \\
\hline $\mathrm{N}$ & 1500 & PU-238 & 3. $1 \mathrm{E}-10$ & $5.5 \mathrm{E}-17$ & 1.1E-17 & $6.6 \mathrm{E}-17$ \\
\hline $\mathrm{N}$ & 1500 & PU-239 & 3.3E-10 & $5.9 \mathrm{E}-17$ & $1.4 \mathrm{E}-17$ & 7.3E-17 \\
\hline $\mathrm{N}$ & 2500 & AM-241 & 2.3E-10 & $4.1 \mathrm{E}-17$ & $8.8 \mathrm{E}-18$ & $5.0 \mathrm{E}-17$ \\
\hline $\mathrm{N}$ & 2500 & PU-238 & $1.9 \mathrm{E}-10$ & $3.4 \mathrm{E}-17$ & $6.6 \mathrm{E}-18$ & $4.0 \mathrm{E}-17$ \\
\hline $\mathrm{N}$ & 2500 & PU-239 & $2.1 \mathrm{E}-10$ & $3.8 \mathrm{E}-17$ & 8.3E-18 & $4.6 \mathrm{E}-17$ \\
\hline $\mathrm{N}$ & 3500 & AM-241 & 1.6E-10 & $2.9 \mathrm{E}-17$ & $6.2 \mathrm{E}-18$ & $3.5 \mathrm{E}-17$ \\
\hline $\mathrm{N}$ & 3500 & PU-238 & $1.3 \mathrm{E}-10$ & $2.3 \mathrm{E}-17$ & $4.7 \mathrm{E}-18$ & $2.8 \mathrm{E}-17$ \\
\hline $\mathrm{N}$ & 3500 & PU-239 & $1.5 \mathrm{E}-10$ & $2.6 \mathrm{E}-17$ & $5.9 \mathrm{E}-18$ & $3.2 \mathrm{E}-17$ \\
\hline $\mathrm{N}$ & 4500 & AM-241 & 1.2 & $2.1 \mathrm{E}-17$ & $4.8 \mathrm{E}-18$ & $2.6 \mathrm{E}-17$ \\
\hline $\mathrm{N}$ & 4500 & PU-238 & $9.4 \mathrm{E}-11$ & $1.7 \bar{E}-17$ & 3.6E-18 & $2.1 \mathrm{E}-17$ \\
\hline $\mathrm{N}$ & 4500 & PU-239 & & $2.0 \bar{E}-17$ & $4.6 \mathrm{E}-18$ & $2.4 \bar{E}-17$ \\
\hline $\mathrm{N}$ & 7500 & AM-241 & $6.4 \mathrm{E}-11$ & $1.2 \mathrm{E}-17$ & $2.8 \mathrm{E}-18$ & $1.4 \mathrm{E}-17$ \\
\hline $\mathrm{N}$ & 7500 & 8 & 5.0 & $9.0 \mathrm{E}-18$ & 2.1 & E-17 \\
\hline $\mathrm{N}$ & 7500 & PU-239 & $6.0 \mathrm{E}-11$ & $1.1 \mathrm{E}-17$ & $2.7 \mathrm{E}-18$ & $1.3 \mathrm{E}-17$ \\
\hline $\mathrm{N}$ & 15000 & AM-241 & $2.7 \mathrm{~B}$ & $4.9 E-18$ & & $6.2 \mathrm{E}-18$ \\
\hline $\mathrm{N}$ & 15000 & PU-238 & 2.1E-11 & 3.8E-18 & 1.0E-18 & $4.8 \mathrm{E}-18$ \\
\hline $\mathrm{N}$ & & PL & 2.6 & 4.6E-18 & -18 & $5.9 \mathrm{E}-18$ \\
\hline $\mathrm{N}$ & 00 & AM-241 & 1.3E-11 & $2.4 \mathrm{E}-18$ & 7.3E-19 & $3.1 \mathrm{E}-18$ \\
\hline $\mathrm{N}$ & 25 & Pl & $1.0 \mathrm{E}$ & $1.8 \mathrm{E}-18$ & 19 & $2.4 \mathrm{E}-18$ \\
\hline $\mathrm{N}$ & 25000 & PU-239 & -11 & 2.3E-18 & 7.0E-19 & $3.0 \mathrm{E}-18$ \\
\hline $\mathrm{N}$ & 35000 & AM-241 & 8.8 & 1.6E-18 & $5.0 \mathrm{E}-19$ & $2.1 \mathrm{E}-18$ \\
\hline $\mathrm{N}$ & 35000 & PU-238 & $6.7 \mathrm{E}-12$ & $1.2 \mathrm{E}-18$ & $3.8 \mathrm{E}-19$ & $1.6 \mathrm{E}-18$ \\
\hline $\mathrm{N}$ & 35000 & PU-239 & $8.3 \mathrm{E}-12$ & $1.5 \mathrm{E}-18$ & $4.8 \mathrm{E}-19$ & $2.0 \mathrm{E}-18$ \\
\hline $\mathrm{N}$ & 45000 & AM-241 & $6.3 \mathrm{E}-12$ & $1.1 \mathrm{E}-18$ & $3.8 \mathrm{E}-19$ & $1.5 \mathrm{E}-18$ \\
\hline $\mathrm{N}$ & & PU-238 & $4.8 \mathrm{E}-12$ & $8.6 \mathrm{E}-19$ & $2.8 \mathrm{E}-19$ & $1.1 \mathrm{E}-18$ \\
\hline $\mathrm{N}$ & 45000 & PU-239 & 5.9E-12 & $1.1 \mathrm{E}-18$ & $3.6 \mathrm{E}-19$ & $1.4 \mathrm{E}-18$ \\
\hline $\mathrm{N}$ & 55000 & AM-241 & $4.5 \mathrm{E}-12$ & $8.1 \mathrm{E}-19$ & $2.9 \mathrm{E}-19$ & $1.1 \mathrm{E}-18$ \\
\hline $\mathrm{N}$ & 55000 & PU-238 & 3.4E-12 & $6.2 \mathrm{E}-19$ & $2.2 \mathrm{E}-19$ & $8.4 \mathrm{E}-19$ \\
\hline $\mathrm{N}$ & 55000 & PU-239 & 4. $3 \mathrm{E}-12$ & 7.7E-19 & $2.8 \mathrm{E}-19$ & $1.0 \mathrm{E}-18$ \\
\hline
\end{tabular}


Waste Isolation Pilot Plant Biennial Environmental Compliance Report DOE/WIPP 99-2171

Apr 24, $2000 \quad 12: 45$ pm

CONCENTRATIONS

Page 2

ESTIMATED RADIONUCLIDE CONCENTRATIONS

AT VARIOUS LOCATIONS IN THE ENVIRONMENT

\begin{tabular}{|c|c|c|c|c|c|c|}
\hline $\begin{array}{l}\text { Wind } \\
\text { Toward } \\
\end{array}$ & $\begin{array}{l}\text { Distance } \\
\text { (meters) }\end{array}$ & Nuclide & $\begin{array}{c}\text { Air } \\
\text { Concentration } \\
(\mathrm{pCi} / \mathrm{m} 3)\end{array}$ & $\begin{array}{c}\text { Dry } \\
\text { Deposition } \\
\text { Rate } \\
\text { (pCi/cm2/s) } \\
\end{array}$ & $\begin{array}{c}\text { Wet } \\
\text { Deposition } \\
\text { Rate } \\
\text { (pCi/cm2/s) } \\
\end{array}$ & $\begin{array}{c}\text { Ground } \\
\text { Deposition } \\
\text { Rate } \\
\text { (pCi/cm2/s) }\end{array}$ \\
\hline $\begin{array}{l}N \\
N\end{array}$ & $\begin{array}{l}70000 \\
70000\end{array}$ & $\begin{array}{l}\text { AM-241 } \\
\text { PU-238 }\end{array}$ & $\begin{array}{l}\text { 2.7E-12 } \\
2.0 \mathrm{E}-12\end{array}$ & $\begin{array}{l}4.8 E-19 \\
3.6 E-19\end{array}$ & $\begin{array}{l}2.0 \mathrm{E}-19 \\
1.5 \mathrm{E}-19\end{array}$ & $\begin{array}{l}6.8 \mathrm{E}-19 \\
5.2 \mathrm{E}-19\end{array}$ \\
\hline $\mathrm{N}$ & 70000 & PU-239 & 2.6E-12 & 4.6E-19 & $1.9 \mathrm{E}-19$ & $6.5 \mathrm{E}-19$ \\
\hline NNW & 250 & AM-241 & 2.3E-09 & $4.2 E-16$ & 1.2E-16 & 5.3E-16 \\
\hline NNW & 250 & PU-238 & 1.8E-09 & $3.2 E-16$ & $8.8 \mathrm{E}-17$ & 4.1E-16 \\
\hline NNW & 250 & PU-239 & $2.1 \mathrm{E}-09$ & $3.8 \mathrm{E}-16$ & $1.1 \mathrm{E}-16$ & $4.9 \mathrm{E}-16$ \\
\hline NNW & 750 & AM-241 & 1.1E-09 & 2.0E-16 & $3.8 \mathrm{E}-17$ & $2.4 \mathrm{E}-16$ \\
\hline NNW & 750 & PU-238 & 8.9E-10 & $1.6 \mathrm{E}-16$ & $2.9 \mathrm{E}-17$ & $1.9 \mathrm{E}-16$ \\
\hline NNW & 750 & PU-239 & 1.1E-09 & $1.9 \mathrm{E}-16$ & $3.7 \mathrm{E}-17$ & $2.3 E-16$ \\
\hline NNW & 1500 & AM-241 & $6.2 \mathrm{E}-10$ & $1.1 \mathrm{E}-16$ & $1.9 \mathrm{E}-17$ & 1.3E-16 \\
\hline NNW & 1500 & PU-238 & 5.0E-10 & $9.1 \mathrm{E}-17$ & $1.5 \mathrm{E}-17$ & $1.1 \mathrm{E}-16$ \\
\hline NNW & 1500 & PU-239 & $5.8 E-10$ & $1.0 \mathrm{E}-16$ & $1.8 \mathrm{E}-17$ & $1.2 \mathrm{E}-16$ \\
\hline NNW & 2500 & AM-241 & $3.8 \mathrm{E}-10$ & $6.8 \mathrm{E}-17$ & $1.1 \mathrm{E}-17$ & $7.9 \mathrm{E}-17$ \\
\hline NNW & 2500 & PU-238 & $3.0 \mathrm{E}-10$ & $5.4 \mathrm{E}-17$ & 8.6E-18 & $6.2 \mathrm{E}-17$ \\
\hline NNW & 2500 & PU-239 & $3.5 E-10$ & 6.3E-17 & $1.1 \mathrm{E}-17$ & $7.4 \mathrm{E}-17$ \\
\hline NNW & 3500 & AM-241 & $2.6 \mathrm{E}-10$ & 4.6E-17 & $8.1 \mathrm{E}-18$ & $5.4 \mathrm{E}-17$ \\
\hline NNW & 3500 & PU-238 & $2.0 \mathrm{E}-10$ & $3.6 \mathrm{E}-17$ & $6.1 \mathrm{E}-18$ & $4.2 \mathrm{E}-17$ \\
\hline NNW & 3500 & PU-239 & $2.4 \mathrm{E}-10$ & 4.3E-17 & 7.7E-18 & $5.1 \mathrm{E}-17$ \\
\hline NNW & 4500 & AM-241 & $1.9 \mathrm{E}-10$ & $3.4 \mathrm{E}-17$ & $6.2 E-18$ & $4.0 \mathrm{E}-17$ \\
\hline NNW & 4500 & PU-238 & $1.5 \mathrm{E}-10$ & $2.6 \mathrm{E}-17$ & $4.7 \mathrm{E}-18$ & $3.1 \mathrm{E}-17$ \\
\hline NNW & 4500 & PU-239 & $1.8 \mathrm{E}-10$ & $3.2 E-17$ & 5.9E-18 & $3.8 E-17$ \\
\hline NNW & 7500 & AM-241 & $9.9 E-11$ & $1.8 \mathrm{E}-17$ & $3.6 E-18$ & $2.2 E-17$ \\
\hline NNW & 7500 & PU-238 & 7.7E-11 & $1.4 \mathrm{E}-17$ & 2.8E-18 & 1.7E-17 \\
\hline NNW & 7500 & PU-239 & $9.4 \mathrm{E}-11$ & $1.7 \mathrm{E}-17$ & 3.5E-18 & 2.0E-17 \\
\hline NNW & 15000 & AM-241 & $4.2 \mathrm{E}-11$ & 7.6E-18 & 1.8E-18 & 9.3E-18 \\
\hline NNW & 15000 & PU-238 & $3.2 \mathrm{E}-11$ & $5.8 E-18$ & 1.3E-18 & $7.1 \mathrm{E}-18$ \\
\hline NNW & 15000 & PU-239 & $4.0 \mathrm{E}-11$ & 7.2E-18 & 1.7E-18 & 8.8E-18 \\
\hline NNW & 25000 & AM-241 & $2.1 \mathrm{E}-11$ & $3.8 E-18$ & 9.7E-19 & $4.8 \mathrm{E}-18$ \\
\hline NNW & 25000 & PU-238 & $1.6 \mathrm{E}-11$ & $2.9 \mathrm{E}-18$ & $7.4 \mathrm{E}-19$ & $3.6 \mathrm{E}-18$ \\
\hline NNW & 25000 & PU-239 & $2.0 \mathrm{E}-11$ & 3.6E-18 & 9.3E-19 & $4.5 \mathrm{E}-18$ \\
\hline NNW & 35000 & AM-241 & $1.4 \mathrm{E}-11$ & $2.5 E-18$ & 6.8E-19 & $3.2 E-18$ \\
\hline NNW & 35000 & PU-238 & $1.1 \mathrm{E}-11$ & $1.9 \mathrm{E}-18$ & $5.1 \mathrm{E}-19$ & $2.4 \mathrm{E}-18$ \\
\hline NNW & 35000 & PU-239 & $1.3 E-11$ & 2.4E-18 & 6.5E-19 & $3.0 \mathrm{E}-18$ \\
\hline NNW & 45000 & AM-241 & $1.0 \mathrm{E}-11$ & $1.8 \mathrm{E}-18$ & 5.1E-19 & 2.3E-18 \\
\hline NNW & 45000 & PU-238 & 7.7E-12 & $1.4 \mathrm{E}-18$ & 3.9E-19 & 1.8E-18 \\
\hline NNW & 45000 & PU-239 & $9.6 \mathrm{E}-12$ & $1.7 \mathrm{E}-18$ & 4.9E-19 & $2.2 \mathrm{E}-18$ \\
\hline
\end{tabular}


Waste Isolation Pilot Plant Biennial Environmental Compliance Report DOE/WIPP 99-2171

Apr 24, $2000 \quad 12: 45$ pm

CONCENTRATIONS

Page 3

ESTIMATED RADIONUCLIDE CONCENTRATIONS

AT VARIOUS LOCATIONS IN THE ENVIRONMENT

\begin{tabular}{|c|c|c|c|c|c|c|}
\hline $\begin{array}{l}\text { Wind } \\
\text { Toward }\end{array}$ & $\begin{array}{l}\text { Distance } \\
\text { (meters) }\end{array}$ & Nuclide & $\begin{array}{c}\text { Air } \\
\text { Concentration } \\
(\mathrm{pCi} / \mathrm{m} 3)\end{array}$ & $\begin{array}{c}\text { Dry } \\
\text { Deposition } \\
\text { Rate } \\
\text { (pCi/cm2/s) }\end{array}$ & $\begin{array}{c}\text { Wet } \\
\text { Deposition } \\
\text { Rate } \\
\text { (pCi/cm2/s) }\end{array}$ & $\begin{array}{c}\text { Ground } \\
\text { Deposition } \\
\text { Rate } \\
\text { (pCi/cm2/s) }\end{array}$ \\
\hline NNW & 55000 & AM-241 & $7.5 \mathrm{E}-12$ & $1.3 \mathrm{E}-18$ & $4.0 \mathrm{E}-19$ & $1.7 \mathrm{E}-18$ \\
\hline NNW & 55000 & PU-238 & $5.7 \mathrm{E}$ & $1.0 \mathrm{E}-18$ & 3.0E-19 & $1.3 \bar{E}-18$ \\
\hline NNW & 55000 & PU-239 & $7.1 \mathrm{E}-12$ & $1.3 \mathrm{E}-18$ & $3.8 \mathrm{E}-19$ & $1.7 \mathrm{E}-18$ \\
\hline NNW & 70000 & AM-241 & $4.6 \mathrm{E}-12$ & $8.4 \mathrm{E}-19$ & $2.8 \mathrm{E}-19$ & $1.1 \mathrm{E}-18$ \\
\hline NNW & 70000 & PU-238 & $3.5 \mathrm{E}-12$ & $6.3 \mathrm{E}-19$ & 2.1E-19 & $8.5 \bar{E}-19$ \\
\hline NNW & 70000 & PU-239 & $4.4 \mathrm{E}-12$ & 8.0E-19 & 2.7E-19 & $1.1 \mathrm{E}-18$ \\
\hline NW & 250 & AM-241 & 2.7E-09 & $4.8 \mathrm{E}-16$ & $1.6 \mathrm{E}-16$ & $6.4 \mathrm{E}-16$ \\
\hline NW & 250 & PU-238 & 2.0E-09 & $3.6 \mathrm{E}-16$ & $1.2 \mathrm{E}-16$ & $4.9 \mathrm{E}-16$ \\
\hline NW & 250 & PU-239 & 2.4E-09 & $4.4 \mathrm{E}-16$ & $1.6 \mathrm{E}-16$ & $6.0 \mathrm{E}-16$ \\
\hline NW & 750 & AM-241 & $1.8 \mathrm{E}-09$ & $3.2 \mathrm{E}-16$ & $5.5 \mathrm{E}-17$ & $8 \mathrm{E}-16$ \\
\hline NW & 750 & PU-238 & 1.4E-09 & $2.5 \mathrm{E}-16$ & $4.2 \mathrm{E}-17$ & $2.9 \mathrm{E}-16$ \\
\hline NW & 750 & PU-239 & 1.6E-09 & $3.0 \mathrm{E}-16$ & $5.2 \mathrm{E}-17$ & $E-16$ \\
\hline NW & 1500 & AM-241 & 1.1E-09 & $2.0 \mathrm{E}-16$ & 2.7E-17 & 2.3E-16 \\
\hline NW & 1500 & PU-238 & $8.8 \mathrm{E}-10$ & 1.6E-16 & $2.1 \mathrm{E}-17$ & $E-16$ \\
\hline NW & 1500 & PU-239 & 09 & $1.9 \mathrm{E}-16$ & $2.6 \mathrm{E}-17$ & $2.1 \mathrm{E}-16$ \\
\hline NW & 2500 & AM-241 & 6.8 & $1.2 \mathrm{E}-16$ & -17 & $E-16$ \\
\hline NW & 2500 & PU-238 & 5.3 & $9.5 \mathrm{E}-17$ & $1.2 \mathrm{E}-17$ & $1.1 \mathrm{E}-16$ \\
\hline NW & 2500 & PU-239 & $6.4 \mathrm{l}$ & $1.1 \mathrm{E}-16$ & -17 & -16 \\
\hline NW & 3500 & AM-241 & 4.6 & $8.2 \mathrm{E}-17$ & 1.1E-17 & $=-17$ \\
\hline NW & & DII & & $6.3 \mathrm{E}-17$ & $8.7 \mathrm{E}-18$ & -17 \\
\hline NW & 35 & PU-239 & 4.3 & 7.7E-17 & $1.1 \mathrm{E}-17$ & $8.8 \mathrm{E}-17$ \\
\hline NW & & AM-2 & & $6.0 \mathrm{E}-17$ & $8.8 \mathrm{E}-18$ & -17 \\
\hline NW & 45 & PU-2 & 2.6 & 4.7E-17 & $6.7 \mathrm{E}-18$ & 5.3E-17 \\
\hline NW & 45 & PU-2 & 3.2 & 5.7E-17 & $8.4 \mathrm{E}-18$ & $6.5 \mathrm{E}-17$ \\
\hline NW & 75 & AM-241 & $1.8 \mathrm{E}$ & $3.2 \mathrm{E}-17$ & $5.2 \mathrm{E}-18$ & 3.7E-17 \\
\hline NW & 7500 & $\mathrm{P}$ & 1.31 & 2.4E-17 & $3.9 \mathrm{E}-18$ & $2.8 \mathrm{E}-17$ \\
\hline NW & 7500 & PU- & $1.7 \mathrm{E}-10$ & 3.0E-17 & $4.9 \mathrm{E}-18$ & $3.5 \mathrm{E}-17$ \\
\hline NW & 15000 & $\mathrm{Al}$ & 7.5 & $1.3 \mathrm{E}-17$ & $2.5 \mathrm{E}-18$ & $E-17$ \\
\hline NW & 15000 & PU-2 & $5.7 \mathrm{E}-11$ & $1.0 \mathrm{E}-17$ & $1.9 \mathrm{E}-18$ & $1.2 \mathrm{E}-17$ \\
\hline NW & 15000 & PU-2 & $7.1 \mathrm{E}$ & $1.3 \mathrm{E}-17$ & $2.4 \mathrm{E}-18$ & $1.5 \mathrm{E}-17$ \\
\hline NW & 25000 & AM-241 & $3.8 \mathrm{E}-11$ & $6.9 \mathrm{E}-18$ & 1.4E-18 & 8.3E-18 \\
\hline NW & 25000 & PU-2 & $2.9 \mathrm{E}-11$ & $5.2 \mathrm{E}-18$ & $1.1 \mathrm{E}-18$ & $E-18$ \\
\hline NW & 25000 & PU-239 & 3.6E-11 & $6.5 \mathrm{E}-18$ & $1.3 \mathrm{E}-18$ & $7.9 \mathrm{E}-18$ \\
\hline NW & 35000 & AM-241 & $2.6 \mathrm{E}-11$ & 4.6E-18 & $9.7 \mathrm{E}-19$ & $5.6 \mathrm{E}-18$ \\
\hline NW & 35000 & PU-238 & 2.0E-11 & $3.5 \mathrm{E}-18$ & 7.3E-19 & $4.2 \mathrm{E}-18$ \\
\hline NW & 35000 & PU-239 & $2.4 \mathrm{E}-11$ & $4.4 \mathrm{E}-18$ & $9.2 \mathrm{E}-19$ & 5.3E-18 \\
\hline
\end{tabular}


Waste Isolation Pilot Plant Biennial Environmental Compliance Report DOE/WIPP 99-2171

Apr 24, $2000 \quad 12: 45$ pm

CONCENTRATIONS

Page 4

ESTIMATED RADIONUCLIDE CONCENTRATIONS

AT VARIOUS LOCATIONS IN THE ENVIRONMENT

\begin{tabular}{|c|c|c|c|c|c|c|}
\hline $\begin{array}{c}\text { Wind } \\
\text { Toward }\end{array}$ & $\begin{array}{l}\text { Distance } \\
\text { (meters) }\end{array}$ & Nuclide & $\begin{array}{c}\text { Air } \\
\text { Concentration } \\
(\mathrm{pCi} / \mathrm{m} 3)\end{array}$ & $\begin{array}{c}\text { Dry } \\
\text { Deposition } \\
\text { Rate } \\
\text { (pCi/cm2/s) }\end{array}$ & $\begin{array}{c}\text { Wet } \\
\text { Deposition } \\
\text { Rate } \\
\text { (pCi/cm2/s) }\end{array}$ & $\begin{array}{c}\text { Ground } \\
\text { Deposition } \\
\text { Rate } \\
\text { (pCi/cm2/s) }\end{array}$ \\
\hline NW & 45000 & AM-241 & $1.9 \mathrm{E}-11$ & $3.4 \mathrm{E}-18$ & 7.3E-19 & 4.1E-18 \\
\hline NW & 45000 & PU-238 & $1.4 \mathrm{E}-11$ & 2.6E-18 & 5.5E-19 & $3.1 \mathrm{E}-18$ \\
\hline NW & 45000 & PU-239 & $1.8 \mathrm{E}-11$ & $3.2 E-18$ & 7.0E-19 & 3.9E-18 \\
\hline NW & 55000 & AM-241 & $1.4 \mathrm{E}-11$ & $2.5 E-18$ & $5.7 E-19$ & $3.1 \mathrm{E}-18$ \\
\hline NW & 55000 & PU-238 & $1.1 \mathrm{E}-11$ & $1.9 \mathrm{E}-18$ & 4.3E-19 & 2.4E-18 \\
\hline NW & 55000 & PU-239 & 1.3E-11 & 2.4E-18 & 5.4E-19 & 2.9E-18 \\
\hline NW & 70000 & AM-241 & $9.0 \mathrm{E}-12$ & 1.6E-18 & 4.0E-19 & 2.0E-18 \\
\hline NW & 70000 & PU-238 & $6.8 E-12$ & 1.2E-18 & 3.0E-19 & $1.5 \mathrm{E}-18$ \\
\hline NW & 70000 & PU-239 & $8.5 \mathrm{E}-12$ & $1.5 \mathrm{E}-18$ & $3.8 \mathrm{E}-19$ & $1.9 \mathrm{E}-18$ \\
\hline WNW & 250 & AM-241 & 1.6E-09 & 3.0E-16 & $1.5 \mathrm{E}-16$ & 4.5E-16 \\
\hline WNW & 250 & PU-238 & 1.3E-09 & $2.3 E-16$ & $1.1 \mathrm{E}-16$ & $3.4 \mathrm{E}-16$ \\
\hline WNW & 250 & PU-239 & $1.5 \mathrm{E}-09$ & $2.7 E-16$ & $1.4 \mathrm{E}-16$ & 4.1E-16 \\
\hline WNW & 750 & AM-241 & 1.5E-09 & 2.6E-16 & 5.0E-17 & $3.1 \mathrm{E}-16$ \\
\hline WNW & 750 & PU-238 & 1.2E-09 & 2.1E-16 & $3.8 \mathrm{E}-17$ & 2.5E-16 \\
\hline WNW & 750 & PU-239 & 1.3E-09 & $2.4 \mathrm{E}-16$ & $4.8 \mathrm{E}-17$ & $2.8 \mathrm{E}-16$ \\
\hline WNW & 1500 & AM-241 & 1.1E-09 & 2.0E-16 & $2.5 \mathrm{E}-17$ & 2.3E-16 \\
\hline WNW & 1500 & PU-238 & 8.8E-10 & $1.6 \mathrm{E}-16$ & $1.9 \mathrm{E}-17$ & 1.8E-16 \\
\hline WNW & 1500 & PU-239 & 1.0E-09 & 1.9E-16 & $2.4 \mathrm{E}-17$ & 2.1E-16 \\
\hline WNW & 2500 & AM-241 & 7.0E-10 & 1.3E-16 & $1.5 \mathrm{E}-17$ & $1.4 \mathrm{E}-16$ \\
\hline WNW & 2500 & PU-238 & $5.4 \mathrm{E}-10$ & $9.8 \mathrm{E}-17$ & $1.1 \mathrm{E}-17$ & $1.1 \mathrm{E}-16$ \\
\hline WNW & 2500 & PU-239 & $6.6 \mathrm{E}-10$ & 1.2E-16 & $1.4 \mathrm{E}-17$ & 1.3E-16 \\
\hline WNW & 3500 & AM-241 & $4.8 E-10$ & 8.6E-17 & 1.0E-17 & $9.6 \mathrm{E}-17$ \\
\hline WNW & 3500 & PU-238 & $3.7 E-10$ & $6.6 \mathrm{E}-17$ & $7.9 E-18$ & $7.4 \mathrm{E}-17$ \\
\hline WNW & 3500 & PU-239 & $4.5 E-10$ & $8.1 \mathrm{E}-17$ & $1.0 \mathrm{E}-17$ & $9.1 \mathrm{E}-17$ \\
\hline WNW & 4500 & AM-241 & $3.5 E-10$ & 6.3E-17 & 8.1E-18 & $7.1 \mathrm{E}-17$ \\
\hline WNW & 4500 & PU-238 & 2.7E-10 & $4.9 E-17$ & $6.1 \mathrm{E}-18$ & $5.5 \mathrm{E}-17$ \\
\hline WNW & 4500 & PU-239 & 3.3E-10 & $6.0 \mathrm{E}-17$ & $7.7 \mathrm{E}-18$ & $6.8 \mathrm{E}-17$ \\
\hline WNW & 7500 & AM-241 & $1.8 E-10$ & 3.3E-17 & 4.7E-18 & 3.8E-17 \\
\hline WNW & 7500 & PU-238 & $1.4 \mathrm{E}-10$ & $2.5 \mathrm{E}-17$ & 3.6E-18 & 2.9E-17 \\
\hline WNW & 7500 & PU-239 & $1.8 \mathrm{E}-10$ & $3.2 E-17$ & $4.5 E-18$ & $3.6 \mathrm{E}-17$ \\
\hline WNW & 15000 & AM-241 & $7.9 E-11$ & 1.4E-17 & 2.3E-18 & $1.6 \mathrm{E}-17$ \\
\hline WNW & 15000 & PU-238 & $6.0 \mathrm{E}-11$ & $1.1 \mathrm{E}-17$ & $1.7 \mathrm{E}-18$ & 1.3E-17 \\
\hline WNW & 15000 & PU-239 & $7.5 \mathrm{E}-11$ & 1.3E-17 & 2.2E-18 & $1.6 \mathrm{E}-17$ \\
\hline WNW & 25000 & AM-241 & 4.0E-11 & 7.3E-18 & 1.2E-18 & $8.5 E-18$ \\
\hline WNW & 25000 & PU-238 & $3.1 \mathrm{E}-11$ & $5.5 \mathrm{E}-18$ & $9.5 \mathrm{E}-19$ & $6.5 \mathrm{E}-18$ \\
\hline WNW & 25000 & PU-239 & $3.8 \mathrm{E}-11$ & $6.9 E-18$ & 1.2E-18 & $8.1 \mathrm{E}-18$ \\
\hline
\end{tabular}


Waste Isolation Pilot Plant Biennial Environmental Compliance Report DOE/WIPP 99-2171

Apr 24, $2000 \quad 12: 45$ pm

CONCENTRATIONS

Page 5

ESTIMATED RADIONUCLIDE CONCENTRATIONS

AT VARIOUS LOCATIONS IN THE ENVIRONMENT

\begin{tabular}{|c|c|c|c|c|c|c|}
\hline $\begin{array}{l}\text { Wind } \\
\text { Toward } \\
\end{array}$ & $\begin{array}{l}\text { Distance } \\
\text { (meters) }\end{array}$ & Nuclide & $\begin{array}{c}\text { Air } \\
\text { Concentration } \\
(\mathrm{pCi} / \mathrm{m} 3)\end{array}$ & $\begin{array}{c}\text { Dry } \\
\text { Deposition } \\
\text { Rate } \\
\text { (pCi/cm2/s) }\end{array}$ & $\begin{array}{c}\text { Wet } \\
\text { Deposition } \\
\text { Rate } \\
\text { (pCi/cm2/s) }\end{array}$ & $\begin{array}{c}\text { Ground } \\
\text { Deposition } \\
\text { Rate } \\
\text { (pCi/cm2/s) }\end{array}$ \\
\hline WNW & 35000 & AM-241 & 2.7E-11 & $4.9 E-18$ & 8.7E-19 & 5.8E-18 \\
\hline WNW & 35000 & PU-238 & $2.1 \mathrm{E}-11$ & $3.7 E-18$ & 6.6E-19 & $4.4 \mathrm{E}-18$ \\
\hline WNW & 35000 & PU-239 & $2.6 \mathrm{E}-11$ & $4.7 E-18$ & 8.3E-19 & $5.5 \mathrm{E}-18$ \\
\hline WNW & 45000 & AM-241 & $2.0 \mathrm{E}-11$ & $3.6 \mathrm{E}-18$ & $6.6 \mathrm{E}-19$ & $4.2 \mathrm{E}-18$ \\
\hline WNW & 45000 & PU-238 & $1.5 \mathrm{E}-11$ & $2.7 \mathrm{E}-18$ & 5.0E-19 & $3.2 E-18$ \\
\hline WNW & 45000 & PU-239 & $1.9 \mathrm{E}-11$ & $3.4 \mathrm{E}-18$ & $6.2 E-19$ & 4.0E-18 \\
\hline WNW & 55000 & AM-241 & $1.5 \mathrm{E}-11$ & $2.7 \mathrm{E}-18$ & 5.1E-19 & $3.2 E-18$ \\
\hline WNW & 55000 & PU-238 & $1.1 \mathrm{E}-11$ & $2.0 \mathrm{E}-18$ & $3.9 E-19$ & $2.4 \mathrm{E}-18$ \\
\hline WNW & 55000 & PU-239 & $1.4 \mathrm{E}-11$ & $2.6 \mathrm{E}-18$ & $4.8 \mathrm{E}-19$ & $3.0 \mathrm{E}-18$ \\
\hline WNW & 70000 & AM-241 & $9.5 \mathrm{E}-12$ & $1.7 \mathrm{E}-18$ & $3.5 E-19$ & 2.1E-18 \\
\hline WNW & 70000 & PU-238 & 7.2E-12 & 1.3E-18 & 2.6E-19 & 1.6E-18 \\
\hline WNW & 70000 & PU-239 & $9.1 \mathrm{E}-12$ & $1.6 \mathrm{E}-18$ & 3.3E-19 & 2.0E-18 \\
\hline W & 250 & AM-241 & 1.3E-09 & $2.4 \mathrm{E}-16$ & $8.5 \mathrm{E}-17$ & 3.3E-16 \\
\hline W & 250 & PU-238 & 1.0E-09 & $1.8 \mathrm{E}-16$ & $6.4 \mathrm{E}-17$ & $2.5 \mathrm{E}-16$ \\
\hline W & 250 & PU-239 & 1.2E-09 & $2.2 E-16$ & $8.1 \mathrm{E}-17$ & $3.0 \mathrm{E}-16$ \\
\hline W & 750 & AM-241 & $9.5 E-10$ & $1.7 \mathrm{E}-16$ & $2.8 \mathrm{E}-17$ & 2.0E-16 \\
\hline W & 750 & PU-238 & $7.4 \mathrm{E}-10$ & 1.3E-16 & 2.1E-17 & $1.5 \mathrm{E}-16$ \\
\hline W & 750 & PU-239 & $8.7 E-10$ & $1.6 \mathrm{E}-16$ & $2.7 E-17$ & $1.8 E-16$ \\
\hline W & 1500 & AM-241 & $6.0 \mathrm{E}-10$ & $1.1 \mathrm{E}-16$ & $1.4 \mathrm{E}-17$ & 1.2E-16 \\
\hline W & 1500 & PU-238 & $4.8 E-10$ & $8.6 \mathrm{E}-17$ & 1.1E-17 & 9.6E-17 \\
\hline W & 1500 & PU-239 & 5.6E-10 & 1.0E-16 & 1.3E-17 & $1.1 \mathrm{E}-16$ \\
\hline W & 2500 & AM-241 & $3.6 \mathrm{E}-10$ & $6.5 \mathrm{E}-17$ & 8.3E-18 & $7.4 \mathrm{E}-17$ \\
\hline W & 2500 & PU-238 & 2.8E-10 & $5.1 \mathrm{E}-17$ & 6.3E-18 & $5.7 \mathrm{E}-17$ \\
\hline W & 2500 & PU-239 & $3.4 \mathrm{E}-10$ & $6.2 \mathrm{E}-17$ & 7.9E-18 & $6.9 \mathrm{E}-17$ \\
\hline W & 3500 & AM-241 & $2.4 \mathrm{E}-10$ & 4.4E-17 & $5.9 \mathrm{E}-18$ & 5.0E-17 \\
\hline W & 3500 & PU-238 & $1.9 \mathrm{E}-10$ & $3.4 \mathrm{E}-17$ & $4.5 \mathrm{E}-18$ & $3.8 E-17$ \\
\hline W & 3500 & PU-239 & $2.3 E-10$ & $4.1 \mathrm{E}-17$ & 5.6E-18 & 4.7E-17 \\
\hline W & 4500 & AM-241 & $1.8 \mathrm{E}-10$ & $3.2 E-17$ & $4.5 \mathrm{E}-18$ & $3.7 \mathrm{E}-17$ \\
\hline W & 4500 & PU-238 & $1.4 \mathrm{E}-10$ & $2.5 \mathrm{E}-17$ & $3.4 \mathrm{E}-18$ & 2.8E-17 \\
\hline W & 4500 & PU-239 & $17 E-10$ & $3.0 \mathrm{E}-17$ & $4.3 \mathrm{E}-18$ & $35 \mathrm{E}-17$ \\
\hline W & 7500 & AM-241 & $9.2 \mathrm{E}-11$ & $1.7 \mathrm{E}-17$ & 2.6E-18 & $1.9 \mathrm{E}-17$ \\
\hline W & 7500 & PU-238 & $71 \mathrm{E}-11$ & $13 \mathrm{E}-17$ & $20 \mathrm{E}-18$ & $15 \mathrm{E}-17$ \\
\hline W & 7500 & PU-239 & $8.8 E-11$ & $1.6 \mathrm{E}-17$ & $2.5 \mathrm{E}-18$ & $1.8 E-17$ \\
\hline W & 15000 & AM-241 & $3.9 E-11$ & 7.0E-18 & 1.3E-18 & 8.3E-18 \\
\hline W & 15000 & PU-238 & $3.0 \mathrm{E}-11$ & 5.3E-18 & $9.6 \mathrm{E}-19$ & 6.3E-18 \\
\hline W & 15000 & PU-239 & $3.7 \mathrm{E}-11$ & $6.6 \mathrm{E}-18$ & 1.2E-18 & 7.8E-18 \\
\hline
\end{tabular}


Waste Isolation Pilot Plant Biennial Environmental Compliance Report DOE/WIPP 99-2171

Apr 24, $2000 \quad 12: 45$ pm

CONCENTRATIONS

Page 6

ESTIMATED RADIONUCLIDE CONCENTRATIONS

AT VARIOUS LOCATIONS IN THE ENVIRONMENT

\begin{tabular}{|c|c|c|c|c|c|c|}
\hline $\begin{array}{l}\text { Wind } \\
\text { Toward }\end{array}$ & $\begin{array}{l}\text { Distance } \\
\text { (meters) }\end{array}$ & Nuclide & $\begin{array}{c}\text { Air } \\
\text { Concentration } \\
(\mathrm{pCi} / \mathrm{m} 3)\end{array}$ & $\begin{array}{c}\text { Dry } \\
\text { Deposition } \\
\text { Rate } \\
\text { (pCi/cm2/s) }\end{array}$ & $\begin{array}{c}\text { Wet } \\
\text { Deposition } \\
\text { Rate } \\
\text { (pCi/cm2/s) }\end{array}$ & $\begin{array}{c}\text { Ground } \\
\text { Deposition } \\
\text { Rate } \\
\text { (pCi/cm2/s) }\end{array}$ \\
\hline W & 25000 & AM-241 & $1.9 E-11$ & $3.5 E-18$ & 6.9E-19 & $4.2 \mathrm{E}-18$ \\
\hline W & 25000 & PU-238 & $1.5 \mathrm{E}-11$ & $2.7 E-18$ & 5.3E-19 & $3.2 E-18$ \\
\hline W & 25000 & PU-239 & $1.8 \mathrm{E}-11$ & $3.3 E-18$ & $6.6 \mathrm{E}-19$ & 4.0E-18 \\
\hline W & 35000 & AM-241 & 1.3E-11 & $2.3 \mathrm{E}-18$ & $4.8 \mathrm{E}-19$ & $2.8 \mathrm{E}-18$ \\
\hline W & 35000 & PU-238 & $9.9 \mathrm{E}-12$ & $1.8 \mathrm{E}-18$ & $3.7 E-19$ & 2.1E-18 \\
\hline W & 35000 & PU-239 & $1.2 \mathrm{E}-11$ & $2.2 E-18$ & $4.6 \mathrm{E}-19$ & 2.7E-18 \\
\hline W & 45000 & AM-241 & $9.4 \mathrm{E}-12$ & $1.7 \mathrm{E}-18$ & 3.6E-19 & 2.1E-18 \\
\hline W & 45000 & PU-238 & $7.2 \mathrm{E}-12$ & 1.3E-18 & $2.8 \mathrm{E}-19$ & 1.6E-18 \\
\hline W & 45000 & PU-239 & $9.0 \mathrm{E}-12$ & $1.6 \mathrm{E}-18$ & $3.5 \mathrm{E}-19$ & $2.0 \mathrm{E}-18$ \\
\hline W & 55000 & AM-241 & $7.0 \mathrm{E}-12$ & 1.3E-18 & 2.8E-19 & $1.5 \mathrm{E}-18$ \\
\hline W & 55000 & PU-238 & 5.3E-12 & $9.6 \mathrm{E}-19$ & 2.1E-19 & 1.2E-18 \\
\hline W & 55000 & PU-239 & $6.6 \mathrm{E}-12$ & $1.2 \mathrm{E}-18$ & 2.7E-19 & $1.5 \mathrm{E}-18$ \\
\hline W & 70000 & AM-241 & $4.3 E-12$ & $7.8 \mathrm{E}-19$ & $1.9 \mathrm{E}-19$ & 9.7E-19 \\
\hline W & 70000 & PU-238 & $3.3 E-12$ & 5.9E-19 & $1.5 \mathrm{E}-19$ & $7.4 \mathrm{E}-19$ \\
\hline W & 70000 & PU-239 & $4.1 \mathrm{E}-12$ & 7.4E-19 & $1.8 \mathrm{E}-19$ & 9.3E-19 \\
\hline WSW & 250 & AM-241 & $9.8 \mathrm{E}-10$ & $1.8 \mathrm{E}-16$ & $5.4 \mathrm{E}-17$ & 2.3E-16 \\
\hline WSW & 250 & PU-238 & $7.4 \mathrm{E}-10$ & $1.3 E-16$ & $4.1 \mathrm{E}-17$ & 1.7E-16 \\
\hline WSW & 250 & PU-239 & $9.1 \mathrm{E}-10$ & $1.6 \mathrm{E}-16$ & $5.1 \mathrm{E}-17$ & $2.1 \mathrm{E}-16$ \\
\hline WSW & 750 & AM-241 & $5.7 E-10$ & 1.0E-16 & $1.8 \mathrm{E}-17$ & 1.2E-16 \\
\hline WSW & 750 & PU-238 & $4.5 \mathrm{E}-10$ & $8.1 \mathrm{E}-17$ & $1.4 \mathrm{E}-17$ & $9.4 \mathrm{E}-17$ \\
\hline WSW & 750 & PU-239 & 5.3E-10 & $9.5 \mathrm{E}-17$ & $1.7 \mathrm{E}-17$ & $1.1 \mathrm{E}-16$ \\
\hline WSW & 1500 & AM-241 & $3.4 \mathrm{E}-10$ & $6.1 \mathrm{E}-17$ & $8.9 E-18$ & 7.0E-17 \\
\hline WSW & 1500 & PU-238 & $2.7 \mathrm{E}-10$ & $4.9 \mathrm{E}-17$ & $6.7 \mathrm{E}-18$ & $5.6 \mathrm{E}-17$ \\
\hline WSW & 1500 & PU-239 & $3.1 \mathrm{E}-10$ & $5.7 \mathrm{E}-17$ & $8.5 \mathrm{E}-18$ & $6.5 \mathrm{E}-17$ \\
\hline WSW & 2500 & AM-241 & $2.1 \mathrm{E}-10$ & $3.8 E-17$ & 5.3E-18 & 4.3E-17 \\
\hline WSW & 2500 & PU-238 & $1.7 \mathrm{E}-10$ & $3.0 \mathrm{E}-17$ & $4.0 \mathrm{E}-18$ & $3.4 \mathrm{E}-17$ \\
\hline WSW & 2500 & PU-239 & $2.0 \mathrm{E}-10$ & $3.5 \mathrm{E}-17$ & $5.0 \mathrm{E}-18$ & 4.0E-17 \\
\hline WSW & 3500 & AM-241 & $1.4 \mathrm{E}-10$ & 2.6E-17 & $3.7 E-18$ & 2.9E-17 \\
\hline WSW & 3500 & PU-238 & $1.1 \mathrm{E}-10$ & 2.0E-17 & 2.8E-18 & 2.3E-17 \\
\hline WSW & 3500 & PU-239 & $1.3 E-10$ & $2.4 \mathrm{E}-17$ & $3.6 \mathrm{E}-18$ & $2.8 \mathrm{E}-17$ \\
\hline WSW & 4500 & AM-241 & $1.1 \mathrm{E}-10$ & $1.9 \mathrm{E}-17$ & 2.9E-18 & 2.2E-17 \\
\hline WSW & 4500 & PU-238 & $8.2 E-11$ & $1.5 \mathrm{E}-17$ & 2.2E-18 & $1.7 \mathrm{E}-17$ \\
\hline WSW & 4500 & PU-239 & 1.0E-10 & $1.8 \mathrm{E}-17$ & 2.7E-18 & 2.1E-17 \\
\hline WSW & 7500 & AM-241 & $5.5 \mathrm{E}-11$ & $1.0 \mathrm{E}-17$ & $1.7 \mathrm{E}-18$ & $1.2 \mathrm{E}-17$ \\
\hline WSW & 7500 & PU-238 & 4.3E-11 & $7.7 \mathrm{E}-18$ & 1.3E-18 & 9.0E-18 \\
\hline WSW & 7500 & PU-239 & $5.2 \mathrm{E}-11$ & $9.4 \mathrm{E}-18$ & $1.6 \mathrm{E}-18$ & $1.1 \mathrm{E}-17$ \\
\hline
\end{tabular}


Waste Isolation Pilot Plant Biennial Environmental Compliance Report DOE/WIPP 99-2171

Apr 24, $2000 \quad 12: 45$ pm

CONCENTRATIONS

Page 7

ESTIMATED RADIONUCLIDE CONCENTRATIONS

AT VARIOUS LOCATIONS IN THE ENVIRONMENT

\begin{tabular}{|c|c|c|c|c|c|c|}
\hline $\begin{array}{l}\text { Wind } \\
\text { Toward }\end{array}$ & $\begin{array}{l}\text { Distance } \\
\text { (meters) }\end{array}$ & Nuclide & $\begin{array}{c}\text { Air } \\
\text { Concentration } \\
(\mathrm{pCi} / \mathrm{m} 3)\end{array}$ & $\begin{array}{c}\text { Dry } \\
\text { Deposition } \\
\text { Rate } \\
\text { (pCi/cm2/s) }\end{array}$ & $\begin{array}{c}\text { Wet } \\
\text { Deposition } \\
\text { Rate } \\
\text { (pCi/cm2/s) }\end{array}$ & $\begin{array}{c}\text { Ground } \\
\text { Deposition } \\
\text { Rate } \\
\text { (pCi/cm2/s) }\end{array}$ \\
\hline WSW & 15000 & AM-241 & 2.3E-11 & $4.2 E-18$ & 8.0E-19 & 5.0E-18 \\
\hline WSW & 15000 & PU-238 & $1.8 \mathrm{E}-11$ & $3.2 \mathrm{E}-18$ & $6.1 \mathrm{E}-19$ & $3.8 \mathrm{E}-18$ \\
\hline WSW & 15000 & PU-239 & $2.2 \mathrm{E}-11$ & $4.0 \mathrm{E}-18$ & 7.6E-19 & 4.7E-18 \\
\hline WSW & 25000 & AM-241 & $1.1 \mathrm{E}-11$ & $2.1 \mathrm{E}-18$ & $4.4 \mathrm{E}-19$ & $2.5 \mathrm{E}-18$ \\
\hline WSW & 25000 & PU-238 & 8.8E-12 & $1.6 \mathrm{E}-18$ & 3.3E-19 & $1.9 \mathrm{E}-18$ \\
\hline WSW & 25000 & PU-239 & $1.1 \mathrm{E}-11$ & $2.0 \mathrm{E}-18$ & $4.2 E-19$ & $2.4 \mathrm{E}-18$ \\
\hline WSW & 35000 & AM-241 & $7.6 \mathrm{E}-12$ & $1.4 \mathrm{E}-18$ & $3.0 \mathrm{E}-19$ & 1.7E-18 \\
\hline WSW & 35000 & PU-238 & $5.8 \mathrm{E}-12$ & $1.0 \mathrm{E}-18$ & 2.3E-19 & 1.3E-18 \\
\hline WSW & 35000 & PU-239 & 7.3E-12 & 1.3E-18 & $2.9 \mathrm{E}-19$ & $1.6 \mathrm{E}-18$ \\
\hline WSW & 45000 & AM-241 & $5.5 \mathrm{E}-12$ & $9.9 \mathrm{E}-19$ & 2.3E-19 & $1.2 \mathrm{E}-18$ \\
\hline WSW & 45000 & PU-238 & $4.2 E-12$ & 7.6E-19 & 1.7E-19 & 9.3E-19 \\
\hline WSW & 45000 & PU-239 & $5.2 \mathrm{E}-12$ & $9.4 \mathrm{E}-19$ & 2.2E-19 & 1.2E-18 \\
\hline WSW & 55000 & AM-241 & $4.1 \mathrm{E}-12$ & 7.3E-19 & $1.8 \mathrm{E}-19$ & $9.1 \mathrm{E}-19$ \\
\hline WSW & 55000 & PU-238 & $3.1 \mathrm{E}-12$ & 5.6E-19 & 1.3E-19 & 6.9E-19 \\
\hline WSW & 55000 & PU-239 & $3.9 \mathrm{E}-12$ & 6.9E-19 & 1.7E-19 & 8.6E-19 \\
\hline WSW & 70000 & AM-241 & $2.5 \mathrm{E}-12$ & $4.4 \mathrm{E}-19$ & 1.2E-19 & 5.6E-19 \\
\hline WSW & 70000 & PU-238 & $1.9 \mathrm{E}-12$ & $3.4 \mathrm{E}-19$ & $9.1 \mathrm{E}-20$ & 4.3E-19 \\
\hline WSW & 70000 & PU-239 & 2.3E-12 & $4.2 \mathrm{E}-19$ & $1.2 \mathrm{E}-19$ & 5.4E-19 \\
\hline SW & 250 & AM-241 & 8.6E-10 & $1.6 \mathrm{E}-16$ & $5.5 \mathrm{E}-17$ & $2.1 \mathrm{E}-16$ \\
\hline SW & 250 & PU-238 & $6.6 \mathrm{E}-10$ & $1.2 \mathrm{E}-16$ & $4.2 \mathrm{E}-17$ & $1.6 \mathrm{E}-16$ \\
\hline SW & 250 & PU-239 & $8.0 \mathrm{E}-10$ & $1.4 \mathrm{E}-16$ & $5.3 \mathrm{E}-17$ & $2.0 \mathrm{E}-16$ \\
\hline SW & 750 & AM-241 & 5.0E-10 & $8.9 E-17$ & $1.8 \mathrm{E}-17$ & $1.1 \mathrm{E}-16$ \\
\hline SW & 750 & PU-238 & 4.0E-10 & $7.1 \mathrm{E}-17$ & $1.4 \mathrm{E}-17$ & 8.5E-17 \\
\hline SW & 750 & PU-239 & $4.5 \mathrm{E}-10$ & $8.2 \mathrm{E}-17$ & $1.8 \mathrm{E}-17$ & $9.9 \mathrm{E}-17$ \\
\hline SW & 1500 & AM-241 & $3.2 E-10$ & $5.7 \mathrm{E}-17$ & $9.1 \mathrm{E}-18$ & 6.6E-17 \\
\hline SW & 1500 & PU-238 & $2.6 \mathrm{E}-10$ & $4.7 \mathrm{E}-17$ & $6.9 \mathrm{E}-18$ & $5.4 \mathrm{E}-17$ \\
\hline SW & 1500 & PU-239 & $2.9 \mathrm{E}-10$ & $5.2 \mathrm{E}-17$ & 8.7E-18 & $6.1 \mathrm{E}-17$ \\
\hline SW & 2500 & AM-241 & 2.1E-10 & $3.7 \mathrm{E}-17$ & $5.4 \mathrm{E}-18$ & 4.3E-17 \\
\hline SW & 2500 & PU-238 & $1.7 \mathrm{E}-10$ & $3.0 \mathrm{E}-17$ & 4.1E-18 & $3.4 \mathrm{E}-17$ \\
\hline SW & 2500 & PU-239 & $1.9 \mathrm{E}-10$ & $3.5 \mathrm{E}-17$ & $5.2 E-18$ & 4.0E-17 \\
\hline SW & 3500 & AM-241 & $1.4 \mathrm{E}-10$ & 2.6E-17 & $3.8 \mathrm{E}-18$ & 3.0E-17 \\
\hline SW & 3500 & PU-238 & $1.1 \mathrm{E}-10$ & 2.1E-17 & 2.9E-18 & 2.3E-17 \\
\hline SW & 3500 & PU-239 & 1.3E-10 & $2.4 \mathrm{E}-17$ & $3.7 \mathrm{E}-18$ & 2.8E-17 \\
\hline SW & 4500 & AM-241 & $1.1 \mathrm{E}-10$ & $1.9 \mathrm{E}-17$ & $3.0 \mathrm{E}-18$ & 2.2E-17 \\
\hline SW & 4500 & PU-238 & $8.5 \mathrm{E}-11$ & $1.5 \mathrm{E}-17$ & 2.2E-18 & $1.8 \mathrm{E}-17$ \\
\hline SW & 4500 & PU-239 & $1.0 \mathrm{E}-10$ & $1.8 \mathrm{E}-17$ & $2.8 \mathrm{E}-18$ & $2.1 \mathrm{E}-17$ \\
\hline
\end{tabular}


Waste Isolation Pilot Plant Biennial Environmental Compliance Report DOE/WIPP 99-2171

Apr 24, $2000 \quad 12: 45$ pm

CONCENTRATIONS

Page 8

ESTIMATED RADIONUCLIDE CONCENTRATIONS

AT VARIOUS LOCATIONS IN THE ENVIRONMENT

\begin{tabular}{|c|c|c|c|c|c|c|}
\hline $\begin{array}{l}\text { Wind } \\
\text { Toward } \\
\end{array}$ & $\begin{array}{l}\text { Distance } \\
\text { (meters) }\end{array}$ & Nuclide & $\begin{array}{c}\text { Air } \\
\text { Concentration } \\
(\mathrm{pCi} / \mathrm{m} 3)\end{array}$ & $\begin{array}{c}\text { Dry } \\
\text { Deposition } \\
\text { Rate } \\
\text { (pCi/cm2/s) }\end{array}$ & $\begin{array}{c}\text { Wet } \\
\text { Deposition } \\
\text { Rate } \\
\text { (pCi/cm2/s) }\end{array}$ & $\begin{array}{c}\text { Ground } \\
\text { Deposition } \\
\text { Rate } \\
\text { (pCi/cm2/s) }\end{array}$ \\
\hline SW & 7500 & AM-241 & $5.8 E-11$ & $1.0 \mathrm{E}-17$ & 1.7E-18 & 1.2E-17 \\
\hline SW & 7500 & PU-238 & $4.5 \mathrm{E}-11$ & 8.1E-18 & 1.3E-18 & $9.4 \mathrm{E}-18$ \\
\hline SW & 7500 & PU-239 & $5.4 \mathrm{E}-11$ & $9.8 \mathrm{E}-18$ & $1.6 \mathrm{E}-18$ & $1.1 \mathrm{E}-17$ \\
\hline SW & 15000 & AM-241 & $2.4 \mathrm{E}-11$ & $4.4 \mathrm{E}-18$ & 8.2E-19 & $5.2 \mathrm{E}-18$ \\
\hline SW & 15000 & PU-238 & $1.9 \mathrm{E}-11$ & $3.4 \mathrm{E}-18$ & 6.2E-19 & 4.0E-18 \\
\hline SW & 15000 & PU-239 & $2.3 E-11$ & $4.2 E-18$ & 7.8E-19 & $4.9 \mathrm{E}-18$ \\
\hline SW & 25000 & AM-241 & $1.2 \mathrm{E}-11$ & $2.2 \mathrm{E}-18$ & $4.4 \mathrm{E}-19$ & $2.6 \mathrm{E}-18$ \\
\hline SW & 25000 & PU-238 & $9.2 \mathrm{E}-12$ & $1.7 \mathrm{E}-18$ & $3.3 E-19$ & $2.0 \mathrm{E}-18$ \\
\hline SW & 25000 & PU-239 & $1.1 \mathrm{E}-11$ & $2.1 \mathrm{E}-18$ & $4.2 \mathrm{E}-19$ & $2.5 \mathrm{E}-18$ \\
\hline SW & 35000 & AM-241 & $8.0 \mathrm{E}-12$ & $1.4 \mathrm{E}-18$ & 3.0E-19 & 1.7E-18 \\
\hline SW & 35000 & PU-238 & $6.1 \mathrm{E}-12$ & $1.1 \mathrm{E}-18$ & $2.3 \mathrm{E}-19$ & 1.3E-18 \\
\hline SW & 35000 & PU-239 & 7.6E-12 & $1.4 \mathrm{E}-18$ & $2.9 \mathrm{E}-19$ & $1.7 \mathrm{E}-18$ \\
\hline SW & 45000 & AM-241 & $5.7 \mathrm{E}-12$ & $1.0 \mathrm{E}-18$ & 2.3E-19 & 1.3E-18 \\
\hline SW & 45000 & PU-238 & $4.4 \mathrm{E}-12$ & $7.9 \mathrm{E}-19$ & 1.7E-19 & $9.6 \mathrm{E}-19$ \\
\hline SW & 45000 & PU-239 & $5.4 \mathrm{E}-12$ & $9.8 \mathrm{E}-19$ & $2.2 \mathrm{E}-19$ & 1.2E-18 \\
\hline SW & 55000 & AM-241 & $4.2 \mathrm{E}-12$ & $7.5 \mathrm{E}-19$ & $1.7 \mathrm{E}-19$ & $9.3 \mathrm{E}-19$ \\
\hline SW & 55000 & PU-238 & $3.2 E-12$ & 5.7E-19 & 1.3E-19 & 7.0E-19 \\
\hline SW & 55000 & PU-239 & $4.0 \mathrm{E}-12$ & $7.1 \mathrm{E}-19$ & $1.7 \mathrm{E}-19$ & 8.8E-19 \\
\hline SW & 70000 & AM-241 & $2.5 \mathrm{E}-12$ & $4.5 \mathrm{E}-19$ & $1.2 \bar{E}-19$ & 5.6E-19 \\
\hline SW & 70000 & PU-238 & $1.9 \mathrm{E}-12$ & $3.4 \mathrm{E}-19$ & 8.8E-20 & 4.3E-19 \\
\hline SW & 70000 & PU-239 & $2.4 \mathrm{E}-12$ & 4.3E-19 & $1.1 \mathrm{E}-19$ & 5.4E-19 \\
\hline SSW & 250 & AM-241 & $8.9 E-10$ & 1.6E-16 & 5.6E-17 & $2.2 \mathrm{E}-16$ \\
\hline SSW & 250 & PU-238 & $6.8 \mathrm{E}-10$ & $1.2 \mathrm{E}-16$ & $4.2 \mathrm{E}-17$ & $1.7 \mathrm{E}-16$ \\
\hline SSW & 250 & PU-239 & $8.2 \mathrm{E}-10$ & $1.5 \mathrm{E}-16$ & 5.3E-17 & $2.0 \mathrm{E}-16$ \\
\hline SSW & 750 & AM-241 & $5.0 \mathrm{E}-10$ & $9.0 \mathrm{E}-17$ & $1.9 \mathrm{E}-17$ & $1.1 \mathrm{E}-16$ \\
\hline SSW & 750 & PU-238 & $4.0 \mathrm{E}-10$ & $7.2 \mathrm{E}-17$ & $1.4 \mathrm{E}-17$ & $8.6 \mathrm{E}-17$ \\
\hline SSW & 750 & PU-239 & $4.5 \mathrm{E}-10$ & $8.2 \mathrm{E}-17$ & $1.8 \mathrm{E}-17$ & $9.9 \mathrm{E}-17$ \\
\hline SSW & 1500 & AM-241 & $3.2 \mathrm{E}-10$ & $5.8 \mathrm{E}-17$ & $9.2 \mathrm{E}-18$ & $6.7 \mathrm{E}-17$ \\
\hline SSW & 1500 & PU-238 & $2.6 \mathrm{E}-10$ & $4.7 \mathrm{E}-17$ & $7.0 \mathrm{E}-18$ & $5.4 \mathrm{E}-17$ \\
\hline SSW & 1500 & PU-239 & $2.9 \mathrm{E}-10$ & 5.3E-17 & $8.8 \mathrm{E}-18$ & $6.1 \mathrm{E}-17$ \\
\hline SSW & 2500 & AM-241 & $2.1 \mathrm{E}-10$ & $3.7 \mathrm{E}-17$ & $5.5 \mathrm{E}-18$ & 4.3E-17 \\
\hline SSW & 2500 & PU-238 & $1.7 \mathrm{E}-10$ & $3.0 \mathrm{E}-17$ & $4.2 \mathrm{E}-18$ & $3.4 \mathrm{E}-17$ \\
\hline SSW & 2500 & PU-239 & $1.9 \mathrm{E}-10$ & $3.5 \mathrm{E}-17$ & 5.2E-18 & $4.0 \mathrm{E}-17$ \\
\hline SSW & 3500 & AM-241 & $1.4 \mathrm{E}-10$ & 2.6E-17 & $3.9 E-18$ & $3.0 \mathrm{E}-17$ \\
\hline SSW & 3500 & PU-238 & $1.1 \mathrm{E}-10$ & $2.0 \mathrm{E}-17$ & $2.9 \mathrm{E}-18$ & $2.3 \mathrm{E}-17$ \\
\hline SSW & 3500 & PU-239 & $1.3 \mathrm{E}-10$ & $2.4 \mathrm{E}-17$ & $3.7 \mathrm{E}-18$ & $2.8 \mathrm{E}-17$ \\
\hline
\end{tabular}


Waste Isolation Pilot Plant Biennial Environmental Compliance Report DOE/WIPP 99-2171

Apr 24, $2000 \quad 12: 45$ pm

CONCENTRATIONS

Page 9

ESTIMATED RADIONUCLIDE CONCENTRATIONS

AT VARIOUS LOCATIONS IN THE ENVIRONMENT

\begin{tabular}{|c|c|c|c|c|c|c|}
\hline $\begin{array}{l}\text { Wind } \\
\text { Toward }\end{array}$ & $\begin{array}{l}\text { Distance } \\
\text { (meters) }\end{array}$ & Nuclide & $\begin{array}{c}\text { Air } \\
\text { Concentration } \\
(\mathrm{pCi} / \mathrm{m} 3)\end{array}$ & $\begin{array}{c}\text { Dry } \\
\text { Deposition } \\
\text { Rate } \\
\text { (pCi/cm2/s) }\end{array}$ & $\begin{array}{c}\text { Wet } \\
\text { Deposition } \\
\text { Rate } \\
\text { (pCi/cm2/s) }\end{array}$ & $\begin{array}{c}\text { Ground } \\
\text { Deposition } \\
\text { Rate } \\
\text { (pCi/cm2/s) }\end{array}$ \\
\hline SSW & 4500 & AM-241 & $1.1 \mathrm{E}-10$ & $1.9 \mathrm{E}-17$ & $3.0 E-18$ & 2.2E-17 \\
\hline SSW & 4500 & PU-238 & $8.4 \mathrm{E}-11$ & $1.5 \mathrm{E}-17$ & 2.3E-18 & 1.7E-17 \\
\hline SSW & 4500 & PU-239 & $1.0 \mathrm{E}-10$ & $1.8 \mathrm{E}-17$ & $2.8 \mathrm{E}-18$ & 2.1E-17 \\
\hline SSW & 7500 & AM-241 & $5.7 \mathrm{E}-11$ & $1.0 \mathrm{E}-17$ & $1.7 \mathrm{E}-18$ & $1.2 \mathrm{E}-17$ \\
\hline SSW & 7500 & PU-238 & $4.4 \mathrm{E}-11$ & $7.9 \mathrm{E}-18$ & $1.3 E-18$ & $9.2 \mathrm{E}-18$ \\
\hline SSW & 7500 & PU-239 & $5.4 \mathrm{E}-11$ & $9.7 \mathrm{E}-18$ & $1.7 \mathrm{E}-18$ & $1.1 \mathrm{E}-17$ \\
\hline SSW & 15000 & AM-241 & $2.4 \mathrm{E}-11$ & 4.3E-18 & 8.3E-19 & 5.1E-18 \\
\hline SSW & 15000 & PU-238 & $1.8 \mathrm{E}-11$ & $3.3 E-18$ & $6.2 \mathrm{E}-19$ & $3.9 E-18$ \\
\hline SSW & 15000 & PU-239 & $2.3 E-11$ & $4.1 \mathrm{E}-18$ & $7.9 \mathrm{E}-19$ & $4.9 \mathrm{E}-18$ \\
\hline SSW & 25000 & AM-241 & $1.2 \mathrm{E}-11$ & $2.1 \mathrm{E}-18$ & $4.5 E-19$ & 2.6E-18 \\
\hline SSW & 25000 & PU-238 & $9.0 \mathrm{E}-12$ & $1.6 \mathrm{E}-18$ & $3.4 \mathrm{E}-19$ & 2.0E-18 \\
\hline SSW & 25000 & PU-239 & $1.1 \mathrm{E}-11$ & $2.0 \mathrm{E}-18$ & $4.3 \mathrm{E}-19$ & $2.4 \mathrm{E}-18$ \\
\hline SSW & 35000 & AM-241 & $7.8 \mathrm{E}-12$ & $1.4 \mathrm{E}-18$ & $3.1 \mathrm{E}-19$ & 1.7E-18 \\
\hline SSW & 35000 & PU-238 & $5.9 \mathrm{E}-12$ & $1.1 \mathrm{E}-18$ & $2.3 \mathrm{E}-19$ & 1.3E-18 \\
\hline SSW & 35000 & PU-239 & $7.4 \mathrm{E}-12$ & 1.3E-18 & $3.0 \mathrm{E}-19$ & $1.6 \mathrm{E}-18$ \\
\hline SSW & 45000 & AM-241 & $5.6 \mathrm{E}-12$ & $1.0 \mathrm{E}-18$ & $2.3 \mathrm{E}-19$ & $1.2 \mathrm{E}-18$ \\
\hline SSW & 45000 & PU-238 & 4.3E-12 & $7.7 \mathrm{E}-19$ & $1.7 \mathrm{E}-19$ & $9.4 \mathrm{E}-19$ \\
\hline SSW & 45000 & PU-239 & 5.3E-12 & $9.6 \mathrm{E}-19$ & 2.2E-19 & $1.2 \mathrm{E}-18$ \\
\hline SSW & 55000 & AM-241 & $4.1 \mathrm{E}-12$ & 7.3E-19 & $1.8 \mathrm{E}-19$ & $9.1 \mathrm{E}-19$ \\
\hline SSW & 55000 & PU-238 & $3.1 \mathrm{E}-12$ & $5.6 \mathrm{E}-19$ & 1.3E-19 & $6.9 \mathrm{E}-19$ \\
\hline SSW & 55000 & PU-239 & $3.9 \mathrm{E}-12$ & 7.0E-19 & 1.7E-19 & 8.7E-19 \\
\hline SSW & 70000 & AM-241 & $2.4 \mathrm{E}-12$ & $4.4 \mathrm{E}-19$ & $1.2 \mathrm{E}-19$ & 5.6E-19 \\
\hline SSW & 70000 & PU-238 & $1.8 \mathrm{E}-12$ & 3.3E-19 & $9.0 \mathrm{E}-20$ & $4.2 \mathrm{E}-19$ \\
\hline SSW & 70000 & PU-239 & 2.3E-12 & $4.2 \mathrm{E}-19$ & $1.1 \mathrm{E}-19$ & 5.3E-19 \\
\hline$S$ & 250 & AM-241 & $9.0 \mathrm{E}-10$ & $1.6 \mathrm{E}-16$ & $5.1 \mathrm{E}-17$ & $2.1 \mathrm{E}-16$ \\
\hline S & 250 & PU-238 & 7.0E-10 & 1.3E-16 & $3.9 \mathrm{E}-17$ & $1.6 \mathrm{E}-16$ \\
\hline S & 250 & PU-239 & $8.2 E-10$ & $1.5 \mathrm{E}-16$ & $4.9 \mathrm{E}-17$ & $2.0 \mathrm{E}-16$ \\
\hline S & 750 & AM-241 & $5.3 \mathrm{E}-10$ & $9.5 \mathrm{E}-17$ & $1.7 \mathrm{E}-17$ & $1.1 \mathrm{E}-16$ \\
\hline S & 750 & PU-238 & $4.2 E-10$ & $7.6 \mathrm{E}-17$ & 1.3E-17 & $8.8 \mathrm{E}-17$ \\
\hline S & 750 & PU-239 & $4.9 \mathrm{E}-10$ & $8.8 \mathrm{E}-17$ & $1.6 \mathrm{E}-17$ & $1.0 \mathrm{E}-16$ \\
\hline S & 1500 & AM-241 & $3.1 \mathrm{E}-10$ & $5.6 \mathrm{E}-17$ & $8.5 \mathrm{E}-18$ & $6.4 \mathrm{E}-17$ \\
\hline $\mathrm{S}$ & 1500 & PU-238 & $2.5 \mathrm{E}-10$ & $4.5 \mathrm{E}-17$ & $6.4 \mathrm{E}-18$ & $5.1 \mathrm{E}-17$ \\
\hline$S$ & 1500 & PU-239 & $2.9 \mathrm{E}-10$ & $5.1 \mathrm{E}-17$ & $8.1 \mathrm{E}-18$ & $5.9 \mathrm{E}-17$ \\
\hline$S$ & 2500 & AM-241 & $1.9 \mathrm{E}-10$ & $3.4 \mathrm{E}-17$ & 5.0E-18 & $3.9 \mathrm{E}-17$ \\
\hline $\mathrm{S}$ & 2500 & PU-238 & $1.5 \mathrm{E}-10$ & 2.7E-17 & $3.8 \mathrm{E}-18$ & $3.0 \mathrm{E}-17$ \\
\hline S & 2500 & PU-239 & $1.7 \mathrm{E}-10$ & $3.1 \mathrm{E}-17$ & $4.8 \mathrm{E}-18$ & $3.6 \mathrm{E}-17$ \\
\hline
\end{tabular}


Waste Isolation Pilot Plant Biennial Environmental Compliance Report DOE/WIPP 99-2171

Apr 24, $2000 \quad 12: 45$ pm

CONCENTRATIONS

Page 10

ESTIMATED RADIONUCLIDE CONCENTRATIONS

AT VARIOUS LOCATIONS IN THE ENVIRONMENT

\begin{tabular}{|c|c|c|c|c|c|c|}
\hline $\begin{array}{l}\text { Wind } \\
\text { Toward }\end{array}$ & $\begin{array}{l}\text { Distance } \\
\text { (meters) }\end{array}$ & Nuclide & $\begin{array}{c}\text { Air } \\
\text { Concentration } \\
(\mathrm{pCi} / \mathrm{m} 3)\end{array}$ & $\begin{array}{c}\text { Dry } \\
\text { Deposition } \\
\text { Rate } \\
\text { (pCi/cm2/s) }\end{array}$ & $\begin{array}{c}\text { Wet } \\
\text { Deposition } \\
\text { Rate } \\
\text { (pCi/cm2/s) }\end{array}$ & $\begin{array}{c}\text { Ground } \\
\text { Deposition } \\
\text { Rate } \\
\text { (pCi/cm2/s) }\end{array}$ \\
\hline S & 3500 & AM-241 & $1.3 \mathrm{E}-10$ & $2.3 \mathrm{E}-17$ & $3.6 \mathrm{E}-18$ & $2.6 \mathrm{E}-17$ \\
\hline S & 3500 & PU- & $9.8 \mathrm{E}-11$ & $1.8 \mathrm{E}-17$ & $2.7 \mathrm{E}-18$ & $2.0 \mathrm{E}-17$ \\
\hline $\mathrm{S}$ & 3500 & PU-239 & $1.2 \mathrm{E}-10$ & $2.1 \mathrm{E}-17$ & $3.4 \mathrm{E}-18$ & $2.5 \mathrm{E}-17$ \\
\hline $\mathrm{S}$ & 4500 & AM-241 & $9.3 \mathrm{E}-11$ & $1.7 \mathrm{E}-17$ & $2.7 \mathrm{E}-18$ & $1.9 \mathrm{E}-17$ \\
\hline $\mathrm{S}$ & 4500 & PU-238 & $7.2 \mathrm{E}-11$ & $1.3 \mathrm{E}-17$ & $2.1 \mathrm{E}-18$ & $1.5 \mathrm{E}-17$ \\
\hline $\mathrm{S}$ & 4500 & PU-239 & 8.7E-11 & $1.6 \mathrm{E}-17$ & $2.6 \mathrm{E}-18$ & $1.8 \mathrm{E}-17$ \\
\hline$S$ & 7500 & AM-241 & $4.8 \mathrm{E}-11$ & 8.7E-18 & $1.6 \mathrm{E}-18$ & 1.0E-17 \\
\hline$S$ & 7500 & PU-238 & $3.7 \mathrm{E}-11$ & $6.7 \mathrm{E}-18$ & $1.2 \mathrm{E}-18$ & $7.9 \mathrm{E}-18$ \\
\hline $\mathrm{S}$ & 7500 & PU-239 & $4.6 \mathrm{E}-11$ & $8.2 \mathrm{E}-18$ & $1.5 \mathrm{E}-18$ & $9.8 \mathrm{E}-18$ \\
\hline$S$ & 15000 & AM-241 & 2.0E-11 & $3.6 \mathrm{E}-18$ & $7.6 \mathrm{E}-19$ & $4.4 \mathrm{E}-18$ \\
\hline S & 15000 & PU-238 & $1.5 \mathrm{E}-11$ & $2.8 \mathrm{E}-18$ & $5.8 \mathrm{E}-19$ & $3.4 \mathrm{E}-18$ \\
\hline S & 15000 & PU-239 & $1.9 \mathrm{E}-11$ & $3.4 \mathrm{E}-18$ & 7.3E-19 & $4.2 \mathrm{E}-18$ \\
\hline S & 25000 & $1-241$ & 1.01 & $1.8 \mathrm{E}-18$ & $4.2 \mathrm{E}-19$ & $2.2 \mathrm{E}-18$ \\
\hline S & 25000 & PU-238 & $7.6 \mathrm{E}-12$ & $1.4 \mathrm{E}-18$ & $3.2 \mathrm{E}-19$ & $1.7 \mathrm{E}-18$ \\
\hline S & 25000 & PU-239 & $9.5 \mathrm{E}-12$ & $1.7 \mathrm{E}-18$ & $4.0 \mathrm{E}-19$ & $2.1 \bar{E}-18$ \\
\hline S & 35000 & AM-241 & 6.6 & $1.2 \mathrm{E}-18$ & $2.9 \mathrm{E}-19$ & $E-18$ \\
\hline S & 35000 & J-238 & 5.0 & $9.0 \mathrm{E}-19$ & $2.2 \mathrm{E}-19$ & $1.1 \mathrm{E}-18$ \\
\hline S & & 99 & & $1.1 \mathrm{E}-18$ & $2.8 \mathrm{E}$ & -18 \\
\hline S & 45 & AM-241 & $4.7 \mathrm{E}$ & $8.5 \mathrm{E}-19$ & $2.2 \mathrm{E}-19$ & $1.1 \mathrm{E}-18$ \\
\hline S & & & & $6.5 \mathrm{E}-19$ & $1.6 \mathrm{E}-19$ & $E-19$ \\
\hline S & 10 & PU-239 & $4.5 \mathrm{E}-12$ & $8.1 \mathrm{E}-19$ & 2. $1 \mathrm{E}-19$ & 1.0E-18 \\
\hline S & & AM-241 & 3.5 & $6.3 \mathrm{E}-19$ & & 7.9E-19 \\
\hline S & 5 & PU-238 & 2.6E-12 & $4.8 \mathrm{E}-19$ & 1.3E-19 & $6.0 \mathrm{E}-19$ \\
\hline$c$ & & PU-239 & $3.3 \mathrm{E}$ & $6.0 \mathrm{E}-19$ & $1.6 \mathrm{E}-19$ & $E-19$ \\
\hline$S$ & 78 & AM-241 & $2.1 \mathrm{E}-12$ & $3.8 \mathrm{E}-19$ & $1.2 \mathrm{E}-19$ & $5.0 \mathrm{E}-19$ \\
\hline 0 & 7( & Pl & 1.6 & $2.9 \mathrm{E}-19$ & $8.8 \mathrm{E}-20$ & $E-19$ \\
\hline S & 70000 & $\mathrm{Pl}$ & 2.0E-12 & 3.6E-19 & $1.1 \mathrm{E}-19$ & $4.7 \mathrm{E}-19$ \\
\hline & 250 & AM-241 & $8.9 \mathrm{E}-10$ & $1.6 \mathrm{E}-16$ & $4.9 \mathrm{E}-17$ & $2.1 \mathrm{E}-16$ \\
\hline & & PU-238 & 7.0E-10 & $1.3 \mathrm{E}-16$ & 3.8E-17 & 1.6E-16 \\
\hline & 25 & PU-239 & 8.1 & $1.5 \mathrm{E}-16$ & 4.7E-17 & $1.9 \mathrm{E}-16$ \\
\hline & 750 & AM-241 & $5.2 \mathrm{E}$ & $9.3 \mathrm{E}-17$ & $1.6 \mathrm{E}-17$ & $1.1 \mathrm{E}-16$ \\
\hline & 750 & PU-238 & $4.1 \mathrm{E}-10$ & 7.4E-17 & $1.2 \mathrm{E}-17$ & 8.7E-17 \\
\hline & 150 & PU-239 & $4.7 \mathrm{E}-10$ & $8.5 \mathrm{E}-17$ & $1.6 \mathrm{E}-17$ & $1.0 \mathrm{E}-16$ \\
\hline & 150 & AM-241 & $3.0 \mathrm{E}-10$ & $5.3 \mathrm{E}-17$ & $8.2 \mathrm{E}-18$ & $6.1 \mathrm{E}-17$ \\
\hline & 15 & PU-238 & 2.4E-10 & 4.3E-17 & $6.2 \mathrm{E}-18$ & $4.9 \mathrm{E}-17$ \\
\hline & 1500 & PU-239 & 2.7E-10 & $4.9 \mathrm{E}-17$ & $7.8 \mathrm{E}-18$ & 5.7E-17 \\
\hline
\end{tabular}


Waste Isolation Pilot Plant Biennial Environmental Compliance Report DOE/WIPP 99-2171

Apr 24, $2000 \quad 12: 45$ pm

CONCENTRATIONS

Page 12

ESTIMATED RADIONUCLIDE CONCENTRATIONS

AT VARIOUS LOCATIONS IN THE ENVIRONMENT

\begin{tabular}{|c|c|c|c|c|c|c|}
\hline $\begin{array}{l}\text { Wind } \\
\text { Toward }\end{array}$ & $\begin{array}{l}\text { Distance } \\
\text { (meters) }\end{array}$ & Nuclide & $\begin{array}{c}\text { Air } \\
\text { Concentration } \\
(\mathrm{pCi} / \mathrm{m} 3)\end{array}$ & $\begin{array}{c}\text { Dry } \\
\text { Deposition } \\
\text { Rate } \\
\text { (pCi/cm2/s) }\end{array}$ & $\begin{array}{c}\text { Wet } \\
\text { Deposition } \\
\text { Rate } \\
\text { (pCi/cm2/s) }\end{array}$ & $\begin{array}{c}\text { Ground } \\
\text { Deposition } \\
\text { Rate } \\
\text { (pCi/cm2/s) }\end{array}$ \\
\hline SSE & 2500 & AM-241 & $1.7 \mathrm{E}-10$ & $3.1 \mathrm{E}-17$ & $4.8 \mathrm{E}-18$ & $3.6 \mathrm{E}-17$ \\
\hline SSE & 2500 & PU-238 & $1.4 \mathrm{E}-10$ & $2.5 \mathrm{E}-17$ & $3.7 E-18$ & 2.8E-17 \\
\hline SSE & 2500 & PU-239 & $1.6 \mathrm{E}-10$ & $2.9 \mathrm{E}-17$ & $4.6 \mathrm{E}-18$ & $3.4 \mathrm{E}-17$ \\
\hline SSE & 3500 & AM-241 & $1.2 \mathrm{E}-10$ & $2.1 \mathrm{E}-17$ & $3.4 \mathrm{E}-18$ & $2.4 \mathrm{E}-17$ \\
\hline SSE & 3500 & PU-238 & $9.0 \mathrm{E}-11$ & $1.6 \mathrm{E}-17$ & $2.6 \mathrm{E}-18$ & $1.9 \mathrm{E}-17$ \\
\hline SSE & 3500 & PU-239 & $1.1 \mathrm{E}-10$ & $2.0 \mathrm{E}-17$ & 3.3E-18 & 2.3E-17 \\
\hline SSE & 4500 & AM-241 & $8.4 \mathrm{E}-11$ & $1.5 \mathrm{E}-17$ & $2.6 \mathrm{E}-18$ & $1.8 \mathrm{E}-17$ \\
\hline SSE & 4500 & PU-238 & $6.5 \mathrm{E}-11$ & $1.2 \mathrm{E}-17$ & $2.0 \mathrm{E}-18$ & $1.4 \mathrm{E}-17$ \\
\hline SSE & 4500 & PU-239 & $8.0 \mathrm{E}-11$ & $1.4 \mathrm{E}-17$ & $2.5 \mathrm{E}-18$ & $1.7 \mathrm{E}-17$ \\
\hline SSE & 7500 & AM-241 & 4.3E-11 & 7.8E-18 & $1.5 \mathrm{E}-18$ & 9.3E-18 \\
\hline SSE & 7500 & PU-238 & $3.3 \mathrm{E}-11$ & $6.0 \mathrm{E}-18$ & $1.2 \mathrm{E}-18$ & $7.2 \mathrm{E}-18$ \\
\hline SSE & 7500 & PU-239 & $4.1 \mathrm{E}-11$ & $7.4 \mathrm{E}-18$ & $1.5 \mathrm{E}-18$ & $8.9 \mathrm{E}-18$ \\
\hline SSE & 15000 & AM-241 & $1.8 \mathrm{E}-11$ & $3.2 E-18$ & 7.3E-19 & $3.9 E-18$ \\
\hline SSE & 15000 & PU-238 & $1.4 \mathrm{E}-11$ & $2.5 \mathrm{E}-18$ & $5.5 \mathrm{E}-19$ & $3.0 \mathrm{E}-18$ \\
\hline SSE & 15000 & PU-239 & $1.7 \mathrm{E}-11$ & $3.0 \mathrm{E}-18$ & 7.0E-19 & $3.7 \mathrm{E}-18$ \\
\hline SSE & 25000 & AM-241 & 8.7E-12 & 1.6E-18 & $4.0 \mathrm{E}-19$ & $2.0 \mathrm{E}-18$ \\
\hline SSE & 25000 & PU-238 & $6.6 \mathrm{E}-12$ & $1.2 \mathrm{E}-18$ & $3.0 \mathrm{E}-19$ & $1.5 \mathrm{E}-18$ \\
\hline SSE & 25000 & PU-239 & $8.3 E-12$ & $1.5 \mathrm{E}-18$ & 3.8E-19 & $1.9 \mathrm{E}-18$ \\
\hline SSE & 35000 & AM-241 & $5.7 \mathrm{E}-12$ & $1.0 \mathrm{E}-18$ & 2.8E-19 & $1.3 E-18$ \\
\hline SSE & 35000 & PU-238 & $4.4 \mathrm{E}-12$ & 7.9E-19 & 2.1E-19 & $1.0 \mathrm{E}-18$ \\
\hline SSE & 35000 & PU-239 & $5.4 \mathrm{E}-12$ & 9.8E-19 & 2.7E-19 & $1.2 \mathrm{E}-18$ \\
\hline SSE & 45000 & AM-241 & $4.1 \mathrm{E}-12$ & $7.4 \mathrm{E}-19$ & 2.1E-19 & $9.5 \mathrm{E}-19$ \\
\hline SSE & 45000 & PU-238 & $3.1 \mathrm{E}-12$ & 5.6E-19 & 1.6E-19 & $7.2 \mathrm{E}-19$ \\
\hline SSE & 45000 & PU-239 & $3.9 \mathrm{E}-12$ & $7.0 \mathrm{E}-19$ & 2.0E-19 & $9.0 \mathrm{E}-19$ \\
\hline SSE & 55000 & AM-241 & $3.0 \mathrm{E}-12$ & 5.4E-19 & 1.6E-19 & 7.0E-19 \\
\hline SSE & 55000 & PU-238 & $2.3 E-12$ & 4.1E-19 & 1.2E-19 & 5.3E-19 \\
\hline SSE & 55000 & PU-239 & $2.8 \mathrm{E}-12$ & $5.1 \mathrm{E}-19$ & $1.5 \mathrm{E}-19$ & $6.6 \mathrm{E}-19$ \\
\hline SSE & 70000 & AM-241 & $1.8 \mathrm{E}-12$ & $3.2 \mathrm{E}-19$ & $1.1 \mathrm{E}-19$ & $4.4 \mathrm{E}-19$ \\
\hline SSE & 70000 & PU-238 & $1.4 \mathrm{E}-12$ & 2.5E-19 & $8.4 \mathrm{E}-20$ & 3.3E-19 \\
\hline SSE & 70000 & PU-239 & $1.7 \mathrm{E}-12$ & $3.1 \mathrm{E}-19$ & $1.1 \mathrm{E}-19$ & $4.2 \mathrm{E}-19$ \\
\hline SE & 250 & AM-241 & $8.9 E-10$ & $1.6 \mathrm{E}-16$ & $4.9 \mathrm{E}-17$ & $2.1 \mathrm{E}-16$ \\
\hline SE & 250 & PU-238 & $7.2 \mathrm{E}-10$ & 1.3E-16 & $3.7 \mathrm{E}-17$ & $1.7 \mathrm{E}-16$ \\
\hline SE & 250 & PU-239 & $8.1 \mathrm{E}-10$ & $1.5 \mathrm{E}-16$ & $4.6 \mathrm{E}-17$ & $1.9 \mathrm{E}-16$ \\
\hline SE & 750 & AM-241 & $4.9 \mathrm{E}-10$ & $8.8 \mathrm{E}-17$ & $1.6 \mathrm{E}-17$ & $1.0 \mathrm{E}-16$ \\
\hline SE & 750 & PU-238 & $3.9 E-10$ & $7.0 \mathrm{E}-17$ & $1.2 \mathrm{E}-17$ & $8.2 \mathrm{E}-17$ \\
\hline SE & 750 & PU-239 & $4.5 \mathrm{E}-10$ & $8.1 \mathrm{E}-17$ & $1.5 \mathrm{E}-17$ & $9.7 \mathrm{E}-17$ \\
\hline
\end{tabular}


Waste Isolation Pilot Plant Biennial Environmental Compliance Report DOE/WIPP 99-2171

Apr 24, $2000 \quad 12: 45$ pm

CONCENTRATIONS

Page 12

ESTIMATED RADIONUCLIDE CONCENTRATIONS

AT VARIOUS LOCATIONS IN THE ENVIRONMENT

\begin{tabular}{|c|c|c|c|c|c|c|}
\hline $\begin{array}{l}\text { Wind } \\
\text { Toward } \\
\end{array}$ & $\begin{array}{l}\text { Distance } \\
\text { (meters) }\end{array}$ & Nuclide & $\begin{array}{c}\text { Air } \\
\text { Concentration } \\
(\mathrm{pCi} / \mathrm{m} 3)\end{array}$ & $\begin{array}{c}\text { Dry } \\
\text { Deposition } \\
\text { Rate } \\
\text { (pCi/cm2/s) }\end{array}$ & $\begin{array}{c}\text { Wet } \\
\text { Deposition } \\
\text { Rate } \\
\text { (pCi/cm2/s) }\end{array}$ & $\begin{array}{c}\text { Ground } \\
\text { Deposition } \\
\text { Rate } \\
\text { (pCi/cm2/s) }\end{array}$ \\
\hline SE & 1500 & AM-241 & $2.6 \mathrm{E}-10$ & $4.6 \mathrm{E}-17$ & 8.0E-18 & $5.4 \mathrm{E}-17$ \\
\hline SE & 1500 & PU-238 & $2.1 \mathrm{E}-10$ & $3.7 \mathrm{E}-17$ & $6.1 \mathrm{E}-18$ & 4.3E-17 \\
\hline SE & 1500 & PU-239 & $2.4 \mathrm{E}-10$ & $4.2 \mathrm{E}-17$ & $7.6 \mathrm{E}-18$ & 5.0E-17 \\
\hline SE & 2500 & AM-241 & $1.5 \mathrm{E}-10$ & $2.7 \mathrm{E}-17$ & $4.8 \mathrm{E}-18$ & $3.2 \mathrm{E}-17$ \\
\hline SE & 2500 & PU-238 & $1.2 \mathrm{E}-10$ & $2.2 E-17$ & $3.6 \mathrm{E}-18$ & $2.5 \mathrm{E}-17$ \\
\hline SE & 2500 & PU-239 & $1.4 \mathrm{E}-10$ & $2.5 \mathrm{E}-17$ & $4.5 \mathrm{E}-18$ & $3.0 \mathrm{E}-17$ \\
\hline SE & 3500 & AM-241 & $1.0 \mathrm{E}-10$ & $1.8 \mathrm{E}-17$ & $3.4 \mathrm{E}-18$ & 2.2E-17 \\
\hline SE & 3500 & PU-238 & $7.9 \mathrm{E}-11$ & $1.4 \mathrm{E}-17$ & $2.5 \mathrm{E}-18$ & 1.7E-17 \\
\hline SE & 3500 & PU-239 & $9.5 \mathrm{E}-11$ & $1.7 \mathrm{E}-17$ & $3.2 \mathrm{E}-18$ & $2.0 \mathrm{E}-17$ \\
\hline SE & 4500 & AM-241 & $7.4 \mathrm{E}-11$ & 1.3E-17 & $2.6 \mathrm{E}-18$ & 1.6E-17 \\
\hline SE & 4500 & PU-238 & $5.8 \mathrm{E}-11$ & 1.0E-17 & 2.0E-18 & 1.2E-17 \\
\hline SE & 4500 & PU-239 & $7.0 \mathrm{E}-11$ & 1.3E-17 & $2.5 \mathrm{E}-18$ & $1.5 \mathrm{E}-17$ \\
\hline SE & 7500 & AM-241 & $3.8 \mathrm{E}-11$ & $6.9 E-18$ & $1.5 \mathrm{E}-18$ & $8.4 \mathrm{E}-18$ \\
\hline SE & 7500 & PU-238 & $3.0 \mathrm{E}-11$ & 5.3E-18 & $1.1 \mathrm{E}-18$ & $6.5 \mathrm{E}-18$ \\
\hline SE & 7500 & PU-239 & $3.6 \mathrm{E}-11$ & $6.5 \mathrm{E}-18$ & $1.4 \mathrm{E}-18$ & 8.0E-18 \\
\hline SE & 15000 & AM-241 & $1.6 \mathrm{E}-11$ & 2.8E-18 & 7.2E-19 & $3.6 \mathrm{E}-18$ \\
\hline SE & 15000 & PU-238 & $1.2 \mathrm{E}-11$ & $2.2 \mathrm{E}-18$ & $5.4 \mathrm{E}-19$ & 2.7E-18 \\
\hline$\overline{S E}$ & 15000 & PU-239 & $1.5 \mathrm{E}-11$ & $2.7 \mathrm{E}-18$ & $6.9 E-19$ & $3.4 \mathrm{E}-18$ \\
\hline SE & 25000 & AM-241 & $7.5 \mathrm{E}-12$ & $1.4 \mathrm{E}-18$ & 3.9E-19 & $1.8 \mathrm{E}-18$ \\
\hline SE & 25000 & PU-238 & $5.8 \mathrm{E}-12$ & $1.0 \mathrm{E}-18$ & $3.0 \mathrm{E}-19$ & 1.3E-18 \\
\hline SE & 25000 & PU-239 & $7.2 \mathrm{E}-12$ & $1.3 \mathrm{E}-18$ & $3.8 \mathrm{E}-19$ & 1.7E-18 \\
\hline SE & 35000 & AM-241 & $4.9 E-12$ & 8.9E-19 & 2.7E-19 & 1.2E-18 \\
\hline SE & 35000 & PU-238 & $3.8 \mathrm{E}-12$ & $6.8 \mathrm{E}-19$ & $2.1 \mathrm{E}-19$ & 8.8E-19 \\
\hline SE & 35000 & PU-239 & $4.7 E-12$ & 8.5E-19 & 2.6E-19 & 1.1E-18 \\
\hline SE & 45000 & AM-241 & $3.5 E-12$ & 6.3E-19 & 2.0E-19 & $8.4 \mathrm{E}-19$ \\
\hline SE & 45000 & PU-238 & $2.7 \mathrm{E}-12$ & $4.8 \mathrm{E}-19$ & $1.5 \mathrm{E}-19$ & $6.4 \mathrm{E}-19$ \\
\hline SE & 45000 & PU-239 & $3.3 E-12$ & $6.0 \mathrm{E}-19$ & $1.9 \mathrm{E}-19$ & 8.0E-19 \\
\hline SE & 55000 & AM-241 & $2.5 \mathrm{E}-12$ & 4.6E-19 & 1.6E-19 & $6.1 \mathrm{E}-19$ \\
\hline SE & 55000 & PU-238 & $1.9 \mathrm{E}-12$ & 3.5E-19 & 1.2E-19 & 4.7E-19 \\
\hline SE & 55000 & PU-239 & $2.4 \mathrm{E}-12$ & 4.3E-19 & $1.5 \mathrm{E}-19$ & $5.8 \mathrm{E}-19$ \\
\hline SE & 70000 & AM-241 & $1.5 \mathrm{E}-12$ & 2.7E-19 & 1.1E-19 & $3.8 E-19$ \\
\hline SE & 70000 & PU-238 & 1.1E-12 & 2.0E-19 & 8.2E-20 & $2.9 \mathrm{E}-19$ \\
\hline SE & 70000 & PU-239 & $1.4 \mathrm{E}-12$ & 2.6E-19 & $1.0 \mathrm{E}-19$ & $3.6 \mathrm{E}-19$ \\
\hline ESE & 250 & AM-241 & $9.7 E-10$ & $1.7 \mathrm{E}-16$ & $5.1 \mathrm{E}-17$ & 2.3E-16 \\
\hline$\overline{E S E}$ & 250 & PU-238 & $7.9 \mathrm{E}-10$ & $1.4 \mathrm{E}-16$ & $3.8 \mathrm{E}-17$ & $1.8 \mathrm{E}-16$ \\
\hline ESE & 250 & PU-239 & $8.8 \mathrm{E}-10$ & $1.6 \mathrm{E}-16$ & $4.8 \mathrm{E}-17$ & 2.1E-16 \\
\hline
\end{tabular}


Waste Isolation Pilot Plant Biennial Environmental Compliance Report DOE/WIPP 99-2171

Apr 24, $2000 \quad 12: 45$ pm

CONCENTRATIONS

Page 13

ESTIMATED RADIONUCLIDE CONCENTRATIONS

AT VARIOUS LOCATIONS IN THE ENVIRONMENT

\begin{tabular}{|c|c|c|c|c|c|c|}
\hline $\begin{array}{l}\text { Wind } \\
\text { Toward }\end{array}$ & $\begin{array}{l}\text { Distance } \\
\text { (meters) }\end{array}$ & Nuclide & $\begin{array}{c}\text { Air } \\
\text { Concentration } \\
(\mathrm{pCi} / \mathrm{m} 3)\end{array}$ & $\begin{array}{c}\text { Dry } \\
\text { Deposition } \\
\text { Rate } \\
\text { (pCi/cm2/s) }\end{array}$ & $\begin{array}{c}\text { Wet } \\
\text { Deposition } \\
\text { Rate } \\
\text { (pCi/cm2/s) }\end{array}$ & $\begin{array}{c}\text { Ground } \\
\text { Deposition } \\
\text { Rate } \\
\text { (pCi/cm2/s) }\end{array}$ \\
\hline ESE & 750 & AM-241 & $5.0 \mathrm{E}-10$ & $9.0 \mathrm{E}-17$ & $1.7 \mathrm{E}-17$ & $1.1 \mathrm{E}-16$ \\
\hline ESE & 750 & PU-238 & $4.0 \mathrm{E}-10$ & $7.1 \mathrm{E}-17$ & $1.3 \mathrm{E}-17$ & 8.4E-17 \\
\hline$\overline{E S E}$ & 750 & PU-239 & $4.6 \mathrm{E}-10$ & 8.3E-17 & $1.6 \mathrm{E}-17$ & $9.9 \mathrm{E}-17$ \\
\hline ESE & 1500 & AM-241 & 2.6E-10 & $4.7 \mathrm{E}-17$ & 8.3E-18 & $5.5 \mathrm{E}-17$ \\
\hline ESE & 1500 & PU-238 & $2.1 \mathrm{E}-10$ & $3.8 \mathrm{E}-17$ & 6.3E-18 & 4.4E-17 \\
\hline$\overline{E S E}$ & 1500 & PU-239 & $2.4 \mathrm{E}-10$ & 4.3E-17 & $7.9 \mathrm{E}-18$ & $5.1 \mathrm{E}-17$ \\
\hline ESE & 2500 & AM-241 & $1.5 \mathrm{E}-10$ & 2.7E-17 & $4.9 \mathrm{E}-18$ & $3.2 E-17$ \\
\hline ESE & 2500 & PU-238 & $1.2 \mathrm{E}-10$ & $2.2 \mathrm{E}-17$ & $3.8 \mathrm{E}-18$ & $2.5 \mathrm{E}-17$ \\
\hline ESE & 2500 & PU-239 & $1.4 \mathrm{E}-10$ & $2.5 \mathrm{E}-17$ & $4.7 \mathrm{E}-18$ & $3.0 \mathrm{E}-17$ \\
\hline ESE & 3500 & AM-241 & $1.0 \mathrm{E}-10$ & $1.8 \mathrm{E}-17$ & $3.5 \mathrm{E}-18$ & 2.2E-17 \\
\hline ESE & 3500 & PU-238 & $7.9 \mathrm{E}-11$ & $1.4 \mathrm{E}-17$ & $2.6 \mathrm{E}-18$ & 1.7E-17 \\
\hline ESE & 3500 & PU-239 & $9.4 \mathrm{E}-11$ & $1.7 \mathrm{E}-17$ & 3.3E-18 & 2.0E-17 \\
\hline ESE & 4500 & AM-241 & $7.4 \mathrm{E}-11$ & $1.3 \mathrm{E}-17$ & $2.7 E-18$ & 1.6E-17 \\
\hline$\overline{E S E}$ & 4500 & PU-238 & $5.7 \mathrm{E}-11$ & $1.0 \mathrm{E}-17$ & $2.0 \mathrm{E}-18$ & 1.2E-17 \\
\hline ESE & 4500 & PU-239 & $6.9 \mathrm{E}-11$ & $1.2 \mathrm{E}-17$ & 2.6E-18 & $1.5 \mathrm{E}-17$ \\
\hline ESE & 7500 & AM-241 & $3.8 \mathrm{E}-11$ & $6.8 \mathrm{E}-18$ & $1.6 \mathrm{E}-18$ & $8.4 \mathrm{E}-18$ \\
\hline ESE & 7500 & PU-238 & $2.9 \mathrm{E}-11$ & 5.3E-18 & $1.2 \mathrm{E}-18$ & $6.5 \mathrm{E}-18$ \\
\hline ESE & 7500 & PU-239 & $3.6 \mathrm{E}-11$ & $6.5 \mathrm{E}-18$ & $1.5 \mathrm{E}-18$ & 8.0E-18 \\
\hline ESE & 15000 & AM-241 & 1.6E-11 & $2.8 \mathrm{E}-18$ & $7.5 \mathrm{E}-19$ & $3.6 \mathrm{E}-18$ \\
\hline ESE & 15000 & PU-238 & $1.2 \mathrm{E}-11$ & 2.2E-18 & 5.7E-19 & $2.7 \mathrm{E}-18$ \\
\hline ESE & 15000 & PU-239 & $1.5 \mathrm{E}-11$ & $2.7 \mathrm{E}-18$ & $7.1 \mathrm{E}-19$ & $3.4 \mathrm{E}-18$ \\
\hline ESE & 25000 & AM-241 & $7.5 \mathrm{E}-12$ & 1.3E-18 & 4.1E-19 & $1.8 \mathrm{E}-18$ \\
\hline ESE & 25000 & PU-238 & $5.7 \mathrm{E}-12$ & $1.0 \mathrm{E}-18$ & $3.1 \mathrm{E}-19$ & 1.3E-18 \\
\hline$\overline{E S E}$ & 25000 & PU-239 & $7.1 \mathrm{E}-12$ & 1.3E-18 & $3.9 E-19$ & 1.7E-18 \\
\hline ESE & 35000 & AM-241 & $4.9 E-12$ & 8.8E-19 & 2.8E-19 & 1.2E-18 \\
\hline ESE & 35000 & PU-238 & $3.7 E-12$ & $6.7 \mathrm{E}-19$ & 2.1E-19 & 8.8E-19 \\
\hline ESE & 35000 & PU-239 & $4.7 \bar{E}-12$ & $8.4 \mathrm{E}-19$ & 2.7E-19 & 1.1E-18 \\
\hline ESE & 45000 & AM-241 & $3.5 E-12$ & 6.3E-19 & 2.1E-19 & 8.4E-19 \\
\hline ESE & 45000 & PU-238 & 2.6E-12 & $4.8 \mathrm{E}-19$ & $1.6 \mathrm{E}-19$ & $6.4 \mathrm{E}-19$ \\
\hline$\overline{E S E}$ & 45000 & PU-239 & $3.3 E-12$ & $6.0 \mathrm{E}-19$ & 2.0E-19 & 8.0E-19 \\
\hline ESE & 55000 & AM-241 & $2.5 \mathrm{E}-12$ & $4.5 \mathrm{E}-19$ & 1.6E-19 & $6.1 \mathrm{E}-19$ \\
\hline ESE & 55000 & PU-238 & $1.9 \mathrm{E}-12$ & $3.4 \mathrm{E}-19$ & $1.2 \mathrm{E}-19$ & 4.7E-19 \\
\hline ESE & 55000 & PU-239 & $2.4 \mathrm{E}-12$ & $4.3 \mathrm{E}-19$ & $1.6 \mathrm{E}-19$ & $5.8 \mathrm{E}-19$ \\
\hline ESE & 70000 & AM-241 & $1.5 \mathrm{E}-12$ & 2.7E-19 & 1.1E-19 & $3.8 \mathrm{E}-19$ \\
\hline ESE & 70000 & PU-238 & $1.1 \mathrm{E}-12$ & 2.0E-19 & 8.6E-20 & 2.9E-19 \\
\hline ESE & 70000 & PU-239 & $1.4 \mathrm{E}-12$ & 2.6E-19 & 1.1E-19 & $3.6 \mathrm{E}-19$ \\
\hline
\end{tabular}


Waste Isolation Pilot Plant Biennial Environmental Compliance Report DOE/WIPP 99-2171

Apr 24, $2000 \quad 12: 45$ pm

CONCENTRATIONS

Page 14

ESTIMATED RADIONUCLIDE CONCENTRATIONS

AT VARIOUS LOCATIONS IN THE ENVIRONMENT

\begin{tabular}{|c|c|c|c|c|c|c|}
\hline $\begin{array}{c}\text { Wind } \\
\text { Toward } \\
\end{array}$ & $\begin{array}{l}\text { Distance } \\
\text { (meters) }\end{array}$ & Nuclide & $\begin{array}{c}\text { Air } \\
\text { Concentration } \\
(\mathrm{pCi} / \mathrm{m} 3)\end{array}$ & $\begin{array}{c}\text { Dry } \\
\text { Deposition } \\
\text { Rate } \\
\text { (pCi/cm2/s) }\end{array}$ & $\begin{array}{c}\text { Wet } \\
\text { Deposition } \\
\text { Rate } \\
\text { (pCi/cm2/s) }\end{array}$ & $\begin{array}{c}\text { Ground } \\
\text { Deposition } \\
\text { Rate } \\
\text { (pCi/cm2/s) }\end{array}$ \\
\hline$E$ & 250 & AM-241 & 1.8E-09 & 3.3E-16 & 5.9E-17 & 3.9E-16 \\
\hline E & 250 & PU-238 & 1.4E-09 & $2.5 \mathrm{E}-16$ & $4.5 \mathrm{E}-17$ & $2.9 E-16$ \\
\hline$E$ & 250 & PU-239 & 1.7E-09 & $3.1 \mathrm{E}-16$ & $5.6 \mathrm{E}-17$ & $3.6 \mathrm{E}-16$ \\
\hline$E$ & 750 & AM-241 & $7.0 \mathrm{E}-10$ & 1.3E-16 & $2.0 \mathrm{E}-17$ & $1.5 \mathrm{E}-16$ \\
\hline$E$ & 750 & PU-238 & $5.4 \mathrm{E}-10$ & $9.7 \mathrm{E}-17$ & $1.5 \mathrm{E}-17$ & $1.1 \mathrm{E}-16$ \\
\hline$E$ & 750 & PU-239 & $6.6 \mathrm{E}-10$ & 1.2E-16 & $1.9 \mathrm{E}-17$ & $1.4 \mathrm{E}-16$ \\
\hline $\mathrm{E}$ & 1500 & AM-241 & $3.3 E-10$ & $6.0 \mathrm{E}-17$ & $9.8 \mathrm{E}-18$ & $6.9 \mathrm{E}-17$ \\
\hline$E$ & 1500 & PU-238 & 2.6E-10 & 4.7E-17 & $7.4 \mathrm{E}-18$ & $5.4 \mathrm{E}-17$ \\
\hline$E$ & 1500 & PU-239 & $3.1 \mathrm{E}-10$ & $5.6 \mathrm{E}-17$ & 9.3E-18 & $6.5 \mathrm{E}-17$ \\
\hline$E$ & 2500 & AM-241 & $1.8 \mathrm{E}-10$ & $3.2 E-17$ & 5.8E-18 & $3.8 E-17$ \\
\hline $\mathrm{E}$ & 2500 & PU-238 & $1.4 \mathrm{E}-10$ & 2.5E-17 & $4.4 \mathrm{E}-18$ & 2.9E-17 \\
\hline$E$ & 2500 & PU-239 & $1.7 E-10$ & $3.0 \mathrm{E}-17$ & 5.5E-18 & 3.6E-17 \\
\hline$E$ & 3500 & AM-241 & $1.2 \mathrm{E}-10$ & $2.1 \mathrm{E}-17$ & $4.1 \mathrm{E}-18$ & 2.5E-17 \\
\hline$E$ & 3500 & PU-238 & 8.9E-11 & 1.6E-17 & $3.1 E-18$ & 1.9E-17 \\
\hline$E$ & 3500 & PU-239 & 1.1E-10 & $2.0 \mathrm{E}-17$ & $3.9 E-18$ & $2.4 \mathrm{E}-17$ \\
\hline$E$ & 4500 & AM-241 & 8.3E-11 & $1.5 \mathrm{E}-17$ & $3.2 E-18$ & 1.8E-17 \\
\hline$E$ & 4500 & PU-238 & $6.4 \mathrm{E}-11$ & $1.2 \mathrm{E}-17$ & 2.4E-18 & $1.4 \mathrm{E}-17$ \\
\hline $\mathrm{E}$ & 4500 & PU-239 & 7.9E-11 & $1.4 \mathrm{E}-17$ & 3.0E-18 & 1.7E-17 \\
\hline $\mathrm{E}$ & 7500 & AM-241 & $4.2 E-11$ & 7.6E-18 & 1.9E-18 & 9.5E-18 \\
\hline$E$ & 7500 & PU-238 & $3.2 E-11$ & 5.8E-18 & $1.4 \mathrm{E}-18$ & 7.2E-18 \\
\hline$E$ & 7500 & PU-239 & $4.0 \mathrm{E}-11$ & $7.2 \mathrm{E}-18$ & $1.8 \mathrm{E}-18$ & 9.0E-18 \\
\hline$E$ & 15000 & AM-241 & $1.7 \mathrm{E}-11$ & $3.1 \mathrm{E}-18$ & 9.0E-19 & 4.0E-18 \\
\hline$E$ & 15000 & PU-238 & $1.3 E-11$ & $2.4 \mathrm{E}-18$ & $6.8 \mathrm{E}-19$ & $3.1 \mathrm{E}-18$ \\
\hline$E$ & 15000 & PU-239 & 1.6E-11 & $3.0 \mathrm{E}-18$ & 8.6E-19 & $3.8 \mathrm{E}-18$ \\
\hline$E$ & 25000 & AM-241 & $8.5 E-12$ & $1.5 \mathrm{E}-18$ & 5.1E-19 & 2.0E-18 \\
\hline $\bar{E}$ & 25000 & PU-238 & $6.5 \mathrm{E}-12$ & $1.2 \mathrm{E}-18$ & 3.9E-19 & 1.6E-18 \\
\hline $\mathrm{E}$ & 25000 & PU-239 & $8.1 \mathrm{E}-12$ & $1.5 \mathrm{E}-18$ & $4.8 \mathrm{E}-19$ & $1.9 E-18$ \\
\hline$E$ & 35000 & AM-241 & 5.6E-12 & $1.0 \mathrm{E}-18$ & $3.5 E-19$ & 1.4E-18 \\
\hline$E$ & 35000 & PU-238 & 4.3E-12 & 7.7E-19 & 2.7E-19 & 1.0E-18 \\
\hline$E$ & 35000 & PU-239 & 5.3E-12 & 9.6E-19 & $3.4 \mathrm{E}-19$ & 1.3E-18 \\
\hline $\mathrm{E}$ & 45000 & AM-241 & 4.0E-12 & 7.3E-19 & 2.7E-19 & 1.0E-18 \\
\hline$E$ & 45000 & PU-238 & $3.1 \mathrm{E}-12$ & 5.5E-19 & 2.0E-19 & 7.6E-19 \\
\hline$E$ & 45000 & PU-239 & $3.8 \mathrm{E}-12$ & 6.9E-19 & 2.6E-19 & 9.5E-19 \\
\hline $\bar{E}$ & 55000 & AM-241 & $3.0 \mathrm{E}-12$ & $5.4 \mathrm{E}-19$ & 2.1E-19 & $7.5 \mathrm{E}-19$ \\
\hline$E$ & 55000 & PU-238 & $2.3 E-12$ & 4.1E-19 & 1.6E-19 & 5.7E-19 \\
\hline$E$ & 55000 & PU-239 & $2.8 \mathrm{E}-12$ & $5.1 \mathrm{E}-19$ & 2.0E-19 & $7.1 \mathrm{E}-19$ \\
\hline
\end{tabular}


Waste Isolation Pilot Plant Biennial Environmental Compliance Report DOE/WIPP 99-2171

Apr 24, $2000 \quad 12: 45$ pm

CONCENTRATIONS

Page 15

ESTIMATED RADIONUCLIDE CONCENTRATIONS

AT VARIOUS LOCATIONS IN THE ENVIRONMENT

\begin{tabular}{|c|c|c|c|c|c|c|}
\hline $\begin{array}{l}\text { Wind } \\
\text { Toward }\end{array}$ & $\begin{array}{l}\text { Distance } \\
\text { (meters) }\end{array}$ & Nuclide & $\begin{array}{c}\text { Air } \\
\text { Concentration } \\
(\mathrm{pCi} / \mathrm{m} 3)\end{array}$ & $\begin{array}{c}\text { Dry } \\
\text { Deposition } \\
\text { Rate } \\
\text { (pCi/cm2/s) }\end{array}$ & $\begin{array}{c}\text { Wet } \\
\text { Deposition } \\
\text { Rate } \\
\text { (pCi/cm2/s) }\end{array}$ & $\begin{array}{c}\text { Ground } \\
\text { Deposition } \\
\text { Rate } \\
\text { (pCi/cm2/s) }\end{array}$ \\
\hline$E$ & 70000 & AM-241 & $1.9 \mathrm{E}-12$ & $3.4 \mathrm{E}-19$ & $1.5 \mathrm{E}-19$ & 4.9E-19 \\
\hline $\bar{E}$ & 70000 & PU-238 & $1.4 \mathrm{E}-12$ & 2.5E-19 & $1.2 \mathrm{E}-19$ & 3.7E-19 \\
\hline $\bar{E}$ & 70000 & PU-239 & $1.8 \mathrm{E}-12$ & 3.2E-19 & $1.5 \mathrm{E}-19$ & 4.7E-19 \\
\hline ENE & 250 & AM-241 & 1.6E-09 & $2.8 \mathrm{E}-16$ & $5.7 \mathrm{E}-17$ & $3.4 \mathrm{E}-16$ \\
\hline ENE & 250 & PU-238 & 1.2E-09 & $2.2 E-16$ & 4.3E-17 & 2.6E-16 \\
\hline ENE & 250 & PU-239 & $1.5 \mathrm{E}-09$ & $2.6 \mathrm{E}-16$ & $5.4 \mathrm{E}-17$ & $3.2 E-16$ \\
\hline ENE & 750 & AM-241 & $6.0 \mathrm{E}-10$ & 1.1E-16 & $1.9 \mathrm{E}-17$ & 1.3E-16 \\
\hline ENE & 750 & PU-238 & $4.7 E-10$ & $8.4 \mathrm{E}-17$ & $1.4 \mathrm{E}-17$ & $9.9 \mathrm{E}-17$ \\
\hline ENE & 750 & PU-239 & $5.6 \mathrm{E}-10$ & $1.0 \mathrm{E}-16$ & $1.8 \mathrm{E}-17$ & $1.2 \mathrm{E}-16$ \\
\hline ENE & 1500 & AM-241 & $2.9 \mathrm{E}-10$ & $5.1 \mathrm{E}-17$ & $9.3 \mathrm{E}-18$ & $6.1 \mathrm{E}-17$ \\
\hline ENE & 1500 & PU-238 & $2.2 \mathrm{E}-10$ & $4.0 \mathrm{E}-17$ & $7.1 \mathrm{E}-18$ & 4.7E-17 \\
\hline ENE & 1500 & PU-239 & $2.7 \mathrm{E}-10$ & $4.8 \mathrm{E}-17$ & $8.9 \mathrm{E}-18$ & $5.7 \mathrm{E}-17$ \\
\hline ENE & 2500 & AM-241 & $1.6 \mathrm{E}-10$ & $2.8 \mathrm{E}-17$ & $5.6 \mathrm{E}-18$ & $3.4 \mathrm{E}-17$ \\
\hline ENE & 2500 & PU-238 & $1.2 \mathrm{E}-10$ & 2.2E-17 & $4.2 \mathrm{E}-18$ & 2.6E-17 \\
\hline ENE & 2500 & PU-239 & $1.5 \mathrm{E}-10$ & $2.6 \mathrm{E}-17$ & 5.3E-18 & $3.2 E-17$ \\
\hline ENE & 3500 & AM-241 & $1.0 \mathrm{E}-10$ & $1.8 \mathrm{E}-17$ & $3.9 E-18$ & 2.2E-17 \\
\hline ENE & 3500 & PU-238 & $7.8 \mathrm{E}-11$ & $1.4 \mathrm{E}-17$ & $3.0 \mathrm{E}-18$ & $1.7 \mathrm{E}-17$ \\
\hline$\overline{E N E}$ & 3500 & PU-239 & $9.5 \mathrm{E}-11$ & $1.7 \mathrm{E}-17$ & $3.8 E-18$ & $2.1 \mathrm{E}-17$ \\
\hline ENE & 4500 & AM-241 & $7.2 \mathrm{E}-11$ & 1.3E-17 & $3.0 \mathrm{E}-18$ & 1.6E-17 \\
\hline ENE & 4500 & PU-238 & $5.6 \mathrm{E}-11$ & $1.0 \mathrm{E}-17$ & 2.3E-18 & 1.2E-17 \\
\hline ENE & 4500 & PU-239 & $6.8 \mathrm{E}-11$ & $1.2 \mathrm{E}-17$ & $2.9 \mathrm{E}-18$ & $1.5 \mathrm{E}-17$ \\
\hline ENE & 7500 & AM-241 & $3.7 E-11$ & $6.6 \mathrm{E}-18$ & $1.8 \mathrm{E}-18$ & $8.4 \mathrm{E}-18$ \\
\hline ENE & 7500 & PU-238 & $2.8 \mathrm{E}-11$ & $5.1 \mathrm{E}-18$ & $1.4 \mathrm{E}-18$ & $6.5 \mathrm{E}-18$ \\
\hline ENE & 7500 & PU-239 & $3.5 \mathrm{E}-11$ & $6.3 \mathrm{E}-18$ & $1.7 \mathrm{E}-18$ & 8.0E-18 \\
\hline ENE & 15000 & AM-241 & $1.5 \mathrm{E}-11$ & $2.7 \mathrm{E}-18$ & 8.6E-19 & $3.6 \mathrm{E}-18$ \\
\hline ENE & 15000 & PU-238 & $1.2 \mathrm{E}-11$ & $2.1 \mathrm{E}-18$ & 6.6E-19 & 2.7E-18 \\
\hline ENE & 15000 & PU-239 & $1.4 \mathrm{E}-11$ & 2.6E-18 & 8.2E-19 & $3.4 \mathrm{E}-18$ \\
\hline ENE & 25000 & AM-241 & $7.4 \mathrm{E}-12$ & 1.3E-18 & 4.9E-19 & $1.8 \mathrm{E}-18$ \\
\hline ENE & 25000 & PU-238 & $5.7 \mathrm{E}-12$ & $1.0 \mathrm{E}-18$ & $3.7 \mathrm{E}-19$ & 1.4E-18 \\
\hline$\overline{E N E}$ & 25000 & PU-239 & $7.1 \mathrm{E}-12$ & 1.3E-18 & $4.6 \mathrm{E}-19$ & $1.7 \mathrm{E}-18$ \\
\hline ENE & 35000 & AM-241 & $4.9 \mathrm{E}-12$ & 8.8E-19 & $3.4 \mathrm{E}-19$ & 1.2E-18 \\
\hline ENE & 35000 & PU-238 & $3.7 E-12$ & $6.7 \mathrm{E}-19$ & 2.6E-19 & 9.3E-19 \\
\hline ENE & 35000 & PU-239 & $4.7 \mathrm{E}-12$ & $8.4 \mathrm{E}-19$ & $3.2 \mathrm{E}-19$ & $1.2 \mathrm{E}-18$ \\
\hline & 45000 & AM-241 & $3.5 \mathrm{E}-12$ & 6.3E-19 & $2.6 \mathrm{E}-19$ & 8.9E-19 \\
\hline ENE & 45000 & PU-238 & $2.7 \mathrm{E}-12$ & $4.8 \mathrm{E}-19$ & $1.9 \mathrm{E}-19$ & $6.8 \mathrm{E}-19$ \\
\hline ENE & 45000 & PU-239 & $3.4 \mathrm{E}-12$ & 6.0E-19 & $2.4 \mathrm{E}-19$ & 8.5E-19 \\
\hline
\end{tabular}


Waste Isolation Pilot Plant Biennial Environmental Compliance Report DOE/WIPP 99-2171

Apr 24, $2000 \quad 12: 45$ pm

CONCENTRATIONS

Page 16

ESTIMATED RADIONUCLIDE CONCENTRATIONS

AT VARIOUS LOCATIONS IN THE ENVIRONMENT

\begin{tabular}{|c|c|c|c|c|c|c|}
\hline $\begin{array}{l}\text { Wind } \\
\text { Toward }\end{array}$ & $\begin{array}{l}\text { Distance } \\
\text { (meters) }\end{array}$ & Nuclide & $\begin{array}{c}\text { Air } \\
\text { Concentration } \\
(\mathrm{pCi} / \mathrm{m} 3)\end{array}$ & $\begin{array}{c}\text { Dry } \\
\text { Deposition } \\
\text { Rate } \\
\text { (pCi/cm2/s) }\end{array}$ & $\begin{array}{c}\text { Wet } \\
\text { Deposition } \\
\text { Rate } \\
\text { (pCi/cm2/s) }\end{array}$ & $\begin{array}{c}\text { Ground } \\
\text { Deposition } \\
\text { Rate } \\
\text { (pCi/cm2/s) }\end{array}$ \\
\hline ENE & 55000 & AM-241 & $2.6 \mathrm{E}-12$ & 4.7E-19 & $2.0 \mathrm{E}-19$ & $6.7 \mathrm{E}-19$ \\
\hline ENE & 55000 & PU-238 & $2.0 \mathrm{E}-12$ & $3.6 \mathrm{E}-19$ & $1.5 \mathrm{E}-19$ & $5.1 \mathrm{E}-19$ \\
\hline ENE & 55000 & PU-239 & $2.5 \mathrm{E}-12$ & $4.5 \mathrm{E}-19$ & $1.9 \mathrm{E}-19$ & $6.4 \mathrm{E}-19$ \\
\hline ENE & 70000 & AM-241 & 1.6E-12 & $2.9 E-19$ & $1.5 \mathrm{E}-19$ & 4.4E-19 \\
\hline ENE & 70000 & PU-238 & $1.2 \mathrm{E}-12$ & 2.2E-19 & 1.1E-19 & 3.3E-19 \\
\hline ENE & 70000 & PU-239 & $1.5 \mathrm{E}-12$ & $2.8 \mathrm{E}-19$ & $1.4 \mathrm{E}-19$ & $4.2 \mathrm{E}-19$ \\
\hline NE & 250 & AM-241 & 1.2E-09 & 2.2E-16 & 5.3E-17 & 2.7E-16 \\
\hline NE & 250 & PU-238 & $9.6 \mathrm{E}-10$ & $1.7 \mathrm{E}-16$ & $4.0 \mathrm{E}-17$ & $2.1 \mathrm{E}-16$ \\
\hline NE & 250 & PU-239 & 1.1E-09 & $2.0 \mathrm{E}-16$ & $5.1 \mathrm{E}-17$ & $2.5 \mathrm{E}-16$ \\
\hline NE & 750 & AM-241 & $4.8 E-10$ & 8.6E-17 & $1.8 \mathrm{E}-17$ & 1.0E-16 \\
\hline NE & 750 & PU-238 & $3.8 E-10$ & $6.9 \mathrm{E}-17$ & 1.3E-17 & 8.2E-17 \\
\hline NE & 750 & PU-239 & $4.4 \mathrm{E}-10$ & $7.9 \mathrm{E}-17$ & $1.7 \mathrm{E}-17$ & $9.6 \mathrm{E}-17$ \\
\hline NE & 1500 & AM-241 & 2.3E-10 & 4.2E-17 & 8.8E-18 & 5.1E-17 \\
\hline NE & 1500 & PU-238 & $1.9 \mathrm{E}-10$ & $3.4 \mathrm{E}-17$ & $6.7 \mathrm{E}-18$ & 4.1E-17 \\
\hline NE & 1500 & PU-239 & $2.2 \mathrm{E}-10$ & $3.9 \mathrm{E}-17$ & $8.4 \mathrm{E}-18$ & 4.7E-17 \\
\hline NE & 2500 & AM-241 & $1.3 \mathrm{E}-10$ & $2.4 \mathrm{E}-17$ & $5.2 \mathrm{E}-18$ & $2.9 \mathrm{E}-17$ \\
\hline NE & 2500 & PU-238 & $1.1 \mathrm{E}-10$ & $1.9 \mathrm{E}-17$ & $4.0 \mathrm{E}-18$ & 2.3E-17 \\
\hline NE & 2500 & PU-239 & $1.2 \mathrm{E}-10$ & 2.2E-17 & $5.0 \mathrm{E}-18$ & 2.7E-17 \\
\hline NE & 3500 & AM-241 & $8.8 \mathrm{E}-11$ & $1.6 \mathrm{E}-17$ & $3.7 \mathrm{E}-18$ & $2.0 \mathrm{E}-17$ \\
\hline NE & 3500 & PU-238 & 7.0E-11 & 1.3E-17 & $2.8 \mathrm{E}-18$ & $1.5 \mathrm{E}-17$ \\
\hline NE & 3500 & PU-239 & $8.3 E-11$ & $1.5 \mathrm{E}-17$ & $3.5 E-18$ & $1.8 \mathrm{E}-17$ \\
\hline NE & 4500 & AM-241 & $6.4 \mathrm{E}-11$ & $1.2 \mathrm{E}-17$ & 2.9E-18 & $1.4 \mathrm{E}-17$ \\
\hline NE & 4500 & PU-238 & $5.0 \mathrm{E}-11$ & $9.1 \mathrm{E}-18$ & $2.2 \mathrm{E}-18$ & $1.1 \mathrm{E}-17$ \\
\hline NE & 4500 & PU-239 & $6.0 \mathrm{E}-11$ & $1.1 \mathrm{E}-17$ & $2.7 \mathrm{E}-18$ & $1.4 \mathrm{E}-17$ \\
\hline NE & 7500 & AM-241 & $3.3 E-11$ & $6.0 \mathrm{E}-18$ & $1.7 \mathrm{E}-18$ & 7.7E-18 \\
\hline NE & 7500 & PU-238 & $2.6 \mathrm{E}-11$ & 4.7E-18 & 1.3E-18 & $5.9 \mathrm{E}-18$ \\
\hline NE & 7500 & PU-239 & $3.2 E-11$ & $5.7 E-18$ & $1.6 \mathrm{E}-18$ & 7.3E-18 \\
\hline NE & 15000 & AM-241 & $1.4 \mathrm{E}-11$ & $2.5 \mathrm{E}-18$ & 8.0E-19 & 3.3E-18 \\
\hline NE & 15000 & PU-238 & $1.1 \mathrm{E}-11$ & $1.9 \mathrm{E}-18$ & $6.1 \mathrm{E}-19$ & $2.5 \mathrm{E}-18$ \\
\hline NE & 15000 & PU-239 & $1.3 \mathrm{E}-11$ & 2.3E-18 & 7.6E-19 & $3.1 \mathrm{E}-18$ \\
\hline NE & 25000 & AM-241 & $6.7 \mathrm{E}-12$ & $1.2 \mathrm{E}-18$ & $4.4 \mathrm{E}-19$ & 1.6E-18 \\
\hline NE & 25000 & PU-238 & $5.1 \mathrm{E}-12$ & $9.2 \mathrm{E}-19$ & $3.4 \mathrm{E}-19$ & 1.3E-18 \\
\hline NE & 25000 & PU-239 & 6.3E-12 & $1.1 \mathrm{E}-18$ & 4.2E-19 & 1.6E-18 \\
\hline NE & 35000 & AM-241 & $4.4 \mathrm{E}-12$ & 7.8E-19 & $3.1 \mathrm{E}-19$ & $1.1 \mathrm{E}-18$ \\
\hline NE & 35000 & PU-238 & $3.3 E-12$ & $6.0 \mathrm{E}-19$ & $2.3 E-19$ & 8.3E-19 \\
\hline
\end{tabular}


Waste Isolation Pilot Plant Biennial Environmental Compliance Report DOE/WIPP 99-2171

$\begin{array}{lllllll}\text { NE } & 35000 & \text { PU-239 } & 4.1 \mathrm{E}-12 & 7.5 \mathrm{E}-19 & 2.9 \mathrm{E}-19 & 1.0 \mathrm{E}-18\end{array}$


Waste Isolation Pilot Plant Biennial Environmental Compliance Report DOE/WIPP 99-2171

Apr 24, $2000 \quad 12: 45$ pm

CONCENTRATIONS

Page 17

ESTIMATED RADIONUCLIDE CONCENTRATIONS

AT VARIOUS LOCATIONS IN THE ENVIRONMENT

\begin{tabular}{|c|c|c|c|c|c|c|}
\hline $\begin{array}{c}\text { Wind } \\
\text { Toward } \\
\end{array}$ & $\begin{array}{l}\text { Distance } \\
\text { (meters) }\end{array}$ & Nuclide & $\begin{array}{c}\text { Air } \\
\text { Concentration } \\
(\mathrm{pCi} / \mathrm{m} 3)\end{array}$ & $\begin{array}{c}\text { Dry } \\
\text { Deposition } \\
\text { Rate } \\
\text { (pCi/cm2/s) }\end{array}$ & $\begin{array}{c}\text { Wet } \\
\text { Deposition } \\
\text { Rate } \\
\text { (pCi/cm2/s) }\end{array}$ & $\begin{array}{c}\text { Ground } \\
\text { Deposition } \\
\text { Rate } \\
\text { (pCi/cm2/s) }\end{array}$ \\
\hline $\mathrm{NE}$ & 45000 & AM-241 & $3.1 \mathrm{E}-12$ & 5.6E-19 & 2.3E-19 & $7.9 \mathrm{E}-19$ \\
\hline NE & 45000 & PU-238 & $2.4 \mathrm{E}-12$ & 4.3E-19 & $1.7 \mathrm{E}-19$ & 6.0E-19 \\
\hline NE & 45000 & PU-239 & $3.0 \mathrm{E}-12$ & 5.3E-19 & 2.2E-19 & $7.5 \mathrm{E}-19$ \\
\hline NE & 55000 & AM-241 & $2.2 E-12$ & 4.0E-19 & 1.8E-19 & 5.8E-19 \\
\hline NE & 55000 & PU-238 & $1.7 \mathrm{E}-12$ & $3.1 \mathrm{E}-19$ & $1.4 \mathrm{E}-19$ & $4.4 \mathrm{E}-19$ \\
\hline NE & 55000 & PU-239 & $2.1 \mathrm{E}-12$ & $3.9 \mathrm{E}-19$ & $1.7 \mathrm{E}-19$ & 5.6E-19 \\
\hline NE & 70000 & AM-241 & $1.4 \mathrm{E}-12$ & 2.4E-19 & 1.3E-19 & 3.7E-19 \\
\hline NE & 70000 & PU-238 & $1.0 \mathrm{E}-12$ & 1.8E-19 & $9.7 E-20$ & 2.8E-19 \\
\hline NE & 70000 & PU-239 & 1.3E-12 & 2.3E-19 & $1.2 \mathrm{E}-19$ & $3.6 \mathrm{E}-19$ \\
\hline NNE & 250 & AM-241 & 1.4E-09 & $2.4 \mathrm{E}-16$ & $6.3 \mathrm{E}-17$ & $3.1 \mathrm{E}-16$ \\
\hline NNE & 250 & PU-238 & 1.1E-09 & $1.9 \mathrm{E}-16$ & $4.8 \mathrm{E}-17$ & $2.4 \mathrm{E}-16$ \\
\hline NNE & 250 & PU-239 & 1.3E-09 & $2.3 \mathrm{E}-16$ & $6.0 \mathrm{E}-17$ & $2.9 \mathrm{E}-16$ \\
\hline NNE & 750 & AM-241 & $4.8 \mathrm{E}-10$ & $8.7 \mathrm{E}-17$ & $2.1 \mathrm{E}-17$ & $1.1 \mathrm{E}-16$ \\
\hline NNE & 750 & PU-238 & $3.9 E-10$ & $7.0 \mathrm{E}-17$ & $1.6 \mathrm{E}-17$ & 8.6E-17 \\
\hline NNE & 750 & PU-239 & $4.5 \mathrm{E}-10$ & 8.0E-17 & 2.0E-17 & $1.0 \mathrm{E}-16$ \\
\hline NNE & 1500 & AM-241 & $2.4 \mathrm{E}-10$ & 4.3E-17 & $1.0 \mathrm{E}-17$ & $5.4 \mathrm{E}-17$ \\
\hline NNE & 1500 & PU-238 & $2.0 \mathrm{E}-10$ & $3.6 \mathrm{E}-17$ & $7.9 \mathrm{E}-18$ & $4.4 \mathrm{E}-17$ \\
\hline NNE & 1500 & PU-239 & $2.2 \mathrm{E}-10$ & $3.9 \mathrm{E}-17$ & $1.0 \mathrm{E}-17$ & $4.9 \mathrm{E}-17$ \\
\hline NNE & 2500 & AM-241 & $1.5 \mathrm{E}-10$ & $2.6 \mathrm{E}-17$ & $6.2 \mathrm{E}-18$ & $3.2 \mathrm{E}-17$ \\
\hline NNE & 2500 & PU-238 & $1.2 \mathrm{E}-10$ & $2.2 \mathrm{E}-17$ & $4.7 \mathrm{E}-18$ & $2.6 \mathrm{E}-17$ \\
\hline NNE & 2500 & PU-239 & 1.3E-10 & $2.4 \mathrm{E}-17$ & $5.9 \mathrm{E}-18$ & $3.0 \mathrm{E}-17$ \\
\hline NNE & 3500 & AM-241 & $1.0 \mathrm{E}-10$ & 1.8E-17 & $4.4 \mathrm{E}-18$ & 2.2E-17 \\
\hline NNE & 3500 & PU-238 & $8.1 \mathrm{E}-11$ & $1.5 \mathrm{E}-17$ & 3.3E-18 & $1.8 \mathrm{E}-17$ \\
\hline NNE & 3500 & PU-239 & $9.3 \mathrm{E}-11$ & $1.7 \mathrm{E}-17$ & $4.2 \mathrm{E}-18$ & $2.1 \mathrm{E}-17$ \\
\hline NNE & 4500 & AM-241 & $7.4 \mathrm{E}-11$ & 1.3E-17 & $3.4 \mathrm{E}-18$ & $1.7 \mathrm{E}-17$ \\
\hline NNE & 4500 & PU-238 & $6.0 \mathrm{E}-11$ & $1.1 \mathrm{E}-17$ & 2.6E-18 & $1.3 \mathrm{E}-17$ \\
\hline NNE & 4500 & PU-239 & $6.9 \mathrm{E}-11$ & $1.2 \mathrm{E}-17$ & $3.2 E-18$ & $1.6 \mathrm{E}-17$ \\
\hline NNE & 7500 & AM-241 & $4.0 \mathrm{E}-11$ & $7.2 \mathrm{E}-18$ & $2.0 \mathrm{E}-18$ & $9.2 \mathrm{E}-18$ \\
\hline NNE & 7500 & PU-238 & $3.2 E-11$ & $5.7 \mathrm{E}-18$ & $1.5 \mathrm{E}-18$ & $7.2 \mathrm{E}-18$ \\
\hline NNE & 7500 & PU-239 & $3.8 \mathrm{E}-11$ & $6.8 \mathrm{E}-18$ & $1.9 \mathrm{E}-18$ & 8.7E-18 \\
\hline NNE & 15000 & AM-241 & $1.7 \mathrm{E}-11$ & $3.1 \mathrm{E}-18$ & $9.5 \mathrm{E}-19$ & $4.0 \mathrm{E}-18$ \\
\hline NNE & 15000 & PU-238 & 1.3E-11 & $2.4 \mathrm{E}-18$ & $7.2 \mathrm{E}-19$ & $3.1 \mathrm{E}-18$ \\
\hline NNE & 15000 & PU-239 & $1.6 \mathrm{E}-11$ & $2.9 \mathrm{E}-18$ & $9.0 \mathrm{E}-19$ & $3.8 \mathrm{E}-18$ \\
\hline NNE & 25000 & AM-241 & 8.3E-12 & $1.5 \mathrm{E}-18$ & 5.2E-19 & 2.0E-18 \\
\hline NNE & 25000 & PU-238 & $6.3 \mathrm{E}-12$ & $1.1 \mathrm{E}-18$ & $3.9 E-19$ & $1.5 \mathrm{E}-18$ \\
\hline
\end{tabular}


Waste Isolation Pilot Plant Biennial Environmental Compliance Report DOE/WIPP 99-2171

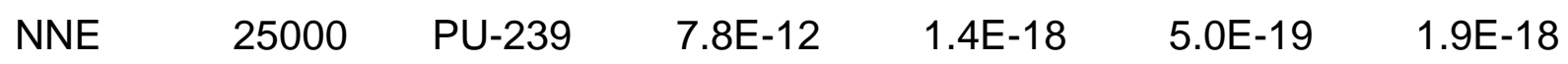


Apr 24, $2000 \quad 12: 45$ pm

CONCENTRATIONS

Page 18

ESTIMATED RADIONUCLIDE CONCENTRATIONS

AT VARIOUS LOCATIONS IN THE ENVIRONMENT

\begin{tabular}{|c|c|c|c|c|c|c|}
\hline $\begin{array}{l}\text { Wind } \\
\text { Toward }\end{array}$ & $\begin{array}{l}\text { Distance } \\
\text { (meters) }\end{array}$ & Nuclide & $\begin{array}{c}\text { Air } \\
\text { Concentration } \\
(\mathrm{pCi} / \mathrm{m} 3)\end{array}$ & $\begin{array}{c}\text { Dry } \\
\text { Deposition } \\
\text { Rate } \\
\text { (pCi/cm2/s) }\end{array}$ & $\begin{array}{c}\text { Wet } \\
\text { Deposition } \\
\text { Rate } \\
\text { (pCi/cm2/s) }\end{array}$ & $\begin{array}{c}\text { Ground } \\
\text { Deposition } \\
\text { Rate } \\
\text { (pCi/cm2/s) }\end{array}$ \\
\hline NNE & 35000 & AM-241 & $5.4 \mathrm{E}-12$ & $9.8 \mathrm{E}-19$ & $36 \mathrm{E}-19$ & $13 \mathrm{E}-18$ \\
\hline NNE & 35000 & 38 & 2 & $7.5 \mathrm{E}-19$ & -19 & 18 \\
\hline NNE & 35000 & PU-239 & $5.2 \mathrm{E}-12$ & $9.3 \mathrm{E}-19$ & 3.5E-19 & 1.3E-18 \\
\hline NNE & 45000 & AM-241 & $3.9 \mathrm{E}-12$ & 7.0E-19 & $2.7 \mathrm{E}-19$ & 9.7E-19 \\
\hline NNE & 45000 & PU-238 & 3.0E-12 & 5.3E-19 & 2.0E-19 & $7.4 \mathrm{E}-19$ \\
\hline NNE & 45000 & PL & 3.7 & 6.6E-19 & 2.6E-19 & $9.2 \mathrm{E}-19$ \\
\hline NNE & 55000 & AM-241 & $2.8 \mathrm{E}-12$ & $5.0 \mathrm{E}-19$ & 2.1E-19 & $7.1 \mathrm{E}-19$ \\
\hline NNE & & PU-238 & 2.1E-12 & 3.8E-19 & 1.6E-19 & $5.4 \mathrm{E}-19$ \\
\hline NNE & 550 & PU-239 & $2.6 \mathrm{E}-12$ & $4.8 \mathrm{E}-19$ & $2.0 \mathrm{E}-19$ & $6.8 \mathrm{E}-19$ \\
\hline & $70 c$ & AM-241 & $1.7 \mathrm{E}-12$ & 3.0E-19 & $1.5 \mathrm{E}-19$ & $4.5 \mathrm{E}-19$ \\
\hline & & PU-238 & $1.2 \mathrm{E}-12$ & 2.2E-19 & 1.1E-19 & $3.4 \mathrm{E}-19$ \\
\hline ININE & 70000 & PU-239 & 1.6E-12 & $2.9 \mathrm{E}-19$ & $1.4 \mathrm{E}-19$ & 4. $3 \mathrm{E}-19$ \\
\hline
\end{tabular}




\author{
C A P $88-P$ C \\ Version 2.00 \\ Clean Air Act Assessment Package - 1988 \\ DOSE AND RISK EQUIVALENT SUMMARIES \\ Non-Radon Population Assessment \\ Apr 24, 2000 12:45 pm
}

$\begin{aligned} \text { Facility: } & \text { Waste Isolation Pilot Project } \\ \text { Address: } & 26 \text { Miles SE of Carlsbad, NM } \\ \text { City: } & \text { Carlsbad } \\ \text { State: } & \text { NM } \quad \text { Zip: } 88221\end{aligned}$

Source Category: exempt DOE facility

Source Type: Stack

Emission Year: 1999

Comments: Run for 1999

Dataset Name: 1999run

Dataset Date: Apr 24, 2000 12:44 pm

Wind File: C:ICAP88PC2IWNDFILESI96-99.WND

Population File: C:ICAP88PC2IPOPFILESIWIPP99.POP 
Apr 24, 2000 12:45 pm

SUMMARY

Page 1

ORGAN DOSE EQUIVALENT SUMMARY

$\begin{array}{lccc}\text { Organ } & \begin{array}{c}\text { Selected } \\ \text { Individual } \\ \text { (mrem/y) }\end{array} & \begin{array}{c}\text { Collective } \\ \text { Population } \\ \text { (person-rem/y) }\end{array} \\ \text { GONADS } & 4.98 \mathrm{E}-07 & & 1.10 \mathrm{E}-06 \\ \text { BREAST } & 4.98 \mathrm{E}-08 & & 1.10 \mathrm{E}-07 \\ \text { R MAR } & 3.15 \mathrm{E}-06 & & 6.93 \mathrm{E}-06 \\ \text { LUNGS } & 3.20 \mathrm{E}-07 & & 7.00 \mathrm{E}-07 \\ \text { THYROID } & 4.91 \mathrm{E}-08 & & 1.08 \mathrm{E}-07 \\ \text { ENDOST } & 3.88 \mathrm{E}-05 & & 8.54 \mathrm{E}-05 \\ \text { RMNDR } & 1.72 \mathrm{E}-06 & & 3.79 \mathrm{E}-06 \\ \text { EFFEC } & 2.23 \mathrm{E}-06 & \end{array}$

PATHWAY EFFECTIVE DOSE EQUIVALENT SUMMARY

\begin{tabular}{|c|c|c|}
\hline Pathway & $\begin{array}{c}\text { Selected } \\
\text { Individual } \\
\text { (mrem/y) }\end{array}$ & $\begin{array}{c}\text { Collective } \\
\text { Population } \\
\text { (person-rem/y) }\end{array}$ \\
\hline $\begin{array}{l}\text { INGESTION } \\
\text { INHALATION } \\
\text { AIR IMMERSION } \\
\text { GROUND SURFACE } \\
\text { INTERNAL } \\
\text { EXTERNAL }\end{array}$ & $\begin{array}{l}1.44 \mathrm{E}-07 \\
2.08 \mathrm{E}-06 \\
1.70 \mathrm{E}-14 \\
7.28 \mathrm{E}-10 \\
2.23 \mathrm{E}-06 \\
7.28 \mathrm{E}-10\end{array}$ & $\begin{array}{l}3.50 \mathrm{E}-07 \\
4.56 \mathrm{E}-06 \\
3.71 \mathrm{E}-14 \\
1.76 \mathrm{E}-09 \\
4.91 \mathrm{E}-06 \\
1.76 \mathrm{E}-09\end{array}$ \\
\hline TOTAL & 2.23E-06 & 4.91E-06 \\
\hline
\end{tabular}


Apr 24, 2000 12:45 pm

SUMMARY

Page 2

NUCLIDE EFFECTIVE DOSE EQUIVALENT SUMMARY

$\begin{array}{lccc}\text { Nuclides } & \begin{array}{c}\text { Selected } \\ \text { Individual } \\ \text { (mrem/y) }\end{array} & \begin{array}{c}\text { Collective } \\ \text { Population } \\ \text { (person-rem/y) }\end{array} \\ \text { AM-241 } & & & 1.90 \mathrm{E}-06 \\ \text { PU-238 } & 8.62 \mathrm{E}-07 & & 1.26 \mathrm{E}-06 \\ \text { PU-239 } & 5.74 \mathrm{E}-07 & & 1.76 \mathrm{E}-06 \\ \text { TOTAL } & 7.94 \mathrm{E}-07 & & \\ & 2.23 \mathrm{E}-06 & 4.91 \mathrm{E}-06\end{array}$

CANCER RISK SUMMARY

Cancer

Selected Individual

Total Lifetime

Fatal Cancer Risk

Total Collective
Population Fatal
Cancer Risk

(Deaths/y)

LEUKEMIA

BONE

2.66E-12

1.71E-12

5.65E-15

4.15E-14

BREAST

9.05E-13

LUNG

3.11E-14

1.81E-14

6.00E-12

BOWEL

LIVER

2.30E-14

$1.21 \mathrm{E}-14$

URINARY

OTHER

2.82E-14

8.28E-11

5.33E-11

1.77E-13

1.31E-12

2.80E-11

9.71E-13

$5.72 \mathrm{E}-13$

1.87E-10

7.19E-13

$3.77 \mathrm{E}-13$

8.79E-13

TOTAL

1.14E-11

3.56E-10 
Apr 24, 2000 12:45 pm

SUMMARY

Page 3

\section{PATHWAY RISK SUMMARY}

Pathway

\begin{tabular}{l}
\hline \\
INGESTION \\
INHALATION \\
AIR IMMERSION \\
GROUND SURFACE \\
INTERNAL \\
EXTERNAL
\end{tabular}

TOTAL

Selected Individual
Total Lifetime
Fatal Cancer Risk

6.97E-13

$1.07 \mathrm{E}-11$

$3.53 \mathrm{E}-19$

$1.51 \mathrm{E}-14$

$1.14 \mathrm{E}-11$

$1.51 \mathrm{E}-14$

1.14E-11
Total Collective

Population Fatal

Cancer Risk

(Deaths/y)

2.39E-11

3.31E-10

$1.09 \mathrm{E}-17$

$5.19 \mathrm{E}-13$

$3.55 \mathrm{E}-10$

$5.19 \mathrm{E}-13$

3.56E-10

PATHWAY GENETIC RISK SUMMARY (Collective Population)

Pathway

INGESTION

INHALATION

AIR IMMERSION

GROUND SURFACE

INTERNAL

EXTERNAL

TOTAL
Genetic Risk (person-rem/y)

3.28E-09

4.19E-08

3.37E-14

1.52E-09

4.51E-08

1.52E-09

4.67E-08 
Apr 24, 2000 12:45 pm

SUMMARY

Page 4

\section{NUCLIDE RISK SUMMARY}

Nuclide

AM-241

$\mathrm{PU}-238$

PU-239

TOTAL
Selected Individual

Total Lifetime

Fatal Cancer Risk

4.40E-12

$3.05 \mathrm{E}-12$

3.99E-12

1.14E-11
Total Collective

Population Fatal

Cancer Risk

(Deaths/y)

1.37E-10

9.42E-11

1.25E-10

3.56E-10 
Waste Isolation Pilot Plant Biennial Environmental Compliance Report DOE/WIPP 99-2171

Apr 24, 2000 12:45 pm

SUMMARY

Page 5

INDIVIDUAL EFFECTIVE DOSE EQUIVALENT RATE (mrem/y) (All Radionuclides and Pathways)

\begin{tabular}{rccccccc}
\hline & \multicolumn{7}{c}{ Distance $(\mathrm{m})$} \\
\cline { 2 - 8 } Direction & 250 & 750 & \multicolumn{7}{c}{} \\
\hline & & & & & & \\
N & $0.0 \mathrm{E}+00$ & $0.0 \mathrm{E}+00$ & $0.0 \mathrm{E}+00$ & $0.0 \mathrm{E}+00$ & $0.0 \mathrm{E}+00$ & $0.0 \mathrm{E}+00$ & $0.0 \mathrm{E}+00$ \\
NNW & $0.0 \mathrm{E}+00$ & $0.0 \mathrm{E}+00$ & $0.0 \mathrm{E}+00$ & $0.0 \mathrm{E}+00$ & $0.0 \mathrm{E}+00$ & $0.0 \mathrm{E}+00$ & $0.0 \mathrm{E}+00$ \\
NW & $0.0 \mathrm{E}+00$ & $0.0 \mathrm{E}+00$ & $0.0 \mathrm{E}+00$ & $0.0 \mathrm{E}+00$ & $0.0 \mathrm{E}+00$ & $0.0 \mathrm{E}+00$ & $0.0 \mathrm{E}+00$ \\
WNW & $0.0 \mathrm{E}+00$ & $0.0 \mathrm{E}+00$ & $0.0 \mathrm{E}+00$ & $0.0 \mathrm{E}+00$ & $0.0 \mathrm{E}+00$ & $0.0 \mathrm{E}+00$ & $2.2 \mathrm{E}-06$ \\
W & $0.0 \mathrm{E}+00$ & $0.0 \mathrm{E}+00$ & $0.0 \mathrm{E}+00$ & $0.0 \mathrm{E}+00$ & $0.0 \mathrm{E}+00$ & $0.0 \mathrm{E}+00$ & $0.0 \mathrm{E}+00$ \\
WSW & $0.0 \mathrm{E}+00$ & $0.0 \mathrm{E}+00$ & $0.0 \mathrm{E}+00$ & $0.0 \mathrm{E}+00$ & $0.0 \mathrm{E}+00$ & $0.0 \mathrm{E}+00$ & $0.0 \mathrm{E}+00$ \\
SW & $0.0 \mathrm{E}+00$ & $0.0 \mathrm{E}+00$ & $0.0 \mathrm{E}+00$ & $0.0 \mathrm{E}+00$ & $0.0 \mathrm{E}+00$ & $0.0 \mathrm{E}+00$ & $0.0 \mathrm{E}+00$ \\
SSW & $0.0 \mathrm{E}+00$ & $0.0 \mathrm{E}+00$ & $0.0 \mathrm{E}+00$ & $0.0 \mathrm{E}+00$ & $0.0 \mathrm{E}+00$ & $0.0 \mathrm{E}+00$ & $6.9 \mathrm{E}-07$ \\
S & $0.0 \mathrm{E}+00$ & $0.0 \mathrm{E}+00$ & $0.0 \mathrm{E}+00$ & $0.0 \mathrm{E}+00$ & $0.0 \mathrm{E}+00$ & $0.0 \mathrm{E}+00$ & $0.0 \mathrm{E}+00$ \\
SSE & $0.0 \mathrm{E}+00$ & $0.0 \mathrm{E}+00$ & $0.0 \mathrm{E}+00$ & $0.0 \mathrm{E}+00$ & $0.0 \mathrm{E}+00$ & $0.0 \mathrm{E}+00$ & $0.0 \mathrm{E}+00$ \\
SE & $0.0 \mathrm{E}+00$ & $0.0 \mathrm{E}+00$ & $0.0 \mathrm{E}+00$ & $0.0 \mathrm{E}+00$ & $0.0 \mathrm{E}+00$ & $0.0 \mathrm{E}+00$ & $0.0 \mathrm{E}+00$ \\
ESE & $0.0 \mathrm{E}+00$ & $0.0 \mathrm{E}+00$ & $0.0 \mathrm{E}+00$ & $0.0 \mathrm{E}+00$ & $0.0 \mathrm{E}+00$ & $0.0 \mathrm{E}+00$ & $0.0 \mathrm{E}+00$ \\
E & $0.0 \mathrm{E}+00$ & $0.0 \mathrm{E}+00$ & $0.0 \mathrm{E}+00$ & $0.0 \mathrm{E}+00$ & $0.0 \mathrm{E}+00$ & $0.0 \mathrm{E}+00$ & $0.0 \mathrm{E}+00$ \\
ENE & $0.0 \mathrm{E}+00$ & $0.0 \mathrm{E}+00$ & $0.0 \mathrm{E}+00$ & $0.0 \mathrm{E}+00$ & $0.0 \mathrm{E}+00$ & $0.0 \mathrm{E}+00$ & $0.0 \mathrm{E}+00$ \\
NE & $0.0 \mathrm{E}+00$ & $0.0 \mathrm{E}+00$ & $0.0 \mathrm{E}+00$ & $0.0 \mathrm{E}+00$ & $0.0 \mathrm{E}+00$ & $0.0 \mathrm{E}+00$ & $0.0 \mathrm{E}+00$ \\
NNE & $0.0 \mathrm{E}+00$ & $0.0 \mathrm{E}+00$ & $0.0 \mathrm{E}+00$ & $0.0 \mathrm{E}+00$ & $0.0 \mathrm{E}+00$ & $0.0 \mathrm{E}+00$ & $0.0 \mathrm{E}+00$ \\
\hline
\end{tabular}

Distance $(\mathrm{m})$

\begin{tabular}{rcccccc} 
Direction & 15000 & 25000 & 35000 & 45000 & 55000 & 70000 \\
\hline & & & & & & \\
$N$ & $3.3 \mathrm{E}-07$ & $0.0 \mathrm{E}+00$ & $0.0 \mathrm{E}+00$ & $7.6 \mathrm{E}-08$ & $0.0 \mathrm{E}+00$ & $0.0 \mathrm{E}+00$ \\
NNW & $0.0 \mathrm{E}+00$ & $0.0 \mathrm{E}+00$ & $0.0 \mathrm{E}+00$ & $1.2 \mathrm{E}-07$ & $9.1 \mathrm{E}-08$ & $0.0 \mathrm{E}+00$ \\
$N W$ & $9.0 \mathrm{E}-07$ & $0.0 \mathrm{E}+00$ & $0.0 \mathrm{E}+00$ & $0.0 \mathrm{E}+00$ & $1.7 \mathrm{E}-07$ & $1.1 \mathrm{E}-07$ \\
WNW & $0.0 \mathrm{E}+00$ & $4.9 \mathrm{E}-07$ & $0.0 \mathrm{E}+00$ & $0.0 \mathrm{E}+00$ & $1.8 \mathrm{E}-07$ & $0.0 \mathrm{E}+00$ \\
W & $0.0 \mathrm{E}+00$ & $2.4 \mathrm{E}-07$ & $1.6 \mathrm{E}-07$ & $1.1 \mathrm{E}-07$ & $8.5 \mathrm{E}-08$ & $5.3 \mathrm{E}-08$ \\
WSW & $0.0 \mathrm{E}+00$ & $0.0 \mathrm{E}+00$ & $0.0 \mathrm{E}+00$ & $6.7 \mathrm{E}-08$ & $4.9 \mathrm{E}-08$ & $3.0 \mathrm{E}-08$ \\
SW & $0.0 \mathrm{E}+00$ & $0.0 \mathrm{E}+00$ & $0.0 \mathrm{E}+00$ & $0.0 \mathrm{E}+00$ & $0.0 \mathrm{E}+00$ & $0.0 \mathrm{E}+00$ \\
SSW & $0.0 \mathrm{E}+00$ & $0.0 \mathrm{E}+00$ & $0.0 \mathrm{E}+00$ & $6.8 \mathrm{E}-08$ & $4.9 \mathrm{E}-08$ & $2.9 \mathrm{E}-08$ \\
S & $0.0 \mathrm{E}+00$ & $0.0 \mathrm{E}+00$ & $8.0 \mathrm{E}-08$ & $5.8 \mathrm{E}-08$ & $0.0 \mathrm{E}+00$ & $2.6 \mathrm{E}-08$ \\
SSE & $0.0 \mathrm{E}+00$ & $0.0 \mathrm{E}+00$ & $7.0 \mathrm{E}-08$ & $5.0 \mathrm{E}-08$ & $0.0 \mathrm{E}+00$ & $2.2 \mathrm{E}-08$ \\
SE & $0.0 \mathrm{E}+00$ & $0.0 \mathrm{E}+00$ & $6.0 \mathrm{E}-08$ & $0.0 \mathrm{E}+00$ & $3.1 \mathrm{E}-08$ & $1.8 \mathrm{E}-08$ \\
ESE & $0.0 \mathrm{E}+00$ & $0.0 \mathrm{E}+00$ & $0.0 \mathrm{E}+00$ & $4.2 \mathrm{E}-08$ & $3.1 \mathrm{E}-08$ & $1.8 \mathrm{E}-08$ \\
E & $0.0 \mathrm{E}+00$ & $0.0 \mathrm{E}+00$ & $6.9 \mathrm{E}-08$ & $4.9 \mathrm{E}-08$ & $3.6 \mathrm{E}-08$ & $2.3 \mathrm{E}-08$ \\
ENE & $0.0 \mathrm{E}+00$ & $0.0 \mathrm{E}+00$ & $0.0 \mathrm{E}+00$ & $0.0 \mathrm{E}+00$ & $0.0 \mathrm{E}+00$ & $2.0 \mathrm{E}-08$ \\
NE & $0.0 \mathrm{E}+00$ & $0.0 \mathrm{E}+00$ & $0.0 \mathrm{E}+00$ & $0.0 \mathrm{E}+00$ & $0.0 \mathrm{E}+00$ & $1.7 \mathrm{E}-08$ \\
NNE & $0.0 \mathrm{E}+00$ & $0.0 \mathrm{E}+00$ & $0.0 \mathrm{E}+00$ & $0.0 \mathrm{E}+00$ & $0.0 \mathrm{E}+00$ & $2.0 \mathrm{E}-08$ \\
\hline
\end{tabular}


Waste Isolation Pilot Plant Biennial Environmental Compliance Report DOE/WIPP 99-2171

Apr 24, $2000 \quad 12: 45$ pm

SUMMARY

Page 6

COLLECTIVE EFFECTIVE DOSE EQUIVALENT (person rem/y)

(All Radionuclides and Pathways)

\begin{tabular}{|c|c|c|c|c|c|c|c|}
\hline \multicolumn{8}{|c|}{ Distance (m) } \\
\hline Direction & 250 & 750 & 1500 & 2500 & 3500 & 4500 & 7500 \\
\hline$N$ & $0.0 E+00$ & $0.0 \mathrm{E}+00$ & $0.0 \mathrm{E}+00$ & $0.0 E+00$ & $0.0 E+00$ & $0.0 \mathrm{E}+00$ & $0.0 \mathrm{E}+00$ \\
\hline NNW & $0.0 E+00$ & $0.0 \mathrm{E}+00$ & $0.0 E+00$ & $0.0 E+00$ & $0.0 \mathrm{E}+00$ & $0.0 \bar{E}+00$ & $0.0 \mathrm{E}+00$ \\
\hline NW & $0.0 E+00$ & $0.0 \mathrm{E}+00$ & $0.0 \mathrm{E}+00$ & $0.0 E+00$ & $0.0 E+00$ & $0.0 E+00$ & $0.0 \mathrm{E}+00$ \\
\hline WNW & $0.0 E+00$ & $0.0 E+00$ & $0.0 E+00$ & $0.0 E+00$ & $0.0 E+00$ & $0.0 E+00$ & 1.3E-08 \\
\hline & $0.0 E+00$ & $0.0 \mathrm{E}+00$ & $0.0 \bar{E}+00$ & $0.0 E+00$ & $0.0 E+00$ & $0.0 \mathrm{E}+00$ & $0.0 \mathrm{E}+00$ \\
\hline WSW & $0.0 E+00$ & $0.0 \mathrm{E}+00$ & $0.0 \mathrm{E}+00$ & $0.0 E+00$ & $0.0 E+00$ & $0.0 E+00$ & $0.0 \mathrm{E}+00$ \\
\hline SW & $0.0 E+00$ & $0.0 \mathrm{E}+00$ & $0.0 E+00$ & $0.0 E+00$ & $0.0 E+00$ & $0.0 E+00$ & $0.0 E+00$ \\
\hline SSW & $0.0 E+00$ & $0.0 \mathrm{E}+00$ & $0.0 \mathrm{E}+00$ & $0.0 E+00$ & $0.0 E+00$ & $0.0 \mathrm{E}+00$ & $6.2 \mathrm{E}-09$ \\
\hline & $0.0 \mathrm{E}+00$ & $0.0 \mathrm{E}+00$ & $0.0 \mathrm{E}+00$ & $0.0 \mathrm{E}+00$ & $0.0 \mathrm{E}+00$ & $0.0 \mathrm{E}+00$ & $0.0 \mathrm{E}+00$ \\
\hline SSE & $0.0 E+00$ & $0.0 \mathrm{E}+00$ & $0.0 \mathrm{E}+00$ & $0.0 E+00$ & $0.0 E+00$ & $0.0 E+00$ & $0.0 E+00$ \\
\hline SE & $0.0 E+00$ & $0.0 \mathrm{E}+00$ & $0.0 E+00$ & $0.0 E+00$ & $0.0 E+00$ & $0.0 E+00$ & $0.0 E+00$ \\
\hline ESE & $0.0 E+00$ & $0.0 \mathrm{E}+00$ & $0.0 E+00$ & $0.0 E+00$ & $0.0 E+00$ & $0.0 E+00$ & $0.0 \mathrm{E}+00$ \\
\hline$E$ & $0.0 E+00$ & $0.0 \mathrm{E}+00$ & $0.0 \mathrm{E}+00$ & $0.0 E+00$ & $0.0 E+00$ & $0.0 E+00$ & $0.0 \mathrm{E}+00$ \\
\hline ENE & $0.0 E+00$ & $0.0 E+00$ & $0.0 E+00$ & $0.0 E+00$ & $0.0 E+00$ & $0.0 E+00$ & $0.0 E+00$ \\
\hline NE & $0.0 E+00$ & $0.0 \mathrm{E}+00$ & $0.0 E+00$ & $0.0 E+00$ & $0.0 E+00$ & $0.0 E+00$ & $0.0 \mathrm{E}+00$ \\
\hline NNE & $0.0 E+00$ & $0.0 \mathrm{E}+00$ & $0.0 \mathrm{E}+00$ & $0.0 E+00$ & $0.0 E+00$ & $0.0 \mathrm{E}+00$ & $0.0 \mathrm{E}+00$ \\
\hline
\end{tabular}

Distance $(\mathrm{m})$

\begin{tabular}{rcccccc} 
Direction & 15000 & 25000 & 35000 & 45000 & 55000 & 70000 \\
\cline { 2 - 7 }$N$ & & & & & \\
$N$ & $5.0 \mathrm{E}-09$ & $0.0 \mathrm{E}+00$ & $0.0 \mathrm{E}+00$ & $1.5 \mathrm{E}-09$ & $0.0 \mathrm{E}+00$ & $0.0 \mathrm{E}+00$ \\
NNW & $0.0 \mathrm{E}+00$ & $0.0 \mathrm{E}+00$ & $0.0 \mathrm{E}+00$ & $2.5 \mathrm{E}-09$ & $4.6 \mathrm{E}-09$ & $0.0 \mathrm{E}+00$ \\
$N W$ & $3.6 \mathrm{E}-08$ & $0.0 \mathrm{E}+00$ & $0.0 \mathrm{E}+00$ & $0.0 \mathrm{E}+00$ & $3.4 \mathrm{E}-09$ & $7.6 \mathrm{E}-07$ \\
WNW & $0.0 \mathrm{E}+00$ & $2.4 \mathrm{E}-08$ & $0.0 \mathrm{E}+00$ & $0.0 \mathrm{E}+00$ & $9.0 \mathrm{E}-09$ & $0.0 \mathrm{E}+00$ \\
W & $0.0 \mathrm{E}+00$ & $4.7 \mathrm{E}-09$ & $1.6 \mathrm{E}-08$ & $3.1 \mathrm{E}-06$ & $1.7 \mathrm{E}-09$ & $2.6 \mathrm{E}-10$ \\
WSW & $0.0 \mathrm{E}+00$ & $0.0 \mathrm{E}+00$ & $0.0 \mathrm{E}+00$ & $9.4 \mathrm{E}-08$ & $1.5 \mathrm{E}-09$ & $1.5 \mathrm{E}-09$ \\
SW & $0.0 \mathrm{E}+00$ & $0.0 \mathrm{E}+00$ & $0.0 \mathrm{E}+00$ & $0.0 \mathrm{E}+00$ & $0.0 \mathrm{E}+00$ & $0.0 \mathrm{E}+00$ \\
SSW & $0.0 \mathrm{E}+00$ & $0.0 \mathrm{E}+00$ & $0.0 \mathrm{E}+00$ & $1.4 \mathrm{E}-09$ & $1.2 \mathrm{E}-09$ & $6.8 \mathrm{E}-10$ \\
S & $0.0 \mathrm{E}+00$ & $0.0 \mathrm{E}+00$ & $2.4 \mathrm{E}-10$ & $2.3 \mathrm{E}-10$ & $0.0 \mathrm{E}+00$ & $6.4 \mathrm{E}-10$ \\
SSE & $0.0 \mathrm{E}+00$ & $0.0 \mathrm{E}+00$ & $2.8 \mathrm{E}-10$ & $3.0 \mathrm{E}-10$ & $0.0 \mathrm{E}+00$ & $2.7 \mathrm{E}-09$ \\
SE & $0.0 \mathrm{E}+00$ & $0.0 \mathrm{E}+00$ & $1.2 \mathrm{E}-10$ & $0.0 \mathrm{E}+00$ & $6.2 \mathrm{E}-11$ & $3.7 \mathrm{E}-10$ \\
ESE & $0.0 \mathrm{E}+00$ & $0.0 \mathrm{E}+00$ & $0.0 \mathrm{E}+00$ & $1.7 \mathrm{E}-10$ & $1.2 \mathrm{E}-10$ & $3.8 \mathrm{E}-08$ \\
$\mathrm{E}$ & $0.0 \mathrm{E}+00$ & $0.0 \mathrm{E}+00$ & $2.7 \mathrm{E}-10$ & $2.5 \mathrm{E}-10$ & $5.1 \mathrm{E}-08$ & $3.2 \mathrm{E}-08$ \\
ENE & $0.0 \mathrm{E}+00$ & $0.0 \mathrm{E}+00$ & $0.0 \mathrm{E}+00$ & $0.0 \mathrm{E}+00$ & $0.0 \mathrm{E}+00$ & $2.8 \mathrm{E}-07$ \\
NE & $0.0 \mathrm{E}+00$ & $0.0 \mathrm{E}+00$ & $0.0 \mathrm{E}+00$ & $0.0 \mathrm{E}+00$ & $0.0 \mathrm{E}+00$ & $2.3 \mathrm{E}-07$ \\
NNE & $0.0 \mathrm{E}+00$ & $0.0 \mathrm{E}+00$ & $0.0 \mathrm{E}+00$ & $0.0 \mathrm{E}+00$ & $0.0 \mathrm{E}+00$ & $2.0 \mathrm{E}-07$ \\
\hline
\end{tabular}


Waste Isolation Pilot Plant Biennial Environmental Compliance Report DOE/WIPP 99-2171 
Waste Isolation Pilot Plant Biennial Environmental Compliance Report DOE/WIPP 99-2171

Apr 24, $2000 \quad 12: 45 \mathrm{pm}$

SUMMARY

Page 7

AVERAGE COLLECTIVE GENETIC DOSE EQUIVALENT (person rem)

(All Radionuclides and Pathways)

\begin{tabular}{rccccccc}
\hline & \multicolumn{7}{c}{ Distance $(\mathrm{m})$} \\
\cline { 2 - 8 } Direction & 250 & 750 & 1500 & 2500 & 3500 & 4500 & 7500 \\
\hline & & & & & & & \\
N & $0.0 \mathrm{E}+00$ & $0.0 \mathrm{E}+00$ & $0.0 \mathrm{E}+00$ & $0.0 \mathrm{E}+00$ & $0.0 \mathrm{E}+00$ & $0.0 \mathrm{E}+00$ & $0.0 \mathrm{E}+00$ \\
NNW & $0.0 \mathrm{E}+00$ & $0.0 \mathrm{E}+00$ & $0.0 \mathrm{E}+00$ & $0.0 \mathrm{E}+00$ & $0.0 \mathrm{E}+00$ & $0.0 \mathrm{E}+00$ & $0.0 \mathrm{E}+00$ \\
NW & $0.0 \mathrm{E}+00$ & $0.0 \mathrm{E}+00$ & $0.0 \mathrm{E}+00$ & $0.0 \mathrm{E}+00$ & $0.0 \mathrm{E}+00$ & $0.0 \mathrm{E}+00$ & $0.0 \mathrm{E}+00$ \\
WNW & $0.0 \mathrm{E}+00$ & $0.0 \mathrm{E}+00$ & $0.0 \mathrm{E}+00$ & $0.0 \mathrm{E}+00$ & $0.0 \mathrm{E}+00$ & $0.0 \mathrm{E}+00$ & $2.8 \mathrm{E}-08$ \\
W & $0.0 \mathrm{E}+00$ & $0.0 \mathrm{E}+00$ & $0.0 \mathrm{E}+00$ & $0.0 \mathrm{E}+00$ & $0.0 \mathrm{E}+00$ & $0.0 \mathrm{E}+00$ & $0.0 \mathrm{E}+00$ \\
WSW & $0.0 \mathrm{E}+00$ & $0.0 \mathrm{E}+00$ & $0.0 \mathrm{E}+00$ & $0.0 \mathrm{E}+00$ & $0.0 \mathrm{E}+00$ & $0.0 \mathrm{E}+00$ & $0.0 \mathrm{E}+00$ \\
SW & $0.0 \mathrm{E}+00$ & $0.0 \mathrm{E}+00$ & $0.0 \mathrm{E}+00$ & $0.0 \mathrm{E}+00$ & $0.0 \mathrm{E}+00$ & $0.0 \mathrm{E}+00$ & $0.0 \mathrm{E}+00$ \\
SSW & $0.0 \mathrm{E}+00$ & $0.0 \mathrm{E}+00$ & $0.0 \mathrm{E}+00$ & $0.0 \mathrm{E}+00$ & $0.0 \mathrm{E}+00$ & $0.0 \mathrm{E}+00$ & $1.3 \mathrm{E}-08$ \\
S & $0.0 \mathrm{E}+00$ & $0.0 \mathrm{E}+00$ & $0.0 \mathrm{E}+00$ & $0.0 \mathrm{E}+00$ & $0.0 \mathrm{E}+00$ & $0.0 \mathrm{E}+00$ & $0.0 \mathrm{E}+00$ \\
SSE & $0.0 \mathrm{E}+00$ & $0.0 \mathrm{E}+00$ & $0.0 \mathrm{E}+00$ & $0.0 \mathrm{E}+00$ & $0.0 \mathrm{E}+00$ & $0.0 \mathrm{E}+00$ & $0.0 \mathrm{E}+00$ \\
SE & $0.0 \mathrm{E}+00$ & $0.0 \mathrm{E}+00$ & $0.0 \mathrm{E}+00$ & $0.0 \mathrm{E}+00$ & $0.0 \mathrm{E}+00$ & $0.0 \mathrm{E}+00$ & $0.0 \mathrm{E}+00$ \\
ESE & $0.0 \mathrm{E}+00$ & $0.0 \mathrm{E}+00$ & $0.0 \mathrm{E}+00$ & $0.0 \mathrm{E}+00$ & $0.0 \mathrm{E}+00$ & $0.0 \mathrm{E}+00$ & $0.0 \mathrm{E}+00$ \\
$\mathrm{E}$ & $0.0 \mathrm{E}+00$ & $0.0 \mathrm{E}+00$ & $0.0 \mathrm{E}+00$ & $0.0 \mathrm{E}+00$ & $0.0 \mathrm{E}+00$ & $0.0 \mathrm{E}+00$ & $0.0 \mathrm{E}+00$ \\
ENE & $0.0 \mathrm{E}+00$ & $0.0 \mathrm{E}+00$ & $0.0 \mathrm{E}+00$ & $0.0 \mathrm{E}+00$ & $0.0 \mathrm{E}+00$ & $0.0 \mathrm{E}+00$ & $0.0 \mathrm{E}+00$ \\
NE & $0.0 \mathrm{E}+00$ & $0.0 \mathrm{E}+00$ & $0.0 \mathrm{E}+00$ & $0.0 \mathrm{E}+00$ & $0.0 \mathrm{E}+00$ & $0.0 \mathrm{E}+00$ & $0.0 \mathrm{E}+00$ \\
NNE & $0.0 \mathrm{E}+00$ & $0.0 \mathrm{E}+00$ & $0.0 \mathrm{E}+00$ & $0.0 \mathrm{E}+00$ & $0.0 \mathrm{E}+00$ & $0.0 \mathrm{E}+00$ & $0.0 \mathrm{E}+00$ \\
\hline
\end{tabular}

Distance $(\mathrm{m})$

\begin{tabular}{|c|c|c|c|c|c|c|}
\hline Direction & 15000 & 25000 & 35000 & 45000 & 55000 & 70000 \\
\hline $\mathrm{N}$ & $1.0 \mathrm{E}-08$ & $0.0 \mathrm{E}+00$ & $0.0 \mathrm{E}+00$ & 3.2E-09 & $0.0 \mathrm{E}+00$ & $0.0 \mathrm{E}+00$ \\
\hline NW & $0.0 \mathrm{E}+00$ & $0.0 \mathrm{E}+00$ & $0.0 \mathrm{E}+00$ & 5.1E-09 & $9.5 \mathrm{E}-09$ & $0.0 \mathrm{E}+00$ \\
\hline NW & $7.5 \mathrm{E}-08$ & $0.0 \mathrm{E}+00$ & $0.0 \mathrm{E}+00$ & $0.0 \mathrm{E}+00$ & 7.1E-09 & 1.6E-06 \\
\hline WNW & $0.0 \mathrm{E}+00$ & 5.1E-08 & $0.0 \mathrm{E}+00$ & $0.0 \mathrm{E}+00$ & $1.9 \mathrm{E}-08$ & $0.0 \mathrm{E}+00$ \\
\hline & $0.0 \mathrm{E}+00$ & $9.8 \mathrm{E}-09$ & 3.3E-08 & 6.4E-06 & 3.5E-09 & $5.5 \mathrm{E}-10$ \\
\hline WSW & $0.0 \mathrm{E}+00$ & $0.0 \mathrm{E}+00$ & $0.0 \mathrm{E}+00$ & $1.9 \mathrm{E}-07$ & 3.1E-09 & 3.1E-09 \\
\hline $\mathrm{WW}$ & $0.0 \mathrm{E}+00$ & $0.0 \mathrm{E}+00$ & $0.0 \mathrm{E}+00$ & $0.0 \mathrm{E}+00$ & $0.0 \mathrm{E}+00$ & $0.0 \mathrm{E}+00$ \\
\hline W & $0.0 \mathrm{E}+00$ & $0.0 \mathrm{E}+00$ & $0.0 \mathrm{E}+00$ & 2.8E-09 & 2.6E-09 & 1.4E-09 \\
\hline & $0.0 \mathrm{E}+00$ & $0.0 \mathrm{E}+00$ & $5.0 \mathrm{E}-10$ & $4.8 \mathrm{E}-10$ & $0.0 \mathrm{E}+00$ & 1.3E-09 \\
\hline SSE & $0.0 \mathrm{E}+00$ & $0.0 \mathrm{E}+00$ & $5.8 \mathrm{E}-10$ & $6.2 \mathrm{E}-10$ & $0.0 \mathrm{E}+00$ & 5.7E-09 \\
\hline ᄂ & $0.0 \mathrm{E}+00$ & $0.0 \mathrm{E}+00$ & $2.5 \mathrm{E}-10$ & $0.0 \mathrm{E}+00$ & 1.3E-10 & 7.7E-10 \\
\hline 5 & $0.0 \bar{E}+00$ & $0.0 \mathrm{E}+00$ & $0.0 \mathrm{E}+00$ & $3.5 \mathrm{E}-10$ & $2.6 \mathrm{E}-10$ & $7.8 \mathrm{E}-08$ \\
\hline & $0.0 \mathrm{E}+00$ & $0.0 \mathrm{E}+00$ & $5.7 \mathrm{E}-10$ & $5.1 \mathrm{E}-10$ & 1.1E-07 & 6.7Е-08 \\
\hline $\mathrm{NE}$ & $0.0 \bar{E}+00$ & $0.0 \bar{E}+00$ & $0.0 \bar{E}+00$ & $0.0 \bar{E}+00$ & $0.0 \bar{E}+00$ & $5.8 \mathrm{E}-07$ \\
\hline NE & $0.0 \bar{E}+00$ & $0.0 \bar{E}+00$ & $0.0 \bar{E}+00$ & $0.0 \bar{E}+00$ & $0.0 \bar{E}+00$ & $4.9 \mathrm{E}-07$ \\
\hline $\mathrm{JE}$ & $0.0 \mathrm{E}+00$ & $0.0 \mathrm{E}+00$ & $0.0 \mathrm{E}+00$ & $0.0 \mathrm{E}+00$ & $0.0 \mathrm{E}+00$ & 4.2E-07 \\
\hline
\end{tabular}


Waste Isolation Pilot Plant Biennial Environmental Compliance Report DOE/WIPP 99-2171 
INDIVIDUAL LIFETIME RISK (deaths)

(All Radionuclides and Pathways)

\begin{tabular}{|c|c|c|c|c|c|c|c|}
\hline \multicolumn{8}{|c|}{ Distance (m) } \\
\hline Direction & 250 & 750 & 1500 & 2500 & 3500 & 4500 & 7500 \\
\hline$N$ & $0.0 E+00$ & $0.0 E+00$ & $0.0 E+00$ & $0.0 E+00$ & $0.0 E+00$ & $0.0 E+00$ & $0.0 E+00$ \\
\hline NNW & $0.0 E+00$ & $0.0 E+00$ & $0.0 \mathrm{E}+00$ & $0.0 E+00$ & $0.0 E+00$ & $0.0 E+00$ & $0.0 \mathrm{E}+00$ \\
\hline NW & $0.0 \mathrm{E}+00$ & $0.0 \mathrm{E}+00$ & $0.0 \mathrm{E}+00$ & $0.0 \mathrm{E}+00$ & $0.0 E+00$ & $0.0 \mathrm{E}+00$ & $0.0 \mathrm{E}+00$ \\
\hline WNW & $0.0 \mathrm{E}+00$ & $0.0 \mathrm{E}+00$ & $0.0 \mathrm{E}+00$ & $0.0 E+00$ & $0.0 E+00$ & $0.0 E+00$ & $1.1 \mathrm{E}-11$ \\
\hline W & $0.0 E+00$ & $0.0 E+00$ & $0.0 \mathrm{E}+00$ & $0.0 E+00$ & $0.0 E+00$ & $0.0 E+00$ & $0.0 E+00$ \\
\hline WSW & $0.0 E+00$ & $0.0 E+00$ & $0.0 \mathrm{E}+00$ & $0.0 E+00$ & $0.0 E+00$ & $0.0 \mathrm{E}+00$ & $0.0 \mathrm{E}+00$ \\
\hline SW & $0.0 E+00$ & $0.0 \mathrm{E}+00$ & $0.0 \mathrm{E}+00$ & $0.0 E+00$ & $0.0 E+00$ & $0.0 E+00$ & $0.0 \mathrm{E}+00$ \\
\hline SSW & $0.0 E+00$ & $0.0 \mathrm{E}+00$ & $0.0 \mathrm{E}+00$ & $0.0 \mathrm{E}+00$ & $0.0 \mathrm{E}+00$ & $0.0 \mathrm{E}+00$ & $3.5 E-12$ \\
\hline & $0.0 \mathrm{E}+00$ & $0.0 \mathrm{E}+00$ & $0.0 \mathrm{E}+00$ & $0.0 E+00$ & $0.0 \mathrm{E}+00$ & $0.0 E+00$ & $0.0 \mathrm{E}+00$ \\
\hline SSE & $0.0 E+00$ & $0.0 \mathrm{E}+00$ & $0.0 \mathrm{E}+00$ & $0.0 E+00$ & $0.0 E+00$ & $0.0 E+00$ & $0.0 E+00$ \\
\hline SE & $0.0 E+00$ & $0.0 E+00$ & $0.0 E+00$ & $0.0 E+00$ & $0.0 E+00$ & $0.0 E+00$ & $0.0 \mathrm{E}+00$ \\
\hline ESE & $0.0 E+00$ & $0.0 E+00$ & $0.0 \mathrm{E}+00$ & $0.0 E+00$ & $0.0 E+00$ & $0.0 E+00$ & $0.0 \mathrm{E}+00$ \\
\hline$E$ & $0.0 \mathrm{E}+00$ & $0.0 \mathrm{E}+00$ & $0.0 \mathrm{E}+00$ & $0.0 \mathrm{E}+00$ & $0.0 \mathrm{E}+00$ & $0.0 \mathrm{E}+00$ & $0.0 \mathrm{E}+00$ \\
\hline ENE & $0.0 E+00$ & $0.0 E+00$ & $0.0 \mathrm{E}+00$ & $0.0 E+00$ & $0.0 E+00$ & $0.0 E+00$ & $0.0 E+00$ \\
\hline NE & $0.0 \mathrm{E}+00$ & $0.0 \mathrm{E}+00$ & $0.0 \mathrm{E}+00$ & $0.0 \mathrm{E}+00$ & $0.0 E+00$ & $0.0 \mathrm{E}+00$ & $0.0 \mathrm{E}+00$ \\
\hline NNE & $0.0 E+00$ & $0.0 \mathrm{E}+00$ & $0.0 \mathrm{E}+00$ & $0.0 E+00$ & $0.0 E+00$ & $0.0 E+00$ & $0.0 \mathrm{E}+00$ \\
\hline
\end{tabular}

\begin{tabular}{rcccccc} 
& \multicolumn{7}{c}{ Distance $(\mathrm{m})$} \\
\cline { 2 - 7 } Direction & 15000 & 25000 & 35000 & 45000 & 55000 & 70000 \\
\hline & & & & & & \\
$N$ & $1.7 \mathrm{E}-12$ & $0.0 \mathrm{E}+00$ & $0.0 \mathrm{E}+00$ & $3.9 \mathrm{E}-13$ & $0.0 \mathrm{E}+00$ & $0.0 \mathrm{E}+00$ \\
NNW & $0.0 \mathrm{E}+00$ & $0.0 \mathrm{E}+00$ & $0.0 \mathrm{E}+00$ & $6.3 \mathrm{E}-13$ & $4.7 \mathrm{E}-13$ & $0.0 \mathrm{E}+00$ \\
NW & $4.6 \mathrm{E}-12$ & $0.0 \mathrm{E}+00$ & $0.0 \mathrm{E}+00$ & $0.0 \mathrm{E}+00$ & $8.7 \mathrm{E}-13$ & $5.6 \mathrm{E}-13$ \\
WNW & $0.0 \mathrm{E}+00$ & $2.5 \mathrm{E}-12$ & $0.0 \mathrm{E}+00$ & $0.0 \mathrm{E}+00$ & $9.3 \mathrm{E}-13$ & $0.0 \mathrm{E}+00$ \\
W & $0.0 \mathrm{E}+00$ & $1.2 \mathrm{E}-12$ & $8.1 \mathrm{E}-13$ & $5.8 \mathrm{E}-13$ & $4.3 \mathrm{E}-13$ & $2.7 \mathrm{E}-13$ \\
WSW & $0.0 \mathrm{E}+00$ & $0.0 \mathrm{E}+00$ & $0.0 \mathrm{E}+00$ & $3.4 \mathrm{E}-13$ & $2.5 \mathrm{E}-13$ & $1.5 \mathrm{E}-13$ \\
SW & $0.0 \mathrm{E}+00$ & $0.0 \mathrm{E}+00$ & $0.0 \mathrm{E}+00$ & $0.0 \mathrm{E}+00$ & $0.0 \mathrm{E}+00$ & $0.0 \mathrm{E}+00$ \\
SSW & $0.0 \mathrm{E}+00$ & $0.0 \mathrm{E}+00$ & $0.0 \mathrm{E}+00$ & $3.5 \mathrm{E}-13$ & $2.5 \mathrm{E}-13$ & $1.5 \mathrm{E}-13$ \\
S & $0.0 \mathrm{E}+00$ & $0.0 \mathrm{E}+00$ & $4.1 \mathrm{E}-13$ & $3.0 \mathrm{E}-13$ & $0.0 \mathrm{E}+00$ & $1.3 \mathrm{E}-13$ \\
SSE & $0.0 \mathrm{E}+00$ & $0.0 \mathrm{E}+00$ & $3.6 \mathrm{E}-13$ & $2.6 \mathrm{E}-13$ & $0.0 \mathrm{E}+00$ & $1.1 \mathrm{E}-13$ \\
SE & $0.0 \mathrm{E}+00$ & $0.0 \mathrm{E}+00$ & $3.1 \mathrm{E}-13$ & $0.0 \mathrm{E}+00$ & $1.6 \mathrm{E}-13$ & $9.4 \mathrm{E}-14$ \\
ESE & $0.0 \mathrm{E}+00$ & $0.0 \mathrm{E}+00$ & $0.0 \mathrm{E}+00$ & $2.2 \mathrm{E}-13$ & $1.6 \mathrm{E}-13$ & $9.3 \mathrm{E}-14$ \\
$\mathrm{E}$ & $0.0 \mathrm{E}+00$ & $0.0 \mathrm{E}+00$ & $3.5 \mathrm{E}-13$ & $2.5 \mathrm{E}-13$ & $1.9 \mathrm{E}-13$ & $1.2 \mathrm{E}-13$ \\
ENE & $0.0 \mathrm{E}+00$ & $0.0 \mathrm{E}+00$ & $0.0 \mathrm{E}+00$ & $0.0 \mathrm{E}+00$ & $0.0 \mathrm{E}+00$ & $1.0 \mathrm{E}-13$ \\
NE & $0.0 \mathrm{E}+00$ & $0.0 \mathrm{E}+00$ & $0.0 \mathrm{E}+00$ & $0.0 \mathrm{E}+00$ & $0.0 \mathrm{E}+00$ & $8.6 \mathrm{E}-14$ \\
NNE & $0.0 \mathrm{E}+00$ & $0.0 \mathrm{E}+00$ & $0.0 \mathrm{E}+00$ & $0.0 \mathrm{E}+00$ & $0.0 \mathrm{E}+00$ & $1.0 \mathrm{E}-13$
\end{tabular}


Waste Isolation Pilot Plant Biennial Environmental Compliance Report DOE/WIPP 99-2171 
COLLECTIVE FATAL CANCER RATE (deaths/y) (All Radionuclides and Pathways)

\begin{tabular}{|c|c|c|c|c|c|c|c|}
\hline \multicolumn{8}{|c|}{ Distance (m) } \\
\hline Direction & 250 & 750 & 1500 & 2500 & 3500 & 4500 & 7500 \\
\hline $\mathrm{N}$ & $0.0 E+00$ & $0.0 E+00$ & $0.0 E+00$ & $0.0 E+00$ & $0.0 E+00$ & $0.0 E+00$ & $0.0 E+00$ \\
\hline NNW & $0.0 E+00$ & $0.0 E+00$ & $0.0 \mathrm{E}+00$ & $0.0 E+00$ & $0.0 E+00$ & $0.0 E+00$ & $0.0 E+00$ \\
\hline NW & $0.0 E+00$ & $0.0 E+00$ & $0.0 \mathrm{E}+00$ & $0.0 E+00$ & $0.0 E+00$ & $0.0 \mathrm{E}+00$ & $0.0 E+00$ \\
\hline WNW & $0.0 E+00$ & $0.0 E+00$ & $0.0 E+00$ & $0.0 E+00$ & $0.0 E+00$ & $0.0 E+00$ & $9.7 E-13$ \\
\hline W & $0.0 E+00$ & $0.0 E+00$ & $0.0 \mathrm{E}+00$ & $0.0 E+00$ & $0.0 E+00$ & $0.0 \bar{E}+00$ & $0.0 E+00$ \\
\hline WSW & $0.0 \mathrm{E}+00$ & $0.0 E+00$ & $0.0 \mathrm{E}+00$ & $0.0 E+00$ & $0.0 E+00$ & $0.0 E+00$ & $0.0 E+00$ \\
\hline SW & $0.0 \mathrm{E}+00$ & $0.0 \mathrm{E}+00$ & $0.0 \mathrm{E}+00$ & $0.0 E+00$ & $0.0 \mathrm{E}+00$ & $0.0 \mathrm{E}+00$ & $0.0 \mathrm{E}+00$ \\
\hline SSW & $0.0 \mathrm{E}+00$ & $0.0 E+00$ & $0.0 \mathrm{E}+00$ & $0.0 \mathrm{E}+00$ & $0.0 \bar{E}+00$ & $0.0 \mathrm{E}+00$ & $4.5 E-13$ \\
\hline & $0.0 E+00$ & $0.0 E+00$ & $0.0 \mathrm{E}+00$ & $0.0 \mathrm{E}+00$ & $0.0 E+00$ & $0.0 \mathrm{E}+00$ & $0.0 E+00$ \\
\hline SSE & $0.0 E+00$ & $0.0 E+00$ & $0.0 E+00$ & $0.0 E+00$ & $0.0 E+00$ & $0.0 E+00$ & $0.0 E+00$ \\
\hline SE & $0.0 E+00$ & $0.0 E+00$ & $0.0 \mathrm{E}+00$ & $0.0 E+00$ & $0.0 E+00$ & $0.0 \bar{E}+00$ & $0.0 E+00$ \\
\hline ESE & $0.0 \mathrm{E}+00$ & $0.0 \mathrm{E}+00$ & $0.0 \mathrm{E}+00$ & $0.0 \mathrm{E}+00$ & $0.0 \mathrm{E}+00$ & $0.0 \mathrm{E}+00$ & $0.0 \mathrm{E}+00$ \\
\hline$E$ & $0.0 E+00$ & $0.0 E+00$ & $0.0 E+00$ & $0.0 \mathrm{E}+00$ & $0.0 E+00$ & $0.0 \mathrm{E}+00$ & $0.0 \mathrm{E}+00$ \\
\hline ENE & $0.0 E+00$ & $0.0 E+00$ & $0.0 \mathrm{E}+00$ & $0.0 E+00$ & $0.0 E+00$ & $0.0 \mathrm{E}+00$ & $0.0 E+00$ \\
\hline NE & $0.0 E+00$ & $0.0 E+00$ & $0.0 \mathrm{E}+00$ & $0.0 E+00$ & $0.0 E+00$ & $0.0 E+00$ & $0.0 E+00$ \\
\hline NNE & $0.0 E+00$ & $0.0 E+00$ & $0.0 E+00$ & $0.0 E+00$ & $0.0 E+00$ & $0.0 E+00$ & $0.0 E+00$ \\
\hline
\end{tabular}

Distance $(\mathrm{m})$

\begin{tabular}{|c|c|c|c|c|c|c|}
\hline irection & 15000 & 25000 & 35000 & 45000 & 55000 & 70000 \\
\hline $\mathrm{N}$ & & 0 & & & 0 & \\
\hline W & & $0.0 \mathrm{E}+00$ & $0.0 \mathrm{E}+00$ & $1.8 \mathrm{E}-13$ & & \\
\hline & & & & & & \\
\hline JW & $0 \mathrm{E}+00$ & 1.8E-12 & $0.0 \mathrm{E}+00$ & $0.0 \mathrm{E}+00$ & 6.6 & 0.0 \\
\hline & & 3.4 & & & & \\
\hline W & 0 & $0.0 \mathrm{E}+00$ & $0.0 \mathrm{E}+00$ & 6.8 & & \\
\hline & & $0.0 \mathrm{E}$ & 0.0 & 0.01 & 0.0 & \\
\hline SSW & & & & & & \\
\hline & & 0.01 & & & & \\
\hline & & & & & & \\
\hline & & 0.01 & 8.7 & 0.01 & & \\
\hline & & & & & & \\
\hline & & 0.01 & & & & \\
\hline & & 0.0 & & & & \\
\hline & & & & & 0.0 & \\
\hline & & -00 & & $0.0 \mathrm{E}+00$ & $0.0 \mathrm{E}+00$ & 15 \\
\hline
\end{tabular}


Waste Isolation Pilot Plant Biennial Environmental Compliance Report DOE/WIPP 99-2171 


\author{
C A P $88-P$ C \\ Version 2.00
}

Clean Air Act Assessment Package - 1988

CHI/Q TABLES

Non-Radon Population Assessment

Apr 24, $200012: 45$ pm

\begin{abstract}
Facility: Waste Isolation Pilot Project
Address: 26 Miles SE of Carlsbad, NM

City: Carlsbad

State: NM Zip: 88221
\end{abstract}
Source Category: exempt DOE facility
Source Type: Stack
Emission Year: 1999

Comments: Run for 1999

Dataset Name: 1999run

Dataset Date: Apr 24, 2000 12:44 pm

Wind File: C:ICAP88PC2IWNDFILESI96-99.WND

Population File: C:ICAP88PC2IPOPFILESIWIPP99.POP 


\section{Waste Isolation Pilot Plant Biennial Environmental Compliance Report}

DOE/WIPP 99-2171

Apr 24, $2000 \quad 12: 45$ pm

$\mathrm{CHI} / \mathrm{Q}$

Page 1

GROUND-LEVEL CHI/Q VALUES FOR AM-241

$\mathrm{CHI/Q}$ TOWARD INDICATED DIRECTION (SEC/CUBIC METER)

\begin{tabular}{|c|c|c|c|c|c|c|}
\hline \multicolumn{7}{|c|}{ Distance (meters) } \\
\hline Direction & 250 & 750 & 1500 & 2500 & 3500 & 7500 \\
\hline $\mathrm{N}$ & $1.585 \mathrm{E}-06$ & 6.061E-07 & 3.342E-07 & $2.096 \mathrm{E}-07$ & 1.455E-07 & $1.087 \mathrm{E}-07$ \\
\hline NNW & 2.127E-06 & 1.045E-06 & 5.730E-07 & $3.465 \mathrm{E}-07$ & 2.344E-07 & 1.731E-07 9.127E-C \\
\hline NW & $2.446 \mathrm{E}-06$ & $1.635 \mathrm{E}-06$ & 1.025E-06 & $6.220 \mathrm{E}-07$ & 4.183E-07 & $3.083 E-07$ \\
\hline NW & $1.508 \mathrm{E}-06$ & 1.333E-06 & 1.026E-06 & $6.452 \mathrm{E}-07$ & 4.375E-07 & 3.236E-07 \\
\hline W & $1.240 \mathrm{E}-06$ & 8.724E-07 & 5.556E-07 & $1 E-07$ & 2.234E-07 & $1.640 \mathrm{E}$ \\
\hline NSW & $9.019 \mathrm{E}-07$ & $5.250 \mathrm{E}-07$ & $3.131 \mathrm{E}-07$ & $1.934 \mathrm{E}-07$ & $1.313 \mathrm{E}-07$ & $9.712 \mathrm{E}-0$ \\
\hline SW & 7.929E-07 & $4.558 \mathrm{E}-07$ & 2.900E-07 & 1.904E-07 & 1.326E-07 & 9.927E-08 \\
\hline SSW & $8.153 \mathrm{E}-07$ & $4.570 \mathrm{E}-07$ & 2.937E-07 & $1.906 \mathrm{E}-07$ & 1.319E-07 & 9.839E-08 5.218E-0 \\
\hline & 8.222E-07 & 4.866E-07 & 2.835E-07 & $1.717 \mathrm{E}-07$ & $1.158 \mathrm{E}-07$ & 8.527E-08 4.444E-0 \\
\hline SSE & 8.153E-07 & 4.747E-07 & 2.722E-07 & 1.597E-07 & $1.060 \mathrm{E}-07$ & 7.743E-08 \\
\hline SE & 8.214E-07 & 4.492E-07 & 2.348E-07 & 1.383E-07 & 9.267E-08 & $6.795 \mathrm{E}$ \\
\hline ESE & 8.923E-07 & 4.578E-07 & 2.374E-07 & $1.386 \mathrm{E}-07$ & $9.241 \mathrm{E}-08$ & $6.757 \mathrm{E}$ \\
\hline & 1.672E-06 & 6.468E-07 & 3.043E-07 & 1.652E-07 & 1.065E-07 & 7.662E-08 3.886E-( \\
\hline ENE & $1.440 \mathrm{E}-06$ & $5.525 \mathrm{E}-07$ & $2.621 \mathrm{E}-07$ & $1.431 \mathrm{E}-07$ & $9.250 \mathrm{E}-08$ & 6.656E-08 3.390E- \\
\hline NE & $1.098 \mathrm{E}-06$ & 4.392E-07 & 2.145E-07 & $1.222 \mathrm{E}-07$ & 8.101E-08 & 5.904E-08 3.069E-0 \\
\hline NNE & 1.247E-06 & 4.442E-07 & 2.216E-07 & $1.338 \mathrm{E}-07$ & $9.199 \mathrm{E}-08$ & 6.844E-08 3.694E-0 \\
\hline
\end{tabular}

Distance (meters)

\begin{tabular}{rcccccc}
\cline { 2 - 7 } Direction & 15000 & 25000 & 35000 & 45000 & 55000 & 70000 \\
\hline$N$ & $2.498 \mathrm{E}-08$ & $1.219 \mathrm{E}-08$ & $8.047 \mathrm{E}-09$ & $5.746 \mathrm{E}-09$ & $4.142 \mathrm{E}-09$ & $2.462 \mathrm{E}-09$ \\
NNW & $3.860 \mathrm{E}-08$ & $1.931 \mathrm{E}-08$ & $1.286 \mathrm{E}-08$ & $9.305 \mathrm{E}-09$ & $6.876 \mathrm{E}-09$ & $4.270 \mathrm{E}-09$ \\
NW & $6.864 \mathrm{E}-08$ & $3.508 \mathrm{E}-08$ & $2.355 \mathrm{E}-08$ & $1.720 \mathrm{E}-08$ & $1.290 \mathrm{E}-08$ & $8.223 \mathrm{E}-09$ \\
WNW & $7.249 \mathrm{E}-08$ & $3.713 \mathrm{E}-08$ & $2.498 \mathrm{E}-08$ & $1.828 \mathrm{E}-08$ & $1.374 \mathrm{E}-08$ & $8.733 \mathrm{E}-09$ \\
W & $3.565 \mathrm{E}-08$ & $1.787 \mathrm{E}-08$ & $1.191 \mathrm{E}-08$ & $8.643 \mathrm{E}-09$ & $6.416 \mathrm{E}-09$ & $3.980 \mathrm{E}-09$ \\
WSW & $2.135 \mathrm{E}-08$ & $1.056 \mathrm{E}-08$ & $7.011 \mathrm{E}-09$ & $5.059 \mathrm{E}-09$ & $3.721 \mathrm{E}-09$ & $2.264 \mathrm{E}-09$ \\
SW & $2.242 \mathrm{E}-08$ & $1.102 \mathrm{E}-08$ & $7.312 \mathrm{E}-09$ & $5.260 \mathrm{E}-09$ & $3.838 \mathrm{E}-09$ & $2.288 \mathrm{E}-09$ \\
SSW & $2.198 \mathrm{E}-08$ & $1.078 \mathrm{E}-08$ & $7.137 \mathrm{E}-09$ & $5.128 \mathrm{E}-09$ & $3.740 \mathrm{E}-09$ & $2.227 \mathrm{E}-09$ \\
S & $1.855 \mathrm{E}-08$ & $9.146 \mathrm{E}-09$ & $6.054 \mathrm{E}-09$ & $4.357 \mathrm{E}-09$ & $3.195 \mathrm{E}-09$ & $1.943 \mathrm{E}-09$ \\
SSE & $1.640 \mathrm{E}-08$ & $8.000 \mathrm{E}-09$ & $5.264 \mathrm{E}-09$ & $3.767 \mathrm{E}-09$ & $2.744 \mathrm{E}-09$ & $1.655 \mathrm{E}-09$ \\
SE & $1.445 \mathrm{E}-08$ & $6.934 \mathrm{E}-09$ & $4.539 \mathrm{E}-09$ & $3.229 \mathrm{E}-09$ & $2.331 \mathrm{E}-09$ & $1.382 \mathrm{E}-09$ \\
ESE & $1.432 \mathrm{E}-08$ & $6.868 \mathrm{E}-09$ & $4.493 \mathrm{E}-09$ & $3.194 \mathrm{E}-09$ & $2.304 \mathrm{E}-09$ & $1.367 \mathrm{E}-09$ \\
E & $1.589 \mathrm{E}-08$ & $7.816 \mathrm{E}-09$ & $5.154 \mathrm{E}-09$ & $3.710 \mathrm{E}-09$ & $2.739 \mathrm{E}-09$ & $1.712 \mathrm{E}-09$ \\
ENE & $1.389 \mathrm{E}-08$ & $6.829 \mathrm{E}-09$ & $4.500 \mathrm{E}-09$ & $3.236 \mathrm{E}-09$ & $2.387 \mathrm{E}-09$ & $1.491 \mathrm{E}-09$ \\
NE & $1.265 \mathrm{E}-08$ & $6.112 \mathrm{E}-09$ & $4.004 \mathrm{E}-09$ & $2.852 \mathrm{E}-09$ & $2.066 \mathrm{E}-09$ & $1.249 \mathrm{E}-09$ \\
NNE & $1.564 \mathrm{E}-08$ & $7.582 \mathrm{E}-09$ & $4.993 \mathrm{E}-09$ & $3.558 \mathrm{E}-09$ & $2.560 \mathrm{E}-09$ & $1.523 \mathrm{E}-09$ \\
\hline
\end{tabular}




\section{Waste Isolation Pilot Plant Biennial Environmental Compliance Report}

DOE/WIPP 99-2171

GROUND-LEVEL CHI/Q VALUES FOR PU-238

CHI/Q TOWARD INDICATED DIRECTION (SEC/CUBIC METER)

\begin{tabular}{|c|c|c|c|c|c|c|}
\hline \multicolumn{7}{|c|}{ Distance (meters) } \\
\hline Direction & 250 & 750 & 1500 & 2500 & 3500 & 4500 \\
\hline $\mathrm{N}$ & 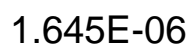 & 07 & & 200 & 7 & \\
\hline NNW & $8 E-06$ & $1 \mathrm{E}-$ & 088E-07 & 3.617E-07 & 422E-07 & $1.779 \mathrm{E}-07$ \\
\hline NW & $1 E-06$ & $2 E-06$ & & & 4.265E-07 & $33 E$ \\
\hline NW & 1 & 6 & 06 & 6. & 4.443E-07 & 3.2 \\
\hline W & 1 & & 07 & 3. & 2.270 & 1. \\
\hline VSW & 8.939E-07 & $22 \mathrm{E}-07$ & $\mathrm{E}-07$ & $2.008 \mathrm{E}-07$ & 1.351E-07 & 9.941 \\
\hline & & & & $2.011 \mathrm{E}-07$ & 1.382E-07 & 1.027 \\
\hline SSW & 8. & 4.838E-07 & $3.176 \mathrm{E}-07$ & 2.006E-07 & 1.370E-07 & $1.015 \mathrm{E}$ \\
\hline & & 5.078E-07 & 2.999E-07 & 1.784E-07 & 1.191E-07 & $8.730 \mathrm{E}$ \\
\hline & & & 07 & 1.6 & & \\
\hline & & & 2.5 & 1.4 & & \\
\hline ESE & & 4. & 2.526E-07 & 1.4 & & \\
\hline ᄃ & & & 3.127E-07 & 1.686E-07 & E-07 & \\
\hline ENE & $8 \mathrm{E}$ & $1 \mathrm{E}-07$ & 2.715E-07 & $1.468 \mathrm{E}-07$ & $9.431 \mathrm{E}-08$ & 6.765 \\
\hline NE & $1.161 \mathrm{E}$ & 4.634E-07 & 2.294E-07 & $1.286 \mathrm{E}-07$ & 8.426E-08 & $6.104 \mathrm{E}$ \\
\hline VNE & $1.309 \mathrm{E}-06$ & 4.711E-07 & $2.445 \mathrm{E}-07$ & $1.449 \mathrm{E}-07$ & $9.797 \mathrm{E}-08$ & \\
\hline
\end{tabular}

Distance (meters)

\begin{tabular}{rcccccc} 
Direction & 15000 & 25000 & 35000 & 45000 & 55000 & 70000 \\
\hline N & $2.549 \mathrm{E}-08$ & $1.232 \mathrm{E}-08$ & $8.117 \mathrm{E}-09$ & $5.788 \mathrm{E}-09$ & $4.166 \mathrm{E}-09$ & $2.447 \mathrm{E}-09$ \\
NNW & $3.905 \mathrm{E}-08$ & $1.944 \mathrm{E}-08$ & $1.293 \mathrm{E}-08$ & $9.352 \mathrm{E}-09$ & $6.905 \mathrm{E}-09$ & $4.264 \mathrm{E}-09$ \\
NW & $6.911 \mathrm{E}-08$ & $3.524 \mathrm{E}-08$ & $2.364 \mathrm{E}-08$ & $1.726 \mathrm{E}-08$ & $1.294 \mathrm{E}-08$ & $8.226 \mathrm{E}-09$ \\
WNW & $7.288 \mathrm{E}-08$ & $3.727 \mathrm{E}-08$ & $2.506 \mathrm{E}-08$ & $1.834 \mathrm{E}-08$ & $1.378 \mathrm{E}-08$ & $8.739 \mathrm{E}-09$ \\
W & $3.585 \mathrm{E}-08$ & $1.793 \mathrm{E}-08$ & $1.195 \mathrm{E}-08$ & $8.666 \mathrm{E}-09$ & $6.430 \mathrm{E}-09$ & $3.978 \mathrm{E}-09$ \\
WSW & $2.155 \mathrm{E}-08$ & $1.062 \mathrm{E}-08$ & $7.046 \mathrm{E}-09$ & $5.081 \mathrm{E}-09$ & $3.735 \mathrm{E}-09$ & $2.262 \mathrm{E}-09$ \\
SW & $2.273 \mathrm{E}-08$ & $1.111 \mathrm{E}-08$ & $7.363 \mathrm{E}-09$ & $5.291 \mathrm{E}-09$ & $3.858 \mathrm{E}-09$ & $2.282 \mathrm{E}-09$ \\
SSW & $2.226 \mathrm{E}-08$ & $1.086 \mathrm{E}-08$ & $7.182 \mathrm{E}-09$ & $5.156 \mathrm{E}-09$ & $3.757 \mathrm{E}-09$ & $2.222 \mathrm{E}-09$ \\
S & $1.873 \mathrm{E}-08$ & $9.197 \mathrm{E}-09$ & $6.083 \mathrm{E}-09$ & $4.374 \mathrm{E}-09$ & $3.206 \mathrm{E}-09$ & $1.940 \mathrm{E}-09$ \\
SSE & $1.653 \mathrm{E}-08$ & $8.038 \mathrm{E}-09$ & $5.285 \mathrm{E}-09$ & $3.780 \mathrm{E}-09$ & $2.752 \mathrm{E}-09$ & $1.653 \mathrm{E}-09$ \\
SE & $1.462 \mathrm{E}-08$ & $6.974 \mathrm{E}-09$ & $4.560 \mathrm{E}-09$ & $3.241 \mathrm{E}-09$ & $2.337 \mathrm{E}-09$ & $1.376 \mathrm{E}-09$ \\
ESE & $1.448 \mathrm{E}-08$ & $6.906 \mathrm{E}-09$ & $4.513 \mathrm{E}-09$ & $3.206 \mathrm{E}-09$ & $2.310 \mathrm{E}-09$ & $1.361 \mathrm{E}-09$ \\
E & $1.598 \mathrm{E}-08$ & $7.840 \mathrm{E}-09$ & $5.167 \mathrm{E}-09$ & $3.718 \mathrm{E}-09$ & $2.744 \mathrm{E}-09$ & $1.710 \mathrm{E}-09$ \\
ENE & $1.398 \mathrm{E}-08$ & $6.856 \mathrm{E}-09$ & $4.515 \mathrm{E}-09$ & $3.245 \mathrm{E}-09$ & $2.393 \mathrm{E}-09$ & $1.490 \mathrm{E}-09$ \\
NE & $1.282 \mathrm{E}-08$ & $6.153 \mathrm{E}-09$ & $4.026 \mathrm{E}-09$ & $2.865 \mathrm{E}-09$ & $2.073 \mathrm{E}-09$ & $1.244 \mathrm{E}-09$ \\
NNE & $1.598 \mathrm{E}-08$ & $7.665 \mathrm{E}-09$ & $5.037 \mathrm{E}-09$ & $3.584 \mathrm{E}-09$ & $2.574 \mathrm{E}-09$ & $1.512 \mathrm{E}-09$ \\
\hline
\end{tabular}




\section{Waste Isolation Pilot Plant Biennial Environmental Compliance Report}

DOE/WIPP 99-2171

GROUND-LEVEL CHI/Q VALUES FOR PU-239

CHI/Q TOWARD INDICATED DIRECTION (SEC/CUBIC METER)

\begin{tabular}{|c|c|c|c|c|c|c|}
\hline \multicolumn{7}{|c|}{ Distance (meters) } \\
\hline Direction & 250 & 750 & 1500 & 2500 & 3500 & 4500 \\
\hline $\mathrm{N}$ & L & 07 & & 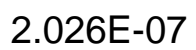 & 07 & \\
\hline NNW & $60 \mathrm{E}-$ & E-06 & 50E-07 & 3.395E-07 & 2.309E-07 & $1.710 \mathrm{E}$ \\
\hline NW & 0E-06 & 2E-06 & 9E-07 & & 07 & $3.058 \mathrm{E}$ \\
\hline NW & 1 & 6 & 66 & 6. & 4.336E & 3.2 \\
\hline W & 1 & & 0.432 & 3. & 2.214 & 1. \\
\hline VSW & 8.758E-07 & 7 & 3.036E-07 & $1.899 \mathrm{E}-07$ & 1.296E-07 & 9.607 \\
\hline & & & 2.778E-07 & $5 E-07$ & 1.302E-07 & 9.779 \\
\hline SW & 7. & $5 E-07$ & 2.820E-07 & $1.861 \mathrm{E}-07$ & 1.297E-07 & 9.703 \\
\hline & 5E-07 & $3 E-07$ & $2.750 \mathrm{E}-07$ & $1.686 \mathrm{E}-07$ & $1.142 \mathrm{E}-07$ & $8.435 \mathrm{E}$ \\
\hline & & & 2.65 & & 1.048E-07 & \\
\hline & & & 2.274 & & $9.122 \mathrm{E}-08$ & \\
\hline ESE & 8. & & 2.302E-07 & 1.3 & $9.103 \mathrm{E}-08$ & \\
\hline ᄃ & $0 E-06$ & 7 & 2.992E-07 & E-07 & 1.057E-07 & \\
\hline ENE & 00E-06 & 09E-07 & $2.570 \mathrm{E}-07$ & $1.413 \mathrm{E}-07$ & $9.164 \mathrm{E}-08$ & 6.60 \\
\hline $\mathrm{NE}$ & 1.057E-06 & 4.258E-07 & 2.078E-07 & 1.195E-07 & 7.965E-08 & $5.822 \mathrm{E}-$ \\
\hline VNE & $1.208 \mathrm{E}-06$ & 4.296E-07 & $2.116 \mathrm{E}-07$ & E-07 & 8.959E-08 & \\
\hline
\end{tabular}

Distance (meters)

\begin{tabular}{rcccccc} 
Direction & 15000 & 25000 & 35000 & 45000 & 55000 & 70000 \\
\hline$N$ & $2.478 \mathrm{E}-08$ & $1.214 \mathrm{E}-08$ & $8.021 \mathrm{E}-09$ & $5.731 \mathrm{E}-09$ & $4.134 \mathrm{E}-09$ & $2.468 \mathrm{E}-09$ \\
NNW & $3.841 \mathrm{E}-08$ & $1.926 \mathrm{E}-08$ & $1.283 \mathrm{E}-08$ & $9.287 \mathrm{E}-09$ & $6.865 \mathrm{E}-09$ & $4.274 \mathrm{E}-09$ \\
NW & $6.841 \mathrm{E}-08$ & $3.501 \mathrm{E}-08$ & $2.350 \mathrm{E}-08$ & $1.717 \mathrm{E}-08$ & $1.288 \mathrm{E}-08$ & $8.223 \mathrm{E}-09$ \\
WNW & $7.228 \mathrm{E}-08$ & $3.706 \mathrm{E}-08$ & $2.494 \mathrm{E}-08$ & $1.826 \mathrm{E}-08$ & $1.373 \mathrm{E}-08$ & $8.732 \mathrm{E}-09$ \\
W & $3.555 \mathrm{E}-08$ & $1.784 \mathrm{E}-08$ & $1.190 \mathrm{E}-08$ & $8.634 \mathrm{E}-09$ & $6.410 \mathrm{E}-09$ & $3.982 \mathrm{E}-09$ \\
WSW & $2.126 \mathrm{E}-08$ & $1.054 \mathrm{E}-08$ & $6.997 \mathrm{E}-09$ & $5.050 \mathrm{E}-09$ & $3.716 \mathrm{E}-09$ & $2.266 \mathrm{E}-09$ \\
SW & $2.229 \mathrm{E}-08$ & $1.099 \mathrm{E}-08$ & $7.292 \mathrm{E}-09$ & $5.247 \mathrm{E}-09$ & $3.831 \mathrm{E}-09$ & $2.291 \mathrm{E}-09$ \\
SSW & $2.186 \mathrm{E}-08$ & $1.074 \mathrm{E}-08$ & $7.120 \mathrm{E}-09$ & $5.118 \mathrm{E}-09$ & $3.734 \mathrm{E}-09$ & $2.230 \mathrm{E}-09$ \\
S & $1.848 \mathrm{E}-08$ & $9.125 \mathrm{E}-09$ & $6.043 \mathrm{E}-09$ & $4.350 \mathrm{E}-09$ & $3.190 \mathrm{E}-09$ & $1.945 \mathrm{E}-09$ \\
SSE & $1.634 \mathrm{E}-08$ & $7.985 \mathrm{E}-09$ & $5.256 \mathrm{E}-09$ & $3.762 \mathrm{E}-09$ & $2.741 \mathrm{E}-09$ & $1.657 \mathrm{E}-09$ \\
SE & $1.438 \mathrm{E}-08$ & $6.919 \mathrm{E}-09$ & $4.532 \mathrm{E}-09$ & $3.225 \mathrm{E}-09$ & $2.329 \mathrm{E}-09$ & $1.385 \mathrm{E}-09$ \\
ESE & $1.425 \mathrm{E}-08$ & $6.854 \mathrm{E}-09$ & $4.485 \mathrm{E}-09$ & $3.190 \mathrm{E}-09$ & $2.302 \mathrm{E}-09$ & $1.370 \mathrm{E}-09$ \\
E & $1.585 \mathrm{E}-08$ & $7.807 \mathrm{E}-09$ & $5.149 \mathrm{E}-09$ & $3.707 \mathrm{E}-09$ & $2.738 \mathrm{E}-09$ & $1.713 \mathrm{E}-09$ \\
ENE & $1.385 \mathrm{E}-08$ & $6.818 \mathrm{E}-09$ & $4.494 \mathrm{E}-09$ & $3.232 \mathrm{E}-09$ & $2.385 \mathrm{E}-09$ & $1.492 \mathrm{E}-09$ \\
NE & $1.258 \mathrm{E}-08$ & $6.096 \mathrm{E}-09$ & $3.996 \mathrm{E}-09$ & $2.848 \mathrm{E}-09$ & $2.063 \mathrm{E}-09$ & $1.252 \mathrm{E}-09$ \\
NNE & $1.551 \mathrm{E}-08$ & $7.552 \mathrm{E}-09$ & $4.977 \mathrm{E}-09$ & $3.549 \mathrm{E}-09$ & $2.555 \mathrm{E}-09$ & $1.528 \mathrm{E}-09$ \\
\hline
\end{tabular}


This page intentionally left blank. 


\title{
Attachment 2 to Appendix B
}

C A P $88-$ P C

Version 2.00

Clean Air Act Assessment Package - 1988

\author{
SYNOPSIS REPORT \\ Non-Radon Individual Assessment \\ Jun 21, 2000 11:59 am
}

\begin{abstract}
Facility: Waste Isolation Pilot Project
Address: 26 Miles SE of Carlsbad, NM

City: Carlsbad

State: NM Zip: 88221

Source Category: exempt DOE facility

Source Type: Stack

Emission Year: 1999
\end{abstract}

Comments: Run for 1999

Effective Dose Equivalent (mrem/year)

3.05E-05

At This Location: 350 Meters Northwest

Dataset Name: 191

Dataset Date: Jun 21, 2000 11:59 am

Wind File: C:ICAP88PC2IWNDFILESI96-99.WND 
Jun 21, 2000 11:59 am

SYNOPSIS

Page 1

MAXIMALLY EXPOSED INDIVIDUAL

Location Of The Individual: 350 Meters Northwest

Lifetime Fatal Cancer Risk: $1.56 \mathrm{E}-10$

ORGAN DOSE EQUIVALENT SUMMARY

$\begin{array}{lc}\text { Organ } & \begin{array}{c}\text { Dose } \\ \text { Equivalent } \\ \text { (mrem/y) }\end{array} \\ \text { GONADS } & 6.81 \mathrm{E}-06 \\ \text { BREAST } & 6.83 \mathrm{E}-07 \\ \text { R MAR } & 4.31 \mathrm{E}-05 \\ \text { LUNGS } & 4.35 \mathrm{E}-06 \\ \text { THYROID } & 6.72 \mathrm{E}-07 \\ \text { ENDOST } & 5.31 \mathrm{E}-04 \\ \text { RMNDR } & 2.35 \mathrm{E}-05 \\ \text { EFFEC } & 3.05 \mathrm{E}-05\end{array}$


Jun 21, 2000 11:59 am

SYNOPSIS

Page 2

RADIONUCLIDE EMISSIONS DURING THE YEAR 1999

\begin{tabular}{|c|c|c|c|c|c|c|}
\hline Nuclide & Class & Size & $\begin{array}{c}\text { Source } \\
\# 1 \\
\mathrm{Ci} / \mathrm{y}\end{array}$ & $\begin{array}{c}\text { Source } \\
\# 2 \\
\mathrm{Ci} / \mathrm{y}\end{array}$ & $\begin{array}{c}\text { Source } \\
\# 3 \\
\text { Ci/y }\end{array}$ & $\begin{array}{c}\text { TOTAL } \\
\text { Ci/y }\end{array}$ \\
\hline $\begin{array}{l}\text { AM-241 } \\
\text { PU-238 } \\
\text { PU-239 }\end{array}$ & $\begin{array}{l}W \\
W \\
W\end{array}$ & $\begin{array}{l}1.00 \\
1.00 \\
1.00\end{array}$ & $\begin{array}{l}2.6 \mathrm{E}-08 \\
1.5 \mathrm{E}-08 \\
2.7 \mathrm{E}-08\end{array}$ & $\begin{array}{l}1.6 \mathrm{E}-09 \\
1.4 \mathrm{E}-09 \\
8.8 \mathrm{E}-10\end{array}$ & $\begin{array}{l}\text { 6.4E-09 } \\
9.4 \mathrm{E}-09 \\
4.6 \mathrm{E}-09\end{array}$ & $\begin{array}{l}3.4 \mathrm{E}-08 \\
2.6 \mathrm{E}-08 \\
3.3 \mathrm{E}-08\end{array}$ \\
\hline
\end{tabular}

\section{SITE INFORMATION}

Temperature: 17 degrees $\mathrm{C}$

Precipitation: $\quad 33 \mathrm{~cm} / \mathrm{y}$

Mixing Height: $1000 \mathrm{~m}$ 
Jun 21, 2000 11:59 am

SYNOPSIS

Page 3

\section{SOURCE INFORMATION}

\begin{tabular}{|c|c|c|c|}
\hline Source Number: & 1 & 2 & 3 \\
\hline $\begin{array}{l}\text { Stack Height }(m) \text { : } \\
\text { Diameter }(m) \text { : }\end{array}$ & $\begin{array}{l}8 . \\
5 .\end{array}$ & $\begin{array}{l}7 . \\
2 .\end{array}$ & $\begin{array}{r}20 . \\
3 .\end{array}$ \\
\hline $\begin{array}{l}\text { Plume Rise } \\
\text { Momentum }(\mathrm{m} / \mathrm{s}) \text { : } \\
\text { (Exit Velocity) }\end{array}$ & 9. & 11. & 3 \\
\hline
\end{tabular}

AGRICULTURAL DATA

Fraction Home Produced:

Fraction From Assessment Area:

Fraction Imported:

\begin{tabular}{llll} 
Vegetable & Milk & Meat \\
\cline { 1 - 1 } & & \\
1.000 & 1.000 & 1.000 \\
0.000 & 0.000 & 0.000 \\
0.000 & 0.000 & 0.000
\end{tabular}

Food Arrays were not generated for this run.

Default Values used.

DISTANCES (M) USED FOR MAXIMUM INDIVIDUAL ASSESSMENT

350 


\author{
C A P $88-P$ C \\ Version 2.00
}

Clean Air Act Assessment Package - 1988

GENERAL DATA

Non-Radon Individual Assessment Jun 21, 2000 11:59 am

Facility: Waste Isolation Pilot Project

Address: 26 Miles SE of Carlsbad, NM

City: Carlsbad

State: NM Zip: 88221

Source Category: exempt DOE facility

Source Type: Stack

Emission Year: 1999

Comments: Run for 1999

Dataset Name: 191

Dataset Date: Jun 21, 2000 11:59 am

Wind File: C:ICAP88PC21WNDFILESI96-99.WND 
Jun 21, 2000 11:59 am

GENERAL

Page 1

\section{VALUES FOR RADIONUCLIDE-DEPENDENT PARAMETERS}

\begin{tabular}{ccccc}
\hline Nuclide & $\begin{array}{c}\text { Clearance } \\
\text { Class }\end{array}$ & $\begin{array}{c}\text { Particle } \\
\text { Size } \\
\text { (microns) }\end{array}$ & $\begin{array}{c}\text { Scavenging } \\
\text { Coefficient } \\
\text { (per second) }\end{array}$ & $\begin{array}{c}\text { Dry } \\
\text { Deposition } \\
\text { Velocity } \\
(\mathrm{m} / \mathrm{s})\end{array}$ \\
\hline AM-241 & W & 1.0 & $3.30 \mathrm{E}-06$ & $1.80 \mathrm{E}-03$ \\
PU-238 & W & 1.0 & $3.30 \mathrm{E}-06$ & $1.80 \mathrm{E}-03$ \\
PU-239 & W & 1.0 & $3.30 \mathrm{E}-06$ & $1.80 \mathrm{E}-03$ \\
\hline
\end{tabular}




\section{Waste Isolation Pilot Plant Biennial Environmental Compliance Report

Jun 21, 2000 11:59 am

GENERAL

Page 2

VALUES FOR RADIONUCLIDE-DEPENDENT PARAMETERS

\begin{tabular}{|c|c|c|c|c|c|c|}
\hline DEUAT UUIVOIAIVI (I LN DAT) & \multicolumn{4}{|c|}{ DECAY CONSTANT (PER DAY) } & \multicolumn{2}{|c|}{ TRANSFER } \\
\hline Nuclide & \multicolumn{2}{|c|}{$\begin{array}{l}\text { Radio- } \\
\text { active (1) }\end{array}$} & Surface & Water & Milk (2) & Meat (3) \\
\hline $\begin{array}{l}\text { AM-241 } \\
\text { PU-238 } \\
\text { PU-239 }\end{array}$ & \multicolumn{2}{|c|}{$\begin{array}{l}0.00 \mathrm{E}+00 \\
0.00 \mathrm{E}+00 \\
0.00 \mathrm{E}+00\end{array}$} & $\begin{array}{l}5.48 \mathrm{E}-05 \\
5.48 \mathrm{E}-05 \\
5.48 \mathrm{E}-05\end{array}$ & $\begin{array}{l}0.00 \mathrm{E}+00 \\
0.00 \mathrm{E}+00 \\
0.00 \mathrm{E}+00\end{array}$ & $\begin{array}{l}4.00 \mathrm{E}-07 \\
1.00 \mathrm{E}-07 \\
1.00 \mathrm{E}-07\end{array}$ & $\begin{array}{l}3.50 \mathrm{E}-06 \\
5.00 \mathrm{E}-07 \\
5.00 \mathrm{E}-07\end{array}$ \\
\hline \multirow[t]{3}{*}{ FOOTNO } & S: (1) & \multicolumn{5}{|c|}{$\begin{array}{l}\text { Effective radioactive decay constant in plume; set to zero if less } \\
\text { than } 1.0 \mathrm{E}-2\end{array}$} \\
\hline & (2) & \multicolumn{5}{|c|}{$\begin{array}{l}\text { Fraction of animal's daily intake of nuclide which appears in each } \\
L \text { of milk (days/L) }\end{array}$} \\
\hline & (3) & \multicolumn{5}{|c|}{$\begin{array}{l}\text { Fraction of animal's daily intake of nuclide which appears in each } \\
\mathrm{kg} \text { of meat (days } / \mathrm{kg} \text { ) }\end{array}$} \\
\hline
\end{tabular}


Jun 21, 2000 11:59 am

GENERAL

Page 3

\section{VALUES FOR RADIONUCLIDE-DEPENDENT PARAMETERS}

\begin{tabular}{|c|c|c|c|c|c|}
\hline \multirow[b]{2}{*}{ Nuclide } & \multicolumn{3}{|c|}{$\begin{array}{l}\text { CONCENTRATION } \\
\text { UPTAKE FACTOR }\end{array}$} & \multicolumn{2}{|c|}{ GI UPTAKE FRACTION } \\
\hline & & Forage (1) & Edible (2) & Inhalation & Ingestion \\
\hline $\begin{array}{l}\text { AM-241 } \\
\text { PU-238 } \\
\text { PU-239 }\end{array}$ & & $\begin{array}{l}5.50 \mathrm{E}-03 \\
4.50 \mathrm{E}-04 \\
4.50 \mathrm{E}-04\end{array}$ & $\begin{array}{l}1.07 \mathrm{E}-04 \\
1.93 \mathrm{E}-05 \\
1.93 \mathrm{E}-05\end{array}$ & $\begin{array}{l}1.00 \mathrm{E}-03 \\
1.00 \mathrm{E}-03 \\
1.00 \mathrm{E}-04\end{array}$ & $\begin{array}{l}1.00 \mathrm{E}-03 \\
1.00 \mathrm{E}-03 \\
1.00 \mathrm{E}-03\end{array}$ \\
\hline \multirow[t]{2}{*}{ FOOTNO } & (1) & \multicolumn{4}{|c|}{$\begin{array}{l}\text { Concentration factor for uptake of nuclide from soil for pasture } \\
\text { and forage (in } \mathrm{pCi} / \mathrm{kg} \text { dry weight per } \mathrm{pCi} / \mathrm{kg} \text { dry soil) }\end{array}$} \\
\hline & (2) & \multicolumn{4}{|c|}{$\begin{array}{l}\text { Concentration factor for uptake of nuclide from soil by edible } \\
\text { parts of crops (in pCi } / \mathrm{kg} \text { wet weight per pCi } / \mathrm{kg} \text { dry soil) }\end{array}$} \\
\hline
\end{tabular}




\section{Waste Isolation Pilot Plant Biennial Environmental Compliance Report DOE/WIPP 99-2171}

Jun 21, 2000 11:59 am

GENERAL

Page 4

\section{VALUES FOR RADIONUCLIDE-INDEPENDENT PARAMETERS}

HUMAN INHALATION RATE

Cubic centimeters/hr

9.17E+05

SOIL PARAMETERS

Effective surface density ( $\mathrm{kg} / \mathrm{sq} \mathrm{m}$, dry weight)

(Assumes $15 \mathrm{~cm}$ plow layer)

2.15E+02

BUILDUP TIMES

For activity in soil (years)

For radionuclides deposited on ground/water (days)

$1.00 \mathrm{E}+02$

$3.65 \mathrm{E}+04$

DELAY TIMES

Ingestion of pasture grass by animals (hr)

Ingestion of stored feed by animals (hr)

Ingestion of leafy vegetables by man (hr)

Ingestion of produce by man (hr)

Transport time from animal feed-milk-man (day)

Time from slaughter to consumption (day)

$0.00 \mathrm{E}+00$

$2.16 \mathrm{E}+03$

$3.36 \mathrm{E}+02$

$3.36 \mathrm{E}+02$

$2.00 \mathrm{E}+00$

$2.00 \mathrm{E}+01$

WEATHERING

Removal rate constant for physical loss (per hr)

2.90E-03

CROP EXPOSURE DURATION

Pasture grass (hr)

$7.20 \mathrm{E}+02$

Crops/leafy vegetables (hr)

$1.44 \mathrm{E}+03$

AGRICULTURAL PRODUCTIVITY

Grass-cow-milk-man pathway $(\mathrm{kg} / \mathrm{sq} \mathrm{m})$

Produce/leafy veg for human consumption $(\mathrm{kg} / \mathrm{sq} \mathrm{m})$

2.80E-01

7.16E-01

FALLOUT INTERCEPTION FRACTIONS

Vegetables

2.00E-01

Pasture

5.70E-01

GRAZING PARAMETERS

Fraction of year animals graze on pasture

Fraction of daily feed that is pasture grass when animal grazes on pasture

4.00E-01

4.30E-01 
Jun 21, 2000 11:59 am

GENERAL

Page 5

\section{VALUES FOR RADIONUCLIDE-INDEPENDENT PARAMETERS}

ANIMAL FEED CONSUMPTION FACTORS

Contaminated feed/forage (kg/day, dry weight) $\quad 1.56 \mathrm{E}+01$

DAIRY PRODUCTIVITY

Milk production of cow (L/day) $\quad 1.10 \mathrm{E}+01$

MEAT ANIMAL SLAUGHTER PARAMETERS

Muscle mass of animal at slaughter $(\mathrm{kg}) \quad 2.00 \mathrm{E}+02$

Fraction of herd slaughtered (per day) 3.81E-03

DECONTAMINATION

Fraction of radioactivity retained after washing for leafy vegetables and produce

FRACTIONS GROWN IN GARDEN OF INTEREST

Produce ingested

Leafy vegetables ingested

$1.00 \mathrm{E}+00$

$1.00 \mathrm{E}+00$

INGESTION RATIOS:

IMMEDIATE SURROUNDING AREA/TOTAL WITHIN AREA

$\begin{array}{ll}\text { Vegetables } & 1.00 \mathrm{E}+00 \\ \text { Meat } & 1.00 \mathrm{E}+00 \\ \text { Milk } & 1.00 \mathrm{E}+00\end{array}$

MINIMUM INGESTION FRACTIONS FROM OUTSIDE AREA

(Minimum fractions of food types from outside

area listed below are actual fixed values.)

$\begin{array}{ll}\text { Vegetables } & 0.00 \mathrm{E}+00 \\ \text { Meat } & 0.00 \mathrm{E}+00 \\ \text { Milk } & 0.00 \mathrm{E}+00\end{array}$

HUMAN FOOD UTILIZATION FACTORS

Produce ingestion $(\mathrm{kg} / \mathrm{y})$

Milk ingestion (L/y)

Meat ingestion $(\mathrm{kg} / \mathrm{y})$

Leafy vegetable ingestion $(\mathrm{kg} / \mathrm{y})$

$1.76 \mathrm{E}+02$

$1.12 \mathrm{E}+02$

$8.50 \mathrm{E}+01$

$1.80 \mathrm{E}+01$

SWIMMING PARAMETERS

Fraction of time spent swimming $\quad 0.00 \mathrm{E}+00$

Dilution factor for water $(\mathrm{cm}) \quad 1.00 \mathrm{E}+00$ 
Waste Isolation Pilot Plant Biennial Environmental Compliance Report DOE/WIPP 99-2171 


\author{
C A P $88-P$ C \\ Version 2.00
}

Clean Air Act Assessment Package - 1988

WEATHER DATA

Non-Radon Individual Assessment Jun 21, 2000 11:59 am

Facility: Waste Isolation Pilot Project

Address: 26 Miles SE of Carlsbad, NM

City: Carlsbad

State: NM Zip: 88221

Source Category: exempt DOE facility Source Type: Stack

Emission Year: 1999

Comments: Run for 1999

Dataset Name: 191

Dataset Date: Jun 21, 2000 11:59 am

Wind File: C:ICAP88PC2IWNDFILESI96-99.WND 
Waste Isolation Pilot Plant Biennial Environmental Compliance Report DOE/WIPP 99-2171

Jun 21, 2000 11:59 am

WEATHER

Page 1

HARMONIC AVERAGE WIND SPEEDS (WIND TOWARDS)

\begin{tabular}{|c|c|c|c|c|c|c|c|c|}
\hline \multirow[b]{2}{*}{$\begin{array}{l}\text { Wind } \\
\text { Dir }\end{array}$} & \multicolumn{8}{|c|}{ Pasquill Stability Class } \\
\hline & A & B & C & D & $\mathrm{E}$ & $\mathrm{F}$ & $\mathrm{G}$ & Freq \\
\hline $\bar{N}$ & 4.316 & 3.287 & 2.956 & 2.406 & 1.861 & 1.673 & 0.000 & 0.065 \\
\hline NNW & 4.678 & 3.731 & 3.211 & 3.161 & 3.516 & 2.173 & 0.000 & 0.102 \\
\hline NW & 4.702 & 3.763 & 3.472 & 3.928 & 4.246 & 2.813 & 0.000 & 0.162 \\
\hline WNW & 4.365 & 3.707 & 3.448 & 3.428 & 3.790 & 3.166 & 0.000 & 0.142 \\
\hline W & 4.490 & 3.680 & 3.132 & 3.718 & 3.432 & 2.539 & 0.000 & 0.074 \\
\hline WSW & 4.374 & 3.449 & 3.466 & 3.733 & 3.465 & 2.200 & 0.000 & 0.045 \\
\hline SW & 4.627 & 3.720 & 3.078 & 3.497 & 2.609 & 2.087 & 0.000 & 0.041 \\
\hline SSW & 4.721 & 3.339 & 3.187 & 3.470 & 2.482 & 2.080 & 0.000 & 0.042 \\
\hline & 4.775 & 3.691 & 3.381 & 3.197 & 2.867 & 2.115 & 0.000 & 0.041 \\
\hline SSE & 4.836 & 3.418 & 2.886 & 2.686 & 2.027 & 2.093 & 0.000 & 0.036 \\
\hline SE & 4.289 & 3.306 & 2.614 & 2.097 & 2.529 & 1.709 & 0.000 & 0.033 \\
\hline ESE & 4.031 & 2.793 & 2.376 & 1.864 & 2.207 & 1.737 & 0.000 & 0.033 \\
\hline & 5.485 & 3.338 & 2.777 & 2.521 & 3.483 & 2.097 & 0.000 & 0.054 \\
\hline ENE & 4.690 & 2.966 & 2.700 & 2.247 & 2.937 & 2.120 & 0.000 & 0.048 \\
\hline NE & 4.160 & 2.780 & 2.366 & 1.762 & 2.116 & 1.696 & 0.000 & 0.037 \\
\hline NNE & 4.062 & 2.997 & 2.541 & 2.030 & 2.072 & 1.548 & 0.000 & 0.045 \\
\hline
\end{tabular}

ARITHMETIC AVERAGE WIND SPEEDS (WIND TOWARDS) Pasquill Stability Class

\begin{tabular}{rccccccc}
\hline & \multicolumn{7}{c}{ Pasquill Stability Class } \\
\cline { 2 - 8 } Dir & A & B & C & D & E & F & G \\
& & & & & & & \\
N & 4.838 & 3.860 & 3.710 & 3.611 & 2.996 & 2.433 & 0.000 \\
NNW & 5.292 & 4.449 & 4.129 & 4.709 & 4.858 & 2.998 & 0.000 \\
NW & 5.366 & 4.460 & 4.444 & 5.514 & 5.410 & 3.574 & 0.000 \\
WNW & 4.915 & 4.409 & 4.249 & 4.871 & 5.008 & 3.921 & 0.000 \\
W & 5.255 & 4.337 & 4.276 & 5.534 & 5.176 & 3.740 & 0.000 \\
WSW & 5.230 & 4.496 & 4.532 & 5.878 & 5.119 & 3.221 & 0.000 \\
SW & 5.636 & 4.642 & 4.515 & 5.550 & 4.448 & 2.944 & 0.000 \\
SSW & 5.536 & 4.247 & 4.289 & 5.238 & 3.817 & 3.016 & 0.000 \\
S & 5.613 & 4.430 & 4.567 & 4.749 & 4.265 & 3.161 & 0.000 \\
SSE & 5.885 & 4.300 & 3.667 & 4.485 & 3.532 & 3.270 & 0.000 \\
SE & 4.968 & 3.927 & 3.526 & 3.644 & 4.203 & 2.832 & 0.000 \\
ESE & 4.831 & 3.371 & 3.247 & 3.745 & 3.902 & 2.869 & 0.000 \\
E & 7.011 & 5.066 & 4.827 & 5.533 & 5.517 & 3.479 & 0.000 \\
ENE & 5.812 & 4.244 & 4.082 & 4.305 & 4.550 & 3.319 & 0.000 \\
NE & 5.173 & 3.558 & 3.285 & 3.231 & 3.477 & 2.651 & 0.000 \\
NNE & 4.695 & 3.535 & 3.223 & 3.279 & 3.312 & 2.329 & 0.000
\end{tabular}


Waste Isolation Pilot Plant Biennial Environmental Compliance Report DOE/WIPP 99-2171 
Jun 21, $200011: 59 \mathrm{am}$

WEATHER

Page 2

FREQUENCIES OF STABILITY CLASSES (WIND TOWARDS)

\begin{tabular}{|c|c|c|c|c|c|c|c|c|}
\hline \multirow[b]{2}{*}{ Dir } & \multicolumn{6}{|c|}{ Pasquill Stability Class } & \multirow[b]{2}{*}{$\mathrm{F}$} & \multirow[b]{2}{*}{$G$} \\
\hline & $A$ & B & C & & D & $E$ & & \\
\hline $\mathrm{N}$ & 0.4054 & 0.0755 & 0.0587 & 0.1246 & 0.1117 & 0.2241 & 0.0000 & \\
\hline NNW & 0.2905 & 0.0542 & 0.0464 & 0.1514 & 0.2004 & 0.2571 & 0.0000 & \\
\hline NW & 0.1586 & 0.0329 & 0.0305 & 0.1327 & 0.2805 & 0.3648 & 0.0000 & \\
\hline WNW & 0.0923 & 0.0241 & 0.0247 & 0.1107 & 0.2048 & 0.5434 & 0.0000 & \\
\hline W & 0.1172 & 0.0356 & 0.0355 & 0.1908 & 0.2368 & 0.3841 & 0.0000 & \\
\hline WSW & 0.1232 & 0.0350 & 0.0449 & 0.2430 & 0.2060 & 0.3480 & 0.0000 & \\
\hline SW & 0.1321 & 0.0361 & 0.0421 & 0.2354 & 0.1389 & 0.4154 & 0.0000 & \\
\hline SSW & 0.1417 & 0.0428 & 0.0490 & 0.2459 & 0.1306 & 0.3900 & 0.0000 & \\
\hline & 0.1824 & 0.0547 & 0.0535 & 0.2204 & 0.1910 & 0.2980 & 0.0000 & \\
\hline SSE & 0.2230 & 0.0678 & 0.0568 & 0.2221 & 0.1631 & 0.2672 & 0.0000 & \\
\hline SE & 0.2240 & 0.0923 & 0.0930 & 0.2069 & 0.1481 & 0.2356 & 0.0000 & \\
\hline ESE & 0.2814 & 0.0879 & 0.0784 & 0.1877 & 0.1323 & 0.2324 & 0.0000 & \\
\hline $\mathrm{E}$ & 0.3832 & 0.0690 & 0.0683 & 0.1695 & 0.1526 & 0.1574 & 0.0000 & \\
\hline ENE & 0.4052 & 0.0835 & 0.0743 & 0.1602 & 0.1175 & 0.1593 & 0.0000 & \\
\hline NE & 0.4123 & 0.0933 & 0.0799 & 0.1439 & 0.1045 & 0.1660 & 0.0000 & \\
\hline NNE & 0.4284 & 0.0968 & 0.0704 & 0.1217 & 0.0919 & 0.1909 & 0.0000 & \\
\hline TOTAL & 0.2272 & 0.0528 & 0.0487 & 0.1635 & 0.1851 & 0.3228 & 0.0000 & \\
\hline
\end{tabular}

ADDITIONAL WEATHER INFORMATION

Average Air Temperature: 17.0 degrees $\mathrm{C}$

$290.16 \mathrm{~K}$

Precipitation: $\quad 33.0 \mathrm{~cm} / \mathrm{y}$

Lid Height: 1000 meters

Surface Roughness Length: 0.010 meters

Height Of Wind Measurements: 10.0 meters

Average Wind Speed: $\quad 4.411 \mathrm{~m} / \mathrm{s}$

Vertical Temperature Gradients:

STABILITY E $\quad 0.073 \mathrm{k} / \mathrm{m}$

STABILITY F $\quad 0.109 \mathrm{k} / \mathrm{m}$

STABILITY G $\quad 0.146 \mathrm{k} / \mathrm{m}$ 


\author{
C A P $88-P$ C \\ Version 2.00 \\ Clean Air Act Assessment Package - 1988 \\ DOSE AND RISK EQUIVALENT SUMMARIES \\ Non-Radon Individual Assessment \\ Jun 21, $200011: 59 \mathrm{am}$
}

Facility: Waste Isolation Pilot Project

Address: 26 Miles SE of Carlsbad, NM

City: Carlsbad

State: NM Zip: 88221

$\begin{aligned} \text { Source Category: } & \text { exempt DOE facility } \\ \text { Source Type: } & \text { Stack } \\ \text { Emission Year: } & 1999\end{aligned}$

Comments: Run for 1999

Dataset Name: 191

Dataset Date: Jun 21, 2000 11:59 am

Wind File: C:ICAP88PC2IWNDFILESI96-99.WND 
Jun 21, 2000 11:59 am

SUMMARY

Page 1

ORGAN DOSE EQUIVALENT SUMMARY

\begin{tabular}{ll}
\multicolumn{1}{c}{ Organ } & \multicolumn{1}{c}{$\begin{array}{c}\text { Selected } \\
\text { Individual } \\
\text { (mrem/y) }\end{array}$} \\
GONADS & $6.81 \mathrm{E}-06$ \\
BREAST & $6.83 \mathrm{E}-07$ \\
R MAR & $4.31 \mathrm{E}-05$ \\
LUNGS & $4.35 \mathrm{E}-06$ \\
THYROID & $6.72 \mathrm{E}-07$ \\
ENDOST & $5.31 \mathrm{E}-04$ \\
RMNDR & $2.35 \mathrm{E}-05$ \\
EFFEC & $3.05 \mathrm{E}-05$
\end{tabular}

PATHWAY EFFECTIVE DOSE EQUIVALENT SUMMARY

Selected

Individual

Pathway

(mrem/y)

$\overline{\text { INGESTION }}$

$2.17 \mathrm{E}-06$

INHALATION

2.83E-05

AIR IMMERSION

2.33E-13

GROUND SURFACE

$1.10 \mathrm{E}-08$

INTERNAL

$3.05 \mathrm{E}-05$

EXTERNAL

$1.10 \mathrm{E}-08$

TOTAL

3.05E-05 
Jun 21, 2000 11:59 am

SUMMARY

Page 2

NUCLIDE EFFECTIVE DOSE EQUIVALENT SUMMARY

Selected

Individual

Nuclide

(mrem/y)

AM-241

PU-238

1.19E-05

PU-239

7.83E-06

1.08E-05

TOTAL

3.05E-05 
Jun 21, 2000 11:59 am

SUMMARY

Page 3

CANCER RISK SUMMARY

Cancer

Selected Individual

Total Lifetime

Fatal Cancer Risk

LEUKEMIA

BONE

3.64E-11

THYROID

2.34E-11

BREAST

7.78E-14

LUNG

$5.75 \mathrm{E}-13$

STOMACH

1.23E-11

BOWEL

4.27E-13

LIVER

$2.51 \mathrm{E}-13$

PANCREAS

8.21E-11

URINARY

$3.16 \mathrm{E}-13$

OTHER

$1.66 \mathrm{E}-13$

3.86E-13

TOTAL

1.56E-10

\section{PATHWAY RISK SUMMARY}

\begin{tabular}{ll} 
Pathway & $\begin{array}{c}\text { Selected Individual } \\
\text { Total Lifetime } \\
\text { Fatal Cancer Risk }\end{array}$ \\
\cline { 2 - 2 } INGESTION & $1.04 \mathrm{E}-11$ \\
INHALATION & $1.46 \mathrm{E}-10$ \\
AIR IMMERSION & $4.85 \mathrm{E}-18$ \\
GROUND SURFACE & $2.29 \mathrm{E}-13$ \\
INTERNAL & $1.56 \mathrm{E}-10$ \\
EXTERNAL & $2.29 \mathrm{E}-13$ \\
TOTAL & $1.56 \mathrm{E}-10$
\end{tabular}




\section{NUCLIDE RISK SUMMARY}

Nuclide

AM-241

PU-238

PU-239

TOTAL
Selected Individual Total Lifetime Fatal Cancer Risk

6.08E-11

4.16E-11

5.40E-11

1.56E-10 
Jun 21, 2000 11:59 am

INDIVIDUAL EFFECTIVE DOSE EQUIVALENT RATE (mrem/y)

(All Radionuclides and Pathways)

Distance $(\mathrm{m})$

Direction 350

$\begin{array}{rr}N & 1.5 \mathrm{E}-05 \\ \text { NNW } & 2.3 \mathrm{E}-05 \\ N W & 3.0 \mathrm{E}-05 \\ \text { WNW } & 2.0 \mathrm{E}-05 \\ \text { W } & 1.6 \mathrm{E}-05 \\ \text { WSW } & 1.1 \mathrm{E}-05 \\ \text { SW } & 9.5 \mathrm{E}-06 \\ \text { SSW } & 9.6 \mathrm{E}-06 \\ \text { S } & 9.8 \mathrm{E}-06 \\ \text { SSE } & 9.6 \mathrm{E}-06 \\ \text { SE } & 9.7 \mathrm{E}-06 \\ \text { ESE } & 1.0 \mathrm{E}-05 \\ \mathrm{E} & 1.8 \mathrm{E}-05 \\ \text { ENE } & 1.5 \mathrm{E}-05 \\ \text { NE } & 1.1 \mathrm{E}-05 \\ \text { NNE } & 1.2 \mathrm{E}-05\end{array}$


Jun 21, 2000 11:59 am

SUMMARY

Page 6

INDIVIDUAL LIFETIME RISK (deaths)

(All Radionuclides and Pathways)

\begin{tabular}{rl}
\hline & \multicolumn{1}{c}{ Distance $(\mathrm{m})$} \\
\cline { 2 - 2 } Direction & 350 \\
\hline $\mathrm{N}$ & $7.8 \mathrm{E}-11$ \\
NNW & $1.2 \mathrm{E}-10$ \\
NW & $1.6 \mathrm{E}-10$ \\
WNW & $1.0 \mathrm{E}-10$ \\
W & $8.2 \mathrm{E}-11$ \\
WSW & $5.7 \mathrm{E}-11$ \\
SW & $4.9 \mathrm{E}-11$ \\
SSW & $4.9 \mathrm{E}-11$ \\
S & $5.0 \mathrm{E}-11$ \\
SSE & $4.9 \mathrm{E}-11$ \\
SE & $5.0 \mathrm{E}-11$ \\
ESE & $5.2 \mathrm{E}-11$ \\
E & $9.0 \mathrm{E}-11$ \\
ENE & $7.6 \mathrm{E}-11$ \\
NE & $5.6 \mathrm{E}-11$ \\
NNE & $6.1 \mathrm{E}-11$ \\
\hline
\end{tabular}




\author{
C A P $88-P$ C \\ Version 2.00 \\ Clean Air Act Assessment Package - 1988 \\ DOSE AND RISK CONVERSION FACTORS \\ Non-Radon Individual Assessment \\ Jun 21, 2000 11:59 am \\ Facility: Waste Isolation Pilot Project \\ Address: 26 Miles SE of Carlsbad, NM \\ City: Carlsbad \\ State: NM Zip: 88221 \\ Source Category: exempt DOE facility \\ Source Type: Stack \\ Emission Year: 1999
}

Comments: Run for 1999
Dataset Name:
191
Dataset Date: Jun 21, 2000 11:59 am
Wind File: C:ICAP88PC2IWNDFILESI96-99.WND 


\section{Waste Isolation Pilot Plant Biennial Environmental Compliance Report

Jun 21, 2000 11:59 am

FACTOR

Page 1

\section{DOSE AND RISK FACTOR UNITS}

The units for each type of dose rate conversion factor are shown below, by pathway:

Pathway Units

Ingestion millirem/picoCurie

Inhalation millirem/picoCurie

Immersion millirem-cubic $\mathrm{cm} /$ microCurie-year

Surface millirem-square $\mathrm{cm} /$ microCurie-year

Risks for internal exposures (inhalation and ingestion) are the lifetime risk of premature death in a birth cohort of 100,000 people for a 1 picoCurie/year intake rate, where the average lifetime is 70.7565 years.

This is simplified to lifetime risk per 100,000 picoCuries.

The units for each type of risk conversion factor are shown below, by pathway:

Pathway Units

Ingestion lifetime risk/100,000 picoCuries

Inhalation lifetime risk/100,000 picoCuries

Immersion lifetime risk-cubic $\mathrm{cm} / 100,000$ picoCurie-years

Surface lifetime risk-square $\mathrm{cm} / 100,000$ picoCurie-years 
Jun 21, 2000 11:59 am

FACTOR

Page 2

DOSE RATE CONVERSION FACTORS

\begin{tabular}{|c|c|c|c|c|}
\hline Organ & Ingestion & $\begin{array}{c}\text { Air } \\
\text { Inhalation }\end{array}$ & $\begin{array}{l}\text { Ground } \\
\text { Immersion }\end{array}$ & Surface \\
\hline $\begin{array}{l}\text { GONADS } \\
\text { BREAST } \\
\text { R MAR } \\
\text { LUNGS } \\
\text { THYROID } \\
\text { ENDOST } \\
\text { RMNDR } \\
\text { EFFEC }\end{array}$ & $\begin{array}{l}1.001 \mathrm{E}-03 \\
9.709 \mathrm{E}-05 \\
6.327 \mathrm{E}-03 \\
9.714 \mathrm{E}-05 \\
9.703 \mathrm{E}-05 \\
7.801 \mathrm{E}-02 \\
3.508 \mathrm{E}-03 \\
4.430 \mathrm{E}-03\end{array}$ & $\begin{array}{r}1.212 \mathrm{E}-01 \\
1.176 \mathrm{E}-02 \\
7.663 \mathrm{E}-01 \\
8.047 \mathrm{E}-02 \\
1.175 \mathrm{E}-02 \\
9.447 \mathrm{E}+00 \\
4.176 \mathrm{E}-01 \\
5.428 \mathrm{E}-01\end{array}$ & $\begin{array}{l}1.151 \mathrm{E}+08 \\
1.469 \mathrm{E}+08 \\
3.737 \mathrm{E}+07 \\
6.919 \mathrm{E}+07 \\
1.099 \mathrm{E}+08 \\
1.273 \mathrm{E}+08 \\
6.778 \mathrm{E}+07 \\
9.104 \mathrm{E}+07\end{array}$ & $\begin{array}{l}3.541 \mathrm{E}+04 \\
5.550 \mathrm{E}+04 \\
1.077 \mathrm{E}+04 \\
2.009 \mathrm{E}+04 \\
3.175 \mathrm{E}+04 \\
3.693 \mathrm{E}+04 \\
1.937 \mathrm{E}+04 \\
2.875 \mathrm{E}+04\end{array}$ \\
\hline
\end{tabular}

GENETIC EFFECT DOSE RATE CONVERSION FACTORS

$\begin{array}{lllll}\text { TESTES } & 9.208 \mathrm{E}-03 & 1.110 \mathrm{E}+00 & 3.452 \mathrm{E}+09 & 1.062 \mathrm{E}+06 \\ \text { OVARIES } & 9.232 \mathrm{E}-03 & 1.112 \mathrm{E}+00 & 1.521 \mathrm{E}+09 & 4.384 \mathrm{E}+05 \\ \text { AVERAGE } & 9.221 \mathrm{E}-03 & 1.111 \mathrm{E}+00 & 2.486 \mathrm{E}+09 & 7.504 \mathrm{E}+05\end{array}$

RISK CONVERSION FACTORS

\begin{tabular}{|c|c|c|c|c|}
\hline Cancer & Ingestion & Inhalation & $\begin{array}{c}\text { Air } \\
\text { Immersion }\end{array}$ & $\begin{array}{l}\text { Ground } \\
\text { Surface }\end{array}$ \\
\hline $\begin{array}{l}\text { LEUKEMIA } \\
\text { BONE } \\
\text { THYROID } \\
\text { BREAST } \\
\text { LUNG } \\
\text { STOMACH } \\
\text { BOWEL } \\
\text { LIVER } \\
\text { PANCREAS } \\
\text { URINARY } \\
\text { OTHER }\end{array}$ & $\begin{array}{l}5.337 \mathrm{E}-04 \\
3.433 \mathrm{E}-04 \\
1.062 \mathrm{E}-06 \\
7.158 \mathrm{E}-06 \\
9.643 \mathrm{E}-06 \\
6.586 \mathrm{E}-06 \\
1.094 \mathrm{E}-05 \\
1.198 \mathrm{E}-03 \\
4.480 \mathrm{E}-06 \\
2.298 \mathrm{E}-06 \\
5.479 \mathrm{E}-06\end{array}$ & $\begin{array}{l}6.457 \mathrm{E}-02 \\
4.152 \mathrm{E}-02 \\
1.283 \mathrm{E}-04 \\
8.639 \mathrm{E}-04 \\
2.284 \mathrm{E}-02 \\
7.140 \mathrm{E}-04 \\
3.603 \mathrm{E}-04 \\
1.448 \mathrm{E}-01 \\
5.408 \mathrm{E}-04 \\
2.773 \mathrm{E}-04 \\
6.614 \mathrm{E}-04\end{array}$ & $\begin{array}{l}1.184 \mathrm{E}+01 \\
2.253 \mathrm{E}+00 \\
4.998 \mathrm{E}+00 \\
5.751 \mathrm{E}+01 \\
3.429 \mathrm{E}+01 \\
1.852 \mathrm{E}+01 \\
8.526 \mathrm{E}+00 \\
2.179 \mathrm{E}+01 \\
9.503 \mathrm{E}+00 \\
8.681 \mathrm{E}+00 \\
1.162 \mathrm{E}+01\end{array}$ & $\begin{array}{l}3.410 \mathrm{E}-03 \\
6.535 \mathrm{E}-04 \\
1.444 \mathrm{E}-03 \\
2.174 \mathrm{E}-02 \\
9.960 \mathrm{E}-03 \\
5.317 \mathrm{E}-03 \\
2.445 \mathrm{E}-03 \\
6.239 \mathrm{E}-03 \\
2.760 \mathrm{E}-03 \\
2.479 \mathrm{E}-03 \\
3.376 \mathrm{E}-03\end{array}$ \\
\hline
\end{tabular}


Waste Isolation Pilot Plant Biennial Environmental Compliance Report DOE/WIPP 99-2171

AVERAGE

3.197E-10

3.843E-08

$6.464 \mathrm{E}+02$

$1.951 \mathrm{E}-01$ 
FACTOR

Page 3

DOSE RATE CONVERSION FACTORS

\begin{tabular}{|c|c|c|c|c|}
\hline Organ & Ingestion & Inhalation & $\begin{array}{c}\text { Air } \\
\text { Immersion }\end{array}$ & $\begin{array}{l}\text { Ground } \\
\text { Surface }\end{array}$ \\
\hline $\begin{array}{l}\text { GONADS } \\
\text { BREAST } \\
\text { R MAR } \\
\text { LUNGS } \\
\text { THYROID } \\
\text { ENDOST } \\
\text { RMNDR } \\
\text { EFFEC }\end{array}$ & $\begin{array}{l}8.603 \mathrm{E}-04 \\
8.419 \mathrm{E}-05 \\
5.485 \mathrm{E}-03 \\
8.419 \mathrm{E}-05 \\
8.419 \mathrm{E}-05 \\
6.763 \mathrm{E}-02 \\
3.085 \mathrm{E}-03 \\
3.853 \mathrm{E}-03\end{array}$ & $\begin{array}{r}1.041 \mathrm{E}-01 \\
1.020 \mathrm{E}-02 \\
6.641 \mathrm{E}-01 \\
7.893 \mathrm{E}-02 \\
1.020 \mathrm{E}-02 \\
8.189 \mathrm{E}+00 \\
3.666 \mathrm{E}-01 \\
4.726 \mathrm{E}-01\end{array}$ & $\begin{array}{l}4.218 \mathrm{E}+05 \\
1.806 \mathrm{E}+06 \\
5.291 \mathrm{E}+04 \\
1.177 \mathrm{E}+05 \\
1.709 \mathrm{E}+05 \\
2.090 \mathrm{E}+05 \\
8.732 \mathrm{E}+04 \\
4.344 \mathrm{E}+05\end{array}$ & $\begin{array}{l}7.548 \mathrm{E}+02 \\
4.070 \mathrm{E}+03 \\
4.514 \mathrm{E}+01 \\
1.225 \mathrm{E}+02 \\
1.510 \mathrm{E}+02 \\
2.050 \mathrm{E}+02 \\
7.659 \mathrm{E}+01 \\
8.530 \mathrm{E}+02\end{array}$ \\
\hline
\end{tabular}

GENETIC EFFECT DOSE RATE CONVERSION FACTORS

$\begin{array}{lllll}\text { TESTES } & 8.657 \mathrm{E}-03 & 1.043 \mathrm{E}+00 & 1.265 \mathrm{E}+07 & 2.264 \mathrm{E}+04 \\ \text { OVARIES } & 8.673 \mathrm{E}-03 & 1.045 \mathrm{E}+00 & 2.331 \mathrm{E}+06 & 2.087 \mathrm{E}+03 \\ \text { AVERAGE } & 8.665 \mathrm{E}-03 & 1.044 \mathrm{E}+00 & 7.492 \mathrm{E}+06 & 1.237 \mathrm{E}+04\end{array}$

RISK CONVERSION FACTORS

\begin{tabular}{|c|c|c|c|c|}
\hline Cancer & Ingestion & Inhalation & $\begin{array}{c}\text { Air } \\
\text { Immersion }\end{array}$ & $\begin{array}{l}\text { Ground } \\
\text { Surface }\end{array}$ \\
\hline LEUKEMIA & 4.695E-04 & 5.676E-02 & 1.676E-02 & $1.430 \mathrm{E}-\mathrm{C}$ \\
\hline BONE & 3.046E-04 & 3.681E-02 & 3.700E-03 & $3.628 \mathrm{E}-\mathrm{C}$ \\
\hline THYROID & 9.438E-07 & 1.140E-04 & $7.775 \mathrm{E}-03$ & $6.866 \mathrm{E}-$ \\
\hline BREAST & 6.493E-06 & 7.839E-04 & 7.072E-01 & 1.594E- \\
\hline LUNG & 8.684E-06 & 2.272E-02 & 5.833E-02 & $6.072 \mathrm{E}-\mathrm{C}$ \\
\hline STOMACH & 5.991E-06 & 6.480E-04 & $2.550 \mathrm{E}-02$ & $1.840 \mathrm{E}-0$ \\
\hline BOWEL & 1.016E-05 & 3.272E-04 & 1.083E-02 & $6.451 \mathrm{E}-0$ \\
\hline LIVER & 1.099E-03 & 1.327E-01 & 2.503E-02 & $9.235 \mathrm{E}-\mathrm{C}$ \\
\hline PANCREAS & 4.054E-06 & 4.895E-04 & 1.656E-02 & $1.864 \mathrm{E}-\mathrm{C}$ \\
\hline URINARY & 2.080E-06 & 2.511E-04 & 1.007E-02 & 3.352E- \\
\hline OTHER & 4.959E-06 & 5.987E-04 & 2.026E-02 & 2.280E- \\
\hline
\end{tabular}


Waste Isolation Pilot Plant Biennial Environmental Compliance Report DOE/WIPP 99-2171

$\begin{array}{lllll}\text { AVERAGE } & 2.992 \mathrm{E}-10 & 3.604 \mathrm{E}-08 & 1.948 \mathrm{E}+00 & 3.216 \mathrm{E}-03\end{array}$ 
FACTOR

Page 4

DOSE RATE CONVERSION FACTORS

\begin{tabular}{|c|c|c|c|c|}
\hline Organ & Ingestion & Inhalation & $\begin{array}{c}\text { Air } \\
\text { Immersion }\end{array}$ & $\begin{array}{l}\text { Ground } \\
\text { Surface }\end{array}$ \\
\hline $\begin{array}{l}\text { GONADS } \\
\text { BREAST } \\
\text { R MAR } \\
\text { LUNGS } \\
\text { THYROID } \\
\text { ENDOST } \\
\text { RMNDR } \\
\text { EFFEC }\end{array}$ & $\begin{array}{l}9.741 \mathrm{E}-04 \\
9.453 \mathrm{E}-05 \\
6.166 \mathrm{E}-03 \\
9.453 \mathrm{E}-05 \\
9.453 \mathrm{E}-05 \\
7.593 \mathrm{E}-02 \\
3.399 \mathrm{E}-03 \\
4.310 \mathrm{E}-03\end{array}$ & $\begin{array}{r}1.180 \mathrm{E}-01 \\
1.145 \mathrm{E}-02 \\
7.471 \mathrm{E}-01 \\
7.609 \mathrm{E}-02 \\
1.145 \mathrm{E}-02 \\
9.199 \mathrm{E}+00 \\
4.054 \mathrm{E}-01 \\
5.278 \mathrm{E}-01\end{array}$ & $\begin{array}{l}4.329 \mathrm{E}+05 \\
9.990 \mathrm{E}+05 \\
1.950 \mathrm{E}+05 \\
2.420 \mathrm{E}+05 \\
3.385 \mathrm{E}+05 \\
3.996 \mathrm{E}+05 \\
2.250 \mathrm{E}+05 \\
4.002 \mathrm{E}+05\end{array}$ & $\begin{array}{l}3.463 \mathrm{E}+02 \\
1.617 \mathrm{E}+03 \\
5.587 \mathrm{E}+01 \\
8.954 \mathrm{E}+01 \\
1.165 \mathrm{E}+02 \\
1.473 \mathrm{E}+02 \\
6.734 \mathrm{E}+01 \\
3.747 \mathrm{E}+02\end{array}$ \\
\hline
\end{tabular}

GENETIC EFFECT DOSE RATE CONVERSION FACTORS

$\begin{array}{lllll}\text { TESTES } & 8.801 \mathrm{E}-03 & 1.061 \mathrm{E}+00 & 1.299 \mathrm{E}+07 & 1.039 \mathrm{E}+04 \\ \text { OVARIES } & 8.777 \mathrm{E}-03 & 1.058 \mathrm{E}+00 & 5.506 \mathrm{E}+06 & 1.798 \mathrm{E}+03 \\ \text { AVERAGE } & 8.789 \mathrm{E}-03 & 1.059 \mathrm{E}+00 & 9.246 \mathrm{E}+06 & 6.094 \mathrm{E}+03\end{array}$

RISK CONVERSION FACTORS

\begin{tabular}{|c|c|c|c|c|}
\hline Cancer & Ingestion & Inhalation & $\begin{array}{c}\text { Air } \\
\text { Immersion }\end{array}$ & $\begin{array}{l}\text { Ground } \\
\text { Surface }\end{array}$ \\
\hline LEUKEMIA & $5.183 \mathrm{E}-04$ & $6.271 \mathrm{E}-02$ & 6.176E-02 & $1.770 \mathrm{E}-05$ \\
\hline BONE & 3.323E-04 & 4.019E-02 & $7.072 \mathrm{E}-03$ & 2.606E-06 \\
\hline THYROID & $1.027 \mathrm{E}-06$ & $1.242 \mathrm{E}-04$ & $1.540 \mathrm{E}-02$ & 5.301E-06 \\
\hline BREAST & $6.868 \mathrm{E}-06$ & $8.298 \mathrm{E}-04$ & 3.913E-01 & $6.333 \mathrm{E}-04$ \\
\hline LUNG & $9.263 \mathrm{E}-06$ & $2.149 \mathrm{E}-02$ & $1.200 \mathrm{E}-01$ & $4.439 \mathrm{E}-05$ \\
\hline STOMACH & $6.254 \mathrm{E}-06$ & $6.858 \mathrm{E}-04$ & 6.736E-02 & $1.961 \mathrm{E}-05$ \\
\hline BOWEL & 9.813E-06 & 3.457E-04 & $3.275 \mathrm{E}-02$ & 8.719E-06 \\
\hline LIVER & $1.148 \mathrm{E}-03$ & 1.387E-01 & 7.186E-02 & 1.699E-05 \\
\hline PANCREAS & 4.289E-06 & $5.181 \mathrm{E}-04$ & 4.236E-02 & $1.502 \mathrm{E}-05$ \\
\hline URINARY & $2.200 \mathrm{E}-\mathrm{C}$ & $2.658 \mathrm{E}-04$ & $2.614 \mathrm{E}-02$ & $6.081 \mathrm{E}-06$ \\
\hline OTHER & $5.246 \mathrm{E}-06$ & 6.337E-04 & $5.181 \mathrm{E}-02$ & $1.838 \mathrm{E}-05$ \\
\hline
\end{tabular}




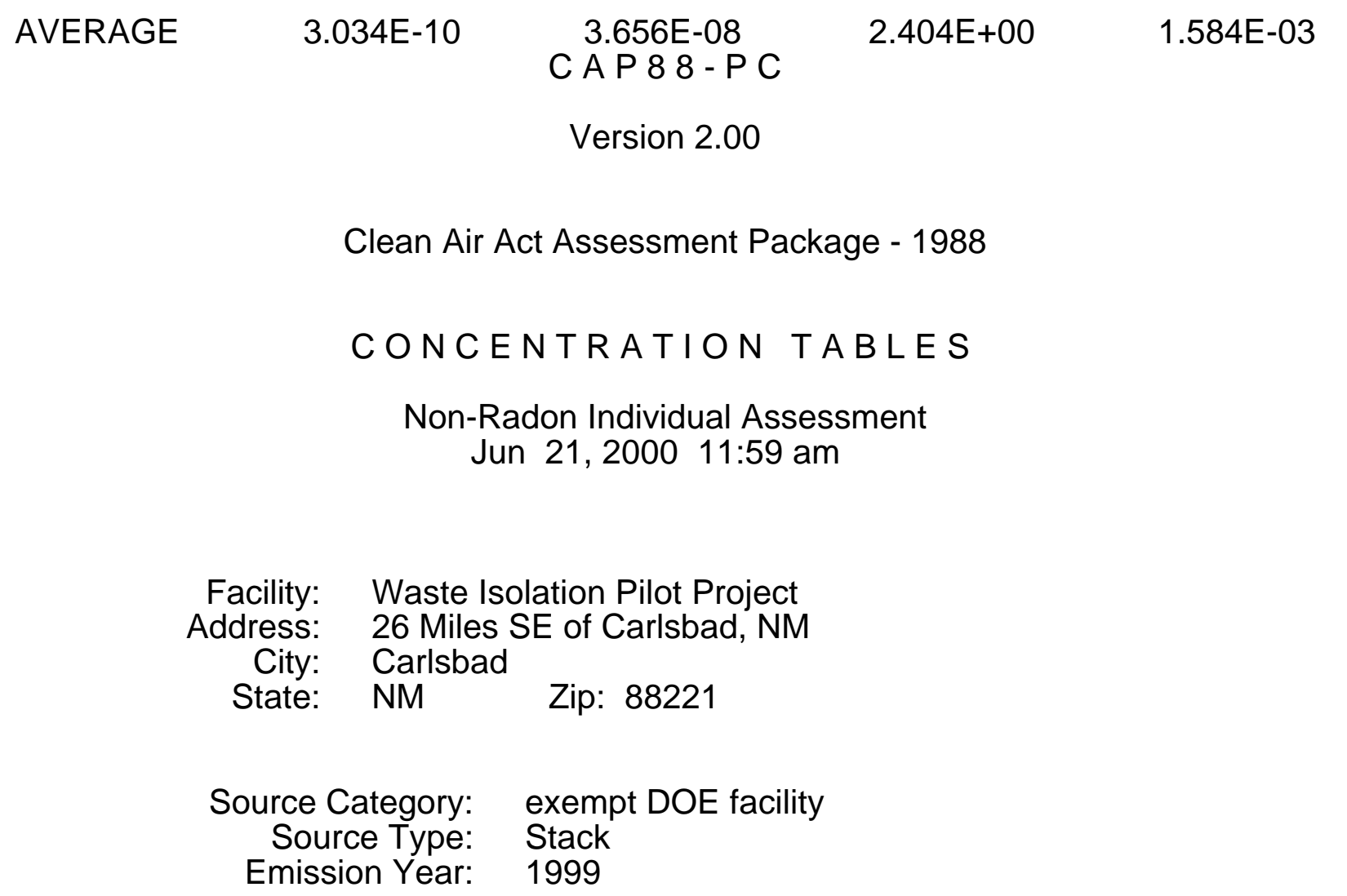

Comments: Run for 1999

Dataset Name: 191

Dataset Date: Jun 21, 2000 11:59 am

Wind File: C:ICAP88PC2IWNDFILESI96-99.WND 
ESTIMATED RADIONUCLIDE CONCENTRATIONS

AT VARIOUS LOCATIONS IN THE ENVIRONMENT

\begin{tabular}{|c|c|c|c|c|c|c|}
\hline $\begin{array}{c}\text { Wind } \\
\text { Toward }\end{array}$ & $\begin{array}{l}\text { Distance } \\
\text { (meters) }\end{array}$ & Nuclide & $\begin{array}{c}\text { Air } \\
\text { Concentration } \\
(\mathrm{pCi} / \mathrm{m} 3)\end{array}$ & $\begin{array}{c}\text { Dry } \\
\text { Deposition } \\
\text { Rate } \\
\text { (pCi/cm2/s) }\end{array}$ & $\begin{array}{c}\text { Wet } \\
\text { Deposition } \\
\text { Rate } \\
\text { (pCi/cm2/s) }\end{array}$ & $\begin{array}{c}\text { Ground } \\
\text { Deposition } \\
\text { Rate } \\
\text { (pCi/cm2/s) }\end{array}$ \\
\hline $\mathrm{N}$ & 0 & AM-241 & 1.2E-09 & $2.2 E-16$ & $6.4 \mathrm{E}-17$ & $2.9 E-16$ \\
\hline $\mathrm{N}$ & 350 & PU-238 & 1.0E-09 & $1.8 \mathrm{E}-16$ & $4.8 \mathrm{E}-17$ & 2.3E-16 \\
\hline $\mathrm{N}$ & 350 & PU-239 & 1.1E-09 & $2.1 \mathrm{E}-16$ & $6.1 \mathrm{E}-17$ & $2.7 E-16$ \\
\hline NNW & 350 & AM-241 & 1.9E-09 & $3.5 \mathrm{E}-16$ & 8.3E-17 & $4.3 \mathrm{E}-16$ \\
\hline NNW & 350 & PU-238 & $1.5 \bar{E}-09$ & $2.7 \mathrm{E}-16$ & $6.3 \mathrm{E}-17$ & $3.3 E-16$ \\
\hline NNW & 350 & PU-239 & 1.8E-09 & $3.2 E-16$ & $7.9 \mathrm{E}-17$ & $4.0 \mathrm{E}-16$ \\
\hline NW & 350 & AM-241 & 2.5E-09 & $4.6 \mathrm{E}-16$ & $1.2 \mathrm{E}-16$ & $5.7 \mathrm{E}-16$ \\
\hline NW & 350 & PU-238 & 1.9E-09 & $3.5 \mathrm{E}-16$ & 8.9E-17 & 4.3E-16 \\
\hline NW & 350 & PU-239 & 2.4E-09 & $4.2 \mathrm{E}-16$ & $1.1 \mathrm{E}-16$ & $5.4 \mathrm{E}-16$ \\
\hline WNW & 350 & AM-241 & 1.7E-09 & $3.0 E-16$ & $1.1 \mathrm{E}-16$ & $4.1 \mathrm{E}-16$ \\
\hline WNW & 350 & PU-238 & 1.3E-09 & $2.3 \mathrm{E}-16$ & 8.2E-17 & $3.1 \mathrm{E}-16$ \\
\hline WNW & 350 & PU-239 & 1.5E-09 & $2.7 E-16$ & 1.0E-16 & 3.8E-16 \\
\hline W & 350 & AM-241 & 1.3E-09 & $2.4 \mathrm{E}-16$ & $6.0 \mathrm{E}-17$ & $3.0 \mathrm{E}-16$ \\
\hline W & 350 & PU-238 & 1.0E-09 & $1.8 \mathrm{E}-16$ & 4.6E-17 & 2.3E-16 \\
\hline W & 350 & PU-239 & 1.2E-09 & $2.2 \mathrm{E}-16$ & $5.8 \mathrm{E}-17$ & 2.8E-16 \\
\hline WSW & 350 & AM-241 & $9.2 E-10$ & $1.7 \mathrm{E}-16$ & $3.8 \mathrm{E}-17$ & $2.0 E-16$ \\
\hline WSW & 350 & PU-238 & $6.9 \mathrm{E}-10$ & $1.2 \bar{E}-16$ & $2.9 \mathrm{E}-17$ & $1.5 \mathrm{E}-16$ \\
\hline WSW & 350 & PU-239 & 8.6E-10 & $1.5 \mathrm{E}-16$ & $3.7 \mathrm{E}-17$ & $1.9 E-16$ \\
\hline SW & 350 & AM-241 & $7.9 \mathrm{E}-10$ & $1.4 \mathrm{E}-16$ & 4.0E-17 & $1.8 \mathrm{E}-16$ \\
\hline SW & 350 & PU-238 & $6.0 \mathrm{E}-10$ & $1.1 \mathrm{E}-16$ & $3.0 \mathrm{E}-17$ & $1.4 \mathrm{E}-16$ \\
\hline SW & 350 & PU-239 & 7.3E-10 & 1.3E-16 & $3.8 \mathrm{E}-17$ & $1.7 \mathrm{E}-16$ \\
\hline SSW & 350 & AM-241 & $7.9 E-10$ & $1.4 \mathrm{E}-16$ & 4.0E-17 & $1.8 \mathrm{E}-16$ \\
\hline SSW & 350 & PU-238 & $6.1 \mathrm{E}-10$ & $1.1 \mathrm{E}-16$ & $3.0 \mathrm{E}-17$ & $1.4 \mathrm{E}-16$ \\
\hline SSW & 350 & U-239 & $7.4 \mathrm{E}-10$ & 1.3E-16 & 3.8E-17 & $1.7 \mathrm{E}-16$ \\
\hline S & 350 & AM-241 & $8.1 \mathrm{E}-10$ & $1.5 \mathrm{E}-16$ & $3.7 \mathrm{E}-17$ & $1.8 \mathrm{E}-16$ \\
\hline S & 350 & PU-238 & 6.3E-10 & $1.1 \mathrm{E}-16$ & $2.8 \mathrm{E}-17$ & $1.4 \mathrm{E}-16$ \\
\hline$S$ & 350 & PU-239 & $7.5 \mathrm{E}-10$ & $1.3 \bar{E}-16$ & $3.5 \mathrm{E}-17$ & $1.7 \mathrm{E}-16$ \\
\hline SSE & 350 & AM-241 & $7.9 \mathrm{E}-10$ & $1.4 \mathrm{E}-16$ & $3.5 \mathrm{E}-17$ & $1.8 \mathrm{E}-16$ \\
\hline SSE & 350 & PU-238 & $6.2 \mathrm{E}-10$ & $1.1 \mathrm{E}-16$ & $2.7 \mathrm{E}-17$ & $1.4 \mathrm{E}-16$ \\
\hline SSE & 350 & PU-239 & $7.2 E-10$ & 1.3E-16 & $3.4 \mathrm{E}-17$ & 1.6E-16 \\
\hline SE & 350 & AM-241 & 8.0E-10 & $1.4 \mathrm{E}-16$ & $3.5 \mathrm{E}-17$ & $1.8 \mathrm{E}-16$ \\
\hline SE & 350 & PU-238 & $6.4 \mathrm{E}-10$ & $1.2 \mathrm{E}-16$ & $2.6 \mathrm{E}-17$ & $1.4 \mathrm{E}-16$ \\
\hline SE & 350 & PU-239 & 7.3E-10 & $1.3 \mathrm{E}-16$ & $3.3 \mathrm{E}-17$ & $1.6 \mathrm{E}-16$ \\
\hline ESE & 350 & AM-241 & $8.4 \mathrm{E}-10$ & $1.5 \mathrm{E}-16$ & $3.6 \mathrm{E}-17$ & $1.9 \mathrm{E}-16$ \\
\hline ESE & 350 & PU-238 & $6.7 \mathrm{E}-10$ & $1.2 \mathrm{E}-16$ & $2.7 \mathrm{E}-17$ & $1.5 \mathrm{E}-16$ \\
\hline ESE & 350 & PU-239 & 7.7E-10 & 1.4E-16 & $3.4 \mathrm{E}-17$ & 1.7E-16 \\
\hline
\end{tabular}




$\begin{array}{ccccccc}\mathrm{E} & 350 & \text { AM-241 } & 1.5 \mathrm{E}-09 & 2.6 \mathrm{E}-16 & 4.2 \mathrm{E}-17 & 3.1 \mathrm{E}-16 \\ \mathrm{E} & 350 & \text { PU-238 } & 1.1 \mathrm{E}-09 & 2.0 \mathrm{E}-16 & 3.2 \mathrm{E}-17 & 2.3 \mathrm{E}-16 \\ \text { Jun 21, } 2000 & 11: 59 \mathrm{am} & & & & \text { CONCEN } \\ \text { Page 2 }\end{array}$

ESTIMATED RADIONUCLIDE CONCENTRATIONS AT VARIOUS LOCATIONS IN THE ENVIRONMENT

\begin{tabular}{|c|c|c|c|c|c|c|}
\hline $\begin{array}{l}\text { Wind } \\
\text { Toward }\end{array}$ & $\begin{array}{l}\text { Distance } \\
\text { (meters) }\end{array}$ & Nuclide & $\begin{array}{c}\text { Air } \\
\begin{array}{c}\text { Concentration } \\
\text { (pCi/m3) }\end{array}\end{array}$ & $\begin{array}{c}\text { Dry } \\
\text { Deposition } \\
\text { Rate } \\
\text { (pCi/cm2/s) }\end{array}$ & $\begin{array}{c}\text { Wet } \\
\text { Deposition } \\
\text { Rate } \\
\text { (pCi/cm2/s) }\end{array}$ & $\begin{array}{c}\text { Ground } \\
\text { Deposition } \\
\text { Rate } \\
\text { (pCi/cm2/s) }\end{array}$ \\
\hline$E$ & 350 & PU-239 & $1.4 \mathrm{E}-09$ & $2.5 \mathrm{E}-16$ & $4.0 \mathrm{E}-17$ & $2.9 \mathrm{E}-16$ \\
\hline ENE & 350 & AM & $1.2 \mathrm{E}$ & $2.2 \mathrm{E}-16$ & $4.0 \mathrm{E}-17$ & 2.6E-16 \\
\hline ENE & 350 & & $9.5 \mathrm{E}$ & $1.7 \mathrm{E}-16$ & $3.1 \mathrm{E}$ & $2.0 \mathrm{E}-16$ \\
\hline ENE & 5 & PU-239 & 1.1E-09 & 2.0E-16 & $3.9 \mathrm{E}-17$ & $2.4 \mathrm{E}-16$ \\
\hline NF & 350 & & $9.0 \mathrm{E}-10$ & 1.6E-16 & $3.8 \mathrm{E}-17$ & $2.0 \mathrm{E}-16$ \\
\hline $\mathrm{NE}$ & 350 & PU & 7.3E-10 & 1.3E-16 & $2.9 \mathrm{E}-17$ & 1.6E-16 \\
\hline $\mathrm{N}$ & 350 & & $8.3 \mathrm{E}$ & $1.5 \mathrm{E}-16$ & 3.6E & $1.9 \mathrm{E}-16$ \\
\hline NNE & 350 & AN & $9.8 \mathrm{E}-10$ & $1.8 \mathrm{E}-16$ & $4.5 \mathrm{E}-17$ & $2.2 \mathrm{E}-16$ \\
\hline & 35 & & $7.8 \mathrm{E}-10$ & $1.4 \mathrm{E}-16$ & $3.4 \mathrm{E}-17$ & $1.8 \mathrm{E}-16$ \\
\hline NNE & 35 & & $9.0 \mathrm{E}-10$ & & 4.3E-17 & $2.1 \mathrm{E}-16$ \\
\hline
\end{tabular}




\author{
C A P $88-P$ C \\ Version 2.00
}

Clean Air Act Assessment Package - 1988

CHI/Q TABLES

Non-Radon Individual Assessment Jun 21, 2000 11:59 am

Facility: Waste Isolation Pilot Project

Address: 26 Miles SE of Carlsbad, NM

City: Carlsbad

State: NM Zip: 88221

Source Category: exempt DOE facility

Source Type: Stack

Emission Year: 1999

Comments: Run for 1999

Dataset Name: 191

Dataset Date: Jun 21, 2000 11:59 am

Wind File: C:ICAP88PC2IWNDFILESI96-99.WND 
Jun 21, 2000 11:59 am

CHIQ

Page 1

GROUND-LEVEL CHI/Q VALUES FOR AM-241

CHI/Q TOWARD INDICATED DIRECTION (SEC/CUBIC METER)

Distance (meters)

\begin{tabular}{rc}
\hline Dir & 350 \\
\hline N & $1.146 \mathrm{E}-06$ \\
NNW & $1.781 \mathrm{E}-06$ \\
NW & $2.331 \mathrm{E}-06$ \\
NW & $1.532 \mathrm{E}-06$ \\
W & $1.222 \mathrm{E}-06$ \\
WSW & $8.459 \mathrm{E}-07$ \\
SW & $7.254 \mathrm{E}-07$ \\
SSW & $7.302 \mathrm{E}-07$ \\
S & $7.460 \mathrm{E}-07$ \\
SSE & $7.252 \mathrm{E}-07$ \\
SE & $7.305 \mathrm{E}-07$ \\
ESE & $7.706 \mathrm{E}-07$ \\
$\mathrm{E}$ & $1.343 \mathrm{E}-06$ \\
ENE & $1.122 \mathrm{E}-06$ \\
NE & $8.310 \mathrm{E}-07$ \\
NNE & $8.987 \mathrm{E}-07$ \\
\hline
\end{tabular}


Jun 21, 2000 11:59 am

$\mathrm{CHIQ}$

Page 2

GROUND-LEVEL CHI/Q VALUES FOR PU-238

CHI/Q TOWARD INDICATED DIRECTION (SEC/CUBIC METER)

Distance (meters)

\begin{tabular}{rr}
\hline Dir & 350 \\
\hline & \\
$N$ & $1.205 \mathrm{E}-06$ \\
NNW & $1.808 \mathrm{E}-06$ \\
$N W$ & $2.320 \mathrm{E}-06$ \\
WNW & $1.556 \mathrm{E}-06$ \\
$W$ & $1.221 \mathrm{E}-06$ \\
WSW & $8.388 \mathrm{E}-07$ \\
SW & $7.283 \mathrm{E}-07$ \\
SSW & $7.420 \mathrm{E}-07$ \\
S & $7.645 \mathrm{E}-07$ \\
SSE & $7.563 \mathrm{E}-07$ \\
SE & $7.739 \mathrm{E}-07$ \\
ESE & $8.161 \mathrm{E}-07$ \\
$\mathrm{E}$ & $1.333 \mathrm{E}-06$ \\
ENE & $1.148 \mathrm{E}-06$ \\
$\mathrm{NE}$ & $8.853 \mathrm{E}-07$ \\
$\mathrm{NNE}$ & $9.497 \mathrm{E}-07$ \\
\hline
\end{tabular}


Jun 21, 2000 11:59 am

$\mathrm{CHIQ}$

Page 3

GROUND-LEVEL CHI/Q VALUES FOR PU-239

CHI/Q TOWARD INDICATED DIRECTION (SEC/CUBIC METER)

Distance (meters)

\begin{tabular}{rr}
\hline Dir & 350 \\
\hline$N$ & $1.108 \mathrm{E}-06$ \\
$N N W$ & $1.735 \mathrm{E}-06$ \\
$N W$ & $2.272 \mathrm{E}-06$ \\
WNW & $1.473 \mathrm{E}-06$ \\
$W$ & $1.189 \mathrm{E}-06$ \\
WSW & $8.291 \mathrm{E}-07$ \\
SW & $7.085 \mathrm{E}-07$ \\
SSW & $7.106 \mathrm{E}-07$ \\
S & $7.221 \mathrm{E}-07$ \\
SSE & $6.978 \mathrm{E}-07$ \\
SE & $7.006 \mathrm{E}-07$ \\
ESE & $7.401 \mathrm{E}-07$ \\
$\mathrm{E}$ & $1.325 \mathrm{E}-06$ \\
ENE & $1.096 \mathrm{E}-06$ \\
$N E$ & $7.994 \mathrm{E}-07$ \\
NNE & $8.690 \mathrm{E}-07$ \\
\hline
\end{tabular}


